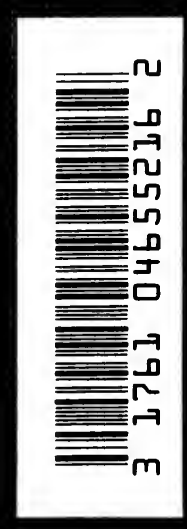





Die

\section{wirtschaftlichen Grundlagen der deutschen}

\section{Hanse und die Handelsstellung Hamburgs}

bis in die zweite Hälfte des 14. Jahrhunderts

von

Dr. jur. G. Arnold Kiesselbach,

Sekretär der Handelskammer in Hamburg.

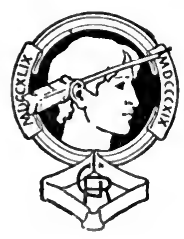

$$
\text { B } 1 \text { lin. }
$$

Druck und Verlag von Georg Reimer.

1907. 


$$
\frac{3.283}{10.5 .56}
$$




\section{Vorwort.}

Die Fülle der Einzelheiten, welche die hansische Geschichts-
forschung in den letzten Jahrzehnten an das Licht gezogen hat, hat es der Geschichtschreibung des mittelalterlichen Handels vielfach erschwert, die großen Grundlinien, auf denen sich der nordwesteuropäische Seehandel damals bewegt hat, richtig zu erkennen und festzuhalten. Infolge dieser Umstände ist das Bild, welches die Geschichtschreibung von diesem Verkehre entworfen hat, meines Erachtens an verschiedenen Stellen stark verzeichnet. Vor allem ist, soviel in der Literatur der hansischen Geschichte von dem Brüggeschen Weltmarkte auch die Rede gewesen ist, doch die zentrale Bedeutung Flanderns für den deutschen Seehandel nicht voll zur Würdigung gelangt. Namentlich hat die überragende Handelsstellung, welche England in den letzten Jahrhunderten gewonnen hat, immer wieder die Forschung zur Verkennung der engbegrenzten Grundlinien des englischen Handels im Mittelalter und zur Verdunkelung der flandrischen Welthandelsstellung verführt. Die vorliegende Arbeit hat es sich zur Aufgabe gesetzt, die großen Grundlinien des nordwesteuropäischen Seehandels bis in die Zeit des zweiten Krieges der Städte gegen König Waldemar von Dänemark zu beleuchten und damit die Stellung, welche der Handel der hansischen Kaufleute im Welthandel einnahm, vor Augen zu führen. Um das Bild dieser Zeichnung klar hervortreten zu lassen, mußte der Lokalverkehr, den jede einzelne der deutschen Städte unterhielt, wie z. B. der Seeverkehr der zahlreichen 
kleineren Ostseeplätze untereinander, beiseite gelassen werden; nur andeutungsweise konnte hier und da im Text und in den Noten ein Seitenblick auf diese für den Welthandel bedeutungslosen kleineren Adern des Verkehrslebens geworfen werden. Dagegen waren, um die Bedeutung Flanderns für den deutschen Handel voll verständlich zu machen, auch die Beziehungen der romanischen Länder zu Flandern zu berüicksichtigen.

Um den Zusammenhang des Handelslebens der einzelnen deutschen Städte mit diesem großen, einen Teil des Welthandels bildenden hansischen Gesamthandelsbetriebe verständlich zu machen, schien es mir ratsam, in die allgemeine Skizze der Grundlinien des deutschen Seehandels das genaue Verkehrsnetz einer einzelnen der Städte einzuzeichnen. Ich wählte Hamburg für diesen Zweck nicht nur, weil die Geschichte des in unserer Zeit ersten Seehafens Deutschlands in der Gegenwart das größte Interesse in Anspruch nimmt, sondern weil gerade das Bild, das die Geschichtschreibung von der hamburgischen Handelsgeschichte entworfen hat, durch die oben dargelegten Umstände besonders entstellt worden ist. Die große Bedeutung des in nenerer Zeit weitrerzweigten Handels Hamburgs hat auch hier wieder die Erkenntnis der bescheidenen einförmigen Grundzïge seines Verkehrs im Mittelalter erschwert. Der Umstand, daß hamburgische Kaufleute seit früher Zeit in England, Norwegen, Schweden und auf Schonen nachweisbar sind, hat die Geschichtsforschung zu der irrigen Annahme geführt, daß die Handelstätigkeit dieser Kaufleute von dort auf Hamburg gerichtet gewesen sei, während sie in Wahrheit sich so gut wie ausschließlich auf Flandern richtete.

Die Literatur über den hansischen Handel des Mittelalters ist auf das engste verflochten mit der Geschichtschreibung der deutschen Städtehanse. Nit der Veränderung des Grundrisses des deutschen Seehandels verschiebt sich zugleich die Grundlage der Städtehanse. Um nachzuweisen, daß auch der Aufbau der Städtehanse im einzelnen ganz mit der in der vorliegenden Arbeit dargelegten Struktur des deutschen Seehandels überein- 
stimmt, mußten schließlich auch die Grundzüge des Ursprungs der Städtehanse verfolgt werden.

Meine Absicht war ursprünglich, die Betrachtung auf das ganze Mittelalter bis zu dessen Ausgange zu erstrecken, weil die spätere Zeit meines Erachtens viele Belege für die Richtigkeit der von mir entwickelten Auffassung von dem Aufbau des deutschen Seehandels bietet und das Durchdringen meiner Auffassungen vielleicht erschwert ist, solange die spätere Zeit noch lediglich unter dem Gesichtswinkel der bisherigen Ergebnisse der Geschichtsforschung gesehen wird. Die Übernahme neuer Pflichten hat mich veranlaßt, diese Absicht aufzugeben und mich schon jetzt zur Veröffentlichung der vorliegenden Arbeit, die mit dem zweiten Drittel des 14. Jahrhunderts, dem Höhepunkte der hansischen Machtstellung, abschließt, zu entschließen.

Hamburg, im Oktober 1907.

Dr. jur. G. Arnold Kiesselbach. 



\section{Inhaltsübersicht.}

Vorwort.

Einleitung. Der baltisch-deutsche Verkehr vom Beginn des 9. bis zum Ausgange des 12. Jahrhunderts und die Handelsbedeutung

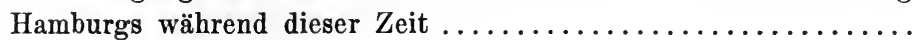

I. Abschnitt. Das 13. Jahrhundert.

1. Kapitel. Brügge mit dem Zwin als Mittelpunkt des westeuropäischen Handels und der Anteil der Dentschen, insbesondere auch der Hamburger, am europäischen Seeverkehr im 13. Jahrhundert..

2. Kapitel. Die Stadt Hamburg als Umschlagsplatz und Zwischen-

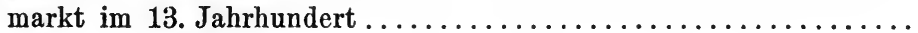

II. Abschnitt. Die beiden ersten Drittel des 14. Jahrhunderts.

3. Kapitel. Die Verschiebungen im wirtschaftlichen Aufbau des westeuropäischen Seehandels und der Anteil der Deutschen, insbesondere auch der Hamburger, an diesem Handel während der beiden ersten Drittel des 14. Jahrhunderts..................... 140

4. Kapitel. Die Stadt Hamburg als Umschlagsplatz und Zwischenmarkt während der beiden ersten Drittel des 14. Jahrhunderts. . . 204

5. Kapitel. Der Ursprung der Städtehanse................ 247 



\section{Einleitung.}

\section{Der baltisch-deutsche Verkehr vom Beginn des 9. bis zum Aus- gange des 12. Jahrhunderts und die Handelsbedeutung Hamburgs während dieser Zeit.}

In der Geschichte des deutschen Wirtschaftslebens bildet einen der wichtigsten Wendepunkte das 13. Jahrhundert. In 13. Jahrhundert setzt die kraftvolle Entfaltung des Städtewesens und Bürgerstandes ein, fangen Handel und Gewerbe an, einen breiteren Platz in der deutschen Volkswirtschaft neben dem Ackerbau und der Viehzucht sich zu erobern. Mit diesem Zeitpunkte tritt dementsprechend auch der Seehandel als ein beachtenswerter Faktor des deutschen Wirtschaftslebens hervor, and mit dem 13. Jahrhundert beginnt auch erst Hamburgs Rolle im Handelsverkehre.

Indessen reichen die Anfänge des deutschen Seehandels in sehr viel frühere Zeiten hinauf, und auch die Grundlinien des Warenverkehrszuges, dem Hamburg später seine Bedeutung verdankte, sind schon in der karolingischen Zeit zu erkennen. Um den wirtschaftlichen Aufbau des deutschen Seehandels und des Handelsverkehrs der Hamburger insbesondere im 13. Jahrhundert zu verstehen, werden wir gut tun, die Grundlagen, auf denen derselbe erwachsen ist, in die frühere Zeit hinein zu verfolgen und den Güterverkehr Norddeutschlands während der vorhergehenden Jahrhunderte seit der Karolingerzeit einer kurzen Betrachtung zu unterziehen.

Unter den Bewohnern der norddeutschen Küsten standen im Beginne des 9. Jahrhunderts, auf welchen Zeitpunkt wir zunächst unsere Aufmerksamkeit richten, in wirtschaftlicher Hinsicht allen andern weit voran die niederrheinischen Friesen und die Flanderer. Dort hatten Gewerbe und Handel bereits 
damals eine beachtenswerte Entwicklung erreicht ${ }^{1}$ ). Die Wollweberei dieser Landschaften lieferte schon in jener Zeit erhebliche Überschüsse für den Export. Friesische Kaufleute treffen wir in der karolingischen Zeit nicht nur auf den Märkten des Binnenlandes, wie Mainz, Worms, Köln, Birten, Duisburg usw. ${ }^{2}$ ), sondern auch in den Handelsplätzen der verschiedensten Gegenden des Auslandes. Wo wir Näheres von dem Gegenstande ihres Handels erfahren, ist es regelmäßig der Tuchhandel, der sie beschäftigt. Manche inländische Handelsstädte, wie Mainz, hatten ganze Kolonien von Friesen aufzuweisen; im Auslande finden wir friesische Kaufleute im 8. und 9. Jahrhundert in in St. Denys bei Paris, in York in England und im dänischen Schleswig. Die Stürme der Normannenzeit haben diese wirtschaftliche Kultur zum großen Teile vernichtet; aber bereits in der ersten Hälfte des 11. Jahrhunderts finden wir das wirtschaftliche Leben in diesen Gegenden wieder hoch entwickelt.

Flandern, der eigentliche Sitz dieser wirtschaftlichen Kultur, tritt schon in der ersten Hälfte des 11. Jahrhunderts als Mittelpunkt des Handels und als Hauptsitz einer bedeutenden Wollindustrie hervor ${ }^{3}$ ). An der Maas und am Mittelrhein hatte übrigens auch die Metallbearbeitung, namentlich die Anfertigung von Waffen, schon seit der karolingischen Zeit eine bemerkenswerte Bedeutung erreicht.

Schon in der Karolingerzeit vermögen wir einen Verkehr zwischen dem deutschen Westen und dem slawischen Osten und skandinavischen Norden zu erkennen. Inwieweit schon im 9. Jahrhundert die friesischen Tuche Gegenstand des Ver-

1) Vgl. vor allem Rudolf Häpke, Die Herkunft der friesischen Gewebe, in Hans. Geschichtsbl. 1906, Heft 2, S. 309 ff., über die Friesen ferner u. a. Gfrörer, Zur Geschichte der deutschen Volksrechte im Mittelalter, Schaffhausen 1865, S. $240 \mathrm{ff}, 263 \mathrm{ff}$; v. Inama-Sternegg, Deutsche Wirtschaftsgeschichte in der Karolingerzeit. Leipzig 1879. I S. 447; Waitz, Deutsche Verfassungsgeschichte. Kiel 1881. IV S. 37. Über die Flanderer u. a. Frensdorff, Aus belgischen Städten und Stadtrechten in Hans. Geschichtsbl. 1878, insbesondere S. $48 \mathrm{ff}$.

$\left.{ }^{2}\right)$ Vgl. Keutgen, Der Großhandel im Mittelalter, in Hans. Geschichtsbl. 1901, S. 90 .

3) S. die Nachweise unten Note 4 zu Kapitel I. 
kehrs nach dem Norden waren, ist uns zwar nicht überliefert ${ }^{4}$ ); für das 11. Jahrhundert und die Folgezeit besitzen wir urkundliche Zeugnisse dafür, daß dieser Handelsartikel den wichtigsten Ausfuhrgegenstand nach dem Norden abgab. Bei dem Umfange, welchen der friesische Tuchhandel schon im 9. Jahrhundert gewonnen hatte, dürfen wir aber vermuten, daß die Tuche in älterer Zeit nicht weniger im Vordergrunde dieser Ausfuhr gestanden haben. Neben den Tuchen mögen u. a. früh auch schon Erzeugnisse der Metallindustrie ihren Weg dorthin gefunden haben, wenigstens spricht ein Verbot der Ausfuhr von Waffen und Harnischen, das Karl der Große erlie $\beta^{5}$ ), für diese Annahme ${ }^{6}$ ), wenngleich freilich später der Austausch mit Metallwaren im Rahmen des Verkehrs nach dem Norden und Osten hinter dem Tuchhandel ganz zurückstand. In den baltischen Ländern auf der andern Seite bildeten einen der ältesten und wichtigsten Ausfuhrartikel Pelze. Noch im 13. Jahrhundert steht der Pelzhandel obenan in diesem Verkehre; aber schon Adam von Bremen berichtet ${ }^{7}$ ) im 11. Jahrhundert, daß deutsche Kaufleute bei den Slawen an der Weichselmündung Pelze gegen Tuch eintauschen, und auch verschiedene andere Quellen ${ }^{8}$ ) zeigen uns die stark hervortretende Bedeutung dieses Artikels schon für die ältere Zeit. Wenn im 9. Jahrhundert neben Tuchen gelegentlich Bernstein als einer der Handelsartikel, den die Friesen einführen, erwähnt wird, so werden wir auch hierin ein Zeugnis für den Handelsverkehr der Friesen nach dem Ostseegebiet sehen dürfen ${ }^{9}$ ).

4) Vgl. allerdings Alexander Bugge, Die nordeuropäischen Verkehrswege im frühen Mittelalter und die Bedeutung der Wickinger für die Entwicklung des europäischen IIandels und der europäischen Schiffahrt, in der Vierteljahrsschrift für Sozial- und Wirtschaftsgeschichte. Stuttgart 1905. Bd. 4, S. 254: friesische 'Tuche und flandrische Schwerter angeblich im 9. Jahrhundert im Norden.

$\left.{ }^{5}\right)$ Kapitular v. 805 Monum. Germ. Hist. LL. Sect II, Bd. I, S. 123.

$\left.{ }^{6}\right)$ Vgl. oben Note 4.

$\left.{ }^{7}\right)$ Adami Gesta IV. 21 in Monumenta Germaniae Historica SS. IX.

${ }^{8}$ ) Vgl. z. B. Weinhold, Altnordisches Leben, Berlin 1856, u. a. S. 100f.; Jacob, Der nordisch-baltische Handel der Araber im Mittelalter. Leipzig 1887.

${ }^{9}$ S. Häpke, a. a. O. S. 323. 
Drei Knotenpunkte sind es hauptsächlich, welche den Verkehr des deutschen Westens mit dem slawischen Osten und dem skandinavischen Norden vermitteln: das dänische Schleswig und die beiden sächsischen Grenzbollwerke an der Elbe: Magdeburg und Bardowik.

Die bedeutendste Rolle hat im Laufe dieser Jahrhunderte unter ihnen vielleicht Schleswig gespielt ${ }^{10}$ ); denn über Schleswig vornehmlich ging der Verkehr nach Schweden, und Schweden wiederum beherrschte den Handel mit Rußland, insbesondere mit Nowgorod, dem wichtigsten Ausgangspunkt des nordischen Handels. Mit Schleswig vollzog sich der Verkehr vom Rheine wahrscheinlich im wesentlichen über die Nordsee und durch die Eidermündung ${ }^{11}$ ).

Stärker im allgemeinen als der Austausch über Bardowik war in jenen Jahrhunderten der Verkehr, der über Magdeburg ins Slawenland führte. Das Aufblühen zahlreicher Städte am Harz und in dessen Umgebung seit dem 10. Jahrhundert infolge des Harzer Bergbaues, der einen der wichtigsten Ausgangspunkte wirtschaftlichen Lebens in Nordwestdeutschland bildete ${ }^{12}$ ), hat zur Belebung dieses Zustromes zweifellos erheblich beigetragen. Zum Harze führte von der Maas und vom Rheine eine vielbegangene Landstraße am Rande des mitteldeutschen Hochlandes entlang ${ }^{13}$ ). Die außerordentliche Verbreitung magdeburgischer Münzen aus dem 11. und 10. Jahrhundert im Slawenlande ${ }^{14}$ ) östlich der Elbe ist $\mathrm{u}$. a. ein deutlicher Fingerzeig für das Überwiegen des magdeburgischen Verkehrs dorthin.

An der Unterelbe ist schon in karolingiseher Zeit Bardowik ein wichtiger Verkehrsplatz. Über Bardowik, Scheeßel, Magde-

$\left.{ }^{10}\right)$ S. meine Abhandlung: Schleswig als Vermittlerin des Handels zwischen Nordsee und Ostsee vom 9. bis 13. Jahrhundert in den Jahrbüchern der Gesellschaft für schleswig-holstein. Geschichte. 1907. S.141ff.

11) Ebenda.

$\left.{ }^{12}\right)$ Vgl. Weiland, Goslar als Kaiserpfalz, in Hans. Geschichtsbl. 188'.

$\left.{ }^{13}\right)$ S. u. a. Hans. Urkdb. I n. 22, 61; III n. 601 und Note 3 daselbst.

14) S. die Münzfunde bei Dannenberg, Die deutschen Münzen der sächsischen und fränkischen Kaiserzeit. Berlin. \& Bände. 1876. 1894. 1898. 1905. Ferner auch Hans. Urkdb. III, S. 394 zu n. 22. 
burg, Erfurt, Halasat, Forchheim, Bremberg, Regensburg, Loreh sollten nach einer Verordnung Karls des Großen die Kaufleute nicht hinausgehen; diese Plätze werden als Grenzmärkte für den Verkehr mit den Slawen und Avaren bezeichnet ${ }^{15}$ ). Für Bardowik sind die Avaren natürlich nicht in Betracht gekommen; es handelte sich hier im Norden nur um den Handel mit den Slawen. Über Bardowiks Handel in der nachkarolingischen Zeit besitzen wir freilich sehr geringe Kunde; erst im 12. Jahrhundert bei dem Aufkommen Lübecks erkennen wir deutlich, daß Bardowik noch, wie im 9. Jahrhundert, den Handel mit den baltischen Ländern vermittelte ${ }^{16}$ ). Daß aber Bardowik auch in der Zwischenzeit seine Stellung als Verkehrsplatz behalten hat, ergibt sich namentlich aus der Bedeutung, welche seine Zollstätte während dieser ganzen Zeit behauptete. In verschiedenen, andern Städten verlichenen Privilegien wurde die Bardowiker Zollstätte in diesen Jahrhunderten den wichtigsten Zollstätten des Reiches gleichgestellt, indem bei der Verleihung der Zollfreiheit im ganzen Reiche nur Bardowik, Tiel und Köln, in älterer Zeit auch noch Mainz, als Reichszollstätten ausgenommen blieben ${ }^{17}$ ). Häufigere Funde von Bardowiker Münzen aus dem 11. Jahrhundert im slawischen Gebiete deuten auch auf die Verkehrsbeziehungen dieses Platzes mit dem Osten hin; doch ist die Bardowiker Münze im Slawenlande ${ }^{18}$ ) nicht annähernd so oft gefunden wie die magdeburgische. Im 12. Jahr-

$\left.{ }^{15}\right)$ Kapitular v. $805 \S 7$. Monum. Germ. Hist. III.

$\left.{ }^{16}\right)$ Helmold, Chronik der Slawen, I c. 72. S. unten S. 22 f.

17) Privilegium Ottos III. von 975 an die Magdeburger, wo auf die gleichen Privilegien Ottos I. und Ottos II. Bezug genommen wird, Hans. Urkdb. I n. 1; Privilegium Lothars III. von 1134 an die Goslarer, wo ebenfalls auf ăltere Privilegien Bezug genommen wird, ebenda n. 10. Bardowiks Zollstätte wird auch sonst mehrfach erwähnt. 965 schenkt Otto I. den zehnten Teil des Bardowiker Zolles an das Kloster Lüneburg (s. Hammerstein, Der Bardengau, Hannover 1869, S. 175 und 512). 1134 erneuert Kaiser Lothar dem Kloster St. Michaclis zu Lüneburg diese Schenkung (ebenda S. 513 und S. 175). 1158 verleiht Ifeinrich der Löwe dem Bischof und der Geistlichkeit von Ratzeburg \%ollfreiheit zu Bardowik für die Gegenstünde ihres eigenen Bedarfs (ebenda S. 14 't und 514).

18) Vgl. die Funde bei Dannenberg oben Note 14. 
hundert tritt die Bedeutung der Bardowiker Münze übrigens auch urkundlich deutlich hervor ${ }^{19}$ ).

Bardowiks Bedeutung beruhte ohne Zweifel auf dem bequemen Übergange über die Elbe an dieser Stelle. Allerdings lag Bardowik selbst nicht an der Elbe, wo es feindlichen Überfällen nordischer Seeräuber zu leicht ausgesetzt gewesen wäre, sondern an einem kleinen, schiffbaren Nebenflüßchen der Elbe, der Ilmenau, zwei Meilen von der Elbe entfernt. Allein etwas weiter unterhalb von Bardowik begann die Elbe sich in verschiedene Arme zu verzweigen, die jetzt zum Teil vom oberen Zuflußs abgeschnitten und tote Wasserarme geworden sind, die heutige Dove (d. h. taube) Elbe und die Goseelbe in den Vierlanden; weiter talwärts bei Hamburg verzweigt sich die Elbe noch heute zu einem Netze von Flußläıfen und Inseln, und unterhalb Hamburgs erschwerten die dort schon recht bedeutende Breite des Flusses und die damals noeh uneingedeichten und schwer zugänglichen breiten Marschen des linken Ufers den Übergang. So bot die Gegend ron Bardowik die bequemste Gelegenheit der Übersehreitung des unteren Flußlaufes, wenngleich anch von Bardowik aus, das selbst noch an der Geest liegt, eine gute Meile Flußmarsch zu passieren war, bis man die Elbe erreichte, während am rechten Ufer die Geest dort unmittelbar an den Strom herantritt.

Über die Wege, auf denen sich der Handel nach Bardowik bewegte, haben wir keinerlei Nachrichten; für diesen Platz können vom Rheine her sowohl der Weg über die Nordsee in die Elbe als der Weg zu Lande in Betracht gekommen sein. Vermutlich sind sie beide benutzt worden. In allgemeinen herrscht bis jetzt die Ansicht vor, daß der Seeverkehr bis zum 12. Jahrhundert im Nordseegebiete wenig ausgebildet gewesen sei und der Landverkehr vorgewaltet habe. Allein diese Auffassung trifft nicht zu. In der Karolingerzeit besuchten die

19) 1114 steuerten die Circipaner aut vulpinam pellem aut bis ter dena nomismata Bardewicensis moneta simillima vel propria (Annal. Corbej. 114, Pertz, Scr. III); vergl. Hammerstein, Der Bardengau, S. 513 (Bardowiker Münze in Bremen, in Verden erwähnt; 1134 werden dem Michaeliskloster in Lüneburg auch Einkünfte aus der Münzstätte von Bardowik rom Kaiser geschenkt). 
friesischen Kaufleute zur See im Osten Schleswig ${ }^{20}$ ), im Westen die englische und französische Küste ${ }^{21}$ ). Adam von Bremen ${ }^{22}$ ) bezeugt uns für das 11. Jahrhundert ausdrücklich das Bestehen der Handelsschiffahrt von der dänischen Küste über die Nordsee nach Sachsen, den Niederlanden und England; die Utrechter Zollrolle ${ }^{23}$ ) von 1122 , welche aber ausdrücklich altbestehende Zustände beurkundet und Verhältnisse.wiedergibt, die gewiß ebenso schon im 11. Jahrhundert bestanden haben, zeigt gleichfalls Handelsverkehr über die Nordsee nach Dänemark, nach Norwegen, nach Sachsen und nach Osterland, worunter wir sehr wahrscheinlich die baltischen Länder, das Gebiet der Osterlinge, zu verstehen haben $\left.{ }^{24}\right)$. Die Londoner Zoll-

$\left.{ }^{20}\right)$ S. meine oben Note 10 angeführte Abhandlung S. 142, $153 \mathrm{f}$. Vgl. auch Vogel, Zur nord- und westeuropäischen Seeschiffahrt im früheren Mittelalter, Hans. Geschichtsbl. 1907, S. 153.

21) York in England; auch in St. Denys ist von den Schiffen der friesischen Kaufleute die Rede.

$\left.{ }^{22}\right)$ Adami Gesta IV. 1.

23) Hans. Urkdb. I n. 8.

24) Die Zollrolle unterscheidet, ob die Friesen vom ,Osterland“" oder von Sachsen Waren bringen; im ersten Falle soll der Zoll 24 Denare, wovon 4 zurückerstattet werden, im letzten 17 Denare, wovon 1 zurückerstattet wird, betragen. Höhlbaum (Hans. Urkdb. I n. 8, Note) versteht unter Hinweis auf Junghans i. d. Forschungen z. deutsch. Geschichte, Bd. IX, S. 513 ff. unter ,Osterland“ Ostfriesland, te Geer (Bijdragen tot de Geschiedenis en Oudheiden der Provincie Utrecht. Utrecht 1860, S. 242; und het oude Trecht, Utrecht 1875, S. 169) erklärt das Osterland als das Land der Osterschen oder Osterlinge, also das baltische Gebiet. Alle drei unterlassen es, eine Begründung für die von ihnen vertretene Deutung zu geben. Daß das Osterland gleichbedeutend mit Ostland ist, dürfte wohl ohne weiteres anzunehmen sein. Unter dem „Ostland“, bisweilen auch in hansischen Urkunden Osterland (H. R. I. 3, n. 240 Ziff. 8 No. 9) genannt, wird regelmäßig das östliche, in den IIänden der Osterlinge liegende Handelsgebiet, also das baltische Gebiet, verstanden. Daß auch für Ostfriesland dieser Ausdruck gebraucht wurde (II n. 266, Note 2) läßt sich nicht bestreiten; auch für Finnland kommt der Ausdruck vor (Hans. Urkdb. III n. 348 und Inhaltsverzeichnis daselbst unter ,Holland"). Das sehr hohe Kopfgeld spricht dafür, daß es sich um besonders gewinnbringenden Handel und wertvolle Waren, wie sie aus fernen Gegenden zugeführt werden, handelte. Auch soll mit dem Osterland offenbar nicht die Heimat dieser. Utrecht besuchenden Friesen bezeichnet werden, wie aus der Gleichstellung desselben mit Sachsen hervorgeht; die Urkundo 
rolle ${ }^{25}$ ), die Höhlbaum in das 11 . Jahrhundert, andere schon in frühere Zeit ansetzen, ergibt ebenso Handelsverkehr flandrischer, deutscher und französischer Kaufleute über das Mecr. Die frühe kommerzielle Entwicklung so vieler Küstenplätze der deutschen Nordsee, die schon durch die Tatsache des Vorhandenseins von Münzstätten in diesen Orten bezeugt wird, ist gar nicht anders denkbar als in Verbindung mit der Seefahrt. Utrecht, Stavorn, Groningen, Emden, Jever, Bremen, Stade, selbst Dokkum, Leuwarden, Bolsward u. a. ${ }^{26}$ ) sind schon im 11. Jahrhundert Sitze von Münzstätten; unter den Münzen jener Zeit, die in den baltischen Ländern in so großen Mengen gefunden worden sind und den Verkehr des deutsehen Westens dorthin für jene Zeit belegen, sind diejenigen dieser Prägstätten zum Teil gar nicht selten $\left.{ }^{26}\right)$. So hat also der Seeverkehr auf der Nordsee während des 11. Jahrhunderts keineswegs geruht, und wenn wir für das 10. Jahrhundert weniger Beläge für sein Bestehen finden, so wird diese Erscheinung darin ihren Grund haben, daf aller Verkehr, auch der Landverkehr, nach den furchtbaren Verheerungen der Normannenzeit damals noeh daniederlagg ${ }^{27}$ ). Bei der Wasserverbindung Bardowiks mit der Nordsee würde es sehr wunderbar erscheinen, wenn der Verkehr mit dem rheinischen Westen diesen bequemsten Weg ganz unbenutzt

hat vielmehr dieselben friesischen Kauffahrer vor Augen, die, wenn sie vom Osterland kommen, den einen, wenn sie von Sachsen kommen, den andern Zollsatz entrichten sollen; nur der Herkunftsort der Einfuhr ist mit dem Osterland bezeichnet. Das Gebiet des heutigen Ostfriesland dürfte damals ebensowenig eine wesentliche Rolle als Produktionsgebiet von Waren für den Großverkehr gespielt haben, wie später, wenngleich zu jener Zeit zu Ostfriesland das ganze Gebiet vom Vlie bis zur Ems gerechnet wurde. - Über die frühe Bedeutung der Friesen im Verkehr nach den baltischen Gebieten vgl. u. a. Schäfer, Der Stamm der Friesen und die niederländische Seegeltung in der Marine-Rundschau, 1905, S. 1361 ; Höhlbaum, Die Gründung der deutschen Kolonien an der Düna, in hans. Geschichtsbl. 1872, S. 58.

$\left.{ }^{25}\right)$ Hans. Urkdb. I n. 2, III n. 599.

$\left.{ }^{26}\right)$ S. Dannenberg oben Note 14, ferner Menadier, Deutsche Münzen, Berlin 1891-1895.

$\left.{ }^{27}\right)$ Über den Seehandel der nordischen Völker in dieser Zeit vgl. u. a. Pappenheim, Altnordische Handelsgesellschaften in der Zeitschrift für das gesamte Handelsrecht. Bd. XXXVI. 
gelassen hätte. Die Nennung Bardowiks in Verbindung mit den beiden Seehandelsplätzen Tiel und Köln in den Zollprivilegien legt sogar den Gędanken nahe, daß die Kaufleute diese Plätze auf ihren Handelsreisen tatsächlich nacheinander besuchten, indem sie die Elbe hinab über die Nordsee und den Rhein hinauf fuhren, und die Tatsache, daß, wie wil sogleich sehen werden, seit der ersten Hälfte des 11. Jahrhunderts auch an der Unterelbe Handelsverkehr und damit zweilellos auch Seeverkehr emporblühte, verleiht dieser Vermutung sogar große Wahrscheinlichkeit.

Seit dem Anfange des 11. Jahrhunderts tritt nämlich Stade an der Schwinge, einem Nebenflüßchen der Unterelbe, als Handelsplatz in die Erscheinung. Im Jahre 1038 erhielt der Erzbischof Bezelin von Kaiser Konrad das Privileg ${ }^{28}$ ), in Stade einen Markt nebst Zoll und Münze zu errichten. Zahlreiche Münzen, die in einem aus der Mitte des 11. Jahrhunderts stammenden Münzfunde ${ }^{29}$ ) enthalten waren, der bei Farwe in Holstein in der Nähe der slawischen Handelsstadt Stargard oder Aldenburg (heute Oldenburg), einem Ausgangspunkte des damaligen Ostseeverkehrs, entdeckt wurde, geben Zeugnis von der raschen Entwicklung dieses Handelsplatzes. Aus den Hindernissen, welche Stade später der Ungehung seines Stapels bei der Fahrt die Elbe hinauf entgegenzusetzen suchte, erkennen wir deutlich, daß Stade Verkehr elbaufwärts unterhielt, und hier wird die Markt- und Zollstätte Bardowiks das natürliche Ziel der Reisen der Stader gewesen sein. Nach Westen hin wird Stade von Anfang an mit den Niederlanden in Verbindung gestanden haben. Unmittelbare urkundliche Zeugnisse hierfür besitzen wir allerdings erst aus der letzten Hälfte des 12. Jahrhunderts ${ }^{30}$ ); sie zeigen uns Stade im Verkehr mit Utrecht; doch ist dieser Verkehr wohl schon erheblich älter. Wenn die Utrechter Zollrolle von 1122 von dem Verkehr der „, friesischen Kaufleute, wenn sie von Sachsen kommen“, spricht, so werden wir hierbei vor allem an Stade zu denken haben,

${ }^{28)}$ Hamb. Urkdb. I n. 69.

$\left.{ }^{29}\right)$ Dannenberg, a. a. O. I. S. 81 .

$\left.{ }^{30}\right)$ Hans. Urkdb. I n. 42, auch 62 und 83. 
und wenn dabei besonders des Zollsatzes gedacht wird, den diese Friesen, ,es venale“ von Sachsen bringend, erlegen sollen, so ist damit höchst wahrscheinlich Kupfer aus den Harzbergwerken gemeint, das noch im 13. Jahrhundert eine so große Rolle unter den von der Elbmündung nach den Niederlanden verschifften Waren spielte ${ }^{31}$ ). Denn für den Verkehr der Harzgegend mit Bardowik besitzen wir schon aus dem Beginne des 12. Jahrhunderts urkundliche Belege ${ }^{32}$ ). Die Utrechter Zollrolle sagt aber, wie schon erwähnt, ausdrücklich, daß sie althergebrachte Ordnungen, nicht neue Verhältnisse aufzeichnet, und so werden wir gewiß nicht fehlgehen, wenn wir diesen Handelszug auch schon in das 11. Jahrhundert zurückdatieren. Stade wird neben Bremen ferner Adam von Bremen im Auge gehabt haben, wenn er für das Ende des 11. Jahrhunderts von dem Verkehre von Ripen nach Sachsen berichtet ${ }^{33}$ ); denn Stade finden wir auch später in enger Beziehung zu Ripen; bestand doch in Stade eine besondere Bruderschaft der Ripenfahrer $\left.{ }^{34}\right)$. Mit dem slawischen Osten wird Stade in der Regel über Bardowik, den Stapelplatz des Austausches mit den Slawen in dieser Gegend, verkehrt haben, wenngleich der Fund der zahlreichen Stader Münzen bei Farwe aus der Miite des 11. Jahrhunderts unwillkürlich die Frage nahelegt, ob etwa auch ein unmittelbarer Weg von Stade nach dem slawischen Handelsplatz Stargard in Wagrien durch Holstein hindurch geführt habe $\left.{ }^{35}\right)$.

${ }^{31}$ ) Vgl. Weiland, Goslar als Kaiserpfalz in Hans. Geschichtsbl. 1884, S. 21 und s. unten S. 105 ff.

${ }^{32}$ ) In dem Güterregister des Abtes Erkenbert von 1106-1128 heißt es von den Litonen der Corveyschen Propstei zu Groningen bei IIalberstadt: pro itinere, quod debent annuatim Corbeyam ire vel ad Barthunwik pro piscibus, IIII litones vadant vel IIII solidos per singulos annos secudum vices suas persolvant excepto servitium. Ebenso schickte Helmstedt seine Dienstpflichtigen nach Bardowik, um Fische und Salz zu holen. S. Hammerstein, Bardengau, S. 186 f., 513.

33) Adami Gesta VI 1.

34) Hans. Urkdb. III n. 183.

${ }^{35}$ ) In dieser Beziehung ist der Handelsverkehr zu beachten, der noch im 13. Jahrhundert auf der Stör sich abspielt. Von Itzehoe gehen Salzschiffe die Stör hinauf. Hans. Urkdb. I n. 693 und 546. Sollten 
Bardowiks Verkehr nach dem Osten vollzog sich auf dem Landwege und war im Slawenlande, wie es scheint, zunächst auch nicht auf einen nahen Hafen der Ostsee gerichtet. Wenigstens ist ein solcher vor dem Ende des 11. Jahrhunderts lür uns nicht mit Sicherheit erkennbar; wir lesen vielmehr bei Adam von Bremen ${ }^{36}$ ), daß man ,,von Hamburg oder von der Elbe", bei welch letzterem Ausdruck Adam gewiß den Elbübergang bei Bardowik im Auge hat, in sieben Tagen nach Julinum an der Odermündung reise. Übrigens erwähnt Adam sowohl an der Odermündung als auch an der Weichsehmündung im 11. Jahrhundert schon deutsche Kaufleute handeltreibend ${ }^{37}$ ).

Hamburg ist in diese Skizze nicht eingezeichnet. 'Zwar' sind auch für Hamburg schon im 9. Jahrhundert Spuren einer Teilnahme am wirtschaftlichen Verkehr nachzuweisen; allein diese Anfänge sind noch in demselben Jahrhundert wieder zugrunde gegangen, und so kommt es, daß Hamburg im 10. und 11. Jahrhundert keine Rolle mehr in dem Austausche zwisehen dem Westen und den baltischen Ländern gespielt hat.

Die ersten Nachrichten über Hamburg führen uns zurück an die Schwelle des 9. Jahrhunderts, als die Einverleibung des Sachsenlandes in das Reich Karls des Großen soeben vollendet war. Der rechtselbische Teil Sachsens - Nordalbingien genannt - in welehem Hamburg liegt, war damals cin Außenzipfel des Reiches. Im Osten begann sehon jenseits der Bille das slawische Grenzgebiet; von der oberen Bille zog sich die Grenze durch das Quellgebiet der Trave bis elwa zur Quclle der Eider hin. Die ganze Ostseeküste des heuligen Holstein und Mecklenburg war im Besitze der Slawen. Im Norden erreichte dieser Teil Sachsens in Eidergebiete die dänische Grenze;

sie nicht nach der Ostsee, dem Hauptziel aller Salzverladungen, bestimmt gewesen sein, wo eine so starke Nachfrage nach Salz zum Einsalzen der Fische bestand, deren Fang dort einen der wichtigsten Erwerbszweige bildete? sie mochten nach Kiel grehen, dessen Bewolnner ja schon im 13. Jahrhundert sich lebhaft am Heringsfang auf der Ostsee beteiligten.

36) Adami Gesta II c. 19.

$\left.{ }^{37}\right)$ Ebenda II c. 19 , IV c. 18. 
nach Westen und Süden hin war er durch die Nordsee und die Elbe von dem übrigen Sachsen abgeschnitten.

Der Übergang nach und von Nordalbingien über die Elbe war schwierig nicht nur wegen der sehr erheblichen Breite und Stärke des Stromes, sondern auch, weil die auf beiden Seiten der Geest vorgelagerten Sümpfe und Moräste der noch nicht eingedeichten Marschen an den meisten Stellen auch den $\mathrm{Zu}-$ gang von der Geest zum Flusse hinderten. Nur bei Hamburg tritt die Geest unmittelbar an die Elbe heran; allein gerade hier verbreitert sich der Strom, der sich oberhalb Hamburgs in mehrere Arme teilt und bei Hamburg versehiedene, damals gewiß schwer zugängliche Inseln in seinem Strome bildet, so bedeutend, daß der Übergang hier auf besonders große Schwierigkeiten stößt. Der Elbübergang weiter stromaufwärts bei Bardowik aber führte auf dem rechten Elbufer sehon in slawisches Grenzgebiet und bot deshalb keine gesicherte Verbindung mit dem rechtselbischen Sachsen. So wiesen die geographischen Verhältnisse den Verkehr geradezu auf die Schiffahrt zwisehen den Häfen Nordalbingiens und dem Hauptlande der Sachsen hin.

Die Elbe nimmt von Nordalbingien verschiedene Zuflüsse auf, deren größte die Stör und die Alster sind. Diese kleinen Wasserläufe bildeten die natürlichen Eingangsstellen für den Verkehr des Westens mit dem Lande der Holsaten und Stormarn; auf ihnen fanden auch die Fahrzeuge einen gegen Wind und Wetter wie gegen feindliche Angriffe besser geschützten Liegeplatz, als ihnen der offene Elbstrom zu bieten vermochte. An beiden Flüssen, dort an der Stelle des jetzigen Itzehoe, hier an der Stelle Hamburgs, sehen wir deshalb zu Karls des Großen Zeit Stützpunkte der fränkischen Herrschaft entstehen.

Ob an dem Ausflusse der Alster in die Elbe bereits vorher ein Ort vorhanden war, muß dahingestellt bleiben. Damals erfolgte nach der 804 vollendeten Unterwerfung Nordalbingiens hier jedenfalls die Gründung einer Kirche. Auch von der Einsetzung eines Priesters namens Heridac an dieser Kirche ist uns Kunde erhalten. Gedacht war diese Schöpfung als Stützpunkt für die Ausbreitung der kirchlichen und wahrscheinlich 
auch der politischen Herrschaft des Frankenreiches über das ostelbische Gebiet ${ }^{38}$ ).

Nach Karls des Großen Tode im Jahre \$14 sank der fränkische Einfluß im ostelbischen Sachsen rasch; die kirchliche Gründung in Hamburg ging wieder ein. Sein Nachfolger Ludwig der Fromme wandte allerdings ebenfalls seine Aufmerksamkeit der Bekehrung des Nordens zu; aber diese Mission nahm unter ihm ihren Ausgang zunächst vom Rheine über die Nordsce nach Dänemark und Schweden. Erst im Beginne des 4. Jahrzehntes des 9. Jahrhunderts griff Ludwig den Plan seines Vaters wieder auf, die Basis dieser Mission in das entfernte, von Slawen umgebene ostelbische Sachsen zu verlegen. So gründete er denn 831 in Hamburg ein Erzbistum und berief den in der nordischen Mission bereits bewährten Bischof Ansgar als Erzbischof dorthin. Aber auch dieser Gründung war nur eine kurze Dauer beschieden; nach Ludwig des Frommen Tode fehlte es dem Erzbistum bald an der nötigen Unterstützung durch die weltliche Macht; wichtige Lehnsgüter, deren Erträge bis dahin im wesentlichen den Unterhalt des Erzbistums geliefert hatten, ${ }^{39}$ ) wurden bei der Teilung des Reiches im Vertrage von Verdun dem Erzbischof genommen; die hamburgische Kirche geriet dadurch in Verlegenheit und sah sich außerstande, ihre Aufgabe zu erfüllen. Wenige Jahre später, 845, wurde dann die ganze Ansiedlung durch einen Normannenüberfall zerstört; der Erzbischof rettete sich mit genauer Not durch die Flucht. Von der Wiederherstellung des erzbischöflichen Sitzes in Hamburg konnte vorläufig aber bei dem Mangel an Mittehn und der Unsicherheit der politischen Verhältnisse keine Rede sein. Seitdem 848 das Bistum Bremen mit Hamburg vereinigt und Ansgar Bischof von Bremen geworden war, wurde tatsächlich Bremen der Ausgangspunkt für die nordische Mission, wenn auch freilich der Titel Erzbischof von Hamburg beibehalten wurde und sich die Mission noch lange Zeit an den Namen der hamburgischen Kirche knüpfte. 880 fiel Hamburg von neuem

${ }^{38}$ ) Vgl. Über die Gründung der ersten Kirche in IIamburg Lappenberg, Hamb. Urkdb. I n. 8; Vita Ansgarii c. 13 in Monumenta Germaniac Historica SS. II.

$\left.{ }^{39}\right)$ Vita Ansgarii c. 21. 
einer Verwüstung durch die Normannen anheim; das Schwergewicht des kirchlichen Regiments verschob sich nun vollends nach Bremen.

Verschiedene Umstände sprechen dafür, daß Hamburg im 9. Jahrhundert, wenigstens in der erzbischöflichen Zeit, nicht ohne wirtschaftlichen Verkehr geblieben ist. Die ersten Beziehungen Hamburgs zu einer andern Gegend, von welchen wir hören, sind Verbindungen nach Flandern: dem Priester Heridac wurde von Karl dem Großen das Kloster Hrodnace (Renaix) ${ }^{40}$ ) in Ostflandern an einem Nebenflüßchen der Schelde, dem Erzbischof Ansgar von Ludwig dem Frommen das westflandrische Klostergut Turholt (Thourout) ${ }^{41}$ ) als wirtschaftlicher Stützpunkt für die Mission zugewiesen. Von den Einkünften dieser flandrischen Güter bestritten diese Geistlichen zunächst ihren Lebensunterhalt und den Aufwand für die Mission; wie sehr Ansgar noch 843 von dem Eingange dieser Erträge seines flandrischen Gutes abhängig war, zeigt die Notlage, in die er durch den Verlust desselben $\mathrm{kam}^{42}$ ). In jenem Zeitalter der Naturalwirtschaft läßt sich aber die Nutzung dieser Erträge seitens der erzbischöflichen Verwaltung kaum anders als in der unmittelbaren Zufuhr der landwirtschaftlichen Erzengnisse des Klostergutes nach Hamburg denken, und die Wahl eines Gutes in dem reichen, aber fern gelegenen Flandern kann schlechterdings nur dann angezeigt gewesen sein, wenn für die Herbeischaffung der Güter der in der Tat bequeme Seeweg in Frage kam; wäre die Zufuhr auf den Landweg angewiesen gewesen, so wäre nicht zu verstehen, warum beide Kaiser gerade in dem ungelegenen Flandern und nicht in größerer Nähe ein Kirchengut auserlesen hätten. Wir finden somit in diesen Tatsachen Anzeichen dafür, daß die Erträgnisse des flandrischen Kirchengutes zur Sce Hamburg zugeführt wurden. Aber nicht nur die Verwaltung des erzbischöflichen Kirchengutes, sondern auch Kaufleute beteiligten sich von Hamburg aus am Verkehrsleben. In der Lebensbeschreibung Ansgars lesen wir von dem Auf-

$\left.{ }^{40}\right)$ S. Hamb. Urkdb. I n. 8 Note $\%$

41) Ebenda Note 12 und Vita Ansgarii c. 12.

42) Vgl. Vita Ansgarii c. 21. 
treten in Hamburg getaufter Christen in der als Zwischenmarkt für den Austausch zwischen Nordsee und Ostsee schon damals bedeutenden dänischen Stadt Schleswig, und es kann sich nach dem Zusammenhange bei diesen Christen nur um Kaufleute gehandelt haben ${ }^{43}$ ). Über die Unterlagen dieses Verkehrs erfahren wir leider nichts; wir wissen weder, um welcherlei Kaufgegenstände es sich handelte, noch auf welchem Wege sie Schleswig erreichten - ob zu Lande oder ob zu Wasser über die Eidermündung. Nur gelegentlich erfahren wir, daß in Nordalbingien wohl Sklavenhandel getrieben wurde $\left.{ }^{44}\right)$.

Es ist sehr wahrscheinlich, daß der Verkehr der Hamburger, dessen Spuren wir soeben verfolgt haben, erst durch die Errichtung des erzbischöflichen Stuhles ins Leben gerufen worden ist, wie ja so oft die Sitze der geistlichen Würdenträger zu Mittelpunkten des Handels und Verkehrs geworden sind, weil die kirchlichen Verwaltungen einerseits mancherlei Zufuhren für die Versorgung der Geistlichkeit und den Dienst der Kirche bedurften und andererseits Überschüsse von den Erträgnissen ihrer Güter an den Verkehr abgeben konnten. Außerdem wurden solche Orte ja häufig der Sammelplatz von Pilgern, Wallfahrern und Volksmengen, die schon zur Bestreitung ihres Unterhaltes mancherlei Tauschgegenstände mit sich brachten und zugleich zu ihrer Beköstigung der Zufuhr von Lebensmitteln u. dgl. bedurften. Auch die hamburgische Kirche besaß bereits Reliquien verschiedener Heiliger ${ }^{45}$ ), welche Wallfahrer heranzichen mochten.

In der zweiten Hälfte des 9. Jahrhunderts sind indessen diese Anfänge eines wirtschaftlichen Verkehrs in Hamburg wieder vernichtet worden. Die Zerstörungen des Ortes, die Unsicherheit der politischen Verhältnisse und vor allem die Verlegung des erzbischöflichen Sitzes nach Bremen geben die Erklärung für diese Erscheinung. In einer Urkunde ${ }^{46}$ ) König Arnulfs aus dem Jahre 888, in welcher dem Erzbischof für handlung.

$\left.{ }^{43}\right)$ Vita Ansgarii c. 24 und meine oben Note 10 angeführte $\mathrm{Ab}$ -

44) Vita Ansgarii c. 38 .

45) Adami Gesta I c. 19.

${ }^{46)}$ Hamb. Urkdb. I n. 22. 
Bremen Verkehrsrecht (negotiandi usus) und das Reeht, Münzen zu schlagen, verliehen wird, heißt es, daß diese Rechte den Leitern der Kirche in Hamburg schon früher zugestanden hätten, wegen der Unsicherheit der Gegend dort aber nicht mehr ausgeübt werden könnten. Die Echtheit dieser Urkunde ist freilich nicht unbestritten. Aber andere Nachrichten aus der folgenden Zeit bestätigen, daß Hamburg kein Handelsplatz mehr war.

Über Hamburgs Verhältnisse vom Ende des 9. bis zum 12. Jahrhundert besitzen wir allerdings nur dürftige Kunde ${ }^{47}$ ). Einige Nachrichten aus dem 10. Jahrhundert zeigen, daß es damals aus den Verwüstungen der Normannenzeit schon wieder erstanden war. 982 erlag es den Angriffen der Slawen. Im Anfange des 11. Jahrhunderts erlitt der Ort sogar eine gänzliche Zerstörung durch die Slawen. Nach Wiederherstellung der Ruhe nahm sich dann der Erzbischof Unwan (1013-1029) der kirchlichen Einrichtungen dort an. Offenbar war die ganze kirchliche Gründung daselbst zerstört und weder Kirche noch Geistlichkeit an dem Orte übrig geblieben. So zog denn Unwan von neuem Geistliche und Ansiedler nach Hamburg heran und ließ wiederum eine Kirche und Gebäude für die Geistlichkeit bauen. Gleichzeitig errichtete auch der Herzog von Sachsen eine Feste, in der er wohnen konnte, neben der erzbischöflichen Niederlassung. Alle diese Bauwerke waren noch von Holz. Bezelin, der 1035 bis 1045 Erzbischof war, vervollkommnete diese Schöpfungen, indem er zum Schutze gegen die Einfälle der umwohnenden Slawen ein steinernes, mit Bollwerk und Befestigungen versehenes Gebäude aufführen ließ, in welchem er bei seinen Aufenthalten in Hamburg Wohnung nahm, und auch an die Stelle der hölzernen Kirche eine solehe von Quadersteinen setzte. Auch der Herzog ließ nahe dem erzbischöflichen Gebäude ein besonderes Kastell für sich herrichten. Herzog Bernhard II. von Sachsen gab dieses Kastell auf und erbaute 1061 eine neue Burg zwisehen Elbe und Alster. 1066 und

47) Für das Folgende ist Quelle namentlich die Hamb. Kirchengeschichte Adam von Bremens; vgl. Lappenberg, Hamburgische Rechtsaltertümer, Bd. I, Hamburg 1845, Einleit. S. 3 ff.; Rüdiger, Barbarossas Freibrief für Hamburg vom 7. Mai 1189, Hamburg 1899, S. \& f.; über die Grafen von Hamburg vgl. Lappenberg, Hamb. Urkdb. I, Beil. III. 
1072 wurde Hamburg wiederum von Slawen völlig zerstört. Im 11. Jahrhundert verweilten übrigens sowohl die Herzöge als auch die Erzbischöfe, namentlich Adalbert (10.43-1072), häufiger auf diesen ihren Residenzen in Hamburg. Seit dem Ende des 11. Jahrhunderts sind als Vertreter und Lehnsträger der Herzöge in Hamburg auch Grafen nachweisbar.

Daß die erzbischöfliche Ansiedlung in Hamburg während des 10. und 11. Jahrhunderts kein Verkehrsplatz gewesen ist, zeigen deutlich die Privilegien ${ }^{4 \succ}$ ) Ottos III. von 988 und Heinrichs III. von 1003 und 1014, in welchen die Rechte der hamburgischen und der bremischen Kirche bestätigt werden; hier ist bei Hamburg, dessen doch eingehend in diesen Urkunden gedacht wird, niemals von irgendwelchen Handels- oder Verkehrsrechten die Rede, während die Markt-, Münz- und Zollrechte, welche die Erzbischöfe in Bremen ausübten, sorgfältig aufgezählt werden. Von der Niederlassung der Herzöge und seit dem Ausgange des 11. Jahrhunderts ihrer Lehnsträger, der Grafen, besitzen wir sehr wenig Nachricht. Jedenfalls aber geben zahlreiche Funde erhaltener Münzen städtischen Gepräges des 10. und 11. Jahrhunderts uns Kunde von der Teilnahme vieler selbst kleiner Plätze des deutschen Binnenlandes wie der Küste am Handelsverkehre, während es für Hamburg an jedem derartigen Zeugnisse fehlt. Erst im Jahre 1189 wird die hamburgische Münze erwähnt; freilich wird in der fraglichen Urkunde von dem Hause des Münzers gesprochen, als ob es schon vorhanden wäre und nicht erst geschaffen werden sollte; auch ist es nach den vorliegenden Nachrichten nicht ganz ausgeschlossen ${ }^{49}$ ), daß die Münze im Besitze des Erz-

48) Hamb. Urkdb. I n. 49, 56, 61; vgl. Gädechens, Hamb. Münzen und Medaillen, Hamburg 185', II. Abt, 2. Heft, S. 162.

$\left.{ }^{49}\right)$ Vgl. Koppmann, Kleine Beiträge zur Geschichte der Stadt Hamburg und ihres Gebietes. Hamburg 1868 II, S. 19. Lappenberg, Hamb. Rechtsaltertümer, I. Einl. S. 5; beide halten die Münze für erzbischöflich, dagegen Gädechens, a. a. O. S. 162, hält die Münze schon im 12. Jahrhundert für gräflich. Hasse, Zur Kritik von Kaiser Friedrich Barbarossas Privileg für Hamburg 1189, in Zeitschr. d. Gesellsch. 〔ür schleswig-holstein.-lauenb. Geschichte, S. 264 ff., hat die Echtheit der Urkunde in diesem Punkte angegriffen; siehe dagegen Schrader in Mitteilungen des Vereins für hamb. Geschichte, XVI. Jahrg., S. 110 ff. 
bischofs, nicht des Grafen war; möglich, daß hier die alten erzbischöflichen Rechte aus dem 9. Jahrhundert wieder aufgelebt waren; lange wird die Hamburger Münzstätte jedoch damals noch nicht wieder in Tätigkeit gewesen sein.

Der Umstand, daß Adam on Bremen die Entfernung Julinums von Hamburg erwähnt, indem er an einer Stelle sagt ${ }^{50}$ ), man reise von Hamburg oder von der Elbe in sieben Tagen nach der Stadt Julinum, und daß ferner der Scholiast, welcher Adams Schrift kommentierte, bei Aldenburg bemerkt ${ }^{51}$ ), daß der Ort eine Tagereise von Hamburg am baltischen Meere liege, ist vielfach als Anhalt für das Bestehen eines Handelsverkehrs von Hamburg nach diesen Plätzen angesehen worden. Es ist indessen zu beachten, daß Adam ausdrücklich als Ausgangspunkt der Reise neben Hamburg einen andern Punkt an der Elbe, offenbar den Elbübergang bei Bardowik, hinstellt; wenn er nicht nur diesen andern Punkt, sondern auch Hamburg nennt, so mag dies seinen Grund darin gehabt haben, daß die Beziehung der Entfernung auf die Mutterstadt des Erzbistums für ihn als Geistlichen besonders nahe lag. Was aber die Angabe des Scholiasten über die Entfernung nach Aldenburg betrifft, so ist auf diese überhaupt recht wenig Gewicht zu legen, da sie offenbar ganz fehlerhaft ist. Denn die Entfernung von Hamburg nach Aldenburg beträgt in der Luftlinie mehr als 100 Kilometer, und es ist bei den mangelhaften Wegen und Beförderungsmitteln jener Zeit gar nicht denkbar, daß Warentransporte dieselbe in einer Tagereise zurückzulegen pflegten, zumal man auf die Reise nach Julinum, die etwa dreimal so weit war, sieben Tage rechnete. Auch stellt Adam Hamburg keineswegs, wie so manche andere Plätze, als große Stadt dar. Von Hamburg, der Hauptstadt der Stormarn, sagt er ${ }^{52}$ ), indem er dabei wohl an die Zeit, wo Erzbischof Ansgar dort seinen Hof gehalten hatte, denkt, sie sei ,,einst mächtig an Männern und Waffen, gesegnet an Feldern und Früchten" gewesen, fügt aber in Hinblick auf die Gegenwart hinzu, jetzt

$\left.{ }^{50}\right)$ Adami Gesta II 66.

$\left.{ }^{51}\right)$ Ebenda, II 8'. Schol. 29.

52) Ebenda, II 61. 
sei sie ,zur Strafe ihrer Sünden in eine Einöde verwandelt", wie er sie denn auch am Eingange seiner Schrift nur in der Vergangenheit als die ,einst angesehenste Stadt der Sachsen“ bezeichnet ${ }^{53}$ ). Wenn er hinzufügt, die Stadt könne sich trösten, da die Zahl ihrer Söhne durch den ganzen Norden sich von Tag zu Tag mehre, so hat er dabei die Ausbreitung des Christentums und die Eigenschaft der hamburgischen Kirche als Mutterkirche der nordischen Mission im Auge. $\mathrm{Zu}$ Adams Zeiten war der Ort offenbar nicht mehr ,mächtig an Männern und Waffen" und zählte also wohl nicht viele Bewohner.

Übrigens würde, selbst wenn der Warenverkehr nach Schleswig vom Rheine her, wie die bisher herrschende Auffassung gewesen ist, den Landweg genommen hätte, nur Bardowik Haltestation dieses Verkehrs gewesen sein, während Hamburg ebensowenig eine besondere Bedeutung zugekommen wäre wie zahlreichen kleinen Orten zwischen den rheinischen Ausgangspunkten dieses Verkehrs und Bardowik. In der karolingischen Verordnung über die Grenzmärkte, unter denen ja auch Bardowik genannt wird, ist indessen nur von dem Handel mit den Slawen und Avaren daselbst ohne Erwähnung der Dänen die Rede.

Bardowik an der Ilmenau und Stade an der Schwinge genossen vor Hamburg den Vorzug, daß sie durch die Elbe vor plötzlichen Überfällen der Slawen geschützt waren und dem Verkehre der Deutschen deshalb eine viel größere Sicherheit boten als Hamburg. Das 12. Jahrhundert brachte indessen in dieser Beziehung eine Änderung.

Bis dahin war die ganze Ostseeküste in Händen von Slawen. An das slawische Wagrien auf der Ostseite der cimbrischen Halbinsel schloß sich das Gebiet der Obotriten, und südlich von diesen saßen als Nachbarn der Stormarn bis an den Sachsenwald und an die Elbe hinan die Polabinger, als deren Stadt Adam Ratzeburg bezeichnet ${ }^{54}$ ). Das Christentum hatte zwar schon in den vorhergehenden Jahrhunderten in diesen Gebieten festen $\mathrm{Fuß} \mathrm{zu}$ fassen begonnen; aber kriegerische Erhebungen

s3) Adami Gesta I. 1.

s4) Ebenda, II 64. 
hatten die Errungenschaften der Kirche immer wieder zerstört. Im 12. Jahrhundert begann nun aber die Germanisierung dieser Länder. Schon Graf Adolf II. von Holstein (1128-1164) zog Ansiedler aus den niederrheinischen Gegenden in das Land ${ }^{55}$ ). Heinrich der Löwe vollends beugte nicht nur die gesamten Slawenvölker der Ostseeküste bis zur Oder seinem Scepter, sondern rottete auch jeden Widerstand in diesen Gebieten endgültig aus. Scharen von deutschen Ansiedlern aus Sachsen, Friesland und Flandern traten an die Stelle der slawischen Bewohner. Gleichzeitig führte weiter südlich im Brandenburgischen und Havelbergischen Albrecht der Bär in ähnlicher Weise die Germanisierung des Landes durch.

Mit diesem allgemeinen Vorrücken des Deutschtums nach Osten verschoben sich erklärlicherweise auch die Grenzstützpunkte, welche den deutschen Kaufleuten zum Ausgange für den Verkehr nach dem Osten und Norden dienten. Schon in der letzten Hälfte des 11. Jahrhunderts lag an dem südwestlichsten Winkel des baltischen Meeres, da, wo die Trave und Schwartau zusammenfließen, ein slawischer Ort, der Buku hieß und einen Hafen hatte $\left.{ }^{56}\right)$. Hier bestand schon zur Zeit der Herrschaft des Slawenfürsten Heinrich (1105-1126), der dort seinen Sitz hatte, eine nicht unbedeutende Ansiedlung deutscher Kaufleute, die sich des Schutzes des Slawenfürsten erfreute ${ }^{57}$ ). Etwas oberhalb der Stätte dieses Ortes, der 1138 von andern Slawen zerstört worden war, gründete 1143 Graf Adolf II. von Holstein an der Trave eine neue Ansiedlung, die er Lubeke nannte $\left.{ }^{58}\right)$, und welche sich rasch als Handesplatz entwickelte; bald hören wir von mit Waren beladenen Schiffen, welche der Slawenfürst Niclot bei einem Überfall des Ortes verbrannte ${ }^{59}$ ). Als 1157 diese Stadt durch eine Feuersbrunst gänzlich zerstört worden war, machte Heinrich der Löwe zunächst vergeblich den Versuch, sie an einer andern Stelle neu zu gründen, baute dann aber, nachdem Graf Adolf

$\left.{ }^{55}\right)$ Helmold, I 53 und 57.

${ }^{56}$ ) Ebenda, I 57.

$\left.{ }^{57}\right)$ Ebenda, I 48.

${ }^{58}$ ) Ebenda, I $5 \%$.

${ }^{59}$ ) Ebenda, I 63. 
nach anfänglichem Widerstreben seine Rechte auf die Einkünfte aus dem lübischen Markte aufgegeben und den alten Platz dem Herzoge überlassen hatte, an derselben Stelle die Stadt von neuem auf $\left.{ }^{60}\right)$. Er sandte Boten an die Städte und Reiche des Nordens, nach Dänemark, Schweden, Norwegen, Rußland, entbot allen Kaufleuten freien Zutritt und sicheres Geleit und forderte sie zum Besuche der neuen Handelsstadt auf. Die Stadt selbst stattete er mit weitestgehenden Rechten aus.

Der Verkehr dieses neuen Platzes nach dem Westen knüpfte naturgemäß an die bestehenden Stapelplätze und Handelsstraßen an und war deshalb zunächst auf Bardowik gerichtet. Noch in dem Privilegium, welches Kaiser Friedrich I. 1188 den Lübeckern verleiht ${ }^{61}$ ), ist diese Richtung des Verkehrs deutlich erkennbar: durch das ganze Herzogtum Sachsen sollen die Lübecker zollfrei passieren dürfen, außer an der Zollstelle Erteneburg, der rechtselbischen Kontrollstation des Bardowiker Elbüberganges. Hier zu Erteneburg aber sollen sie soviel Wagen, wie sie unter Erlegung des Zolles über die Elbe hinüber geführt haben, binnen Jahresfrist zollfrei wieder zurückführen dürfen ${ }^{62}$ ).

$\left.{ }^{60}\right)$ Ebenda, I 85.

61) Hans. Urkdb., I n. 33.

${ }^{62}$ ) Es scheint mir sehr naheliegend, daß unter dem transfretare der Fremden in jener Urkunde nicht das Verschiffen ostwärts über das Meer, sondern das Verfrachten zur Elbe hinüber und von dort über die Nordsee (nach Flandern) zu verstehen ist (vgl. über das Wort var Hans. Urkdb. I n. 665 und III Wörterverzeichnis und die ,lübecker var“ unten Kapitel IV Note 25 und die Ausführungen im Text daselbst). Dann wäre allerdings die Urkunde von 1227 in diesem Punkte nicht ohne weiteres die Übersetzung der Urkunde von 1188. Die letztere hätte vielmehr den im Osten wohnenden, von dort kommenden, nach dem Westen weiterreisenden Fremden, also den Russen, den Goten usw., vor Auge, wăhrend die erstere bei dieser Stelle an den im Westen beheimateten, von dort nach dem Osten reisenden Fremden, den Westfalen, Friesen usw., dächte. Das könnte aber in den Verănderungen, welche der aktive Handel der Völker im Westen und Osten durchmachte, seine Ursache haben. Denn die Völker des Ostens wurden durch die Völker des Westens aus diesem Handel immer mehr verdrăngt. Die verănderte Vorstellungsweise der Urkunde von 1227 wăre also sehr erklärlich; vielleicht wurde die Ur. 
Durch das Aufblühen Lübecks sah schon zur Zeit, als die Stadt noch im Besitze des Grafen von Schauenburg war, Bardowik seine Stellung als Grenzstützpunkt des deutschen Handels mit dem Osten stark erschüttert; Bardowik suchte dem Emporkommen Lübecks deshalb mit allen Mitteln entgegenzuarbeiten ${ }^{63}$ ). Es erhob bei dem Landesherzoge Heinrich dem Löwen Klagen über die schwere Benachteiligung, welche ihm durch den Wettbewerb Lübecks erwachse, und fand damit

kunde von 1188 in diesem Punkte 1227 aus diesem Grunde schon gar nicht mehr verstanden. Unter dem homo pergens ad mare in der Lübecker Zollrolle von 1227 scheint mir der mit seinen Waren Durchreisende gemeint zu sein; nicht die Ausfuhr zur See, sondern die Durchfuhr vom Westen her durch Lübeck seewärts wird von den hohen Zollsätzen (15 Denare die Schiffslast) getroffen. So gewinnt auch der im Zolltarif vorhergehende Satz eine andere Bedeutung: ,Wenn der Fremde, welcher zur See angekommen ist - nur die seewärts Angekommenen hat die Zollrolle bis dahin im Auge, die mit Wagen, also zu Lande, Ankommenden werden später aufgeführt - in seinem Geschäfte zur Elbe hinüberreist, so soll er, wenn er von seinem westlichen Reiseziele - von jenseits der Elbe zurückkehrt und zur See von Lübeck aus ostwărts weiterreisen will, die Marktabgabe der 4 Denare nicht zu bezahlen brauchen (nur die Marktabgabe der 4 Denare scheint mir mit den Worten quicquam dare gemeint zu sein, denn nur von dieser ist bisher die Rede gewesen); wenn er, vom Westen kommend, nicht ostwärts zum Meere mit seinen Waren weiter zu gehen beabsichtigt, also die Waren auf dem Lübecker Markt absetzen will, soll er die Marktabgabe von 4 Denaren zahlen. Frei ist er von dieser Marktgabe indessen auch in diesem Falle, wenn er in Lübeck seine rechtmäßige Ehefrau, also dort seinen Wohnsitz hat. - Für die Warendurchfuhr, den homo pergens ad mare, der also nicht in Lübeck emere und vendere will, den dortigen Markt also nicht beschickt, gelten die weiterhin aufgeführten hohen Zollsătze; diesen unterliegt also auch der Mann, der von jenseits der Elbe zurückkehrt und zum Meere hin will, seine Waren somit nur durchfürt und deshalb von der Marktabgabe frei ist. Daß der Gesetzgeber, wie Frensdorff a. a. O. S. 131,132 meint, eine Bestimmung über den Zoll getroffen hätte, den der Mann zu zahlen hat, der von Lübeck aus westwärts fahren will, die Elbe bereits überschritten hat, sich dann aber eines andern besinnt (!), und nach Lübeck umkehrt, um seewärts zu fahren, erscheint schlechterdings nicht möglich. Solche Leute sind ganz gewiß nicht häufig vorgekommen, und der Gesetzgeber hat doch zweifellos die regelmäßig vorkommenden Fălle im Auge. Jedenfalls ist damit keine Erklärung der Stelle von Frensdorff gegeben.

${ }^{63}$ ) S. über das folgende Helmold, I 76. 
bei Heinrich Gehör, da auch des Herzogs Einnahmen aus den Gefällen des Bardowiker Verkehrs - die Einnahmen Lübecks flossen noch dem Grafen zu - unter diesen Verhältnissen gelitten hatten. Herzog Heinrich verlangte nun, wohl als Ersatz für den Ausfall seiner Bardowiker Einkünfte, die Abtretung der Hälfte der Einnahmen aus dem Lübecker Verkehr und verbot schließlich, da Adolf II. dies Ansinnen ablehnte, zugunsten seiner Stadt Bardowik überhaupt den Handelsverkehr in Lübeck, abgesehen vom Lokalverkehre. Welche unmittelbaren Folgen dieses Verbot nach sich zog, entzieht sich unserm Auge; jedenfalls blieben viele Kaufleute dort ansässig ${ }^{64}$ ), und die Maßregel wird also wohl kaum streng zur Durchführung gelangt sein. Als nach der Zerstörung Lübecks durch eine Feuersbrunst im Jahre 1157 die Stadt von Heinrich dem Löwen nach Abtretung des Grund und Bodens seitens des Grafens an den Herzog wieder aufgebaut wurde ${ }^{64}$ ), war das Verkehrsverbot jedenfalls endgültig beseitigt.

Der Verkehr von den niederrheinischen Gebieten her wird, wie bereits oben dargelegt, schon früh und jedenfalls bereits im 12. Jahrhundert überwiegend den Weg über die Nordsee gewählt haben. Für die Vermittlung dieses Verkehrs nach Lübeck war von der Zeit an, wo das rechtselbische Gebiet gegen die Überfälle der Slawen genügend gesichert war, naturgemäß ein Platz auf dem rechten Elbufer weit günstiger gelegen als die älteren Handelsplätze Stade und Bardowik, und kein Platz empfahl sich mehr für diesen Umschlag als Hamburg, von wo der Weg nach Lübeck am kürzesten war und wo sich zugleich eine günstige Stelle zum Landen der Schiffe bot. Daß sich auch hier bereits vor 1189 Verkehr zu regen begann, beweist ein Zollprivilegium ${ }^{65}$ ), welches Heinrich der Löwe den Hamburgern für die nahegelegenen oberelbischen Zollstätten Eßlingen (d.i. Zollenspieker), Kraul und Geesthacht verlieh. Die Tatsache, daß es noch 1189 in Hamburg überhaupt an Hafeneinrichtungen

64) Helmold, I 85.

$\left.{ }^{65}\right)$ S. Hans. Urkdb. I n. 133. Charakteristisch ist, daß die Hamburger die Geltung der Zollbefreiungen für Lauenburg schon nicht mehr nachweisen konnten, sondern nur für die drei der Stadt nächstgelegenen Zollstätten. 
zur Aufnahme einer größeren Anzahl Schiffe fehlte, zeigt indessen, daß dieser Weg über Hamburg rom Handel doch bis dahin nur sehr wenig betreten worden war und der regelmäßige Handelszug noch immer, wie auch das kaiserliche Privileg für Lübeck von 1188 erkennen läßt, auf den Elbübergang von Erteneburg (gegenüber Artlenburg) und Bardowik gerichtet war. Der Handel war in jener Zeit an die wenigen hierfür besonders privilegierten und befriedeten Orte und Straßen in einer Weise gebunden, von der wir uns heute schwer eine Vorstellung machen können; Hamburg aber gehörte bis dahin noch nicht zu diesen Plätzen.

Erst im Jahre 1189 trat hierin für Hamburg eine Änderung ein $\left.{ }^{66}\right)$. Der Graf Adolf IJI. von Schauenburg nahm, offenbar einem immer stärker hervortretenden Bedürfnisse des Verkehrs folgend, die Anlage einer größeren kaufmännischen Ansiedlung mit Hafen und Markt in Hamburg in Angriff ${ }^{67}$ ). Er übertrug einem Manne namens Wirad von Boizenburg, der wohl schon zu den Leitern der vorhandenen Ansiedlung gehörte - wenigstens finden wir ihn im Jahre 1190 als einen der Ratmänner Hamburgs urkundlich erwähnt ${ }^{68}$ ) —, die Stadt (urbs) Hamburg an der Alster, also offenbar die dem Grafen gehörige, dort schon vorhandene kleine städtische Niederlassung um seine Burg herum und ein an dieselbe angrenzendes Gebiet bis zur Mitte des Alsterflusses ,,mit dem Narktrechte“ erblich zum Anbau und zu dem Zwecke, daß Wirad mit den von ihm heranzuziehenden Mitbewohnern der neuen Ansiedlung einen ,für die von vielen Orten ringsumher kommenden Leute" geeigneten Hafen baue. Als Lohn sollte Wirad, ausgenommen die ersten drei Jahre, die Strafgefälle der Gerichtsbarkeit an Haut und Haar - also der niederen Gerichtsbarkeit - und ein Drittel der Gefälle der Gerichtsbarkeit an Hals und Hand in dieser neuen Stadt erblich zustehen. Nur die Strafgefälle wegen falschen Maßes bei Bier, Brot und Wein sollten zu zwei Dritteilen der Stadt, zu einem

${ }^{66}$ ) Über das Folgende s. auch Lappenberg, Hamb. Rechtsaltertümer, S. 9 ff.; Koppmann, Beiträge, Bd. II S. 7 ff.; Rüdiger, Barbarossas Freibrief für Hamburg rom 11. Mai 1189.

${ }^{67)}$ Hamb. Urkdb. I n. 285.

${ }^{68)}$ Hamb. Urkdb. I n. 292. 
Dritteil dem Richter zufallen. Zur Förderung des Unternehmens sicherte der Graf den Kolonisten von vornherein Befreiung vom Zoll in Hamburg und im ganzen gräflichen Gebiete, sowie freie Verfügung über den ihnen zugeteilten Grund und Boden, Befreiung vom Bodenzins und Nutznießung von Weide und Wald zu. Im Jahre $1195^{69}$ ) fügte der Graf auf Bitten der von Wirad herangezogenen Kaufleute auch noch die Erlaubnis zur Erbauung einer Kapelle zu Ehren des heiligen Nikolaus, des Patrons der Schiffahrt, ,wegen des Zustroms der Schiffe“ (propter navium affluentiam) unter unentgeltlicher Zuweisung des hierfür erforderlichen Grund und Bodens hinzu und legte damit den Grund zur Nikolaikirche. Charakteristisch für diese ganze Gründung ist, daß den Ansiedlern der Grund und Boden nach lübischer Gerechtsame übergeben wurde. Ursprünglich war Stade nur wohl der Umschlags- und Vermittlungsplatz für die Weiterversendung der zur See vom Westen kommenden oder dorthin bestimmten Waren im Verkehr nach Bardowik gewesen; denn in Stade war, so lange Hamburg noch nicht emporgewachsen war, der natürliche Endpunkt der Seeschiffahrt. Noch am Ende des 13. Jahrhunderts war Stade zum Mindesten für einen Teil der Hamburger Schiffe der Ausgangsund Endpunkt der Wattenschiffahrt nach den Niederlanden ${ }^{70}$ ), und noch während des ganzen späteren Mittelalters sehen wir die Hamburger Schiffe oft in den Mündungen der kleinen Nebenflüsse der Elbe, in der Stör und Schwinge, wo sie gegen Unwetter und Seegang geschützt waren, liegen, um auf günstigen Wind und günstiges Wetter zum Antritt der Seereise zu warten. So mögen alle Waren, welche die Elbe aus- und eingingen, ohne weiteres nach Stade gekommen und dementsprechend dem Marktzolle unterworfen gewesen sein. Als mit dem Aufkommen Hamburgs die Schiffe nun zum Teil an der Schwinge vorbeifahren wollten, wird der Erzbischof von Bremen gegen diese Schmälerung der Zolleinkünfte aus dem Markte vermutlich Einspruch erhoben haben. Als einen Ausgleich der widerstreitenden Interessen werden wir es ansehen dürfen, wenn fortan die

$\left.{ }^{69}\right)$ Hamb. Úrkdb. I n. 310. Die Nikolaikapelle wird u. a. erwăhnt auch 1223 (n. 463) und 1238 (n. 509); s. auch n. 809. 840, 879 usf. $\left.{ }^{70}\right)$ S. unten Kapitel II Note 170 und die Ausführungen im Texte daselbst. 
von der See kommenden Schiffe zwar nicht mehr gezwungen wurden, in die Schwinge nach Stade einzulaufen, wie sie früher getan hatten, sondern die Elbe weiter hinauffahren durften, aber erst, nachdem sie am Ausgange der Schwinge gelandet, den früher in Stade gezahlten Zoll erlegt sowie drei Gezeiten hatten vorübergehen lassen und damit also wohl den Stadern auch die Möglichkeit zum Handeln gegeben hatten ${ }^{71}$ ). An diesem Stader Zolle hatte nun Graf Adolf III. von Holstein kein Interesse; denn Stade gehörte zum Erzbistum Bremen. So erwirkte denn der Graf, welcher mit Kaiser Friedrich zum Kreuzzuge aufbrach und zu seiner Ausrüstung eine nicht unbedeutende Summe von den Bürgern Hamburgs erhalten hatte, am 7. Mai 1189 ein Privileg ${ }^{72}$ ) von Kaiser Friedrich I., welches u. a. die Hamburger auch von diesem Zolle befreite und bestimmte, daß sie selbst mit ihren Schiffen, Waren und Leuten vom Meere

i1) S. A. Soetbeer, Des Stader Elbzolles Ursprung, Fortgang und Bestand, Hamburg 1839.

$\left.{ }^{72}\right)$ Hans. Urkdb. I n. 36. Die Echtheit des Privilegs ist allerdings von IIasse, Zur Kritik von Kaiser Friedrich Barbarossas Privileg für Hamburg 1189, in Zeitschr. der Gesellsch. f. schleswig-holstein-lauenb. Geschichte, Bd. 23, in verschiedenen Punkten angegriffen; indessen hat Schrader in d. Mitteil. des Vereins f. Hamb. Geschichte, 16. Jahrg., 1894, S. 10 ff. die von Hasse vorgebrachten Gründe m. E. entkräftet. Gegen die Echtheit des Siegels der Urkunde hat Perlbach in Hans. Geschichtsbl. 1898, S. 141 Einwendungen geltend gemacht. Die Ausführungen Weißenborns, Die Elbzölle und Elbstapelplätze im Mittelalter, Halle 1901, S. 66 ff., sind nicht stichhaltig. Die Tatsache, daß die Schiffe, wenn sie bei Stade vorbeikamen, das übrigens nicht an der Elbe, sondern etwa $5 \mathrm{~km}$ landeinwärts an der Schwinge liegt, nicht nur Zoll zu zahlen, sondern anzulegen und 3 Tiden vorübergehen zu lassen hatten, deutet eben darauf hin, daß es sich hier nicht nur um einen eigentlichen Wasserzoll, sondern um einen Ausfluß des Marktzolles, des Anspruches auf den Stapel, an den Stade gewöhnt war, handelt. Daß der Stader Zoll erst seit der Mitte des 13. Jahrhunderts bestanden haben sollte, ist schon an sich höchst unwahrscheinlich. Die Einrichtung eines solchen neuen Zolles würde sicherlich auch bei den Kaufleuten der andern Städte Deutschlands und des Auslandes, insbesondere Lübecks, auf heftigen Widerstand gestoßen sein, während die uns überkommenen Nachrichten keine Spur solcher Einsprüche anderer Städte um jene Zeit enthalten. Vor allem aber würden die Hamburger, wenn der Zoll oder die Verpflichtung zum Anlegen bei der Schwinge vor Mitte des 13. Jahrhunderts für die in die Elbe einfahrenden Schiffe noch nicht bestanden hătte, 
bis zur Stadt frei sein sollten von jedem Zoll und Ungeld sowohl bei der Ausfahrt als auch bei der Rückfahrt; führten sie Waren fremder Kaufleute auf ihren Schiffen, so sollten diese zwar den Stader Abgaben unterliegen, die Schiffe der Hamburger sollten indessen auch dann von der Verpflichtung, Stade anzulaufen, befreit sein und das Recht haben, nur einen Boten nach Stade zu entsenden, welcher dort auf Grund eidlicher Angabe den Zoll gemäß der Menge der Güter zu erlegen hätte; glaube aber der Stader Zöllner, daß der Zoll nicht richtig entrichtet sei, so solle es ihm freistehen, mit nach Hamburg zu fahren und hier sich von den Verhältnissen zu überzeugen und sich Recht zu verschaffen.

Inwieweit etwa der Erzbischof und die Stadt Stade der Durchführung dieses Privilegiums Widerstand leisteten, vermögen wir nicht $\mathrm{zu}$ verfolgen. Wir wissen nur ${ }^{73}$ ), daß der Graf alsbald nach seiner Rückkehr mit dem Erzbischof in Fehde lag, zu Harburg, vermutlich um die Süderelbe zu sperren, ein festes Schloß anlegte ${ }^{74}$ ), Stade eroberte und diesen Platz schließlich auch dauernd in seine Gewalt brachte, indem er sich 1195 vom Erzbischof mit der Grafschaft Stade belehnen ließ; ein Drittel der Stader Einkünfte sollte fortan dem Grafen, zwei Drittel dem Erzbischof zufallen.

Um die neue Ansiedlung noch weiter zu fördern, gewährleistete das kaiserliche Privileg im Einverständnis mit dem Grafen weitgehende Freiheiten für den Verkehr und Vorteile für die Ansiedlung, und der Graf verbriefte 1190 auch seinerseits diese Rechte noch besonders. Die Bürger sollten in Hamburg und im ganzen gräflichen Gebiete von Zoll und Ungeld

schwerlich mit einem schon 1189 verliehenen Privileg, welches sie von dieser Verpflichtung befreite, damals haben Eindruck machen können, da es ja den Stempel der Fälschung an der Stirn getragen hätte. Daß der Zoll in der ersten Hälfte des 13. Jahrhunderts schon bestanden hatte und daß die Hamburger demselben bis zum Ausbruche des Zwistes um die Mitte des Jahrhunderts nicht bezahlt hatten, scheint mir nach dem vorliegenden Urkundenmaterial sicher, selbst wenn das Privileg von 1189 in diesen Punkten gefälscht sein sollte, um einen Rechtsanspruch auf die Fortdauer des bestehenden Zustandes zu schaffen.

73) Hamb. Urkdb. I n. 307.

${ }^{74)}$ Rüdiger, a. a. O. S. 18. 
befreit sein, also nur die Fremden diesen Abgaben unterworfen werden; zugleich wurde ihnen das für die Sicherheit des Handels hochwichtige Recht verliehen, die von der Münzstätte in Hamburg geprägten Münzen auf Reinheit und Gewicht zu prüfen; das Geldwechselgeschäft, das in anderen Orten vielfach der Münzstätte vorbehalten war, die dabei einen für den Verkehr empfindlichen Aufschlag zu fordern pflegte, sollte in Hamburg vollständig frei sein; nur sollte es nicht gerade gestattet sein, unmittelbar vor dem Münzhause bei andern Geld zu wechseln. In der ganzen Grafschaft sollten die Bürger ungehindert einkaufen dürfen und ihre Waren gegen obrigkeitliche Anhaltung außer im Falle von Straftaten gesichert sein. Die Befreiung vom Heerbann, von der Landesverteidigung und von allen Kriegsverpflichtungen, die Zusicherung, daß im Umkreise von zwei Meilen um die Stadt keine Burg oder sonstige Befestigung sollte angelegt werden dürfen, das Recht der Bürger zum Fischfange auf der Elbe und auf der Bille und die Nutznießung von Wald und Weide waren weitere Vorteile, durch welche das Privileg die Entwicklung der Stadt zu begünstigen suchte.

Außer diesem Privileg brachte das Jahr 1189 aber noch eine sehr wichtige Wendung für den Handelsverkehr zwischen Lübeck und der Elbe und für die Entwicklung Hamburgs mit sich. Wenige Monate nach der Verleihung des kaiserlichen Privilegiums an Hamburg wurde nämlich der bisherige Stapelplatz für den Verkehr von der Elbe nach der Ostsee vernichtet und damit der bisher begangene Handelsweg verschüttet. Am 28. Oktober $1189^{75}$ ) nahm der aus der Verbannung zurückgekehrte Heinrich der Löwe Bardowik, welches ihm die-Tore verschloß, mit Gewalt ein und machte die Stadt dem Erdboden gleich. Damit war die wichtigste Rivalin Hamburgs beseitigt und der Verkehr geradezu auf den neu gegründeten Handelshafen Hamburgs hingedrängt. So trafen denn in diesem Zeitpunkte die verschiedensten Umstände zusammen, um Hamburg in kürzester Frist zu einem wichtigen Knotenpunkte des Handelsverkehrs zu entwickeln.

$\left.{ }^{75}\right)$ S. Lappenberg, Hamburgische Chroniken in niedersächsischer Sprache, Hamburg 1861, S. 386, Note 1. 


\section{Erster Abschnitt.}

\section{Das 13. Jahrhundert.}

Erstes Kapitel.

\section{Brügge mit dem Zwin als Mittelpunkt des westeuropäischen Handels und der Anteil der Deutschen, insbesondere der Ham- burger, am europäischen Seehandel des 13. Jahrhunderts.}

Der Hebel, welcher Hamburg seit dem Ende des zwölften Jahrhunderts zum Handelsplatze emporhob, war der Verkehrsarm, der einerseits in dem unentwickelten, an das baltische Meer grenzenden Norden Europas, insbesondere in Rußland und andererseits in den dicht bevölkerten gewerbereichen Gebieten der Niederlande seinen Angelpunkt fand. In dem Maße, in welchem dieser Handelszug seinen Lauf über Lübeck-Hamburg richtete, wuchs auch die Handelsbedeutung dieser Städte. Tatsächlich fiel dieser Verkehr im 13. Jahrhundert ganz überwiegend in diese Linie; nicht nur Bardowik und Stade, sondern vor allem auch das dänische Schleswig, das bis dahin eine sehr wichtige Rolle in dem Austausche der deutschen Kaufleute mit dem Norden und Osten gespielt hatte ${ }^{1}$ ), und wohl auch Magdeburg mußten mehr oder weniger ihren Anteil an diesem Verkehr an Lübeck abtreten. Lübeck besorgte den Austausch nach dem Westen über Hamburg weiter, und so wurden auch die Hamburger in den nordeuropäischen Großhandel hineingezogen.

1) S. meine Abhandlung: Schleswig als Vermittlerin des Handels zwischen Nordsee und Ostsee vom 9. bis in das 13. Jahrhundert in den Jahrb. d. Gesellschaft für schleswig-holstein. Geschichte, 1907, S. $141 \mathrm{ff}$. 
Als Mittelpunkt des ganzen westeuropäischen Verkehrs hebt sich seit dem Beginne des 13. Jahrhunderts im Netze der Verkehrsstraßen und größeren und kleineren Handelsplätze deutlich das flandrische Land $a b^{2}$ ). Den Mittelpunkt des Welthandels bildeten in jener Zeit die sechs großen Messen der Städte in der Champagne und Brie sowie die Messen ron Paris, auf denen sich der Austausch West- und Nordeuropas mit den Mittelmeerländern und dem Orient voll $\left.\mathrm{zog}^{3}\right)$. Flandern nun vermittelte den Verkehr des europäischen Westens und Nordens dorthin. In Flandern liefen deshalb die Fäden des ganzen nordund südwesteuropäischen Handelsverkehr's zusammen. Der vornehmlichste Markt Flanderns war Brügge. Sein Hafen, das Zwin, gab den Mittelpunkt des ganzen westeuropäischen Seehandels $\left.a b^{4}\right)$.

$\left.{ }^{2}\right)$ S. das Gedicht des Wilhelmus Brito von 121' (Monum. Germ. Hist., Scr. XXVI 3'z), wo Brügge gepriesen wird als Mittelpunkt des Handels und der Schiffahrt, wo h i n die Waren aus Phönizien, Syrien, von den Zykladen, aus Ungarn, von Rochelle und der Gascogne, England und allen sonstigen Teilen des Erdkreises z us a m m e n s t r ö m e n, damit sie vo n dort nach allen Teilen der Welt wieder ausgesandt werden (illuc mittantur, ut inde in varias partes mundi dominisque reportent lucra suis).

$\left.{ }^{3}\right)$ M. F. Bourquelot, Études sur les foires de Champagne, Paris 1865. 2 Bde.; s. auch Goldschmidt, Universalgeschichte des Handelsrechtes, Stuttgart 1891 , S. 195 und 22 iff., und die dort angeführten Quellen.

4) Diese Verhältnisse sind schon in sehr viel früheren Zeiten erkennbar. Die Messen der Champagne lassen sich bis in das 11., vielleicht sogar bis in das 10. Jahrhundert zurückverfolgen (Bourquelot, Les foires de Champagne, I. S. 70 ff., 192 ff.). Sehr alt auch die Pariser Messen; die Messe von St. Denys schon im 7. Jahrhundert nachweisbar; italienische und deutsche Kaufleute im 7. und 8. Jahrhundert auf jener Messe (Bourquelot, I S. 10; Doren, Florentiner Wolltuchindustrie vom 14. bis 16. Jahrhundert. Stuttgart 1901, S. 13). Brügge schon im 11. Jahrhundert von einem englischen Schriftsteller sowohl wegen des lebhaften Verkehrs der Kaufleute, als auch wegen der Zufuhr alles dessen, was die Sterblichen köstlich dünkt, gepriesen. (S. Lappenberg, Urkundliche Geschichte des hansischen Stahlhofes, Hamburg 1851, S. 5, Note 4). Über Brügges Schätze im 11. Jahrhundert s. auch $H$. Pirenne, Geschichte Belgiens, übersetzt von Fritz Arnheim, Gotha 1899, Bd. I, S. 190, Note 1. Auch in der Reiseroute, welche der Scholiast, der Adam von Bremens Werk im 11. Jahrhundert kommentierte, für die Seefahrt von Ripen nach dem Heiligen Lande auf- 
Wer heute von dem kleinen seeländischen Bade Katzand westwärts oder von dem belgischen Bade Knocke ostwärts auf der Dünenkette am Meere entlang wandert, kommt nach einigen Kilometern Weges an eine Stelle, wo die Dünenkette auf etwa einen halben Kilometer unterbrochen ist und die weiße Sandfläche des breiten Strandes sich über die Linie der Dünenkette hinaus in das Land hinein erstreckt. Der Wanderer hat hier den letzten Eingang des alten Zwin ror sich. Der dicke stumpfe Turm von St. Anna ter Muiden, den der Wanderer von hier fern in der Ebene erblickt, auf der einen Seite, und die fünfspitzige Krone des Belfrieds von Sluis, die in der Ferne aus den Sluis umgebenden Baummassen hervorragt, auf der andern Seite, bezeichnen die beiden Punkte, zwischen denen nach den Karten aus dem Ende des 16. Jahrhunderts ${ }^{1 a}$ ) noch damals das Zwin in eine weite, nach dem Meere hin vollständig offene Bucht mündete. Am Ende des 16. Jahrhunderts aber war das Zwin im Vergleiche zu der älteren Zeit schon ganz zusammengeschrumpft und für die Schiffahrt infolge seiner Versandung nicht mehr brauchbar; im früheren Mittelalter muß es ein Meereseinschnitt von erheblicher Breite und mit einer Reihe von Mündungen gewesen sein, der ursprünglich vielleicht bis Brügge selbst, im Anfange des 13. Jahrhunderts aber jedenfalls noch bis zu dem etwa $4 \mathrm{~km}$ von Brügge entfernten Orte Damme hinaufreichte, mit welchem Brügge durch einen $\mathrm{Kanal}^{5}$ ) verbunden war. Dieser Meereseinschnitt bildete im Mittelalter bis in die

führt, ist als erste Station Zinkfall, das ist das Zwin, in Flandern angegeben. Über die Zunahme der Messen der Champagne im 12. Jahrhundert vgl. Bourquelot I. S. 31, 74, 211 usw.; über den Verkehr der Flanderer dorthin ebenda, S. 192 f.; vgl. ferner Finot, Études historiques sur les rélations commerciales entre la France et la Flandre, Paris 189'x. Úber die Zunahme von Handel und Gewerbe in Flandern im 12. Jahrhundert s. Frensdorff, Aus belgischen Städten und Stadtrechten, in Hans. Geschichtsbl. 1878, S. 48 f., $53 \mathrm{ff}$.

4a) Vgl. u. a. die Karte von Lucas Joh. Aurigarius (Wagenaar) aus dem Jahre 1583 und die Karte Merkutors aus derselben Zeit.

$\left.{ }^{5}\right)$ Vgl. das oben Note 2 angeführte GedichtWilhelms des Bretonen; ferner auch Hans. Urkdb. I, n. 274 und 627; Th. Kiesselbach, Grundlage und Bestandteile des ältesten Hamburger Schiffrechts in Hans. Geschichtsbl. 1901, S. $64 \mathrm{f}$. 
Mitte des 15. Jahrhunderts ungeachtet vieler Veränderungen, welche er durchmachte, den vorzüglichsten Hafen an der ganzen Nordsee und war schon im 13. Jahrhundert der Mittelpunkt des ganzen westeuropäischen Schiffahrtsverkehrs. ${ }^{6}$ )

Flanderns wirtschaftliche Bedeutung stützte sich aber nicht lediglich auf seine Weltmarktstellung, sondern in erster Linie auf seine hochentwickelte Gewerbetätigkeit. Den Grundstock des Welthandels geradezu bildete in jener Zeit der Handel mit Wolltuchen; Flandern war der Sitz der Industrie, welche diese Tuche herstellte ${ }^{7}$ ); neben Flandern nahmen auch die benachbarten Teile Frankreichs bis in die Champagne hinein an dieser Industrie Anteil $\left.{ }^{8}\right)$. England lieferte in großen Mengen den Rohstoff für diese Industrie, die Wolle.

Die Tuche Flanderns sehen wir im 13. Jahrhundert einerseits über die Messen der Champagne und über die südfranzösischen Häfen ${ }^{9}$ ) in die Mittelmeerwelt und den Orient und

$\left.{ }^{8}\right)$ Vgl. auch Schäfcr, Die Hanse, Bielefeld und Leipzig 1903, S. 25; Hirsch, Danzigs Handels- und Gewerbegeschichte, Leipzig 1858, S. 121.

${ }^{7}$ S. u. a. Pirenne, Geschichte Belgiens, übersetzt von Arnheim Gotha 1899 I S. 298. Diese Industrie bestand damals schon Jahrhunderte in Flandern. Vgl. Frensdorff, Aus belgischen Städten und Stadtrechten in hans. Geschichtsbl. 1878: Pirenne u. a. O. I. S. 19;; Doren a. a. O. S. 19.

${ }^{8}$ ) L. a. hatten Châlons sur Marne und Provins bedeutende Tuchindustrien aufzuweisen. S. Bourquelot, I S. 224 ff., 2't' ff.

${ }^{9}$ ) Der Hauptrerkehrszug umgeht die Alpen und nimmt seinen Weg durch das Rhonethal, wo Montpellier bis zur zweiten Hălfte des 13. Jahrhunderts Hauptknotenpunkt der Verbindungen mit Italien ist, bis es seit dem letzten Drittel des 13. Jahrhunderts von Nîmes verdrăngt wird. Eben daraus, daß der Handel den Übergang über die nur mit großen Kraftaufbietungen und Kosten zu überschreitenden Alpen zu vermeiden bestrebt war, erklärt es sich, daß er seinen Weg von Flandern nach Italien nicht durch das Rheintal über die Alpen, sondern durch Frankreich und das Rhonetal über die südfranzösische Küste nahm. Schon im Altertum beruhte die Bedeutung Marseilles darauf, daß der Verkehr Italiens nach dem Yorden über diesen Platz die Alpen umging (s. Schulte, Geschichte des mittelalterlichen Handels und Verkehrs zwischen Westdeutschland und Italien, Leipzig 1900, S. 49, und die dort angegebene Literatur). - Über die Bedeutung von Montpellier auf den Messen der Champagne s. Bourquelot, I S. 150 ff.; Goldschmidt, Universalgeschichte d. H., S. 194 f.; über den Verkehr Montpelliers mit Italien s. Germain, Histoire du commerce de Montpellier, I S. 49-178; ferner 
andererseits von Brügge und dem Zwin aus zu Schiff in alle Gegenden Westeuropas vom russischen Norden bis zum spanischen Süden hinausgehen.

Auf den Messen der Champagne, wo die italienischen, südfranzösischen und katalonischen Kaufleute die Produkte Nordund Westeuropas gegen diejenigen der Mittelmeerländer und des Orients eintauschten, bildeten diese Tuche den wichtigsten Handelsartikel ${ }^{10}$ ). Aus der Färbung und Herrichtung der flandrischen und nordfranzösischen Tuche für den orientalischen Geschmack wurde im 13. Jahrhundert in den südfranzösischen und italienischen Handelsstädten eine hochbedeutende In-

die Handelsverträge Montpelliers mit Genua 1201 bei Germain, Histoire de la commune de Montpellier, Montpellier 1851, S. 422 ff., mit Venedig 1267 und mit Cremona 1254 bei Germain, Histoire du commerce de Montpellier, I n. 17ł́ f.; über die Bedeutung von Nîmes und Narbonne für den italienischen Handel s. Bourquelot, I. S. 153 f., Goldschmidt, S. 195. Verträge von Narbonne mit Genua 1109, 1311 u. s. f. Goldschmidt, a. a. O. S. 215 Note 83. Kohler, Handelsverträge zwischen Genua und Narbonne im 12. und 13. Jahrhundert, Berlin 1904. Vgl. ferner die Verträge von Narbonne mit Pisa 1173, von Marseille mit Pisa 1210; Goldschmidt, S. 215 Note 82 und 83; Niederlassungen der Italiener in den südfranzösischen Häfen schon im 12. Jahrhundert, ebenda S. 185 Note 151 Ziff. 2. Die Venetianer mußten im 14. Jahrhundert alle Waren, mit denen sie die südfranzösischen Häfen besuchten, weiter auf die Messen der Champagne bringen; 1351 wurde dieser Zwang aufgehoben, Bourquelot, I S. 191. Die italienischen Kaufleute treten in Frankreich mit den provençalischen gemeinsam auf, erwerben z. B. 1245 mit diesen gemeinsam Privilegien usw., s. Bourquelot, I S. 153; Goldschmidt, S. 195; 1295 schließt die, societas mercatorum cambitorum Lombardorum, Italiarum et ultramontanorum omnium nundinas Campanie, civitatem Nemausum (Nîmes) et provinciam Narbonnensem frequentantium" einen Vertrag mit dem König von Frankreich, s. Cioldschmidt S. $197 \mathrm{f}$. Gewils sind von den Italienern auch die Alpenpässe für den Verkehr nach der Champagne benutzt, s. u. a. Schulte, a. a. O. II. Urkdn. n. 251 und I. u. a. S. 75, 164, 200 usw., Goldschmidt, S. 197; nur ist der Weg über die Alpen weit entfernt gewesen, die eigentliche Hauptroute des Warenverkehrs zwischen der Champagne und Italien zu sein. DieseTatsache ist von Schulte verkannt (s. ebenda, I S. 199, 200, 344 ff. usw.).

$\left.{ }^{10}\right)$ Die ersten zehn Tage der Messe von Provins waren im wesentlichen dem Tuchhandel gewidmet, Bourquelot, I S. 84 ff.; Doren, Die Florentiner Wolltuchindustrie, S. 17 usw. 
dustrie ${ }^{11}{ }^{12}$ ). Durch die Hände der Italiener ${ }^{13}$ ), insbesondere der Genuesen und Pisaner, aber auch der Südfranzosen ${ }^{13}$ ) und Katalanen ${ }^{13}$ ) gingen die Tuche Flanderns und Nordfrankreichs weiter in den Orient ${ }^{14}$ ). Orientalische Gewürze und Kostbarkeiten, orientalische und italienische Gewebe von Seide und Baumwolle, Brokate, Korduanleder aus katalonischen und südfranzösischen Plätzen u. dgl. bildeten die Gegenwerte, mit welchen die flandrischen Tuche auf den Messen derChampagne eingetauscht wurden ${ }^{15}$ )

11) Namentlich in den toskanischen Städten, besonders Florenz und Lucca, ferner in Genua, ebenso in Montpellier und Marseille. Über die italienischen Städte s. namentlich Doren, Die Florentiner Wolltuchindustrie, S. 19 ff.; über Piacenza. Cremona, Brescia s. Schulte, a. a. O. S. 13' Note 8 und S. 133 Note 14 (panni de melioramento de Cremona et Breccia). Vgl. ferner namentlich A. Germain, Histoire du commerce de Iontpellier Bd. I, S. 20 f. Die Charte von 120: verbietet den Fremden, in Montpellier Wolltïcher mit Kermes-oder andern Farben zu färben (über die Beliebtheit der mit Kermes gefärbten Tuche im Orient s. Heyd, Geschichte des Levantehandels im Mittelalter, Stuttgart 1879, II S. 696 Note 6); ferner Germain ebenda S. 254 pièces justificatives n. 39. Die alte Satzung für das Färben der Tuche in Iontpellier wird 1265 verandert; als Tuche, welche dort gefärbt werden, werden erwähnt Tuche aus Chalons, Arras, England usw.; die Tuche, die in Genua, Lucca, Marseille gefärbt würden, erzielten einen höheren Preis, weil das Färbeverfahren dort besser sei; die Methode soll deshalb in Montpellier verändert werden. Ferner über den Weltruf der in Montpellier gefärbten Tuche usw., ebenda S. 299, n. 60; flandrische Tuche in Montpellier, S. 441, n. 81. - Noch 13:0 37 Färbermeister mit zahlreichen Arbeitern in Montpellier ansăssig; s. ebenda, Bd. II, S. 179, n. 119 ; s. ferner Bourquelot, I, S. 229 und 239.

12) Flandrische Tuche in Genua 1251 und im Venetianer Tarif von 1265, s. Schulte, a. a. O., S. 127 Note 1, 128 Note 1; Venetianer mit panni de Francia (d. h. von den Messen) in Cremona 1275 ebenda S. 133 Note 14; panni draperie de Francia in Mailand 1270 ebenda, S. 132 Note 1; in Brescia 1313 ebenda Note 2. Vgl. auch Schulte, S. 125 Note 2.

${ }^{13}$ ) S. namentlich Germain, Histoire du commerce de Montpellier, I S. 91-178. Übrigens finden wir auch die Venetianer und die Kaufleute der lombardischen und toskanischen Industriestädte lebhaft an dem Handel auf den Messen der Champagne beteiligt: Kaufleute von Genua, Mailand, Cremona, Asti, Pistoja, Piacenza, Venedig, Pisa, Florenz, Lucca, Siena, Rom, Urbino s. Bourquelot, I S. 163 ff., 168 ff., 186 f. usw. II $137 \mathrm{ff}$.

14) S. u. a. Heud, II S. 696 f., ferner 11 und 415 usw.

15) Bourquelot, I S. 191, 259 ff., 284 ff. Korduanleder einer der wichtigsten Handelsartikel auf den Messen, s. Bourquelot, I 84 ff., 153, 197, $274 \mathrm{ff}$. 
und die die Kaufleute dafür nach Flandern zurückbrachten. Früh dringen übrigens die Südländer über die Messen der Champagne nach Flandern selbst vor. Auf den Märkten von Ypern sind Lombarden schon im 12. Jahrhundert nachweisbar ${ }^{16}$ ). In der zweiten Hälfte des 13. Jahrhunderts lassen sich in Brügge Niederlassungen von Kaufleuten sowohl aus zahlreichen Städten des nördlichen Italien als auch aus der Provence, Languedoc und Katalonien nachweisen ${ }^{17}$ ).

Wie die flandrischen Wolltuche den Hauptgegenstand des Verkehrs vom Zwin über die Nordsee bildeten, werden wir im Verlaufe der Darstellung noch genugsam Gelegenheit haben $\mathrm{zu}$ beobachten. An dieser Stelle ist noch zu schildern, wie auch im Verkehr mit dem atlantischen Süden diese Tuche eine ähnliche Rolle spielten. Spanische und portugiesische Urkunden aus dem 13. Jahrhundert zeigen uns eine staunenswerte Fülle verschiedener Tuche aus Flandern und seinen Nachbargebieten auf den dortigen Märkten. In Sevilla führt eine Urkunde ${ }^{18}$ ) von 1268 Tuche verschiedenster Arten auf von Brügge, Gent, Ypern, St. Omer, Poperingen, Cambray, Douay, Tournay, Lille, Comines, Arras, Valenciennes; eine portugiesische Urkunde ${ }^{19}$ ) von 1253 erwähnt auf den Märkten Portugals zwischen Minho und Duero Tuche verschiedener Sorten aus Brügge, Gent, Ypern, St. Omer, Lille, Tournay, Valenciennes. Das Statut der Bayonner Seefahrergenossenschaft ${ }^{20}$ ) aus dem Jahre 1214 spricht ebenfalls von den feinen Tuchen, welche die Bayonner Schiffer in Flandern für die Rückreise einnehmen, und eine urkundliche Nachricht ${ }^{21}$ ) von 1269 meldet von Zollbefreiungen

$\left.{ }^{16}\right)$ Frensdorff, Aus belgischen Städten und Stadtrechten, i. Hans. Geschichtsbl. 1878, S. 45 und 64 Note 4.

17) S. u. a. die Übersicht bei Goldschmidt, Universalgeschichte des Handelsrechtes, Stuttgart 1891, S. 181 Note 151 Ziff. 4.

${ }^{18)}$ G. Rolin, Documents relatifs à l'histoire du commerce des draps dans la Péninsule ibérique au XIII siècle, Prag 1892 (36. Jahresbericht über die Prager Handelsakademie), S. 30, Doc. A.

19) Ebenda, S. 34, Doc. B. S. $283 \mathrm{ff}$.

$\left.{ }^{20}\right)$ Pardessus, Collections des lois maritimes, Bd. IV, Paris 1837,

21) Finot, Relations commerciales entre la France et la Flandre, S. 96 . 
für Tuche aus St. Omer, welche auf dem Seewege nach Rochelle verladen wurden.

Wir haben uns bei den Verkehrsbeziehungen Brügges mit dem Süden und Südwesten Europas so lange aufgehalten, um zu veranschaulichen, in welch ausgesprochenem Maße der Verkehr des Südens wie des Südwestens auf Flandern gerichtet war, um so es verständlich zu machen, daß auch die Linien des gesamten, durch die Kaufleute Norddeutschlands vermittelten Verkehrs des Nordwestens und Nordens von Europa so gut wie ausschließlich die Richtung auf Flandern hatten. In Flandern trafen die beiden großen Verkehrsströmungen des atlantischen Südens und Nordens senkrecht aufeinander, um sich hier miteinander zu verschlingen und mit zu dem großen Verkehrsstrome beizutragen, der sich von Flandern nach den Messen der Champagne bewegte, und jeder dieser auf Flandern gerichteten Verkehrsströme erzeugte naturgemäß eine Gegenströmung, die ihren Ausgangspunkt in Flandern hatte.

Wenden wir uns nunmehr wieder den Hamburger Kauffahrern zu, deren Spuren uns alsbald auf die verschiedenen großen Handelsstraßen führen werden, auf denen sich der Verkehr des Nordens nach dem Mittelpunkte des damaligen westeuropäischen Welthandels bewegte. Es war, wie schon oben hervorgehoben, der vom baltischen Gebiete nach dem Westen gerichtete Verkehr, dem Lübeck und Hamburg ihre Stellung als Handelsstädte verdankten, und dieser Verkehrszug war es auch, der die Hamburger nach dem Hafen von Brügge führte. Die Anziehungskraft dieses Verkehrszentrums hielt die Hamburger dort fest. Die Tatsache, daß der größte Teil des hamburgischen Schiffrechtes dort entstanden ist und das Zwin als den Ausgangshafen der Ausreisen und als das Ziel der Rückreisen voraussetzt ${ }^{22}$ ), ist von grundlegender Bedeutung für das Verständnis des Schiffahrts- und Handelsbetriebes der Hamburger im 13. Jahrhundert. Zwar stammt die uns erhaltene Abfassung des hamburgischen Schiffrechtes erst aus dem Jahre 1292; allein sie ist in ihrem Hauptteile nur die

$\left.{ }^{22}\right)$ S. Th. Kiesselbach, Hamb. Schiffr., in Hans. Geschichtsbl. 1900, S. 49 ff. Der Text des Schiffrechtes ist daselbst als Anhang abgedruckt. 
Aufzeichnung der im Verkehr der hamburgischen Niederlassung am Zwin entstandenen Rechtssätze, und die Ausbildung dieses Genossenschaftsrechtes, das den Charakter des Gewohnheitsrechtes an sich trägt, setzt eine langjährige Übung voraus. Wir dürfen in den Zuständen, von welchen diese Aufzeichnungen Kunde geben, deshalb nicht Verhältnisse sehen, welche am Schlusse des 13. Jahrhunderts entstanden sind, sondern müssen uns vor Augen halten, daß diese Zustände sich in fortschreitender Entwicklung im Laufe von Menschenaltern herausgebildet haben und ihre Anfänge sicherlich in die erste Hälfte des 13. Jahr'hunderts und möglicherweise noch in den Ausgang des 12. Jahrhunderts zurückführen.

Das Schiffrecht läßt nun erkennen, daß dort am Zwin und nicht in Hamburg der eigentliche Sitz der Geschäftsunternehmungen der Hamburger Reeder und Schiffer war ${ }^{23}$ ), wie denn auch aus dem Umstande, daß das Zwin das regelmäßige Reiseziel der Schiffe war, daß sich hier das hamburgische Schiffrecht ausbildete und daß hier die Niederlassung der Hamburger bestand, folgt, daß die Schiffe regelmäßig auch von dort ihre Ausreisen machten ${ }^{24}$ ). In das richtige Licht aber wird diese Erscheinung erst durch die Tatsache gerückt, daß das Lübecker Schiffrecht, das in einer Zusammenstellung aus dem Jahre 1299 erhalten ist ${ }^{25}$ ), in gleicher Weise das Zwin als den Ort seiner Entstehung und die Niederlassung der Lübecker am Zwin als den Mittelpunkt der Geschäftstätigkeit der Lübecker im Nordseegebiete erkennen läßt ${ }^{26}$ ), und daß die Bremer das hamburgische Schiffrecht im Anfange des 14. Jahrhunderts wörtlich übernommen haben ${ }^{27}$ ), die Verhältnisse also für Bremen jedenfalls ähnlich lagen wie für Hamburg und Lübeck. Verschiedene Urkunden geben uns endlich deutliche Hinweise dafür, daß auch für die in der Zuidersee beheimateten und für die Groninger Schiffe

$\left.{ }^{23}\right)$ S. Th. Kiesselbach, a. a. O.

$\left.{ }^{24}\right)$ Das lübische Schiffrecht bezeichnet ausdrücklich an einer Stelle (Art. 35) Flandern als Ausgangspunkt der Ausreisen der Lübecker Schiffe.

$\left.{ }^{25}\right)$ S. das lübeckische Schiffrecht im Lübecker Urkdb., Lübeck 1858, II. Teil, 1. Abteilung, S. $83 \mathrm{ff}$.

${ }^{26)}$ Th. Kiesselbach, Hamb. Schiffrecht, insbesondere S. 50 u. 85 If.

27) Ebenda. 
das Zwin eine ähnliche Rolle spielte wie für die Hamburger und Lübecker. Als um 1276 die Hamburger, vermutlich wegen des flandrisch-englischen Zerwürfnisses, über eine Verlegung des Stapels vom Zwin nach Dordrecht mit den Dordrechtern verhandeln ${ }^{28}$ ), wird ihnen 1277 ein Privileg ${ }^{29}$ ) von Graf Florenz V. von Holland für den Besuch von Dordrecht gewährt, in welchem es heißt, daß sie, ,die bisher nach Flandern zu dem Hafen dort, der Zwin heißt, mit ihren Waren sich zu begeben pflegten, nun zu unserm Hafen von Dordrecht... von jetzt ab sich zu begeben wünschen". Ein ganz gleichlautendes 'Privileg wird aber schon 1276 den Kaufleuten der Städte ,Kampen, Zwolle, Deventer, Wilsum und den andern dazwischenliegenden oder benachbarten Orten, welche bisher nach Flandern zu dem Hafen dort, welcher Zwin heißt, mit ihren Waren sich zu begeben pflegten, nun aber zu unserm Hafen von Dordrecht.... mit ihren Waren von jetzt ab sich zu begeben wünschen", erteilt $\left.{ }^{30}\right)$. In gleicher Weise werden bei den flandrisch-französischen Kämpfen am Ende des 13. Jahrhunderts den Lübeckern ${ }^{31}$ ), den Kampenern und den übrigen Süderseern ${ }^{32}$ ) und den Groningern ${ }^{33}$ ), wiederum unter Hinweis auf ihren bisherigen Besuch des Zwin und die Verlegung ihrer dortigen Stapeltätigkeit nach Dordrecht, Privilegien von dem Grafen von Holland ausgestellt.

Der Verkehr der Hamburger von Flandern aus hatte, wie bereits erwähnt, seinen Stützpunkt in der hamburgischen Genossenschaft oder „Hanse“ am Zwin. Bis Brügge selbst reichte wenigstens im 13. Jahrhundert das Zwin nicht mehr hinauf; andere dem Meere nähergelegene Orte dienten Brügge als Hafenplätze. In der ersten Hälfte des 13. Jahrhunderts war es namentlich der bereits erwähnte, $4 \mathrm{~km}$ von Brügge gelegene und mit diesem durch einen Kanal verbundene Ort Damme ${ }^{34}$ ),

${ }^{28)}$ Hans. Urrkdb. I n. 801.

$\left.{ }^{29}\right)$ Ebenda, n. 802 .

$\left.{ }^{30}\right)$ Ebenda, n. 779. Deventer erhält 1278 noch eine Bestätigung dieses Privilegs in gleicher Form, ebenda, n. 813. 814.

31) Ebenda n. 1276.

32) n. 1332; vgl. auch n. 1173.

33) ก. 1277.

34) Damme beginnt in der zweiten Hälfte des 12. Jahrhunderts. 
wo um die Mitte des 13. Jahrhunderts offenbar auch noch der Liegeplatz der deutschen Schiffe war ${ }^{35}$ ). Aber schon um die Mitte des 13. Jahrhunderts scheint dieser Hafenplatz nicht mehr ganz den Anforderungen genügt zu haben; denn schon um diese Zeit verhandelten die deutschen Kaufleute mit der Gräfin von Flandern über die Gründung einer neuen Hafenstadt, die auf dem Gebiete zwischen Damme und dem weiter nördlich gelegenen Muden (dem heutigen St. Anna ter Muiden) und dem Zwin am Wasser, wo sie wollten, von den Deutschen angelegt werden sollte ${ }^{36}$ ); zu der Gründung dieses ,,Neudamme“ scheint es zwar nicht gekommen zu sein; wir finden indessen tatsächlich die Deutschen einige Jahrzehnte später in weiter unterhalb am Zwin gelegenen Hafenplätzen, und die Vermutung liegt nahe, daß der Grund dieser Verlegung ihres Verkehrs nach weiter unterhalb gelegenen Hafenplätzen des Zwin derselbe war, der sie im 14. Jahrhundert schließlich veranlaßte, auch diese Häfen wieder aufzugeben und das noch weiter unterhalb gelegene Sluis als Hafen zu benutzen. Die Veränderungen des Fahrwassers, die durch die Jahrhunderte fortschreitende Verschlickung oder Versandung des Zwin, welche in der zweiten Hälfte des 15. Jahrhunderts schließlich so weit fortgeschritten war, daß das Zwin überhaupt unbrauchbar geworden war und Brügges Weltmarkt zugrunde ging, werden die Ursachen dieser Verschiebungen der Hafenplätze am Zwin gewesen sein. Zur Zeit der Aufzeichnung des hamburgischen Schiffrechtes 1292 war das 2 bis $3 \mathrm{~km}$ unterhalb Damme gelegene Ostkerke Sitz der hamburgischen Genossenschaft am Zwin; später nach andern Städten gelangte Handschriften des Seerechts nennen das noch $3 \mathrm{~km}$ weiter abwärts gelegene Houcke als Ort dieser Hanse; hier hatte 1299 nach dem

aufzukommen; s. Häpke, Die Entstehung von Sluis in den Hans. Geschichtsbl., 1904-05, S. 76.

$\left.{ }^{35}\right)$ S. u. a. Art. 2, 13, 17 der Urkunde über die Forderungen der Lübecker bei Stein, Über die ältesten Privilegien der deutschen Hanse in Flandern und die ältere Handelspolitik Lübecks i. Hans. Geschichtsb!. 1902, S. $68 \mathrm{ff}$.

$\left.{ }^{36}\right)$ S. hierüber Stein, a. a. O., insbesondere S. 71 ff.; die Verlegung von Damme schon 1228 in Erwägung gezogen, s. Hans. Urkdb. I S. 91 Note 1. 
lübischen Schiffrecht auch die Hanse der Lübecker ihren Sitz ${ }^{37}$ ). Das hamburgische Schiffrecht sieht ausdrücklich übrigens den Fall der Verlegung der Hanse nach einem andern Orte vor, indem es bestimmt, daß eine solche nur von dem Vorstande nach Beratung mit den Hansebrüdern angeordnet werden darf ${ }^{38}$ ). Neben Ostkerke und Houcke kommt auch noch das zwischen beiden gelegene Monikerede als Nebenhafen Dammes vor. Unter dem Begriff der pertinentia von Damme, der sich schon in den Urkunden aus der Mitte des 13. Jahrhunderts findet ${ }^{39}$ ), werden diese Nebenplätze Dammes in der Regel zusammengefaßt. Noch in der Mitte des 14. Jahrhunderts sehen wir Damme als Hafenplatz der Fremden dienen; aber immer mehr sah sich der Verkehr dorthin auf die Benutzung von Leichtern angewiesen, weil immer häufiger die Wassertiefe zu gering war, um den Schiffen selbst das Herankommen an die Stadt zu gestatten ${ }^{40}$ ), und immer stärker treten deshalb andere weiter unterhalb am Zwin gelegene Orte als Hafenplätze hervor.

Fünf Hauptrouten führt nun das hamburgische Schiffrecht an, auf denen die hamburgischen Schiffe im Zwin aus- und einlaufen. Sie werden aufgezählt bei der Festsetzung der Pacotille, des Rechtes des Schiffsmannes auf Mitnahme einer bestimmten Warenmenge für seine eigene Rechnung. Es werden nämlich dabei unterschieden die Fälle ${ }^{11}$ ): ,wenn das Schiff von Norwegen oder von Gotland kommt", ,wenn es von Rochelle kommt", ,wenn es von England kommt" und ,wenn es von Hamburg kommt". Eben diese letzte Reiseroute zeigt deutlich, daß das Schiffrecht in diesen Bestimmungen nicht Hamburg als Endpunkt der Reisen im Auge hat. Außer diesen Schiffahrtsrouten erwähnt das Schiffrecht noch den Fall, daß das Schiff von Norwegen oder von Schonen mit Fischen nach Flandern

$\left.{ }^{37}\right)$ Th. Kiesselbach, a. a. O. S. 61 und $6 \dot{4} \mathrm{ff}$.

$\left.{ }^{38}\right)$ Hamb. Schiffrecht, Art. 2.

$\left.{ }^{39}\right)$ Hans. Urkdb. I n. 432; s. auch Stein i. Hans. Geschichtsbl. 1902 , S. 60 .

$\left.{ }^{40}\right)$ S. unten Kapitel III Noten 211-216 und die Ausführungen im Texte daselbst. Ưber den Wechsel der Hafenplätze am Zwin vgl. auch Häpke, a. a. O. i. Hans. Geschichtsbl., 1904-05, S. 76 ff.

$\left.{ }^{41}\right)$ Art. 9a-d. 
kommt ${ }^{42}$ ); hier wird aber neben Flandern auch noch England als Endpunkt der Reise angegeben ${ }^{43}$ ). Als Gegenstand der Pacotille werden bei jeder der Reiserouten diejenigen Waren genannt, welche die eigentlichen Stapelartikel auf der Route bildeten. So geben uns diese Vorschriften einen wertrollen Einblick in die Reiserouten und den Warenverkehr des damaligen Seehandels. Zum Verständnis der hierdurch angedeuteten Verkehrsbeziehungen vernotwendigt es sich, die erwähnten einzelnen Linien des Handels näher zu verfolgen.

Betrachten wir zunächst den Handel aus dem baltischen Gebiet nach Brügge, auf dem recht eigentlich das Schwergewicht der deutschen Kaufleute in Flandern beruhte und durch den, wie bereits erwähnt, Lübeck und Hamburg erst zu Handelsplätzen großgezogen worden sind. Das Rückgrat dieses Verkehrs bildete der russische Handel, dessen Hauptartikel auf der einen Seite Pelze und Wachs, auf der andern Seite flandrische Tuche waren ${ }^{44}$ ). Seinen Mittelpunkt hatte dieser Verkehr in Rußland in der Stadt Nowgorod am Ilmensee ${ }^{45}$ ), wo die deutschen Kaufleute mindestens seit dem 12. Jahrhundert, vielleicht schon eher

42) Art. 10a.

43) Unter der hovede wird der Vorkanal verstanden, die See zwischen der Themsemündung und Flandern bis Dover-Calais; noch heute îndet sich die Beziehung Hoofde für jene Gegend auf den Seekarten. Wenn die Schifie von England durch die hovede noch weiterfahren, so ist damit die Fahrt von England nach Flandern gemeint, auf der sie durch die hovede, nämlich die hovede durchquerend, fuhren, nicht, wie Lappenberg meint, die Fahrt in der Längsrichtung durch die hovede über Dover-Calais hinaus. Von Schonen ging der Kurs, wie es scheint, auf die englische Küste und von dort nach Flandern durch die hovede weiter. (Vgl. die Urkunde bei Lappenberg-Sartorius, Urkundliche Geschichte des Ursprungs der deutschen Hanse, Bd. II, n. 183; die Erklärung Note 1 daselbst ist unzutreffend; es handelt sich um die Schiffe, die zu England, Schottland oder Norwegen oder westwärts von Flandern sich befinden und bereits eine Reise nach Flandern übernommen haben, ehe sie Nachricht erhalten haben.) Dieser Kurs war vielleicht der eigentliche Grund, daß diese Schiffe so oft England anliefen.

44) Vgl. u. a. Riesenkampff, Der deutsche Hof zu Nowgorod, Dorpat 1854, S. $120 \mathrm{ff}$; ferner $A$. Winckler, Die deutsche Hansa in Rußland, Berlin 1886, Kap. 3, Note 21.

$\left.{ }^{45}\right)$ Vgl. über das Folgende Riesenkampff, a. a. O. S. $11 \dot{1} \mathrm{fr}$. 
festen Fuß gefaßt hatten ${ }^{46}$ ). Nowgorod war der politische und wirtschaftliche Mittelpunkt eines mächtigen Reiches; seine Beziehungen umfaßten den ganzen Norden bis zum fernen Biarmien und reichten im Osten bis über den Ural hinaus. Nach Nowgorod flossen die Tribute aller dieser weiten Gebiete in Gestalt von großen Massen von Pelzwerk und andern Waren des Nordens und Ostens ab; Nowgorod war die Pforte, durch welche diese großen Länderstrecken mit westeuropäischer Zivilisation in Berührung kamen; dorthin strömten die Naturerzeugnisse dieser ausgedehnten Länder zusammen, und von dort erhielt der ganze russische Norden dafür die Produkte Westeuropas zurück.

Gerade der Handel mit den russischen Waren und den flandrischen Tuchen nahm vorzugsweise seinen Weg nicht zu Schiff um Jütland herum, sondern über Lübeck und Hamburg und weiter über die Nordsee ${ }^{47}$ ). Die Route durch das Skagerrak und Kattegatt bot nämlich für die damalige Schiffahrt noch zu große Gefahren, und die Schiffahrt auf der Nordsee barg für die Schiffer der Ostsee auch so erhebliche Schwierigkeiten, daß man wenigstens in denjenigen Fällen, in denen es sich, wie bei den russischen Produkten, um besonders wertvolle und leicht zu befördernde Güter handelte, den sichereren Weg vom baltischen Meere durch den Isthmus der cimbrischen Halbinsel zur Nordsee vorzog. Der Hafenplatz, über den sich dieser Verkehr jetzt bewegte, war Lübeck; dort liefen infolgedessen die wichtigsten Fäden des baltischen Verkehrs zusammen. Da

$\left.{ }^{46}\right)$ S. meine oben Note 1 angeführte Abhandlung: S. 149.

$\left.{ }^{47}\right)$ S. unten S. 93 ff. und 125 ff. Daß z. B. das russische Wachs, der Stapelartikel Rigas, von Riga regelmäßig über Lübeck nach Flandern ging, läßt das Rigasche Schuldbuch, herausgegeben von Hildebrand, St. Petersburg 1872, deutlich erkennen. Vielfach sind Schulden für Wachs eingetragen, deren Höhe überhaupt nicht durch einen zahlenmäßigen Betrag bezeichnet ist, sondern sich nach dem Erlös bestimmen soll, den der Verkauf in Lübeck ergeben wird. Gleiche Eintragungen kommen auch mit der Maßgabe vor, daß der in Flandern erzielte Marktpreis maßgebend sein soll (s. die im Ortsverzeichnis unter ,Lübeck" und unter ,,Flandern" aufgeführten Stellen und Einl. S. XXV f.). Auf andere Märkte als Lübeck und Flandern lautende derartige Eintragungen kommen bezeichnender Weise nicht vor. 
es überdies gelang, den Kaufleuten der westlichen Nationen, insbesondere den Flanderern, Italienern, Holländern und Engländern, die Teilnahme am russischen Handel zu verschließen, indem die Deutschen sie in ihrer Genossenschaft zu Wisby ${ }^{48}$ ), welche den Stützpunkt der Deutschen im russischen Handel bildete ${ }^{49}$ ), und ebenso auf ihrer Niederlassung in Nowgorod ${ }^{50}$ ) nicht zuließen, jene Fremden aber im IViderspruche mit den Deutschen in Rußland nicht Fuß zu fassen vermochten, und da auch das Bestreben, die Goten und Russen vom Nordseeverkehre fernzuhalten, von Erfolg gekrönt war und diese unentwickelten Nationen sogar im Ostseeverkehre ohne Schwierigkeiten in den Hintergrund gedrängt wurden ${ }^{51}$ ), so wurde

${ }^{48}$ ) Versagt ist diesen westlichen Nationen nicht schlechthin die Fahrt in die Ostsee, sondern nur nach Gotland. Hans. Urkdb. I. n. 115'. 1155.

49) Der Verkehr war von Rußland aus, sowohl von Nowgorod als von Riga, Reval und den übrigen Plätzen zunächst auf Gotland gerichtet und nahm von dort seinen Weg nach Lübeck. In den Verträgen mit den Fürsten von Nowgorod erscheinen als am Handel in Rußland beteiligt die Kaufleute von Gotland und diejenigen von Lübeck (Hans. Urkdb. I n. 50, 532, 663, 665), später auch diejenigen von Riga (n. 1353); in den Verträgen mit den Fürsten von Smolensk und ebenso in denjenigen mit den Fürsten von Polozk sind es gleichfalls die Gemeinschaft der Kaufleute von Gotland, die Lübecker und die Rigaer, welche in den russischen Handelsplätzen erwähnt werden (ebenda n. 232, 398, 943, $595,616)$. In allen diesen Verträgen heißt es, daß die russischen Kaufleute Riga und Gotland besuchen; es werden sogar Lagerplätze der russischen Kaufleute auf Gotland erwähnt (n. 532); weiter aber wird in dem Vertrage von 1229 ('่. 232 Art. 20) bestimmt, daß ein Russe, wenn er von Gotland aus in das deutsche Land und nach Lübeck ziehen wolle, daran nicht gehindert werden dürfe; ebenso bedingt der Fürst von Polozk 1265 (n. 616) seinen Kaufleuten außer in Riga und auf Gotland auch in Lübeck Handelsrechte aus; über die Verkehrsroute Lübeck-GotlandRiga, vgl. auch hans. Urkdb. I n. 456, 863, 906; ebenso war Revals Verkehr auf Gotland und Lübeck gerichtet (ebenda, n. 88, 838, 858, 904, 1020). Es erhellt aus diesen Urkunden deutlich, wie der Handel von Rußland auf Gotland konzentriert war und wie der Aktivhandel der Russen meist nur bis Gotland ging; zugleich aber zeigen die Urkunden, wie der Verkehr ron Gotland ganz ausgesprochen auf Lübeck gerichtet war. ${ }^{\text {so) }}$ Vgl. auch Daenell, Die Blütezeit der deutschen Hanse, Berlin 1905, S. 10.

si) Schäfer, Die Hanse, S. 78. 
der russische Norden recht eigentlich zur wirtschaftlichen Domäne der deutschen Kaufleute.

An dem Warenhandel des baltischen Gebietes hatten die Hamburger Kaufleute indessen nur sehr geringen Anteil. Im baltischen Gebiete lag der russische Handel, wie schon erwähnt, in den Händen der Mitglieder der deutschen Genossenschaft auf Gotland, unter denen bald die Lübecker allen voran standen, da sie durch ihre Teilnahme an dieser Genossenschaft zu Wisby, durch ihre Hanse am Zwin und durch die zentrale Lage ihrer Heimatstadt die drei Hauptstationen dieser Verkehrslinie beherrschten und dadurch Vorteile vor allen anderen voraus hatten. Schon im Laufe des 13. Jahrhunderts sehen wir die Lübecker in der Genossenschaft in Gotland, welche bereits im 12. Jahrhundert diesen Verkehr beherrscht hatte, neben den schon früher hier stark vertretenen Westfalen eine eigene , Bank“, d. h. eine besondere lübeckische Hanse mit eigenem Ältermanne an der Spitze, bilden ${ }^{52}$ ). Am Ende des 13. Jahrhunderts hatte Lübeck dann schon die Bedeutung Wisbys in diesem Verkehre überflügelt ${ }^{53}$ ). In dieser Beziehung war von großem Einflusse, daß die an der Küste von Livland gegründeten deutschen Kolonien, vor allem Riga, zu erstarken und zu selbständigen Ausgangspunkten des russischen Verkehrs mit dem Westen zu werden begannen. Anfangs in vollkommener Abhängigkeit

$\left.{ }^{52}\right)$ Die Lübecker gestatten 1263 den Salzwedelern, auf ihrer Bank in Wisby Platz zu nehmen, Hans. Urkdb. I n. 593. Daß unter der ,,Bank“ eine Hanse zu verstehen ist, scheint mir nach dem lübischen Schiffrecht, wo die Mitglieder der Hanse am Zwin bei ihren Morgensprachen gleichlalls eine ,Bank" bilden, anzunehmen zu sein. Andere ,Bänke“ hatten in Wisby jedenfalls außer Wisby selbst noch Soest und Dortmund, wie schon aus der Tatsache zu schließen ist, daß jeder dieser Orte dort einen Oldermann hatte; noch um das Jahr 1350 ernennt Dortmund wieder seinen Oldermann auf Wisby; s. Hans. Urkdb. III n. 187. Den Olderleuten dieser vier Orte wurden die Schlüssel zu dem die Nowgoroder Gelder enthaltenden Peterskasten der Marienkirche zu Wisby anvertraut.

${ }^{53}$ ) Die Gleichberechtigung Lübecks neben Wisby in diesem Verkehre tritt seit der zweiten Hälfte des 13. Jahrhundetrs deutlich hervor. Als es sich 1268 um Einstellung des Verkehrs mit Rußland handelt, richtet der Deutschordensmeister von Livland sein diesbezügliches Ersuchen an „Lübeck und die gesamten Kaufleute“ (Hans. Urkdb. I n. 655 bis 657,667 , unter der universitas mercatorum ist immer die deutsche 
von Gotland, mit gotländischem Rechte und gotländischer Münze begabt, Stützpunkte der Deutschen von Gotland in ihrem Verkehr mit den Russen, wurden sie nun zu Nebenbuhlerinnen Wisbys ${ }^{54}$ ) und traten mit Lübeck in unmittelbaren Verkehr. Nicht mehr Wisby, sondern Lübeck wurde nun vorherrschend der Ausgangspunkt und das Ziel der den Handel mit Rußland betreibenden Kaufleute; Wisby verlor mehr und mehr seine Rolle als Zwischenmarkt und begann, selbst für denjenigen Teil des Verkehrs, der noch über Gotland seinen Weg nahm, zum Umschlagsplatz oder auch nur zum Zwischenhafen, zur bloßen Durchgangsstation herabzusinken.

Hamburg war durch seine Lage vom unmittelbaren Anteile am Seeverkehre der Ostsee abgeschnitten, ein Aufkommen der Hamburger gegen die Lübecker im Ostseegebiete war ausgeschlossen, und von der Beteiligung hamburgischer Kaufleute am russischen Warenhandel in Wisby oder Nowgorod vernehmen wir deshalb kaum ${ }^{55}$ ). Ihr Betätigungsfeld blieb im wesentlichen die Nordsee, auf die sie durch die Lage der Stadt mehr als alle andern hingewiesen waren.

Im Nordseegebiete lagen die Verhältnisse indessen völlig anders als in der Ostsee. Hier waren die deutschen Seefahrer keineswegs so unbeschränkte Herrscher wie im baltischen Handel; in Brügge mußten sie nicht nur mit den Flanderern

Genossenschaft auf Gotland $\mathrm{zu}$ verstehen); ebenso kommt das Verbot der Nowgorodfahrt 1277 unter dem Zusammenwirken Lübecks und der universitas mercatorum zustande (Hans. Urkdb. I n. 821, 827; Hansarezesse, I 1, S. 7). "Das Übergewicht Lübecks über Wisby erhellt am Ende des 13. Jahrhunderts, als der Kassenüberschuß des Hofes von Nowgorod, der nach der ältesten Skra in der Marienkirche zu Wisby aufbewahrt werden sollte, in Lübeck zur Aufbewahrung kam, ferner auf Lübecks Veranlassung Wisby die Führung eines Siegels des gemeinen Kaufmannes untersagt wurde(s. Winckler, Die deutsche Hanse in Rußland, Berlin 1886, S. 19 ff.) und Lübeck den Versuch machte, sich an die Stelle Wisbys als Oberhof für die Appellationen gegen die Urteile des Hofes zu Nowgorod zu setzen.

54) Vgl. auch Schäfer, Die. Hansestädte und König Waldemar, Jena 1879, S. $42 \mathrm{ff}$.

$\left.{ }^{55}\right)$ Allerdings wird auch Hamburg 1293 um Anerkennung Lübecks als Oberhof gegenüber den Urteilen des Hofes von Nowgorod ersucht. (Hansarezesse I 1, n. 66); eine Antwort Hamburgs ist nicht erhalten. 
selbst, sondern auch mit Italienern, Franzosen, Spaniern, Holländern und Engländern konkurrieren, und nicht viel besser stand es in England und in Norwegen. Das Zugeständnis an die Ausländer, in den deutschen Seestädten die gleichen Rechte, welche den Deutschen bei jenen eingeräumt waren, zu genießen, war in den Nordseestädten sehr viel folgenschwerer als im Ostseegebiete, weil im Nordseegebiete im Gegensatze zu den Ostseevölkern auch andere kaufmännisch ebenso hochentwickelte Nationen am Handelsleben teilnahmen.

Auch das Ziel des russischen Warenhandels war, wie schon erwähnt, der Weltmarkt Brügge. In Brügge finden wir deshalb auch jene deutschen Kaufleute, welche den baltischen Handel in Händen hatten, wieder vor, und zwar in zwei getrennten Gruppen, nämlich die Gemeinschaft der ,Gotland besuchenden Kaufleute ${ }^{656}$ ) und diejenige der Lübecker ${ }^{57}$ ).

Der Anteil, der den Hamburgern an dem russisch-flandrischen Handel übrig blieb, beschränkte sich in der Hauptsache auf das Frachtgeschäft im Verkehr zwischen Hamburg und Flandern; es ist bezeichnend, daß das Schiffrecht der lübischen Hanse am Zwin, das im übrigen fast ganz dieselben Reiserouten aufführt wie das hamburgische, die Fahrt Hamburg-Flandern nicht erwähnt; auf dieser Route werden eben die Hamburger Schiffe im Vordergrunde gestanden haben. Da nun aber die hauptsächlichsten Stapelartikel dieses Handelszuges — Pelze und Wachs von Rußland und Tuche von Flandern - im Verhältnisse zu ihrem hohen Werte geringes Volumen haben, also wenig Schiffsraum erforderten, so darf auch der unmittelbare Vorteil für die hamburgische Schiffahrt aus diesem Verkehre nicht $\mathrm{zu}$ hoch veranschlagt werden. Die Bedeutung, welche dieser Verkehrszug für die Stadt gewann, ist vornehmlich darin zu sehen, daß Hamburg erst dadurch, daß es Umschlagsplatz in diesem Austausche wurde, eine Stelle im nordwesteuropäischen Weltverkehre erlangte ${ }^{58}$ ), daß ferner zahlreiche fremde

${ }^{56}$ ) Hans. Urkdb. I n. 422.

$\left.{ }^{57}\right)$ Ebenda, n. 434.

$\left.{ }^{58}\right)$ Der Elbverkehr hätte ebensogut an einen der älteren linkselbischen Handelsplätze geknüpft bleiben können; erst der Verkehr 
Kaufleute, vom Osten und vom Westen kommend, in diesem Verkehre den Ort passierten, und daß endlich die Hamburger als Frachtfahrer dieser Fremden in den nordwesteuropäischen Weltverkehr hineingezogen wurden und dieser Handelszug den Grundstock bildete, an welchem sich die Blüte der Schiffahrt und des Handels der Stadt im Mittelalter emporrankte.

Neben dem Verkehrswege, der von Rußland über LübeckHamburg nach Flandern führte, wurde indessen schon im 13. Jahrhundert der Seeweg um Jütland herum nach dem Zwin benutzt, und auf dieser Route zeigt uns das hamburgische Schiffrecht auch die hamburgischen Schiffe an dem Verkehre von Gotland nach Flandern beteiligt. Als Stapelartikel dieses Verkehrs nennt das hamburgische und ebenso das lübische Schiffrecht, welch letzteres auch die Fahrt in umgekehrter Richtung von Flandern durch den Sund nach Gotland ausdrücklich behandelt ${ }^{59}$ ), „Schweres“, wobei wir wohl an schwedische Bergwerksprodukte zu denken haben - denn der Verkehr mit den schwedischen Küstenplätzen lag zum großen Teile in der Hand der von Wisby aus handeltreibenden Kaufleute ${ }^{60}$ ) - , also Waren, die wegen ihres schweren Gewichtes schlecht über den Landweg von Lübeck nach Hamburg zu befördern waren. Ob das Holz, welches das hamburgische Schiffrecht ebenfalls als Pacotille nennt, an dieser Stelle nur auf die Reisen von Norwegen nach dem Zwin oder auch auf diejenigen von Gotland zu beziehen ist, läßt der Wortlaut nicht mit Sicherheit erkennen. Das lübische Schiffrecht erwähnt jedenfalls für diese Reise Holz als Pacotilleartikel nicht.

Der Transport dieser Erze oder Metalle führte die Hamburger auch nach dem schwedischen Festlande selbst. Verschiedene Urkunden des 13. Jahrhunderts zeigen uns die Hamburger in Schweden insbesondere auch am Warenhandel neben den Kaufleuten anderer Nordsee- und Ostseestädte beteiligt. 1261 gesteht der Herzog Byrger von Schweden den mit ihren

von und nach Lübeck machte es notwendig, einen Ort auf dem rechten Elbufer zu wăhlen.

$\left.{ }^{59}\right)$ Lüb. Schiffrecht, Art. 35 u. Art. 10.

$\left.{ }^{60}\right)$ Vgl. Hans. Urkdb. I. n. 772, 773, 1043. 
Waren nach Schweden kommenden Hamburgern die Rechte zu ${ }^{61}$ ), welche die Lübecker bereits dort besitzen und besessen haben ${ }^{62}$ ); als solche Rechte werden aufgeführt Schutz des Verkehrs und gänzliche Zollfreiheit, Befreiung von dem Rechte des Königs auf das Strandgut, dergestalt, daß sie im Falle des Schiffbruches zu eigen behalten dürfen, was sie selbst retten können, sichere Verwahrung des Erbgutes der in Schweden sterbenden Hamburger Jahr und Tag lang, nach Ablauf welcher Frist erst das Erbe dem königlichen Schatze anheimfallen soll, endlich Befreiung der Handelsherren von der Haftung für Vergehen der von ihnen mit dem Vertriebe ihrer Waren Beauftragten; der Schiffer soll in jedem Falle vor dem Vogte unter Eid diejenigen unter den auf seinem Schiffe reisenden Seefahrern bezeichnen, welche Hamburger Bürger sind und demnach Anteil an diesen Privilegien haben. 1275 werden den Hamburgern diese Privilegien bestätigt ${ }^{63}$ ). Die Waren, welche die Hamburger holen, werden in den Privilegien ebensowenig wie diejenigen, welche sie bringen, genannt.

Das lübische Schiffrecht aus dem Ende des 13. Jahrhunderts führt auch bereits die Fahrt von Flandern durch den Sund über Gotland hinaus nach Riga und Reval an ${ }^{64}$ ), und auch rigaische Schiffe haben schon in dieser Zeit die Fahrt von Riga durch den Sund nach dem Westen gemacht ${ }^{65}$ ). Russische Getreideladungen ${ }^{66}$ ) werden es gewesen sein, die auf diesem Wege Flandern zugeführt wurden. Im ganzen spielte übrigens die Ausfuhr Rußlands an Getreide u. dgl. Gütern, welche nicht

${ }^{61)}$ Hans. Urkdb. I 565.

$\left.{ }^{62}\right)$ Vgl. über den Vertrag König Kanuts und Herzog Byrgers von Schweden 1167-1179, in welchem den Lübeckern u. a. Zollfreiheit für Schweden zugesichert wird. Hans. Urkdb. I n. 15 Note 1.

$\left.{ }^{63}\right)$ Hans. U'rkdb. I n. 76 ' $^{\top}$.

${ }^{64)}$ Lüb. Schiffrecht Art. 35.

$\left.{ }^{65}\right)$ Rigaische Schiffe in direkter Fahrt von Riga nach Flandern; s. Rigisches Schuldbuch, Hildebrandt, S. 35 n. 470.

${ }^{66)}$ Vgl. die Bestimmungen des Rigaer Schiffrechtes, Art. XI, Über das Windegeld, bei denen Korn an erster Stelle genannt wird. Napierski, Die Quellen des Rigaer Stadtrechtes bis zum Jahre 1673, Riga 1876. 
über Hamburg-Lübeck befördert werden konnten, in dieser Zeit noch eine untergeordnete Rolle im baltisch-flandrischen Verkehre ${ }^{67}$ ).

Ähnlich lagen die Verhältnisse in Preußen. Auch preußische Städte, namentlich Thorn und Elbing, finden wir in der zweiten Hälfte des 13. Jahrhunderts schon auf dem flandrischen Markte. vertreten ${ }^{68}$ ); doch wird der Warenverkehr Preußens im 13. Jahrhundert ganz überwiegend noch den Weg über HamburgLübeck ${ }^{69}$ ) oder den Landweg ${ }^{70}$ ) bevorzugt haben, und anstatt Holz und Getreide, welche Produkte in den folgenden Jahrhunderten die Hauptgegenstände der Ausfuhr abgaben, werden noch Bernstein, Pelze u. dgl. im Vordergrunde des Exportes gestanden haben. Immerhin zeigt das lüb:sche Schiffrecht, welches auch die Fahrt von Flandern durch den Sund nach Polen als ständige Route erwähnt, daß auch di Seeverbindung um Jütland herum nach Flandern schon damals bestand $\left.{ }^{71}\right)$.

Auch die wendischen Städte unterhielten bereits im 13. Jahrhundert die Schiffahrt durch den Sund nach Flandern. Stralsund und Greifswald namentlich, Hand in Hand mit verschiedenen kleineren Plätzen wie Wolgast, Anklam, Stettin, vermittelten den Austausch der waldreichen Hinterländer der Oder mit dem Westen und verschifften die ihnen aus dem Stromgebiete der Oder zugehenden Zufuhren an Holz und Holzprodukten, wie Asche, Teer, Pech, und auch an Getreide auf dem Seewege um Jütland nach Flandern ${ }^{72}$ ). Alle diese Städte besaßen allerdings

${ }^{67}$ ) Vgl. Iildebrandt, Rigisches Schuldbuch, S. L u. LV.

$\left.{ }^{68}\right)$ 1280, Thorn, hans. Urkdb. I n. 860; Elbing, ebenda n. 1173, 1175.

$\left.{ }^{69}\right)$ S. über die Lübecker in Preußen seit 1242 Hans. Urkdb. I n. 327, 343, 425, 758; im polnischen Danzig 708, 709, 1310, 1311, 1318 bis 1320; in Polen überhaupt 1202, 1287, 1288.

${ }^{70}$ ) Kulm-Magdeburg. (?)

71) Lüb. Schiffrecht Art. 35; s. auch Waren des Deutschen Ordens $1294 \mathrm{im}$ Sund angehalten, Hans. Urkdb. I n. 1157. Elbinger Schiffer, der vermutlich von Norwegen nach England gekommen war, etwa 1294 bei England, anscheinend auf der Fahrt von England (nach dem Zwin?) gestrandet. Vermutlich waren Norweger an der Ladung interessiert (15 Sack Wolle, 250 Mark Silber, 2 Mark Gold war der Anteil des Schiffers an der Ladung) Hans. Urkab. III n. 621.

${ }^{72}$ ) Stralsund verschifft Asche aus Stargard und aus Frankfurt (vgl. auch die Vereinbarungen von 135' zwischen Frankfurt und Stettin 
keine für größere Schiffe zugänglichen Häfen; aber Stralsund und Greifswald, die diesen Verkehr besorgten, benutzten für die Verfrachtung von und nach dem Odergebiete den durch die Insel Hiddensee geschützten Gellenstrom als Hafen ${ }^{73}$ ); Greifswald diente daneben auch wohl die Insel Ruden als Ver-

über die Odèrschiffahrt, Hans. Urkdb. III n. 302), Pech in Fässern von der Größe stargardscher Fässer nach Flandern (Hans. Urkdb. I n. 868) Holz, Asche, Pech, Teer, Weizen als Gegenstand der Verschiffung von Stralsund nach Flandern s. ebenda n. 810 und n. 868 - Greifswald erhält 1274 das Niederlagerecht für alles aus dem Herzogtum Pommern zur Ausfuhr kommende Holz, Pech, Asche, ebenda n. 7ł0; für alles die Swine und Peene herabkommende Holz n. 1136; vgl. auch die Beteiligung süderseeischer Kaufleute an dieser Holzausfuhr des Odergebietes ebenda n. 1331.

$\left.{ }^{73}\right)$ Über den Gellenstrom als Hafen Stralsunds und Greifswald und über den Verkehr dorthin vgl. Koppmann, Hans. Geschichtsbl. 1876, S. 174, und Hans. Urkdb. I n. 810, 469, 1050, 1331; nach Schäfer, Die Hansestädte und König Waldemar, S. 43', sind von der Nordspitze Hiddensees bei klarem Wetter die Kreidefelsen Möens, der Einfahrt zum Sund, sichtbar; 1306 errichtet Stralsund auf der Insel Hiddensee einen Leuchtturm, ebenda II n. 91; die Urkunde hans. Urkdb. I n. 810 bestimmt, daß der Kaufmann in Stralsund bei Holz, Pech, Asche und andern in Fässern verpackten Waren kein Windegeld bezahlen soll; dem Kaufmann soll nach diesen Bestimmungen nur die Beladung des Leichter. fahrzeuges obliegen; die Übernahme aus dem Leichterfahrzeuge in das Schiff selbst soll Sache des Schiffers sein; der Schiffer soll die Ware also schon im Prahm übernehmen; das Windegeld, d. i. der vom Kaufmann an die Schiffsleute zu zahlende Lohn für das Einladen bzw. das Ausladen der Waren, das nach damaliger Auffassung zu den Obliegenheiten des Kaufmannes gehörte, fiel damit natürlich weg (vgl. Hamb. Schiffrecht Art. 16a., Lüb. Schiffrecht Art. 19 f.. Rigisches Schiffrecht Art. 9). Nach der Urkunde war zwischen fremden Schiffern und Stralsunder Kaufleuten Streit darüber entstanden, wem das Einladen der Waren vom Prahme in das Schiff oblag. Der Fürst von Rügen und Stralsund entschied zugunsten der Kaufleute, erklärte das Einladen vom Prahm in das Schiff für Sache des Schiffers. Diese Entscheidung stand aber offenbar im Widerspruche mit den an anderen Orten geltenden Rechtsgrundsätzen und ließ sich deshalb den fremden Frachtfahrern gegenüber nicht aufrecht erhalten. S. Hans. Urkdb. I n. 868. Wir finden sie schon deshalb wenige Jahre später umgestoßen; wie anderswo, wurde fortan auch in Stralsund das Einladen in das Schiff als Sache des Befrachters angesehen und demgemä $\beta$ Windegeld bezahlt. Die Ausführungen Hans. Urkdb. I n. 868, Note 2, sind ganz irrig. 
schiffungsplatz $\left.{ }^{74}\right)$; Leichterfahrzeuge - als Prahme werden sie bezeichnet - vermittelten die Verbindung zwischen diesen Verschiffungshäfen und den vorgenannten Handelsstädten. So erklärt es sich, daß wir Bürger ${ }^{75}$ ) und Schiffe ${ }^{76}$ ) von Stralsund und Greifswald gegen Ende des 13. Jahrhunderts im flandrischen Verkehre erwähnt finden. Auch Rostock und Wismar, deren Bedeutung für den Westen, namentlich in ihrer Heringsfischerei und in dem Zuflusse der Überschüsse der mecklenburgischen Großgrundwirtschaften ${ }^{77}$ ) und in ihrer Brauerei ${ }^{78}$ ) lag, begegnen wir schon im 13. Jahrhundert unter den in Flandern vertretenen wendischen Städten, und das Vorkommen von Rostok-

$\left.{ }^{74}\right)$ Über die Insel Ruden als Hafen von Greifswald s. Hans. Urkdb. I n. 469 und 1050; 1297 erhält Greifswald das Recht zur Anlage eines Hafens beim Dorfe Densche Wyk, ebenda n. 1245. Der Hafen Wyk wurde aber schon früher benutzt, wenn auch nur für kleine Schiffe.und Leichterfahrzeuge, s. Hans. Urkdb. I n. 746 und Note 1 S. 262 ebenda.

${ }^{75}$ ) Hans. Urkdb. I n. 1173, 1175.

$\left.{ }^{76}\right)$ Kunze, Hanseakten in England von 1275-1412, Halle 1891, n. 16, 1294: 7 Stralsunder, 2 Greifswalder Schiffe mit Holz, Holzprodukten und Hering auf der Fahrt nach Flandern bei Ravenser in England angehalten; 1295: 3 Stralsunder in Scardeburg, 6 Stralsunder Schiffe in Newcastle angehalten; die Ladung besteht auch bei diesen Schiffen vorwiegend aus $\mathrm{Holz}$ und Holzprodukten; auch diese Schiffe wollten nach Flandern, s. n. 11c. Stralsunder Schiffe im 13. Jahrhundert in England an der Ausfuhr beteiligt s. ferner ebenda n. 367, 368, 369.

${ }^{77)}$ Ein Hauptausfuhrprodukt der wendischen Städte nach Norwegen war Getreide und Mehl. Als 1310 in Flandern und England Kornteuerung war, wandte man sich an die wendischen Städte, um Getreide zu holen, Hansarezesse I 1, S. 51. Vgl. den Wismarer Zolltarif von 1328 (Hans. Urkdb. II n. 476): Vortmer efte en kogge efte en scip kumpt seghelende umme lant (d.h. um Skagen herum, also aus der Nordsee), vordat gut, dat id inne heft, schal men nicht tollen; were aver, dat de sciplude in dat schip korn koften ut to vorende, so scholen se gheven vor jewelke metene last achte penninge; ferner die wiederholten Eintragungen über Getreideverschiffungen von Rostock nach Flandern in dem den Jahren 1345-1350 angehörenden Handlungsbuch Johann Tölners, bei Karl Koppmann Johann Tölners Handlungsbuch, Rostock 1885, n. 180, 196, 198.

${ }^{78}$ ) S. die zahlreichen Beraubungen Rostocker Schiffe in der Ostsee in der ersten Hăfte des 14. Jahrhunderts im Hans. Urkdb. II 11. 726, deren Ladung vorwiegend in Bier besteht; daneben in Getreide, Mehl, Hopfen, Malz, Heringen, Tuchen und Leinen u. a. m. 
ker Schiffen im Nordssegebiete beweist ${ }^{79}$ ), daß auch diese Stadt bereits zur See um Jütland herum Verkehr nach dem Westen unterhielt, wenn auch die Rostocker Schiffe dort seltener gewesen sein mögen als die Stralsunder.

Das hamburgische Schiffrecht kennt weder die Reisen nach $R$ ga und Reval noch auch diejenigen nach Preußen und nach den wendischen Städten, und Hamburger Schiffe werden im 13. Jahrhundert auf diesen Schiffahrtsrouten also wohl nicht viel verkehrt haben.

Außer Gotland und den schwedischen Häfen war aber schon im 13. Jahrhundert Schonen ein Ziel auch der Hamburger Seefahrer. Die Bedeutung dieser damals dänischen kleinen Landzunge an der Südspitze der skandinavischen Halbinsel für den Verkehr beruhte auf dem dort betriebenen Heringsfange. Der Vertrieb dieser Fische hat im mittelalterlichen Handelsverkehre eine außerordentlich hohe wirtschaftliche Bedeutung gewonnen. Der Verbrauch an Fischen war auch im Binnenlande infolge der zahlreichen kirehlichen Fastentage ein sehr großer, und gesalzene oder getrocknete ${ }^{80}$ ) Heringe bildeten eines der verbreitetsten und wichtigsten Volksnahrungsmittel. An den schonenschen Küsten pflegte der Hering alljährlich im Hochsommer in riesigen Schwärmen aufzutreten. Der Fang der Fische war dort fast ausschließlich Sache der Dänen ${ }^{81}$ ). Die Fremden führten einerseits das Salz ${ }^{82}$ ) zum Einsalzen der Fische und die Holztonnen ${ }^{83}$ ) zur Verpackung derselben sowie die nötigen Lebensmittel ${ }^{84}$ ) für die Versorgung der großen,

$\left.{ }^{79}\right)$ S. Kunze, n. 16 (1294 ein Rostocker Schiff auf der Fahrt nach Flandern in England angehalten), n. 368 (1286-87 ein Rostocker Schiff an der Wollausfuhr in England beteiligt).

${ }^{80}$ ) Vgl. z. B. Greifswalder Zollrolle n. 746: plaustrum sicci allecis sive spichering.

$\left.{ }^{81}\right)$ S. Schäfer, Das Buch des lübeckischen Vogts von Schonen, Halle 1887, S. $47 \mathrm{ff}$.

$\left.{ }^{82}\right)$ Sal: Hans. Urkdb. I n. 411.

${ }^{83}$ ) Vgl. Hansarezesse I n. 105 ff.; z. B. wird 1336 ein Stralsunder Schiff mit 5 Last Salz und 9 Last leerer Tonnen zwischen Moen und Felsterboe geraubt; ebenso hatte ein 1342 bei Kopenhagen geraubtes Stralsunder Schiff außer Bier, Brot und Salz auch Tonnen als Ladung; s. Hans. Urkdb. II n. 727.

${ }^{84)}$ Victualia, s. Hans. Urkdb. I n. 411. 
auf kurze Zeit dort zusammenströmenden Menschenmenge herbei und erwarben andererseits das Produkt, um es nach allen Richtungen auszuführen. Mancherlei Waren ${ }^{85}$ ) sowie bares Geld flossen zugleich als Gegenwert dort zu. Der massenhafte Zustrom von Kaufleuten des Nordsee- wie des Ostseegebietes hatte zur Folge, daß sich hier zugleich ein bedeutsamer Markt und Umschlagsplatz für andere Produkte des Westens wie des Ostens herausbildete ${ }^{86}$ ).

Durch ihre Lage begünstigt, standen natürlich die Ostseestädte, vor allem Lübeck, und ferner die wendischen Städte Wismar, Rostock, Demmin, Stralsund, Greifswald, Stettin, Anklam sowie Kiel ${ }^{87}$ ) obenan in diesem Handel; auch das rigaische Recht enthält Bestimmungen über die Schonenfahrt ${ }^{88}$ ). Aber auch Seefahrer des Nordseegebietes, namentlich von Kampen ${ }^{89}$ ), Utrecht ${ }^{89}$ ), Hamburg ${ }^{90}$ ) und andern Plätzen beteiligten sich an demselben, und zwar bestand dieser Verkehr der Nordseefahrer in Schonen schon in der ersten Hälfte des 13. Jahrhunderts ${ }^{91}$ ). Die Nordseefahrer, namentlich die Niederländer, beteiligten sich von hier aus, wie die Zollbestimmungen von 1251 ausdrücklich bezeugen, auch an der Ostseeschiffahrt; offenbar holten sie schon damals, wie wir das auch im 14. Jahrhundert beobachten können, Waren aus den verschiedenen

85) Pannum lineum als Gegenstand der Zufuhr ebenda.

${ }^{88)}$ Vgl. Schäfer, Das Buch des lübeckischen Vogts auf Schonen, S. 53 ff.

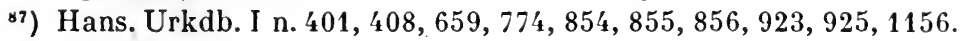

88) Art. 29.

$\left.{ }^{89}\right)$ Schon die Tatsache, daß Ausfertigungen der Urkunde von 1251 (Hans. Urkdb. I 411) sich in Kampen und Utrecht finden, zeigt, daß die Schiffe dieser Plätze sich bereits um die Mitte des 13. Jahrhunderts an der Schonenfahrt beteiligten. Vgl. ferner Strandrechtsprivilegien der Kampener für Dänemark, 1289, Hans. Urkdb. I n. 1286.

$\left.{ }^{90}\right)$ S. auch Hans. Urkdb. I n. 800.

91) S. die Zollbestimmungen von 1251 für die Umlandsfahrer, d. h. die von der Nordsee her um Jütland herum kommenden Seefahrer, welche auf ein schon lăngeres Bestehen der Umlandsfahrt deutlich hinweisen. Utber die Umlandsfahrer vgl. Schäfer, Das Buch des lübeckischen Vogts auf Schonen, S. 68 ff. Die Reise umme land steht aber nicht eigentlich, wie Schäfer a. a. O. S. 70 Note 1, meint, im Gegensatz zur Reise zu Lande nach dem Osten, sondern im Gegensatz zu der Reise von der Nordsee zur Ostsee unter Kreuzung der cimbrischen Halbinsel zu laande. 
Gegenden des Ostseegebietes nach Schonen zusammen, um sie von hier mit den schonenschen Heringen zusammen in neuen Schiffsladungen nach dem Westen weiter zu bringen. Die meisten der beteiligten Städte erwarben durch besondere Privilegien eigene Plätze auf Schonen, sog. Vitten ${ }^{92}$ ), wo sie ihre Schiffe landen und die Waren und Fische verladen und ihre Buden aufschlagen konnten. Auch den Hamburgern wurden früh besondere Vergünstigungen in diesem Verkehre zuteil. Schon 1225 wurden ihnen wie den Lübeckern und andern Kaufleuten Rechte, die sie früher in Dänemark besessen hatten, bestätigt ${ }^{93}$ ); 1250 wurde ihnen Befreiung rom Strandrecht für ganz Dänemark gewährt ${ }^{94}$ ); 1282 wurde diese Vergünstigung bestaitigt ${ }^{95}$ ); 1283 erhielten sie ein Privileg, in welchem ihnen auf Fürlitte des holsteinischen Grafen für die schonenschen Märkte alle Rechte, welche andern Stälten zugestanden seien, eingeräumt wurden, insbesondere auch die Ermächtigung zur Errichtung einer besonderen Vilte ${ }^{96}$ ).

Auch für die Ausfuhr der Heringe Schonens fiel der Weltmarkt Brügges stark ins Gewieht; das Hamburger Sehiffrecht erwähnt ausdrücklich als Ziel der von Schonen kommenden Schiffe Flandern ${ }^{97}$ ). Indessen war der Verkehr mit Heringen von Schonen aus doch keineswegs so ausschließlich auf Flandern gerichtet, wie der Itamdel mit manchen andern Waren des Ostseegebietes; der Umstand, daß der Hering bereits bis tief in das deutsche Binnenland ${ }^{98}$ ) hinein ein regelmäßiges Nah-

$\left.{ }^{92}\right)$ Z. B. die Greifswalder 1280, s. Hans. Urkdb. I n. 856; die Stralsunder schon früher (ebenda).

$\left.{ }^{93}\right)$ Hans. Urkib. I n. 193.

94) Ebenda n. 392.

${ }^{95}$ ) Ebenda n. 909.

${ }^{96}$ ) Ebenda n. 922.

$\left.{ }^{97}\right)$ Schiffrecht Art. 10a.; Heringstonnen von der Art, wie sie am Zwin verkauft werden, s. Hans. Urkdb. I n. 1216.

${ }^{98}$ ) 1238 und 1243 Wagenladungen mit Heringen, z. B. von der Weichselmündung kommend, im Verkehre zwischen Gnesen, Posen und Bentschen, Hans. Urkdb. I n. 291 und 328 ; 1278 Bestimmungen für die Heringswascher in Hildesheim n. 811; Heringe als Gegenstand des Handels in Frankfurt a. O. n. 459, in Hildesheim n. 811, in Eisenach n. 1359, in Westfalen n. 769. 
rungsmittel der Bevölkerung geworden war, hatte zur Folge, daß der Umsatz dieser Ware im Gegensatze zu fast allen andern Waren schon nicht mehr auf den Weltmarkt Brügges beschränkt blieb, sondern daß sich bereits eine ganze Anzahl wenn auch kleinerer Märkte für den Großhandel mit diesem Artikel bildeten, wo die Verkäufer auf Absatz rechnen konnten. Nur das Bier ${ }^{99}$ ) hat im Mittelalter in Deutsehland und seinen Nachbarländern stellenweise noch eine ähnliche Verbreitung als Handelsware erlangt wie der Hering. Die wendisehen Kaufleute führten einen bemerkenswerten Teil der Heringsausbeute in ihre Heimatsstädte und vertrieben sie von da unmittelbar in das Hinterland, in das Gebiet der mittleren Elbe und der mittleren Oder, wo überall der Hering ein weitverbreitetes Nahrungsmittel war. Lüneburg, Uelzen, Stendal, Salzwedel wurden unmittelbar von Lübeck und den wendischen Städten aus mit Hering versorgt $\left.{ }^{100}\right)$. Aber auch im Nordseegebiete war Flandern, wenn auch wohl der wichtigste $\left.{ }^{101}\right)$, so doch nicht der einzige Markt für den Absatz der Heringe. Auch das Hamburger Schiflrecht führt bezeichnenderweise an dieser Stelle neben Flandern anch noch England an ${ }^{102}$ ). Hamburg selbst lreilich wird selten das Reiseziel der von Schonen abgehenden Schiffe gewesen sein.

$\left.{ }^{99}\right)$ Vgl. Schäfer, Die IIansestädte und König Waldemar, S. $305 \mathrm{f}$.

${ }^{100}$ ) Vgl. die Urkunde von 1278, Hans. Urkdb. I n. 807, welehe Bestimmungen über die Zölle enthält, welche die Lüneburger für Heringsladungen zu entrichten haben, die sie über die Kollstelle Möllı führen; es werden Heringe von Rügen, von Schonen und von Norwegen unterschieden; s. auch n. 822. Salz bildet offenbar die Rückfracht. Eine in diesem Verkehre erhobene, oft in Salz entrichtete Abgabe heißt aringpenninghe (= Heringspfennige). Eine Urkunde von 1248 setzt die auf der Straße zwischen Lübeck und Salzwedel zu zahlenden Geleitsgeldsätze fest; auf dem Hinwege sollen sie in Hitzacker, auf dem Rückwege in Mölln bezahlt werden, n. 357. In Salzwedel wurde wie in Lüneburg Salz gewonnen; s. Hamb. Urkdb. I n. 709; Hans. Urkdb. I n. 924. Eine Urkunde von 1258 zeigt Stendal im Verkehre mit Wismar (n. 807); eine Urkunde aus dem Jahre 1278 belegt den Verkehr Ülzens über Mölln und Ratzeburg (n. 822).

101) Einige Kampener, Harderwyker, Stralsunder, Greifswalder, Lübecker Schiffe mit Hering anf der Reise nach Flandern 1294 in Eng. land, s. Kunze, Hanseakten in England, Urkd. n. 16 102) Art. 10a. 
Das Elbgebiet wurde, wie erwähnt, schon von den Ostseestädten aus unmittelbar versorgt, und Heringe spielten auf dem Hamburger Warenmarkte eine sehr geringe Rolle ${ }^{103}$ ). Heringe und namentlich Heringsfett ${ }^{104}$ ) zählten sogar zu den Exportartikeln, welche die Brandenburger, Magdeburger, Braunschweiger und sonstigen Fremden über Hamburg nach Flandern ausführten ${ }^{105}$ ). $\mathrm{Ob}$ sie diese Ware von ihren Heimatstädten oder aber auf der Rückreise von den Ostseeländern, die sie ja viel besuchten, nach Hamburg brachten, muß hier dahingestellt bleiben; beachtenswert ist in dieser Beziehung jedenfalls, daß Hering auch auf der Landstraße von Lübeck nach Hamburg befördert wurde $\left.{ }^{106}\right)$. Unter den Handelsartikeln, welche von Hamburg nach Flandern verfrachtet wurden, war der Hering übrigens von nebensächlicher Bedeutung, wie schon daraus erhellt, daß die Bestimmungen des Schiffrechtes über das Windegeld, welche alle auf dieser Route gangbaren Frachtartikel aufzählen ${ }^{107}$ ), die Heringe nicht erwähnen. Die hamburgischen

${ }^{103}$ ) In den ältesten, von Adolf $\mathrm{W}$. herrührenden Bestimmungen der Hamburger Zollrolle aus der Zeit von 1236 wird IJering unter den seewärts eingeführten Waren überhaupt nicht erwähnt. In den von den Grafen Gerhard und Johann später erlassenen Bestimmungen der Zollrolle findet sich der Hering allerdings an letzter Stelle unter diesen Waren aufgeführt. In der Handschrift Nummer 1 Hans. Urkdb. n. 573 wird Hering als Artikel, der in das Inland von Hamburg aus eingeführt wird, überhaupt nicht genannt. In der Handschrift Nummer 2 ist unter den Waren, welchedie Brandenburger in Hamburg kaufen und von dort in ihre Heimat führen, allerdings hinter ,Pferde und Vieh“ der Zusatz „Hering“ und ,'Tonnen" eingeschoben. Bei den übrigen Kaurleuten werden Heringe auch in der Handschrift 2 nicht als Gegenstand der Einfuhr in das Binneland genannt.

104) Heringsmer, aus den Abfällen des Herings gewonnen; s. Schäfer, Das Buch des Lübecker Vogts auf Schonen, S. 59.

${ }^{105}$ ) Vgl. die Zollrollen Hans. Urkdb. I n. 573. Hinsichtlich der Brandenburger heißt es:, de last allecis $2 \beta$.., et sciendum, si de omnibus hiis bonis supradictis dederint ungheldum in Hamborch et ducuntur in Flandriam - _ - (ebenso schon die Zollrolle von 1236 ebenda n. 277). Hinsichtlich der Magdeburger usw.: dant enim.... de last allecis $2 \beta \ldots$...; cum autem veniunt de mari, dabunt de pacca lanei panni $2 \beta$ usw.

${ }^{106)}$ Hans. Urkdb. I n. 307 und unten S. 96.

${ }^{107)}$ Art. $16^{b}$. 
Schiffe führten vielmehr den Hering von Schonen unnittelbar nach Flandern und andern westlichen Märkten.

Endlich haben wir hier noch der Verkehrstoute von Norwegen nach Flandern zu gedenken, an welcher die Hamburger', wie das Schiffrecht ergibt, ebenfalls Anteil hatten. Norwegen bot dem Handel zur Ausfuhr vor allen Dingen Heringe, wenn auch nicht in den Mengen und der Güte wie Schonen, daneben Holz aus seinen ausgedehnten Wäldern und allerlei andere Erträge der Fischerei außer dem Heringsfang. Die Fremden, insbesondere die Hamburger, waren dort selbst am Heringsfang beteiligt. Auf der andern Seite bedurfte das Land, dessen Boden arm war und die Bevölkerung nicht zu ernähren vermochte, erheblicher Zufuhren an Lebensmitteln; Mehl und Bier, auch Getreide und Hülsenfrüchte, wie Bohnen und Erbsen, bildeten die wichtigsten Einfuhrartikel dorthin ${ }^{108}$ ).

Auch in Norwegen lag der Handel vorwiegend in Händen der Ausländer. Mancherlei Bezichungen verknüpften Norwegen eng mit England, von wo es auch das Christentum erhalten hatte. So erklärt es sich, daß wir am Verkehre mit diesem Lande namentlich englische Kauffahrer beteiligt finden ${ }^{109}$ ). Neben ihnen treten früh auch deutsche Kaufleute und Kauffahrer der Städte an der Südersee, insbesondere aus Kampen und Stavorn sowie aus dem friesischen Groningen ${ }^{110}$ ) in Norwegen in die Erscheinung. Zu König Sverrirs Zeit (1177-1202) wird die Vertreibung der deutsehen Händler von dort aus Anlaß eines Zwistes gemeldet ${ }^{111}$ ), die indessen nur vorübergehend war. Abgesehen von dem hamburgischen Schiffrechte bezeugen auch verschiedene andere Urkunden den Aufenthalt der Hamburger in den norwegischen Handelsplätzen. Eine Urkunde von 126' über die Beilegung einer Streitigkeit des Königs von Nor'wegen mit den Hamburgern setzt ihren Verkehr dort längere

${ }^{108}$ ) Hans. Rezesse I n. 30.

${ }^{109}$ ) Vgl. Harttung, Norwegen und die deutschen Seestädte bis zum Schluß des 13. Jahrhunderts, Berlin 1877, S. 5 fr.

$\left.{ }^{110}\right)$ Hansarezesse I 1 S. 24 und n. 44, 45, 49, 50, 51, 56, 62, 63.

111) Die Deutschen bringen 1186 Wein und holen Butter und getrocknete Fische; s. Hartlung, ebenda S. 15. 
Zeit vorher jedenfalls voraus $\left.{ }^{112}\right)$. Streitigkeiten mit den Norwegern führten $1284 \mathrm{zu}$ einem Abbruch des Verkehrs der wendischen Städte und Hamburgs, welche im Rostocker Friedensbündnis vereinigt waren, mit Norwegen ${ }^{113}$ ). Auch Dänemark machte mit den Städten gemeinsame Sache $\left.{ }^{114}\right)$; den Norwegern wurde die Durchfuhr durch den Sund verboten ${ }^{115}$ ). Diese Verkehrssperre dauerte bis $1285^{116}$ ); aber auch nach Wiederherstellung des freien Verkehrs der wendischen Städte und der Hamburger in Norwegen im Jahre $1286^{117}$ ) kamen von neuem Mißhelligkeiten vor. 1296 erhielten die Hamburger besondere Privilegien für ihren Handel in Norwegen ausgefertigt ${ }^{118}$ ).

$\left.{ }^{112}\right)$ Hans. Urkdb. I 601.

$\left.{ }^{113}\right)$ Hans. Urkdb. I n. 931, 935, 936, 938, 97'́-979, 981, 985-989, 973-979. Hansarezesse I n. 28 fr.

114) Hans. Urkdb. I 953, 956.

${ }^{115}$ ) Ebenda 936.

$\left.{ }^{116}\right)$ Ebenda n. 970.

$\left.{ }^{117}\right)$ Ebenda n. 1008.

${ }^{118}$ ) Ebenda n. 1215. Die Hamburger sollten im ganzen Reiche überall mit ihren schiffen an den Brücken anlegen und wieder ablegen dürfen, ohne dazu gezwungen zu sein, Waren auszuladen oder einzunehmen, und im ganzen Reiche in ihren Schiffen ihre Waren zum Verkauf bringen und in fremden Schiffen, wann nur sie wollten, Waren jeder Art einkaufen dürfen. Während der ersten zwei Tage nach ihrer Ankunft sollten sie gehalten sein, den Boten des Königs zu erwarten, der, was er für den König von ihnen kaufte, binnen 14 Tagen sollte bezahlen müssen. Kein Mitglied der königlichen Familie sollte beim Kauf einen Druck auf den Verkäufer ausüben dürfen. Für die Bezahlung solcher von den Mitgliedern der königlichen Familie entnommenen Gïter suchte das Privileg besondere Sicherheit zu schaffen; sie sollte binnen 8 Tagen geleistet werden müssen; beim Ausbleiben der Zahlung nach dieser Frist sollte der Verkäufer die Bestellung eines Pfandes bei den Richtern zu beantragen berechtigt sein usw. Im Falle des Schiffbruches an der norwegischen Küste sollten sie die von ihnen geborgenen Güter behalten dürfen, und, wenn sie fremde Hilfe zuzogen, den Hilfeleistenden nur einen Bergelohn zu zahlen brauchen, der auf 6 norwegische Öre für jede Last des durch die Fremden geborgenen Gutes bemessen wird. Die Richter und Beamten sollen die Hamburger in gleicher Weise wie die Einheimischen fördern; vor Gericht sollte sich der Hamburger durch den Eid zweier Männer, Deutscher oder Norweger, von jeder Anklage reinigen können. Von allen öffentlichen Lasten und Diensten sollten sie befreit sein. Die Hamburger sollten in Norwegen einem Schiffszoll unterliegen, dagegen keinem Warenzoll. Jedes ankommende Schiff sollte 1 Pfund 
An der norwegischen Küste pflegten die Heringszüge erst im Beginne des Winters aufzutreten. In Jahren, in denen sie an den schonenschen Küsten ausblieben oder nur in geringer Zahl erschienen, fuhren die Kaufleute vielfach von Schonen nach Norwegen weiter und suchten die Ladung dort zu ergänzen, wie das Hamburger Schiffrecht, das den Frachtzuschlag für diesen Fall bestimmt, erkennen läß $\left.{ }^{119}\right)$. Ausdrücklich wird den Hamburger Schiffen in dem Privileg von 1296 das Recht zugestanden, wenn sie in Winterszeit nach Norwegen kommen, dort den ganzen Winter zu bleiben ohne weitere Beschwerung als die Erlegung des regelmäßigen Schiffszolles bei der Ankunft.

Nach dem Schiffrecht war bei den Reisen der hamburger Schiffe mit Holzladungen und Schwergut von Norwegen regelmäßig das Zwin Bestimmungshafen ${ }^{120}$ ). Auch für Fahrten von

Mehl als Abgabe erlegen, einerlei was für Waren es brachte; nach Erlegung des Zolles sollten sie ihr Schiff mit Holz und was für sonstige Waren inmer sie wollten, frei beladen dürfen. Besonders angeführt wird der Fall, wenn ein Hamburger Schiff mit ,grave pondus“, also mit Erz oder Metall, nach Norwegen kam; in diesem Falle sollte es zunächst 1 Pfund Mehl als Zoll erlegen, alsdann aber Holz und was für Waren es sonst wollte, kaufen und mit sich führen dürfen, wohin es wollte. Das Hamburger Schiffrecht gibt bei der Fahrt von Norwegen nach Flandern Holz oder ,Swares“ als Pacotille an. Offenbar handelt es sich bei beiden Bestimmungen um Schiffe, die mit Erz- oder Metalladung nach dem norwegischen Iafen kamen, dort aber diese Ladung nicht absetzten, sondern nur durch Holzladung ergänzen wollten. So erklärt es sich auch, daß das Privileg den Fall, daß das Schiff mit Meiall ankommt, besonders neben dem Fall, daß ein Schilf andere Waren bringt, behandelt und dabei betont, daß der Zoll in beiden Fällen in gleicher Höhe zu entrichten ist. Fraglich ist nur, ob das Metall aus Schweden stammte oder aber norwegischen Ursprung hatte und etwa nur in andern norwegischen Häfen eingenommen war. Die Abgabe an Mehl läßt indessen annehmen, daß die Schiffe aus einem andern Lande, aus der Ostsee, kamen. AuBer Holz spielt in der norwegischen Ausfuhr für die Hamburger der Hering eine bedeutsame Rolle; die Hamburger sind, wie schon erwăhnt, dort selbst am Heringsfang beteiligt. Solche hamburgischen Heringsfahrzeuge sollten von jeder Last Hering 3 Pfennige Sterling als Zoll geben, ohne im übrigen einem Schiffszolle zu unterliegen, nach Erlegung dieses \%olles soll die Besatzung Brennholz und anderes Holz, das sic benötigt, frei holen dürfen.

${ }^{119}$ ) Art. $10^{\text {b }}$; vgl. anch Hans. Urkdb. I II. 411, wo gleichfalls von der Reise der Nordseefahrer von Schonen nach Norwegen die Rede ist.

${ }^{120}$ ) Art. 9 a und dazu Th. Kiesselbach, Hamb. Schifrrecht S. 70 fr. 
Norwegen mit Fischen setzt eine Stelle des hamburgischen Schiffrechtes nur das Zwin als Endpunkt der Reise voraus ${ }^{121}$ ). Indessen erwähnt das Hamburger Schiffrecht an einer Stelle, wo von den Reisen von Norwegen und von Schonen die Rede ist, doch neben Flandern England als Reiseziel der Fahrten mit Heringsladungen ${ }^{122}$ ), und andere Urkunden bestätigen das Bestehen unmittelbarer Handelsbeziehungen zwischen Norwegen und England ${ }^{123}$ ). Gerade wie bei Schonen sind es auch bei Norwegen wieder die Heringe, für die neben dem Welt- markte Brügge auch bereits an andern Plätzen mit genügender Sicherheit auf Absatz zu reehnen ist. Aber auch die Zufuhren Norwegens gingen nicht so ausschließlich rom Zwin aus, wie bei den übrigen Ländern. Norwegen unterschied sich von diesen übrigen Ländern dadurch, daß es Mangel an Ackerbauprodukten, insbesondere an Getreide, hatte, und so bot sich hier für die andern Länder Gelegenheit zum Absatze des Überschusses ihrer Bodener'zeugnisse. Was England in dieser Beziehung Norwegen zu bieten hatte, wird bescheiden gewesen sein, da England jedenfalls große Überschüsse an Getreide und Getreideerzeugnissen nicht aufzuweisen hatte, wie denn überhaupt der Verkehr zwischen Norwegen und England nicht überschätzt werden darf, da England bei seinem niedrigen wirtsehaftlichen Kulturzustande doch auch für die norwegischen Hölzer und Fischereiprodukte einen verhältnismäßig nur bescheidenen $\mathrm{Ab}$ satzmarkt abgegeben haben kann $\left.{ }^{124}\right)$. Namentlich die wendischen Städte sehen wir aus ihrem Hinterlande Mehl und Bier,

121) Art. 11 a.

122) Art. 10a.

123) Vgl. Hans. Urkdb. I n. 601 Note a. n. 966, 969, 974-979. Verkehr sächsischer Kaufleute auf norwegischen Schiffen zwischen Norwegen und England, ebenda n. 227 und Note a. Verkehr der Stralsunder zwischen Norwegen und England, Hansarezesse I n. 28; Lappenberg, Stahlhof S. $37 \mathrm{ff}$.

124) Anders die herrschende Meinung. Vgl.u.a.Harttung, a.a.O.S. 5 ff.; Schanz, Engl. Handelspolitik I, S. 247 f. Daß Heringe von Norwegen nach England kamen, ist schon oben erwähnt. Bei dem Fehlen der Wälder in den südöstlichen Landesteilen bedurfte England auch der Zufuhr von Holz. Vgl. schon die Zollrolle König Ethelrets, wo das Schiff mit Holz an erster Stelle genannt wird, Hans. Urkdb. I n. 2. 
auch Getreide und Hülsenfrüchte nach Norwegen ausführen ${ }^{125}$ ), und ebenso zeigen die Beziehungen, welche die Bremer in ausgesprochenem Gegensatze zu den übrigen Städten mit Norwegen unterhalten konnten ${ }^{126}$ ), ohne dabei jahrzehntelang an den gemeinsamen Einrichtungen der übrigen Deutschen in Flandern teilzunehmen, daß der Verkehr mit Norwegen nicht so ausschließlich in Brügge seinen Ausgangs- und Endpunkt fand, wie z. B. der baltische Handel, wenn auch die Bremer während der Zeit, wo sie nicht an den Privilegien der übrigen Städte teilnahmen, dessenungeachtet wahrscheinlich Flandern nicht fernblieben. Zweifellos wird allerdings auch für Norwegen die wichtigste Verbindung diejenige mit Flandern gewesen sein. Insgesamt spielte übrigens der norwegische Verkehr im damaligen Welthandel eine nebensächliche Rolle.

Sehr viel wichtiger als der norwegische Handel war der Verkehr mit England. Er besaß nächst dem baltischen Handel für die deutschen Kaufleute die größte Bedeutung. Die Engländer selbst waren damals freilich eigentlich noch kein Handelsvolk; der Handel lag im wesentlichen in den Händen ausländischer Kaufleute ${ }^{127}$ ); Viehzucht und Ackerbau bildeten noch ganz überwiegend die Erwerbsquelle der Engländer, und das Land war nur erst dünn bevölkert. Die englische Landwirtschaft spielte indessen, wie schon erwähnt, eine wichtige Rolle für den damaligen Welthandel; sie lieferte dank den günstigen Bedingungen des Klimas und Bodens für die Schafzucht eine Wolle von so ausgezeichneter Güte, wie sie kein anderes Land hervorzubringen vermochte. Die Schafzucht besaß in England

${ }^{125}$ ) Hansarezesse I. n. 30; Hans. Urkdb. I n. 961 , auch n. 366 (Zufuhr von Getreide, Mehl, Malz aus Lübeck) und n. 1101 (Zufuhr von Mehl aus Greifswald).

$\left.{ }^{126}\right)$ Vgl. Schäfer, Die Stellung Bremens in der Hanse, Hans. Geschichtsbl. 1874, S. 3 ff.; Bremen hat offenbar im flandrisch-russischen Seeverkehre, an welchem es ursprünglich stark beteiligt war, infolge seiner Lage spăter hinter andere Seestădte zurücktreten müssen und deshalb lange Zeit außerhalb der Gemeinschaft dieser andern Städte bleiben können, bis es sich $1358 \mathrm{ihr}$ wieder anschloß.

${ }^{127}$ ) Vgl. Schanz, Englische Handelspolitik, Leipzig 1881, S. 3; Kunze, Hanseakten in England, Halle 1891, S. 5 u. 42. 
bereits im 11. Jahrhundert eine große Ausdehnung ${ }^{128}$ ); schon im 11. Jahrhundert war Wolle auch ein Gegenstand der Ausfuhr Englands ${ }^{129}$ ), und schon damals treffen wir flandrische Kaufleute ${ }^{130}$ ) in England an. Auf der Zufuhr dieses vorzüglichen Rohstoffes beruhte der Umfang und der Ruf der flandrischen Tuchindustrie ${ }^{131}$ ). Im Verhältnis zum Wollexporte trat die englische Ausfuhr an andern Waren - es sind in dieser Beziehung Häute und die Erzeugnisse des englischen Bergbaus Blei und Zinn zu erwähnen - ganz zurück ${ }^{132}$ ).

Schon aus dem Gesagten ergibt sich, daß der englische Ausfuhrhandel ganz vorherrschend auf Flandern gerichtet sein mußte. Wir finden ihn denn auch tatsächlich in gleicher Weise wie den baltischen Handel der Deutschen und den Weinhandel der Franzosen auf Brügge konzentriert. Diese Erscheinung tritt bei Gelegenheit der Verbote der Ausfuhr nach Flandern, welche Eduard I. von England in den siebziger Jahren wiederholt erließ, deutlich hervor. Ganz ähnlich wie die Deutschen und Romanen 1280 ihren Stapel von Brügge nach einem andern Platze vorübergehend verlegen, ist auch bei diesem Verbote von der Verlegung des Stapels mit englischen Waren nach Dordrecht die Rede $\left.{ }^{133}\right)$. Auch das hamburgische und das lübi-

${ }^{128}$ ) Große Schafherden auf den Gütern des Königs und des Adels im Domesday book erwähnt, s. v. Ochenkowski, Englands wirtschaftliche Entwicklung, Jena 1879, S. 6, 25.

${ }^{129}$ ) Hans. Urkdb. I n. 2 (lana discarcata); Häpke, Die Herkunft der friesischen Gewebe, Hans. Geschichtsbl. 1906, Heft 2, S. 312; Weiland in s. Aufsatze Goslar als Kaiserpfalz i. d. Hans. Geschichtsbl. 1884, S. 18, Note 2 scheint mir durchaus im Irrtume zu sein, wenn er meint, daß um das Jahr 1000 an Ausfuhr von Wolle in England noch nicht zu denken sei.

$\left.{ }^{130}\right)$ Hans. Urkdb. I. n. 2.

131) Vgl. Hildebrandt, Zur Geschichte der deutschen Wollindustrie, i. d. Jahrb. f. Nationalökonomie und Statistik, VI, Jena 1866, S. 199 f.

${ }^{132}$ ) Vgl. Kunze, Hanseakten, S. 42; 1297 erklärt das englische Parlament: Lana Anglie ascendit fere ad valorem medietatis totius terre et vectigal, quod inde solvitur, ascendit ad quintam partem valoris totius terre, s. Pirenne, Gesch. Belg. I. S. 438, Note 1.

$\left.{ }^{133}\right)$ Vgl. o. Ochenkowski, Englands wirtschaftliche Entwicklung, S. 187; Schanz, Englische Handelspolitik, I S. 330, 437. Die Urkunde n. 54 bei Gilliodts van Severn Cartulaire de l'ancienne Estaple de Bruges, Bruges 1904, Bd. I, betr. eine Bestätigung des Stapels von Calais, angeb- 
sche Schiffrecht bestätigen uns, daß die englische Wollausfuhr auf Brügge gerichtet war $\left.{ }^{134}\right)$.

Für den Absatz der Erzeugnisse höher entwickelter Völker bot die dünngesäte, bedürfnislose Bauernbevölkerung Englands kein günstiges Gebiet. Nur der Großgrundbesitz, vor allem der königliche $\mathrm{Hof}^{135}$ ), die Barone des Landes ${ }^{136}$ ) und die geistlichen Würdenträger ${ }^{137}$ ) kamen in dieser Beziehung in Betracht und waren allerdings um so wichtigere Abnehmer, als ihnen durch den fortgesetzten Export der Wolle sehr bedeutende Reichtümer zuflossen ${ }^{138}$ ). Denn die große Ausfuhr dieses Landes

lich 1251, gehört dem 15. Jahrhundert an, s. auch Stein, in den Hans. Geschichtsbl. 1906, Heft 2, S. 382. - Der Stapel der englischen Waren in Brügge dürfte ebenso wie derjenige der französischen Weine, der baltischen Waren, der schwedischen Produkte usw. nicht auf einer rechtlichen Grundlage erwachsen, sondern durch die Notwendigkeit der wirtschaftlichen Verhältnisse ins Leben gerufen sein, wenngleich der auf tatsächlicher Grundlage erwachsene Stapel nach träglich auch eine rechtliche Ordnung erhalten hat. Es würde ganz unverständlich sein, wenn der englische Ausfuhrhandel - im Gegensatze zu dem Handel aller anderen Länder nicht in Brügge seinen Stapel gehabt hätte, d. h. zen tralisiert gewesen wäre,und zwar um so unverständlicher deshalb, weil die englische Ausfuhr größtenteils durch ausländische Kaufleute besorgt wurde, denen nachweislich Brügge als Stapelplatz diente. Dieses auf tatsächlicher Grundlage erwachsenen Institutes des Stapels der englischen Waren bedienten sich die englischen Könige alsdann $\mathrm{zu}$ ihren Zwecken, namentlich allerdings erst seit dem 14. Jahrhundert.

134) Hamb. Schiffr. Art. 9c; Lüb. Schiffr. Art. 10; s. S. 40, 69 ff. u. 124. Durchaus verfehlt ist die u. a. von Schäfer, Der Stamm der Friesen und die niederländische Seegeltung, Marine-Rundschau 1905, S. 1362, vertretene herrschende Meinung, die Hamburger hätten damals von Hamburg direkt nach London verfrachtet.

${ }^{135}$ ) Vgl. die zahlreichen Schuldurkunden des Königs über Pelz- und Wachslieferungen $u$. a. im Hans. Urkdb. 1237 schuldet der König 54 Pfund für Pelze, I n. 283; 1242: 200 Pfund n. 322; 1248: einmal 856 Pfund, ein anderes Mal 668 Pfund für Pelze und Wachs, n. 359. Weitere derartige Schulden s. n. 333, 395, 475.

136) Die Schafherden mancher englischer Adliger zählten im 14. Jahrhundert 2000 Stück und mehr; s. Hildcbrandt, a. a. O.

${ }^{137}$ ) In der Mitte des 13. Jahrhunderts beteiligten sich nicht weniger als 102 Abteien am Wollexport; Hans. Urkdb. III S. 407, Note 15. Schanz, I S. 136, Note 3.

138) Als 1291 die-Londoner über die fremden Kaufleute Klage führen, erwidert der König: mercatores extranei sunt ydonei et utiles magnatibus; s. Kunze, Hanseakten aus England, S. 5. 
muß, wie regelmäßig bei solchen landwirtschaftlichen Produktionsgebieten, die Einfuhr weit überragt haben. Aus der starken Verbreitung des englisehen Geldes außerhalb Englands hat man wohl den umgekehrten Schluß gezogen, indem man folgerte, die Einfuhr nach England habe nicht durch die Ausfuhr beglichen werden können und der Überschuß deshalb mit großen Mengen baren Geldes bezahlt werden müssen. Die dargelegten Tatsachen des großen englischen Exportes und des unentwickelten Zustandes der englischen Volkswirtschaft widerlegen diese Auffassung genugsam. Das Festland hat im Gegenteile die englische Wolle zum großen Teile mit barem Gelde bezahlen müssen ${ }^{139}$ ), und dieser dauernde AbfluB der Edelmetalle vom Kontinent nach England ist ohne Zweifel die Ursache gewesen, daß das Silber, welches durch den Klerus und päpstliche Schatzungen ${ }^{140}$ ), durch Verpachtung von Zöllen und Einnahmen seitens der englischen Könige und Machthaber an Ausländer gegen Vorschüsse und Darlehen ${ }^{141}$ ) und durch ähnliche Transaktionen seinen Weg zum Kontinent zurückfand ${ }^{\mathbf{4} 2}$ ), so allgemein das englische Münzgepräge trug. Dieser Zufluß der Edelmetalle nach England war es gerade, der so früh Kapitalisten, insbesondere italienische Bankiers, dorthin zog, welche ihre Kapitalien dort anlegten und dadurch den Ausgleich der Handelsbilanz mit dem Kontinente herbeiführten ${ }^{143}$ ). Schon seit dem 11. Jahrhundert sind die Italiener, die ja im ganzen Mittelalter die Hauptträger des Geldverkehrs waren, urkundlich

139) S. auch Schanz, I S. 488, 494.

$\left.{ }^{140}\right)$ S. Schanz, I S. $111 \mathrm{ff}$. Italienische Kaufleute in England als Einsammler der dem Papst zufließenden Beträge.

141) Zu Heinrichs III. Zeiten waren die meisten Ämter in Händen von Ausländern. Die Gesamtschuld Eduards I. an die Lombarden betrug 129728000 Lstr., bei seinem Tode 118000 Lstr.; die Zölle waren im Pfandbesitze von Italienern; s. Kunze, Hanseakten, S. 9. - Vgl. auch Goldschmidt, Universalgeschichte des Handelsrechts, Stuttgart 1891, S. 186.

142) Diesem Abflusse versuchte schon Eduard I. vorzubeugen; vgl. Hans. Urkdb. I n. 835, Note 1.

143) Zahlreiche kirchliche Pfründen in England wurden in der Folgezeit von den Päpsten an Ausländer verliehen, die gar nicht persönlich in England ihres Amtes walteten, sondern auf dem Kontinente lebten und nur ihre Revenuen aus England bezogen, Schanz, I S. 489. 
in England nachweisbar $\left.{ }^{\mathbf{1 4}}\right)$. Der Geldmarkt vor allem war es, der England und London so früh eine so hohe wirtschaftliche Bedeutung gegeben hat.

Der Handelsverkehr der Deutschen nach England war bereits Jahrhunderte alt ${ }^{145}$ ). Schon die sogenannte Zollrolle des Königs Ethelret aus dem 10. oder 11. Jahrhundert ${ }^{146}$ ) erwähnt sie neben Flanderern und Nordfranzosen auf dem Londoner Markte. Unter ihnen stehen im 12. Jahrhundert voran die Kölner ${ }^{147}$ ), die schon in der Mitte des 12. Jahrhunderts in London ein eigenes Haus besaßen. Schon die Zollrolle König Ethelrets nennt als Gegenstand der Ausfuhr der Deutschen aus England vor allem Wolle, und unter den Gegenständen, in denen die Deutschen ihre Abgaben in England zu entrichten haben, die sie also dort einführen, stehen in jener Urkunde an erster Stelle Tuche aufgeführt. Durch den Wollhandel aber müssen die Deutschen naturgemäß in den Handel nach Flandern hineingezogen $\operatorname{sein}^{\mathbf{1 4 8}}$ ), wo zuerst die Tuchfabrikation größere Ausdehnung annahm. Die Beziehungen der Kölner zu Flandern sind für das 12. Jahrhundert auch schon anderweitig urkundlich belegt ${ }^{149}$ ). Als Einfuhrartikel der Kölner in England wird im 12. Jahrhundert namentlich auch Wein erwähnt ${ }^{150}$ ).

Die Kölner gestatteten den Angehörigen anderer Städte, insbesondere den Westfalen, den Zutritt zu ihrer Genossenschaft und ihrem Hause in London gegen ein Eintrittsgeld. Auch die Lübecker und Hamburger, einmal in den flandrischen Verkehr hineingezogen, finden wir bald an dem flandrisch-

144) Schanz, I S. 111f. Goldschmidt, S. 186.

${ }^{145}$ ) Vgl. Lappenberg, Stahlhof, S. 3 ff.

146) Hans. Urkdb. I n. 2, III n. 599.

${ }^{147}$ ) Ebenda, I n. 13, 14, 25, 40.

${ }^{148}$ ) Es kann m. E. kaum ein Zweifel bestehen, daß in der Urkunde über den Aufenthalt und Handel der Lothringer, der Untertanen des Kaisers usw. in England, aus der Mitte des 12. Jahrhunderts, Hans. Urkdb. III n. 602, anstatt Brune zu lesen ist: Bruge (Bruges); sowohl die Deutschen von Tiel wie die von Brügge sollen in London wohnen dürfen. Wir haben hier die kölnisch-westfälische Hanse in Flandern, welche Tuche nach England ausführt und Wolle zurückbringt, vor uns.

${ }^{149}$ ) Hans. Urkdb. I n. 22 Note 1, n. 23, 29, 46.

150) Ebenda, n. 13. 
englischen Handelszuge beteiligt. Für den Verkehr der Hamburger daselbst besitzen wir bereits aus dem Jahre 1224 ein Zeugnis ${ }^{151}$ ), indem der Hamburger Schiffer Gottschalk und zwei Stavorner Schiffe im Hafen von Portsmouth mit ihren Schiffen angehalten und wieder freigelassen wurden. Die Kölnische Genossenschaft, die wohl unter der rasch aufstrebenden Konkurrenz der Lübecker litt, bereitete denselben zunächst Schwierigkeiten. Den Lübeckern gelang es aber, diese Hindernisse zu überwinden, indem sie 1226 von Kaiser Friedrich II. ein Privileg ${ }^{152}$ ) erwirkten, in welchem er sie den Kölnern und Tielern und deren Genossen in England völlig gleichstellte und die Erhebung der bisher dort von ihnen geforderten besonderen Abgabe untersagte. Dieser Gleichberechtigung erfreuten sich im 13. Jahrhundert jedenfalls auch die Hamburger; von ihrer Zurücksetzung in England hören wir nichts, finden sie später vielmehr mit den übrigen Deutschen in England eng verbunden. Vielleicht waren sie von der kölnischen Genossenschaft von vornherein freundlicher aufgenommen, etwa weil sie im Gegensatze zu den Lübeckern zunächst weniger als Kaufleute wie als gern gesehene Frachtschiffer dorthin kamen. Die Lübecker und neben ihnen die Hamburger gewannen an dem englischen Verkehre bald bemerkenswerten Anteil. 1238 wurden den Lübeckern von dem Könige von England die den übrigen Deutschen dort zustehenden Freiheiten besonders gewährleistet; zugleich wurde ihnen Befreiung vom Standrecht verliehen ${ }^{153}$ ). 1251 sicherte ihnen die Stadt London in Anlaß eines Vergleiches den ungehinderten Besuch der Stadt zu ${ }^{154}$ ). 1258 nahm der König sie von neuem in Schutz ${ }^{155}$ ). 1266 wurde den Hamburgern ${ }^{156}$ ), 1267 den Lübeckern das Recht zugestanden ${ }^{157}$ ), in England eine eigene Hanse nach Art derjenigen der Kölner zu haben. Der Sitz dieser hamburgischen Hanse in England

151) Hans. Urkdb. I. n. 161.

$\left.{ }^{152}\right)$ Ebenda, n. 205.

153) Ebenda, n. 292.

${ }^{154)}$ Ebenda, n. 406.

${ }^{155)}$ Ebenda, n. 506.

${ }^{156)}$ Ebenda, ก. 633.

$\left.{ }^{157}\right)$ Ebenda, n. 636. 
scheint jedoch nicht London selbst, sondern ein naher anderer Hafenplatz, vielleicht am Ausflusse der Themse, gewesen zu sein $\left.{ }^{158}\right)$. Der Verkehr der Deutschen beschränkte sich, wie schon angedeutet, übrigens nicht auf London; Newcastle on Tyne, Hull, Boston und Lynn, ferner Harmouth, Gravesend werden schon im 13. Jahrhundert als Plätze genannt, an denen deutsche Kaufleute und Schiffe verkehrten und zum Teil sogar deutsche Niederlassungen bestanden ${ }^{159}$ ). Auch Hamburger Schiffe werden an einzelnen dieser Plätze gelegentlich erwähnt ${ }^{160}$ ).

Außer den Gruppen der Kölner, der Lübecker und der Hamburger nebst ihren Gefolgschaften aus andern Städten sehen wir endlich auch als weitere Gruppe die Mitglieder der deutschen Genossenschaft auf Gotland in England auftreten ${ }^{161}$ ). Schon 1235 werden drei Kaufleute aus Gotland mit ihren Genossen in England erwähnt ${ }^{162}$ ). 1237 erwerben ,die Kaufleute, welche Gotland besuchen", besondere Handelsprivilegien ${ }^{163}$ ). Von einer besonderen Hanse dieser Kaufleute in England hören wir freilich nichts.

Als Konkurrenten der Deutschen, wahrscheinlich sogar als überlegene Konkurrenten, treffen wir in England namentlich die Flanderer und die Italiener $\left.{ }^{\mathbf{1 6 4}}\right)$. Die Kaufleute der flandrischen

${ }^{158)}$ Gravesend? vgl. Hans. Urkdb. I n. 458; vgl. Kunze, Das erste Jahrhundert der deutschen Hansa in England, i. Hans. Geschichtsbl. Jahrg. 1889, S. 135 ff.; Lappenberg, Stahlhof, S. 166; Hans. Urkdb. I n. 673. Die Voraussetzung Kunzes, daß der Handel der Hamburger und Lübecker von England auf die Heimatstädte dieser Kaufleute gerichtet sei (S. 135 f.), ist irrig; sein Argument dafür, daß der Hafenplatz vermutlich an der Ostküste gelegen habe, wird damit hinfällig.

${ }^{159}$ ) Vgl. Lappenberg, Stahlhof, S. 33, 162 ff., 165 ff.; Kunze, Hanseakten, n. 367 ก.

$\left.{ }^{160}\right) 1247$ in Lynn Regis, Hans. Urkdb. I 352; Gravesend 1253; ebenda n. 458.

161) So auch Schäfer, Die Hanse, S. 24.

162) Hans. Urkdb. I n. 270.

${ }^{163)}$ Ebenda, n. 281.

164) Utber die Bedeutung der Italiener für die englische Wollausfuhr vgl. auch Schulte, Geschichte des mittelalterlichen Handels und Verkehrs zwischen Westdeutschland und Italien, Bd. I, S. 125. Die Übersichten über die englischen Wollausfuhren des Jahres 1273 in Hans. Urkdb. III S. 405 ff. zu n. 435, und des Jahres 1277-78 bei Kunze, n. 366, ge- 
Wollindustriestädte hatten hier ihre Genossenschaften. Die sog. Londoner Hanse von Brügge und seinen Genossen, zu denen Ypern, Dixmuiden, Aardenburg, Oudenburg, Oostburg, Damme, Thourout, Winnoxbergen, Veurne Belle, Poperingen, Lille, Tournai und Orchies gehörten, spielte unter diesen flandrischen Hansen in England wohl die wichtigste Rolle. Neben ihr standen die Hansen der Kaufleute von St. Omer, derer

statten m. E. keinerlei Schlüsse auf die Beteiligung der verschiedenen Nationen an dem Wollhandel zu normalen Zeiten, da die Ausfuhr der Wolle nach Flandern, wohin sie sonst ausschließlich gerichtet war, damals in England offenbar verboten war (s. auch Hans. Urkdb. I n. 788). Die Flanderer, denen sonst ein Löwenteil an dieser Ausfuhr zufiel, erscheinen infolge dessen überhaupt nicht an dem Export beteiligt. Der Anteil der Holländer, in deren Gebiet vorübergehend der Stapel verlegt war, erscheint unverhältnismäßig groß (s. die Versuche aus dieser Zeit, die holländische Weberei zu beleben, Hans. Urkdb. I n. 776, 778, 806; ein Erfolg ist wenigstens im internationalen Verkehr nicht zu spüren). Auch der Anteil der Flandern benachbarten Franzosen war vielleicht infolge des Verbotes in die Höhe geschnellt, der Anteil der Deutschen dagegen, die übrigens selbst in dieser Zeit von der Ausfuhr der Wolle nach Flandern nicht ganz Abstand nahmen (s. Hans. Urkdb. I n. 788), dürfte herabgedrückt sein. Nach der Zusammenstellung im Hans. Urkdb. III S. 405 ff. entfielen von ca. 30000 im Jahre 1273 ausgeführten Sack Wolle etwa 2100 auf Deutsche, etwa 1/6 der Ausfuhr auf Brabant, etwa 1/12 der Ausfuhr auf Amiens, das übrige auf Kaufleute aus England, aus Abbeville, Arras, Bayonne, Boulogne, Caen, Cahors, Calais, Cambrai, Corbie, Dieppe, Dinant, Florenz, Gascogne, Lucca, Navarra, Normandie, S. Omer, S. Quen, Paris, Piacenza, Pont-Audemer, Rouen, St. Quentin, Senlis, Spanien, Huy, Lüttich.

Nach der Tabelle bei Kunze fielen in dem Ausnahmejahr 1277/78 von der Wollausfuhr:

$$
\begin{aligned}
& 30 \% \text { auf die Italiener, } \\
& 22 \% \text { auf die Franzosen, } \\
& 21 \% \text { auf die Holländer, } \\
& 12 \% \text { auf die Deutschen, } \\
& 10 \% \text { auf die Brabanter. }
\end{aligned}
$$

Ebensowenig kann die Zusammenstellung bei Kunze, n. 368, über die Beteiligung an der Ausfuhr von 222 Sack Wolle, welche während der Zeit von 1294 bis 1298 aus Newcastle on Tyne erfolgte und bei der $69 \%$ auf Italiener, $25 \%$ auf Deutsche, $6 \%$ auf Flanderer und Holländer entfallen, einen Anspruch darauf erheben, eine Anschauung ron dem Gesamtanteil der verschiedenen fremden Nationen an der englischen Wollausfuhr zu geben. 
von Gent, derer von Douai, derer von Amiens, Corbie und Nesle, derer von Vermandois, derer von Cambrai usw. ${ }^{165}$ ). Die Italiener beherrschten den englischen Geldmarkt ${ }^{166}$ ), waren aber infolge ihrer Geldanlagen in England auch an der Wollausfuhr sehr stark beteiligt ${ }^{167}$ ). Daneben kamen außer den Engländern selbst in Betracht Franzosen, Brabanter, Holländer und in bescheidenem Maße auch Spanier und Portugiesen ${ }^{168}$ ).

Alle diese Nationen nehmen einerseits an der Wollausfuhr nach Flandern ${ }^{169}$ ) und andererseits an der Einfuhr der Waren vom flandrischen Weltmarkte teil. Außer flandrischen Tuchen, in deren Gestalt die englische Wolle von Brügge nach England zurückkehrte ${ }^{170}$ ), werden als Einfuhrprodukte der Deutschen namentlich nordische Produkte, insbesondere Pelze und Wachs erwähnt. Auch diese Handelsartikel aber gingen England vom flandrischen Weltmarkte aus zu. ${ }^{171}$ ) Von den romanischen

${ }^{165}$ ) S. Höhlbaum, Über die flandrische Hanse von London, in Hans. Geschichtsbl. 1898, S. 147 ff. Daß der Gegenstand des Handels dieser Hansen die englische Wolle war, s. für Donai ebenda S. 164. Daß eine Vereinigung unter diesen flandrischen Hansen in England bestand, ist nach Höhlbaum wahrscheinlich, ebenda S. 157 Note 2.

${ }^{166)}$ Vgl. u. a. Kunze, Hanseakten S. 8.

167) Als Eduard I. eines Tages die Waren der Italiener in seinem Reiche beschlagnahmen ließ, befanden sich in ihren Händen nicht weniger als 2380 Säcke Wolle, deren Wert auf 30000 Lstr. damaligen Geldes veranschlagt wurde. S. Schanz, I S. 112.

${ }^{168)}$ Schanz, I S. 7 ff., 268, 283, 291 ff., 327 ff.

${ }^{169}$ S. oben S. 62 f. und Note 133 daselbst.

170) 1265 ,tibi, o Anglia, de tua materia vestes pretiosas tua textrix Flandria texuit". S. u. a. Schanz, I, S. 435.

171) Das Privileg an die „Kaufleute, welche Gotland besuchen“, von 1237 erweckt fast die Vermutung, als wenn diese Kaufleute auf direktem Wege von Gotland nach England Handel getrieben hätten. Diese Vermutung ist indessen m. E. nicht haltbar. Es heißt in dem Privileg, Hans. Urkdb. I. n. 281: „quod ipsi et heredes eorum in perpetuum salvo et secure veniant in Angliam cum rebus et mercandisiis suis, quas d u c e $\mathrm{n} \mathrm{t}$ de partibus suis Guthland, et quod salvo ibi morentur et salvo inde recedent cum rebus et mercandisiis suis quas emerint in terra nostra Angliae d u c e n d a s v e r s u s p a r t e s s u a s." Solltesich dieses Privileg wirklich nur auf den direkten Handel von Gotland nach England und von England nach Gotland bezogen haben (so Schanz, Engl. Handelspolitik I, S. 185, Note 1), im Gegensatze zu dem Handel zwischen dem Stapel der russischen Waren in Brügge und England, so ist das Beginnen 
Nationen werden, und zwar wiederum ron ihrem Stapel in Brügge aus, die Erzeugnisse der südlichen Länder auf die englischen Märkte gebracht sein. Alle endlich, Germanen wie Romanen, werden Edelmetalle dorthin haben führen müssen.

Über die hamburgische Hanse in England sind wir wenig unterrichtet; an ihrer Spitze wird, wie in Flandern, ein Älter-

des englischen Königs jedenfalls erfolglos geblieben. Bei der Schwierig. keit, Rückfracht nach Gotland in England zu finden - für Wolle war in Gotland kein Markt und ebensowenig für die übrigen Artikel, welche England dem Auslande zu bieten vermochte - , und bei der sehr viel größeren Anziehungskraft des großen brüggischen Marktes und der in den damaligen wirtschaftlichen Verhältnissen begründeten Notwendigkeit der Konzentration eines solchen Verkehrs würde diese Politik des Königs naturgemäß ihre Wirkung verfehlt haben müssen. Gerade den russischen Verkehr sehen wir ja in der Folgezeit besonders ausschließlich auf Flandern gerichtet, und was in der Beziehung für die spätere Zeit gilt, darf in noch höherem Maße für die ältere Zeit, in der das wirtschaftliche Bedürfnis nach Konzentration des Angebotes und der Nachfrage noch stärker war, angenommen werden. Höchstwahrscheinlich hat aber mit den Worten ducent de partibus suis Guthland in dem vorerwăhnten Privileg überhaupt nur die Herkunft der Ware bezeichnet sein sollen, nicht der Weg, auf dem sie England zugeführt wurde, d. h. das Privileg bezog sich nur auf die Zufuhr von Pelzen, Wachs und dergl. russischen, von den Kaufleuten über Gotland nach dem Westen gebrachten Waren, die ja übrigens in den meisten Fällen über Lübeck-Hamburg befördert wurden, so daß von einem direkten Verkehr zwischen Gotland und England schon deshalb kaum die Rede sein konnte. Eine derartige auf einen direkten Handel im Gegensatz zum indirekten Handel abzielende Handelspolitik lag überdies den Machthabern jener Zeit, insbesondere den englischen Königen, ganz fern; das Interesse, welches sie an dem Handel nahmen, pflegte sich auf die finanziellen Nutzungen, die sie aus demselben zogen, zu beschränken. Daß die russischen Waren über den Stapel von Brügge nach England kamen, zeigt sehr hübsch die Urkunde von 1309 bei Kunze, Hanseakten, n. 40: 8 deutsche Kaufleute werden in England zur Rechenschaft gezogen, weil sie sich vereinbart hätten, die Zufuhr von Wachs zu unterbinden. ,dicunt, quod nullam compositionem seu collusionem aliqualem fecerunt ad impediendum, quin cera et aliae merces venire possint de partibus Alemanniae in Angliam secundum quod venire solebant, nec aliquam penam inter se statuerunt, prout eis imponitur. Dicunt tamen, quod, ubi c e ra venire solebat de partibus de Russhye et aliis longinquis $\mathrm{us} \mathrm{qu}$ e i $\mathrm{Flan} \mathrm{d} \mathrm{ri} \mathrm{a} \mathrm{m} \mathrm{quolibet} \mathrm{anno} \mathrm{circa} \mathrm{festum}$ pasche, quo tempore providentia regis facta fuit pro toto dimidio anno sequenti, nulla cera adhuc i b i d e m venit, propter quod iidem mercatores, 
mann erwähnt ${ }^{172}$ ). Gegenstand ihres Geschäftsbetriebes ist zweifellos vor allem der Warenhandel, die Wollausfuhr, gewesen. Dagegen findet sich von einem im Verkehr der hamburgischen Hanse in England ausgebildeten Schiffrechte keine Spur; hätte ein solches existiert, so würde es zweifellos in gleicher Weise wie die Schiffrechte der Hamburger Hansen von Flandern und von Utrecht in die 1292 in Hamburg angefertigte Zusammenstellung des ,hamburgischen Schiffrechtes" aufgenommen sein. Es ist aber auch nur natürlich, daß es ein Schiffrecht der hamburgischen Hanse in England niemals gegeben hat; England war nicht Mittelpunkt eines nach den verschiedensten Richtungen weit verzweigten Schiffahrtsverkehrs. Der englische Verkehr war, wie schon betont, nahezu ausschließlich auf Flandern gerichtet, den Mittelpunkt der Wollindustrie; auch der Verkehr der hamburgischen Hanse und ebenso derjenige der lübischen Hanse in England spielte sich so gut wie ausschließlich zwischen England und dem Zwin ab, und nicht etwa zwischen England und Hamburg, das für die englische Wollausfuhr, die den Schlüssel zum englischen Verkehr bildete, ebensowenig in Betracht kommen konnte, wie Lübeck, da beide Städte ebensowenig wie ihre Hinterländer Sitz einer irgend nennenswerten Wollindustrie waren. England war wirtschaftlich lediglich ein Punkt in der Peripherie des Welthandelskreises, der in Brügge seinen Mittelpunkt hatte. So kommt es, daß die hamburgische und lübische Schiffahrt von und nach England ihre rechtliche Regelung in dem Schiffrecht der hamburgischen und lübischen Hanse am Zwin fanden ${ }^{173}$ ). Wolle führen beide Schiff-

qui soliti sunt ceram in dictis partibus Flandrie emere e t A n g l i a m d u c e r e, nullam ceram ibidem invenire possunt. Der König ordnet daraufhin eine Untersuchung an, ob diese Angaben wahr sind, und gibt Auftrag, die Wollhändler, die Spezereihändler, die Pelzhändler, die Ölhändler, also alle diejenigen, die gleichfalls vom flandrischen Markte aus England zu versorgen pflegen und deshalb die flandrischen Marktkonjunkturen kennen (lanarii, apotecarii, pelliparii, ollearii qui soliti sunt transfretare ad partes Flandriae et Alemannie) darüber zu vernehmen.

172) Hans. Urkdb. I n. 673.

${ }^{173}$ ) Art. 9c. des Hamb. Schiffrechtes, Art. 10 des Lübischen Schiffrechtes. 
rechte als den Gegenstand an, welchen die hamburgischen und lübeckischen Schiffe von England nach dem Zwin bringen ${ }^{173}$ ).

Die verschiedenen Hansen in England sehen wir schon in enger Verbindung stehen und noch im 13. Jahrhundert zu einer gemeinsamen Genossenschaft sich verschmelzen. Sie alle haben schon vor ihrer Vereinigung an der ursprünglich nur den Kölnern gehörenden Gildhalle in London teil ${ }^{174}$ ), und die Hausordnung für die gemeinsame Benutzung dieser Gebäude wird früh $\mathrm{zu}$ einem sie alle dauernd vereinigenden Bande ${ }^{175}$ ). Mit der Teilnahme an den gemeinsamen Vorrechten ist andererseits wohl die gemeinsame Übernahme gewisser von alters her von der kölnischen Genossenschaft getragener städtischer Lasten, die Instandhaltung des Stadttores Bishopsgate und die Mitbewachung desselben, verbunden ${ }^{176}$ ). Vielleicht hängt es auch mit diesen öffentlich rechtlichen Verpflichtungen zusammen, daß sie - neben ihren deutschen Älterleuten gemeinsam einen Londoner Bürger zum Ältermann haben ${ }^{177}$ ), der gemeinsamer Schutzherr der verschiedenen deutschen Hansen an den verschiedenen englischen Plätzen war ${ }^{178}$ ) und in gewissen Fällen auch Recht zu sprechen hatte, wenngleich rechtes.

173) Art. 9c. des Hamb. Schiffrechtes, Art. 10 des Lübischen Schiff-

174) Vgl. schon Hans. Urkdb. I n. 552, darüber Kunze, Hans. Geschichtsbl. 1889, S. 131. Das Eigentum des Gebăudes mag rechtlich lediglich den Kölnern zugestanden haben; die Hamburger und Lübecker werden zunächst nur in der Weise Anteil an der Gildhalle gehabt haben, daß ihnen die Kölner die Mitbenutzung der Gildhalle - wohl gegen eine Entschädigung - gestatteten. Die kölnische „Hanse“ hatte nach 1260 ebenso wie die hamburgische und die lübische Hanse eine Abgabe zu zahlen, während von der Gildhalle keine Abgabe mehr zu zahlen war, s. Lappenberg, Stahlhof, S. 142. Vgl. zu der im Texte ausgesprochenen Auffassung: Stein, Über die ältesten Privilegien der deutschen Hanse in Flandern usw., i. Hans. Geschichtsbl. 1902, S. 9'.

$\left.{ }^{175}\right)$ S. Lappenberg, Stahlhof, S. $24 \mathrm{f}$. und das Statutenbuch ebenda S. 102 ff. Die ältesten Teile der Statuten sind lediglich hauspolizeilicher Natur.

${ }^{176)}$ Vgl. Hans. Urkdb. I n. 902; auch n. 747.

${ }^{177)}$ Ebenda und Lappenberg, Stahlhof, S. 18.

${ }^{178)}$ Lappenberg, Stahlhof, S. 17, 18 f. und Anhang S. 22, Urkde. von 1383. 
Streitigkeiten der Deutschen untereinander oder gar zwischen den Mitgliedern einer der Hansen nicht vor sein Forum gehörten ${ }^{179}$ ).

Die Gemeinsamkeit der Interessen der deutschen Kaufleute in England hat, wie erwähnt, bereits im 13. Jahrhundert zur Verbindung der verschiedenen deutschen Hansen in England $\mathrm{zu}$ einer gemeinsamen Genossenschaft geführt. In einer Urkunde von $1282^{180}$ ), in welcher u.a.die Privilegien des , Kaufmannes von der deutschen Hanse" bestätigt werden, werden als Vertreter der Deutschen ein Ältermann aus Dortmund ${ }^{181}$ ), und ferner drei Bürger von Dortmund und je einer aus Köln, aus Münster und aus Hamburg aufgeführt. Ob damit freilich die Existenz der Einzelhansen der Kölner, Hamburger und Lübecker in jeder Beziehung aufgehört hatte, muß dahingestellt bleiben ${ }^{182}$ ). Bei der Ordnung der gemeinsamen Angelegenheiten der Deutschen in England treten sie in der Folgezeit freilich nicht wieder hervor. Die in England handelnden Kaufleute der einzelnen Städte finden wir aber auch später noch zu besonderen Genossenschaften vereinigt.

Neben England nennt das hamburgische Schiffrecht auch die Fahrt von Irland ${ }^{183}$ ) nach dem Zwin als häufigere Reiseroute hamburgischer Schiffe. In einem Privilegium von 1297 wird den Hamburgern und Lübeckern Sicherheit für den Besuch aller schottischen Häfen zugesichert ${ }^{184}$ ). Beide Länder kommen wie England als Wollproduktionsgebiete für den Handel in Betracht, spielten aber im nordeuropäischen $\mathrm{Handel}$, wie auch insbesondere im Verkehr der Hamburger eine nebensächliche Rolle.

Der Verkehr der Hamburger vom Zwin aus war nicht auf die nördliche Hälfte Europas beschränkt; auch an dem Seeverkehr mit der atlantischen Südhälfte nahmen ihre Schiffe teil.

Mit den atlantischen Küsten des südlichen Europa stand Flandern damals schon lange in hochentwickeltem Verkehr.

$\left.{ }^{179}\right)$ Ebenda, S. $20 \mathrm{ff}$.

${ }^{180}$ ) Hans. Urkdb. I n. 902.

181) Hans. Urkdb. III n. 613.

182) Anders Kunze i. Hans. Geschichtsbl. 1889 S. 136.

${ }^{183}$ ) Art. 9c. Wolle wird als Pacotilleartikel erwăhnt; s. auch die Ausreise Hamburger Kaufleute nach Irland bei Koppmann, Hamb. Schuldbuch, i. Zeitschrift des Vereins f. hamb. Geschichte, Bd. VI, S. 501 Note 104. 184) Hans. Urkdb. I n. 1251. 
In voller Blüte befand sich schon im Anfang des 13. Jahrhunderts ${ }^{185}$ ) namentlich der Verkehr mit französischen Weinen von Rochelle nach dem Zwin. Das oléronensische Seerecht als der gewohnheitsrechtliche Niederschlag dieses Seehandels ist ein Denkmal dieses Verkehrs. Seine Entstehung ${ }^{186}$ ) als Gilderecht der Genossenschaft ${ }^{187}$ ) der Seefahrer und Kaufleute von

$\left.{ }^{185}\right)$ Schon Wilhelmus Brito preist in seinem um 1214 verfaßten Gedicht (s, oben Note 2) den Nebenort Brügges, Damme am Zwin, als den Stapelplatz der Weine von Rochelle. Das Statut der Genossenschaft der Seefahrer von Bayonne (Pardessus IV, S. 283 ff.), das aus derselben Zeit stammt, zeigt uns die Bayonner als Reeder und Schiffer regelmäßig an dem Verkehre von Rochelle nach Flandern beteiligt. Wenn Finot, relations commerciales entre la France et la Flandre au moyen-âge S. 37, 42, 82, meint, der Wein von Rochelle, der u. a. 1202 die Zollstătte von Bapaume passierte, sei zu Lande von Rochelle gekommen, so irrt er zweifellos. Dieser Wein wird nicht nach Flandern, sondern vielmehr von dem Stapel der Rocheller Weine am Zwin in Flandern aus in das Inland bestimmt gewesen sein. Eine Prämie von einem Denare vermochte doch zweifellos den gewaltigen Unterschied zwischen den Kosten des Landtransportes und des Seetransportes von Rochelle nach Flandern nicht auszugleichen und kann in dieser Beziehung gar nicht in Betracht gekommen sein, wie Finot meint.

${ }^{186)}$ ) S. Th. Kiesselbach, Der L'rsprung der rôles d'Oléron und des Seerechtes von Damme, i. Hans. Geschichtsbl., 1906, S. 1 ff.

${ }^{187}$ ) Die Urkunden berichten uns erst in verhältnismäßig später Zeit von dieser Genossenschaft; wir hören von ihr erst in der Mitte des 13. Jahrhunderts, als sie wegen in Flandern erlittener Zollbedrückungen eine Verkehrssperre gegen den flandrischen Markt verhängt (vgl. Jules Finot, Étude historique sur les relations commerciales entre la France et la Flandre au moyen-âge. Paris 1894, S. 85) und die Gräfin Margarete sich deshalb 1262 veranlaßt sieht (vgl. W. Arcère, Histoire de la ville de la Rochelle et du pays d'aulins. La Rochelle 1756, S. 219 ; auch Finot, S. 343), ihr offenbar an stelle ihres bisherigen Stapelplatzes ein Privileg für Gravelingen einzuräumen. Daß dieser bisherige Stapelplatz Brügge gewesen war, geht aus dem Privileg für Gravelingen, welches auf die Rechte der Genossenschaft in Brügge und auf die Einrichtungen für ihren dortigen Weinhandel mehrfach Bezug nimmt, deutlich hervor; übrigens zeigen spätere urkundliche Nachrichten des 13. Jahrhunderts sie uns wieder am Zwin tätig (F inot, S. 93 ff.); lange hat also wohl diese Verkehrs. sperre gegen Brügge nicht gedauert.

Wie im 1'. und 15. Jahrhundert (rgl. Gilliodts van Severn, Cartulaire de l'ancienne Estaple de Bruges. Bruges 190', Bd. I, n. 240, Urkunde von 1331, den Weinstapel der Kaufleute von La Rochelle und 
La Rochelle nebst Oléron, von Poitou und von der Gascogne, welche in Flandern am Zwin, als dem großen Weltmarkte, auf den sie ihre Verschiffungen konzentrierten, ihren Sitz hatte und dort die aus den Verschiffungen sich ergebenden Rechtsverhältnisse für den Kreis der Genossenschaftsmitglieder ordnete, wirft ein grelles Licht auf die herrschende Welthandelsstellung Flanderns auch für die atlantische Küste Südwesteuropas.

Schon im Anfang des 13. Jahrhunderts finden wir fremde Schiffer an diesem Verkehr beteiligt. Das bereits mehrfach erwähnte Statut der Bayonner Seefahrer von 1214 zeigt uns Bayonner Schiffe, eine Urkunde von $1226{ }^{188}$ ) auch eine größere Flotte meist flandrischer Schiffer und Kauffahrer mit Weinen von Rochelle, Saint Jean d'Angely und Saintongue auf der Fahrt von Rochelle nach dem Zwin. Auch das hamburgische und ebenso das lübische Schiffrecht führen als regelmäßige Fahrt die Reiseroute von Rochelle nach dem Zwin an; auch hier wird Wein als Gegenstand der Verfrachtung genannt, daneben auch bereits Salz, das an den französischen Küsten schon früh in großen Mengen gewonnen wurde und von Flandern aus seinen Absatz besonders im Ostseegebiete fand, wo fast gar kein Salz erzeugt, für das Einsalzen von Fischen aber Salz in großen Mengen verbraucht wurde.

Flanderns Seeverkehr nach dem Südwesten reichte noch über Rochelle hinaus. Wie schon erwähnt, spielt die Fahrt nach Flandern eine hervorragende Rolle in dem Bayonner Seefahrerstatut von 1214. Dieses Statut läßt aber zugleich erkennen, daß die Bayonne die Vermittlung des Verkehrs

St. Jean d'Angely in Damme betr., bestätigt 1385, 1409, 1435, 1502), so war nach dem bereits angeführten Gedichte des Wilhelmus Brito auch schon im Beginne des 13. Jahrhunderts das einige Kilometer von Brügge entfernte Damme am Zwin der Platz, wo diese Kaufleute von Rochelle ihren Weinstapel hatten. Daher die rôles d'Oléron auch als Seerecht von Damme bezeichnet; s. Th. Kiesselbach, a. a. O., S. $25 \mathrm{ff} ., 38 \mathrm{fr}$.

${ }^{188}$ ) Hans. Urkdb. I n. 201. Weinflotte, bestehend aus 5 Koggen und 7 ,,naves“, kommend von Rochelle, Saint Jean d'Angely und Saintongue (Senomanum, vgl. Gilliodts van Severen, Cartulaire de Bruges, I n. 240). Die Schiffer sind zum Teil von Munekerede, de la Mue, Damme, Gravelingen, Ardenburg; die Kaufleute von Brügge, Lille, Gent, Damme, Ypern, Ardenburg, Gravelingen, Bergen, Bailleul, Toulouse. 
zwischen den atlantischen Häfen der iberischen Halbinsel und den nördlichen Handelsplätzen besorgten; von der Küste der iberischen Halbinsel wird die Strecke von Faro, worunter nach Pardessus El Ferrol am Westende der spanischen Nordküste zu verstehen sein soll ${ }^{189}$ ), bis St. Sebastian als Ziel der Fahrten ihrer Schiffe erwähnt. Die coutumes de Bayonne, die noch dem 13. Jahrhundert anzugehören scheinen, zeigen die Bayonner aber auch in Sevilla handeltreibend ${ }^{190}$ ). Außer den Bayonnern scheinen auch schon kastilianische Schiffer im 13. Jahrhundert die Fahrt nach Flandern unterhalten zu haben. Schon aus dem Jahre 1266 wird von einer Übersetzung der rôles d'Oléron in das Kastilianische berichtet ${ }^{191}$ ); vermutlich nahmen also schon damals auch kastilianische Schiffe an der Fahrt von Rochelle nach Flandern teil ${ }^{192}$ ). Fest steht jedenfalls, daß die Kaufleute von Kastilien, Aragon, Navarra und mit ihnen sogar portugiesische Kaufleute im 13. Jahrhundert Flandern in großer Zahl besuchten und dort eine wichtige Rolle spielten ${ }^{\mathbf{9 3}}$ ).

189) Finot, relations commerciales entre la France et la Flandre, S. 116, scheint darunter Faro an der portugiesischen Südküste zu verstehen.

$\left.{ }^{190}\right)$ Jules Balasque, Études historiques sur la ville de Bayonne. Bayonne 1862, Bd. II, S. 3'1 f.; die coutumes selbst s. ebenda S. 674. Es ist dort von dem Falle die Rede, wenn der Bayonner Geld für fremde Rechnung oder dafür gekaufte Waren zu Schiffe von Flandern oder England oder von Sevilla nach Bayonne bringen will.

${ }^{191)}$ S. Th. Kiesselbach, a. a. O. S. 2.

${ }^{192}$ ) Für das 14. und 15. Jahrhundert bezeugen zahlreiche urkundliche Nachrichten die große Bedeutung, welche die kastilianische Flotte im spanisch-flandrischen Verkehr gehabt hat.

${ }^{193}$ ) Schon die Dammer Zollrolle von 1252 enthălt Zollsătze für Eisen aus Spanien und prunelles (Schlehen? zum Färben) aus Spanien, Hans. Urkdb. I. n. 432; vgl. III. S. 421, Note 10. Aus dem Jahre 1267 ist uns eine Urkunde erhalten, laut welcher den Kaufleuten von Kastilien, Spanien, Portugal, Aragon, Navarra, in Gemeinschaft mit denen von der Gascogne und von Cahors und mit den Kataloniern Privilegien für ihren Verkehr in Lille zuteil wurden (Finot, Étude historique sur les relations commerciales entre la France et l'Espagne an moyen-âge, Paris 1899, S. 41 f.), und im Jahre 1280 finden wir die Kaufleute von Kastilien, Navarra, Aragon, Portugal zusammen mit denen von der Gascogne und von der Provence in Flandern mit den deutschen Kaufleuten zur Verlegung ihres Stapels von Brügge nach Ardenburg vereinigt. Der Umstand, daß die 
Daß indessen die Hamburger und Lübecker Schiffe an dem Verkehr der iberischen Halbinsel mit Flandern teilgenommen hätten, ist sehr unwahrscheinlich. Gerade auf der hafenlosen Strecke zwischen der Mündung der Garonne und Bayonne erforderte die Seefahrt wegen der starken Brandung besondere örtliche Kenntnisse und Erfahrungen, und schon diese Schwierigkeiten dürften die Hamburger und Lübecker damals von dieser Fahrt abgehalten haben. La Rochelle ist vielmehr der südlichste Punkt, den die Schiffrechte für die Fahrten der Hamburger und Lübecker erwähnen.

Der Handelsverkehr der norddeutschen Kaufleute von Flandern aus war übrigens, auch abgesehen von dem unmittelbaren Verkehr der rheinischen und westfälischen Städte mit Flandern, nicht ausschließlich über See gerichtet. Vom Zwin aus besuchten die deutschen Kaufleute die flandrischen Märkte, z. B. die Messen von Thourout ${ }^{194}$ ). In dem Entwurfe eines Privilegs der Gräfin von Flandern an die Deutschen aus der Mitte des 13. Jahrhunderts ist sogar die Verpflichtung zum Besuche der flandrischen Messen vom Zwin aus vorgesehen ${ }^{195}$ ). Dieselbe Urkunde räumt ihnen ausdrücklich das Recht ein, von ihrer Niederlassung am Zwin aus die französischen Messen, also die Messen der Champagne und von Brie, zu besuchen. Urkunden ${ }^{196}$ ) aus dem Ende des 13. Jahrhunderts bezeugen ebenso, daß die Lübecker die Messen der Champagne von Flandern aus besuchten. Dafür, daß die Hamburger den Lübeckern dorthin gefolgt wären, liegt freilich kein Anhalt vor. Wir wissen aber, daß wenigstens in späterer Zeit die deutschen Kaufleute von Brügge aus die zu bestimmten Zeiten des Jahres abgehaltenen Jahrmärkte in den benachbarten Plätzen Antwerpen und Bergen op Zoon zu besuchen pflegten ${ }^{197}$ ), und wenn uns verschiedene Urkunden im 13. Jahrhundert die

Gesamtheit dieser französischen und spanischen Kaufleute in diesen Urkunden vielfach kurz nur als die spanischen Kaufleute bezeichnet wird, weist darauf hin, daß die Kaufleute der iberischen Halbinsel jedenfalls die Mehrzahl unter ihnen bildeten.

194) Hans. Urkdb. I n. 435, III n. 606.

$\left.{ }^{195}\right)$ Stein, i. Hans. Geschichtsbl. 1902, S. 73, 88.

${ }^{196)}$ Hans. Urkdb. I n. 1140, 1285.

197) Hansarezesse II 2 n. 184; 4 n. 8. 
Hamburger schon an dem Handel in Brabant beteiligt zeigen, so besteht zum mindesten ein hoher Grad ron Wahrscheinlichkeit dafür, daß dieser Verkehr damals ebenso wie später von der brüggischen Niederlassung aus vor sich ging und dorthin gerichtet war. Der Herzog von Lothringen und Brabant sichert ihnen in einem Privileg von 1256 Schutz für den Handel in seinen Landen $\mathrm{zu}^{198}$ ); die Aufkündigung dieses Schutzes soll an eine Frist von drei Wochen gebunden sein, um den Hamburgern in solchem Falle Zeit, sich und ihre Waren in Sicherheit zu bringen, zu gewährleisten. In einer weiteren Urkunde ${ }^{199}$ ) von 1257 verspricht der Herzog ihnen nochmals sein Geleit und fügt hinzu, daß dieses Privileg sogar im Falle des Ausbruches eines Streites zwischen ihm und den holsteinischen Landesherren bestehen bleiben soll. Zugleich läßt die Urkunde erkennen, daß es der Markt Antwerpens war. den die Hamburger besuchten, indem ihnen nämlich in dem Privilegium das Recht eingeräumt wird, dort den Zoll, den sie bisher in englischem Gelde hatten entrichten müssen, in ihrer eigenen Münze zu bezahlen. 1266 werden den Hamburgern diese ihre Rechte in Brabant nochmals bestätigt ${ }^{200}$ ). Aber auch den Rhein hinauf bis nach Köln können wir die Hamburger Frachtfahrer schon im 13. Jahrhundert verfolgen. Für die Fahrt den Rhein hinauf mit ihren Schiffen wird ihnen, ebenso wie den Lübeckern, 1251 von dem Grafen von Kleve freies Geleit zugesichert und der Zoll für das Pelzwerk, das sie bringen, und den Wein, den sie holen, festgesetzt ${ }^{201}$ ). 1270 wird die Zusicherung dieses Schutzes erneuert ${ }^{202}$ ). Im Jahre 1258 sichert Köln in Anlaß der Beilegung eines Streites mit den Kölnern den Hamburgern seinen Schutz für den Besuch Kölns mit ihren Waren $\mathrm{zu}^{203}$ ). Daß nun auch der Verkehr der Hamburger von Köln her auf die hamburgische Niederlassung am Zwin gerichtet war, beweist die Bestimmung des hamburgischen Schiffrechtes über das

${ }^{198)}$ Hans. Urkdb. I n. 496.

${ }^{199)}$ Ebenda n. 501.

${ }^{200}$ ) Ebenda n. 639.

201) Ebenda n. 403.

${ }^{202)}$ Ebenda n. 679.

203) Ebenda n. 513. 
Windegeld für das Faß Rheinwein ${ }^{204}$ ), den Lohn, welchen der Kaufmann an die Schiffsleute zu zahlen hatte für das Einladen der Ware in das Schiff am Abgangsorte und das Ausladen am Bestimmungsorte, das beides mittels einer am Schiffsmast oder an der Gaffel angebrachten Winde geschah; denn bei allen im Artikel 16 des Schiffrechtes aufgeführten Windegeldsätzen ist das Zwin als der Ort des Ausladens vorausgesetzt ${ }^{205}$ ).

Seinen Halt fand dieser gesamte vom Zwin ausgehende Verkehr der Hamburger, wie bereits erwähnt, in der dortigen hamburgischen Genossenschaft. Dorthin wird der Hamburger Kauffahrer mit Eröffnung der Schiffahrt im Frühjahre ausgezogen sein, um vielfach erst mit dem Schlusse der Schiffahrt um Martini wieder in die Heimat zurückzukehren; manchmal mag er auch den Winter über fortgeblieben sein ${ }^{206}$ ). Der Umstand, daß der deutsche Kauffahrer tatsächlich am Zwin den eigentlichen Mittelpunkt seiner geschäftlichen Tätigkeit hatte, erklärt es auch, wie der noch unten zu erörternde Gedanke aufkommen konnte, daselbst eine deutsche Kolonie anzulegen, in der die Deutschen mit Weib und Kind als Bürger ihren Wohnsitz nehmen sollten ${ }^{207}$ ). Die hamburgische Hanse am Zwin weist eine durchgebildete Organisation mit eigener Gerichtsbarkeit und selbständiger Finanzordnung auf. Jeder hamburger Schiffer oder Kaufmann, der nach Flandern kam, gehörte zur Hanse und war verpflichtet, an ihren alle Sonntage stattfindenden Versammlungen - Morgensprachen - teilzunehmen, bei Strafe von zwei Pfennigen englisch für den Fall des Ausbleibens. An der Spitze stand der Oldermann, dem die Vertretung der Genossenschaft nach außen wie auch die Leitung und Ordnung im Innern derselben oblag. Streitigkeiten zwischen Mitgliedern der Hanse durften nicht vor die flandrische Gerichtsobrigkeit ${ }^{209}$ ), sondern nur vor die Genossenschaft gebracht werden, die in

204) Art. 16 vv.

$\left.{ }^{205}\right)$ Th. Kiesselbach, Hamb. Schiffrecht, S. 68 ff.

$\left.{ }^{206}\right)$ Lüb. Schiffrecht Art. 31. Th. Kiesselbach, a. a. O. S. 75.

$\left.{ }^{207}\right)$ Vgl. die Urkunde bei Stein, Über die ăltesten Privilegien der deutschen Hanse in Flandern, i. Hans. Geschichtsbl. 1902, S. 73.

${ }^{208)}$ Hamb. Schiffrecht Art. 3a.

${ }^{209)}$ Hamb. Schiffrecht Art. 4a. 
der Morgensprache über die Sache entschied ${ }^{210}$ ). Wer gegen dieses Gebot verstieß und einen Hansebruder vor der flandrischen Gerichtsobrigkeit verklagte, verfiel in schwere Strafe und haftete dem andern für allen Schaden, der daraus erwuchs. Den Beklagten, der, zum Gerichtstermin geladen, nicht erschien, traf gleichfalls eine Geldbuße ${ }^{211}$ ). Zur Bestreitung der Ausgaben der Genossenschaft wurde von jedem Hamburger Bürger, der nach Flandern kam, wenn er Waren im Werte von 13 Schilling englisch oder mehr mit sich führte, ein Schilling englisch für die Hanse und außerdem zwei Pfennige vlämisch für, ,unser lieben Frauen Sankt Marien", also für einen kirchlichen Zweck, erhoben ${ }^{212}$ ). Zwei Drittel der Einnahme der Hanse wurden zur Bestreitung der laufenden Ausgaben und des Aufwandes für Festlichkeiten von dem Ältermanne und den Hansebrüdern verbraucht; ein Drittel sollte ,in den Block gelegt" werden, um im Bedarfsfalle darauf zurückgreifen zu können ${ }^{213}$ ).

Wie schon das bisher Gesagte erkennen ließ, traten außer der hamburgischen Hanse am Zwin noch andere Gruppen deutscher Kaufleute dort auf. Mehrfach ist schon hervorgehoben, daß auch die Lübecker am Zwin eine Hanse hatten, deren Organisation, wie das lübische Schiffrecht ergibt, mit derjenigen der hamburgischen Hanse fast genau übereinstimmt. Urkunden aus der Mitte des 13. Jahrhunderts erweisen uns, daß diese beiden Gruppen schon damals bestanden, daß es aber neben ihnen noch zwei andere gesondert organisierte Gruppen deut-

$\left.{ }^{210}\right)$ Hamb. Schiffrecht Art. 4 b.

211) Hamb. Schiffrecht Art. 3 b.

$\left.{ }^{212}\right)$ Art. 1b. Um welche Marienkirche es sich dabei handelte, muß hier dahingestellt bleiben; die Tatsache, daß die Utrechter Hanse der Hamburger ebenfalls eine Abgabe an diese Kirche zahlte, scheint darauf hinzuweisen, daß es sich nicht um eine in Flandern gelegene, sondern um eine Kirche des gemeinsamen Heimatshafens der beiden Hansen handelte. Über die Marienkirche in Hamburg und ihre Bedeutung vgl. z. B. Lappenberg, Hamb. Urkdb. I. n. 388 (ecclesia beatae virginis, quae aliquando prima et praecipua fuerat inter omnes ecclesias occidentales) auch n. 561, $670,780,826,839$. - Auf der andern Seite ist zu bemerken, daß auch die Lübecker Hanse am Zwin eine Abgabe für einen solchen kirchlichen Zweck hatte. (S. Lüb. Schiffrecht.)

213) Art. 1 d. 
scher Kaufleute dort gab. Die verschiedenen Gruppen werden erkennbar bei Gelegenheit des gemeinsamen Erwerbes von Privilegien in Flandern in den Jahren 1252-1253, welche nämlich für die vier Gruppen getrennt ausgefertigt werden ${ }^{213}$ ). Wenigstens ist uns für eines dieser Privilegien sowie für ein an die Kaufleute gerichtetes Schreiben über die Niederlegung desselben in der Zisterzienserabtei Doest bei Brügge das ausdrückliche urkundliche Zeugnis erhalten, daß davon vier Ausfertigungen, nämlich an die Gotland Besuchenden, an die Stadt Lübeck, an die Stadt Hamburg und an ,,alle Städte des römischen Reiches" (universis civitatibus Romani imperii) ausgestellt seien. Erhalten sind uns von diesen Ausfertigungen nur zwei, von denen die eine ${ }^{\mathbf{2 1 4}}$ ) an ,alle Kaufleute des römischen Reiches und die Stadt Hamburg“", die andere ${ }^{215}$ ) an ,die Kaufleute des römischen Reiches, welche Gotland besuchen", gerichtet ist. Eine weitere auf die gleiche Angelegenheit bezügliche Urkunde ${ }^{\mathbf{2 1 6}}$ ) der Gräfin von Flandern ist an die ,Kaufleute von Köln, Dortmund, Soest, Münster und alle mit ihnen übereinstimmenden (cum eis concordantibus) Städte" ausgefertigt. In einer an diese Städtegruppe gerichteten weiteren Urkunde ist auch noch Aachen miterwähnt und sind,,alle Kaufleute von Köln, Dortmund, Soest, Münster, Aachen und andern Kaufleute des römischen Reiches" als die Empfänger. des Privilegs bezeichnet; von dieser Urkunde ist noch ein zweites nur an ,die Kaufleute und Bürger des römischen Reiches“" adressiertes Exemplar erhalten ${ }^{217}$ ). Ein weiteres damals ausgestelltes Privilegium findet sich in einer Ausfertigung an ,die Kaufleute des römischen Reiches und alle Bürger der Stadt Lübeck" vor ${ }^{218}$ ). Es sind also eine lübeckische,

213a) Vgl. über das folgende: Stein, Ưber die ältesten Privilegien der deutschen Hanse in Flandern und die ältere Handelspolitik Lübecks, in Hans. Geschichtsbl. 1902, S. 51 ff.

214) Hans. Urkdb. I n. 421.

$\left.{ }^{215}\right)$ Ebenda n. 422; über den Handel der Gotland besuchenden Kaufleute nach Flandern vgl. auch n. 866, 1173.

${ }^{216)}$ Ebenda n. 428.

217) Stein, a. a. O.

${ }^{218)}$ Hans. Urkdb. I n. 434. 
eine hamburgische, eine gotländische und eine kölnisch-westfälische Gruppe, welche letztere offenbar mit der oben erwähnten Gruppe aller Städte des römischen Reiches identisch ist ${ }^{219}$ ), auf dem Weltmarkt Brügge, $\mathrm{zu}$ welchem selbstverständlich der gesamte Verkehr des Zwin zu rechnen ist, nachweisbar, und es kann wohl kaum einem Zweifel unterliegen, daß wir hier schon ebendieselben hamburgischen und lübeckischen Hansen vor uns haben, denen wir mehrere Jahrzehnte später in den Schiffrechten wieder begegnen. Die bei den Hamburgern wie bei den Lübeckern im Vordergrunde stehenden Reedereiinteressen sind es, welche die Erklärung dafür geben, daß nicht Brügge selbst, auf das ihr ganzer Verkehr gerichtet war ${ }^{220}$ ), sondern die Hafenplätze am Zwin, ursprünglich Damme, später Ostkerke, dann Houcke, wo ihre Schiffe lagen, ihr Zusammenkunftsort war ${ }^{221}$ ). Daß aber die Hansen der Hamburger und Lübecker am Zwin am Ende des 13. Jahrhunderts nicht etwa, wie bisher gewöhnlich angenommen ist, ,Privathansen“" ge-

219) Die Bezeichnung dieser rheinisch-westfälischen Gruppe als Gemeinschaft aller Kaufleute und Städte des deutschen Reiches mag vielleicht darauf zurückzuführen sein, daß sie die älteste und deshalb ursprünglich einzige deutsche Genossenschaft auf dem Brügger Markte war.

${ }^{22^{\circ}}$ ) In Brügge selbst ist seit 1306 eine Straße der Hamburger, seit 1282 eine Straße der Lübecker nachweisbar; Hans. Urkbd. III S. 474.

${ }^{221}$ ) Dieses Interesse an den Liegeplatzen der Schiffe gibt auch die Erklärung für den schon in den die Wünsche der Deutschen und der Lübecker enthaltenden Urkunden von 1252-1253 mit Bezug auf den Geltungsbereich gewisser angestrebter Bestimmungen vorkommenden Ausdruck in toto portu de Dam et Brugis; es soll damit zum Ausdruck kommen, daß der Geltungsbereich dieser Vorschriften sich auf das ganze Zwin, insbesondere also auf die sog. pertinentia, d. h. die Nebenorte Dammes, als welche namentlich Ostkerke, Monekerede und Houcke galten und zu denen auch die zu gründende neue Kolonie zu rechnen gewesen sein würde, erstrecken sollte, vermutlich weil schon damals unter Umständen wegen der Wasserverhältnisse oder aus andern Gründen mit andern Liegeplătzen als Damme gerechnet werden mußte. Wenn die Urkunde Hans. Urkdb. III n. 433 die auf S. 97 der Hans. Geschichtsbl. v. 1902 erörterten Rechte nicht, wie der $\$ 17$ der Lübecker Forderungen, auf die von Damme abgehenden Schiffe beschränkte, so war die Absicht wohl nicht, wie Stein meint, diese Rechte ,auf alle Häfen Flanderns“ auszudehnen, sondern die Urkunde hat damit offenbar die andern Hafenplätze am Zwin, die Nebenorte Dammes, im Auge. 
wesen sind, die neben einer allgemeinen Genossenschaft der deutschen Kaufleute in Brügge bestanden hätten, geht schon mit Sicherheit aus dem Artikel 2 des hamburgischen Schiffrechtes hervor, der den Hamburgern verbietet, in Flandern anderswo als in Ostkerken die Hanse zu halten, d. h. Genossenschaftsversammlungen zu veranstalten und zu besuchen. Hätten die Hamburger damals noch zu einer andern Hanse oder Genossenschaft in Flandern gehört, so wäre derselben zweifellos an dieser Stelle Erwähnung getan.

Die oben genannten vier Gruppen deutscher Kaufleute bestanden also bereits um die Mitte des 13. Jahrhunderts am Zwin. Daß aber der Verkehr der Deutschen dorthin schon älter war, geht, abgesehen von andern urkundlichen Nachweisen für denselben aus früherer Zeit, schon aus den Privilegien selbst hervor, in welchen es u. a. an einer Stelle heißt, daß die deutschen Kaufleute in Flandern in Zukunft dieselben Rechte und Freiheiten genießen sollten, deren ihre Vorfahren sich seit alters her erfreut hätten, und ebenso ist von Zöllen die Rede, welche die Gräfin von Flandern früher zu Unrecht von den Deutschen erhoben hätte ${ }^{222}$ ). Es spricht demnach auch alles dafür, daß die damals in Brügge bestehenden vier offenbar genossenschaftlich organisierten Gruppen deutscher Kaufleute schon längere Zeit am Zwin bestanden.

Wie im einzelnen sich das Verhältnis der vier Genossenschaften, deren Bestehen wir hiernach annehmen dürfen, zueinander gestaltete, ist nur undeutlich erkennbar. In welcher der in Flandern hervortretenden Gruppen wir z. B. die westfälischen oder die lübischen Gotlandsfahrer zu suchen haben, und ob etwa derselbe Kaufmann mehreren dieser Gruppen gleichzeitig angehören konnte, steht dahin. Beachtenswert ist in dieser Beziehung, daß das Schiffrecht der lübischen Hanse den Schiffsherren aus Lübeck und deren Schiffsleuten einschärfte, Sonntags i h r e Bank zu besuchen, die ,,der heren van Lubeke، $\left.{ }^{223}\right)$; es mußte also wohl auch der Besuch einer andern Bank an sich für sie in Frage kommen. Dafür, daß neben den beiden Gruppen, welche einerseits in Wisby und anderer-

$\left.{ }^{222}\right)$ Hans. Urkdb. I n. 432.

${ }^{223)}$ Th. Kiesselbach, Hamb. Schiffrecht, S. 62. 
seits in Köln ihr Haupt hatten und von denen jene das Spiegelbild der deutschen Genossenschaft auf Gotland, diese möglicherweise dasjenige der kölnischen Hanse in London war, schon im 13. Jahrhundert eine dritte, auch die Hamburger umschließende engere Vereinigung unter Lübecks Leitung bestanden habe, wie angenommen zu werden pflegt, fehlt es nicht nur an jedem Anhalt, sondern das oben angeführte Urkundenmaterial spricht sogar entschieden dagegen. Daß die Hansen der Hamburger und der Lübecker am Zwin noch am Ende des 13. Jahrhunderts völlig voneinander getrennt bestanden, stellt am deutlichsten ihre verschieden geartete Finanzordnung ans Licht; die Lübecker legten nämlich zwei Drittel der Einnahmen in die Büchse und verwandten ein Drittel ,,blideliken“, während die Hamburger nur ein Drittel in den Block legten und zwei Drittel bei ihren Gelagen vertaten ${ }^{224}$ ).

Ob schon im 13. Jahrhundert dauernd eine Verbindung unter den vier Genossenschaften deutscher Kaufleute in Flandern bestand, lassen die vorhandenen Nachrichten nicht mit voller Sicherheit entscheiden ${ }^{225}$ ). Festzustellen vermögen wir

${ }^{224}$ ) Th. Kiesselbach, Hamb. Schiffrecht, S. 61.

${ }^{225}$ ) Aus dem Anerbieten der Lübecker bei den Verhandlungen von 1252-1253, die Urkunde mit dem Siegel der Gesamtheit (sigillo universitatis) zu unterzeichnen (s. Stein, Hans. Geschichtsbl. 1902, S. 68 I $\$ 6$ und S. 89 f.), könnte man vielleicht auf das Bestehen einer dauernden gemeinsamen Organisation der vier Gruppen schließen wollen; indessen ist über ein gemeinsames Siegel der Deutschen in Flandern aus jener Zeit sonst nichts bekannt und es dürfte ein solches auch kaum im 13. Jahrhundert gegeben haben; vielleicht war das Siegel der gotländischen Genossenschaft (vgl. oben S. 44 Note 53) gemeint. Jedenfalls wird sich auf diese Nachricht die Annahme des Bestehens einer dauernden gemeinsamen Organisation aller Deutschen am Zwin nicht mit genügender Sicherheit stützen lassen. Vgl. übrigens die Ausdrücke,,communitas mercandisando perseverans Brugis“" und ,universi mercatores Teutonici n u n c in partibus Flandriae existentes" in der angeblich aus dem Jahre 1308 stammenden Urkunde in Hans. Geschichtsbl. 1898, S. 145. Die Auffassung Schäfers (Die Hansestädte und König Waldemar, S. 65 ff. u. S. 65 Note 1), daß die deutschen Kaufleute in Flandern von vornherein eine einheitliche Organisation gehabt hätten, scheint mir unbewiesen und verfehlt. Allerdings treten sie 1252 einheitlich gegenüber den flandrischen Behörden auf, aber unter Leitung nicht etwa eines Genossenschaftsvorstandes, sondern 
nur, daß sie im Jahre 1252, nachdem sie gemeinsam die Beseitigung gewisser Mißstände im Brüggischen Verkehr angestrebt hatten, gemeinsam Privilegien erwirkten, und daß sie auch 1280 wieder gemeinsam den Stapel von Brügge nach Aardenburg verlegten, bis Brügge sich ihren Forderungen gefügig zeigte. Endlich wissen wir ${ }^{226}$ ), daß sie im Anfang des 14. Jahrhunderts schon gemeinsame Versammlungen abhielten, in denen über die Angehörigen der Genossenschaften Recht gesprochen wurde, da $\beta$ damals bereits eine Ordinance, ein Statut, bestand, welches die Rechtsverhältnisse der Gemeinschaft ordnete, und daß diese Verhältnisse damals auch bereits die ausdrückliche rechtliche Anerkennung der flandrischen Obrigkeit erfuhren. Eine schon oben erwähnte Stelle des in einer Aufzeichnung von 1299 erhaltenen lübischen Schiffrechtes scheint darauf hinzuweisen, daß schon bei den Morgensprachen der lübischen Hanse auch andere nicht lübische Kaufleute zugegen waren. Das lübische Schiffrecht zeigt uns, daß die Lübecker bei den Morgensprachen in Flandern wie in der gotländischen Genossenschaft zu Wisby

zweier städtischer Bevollmächtigter, nämlich eines Lübecker Ratsherrn und eines Hamburger Ratsnotars. Das läßt nicht auf das Bestehen einer dauernden Verbindung der Deutschen dort, vielmehr auf eine vorübergehende Einigung der Städte zur gemeinsamen Vertretung der Interessen ihrer Kaufleute in Flandern schließen. Ganz verfehlt aber ist die Ansicht Schäfers, daß die Hamburger und Lübecker erst um die Mitte des 13. Jahrhunderts sich den Zugang zu den flandrischen Märkten gebahnt hätten. Ganz abgesehen davon, daß wir urkundliche Nachweise über älteren Verkehr dorthin von der Elbe haben (1236 wurde ja z. B. schon der Zoll in Hamburg für den Verkehr der Brandenburger nach Flandern ermäßigt; dieser Verkehr bestand also damals schon längere Zeit), kann es auch ohne solche gar keinem Zweifel unterliegen, daß die Hamburger seit Ausgang des 12. Jahrhunderts und die Lübecker schon früher die flandrischen Mărkte besuchten; in der Vermittlung des Verkehrs dorthin bestand ja überhaupt eigentlich die ganze Handelstätigkeit dieser Städte, die doch für Hamburg seit 1189 nachweisbar ist. Die Verhandlungen und Privilegien von 1252-1253 lassen aber auch deutlich genug erkennen, daß es sich hier um einen bereits hochentwickelten, nicht erst neu beginnenden Handelsverkehr handelte.

$\left.{ }^{226}\right)$ Urkunde von 1307 in Hanserezesse I 1 n. 84; Hans. Urkdb. II n. $121 \S 6 ; 154 \S 12$. Stein, Die Genossenschaft der deutschen Kaufleute zu Brügge in Flandern, Berlin 1890. S. 11 f. S. auch die Urkunde von 1308 in Hans. Geschichtsbl. 1898, S. 145. 
eine „Bank“ bildeten. Das Schiffrecht ermahnt nun die Schiffsherren aus Lübeck und deren Schiffsleute sowie die Lübecker Kaufleute ausdrücklich, jedesmal Sonntags, wenn der Ältermann die Morgensprache berufe, die Bank der Lübecker zu besuchen zu ihrer Stadt Ehre. Es scheinen also auch Kaufleute anderer Städte bei den Versammlungen zugegen gewesen zu sein, auf welche die große Anzahl der Lübecker Eindruck machen sollte, und neben der Bank der Lübecker auf andern Bänken andere Kaufleute gesessen zu haben ${ }^{227}$ ). Ob indessen bei diesen andern Kaufleuten an die Mitglieder der andern Hansen zu denken ist, muß dahingestellt bleiben. Ebenso nämlich, wie die Kölner die westfälischen Kaufleute zu ihrer Hanse zugelassen hatten, werden auch die Lübecker und Hamburger den regelmäßig mit ihnen reisenden Kaufleuten anderer Städte den Zutritt zu ihren flandrischen Hansen gestattet haben ${ }^{228}$ ). Unter Lübecks Schutz stellten sich die Kaufleute der wendischen Städte, die wir auch in andern Urkunden schon früh in enger Verbindung mit Lübeck sehen ${ }^{229}$ ). In einer undatierten Urkunde, in welcher von den gemeinsamen Maßnahmen gegen die Bedrückungen in Flandern die Rede ist, dankt Wismar Lübeck lebhaft für die Aufnahme in die Gemeinschaft und Genossenschaft der Lübecker, worunter wir vermutlich die Hanse der Lübecker am Zwin zu verstehen haben werden $\left.{ }^{230}\right)$. Unter den Kaufleuten, welche sich an Hamburg anschlossen, werden wir diejenigen aus den Städten Brandenburgs und Sachsens, insbesondere der Harzgegend, zu vermuten haben, welche, wie wir unten sehen werden, über Hamburg auf den Schiffen der Hamburger Flandern zu besuchen pflegten. Diese Gefolgschaften nahmen vermutlich mit auf

${ }^{227}$ ) Vgl. Th. Kiesselbach, Hamb. Schiffrecht, S. 62.

${ }^{228}$ ) Vgl. z. B. Braunschweiger auf einem Hamburger Schiffe, Hans. Urkdb. I n. 893, 892.

${ }^{229}$ ) Vgl. Hansarezesse I 1 n. 1-4, 7-9.

${ }^{230}$ ) vobis proinde, quia nos in consortium et societatem vestram non dedignatis recipere, gratiarum actiones referimus in immensum. Hansarezesse I 1 n. 77. Vgl. auch die Rostocker Kauffahrer in Houcke, dem Sitze der lübischen Hanse; Stein, Die ăltesten Privilegien der deutschen Hanse in Flandern, Hans. Geschichtsbl. 1902, S. 93. 
der Bank derjenigen Hanse, zu welcher sie sich hielten, Platz, wie in Wisby die Salzwedeler mit auf der Bank der Lübecker saßen. Unter den Kaufleuten anderer Städte, auf deren Gegenwart bei den Morgensprachen der Lübecker das lübische Schiffrecht schließen läßt, könnte demnach auch diese Gefolgschaft $\mathrm{zu}$ verstehen sein. Die Gleichartigkeit der Rechtsbestimmungen ${ }^{231}$ ) des hamburgischen und des lübischen Schiffrechtes, welche beide auf der Grundlage des Gewohnheitsrechtes und langjährigen Gerichtsgebrauches erwachsen sind, weist zwar augenscheinlich auf eine bis zum gewissen Grade gemeinsam ausgeübte Gerichtsbarkeit beider Hansen hin, ungeachtet der durchaus gesonderten Organisation dieser Genossenschaften im übrigen. Es ist auch wahrscheinlich, daß an dieser gemeinsamen Gerichtsbarkeit wenigstens bis zu einem gewissen Grade auch die Mitglieder der kölnischen und der gotländischen Genossenschaft früh teilgenommen haben, weil ja die Mitglieder dieser Genossenschaften an der Befrachtung hamburgischer und lübeckischer Schiffe nicht selten beteiligt gewesen sein werden ${ }^{232}$ ). Auf der andern Seite zeigt aber die Bestimmung des Hamburger Schiffrechtes, daß gegen das Urteil der Morgensprache nur die Berufung an das Rathaus zu Hamburg zulässig sein soll, und die gleiche Bestimmung im Lübecker Schiffrecht über die Berufung gegen die Urteile der Lübecker Hanse an den Rat zu Lübeck, daß die Gerichtsbarkeit für die Regel keineswegs von beiden Hansen gemeinsam ausgeübt wurde, sondern wie die Finanzordnung durchaus getrennt war.

Erscheint es hiernach zwar nicht ausgeschlossen, daß schon im 13. Jahrhundert eine gewisse dauernde Verbindung unter den vier Genossenschaften am Zwin bestand, so zeigt doch die vollständig gesonderte Organisation der Hansen der Lübecker und Hamburger am Zwin noch am Ende des 13. Jahrhunderts, daß dieses gemeinsame Band auf jeden Fall noch ein sehr loses war und $d a ß$ der Schwerpunkt jedenfalls durchaus in den so

231) Vgl. Th. Kiesselbach, Hamb. Schiffrecht, insbesondere S. $81 \mathrm{ff}$.

${ }^{232}$ ) Schon die Tatsache, daß die deutschen Kaufleute 1252 von einem Hamburger und einem Lübecker vertreten werden, läßt auf die Benutzung der Schiffe dieser Bürger auch durch die Westfalen und die Kaufleute von Gotland schließen. 
gut wie ganz selbständigen einzelnen Hansen lag. In dieser Beziehung lagen die Verhältnisse in Flandern verschieden von denjenigen in England infolge der freiheitlicheren Handhabung des Gastrechtes, der sich die Fremden in Flandern von jeher erfreuten ${ }^{233}$ ). In Flandern hören wir nichts von Verleihungen des Rechtes, eine Hanse zu haben, wie es die Hamburger und Lübecker 1266 und 1267 in Nachbildung ihrer flandrischen Einrichtungen in England erwirkten; das Recht, Zusammenkünfte abzuhalten, Organisationen zu bilden und die Angelegenheiten ihrer Landsleute in diesen selbständig zu ordnen, stand in Flandern offenbar schon in der Mitte des 13. Jahrhunderts seit langer Zeit allen Fremden ohne weiteres zu. In Brügge konnten die Fremden ferner überall in der Stadt bei den Bürgern wohnen und ihre Waren niederlegen, während die Deutschen in London, wie es scheint, auf die ihnen dort zugewiesenen Gebäude angewiesen waren. Eben dieser letzterwähnte Zustand führte in London wohl früh zu einer für alle gemeinsamen hauspolizeilichen Ordnung, einem Bindegliede zwischen den verschiedenen Genossenschaften, das in Flandern gar nicht in Frage kommen konnte. Im übrigen sehen wir ja die Gruppierung der deutschen Kaufleute in Flandern sich in England widerspiegeln, wo wir schon oben ebendieselben vier Gruppen nachgewiesen haben.

Was nun die Rolle der Hamburger in Brügge betrifft, so geben uns die Verhandlungen von 1252/53 einen interessanten Einblick in die Stellung, deren sie sich dort im Kreise der Deutschen erfreuten. Wir finden nämlich die Vertretung der Gesamtheit der deutschen Kaufleute damals ausgeübt durch einen Lübecker und einen Hamburger. Die Lübecker und Hamburger Frachtfahrer, die auf ihren Schiffen ja auch die Kaufleute der rheinischen und westfälischen Städte und die Mitglieder der got-

${ }^{233}$ ) Vgl. u. a. Stein, Die Genossenschaft der deutschen Kaufleute in Flandern, Berlin 1890, S. 108; vgl. treffend Lappenberg-Sartorius, Urkundliche Geschichte des Ursprungs der deutschen Hanse, Hamburg 1830, S. 286: ,Es war damals, wie auch in den folgenden Zeiten, gar nicht jene freiere Ansicht in England, welche in den Niederlanden in Hinsicht auf Fremde vielmehr vorherrschte" usw. Ebenso Stein, Die ältesten Privilegien der deutschen Hans ein Flandern, Hans. Geschichtsbl.1902, S. 9'. 
ländischen Genossenschaft einerseits rom Zwin aus über das Meer nach England, Norwegen, der Ostsee und der Elbe und andererseits von jenen fremden Ländern nach dem Zwin gebracht haben werden, sind es, welchen von allen beteiligten deutschen Städten Vollmacht gegeben wird. Denn für die Kaufleute der westfälischen, rheinischen, sächsischen und sonstigen binnenländischen Städte ${ }^{234}$ ) war Brügge nicht in geringerem Maße der Mittelpunkt ihrer Geschäftstätigkeit, der Ausgangspunkt und Endpunkt ihrer Handelsreisen, als für die Hamburger und Lübecker. Nicht ihre Heimatstädte, sondern der große brüggische Weltmarkt waren der Punkt, wohin sie die Produkte des Nordens, Ostens und Westens führten, und nach dem Maße, in welchem sie sich an diesem von dem Auslande nach dem Auslande gehenden Verkehre beteiligten, bestimmte sich die Rolle, welche ihre Bürger im 13. Jahrhundert im nordeuropäischen Welthandel spielten. Der unmittelbare wirtschaftliche Austausch der deutschen Binnenstädte mit Brügge fiel in dieser Beziehung erst in zweiter Linie ins Gewicht, und von einem unmittelbaren Austausche der Binnenstädte mit den Ländern des Nordens, des Ostens und des Westens kann bei den meisten gar nicht, bei den übrigen nur in ganz verschwindendem Maße die Rede sein ${ }^{235}$ ). Eine Ausnahme bildet in dieser Beziehung eigentlich nur Köln, das als Vermittlerin des Verkehrs mit Ungarn, Böhmen, Polen, Bayern, Schwaben und dem Rheingebiete eine etwas selbständigere Stellung als Mittelpunkt eines ausgedehnten Handelsverkehrs behauptete ${ }^{236}$ ).

$\left.{ }^{234}\right)$ Daß z. B. die Kaufleute von Soest, wenn sie von Osten kommen, von Holland nicht in ihre Heimat, sondern nach Flandern weiter reisen, s. Hans. Urkdb. I n. 445 (anno 1252); auf das den Hamburgern und Lübeckern in Holland 1243 zugestandene Privileg für ihre Reisen nach Flandern (Hans. Urkdb. I n. 331), nehmen auch das den Dortmundern 1248 ( $\mathrm{I}$ n. 367) und die den Brandenburgern ( $\mathrm{I}$ n. 424), den Bremern und den Stadern (I n. 438) 1252 verliehenen Privilegien Bezug.

${ }^{235}$ ) Wenn wir die Kaufleute dieser Binnenstădte im baltischen Gebiete, in Norwegen, in England usw. erwăhnt finden, so dürfen wir ihre dort ausgeübte kaufmännische Tätigkeit keineswegs auf ihre Heimatsstădte beziehen; regelmäßig ist sie vielmehr auf den flandrischen Weltmarkt gerichtet.

${ }^{236}$ ) Vgl u. a. Hans. Urkdb. I n. 523, III. 610. 
Bei der Verlegung des Stapels nach Aardenburg 1280 tritt nur ein Lübecker als Bevollmächtigter der Gesamtheit der deutschen Kaufleute hervor, dem alsdann auf seinen Wunsch von einigen andern Städten noch Spezialgesandte zu seiner Unterstützung sich beigesellen ${ }^{237}$ ). Es kann auch keinem Zweifel unterliegen, daß die Bedeutung der lübischen Hanse diejenige der hamburgischen noch überragte, da die Lübecker neben ihren bedeutenden Reedereiinteressen einen sehr viel ausgedehnteren Warenhandel mit in die Wagschale zu werfen hatten.

Es bleibt noch übrig, das Verhältnis der deutschen Kaufleute zu der flandrischen Obrigkeit einer kurzen Betrachtung $\mathrm{zu}$ würdigen. Das Privilegium von $1253^{238}$ ) gestattet uns in dieser Hinsicht einigen Einblick. Auch diese Urkunden und der durch sie belegte hochentwickelte Zustand der Handelsverhältnisse in Brügge und seinem Hafenplatze Damme weisen wieder darauf hin, daß dieser Verkehr damals schon eine lange Geschichte hinter sich gehabt haben muß.

In den Privilegien von $1253^{239}$ ) werden den Deutschen erstens gewisse Sicherheiten für ihre Person und ihre Güter gegen Beeinträchtigungen durch die bestehenden Rechtseinrichtungen zugestanden. Jeder Kaufmann soll nur für seine eigenen Schulden haften, und Schadloshaltung an seinem Gute für Schulden oder Vergehen seiner Landsleute soll nicht statthaft sein, das Recht des Gläubigers soll bei Forderungen gegen abwesende Ausländer vielmehr darauf beschränkt sein, den Schuldner in seiner Heimatstadt zu verklagen; das Recht des Landesherrn auf die im Schiffbruch geretteten Güter der Fremden soll beseitigt sein und das Anrecht der Eigentümer an solchen Gütern ungeschmälert bleiben. Das Privileg ergibt, daß die Fremden in kaufmännischen Streitigkeiten - offenbar solchen mit Flanderern oder nichtdeutschen Ausländern -

${ }^{237}$ ) S. Hans. Urkdb. I n. 885; Gesandte von Dortmund und Soest, s. Hans. Urkdb. I. n. 1035 u. Hanserezesse I. 1 n. 26, 27.

${ }^{238}$ ) Über die Datierung vgl. Stein, Ưber die ältesten Privilegien der deutschen Hanse in Flandern in Hans. Geschichtsbl. 1902, S. 80 f.

${ }^{239}$ ) Hans. Urkdb. I n. 421. Vgl. hierzu Stein, a. a. O. S. $51 \mathrm{ff}$., insbesondere S. 80 f. und $94 \mathrm{ff}$. 
vor den Schöffen des Hafens von Damme und von Brügge (in portu de Damme et de Brugis) Gericht zu nehmen hatten; kaufmännische Angelegenheiten sollen binnen drei Tagen oder höchstens acht Tagen erledigt werden; wenn die Schöffen eidlich erhärten, daß die Entscheidung nicht innerhalb dieser Frist getroffen werden kann, so soll sie wenigstens so rasch wie möglich stattfinden. Kann der Kaufmann nicht so lange warten, so soll er einen Bürgen oder einen andern als seinen Vertreter bestellen und selbst abreisen dürfen. Bei der Abfahrt soll er und seine beladenen Schiffe nur unter ganz besonderen Umständen zurückgehalten werden dürfen; handelt es sich dabei um eine nicht vor den Schöffen eingegangene Schuld, so soll ihm das Recht zustehen, durch eidliches Bestreiten den Anspruch zu entkräften. Auch soll der Kaufmann und sein Schiff nicht angehalten werden dürfen, wenn etwa das Schiff oder sein Gerät, wobei vor allem an das Ankergerät zu denken sein wird, bei der Abfahrt ohne Verschulden einen Schaden oder eine Verletzung einer Person verursacht. Auch für den Fall der strafrechtlichen Verfolgung regelt das Privileg den Gerichtsstand der deutschen Kaufleute und gibt ihnen gewisse Sicherungen der persönlichen Freiheit. Vor allem soll der Zweikampf für die Kaufleute als Entscheidung ihrer zivil- und strafrechtlichen Streitigkeiten abgeschafft sein. Neben diesen die Sicherheit der Person und Habe der Kaufleute erhöhenden Bestimmungen werden in verschiedenen Urkunden aber zugleich auch die im Hafenplatze Damme und die in Brügge und in Thourout von den Ausländern zu erlegenden Zölle aufgezeichnet ${ }^{240}$ ) und dabei zum Teil erheblich ermäßigt ${ }^{241}$ ).

Das Verhältnis der Deutschen zu den flandrischen Behörden blieb indessen nicht immer ungetrübt. Reibungen mit den einheimischen Kaufleuten und Behörden führten zeitweise zu ernstlichen Störungen des Verkehrs. Schon im Jahre 1267 sehen wir die Hamburger sich mit dem Gedanken der Verlegung des Stapels an einen andern Platz tragen. Nach Dordrecht und Zieriksee gingen damals Gesandte mit der Anfrage, ob diese Städte zu künftiger Aufnahme der Hamburger bereit

$\left.{ }^{240}\right)$ Hans. Urkdb. I n. 432, 433, 435.

241) Ebenda n. 431. 
seien; beide Städte antworteten zustimmend ${ }^{242}$ ). In der zweiten Hälfte der siebziger Jahre wurde die Frage ron neuem erwogen. Dordrecht erklärte sich auf Anfrage Hamburgs, Kampens, Deventers, Zwolles, Winsums, Orte, deren Bürger, wie die Schreiben erklären, sämtlich bisher das Zwin besucht hatten ${ }^{\mathbf{2 4 3}}$ ), zur Aufnahme des Stapels bereit und sicherten den Fremden umfangreiche Privilegien zu. $1280 \mathrm{kam}$ es tatsächlich zu einem Bruche mit Brügge. Die Unzufriedenheit der Fremden muß allgemein gewesen sein. Die Deutschen einigten sich mit den romanischen Kaufleuten aus Kastilien, Aragon, Navarra, Gascogne, Portugal und der Provence zu einem gemeinsamen Vorgehen, und es kam nun in der Tat zur Verlegung des gesamten Stapels von Brügge nach dem gleichfalls flandrischen Aardenburg ${ }^{244}$ ), das sie mit offenen Armen aufnahm. Der Landesherr war, wie es scheint, an dem Streite nicht unmittelbar beteiligt, verlieh den Fremden vielmehr Privilegien für den neuen Stapel in Aardenburg $\left.{ }^{245}\right)$. Die Streitpunkte betrafen, soweit erkennbar, in der Hauptsache die damals unter obrigkeitlicher Aufsicht erfolgende Feststellung des Gewichts der Waren beim Verkauf, insbesondere die Art der Wägung, durch welche die Fremden sich bisher benachteiligt sahen, ferner die Höhe der Zollsätze, deren schriftliche Festlegung gefordert wurde, die Rückgewährung zu Unrecht erhobener Zölle, die Sicherung der Person und Güter gegen Arrestierung und gegen Haftung für Schulden oder Vergehen von Landsleuten und Vergehen der kaufmännischen Angestellten u. a. m. Länger als ein Jahr dauerte diese Verkehrssperre, bis sich Brügge 1282 schließlich zum Nachgeben gezwungen sah und die Fremden ihren Stapel wieder dorthin zurückverlegten ${ }^{246}$ ).

Der auf Brügge gerichtete Handel der norddeutschen Kaufleute muß während des 13 . Jahrhunderts eine gewaltige Entwicklung durchgemacht haben. Bis zum Beginne des 13. Jahr-

$\left.{ }^{242}\right)$ Hamb. Urkdb. I n. 714, 699, 701.

${ }^{243}$ ) S. oben S. $37 f$.

${ }^{244)}$ Hans. Urkdb. I n. $864-866,871,872,875-877$.

${ }^{245}$ ) Ebenda n. 862.

${ }^{246}$ ) Vgl. über die Verlegung des Stapels Hans. Urkdb. I n. 885, 891, 905, 912, 918; Hansarezesse I 1, S. 8 ff. 
hunderts war Lübeck noch die einzige deutsche Stadt am Baltischen Meere. Erst in der ersten Hälfte des 13. Jahrhunderts treten alsdann allmählich die livländischen, pommerschen, wendischen und die preußischen Hafenplätze als deutsche Städte in die Erscheinung. Erst mit dieser Ausbreitung des deutschen Städtetums und Bürgertums an der Ostsee konnte die Grundlage des baltischen Handels nach dem Westen eine breitere werden. Die friesischen und westfälischen Kauffahrer, welche in der ersten Hälfte des 13. Jahrhunderts noch entschieden im baltischen Handel als Träger dieses Verkehrs neben den lübischen im Vordergrunde stehen, treten dort nun hinter den Bürgern der neu entstandenen deutschen Ostseestädte zurück; die Genossenschaft der deutschen Kaufleute auf Gotland, bisher der hauptsächlichste Stützpunkt der diesen Handel betreibenden, im Westen beheimateten Kaufleute, verliert jetzt, wo die neuen Träger dieses Verkehrs eine Reihe anderer gesicherter Ausgangspunkte für ihren Geschäftsbetrieb auch in Rußland gefunden haben, mehr und mehr seine Bedeutung. Zweifellos hat der russische Verkehr dank dieser Entwicklung einen starken Aufschwung erfahren. Gleichzeitig sind Mecklenburg und Pommern und vor allem das Hinterland der Oder, schließlich auch das Hinterland der Weichsel dem Verkehre der Deutschen erschlossen und durch sie mit dem flandrischen Weltmarkte in Verbindung gesetzt worden. Entsprechend der Entwicklung des Verkehrs sind uns aus der ersten Hälfte des Jahrhunderts nur verhältnismäßig wenige urkundliche Zeugnisse über den Verkehr zwischen dem baltischen Gebiete und dem Westen erhalten. Nur vereinzelte urkundliche Nachrichten aus den ersten drei Jahrzehnten lassen uns erkennen, daß die Lübecker und Hamburger schon damals im Westen verkehrten; wenn die ersten Nachrichten von ihrem Handel in England melden, so ist damit natürlich nicht gesagt, daß sie nicht eher den flandrischen Markt als den englischen aufgesucht haben; denn erst durch den Verkehr auf dem Weltmarkt am Zwin, auf den der ganze englische Handel ja gerichtet war, werden sie in den englischen Handel hineingezogen sein. Der Zufall, daß über ihren Verkehr in England ältere Nachrichten vorliegen als über ihren Handel in Flandern wird zum Teil seine Erklärung darin 
finden, daß das Fremdenrecht in Flandern den Anforderungen des Weltmarktes entsprechend bereits freier gestaltet war als in England, und deshalb dort nicht so häufig Arrestierungen und sonstige Erschwerungen des Verkehrs, die zur Erörterung in Urkunden Veranlassung boten, vorkamen. Daß aber Brügge schon am Beginne des 13. Jahrhunderts der Mittelpunkt des westeuropäischen Seehandels war und deshalb auch der Hauptanziehungspunkt für den nordischen Handel gewesen sein muß, geht mit Sicherheit aus der Schilderung seines Handels bei Wilhelm Brito und aus der Tatsache hervor, daß das Zwin schon damals für den Handel der Gaskogner und Bayonner in gleicher Weise der allein maßgebende Konzentrationspunkt ihres Seehandels sein konnte, wie wir es später für den Verkehr der Lübecker und Hamburger nachweisen können.

Der Schwerpunkt des aktiven Handels der Flanderer selbst lag im 13. Jahrhundert offenbar einerseits im englischen Wollhandel und andererseits im Tuchhandel nach den französischen Messen. Auch am Weinhandel von Rochelle nach Flandern zeigen die Urkunden sie beteiligt, wenn auch dieser Zweig ihres Verkehrs sich in verhältnismäßig bescheidenen Grenzen gehalten haben mag, da die Entstehung des oléronensischen Seerechtes, dem dieser Verkehr zugrunde liegt, als Genossenschaftsrecht der Gascognerseefahrer die Westfranzosen als die eigentlichen Träger dieses Verkehrs erkennen läßt. Am nordischen Handel endlich finden wir die Flanderer überhaupt nicht beteiligt. In ihm haben wir offenbar den zuletzt entwickelten Zweig des Brügger Verkehrs vor uns. Für den Handel mit dem unwirtlichen Norden hatten die flandrischen Kaufleute, welche schon den für sie viel gewinnreicheren und näherliegenden Handel mit England und der Champagne nicht allein zu bewältigen vermochten, nicht Arbeits- und Kapitalkraft und Unternehmungslust mehr übrig. Hier fand der norddeutsche Kaufmann deshalb ein unbestrittenes Arbeitsfeld. 


\section{Zweites Kapitel.}

\section{Die Stadt Hamburg als Umschlagsplatz und Zwischenmarkt.}

Nachdem wir im vorstehenden Kapitel die Tätigkeit der hamburgischen Schiffer und Kaufleute von ihrer Niederlassung am Hafen von Brügge aus und ihre Bedeutung im Welthandel beleuchtet haben, verlegen wir jetzt unsern Standpunkt nach ihrer Heimatstadt Hamburg selbst.

Die wichtigste Aufgabe Hamburgs im Welthandelsverkehre jener Zeit lag, wie aus dem früher Gesagten ohne weiteres erhellt, in der Vermittlung des flandrisch-baltischen, insbesondere des flandrisch-russischen Verkehrs. Die Verbindungslinien einerseits nach Lübeck und andererseits nach Flandern sehen wir deshalb von jeher im Vordergrunde stehen.

Schon aus dem ersten Viertel des 13. Jahrhunderts liegt ein Vertrag ${ }^{1}$ ) zwischen Lübeck und Hamburg vor, in welchem es heißt: „Unser Recht soll auch euer Recht sein und euer Recht das unsrige, und euere Bürger sollen mit ihren Waren, die sie ohne Arrest nach unserer Stadt bringen, dieselbe Sicherheit genießen wie unsere Bürger." Das Privilegium von 1226²), in welchem Kaiser Friedrich II. den Lübeckern überall sicheres Geleit verspricht, nennt an erster Stelle die Verbindung Lübecks mit Hamburg. 1241 schließen die Hamburger mit den Lübeckern infolge von Störungen, welche ihr Verkehr zwischen den Städten auf der über Oldesloe führenden Straße durch den Landesherrn

1) Im Hans. Urkdb. I n. 239 ist die Urkunde um 1230 angesetztLappenberg, Hamb. Urkdb. I n. 381 datiert die Urkunde von 1210; im Lüb. Urkdb. n. 31 wird sie vor 1226 datiert; s. auch Koppmann, Beiträge zur Geschichte der Stadt Hamburg II, S. 20 und Hansarezesse I Einl. XXXII.

2) Hans. Urkdb. I n. 205. 
erleidet, einen Vertrag ${ }^{3}$ ) zur Sicherung einer andern über Parkentin sie verbindenden Straße, die zwar einen Umweg bedeutet, auf welche sie aber den Verkehr wegen jener Störungen verlegen wollen, $a b$; von der Mündung der Trave in die Ostsee bis zur Mündung der Elbe in die Westsee wollen sie gemeinsam den Verkehr schützen. Zugleich rief Lübeck den Beistand des Herzogs Albrecht von Sachsen an gegen die Erschwerungen des Verkehrs durch die landesherrliche Gewalt, welche damals in Händen des Herzogs Abel von Jütland als Vormund der unmündigen Grafen von Holstein lag, und der Herzog nahm noch in demselben Jahre alle Kaufleute mit ihren Waren für die Hin- und Rückfahrt zwischen Lübeck und Hamburg in Schutz ${ }^{4}$ ) gegen ein Geleitgeld von zwei Pfennigen für jedes Pfund, ausgenommen Fässer mit Wein und Fässer mit Fett, für welche die Abgabe stückweise mit zwei und mit einem Schilling bezahlt, und ferner ausgenommen Heringe, für die der bisherige Brauch unverändert beibehalten werden sollte. In demselben Jahre schlossen die beiden Städte einen weiteren Vertrag ${ }^{5}$ ) $\mathrm{ab}$, laut welchem diejenigen Frevler, welche auf Grund ordentlichen Gerichtsverfahrens aus einer Stadt verwiesen waren, auch als aus der andern verbannt gelten sollten. In einem

3) Hans. Urkdb. 1 n. 305; vgl. Koppmann in den Hans. Geschichtsblättern, 18/2, und Zeitschr. des Vereins für Hamb. Geschichte, Bd. 6, 1875. Koppmann meint i. Zeitschr. S. 414, der Vertrag von 1241 wolle nicht ausdrücken, daß die Städte sich dessen bewußt seien, eine Verbindung zwischen ihnen bedeute eine Verbindung zwischen Ostsee und Westsee, und daß sie deshalb das Recht und die Pflicht zu haben meinten, diese Verbindung mit gemeinsamer Hand zu schützen. Koppmann verkennt damit die Bedeutung dieses Vertrages vollständig. Abgesehen von allem andern bezeugt ja doch der Wortlaut dieses Vertrages selbst, in welchem ausdrücklich die Nordsee und die Ostsee erwähnt werden, dieses Bewußtsein. Freilich war es nicht das sittliche Bewußtsein, ,die Rechte und die Pflicht" zu haben, diese Verbindungen zu schützen, sondern es war die dringende Notwendigkeit der Lebensverhältnisse, welche die beiden Städte zum Zusammengehen in dieser Sache trieb. Vgl. auch Hasse i. d. Zeitschr. f. schleswig-holst.-lauenb. Geschichte, Bd. V, S. 531 ff., Koppmanns Entgegnung ebenda, VI, S. 125 ff. und Hasses Erwiderung ebenda, S. $218 \mathrm{ff}$.

4) Hans. Urkdb. I n. 307 .

$\left.{ }^{5}\right)$ Ebenda n. 303, 304. 
Privileg von 1253 sicherten auch die inzwischen volljährig gewordenen Grafen Johann und Gerhard von Holstein allen Bürgern des römischen Reiches für die Straße von Hamburg nach Lübeck Schutz zu ${ }^{6}$ ). 1255 schlossen alsdann die beiden Städte zu Oldesloe ein Bündnis ${ }^{7}$ ), in welchem sie geloben, einander in jedem Falle, in dem ein Bürger einer der beiden Städte Schaden an seiner Person oder seinen Gütern erleide, oder ein Handlungsdiener oder ein Ritter - die Städte unterhielten also wohl schon zum Schutze der Straße Bewaffnete gefangen genommen werde, einander beizustehen und gemeinsam Genugtuung zu fordern sowie die Kosten der Durchführung solches gemeinsamen Vorgehens zu teilen. Der Vertrag wurde auf drei Jahre geschlossen. Aus dem Jahre 1259 sind uns Verhandlungen zwischen Lübeck und Hamburg über gemeinsame Unterhaltung der von Lübeck gegen die Straßenräuber ausgerüsteten Reiter und der von Hamburg auf der Elbe zum Schutze des Verkehrs postierten Schiffe erhalten ${ }^{8}$ ). Ob der Vertrag zustande kam, wissen wir nicht. Der Ritter von Barmstede ${ }^{9}$ ), der vom bremischen Erzbischof mit der Haseldorfer Marsch an der Unterelbe belehnt worden war, hatte um jene Zeit den Verkehr auf der Elbe und, wie es scheint, auch auf der Straße zwischen Hamburg und Lübeck gestört und war von den Hamburgern, welche auch Schiffe gegen ihn ausgerüstet hatten, in seinem Schlosse Wildenscharen belagert; in dem am 21. Dezember 1259 zwischen ihm und dem Grafen von Holstein geschlossenen Friedensvertrage versprach er, den Bürgern von Hamburg und Lübeck, wie auch allen ihren Gästen fortan weder auf der Elbe noch auch auf der gemeinsamen Verbindungsstraße der beiden Städte Schaden zufügen zu wollen ${ }^{10}$ ). Im Jahre 1260 finden wir beide Städte zu Oldesloe in Verhandlungen begriffen, bei denen sich die Lübecker auf ein Bündnis beriefen, das die Hamburger nicht anerkannten, die Hamburger auf ein anderes, von dem die Lübecker nichts

') Ebenda n. 454.

7) Ebenda n. 484 .

$\left.{ }^{8}\right)$ Ebenda n. 537; Hanserezesse I S. 1 ff.

9) Bramstedt a. d. Stör in Holstein.

$\left.{ }^{10}\right)$ Vgl. Hamb. Urkdb. I n. 648 , n. 716 , n. 818 
wissen wollten ${ }^{11}$ ). Das Ergebnis dieser Verhandlungen ist zwar nicht bekannt, doch vernehmen wir seitdem längere Zeit nichts von Störungen des Verkehrs auf der die Städte verbindenden Straße, und es ist nicht ausgeschlossen, daß die Städte damals Einrichtungen getroffen hatten, welche die Straße mit einigem Erfolg sicherten. Anfang der siebziger Jahre hören wir von neuen Belästigungen. Graf Gunzelin von Schwerin störte damals den Verkehr der Lübecker auf der Straße über Oldesloe, beraubte ihre Wagen und nahm viele Waren weg ${ }^{12}$ ). Lübeck schloß hierauf 1273 mit dem Grafen Johann von Braunschweig-Lüneburg ein Bündnis gegen den Grafen, der mit dem Herzoge von Sachsen und dem Grafen von Dannenberg im Bunde stand, ab; auch Hamburg beteiligte sich an den Verhandlungen in der Angelegenheit, die in den folgenden Jahren nach erfolgreichem Kampfe, in welchem auch der Herr von Rostock sich Lübeck anschloß, beigelegt wurde ${ }^{13}$ ). In der späteren Zeit sind verschiedene Schutzbündnisse allgemeinerer Art, welche auch das Gebiet zwischen Hamburg und Lübeck einschließen, zu verzeichnen. So versprachen 1281 die Grafen von Holstein, die hamburgischen Bürger innerhalb wie auch außerhalb ihres Gebietes gegen Schädigungen an Leib oder Gut durch den Ritter von Barmstedt und dessen Lehnsherrn, den bremischen Erzbischof, zu schützen ${ }^{14}$ ), und 1283 wird diese Zusicherung erneuert ${ }^{15}$ ). Hamburgs nachträglicher Beitritt im Jahre 1284 oder $1285 \mathrm{zu}$ dem am 14. Juli 1283 zu Rostock unter Führung des Herzogs ron Sachsen geschlossenen Landfriedensbündnisse Lübecks, der wendischen Städte Wismar, Rostock, Stralsund, Greifswald, Stettin, Demmin, Anklam und der wendischen Territorialfürsten, denen auch Dänemark 1284 sich anschloß, mag zwar in erster Linie durch die Interessen, welche auch Hamburg am Handel mit Norwegen hatte, veranlaßt sein, wenn auch Hamburg sich weder an dem bewaffneten Vorgehen der übrigen Mitglieder des Bundes gegen Norwegen,

11) Hans. Urkdb. I n. 551; Hanserezesse I S. 1 ff.

12) Hans. Urkdb. I n. 719, Note 2.

13) Ebenda n. 719-721, 727, 728, 730.

14) Hamb. Urkdb. I n. 791.

15) Ebenda n. 796. 
noch an den Friedensverhandlungen beteiligte $\left.{ }^{16}\right)$. Ausschließlich die Sicherung des Handels und der Verkehrsstraßen haben dagegen Hamburg und Lübeck zum Abschlusse des Bündnisses von 1285 auf acht Jahre mit dem Erzbischof von Bremen, dem Adel und den Landschaften Holsteins veranlaßt, das 1289 durch den Beitritt Herzog Waldemars von Schleswig, des Grafen Nicolaus von Schwerin und des Herrn Johann von Mecklenburg erweitert und von dem Herzog von Sachsen bestätigt wurde ${ }^{17}$ ). Aus dem Jahre 1300 ist uns noch eine Urkunde erhalten, welche von der zeitweiligen Unsicherheit der Gegend zwischen Hamburg und Lübeck berichtet; es ist ein Schreiben ${ }^{18}$ ) Lübecks an Leuwarden, in welchem die Kaufleute jener Stadt vor der Benutzung der Straße wegen der gegenwärtigen Unsicherheit derselben gewarnt werden.

Nicht weniger als in der Fürsorge der Hamburger und Lübecker für die Sicherheit der sie verbindenden Straße drückt sich die Wichtigkeit des baltischen Verkehrs für beide Städte in den Zollvergünstigungen aus, welche demselben zuteil wurden. Den Lübeckern selbst war in dem Freibriefe Kaiser Friedrichs I. von 1188 Freiheit vom Hansegeld und vom Zoll in ganz Sachsen, ausgenommen an dem nach Bardowik führenden Elbübergange bei Ertheneburg zugesagt ${ }^{19}$ ). Das Privileg Kaiser Friedrichs II. ${ }^{20}$ ) von 1226 erklärte sie für befreit von allem Geleitsgeld in ganz Sachsen und stellt ausdrücklich auch ihre Freiheit vom Zoll zu Oldesloe fest ${ }^{21}$ ). Auch die Lübecker Zoll-

16) Hans. Urkdb. I n. 917, 931, 954, 970; Hanserezesse I S. 17.

17) Hans. Urkdb. I n. 973, 1057.

${ }^{18)}$ Ebenda n. 1342.

${ }^{19}$ ) Ebenda n. 33: cum mercibus suis libere eant et redeant per totum Saxonie absque hansa et absque theloneo preter Ertheneburch, ubi 5 denarios de plaustro solvent, hoc addentes quot plaustra illuc transduxerint, pro quibus theloneum supradictum dederint, tot plaustra libere sine theloneo reducent.

${ }^{20}$ ) Ebenda n. 205.

21) Es scheint allerdings, daß die Lübecker die Zollfreiheit zu Oldesloe gegenüber den holsteinischen Grafen, denen der Zoll zustand, nicht lange haben behaupten können; denn 1238 wird die Zahlung des Zolles seitens der Lübecker an dieser Zollstelle wieder als Tatsache erwăhnt. (Hans. Urkdb. I n. 287) und 1247 wird von neuem ihre Befreiung, von 
rolle von $1227^{22}$ ) stellt fest, daß die Lübecker Zollfreiheit in ganz Sachsen genießen, außer in Ertheneburg und in Mölln, welch letztere Zollstätte wohl inzwischen im Falle der Benutzung des Wasserweges der Stecknitz an die Stelle der Zollstätte von Ertheneburg getreten war ${ }^{23}$ ). Auch in Hamburg unterlagen die Lübecker also weder dem Zoll noch dem Geleitsgelde, wie andererseits die Hamburger in Lübeck und ebenso in Oldesloe schon auf Grund des kaiserlichen Privilegiums von 1189 frei von Zoll und Ungeld waren ${ }^{24}$ ). Ein Versuch des Grafen von Schauenburg gegen Ende des 13. Jahrhunderts, für die Lübecker in Hamburg einen neuen Zoll einzuführen ${ }^{25}$ ), war jedenfalls ohne Erfolg. Aber nicht nur die Lübecker und Hamburger genossen in diesem Verkehr Zollbefreiungen. Schon Heinrich der Löwe war bestrebt gewesen, den Verkehr des baltischen Gebietes mit dem Westen durch Zollbegünstigungen möglichst an Lübeck zu fesseln. Bereits 1163 wurden die Gotländer von ihm im ganzen Herzogtum Sachsen vom Zoll befreit ${ }^{26}$ ). In einem Privileg der Grafen Johann und Gerhard von Holstein, ,welches allen Bürgern sowohl in der Stadt Wisby als in ganz Gotland" die Rechte bestätigt, welche sie zur Zeit Adolfs IV. von Holstein und der Vorfahren desselben in Hamburg genossen hatten, wird ausdrücklich bemerkt, daß diese Vergünstigungen bereits auf Heinrich den Löwen zurück-

Zoll und Ungeld zu Oldesloe ausgesprochen (n. 353). In den Privilegien an die Stader von 1251 (n. 410 ; Hamb. Urkdb. I n. 613) heißt es wieder, die Stader sollen in Oldesloe den Zoll entrichten, den die Lübecker zahlen; indessen ist dies wohl nur eine abschriftliche Wiederholung des Wortlautes des den Stadern 1238 verliehenen Privilegs; die Lübecker blieben offenbar zollfrei in Oldesloe; 1299 versuchten die Grafen von Holstein noch einmal, sie dem Zolle zu Oldesloe zu unterwerfen, mußten aber wenige Jahre darauf ihre Zollfreiheit daselbst bestätigen (Hans. Urkdb. I n. 1326 und 1327 Note 3 ).

$\left.{ }^{22}\right)$ Hans. Urkdb. I n. 233.

${ }^{23}$ ) Dieser Elbübergang kam seit der Zerstörung Bardowicks und Ablenkung des Lübecker Verkehrs nach Hamburg nur noch für den Verkehr Lübecks mit Lüneburg, der Altmark und den Harzstădten in Frage. S. oben S. 21.

24) Hans. Urkdb. I n. 36.

$\left.{ }^{25}\right)$ Ebenda n. 1328.

${ }^{26)}$ Ebenda n. 15. 
gingen ${ }^{27}$ ). Daß es sich tatsächlich auch dabei wieder um Befreiung vom Zoll handelte, bestätigt eine spätere schauenburgische Zollrolle, in der ausdrücklich festgestellt wird, daß ,die von Gotland" in Hamburg keinen Zoll zahlen ${ }^{28}$ ). Ob sich diese Vergünstigung nur auf die Bürger von Wisby und Gotland, also die Mitglieder der deutschen und der gotischen Gemeinde, daselbst, oder aber auch auf die Angehörigen der deutschen Genossenschaft auf Gotland erstreckte, ist nicht mit Sicherheit zu entscheiden ${ }^{29}$ ). Das Privileg von 1255 ist nur den Bürgern von Wisby und Gotland ausgestellt; die spätere schauenburgische Zollrolle nennt schlechthin ,die von Gotland". Beachtenswert ist aber, daß Herzog Albrecht von Sachsen 1232 ,,der Gesamtheit der gemeinen Kaufleute“, unter Bestätigung der ihnen von dem Bischof von Livland und dem päpstlichen Legaten erteilten Vergünstigungen, Freiheit vom Zoll und Ungeld in seinem ganzen Gebiet zusichert ${ }^{30}$ ); mit diesem Ausdruck wird regelmäßig die Gemeinschaft der nach Rußland hin handeltreibenden, in der gotländischen Genossenschaft vereinigten Kaufleute bezeichnet ${ }^{31}$ ). Die der Mitte des 13. Jahrhunderts angehörende gräfliche Zollrolle ${ }^{32}$ ) für Hamburg widmet dem Verkehr mit Lübeck verhältnismäßig wenig Worte ${ }^{33}$ ); zwar enthält sie Zollsätze für ,,den Fremden, der von der Ostsee kommt und auf die Nordsee hinauswill“", und ,den Wagen, der nach Oldesloe geht"; aber bezeichnenderweise wird dabei

27) Hans. Urkdb. I n. 483.

${ }^{28)}$ Ebenda n. 573, Handschrift 3.

29) Nach einer Bestimmung Heinrichs des Löwen (Hans. Urkdb. I n. 16,) sollten die Rechte, welche er den Goten in Deutschland eingeräumt hatte, auch den in Gotland aufhältlichen Deutschen zugute kommen.

${ }^{30}$ ) Hans. Urkdb. I n. 243.

$\left.{ }^{31}\right)$ Vgl. z. B. n. 655 , n. 932 . S. auch oben S. 44 Note 53 u. 84 Note 225.

${ }^{32}$ ) Diese Zollrolle ist in zwei voneinander abweichenden Hand. schriften erhalten. Die im Hans. Urkdb. I n. 573 abgedruckte dritte Handschrift in niederdeutscher Sprache gehört ihrem Inhalte nach jedenfalls nicht mehr dem 13. Jahrhundert, sondern wahrscheinlich erst dem 15. Jahrhundert an. Elsässische, Mühlhausensche, Braunschweigische Tuche kommen im 13. Jahrhundert im Welthandel nicht vor.

$\left.{ }^{33}\right)$ S. Handschrift 2 Hans. Urkdb. I n. 573. 
ausdrücklich vermerkt, daß diese Zollsätze für den Verkehr zwischen Nordsee und Ostsee nur für diejenigen Gäste gelten, welche zollpflichtig sind. Auch den Kaufleuten des in der ersten Hälfte des 13. Jahrhunderts aufkommenden Riga wurde 1251 von den holsteinischen Grafen Freiheit von Zoll und Geleitsgeld für ganz Holstein eingeräumt ${ }^{34}$ ), und 1254 wurden ihnen diese Rechte nochmals verbrieft ${ }^{35}$ ). Ebenso genossen die Schweden, die auch auf dem Wege über Lübeck Hamburg besucht haben werden ${ }^{36}$ ), in Hamburg Zollfreiheit ${ }^{37}$ ). Kaufleute aus den wendischen Ostseestädten werden im 13. Jahrhundert in Hamburg überhaupt kaum erwähnt. Zollfreiheiten genossen sie hier wohl nicht, kamen für sie aber auch nicht in Frage. Ihre geographische Lage wies sie naturgemä $\beta$ in ähnlicher Weise auf den Ostseeverkehr hin, wie Hamburg sich auf das Nordseegebiet hingewiesen sah; die Teilnahme der Bürger der wendischen Städte am russischflandrischen Austausche, diesem wichtigsten Verkehrsstrome des baltischen Handels, war im wesentlichen auf den Verkehr zwischen Rußland und Lübeck beschränkt ${ }^{38}$ ). Lübeck versah ihnen, wie überhaupt den Kaufleuten des Ostseegebietes gegenüber, die Rolle eines Zwischenmarktes, der den Verkehr des baltischen Gebietes mit dem Westen weitervermittelte. Der von Rußland aus auf Lübeck gerichtete Ostseeschiffahrts- und Handelsbetrieb war für sie eine der wichtigsten, wenn nicht die wichtigste Verkehrsroute. Daneben spielte für sie, wie schon erwähnt, der Heringsfang an den Küsten Schonens, Norwegens und Rügens ${ }^{39}$ )

34) Hans. Urkdb. I n. 407.

${ }^{35}$ ) Ebenda n. 467.

$\left.{ }^{36}\right)$ Utber schwedische Kaufleute in Lübeck vgl. Hans. Urkdb. I n. 223, $448,566$.

${ }^{37)}$ Hans. Urkdb. I n. 565, 764.

${ }^{38}$ ) An ihrer Beteiligung an diesem Verkehre kann kein Zweifel sein. Sie geht schon aus der Lebhaftigkeit hervor, mit der sich die wendischen Städte für die Anerkennung Lübecks als Berufungsinstanz für die Entscheidungen des Nowgoroder Hofes an Stelle von Wisby interessierten (Hans. Urkdb. I n. 1131, 1132; Hanserezesse I n. 66 Ziff. 1 u. 2; auch Hans. Urkdb. n. 1168, 1170, 1197).

39) In Schonen: Rostocker s. Hans. Urkdb. I n. 401, 774, 925; Wismarer s. ebenda n. 408, 452, 645, 925; Stralsunder n. 1122; Greifswalder n. 854, 856, 925. In Norwegen am Heringsfang beteiligt: Rostocker, 
eine sehr bedeutende Rolle. Über den unmittelbaren Seeverkehr der wendischen Städte mit Holz und Holzprodukten des Hinterlandes der Oder nach Flandern um Jütland herum ${ }^{40}$ ) und über den Handel nach Norwegen ${ }^{41}$ ) ist schon oben ausführlich berichtet $\left.{ }^{42}\right)$. So erklärt es sich, daß uns die Kaufleute der wendischen Städte in Hamburg kaum begegnen.

Der Verkehr vom Baltischen Neere nach Flandern war somit in Hamburg zum größten Teile zollfrei. Der Zollpflicht unterlagen natürlich die Ausländer der westlichen Länder, die Flanderer, Holländer und Friesen, deren Zutritt zur Ostsee zu fördern nicht im Interesse der Deutschen lag und die deshalb zu den deutschen Genossenschaften auf Gotland und in Nowgorod nicht zugelassen wurden ${ }^{43}$ ).

Nicht minder als die Straße nach Lübeck lag Hamburg die Verbindung nach Flandern am Herzen. Bevor wir indessen diesen Verkehrsweg verfolgen und die Maßnahmen Hamburgs zum Schutze und zur Förderung desselben ins Auge fassen, bedarf es einer näheren Betrachtung des Verkehrs, der sich auf dieser Straße bewegt.

Was im Verkehr von und nach Lübeck zwischen Flandern und Hamburg verfrachtet wurde, waren einerseits vor allem

Wismarer, Stralsunder, Greifswalder, ebenda n. 1045 u. 1299; an den Küsten Rügens: Lübecker n. 375, 376, 514, 555; Stralsunder n. 1068, 1077; über die Lübecker s. auch Karl Mollwo, Die ältesten lübischen Zollrollen, Lübeck 1894, S. 27 ff.; Rügensche Heringe als Handelsware, s. Lüneburger Zollrolle ebenda n. 807 .

${ }^{40)}$ S. oben S. $49 \mathrm{ff}$.

41) S. oben S. 60 .

$\left.{ }^{42}\right)$ Uns liegt hier nur daran, die Hauptlinien des Verkehrs der wendischen Städte, soweit sie für den Welthandel von Bedeutung sind, in allgemeinen Umrissen zu kennzeichnen. Daneben ging natürlich noch ein mehr oder weniger umfangreicher lokaler Ostseeverkehr her. So zeigt die Zollrolle von Greifswald (n. 746) aus der Zeit vor 1275 z. B. Dänen, Schleswiger, Holsteiner, Norweger, Schweden (namentlich Kalmar), Kaufleute von Gotland, Riga, Elbing, Fehmarn in Greifswald. Hering, Wein, Vieh, und Pferde, auch Getreide sind fast die einzigen Erzeugnisse, die gehandelt werden. Nur am Schlusse der Zollrolle werden noch flüchtig - offenbar ein Nachtrag - Tuche, Kupfer, Zinn, Blei und Synter erwähnt.

$\left.{ }^{43}\right)$ S. die Schreiben Kampens und Zwolles an Lübeck, Hans. Urkdb. I n. 1154, 1155. 
die russischen Produkte, anderseits flandrische Tuche. Die der Mitte des 13. Jahrhunderts angehörende gräfliche Zollrolle ${ }^{44}$ ) für Hamburg enthält für den Durchgangsverkehr von der Ostsee zur Westsee neben dem allgemeinen Zollsatze für Waren, die nach Lasten verzollt werden, Zollsätze für drei Artikel, welche nach Tonnen verzollt werden; unter ihnen steht an erster Stelle Pelzwerk, außerdem sind es Tran und Fett. Die oben bereits angeführte Urkunde ${ }^{45}$ ) Herzog Albrechts von Sachsen zeigt, daß in umgekehrter Richtung u. a. Wein auf dieser Straße von Hamburg nach Lübeck verfrachtet wurde. Es kann kein Zweifel sein, daß unter den russischen Erzeugnissen neben Pelzwerk Wachs die erste Rolle spielte ${ }^{46}$ ).

Für den baltisch-flandrischen Handelszug war Hamburg, wie schon mehrfach erwähnt, in der Hauptsache nur Durchgangsplatz; zwar setzte sich an diesen Durchgangsverkehr auch wohl etwas Zwischenhandel mit flandrischen Marktwaren nach Lübeck an; aber dieser Eigenhandel der Hamburger blieb jedenfalls in sehr bescheidenen Grenzen. In dem noch dem 13. Jahrhundert angehörenden Hamburger Schuldbuche, welches der Eintragung von Kreditgeschäften diente, treten deshalb die Geschäftsverbindungen mit Lübeck hinter den Beziehungen mit vielen andern Plätzen zurück ${ }^{47}$ ). Auf dem Wege von Hamburg nach Flandern bewegten sich indessen neben dem baltischen Warenzuge noch die Frachtgüter zweier anderer in Hamburg mündender Verkehrsströmungen.

Über Hamburg vollzog sich nämlich der Anschluß des namentlich vom Harze ${ }^{48}$ ), daneben seit der Mitte des 12. Jahr-

44) Handschrift 2 Hans. Urkdb. I n. 573. Item omnis hospes de orientali mari veniens, qui tenetur dare theloneum, et volens transire in mare occidentale dabit de quolibet last $4 \mathrm{r}$, de tunna varii operis (opus = Werk, d.i. Pelzwerk), de tunna sagiminis focarum, de tunna ungenti specialiter 4 भे.

$\left.{ }^{45}\right)$ Hans. Urkdb. I n. 307.

$\left.{ }^{46}\right)$ S. oben Note 47 zu Kapitel I.

47) Koppmann, Das hamb. Schuldbuch, i. Zeitschr. d. Vereins f. hamb. Geschichte, Bd. VI, S. 504 .

${ }^{48)}$ Vgl. auch Weiland, Goslar als Kaiserpfalz, Hans. Geschichtsblätter 1884 . 
hunderts ${ }^{49}$ ) auch vom Erzgebirge ausgehenden Zuflusses von Bergwerkserzeugnissen an den Handelszug nach Flandern; Kupfer ${ }^{50}$ ), daneben Blei und Zinn, ,Erz" und ,Metall" waren die wichtigsten Gegenstände ${ }^{51}$ ) dieses Handels. Außerdem wird mehr nebensächlich auch noch Eisen unter ihren Exportartikeln genannt $\left.{ }^{52}\right)$. Unter dem ,Erz" und ,Metall" befand sich vor allem auch Silber. Die gräflich schauenburgische Zollrolle ${ }^{53}$ ) für Hamburg aus der Mitte des 13. Jahrhunderts erwähnt, daß das gemünzte und ungemünzte Silber, welches diese Kaufleute bringen, dem Zoll und Geleitsgelde nicht unterliege. Auch ein etwa aus der Mitte des 13. Jahrhunderts stammendes Schreiben Hamburgs an den Lübecker Rat bezeugt die Ausfuhr von Silber über Hamburg unter Hinweis auf eine ältere, weit zurückliegende Zeit, in welcher die Verschiffung von Gold und Silber über das Meer noch nicht üblich gewesen sei ${ }^{54}$ ). Die Bedeutung eines Handelszuges mit solchen Erzen und Metallen liegt auf der Hand, und es ergibt sich von selbst, daß den Trägern desselben eine wichtige Rolle auf dem Weltmarkte zufiel ${ }^{55}$ ).

Unter den Städten des Binnenlandes, deren Kaufleute diesen Handel besorgten, sind im Harzgebiete die Stadt Braunschweig, die seit dem Anfange des 13. Jahrhunderts Goslars Markt zur Seite gedrängt und dessen Stapel an sich gezogen

$\left.{ }^{49}\right)$ S. unten S. 109 und Note 72 daselbst.

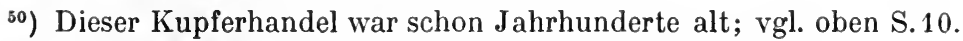

$\left.{ }^{51}\right)$ S. u. a. die Zollrollen, Hans. Urkdb. I n. 466 u. 573.

${ }^{52}$ ) Nummer 1 der Handschriften der Zollrolle n. 573 nennt Eisen nur bei den Zollsätzen, nicht bei den Ungeldsătzen. Nummer 2 der Handschriften nennt auch bei den Zollsätzen Eisen nur als Ausfuhrartikel der Brandenburger, nicht auch der Magdeburger, Meißener, Braunschweiger usw. Eisen wurde damals im Hannoverschen gewonnen, vgl. Hans. Urkdb. I n. 1046.

$\left.{ }^{53}\right)$ Hans. Urkdb. I. n. 573.

${ }^{54)}$ Ebenda n. 538.

${ }^{55}$ ) Es ist sehr bezeichnend, daß die Urkunde von 1307, betr. die Freiheiten des deutschen Kaufmannes in Aardenburg, wohin der Stapel damals verlegt worden war, indem sie nur die wichtigsten Stapelartikel der Deutschen aufführen will, nur Wolle, Wachs und Pelzwerk und $\mathrm{K}$ u p f e r nennt. Hansarezesse I 1 n. 8'. 
hatte ${ }^{56}$ ), in dem zwischen dem Harz und der Unterelbe gelegenen Gebiete Salzwedel vor allen andern hervorzuheben. Ein wichtiger Teil des Verkehrszuges vollzieht sich vom Harz über die Stadt Magdeburg, welche neben Braunschweig und Salzwedel genannt werden muß. In einem Privileg ${ }^{57}$ ) von 1254 für den Verkehr in Hamburg werden außer Magdeburg und Braunschweig die rings herumliegenden Orte und Städte in die Vergünstigungen eingeschlossen; wir werden darunter Goslar, Wernigerode, Halberstadt, Quedlinburg, Helmstedt vermuten dürfen, welche wir sämtlich in Flandern vertreten finden; erwähnt wird in den auf Hamburg bezüglichen Urkunden keine von ihnen. Hildesheim wird seine Verfrachtungen über Bremen vorgenommen haben, wie denn auch Braunschweig außer der Elbe auch den Weg über Bremen benutzte $\left.{ }^{58}\right)$. Von den in der Altmark und in Niedersachsen gelegenen Städten sind noch Lüneburg, Stendal, vielleicht auch Hannover, das als Sitz der Gewinnung von Eisen Bedeutung hatte ${ }^{59}$ ) und jedenfalls mit Hamburg Handelsverbindungen unterhielt, als an diesem Verkehre besonders beteiligt zu nennen. Fassen wir nunmehr die Beziehungen dieser Städte zu Hamburg einzeln näher ins Auge.

Von den Verbindungen der Stadt Braunschweig zu Hamburg gibt bereits eine Urkunde aus dem Jahre $1241^{60}$ ) Kunde, in welcher die gütliche Beilegung eines Streites zwischen den beiden Städten über in Hamburg angehaltene Güter unter Bezugnahme auf die engen Beziehungen der Städte zueinander bezeugt wird. Aus dem Jahre 1247 liegt ein Vertrag vor, in welchem sich die beiden Städte gegenseitig für den Fall eines Krieges zwischen ihren beiderseitigen Landesherren volle Sicherheit für Person und Gut ihrer Kaufleute bis nach Ablauf von vierzig Tagen gewährleisten ${ }^{61}$ ). Den Kaufleuten ,von Braunschweig und Magdeburg und den übrigen darumliegenden Orten

${ }^{56}$ ) S. Chronik Arnold v. Lübecks, Buch VI, Kapitel 6 und 7.

$\left.{ }^{57}\right)$ Hans. Urkdb. I n. 466.

${ }^{58)}$ Ebenda n. 218, 219, 609.

59) Ebenda n. 1046.

$\left.{ }^{60}\right)$ Ebenda n. 315.

61) Ebenda n. 351. 
und Städten“"werden alsdann $1254^{62}$ ) besondere Abgabenermäßigungen in Hamburg seitens der Grafen von Holstein zuteil; gleichzeitig wird ihnen freies Geleit und Innehaltung der vierzigtägigen Kündigungsfrist für den Fall des Ausbruches eines Krieges versprochen. Diese Kündigungsfrist wird für die Stadt Braunschweig 1258 in Anlaß eines Streitfalles in einer von dem Vogt und dem Rate der Stadt Hamburg ausgestellten, alsbald von den Grafen von Holstein bestätigten Urkunde ${ }^{63}$ ) auf drei Monate verlängert und den Braunschweigern von neuem günstige Aufnahme zugesichert. 1288 wird den Hamburgern von dem Herzoge von Braunschweig sogar für den Fall des Krieges zwischen ihm und den Grafen von Holstein Schutz und Neutralität versprochen. ${ }^{64}$ ) Die Kaufleute der Stadt Braunschweig genossen vor den Angehörigen der übrigen Harzstädte und Magdeburgs den besonderen Vorteil, daß sie von dem Tuche, welches sie aus Flandern auf dem Rückwege von dort über Hamburg einführten, nur 2 Schillinge Ungeld für jeden Packen zu zahlen hatten ${ }^{65}$ ), während das Geleitsgeld für die übrigen Fremden 14 Schillinge für den Packen betrug.

Über den Verkehr der Altmärker mit Erz und Metall nach Hamburg ist uns bereits aus dem Jahre 1236 eine Urkunde ${ }^{66}$ ) erhalten, in welcher die bis dahin in Hamburg von ihnen erhobenen Zölle erheblich ermäßigt werden; schò damals war also dieser Handelszug in vollem Schwunge. Ausdrücklich wird Flandern als das Ziel der Reisen bezeichnet. Eine Bestätigung dieser Privilegien, die auch in die aus der Mitte des 13. Jahrhunderts stammende gräflich schauenburgische Zollrolle für den Verkehr in Hamburg aufgenommen sind, liegt aus dem Jahre 1262 vor ${ }^{67}$ ); auch aus dem Jahre 1283 ist noch ein Privilegium ${ }^{68}$ ) der Stadt Hamburg an die Kaufleute der Markgrafschaft Brandenburg erhalten, in welchem ihnen Schutz versprochen wird.

$\left.{ }^{62}\right)$ Hans. Urkdb. I n. 466.

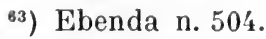

64) Ebenda n. 1038.

${ }^{65}$ ) Schauenburgische Zollrolle für Hamburg, ebenda n. 573.

$\left.{ }^{66}\right)$ Ebenda n. 277.

${ }^{67)}$ Ebenda n. 572.

${ }^{68}$ ) Ebenda n. 928. 
Den Kaufleuten der Mark Brandenburg ist in den Privilegien die Vergünstigung zugestanden, daß das Tuch, welches sie in Flandern für die von ihnen über Hamburg ausgeführten Waren erstehen, bei der Rückkehr über Hamburg von der Abgabe des Geleitsgeldes befreit bleibt, vorausgesetzt, daß die nach Flandern ausgeführten Waren dem Geleitsgelde unterlegen haben: denn wenn sie das Tuch für Waren, wie z. B. Silber, eintauschen, für welche in Hamburg kein Geleitsgeld erhoben wird, haben sie für dasselbe bei der Rückkehr Ungeld zu zahlen. Im übrigen sind freilich die Ungeldsätze für die Kaufleute aus den Herzogtümern Braunschweig und Sachsen, dem Erzbistume Magdeburg und der Mark Meißen bei Bergwerkserzeugnissen niedriger als für die Brandenburger. Jene zahlen vom Kupfer 1 Schilling für jede Last, die Brandenburger dagegen 4, und ähnlich ist das Verhältnis bei den übrigen Metallen. In bezug auf die Höhe des neben dem Ungelde zur Erhebung gelangenden Zolles bestand kein Unterschied zwischen diesen Kaufleuten; der Zoll war übrigens niedriger als das Geleitsgeld und betrug z. B. bei Kupfer 4 Pfennige $=1 / 3$ Schilling ${ }^{69}$ ). Unter den Städten der Mark tritt in diesem Verkehre, wie schon erwähnt, besonders Salzwedel hervor, dessen Bürger wir in Flandern wie in Wisby antreffen. Von ihrem Verkehr nach Hamburg zeugt ein Privileg ${ }^{70}$ ) des Herzogs Albrecht von Sachsen aus dem Jahre 1248, in welchem das auf der Straße zwischen Hamburg und Salzwedel $\mathrm{zu}$ entrichtende Geleitsgeld festgesetzt wird. Nur einmal soll auf diesem Wege Ungeld bezahlt worden, und zwar auf dem Hinwege nach Hamburg in Hitzacker, auf dem Rückwege in Lauenburg. Kupfer, Zinn uud Blei erscheinen auch hier wieder unter den Gegenständen der Zufuhr nach Hamburg, Tuche als Gegenstand der Rückfracht. In gleicher Weise zeigt auch die Zollrolle ${ }^{71}$ ) der Lüneburger für den Verkehr nach Hamburg die Kaufleute dieser Stadt am Zwischenhandel mit Kupfer, Zinn und Blei beteiligt; ausdrücklich besagt auch hier die Zollrolle, daß sie diese Waren nach Flandern ausführen.

69) Ebenda n. 573.

$\left.{ }^{70}\right)$ Ebenda n. 357.

$\left.{ }^{71}\right)$ Ebenda n. 808. 
Die Heimatstädte der Kaufleute aus der Mark Meißen, welche nach der Zollrolle gleichfalls Erz, Kupfer, Zinn, Blei und Metall nach Hamburg bringen, werden nicht genannt. Aus andern Nachrichten ${ }^{72}$ ) wissen wir, daß Freiberg dort ein wichtiger Bergwerksmittelpunkt war. Der Verkehr der Kaufleute aus der Markgrafschaft Meißen tritt überhaupt gegenüber dem Handel der übrigen oben aufgeführten Landschaften zurück und wird wohl in der Regel kaum über Hamburg hinausgegangen sein.

An die Ausfuhr der Bergwerksprodukte schloß sich, nachdem das Binnenland erst einmal in den Handelsverkehr hineingezogen war, die Ausfuhr einer Reihe anderer Erzeugnisse an. Bei allen diesen Kaufleuten des Binnenlandes werden Wachs und Fett und die Waldprodukte Asche und Pech als Gegenstände der Zufuhr erwähnt; auch diese Waren fanden in der Regel ihren Markt in Flandern, wo Holzasche in großen Mengen von der Tuchindustrie zum Reinigen der Wolle verbraucht wurde, Pech zur Verwendung beim Schiffbau ein gesuchter Artikel war. Die Bürger der Stadt Braunschweig und ebenso die Kaufleute der Mark Brandenburg bringen außerdem noch Getreide und Waid, welch letztgenannter Artikel ein wichtiger Farbstoff für die flandrische Tuchindustrie war. Die Altmärker, vor allem die Salzwedeler, endlich haben auch bereits ein Erzeugnis des bei ihnen lebhaft emporstrebenden ländlichen Gewerbfleißes vorzuweisen; sie führen Leinen herbei. Daß auch alle diese Handelswaren zum großen Teile von Hamburg wieder nach Brügge abflossen, zeigt das Schiffrecht der hamburgischen Hanse am Zwin, das alle diese Artikel als regelmäßiges Frachtgut der dort ankommenden hamburgischen Schiffe aufweist ${ }^{73}$ ).

In den gegenseitigen Vereinbarungen ${ }^{74}$ ) Braunschweigs und Hamburgs wird auch den Hamburgern und ihren Gütern in

72) S. Klotzsch, Ursprung der Bergwerke in Sachsen, Chemnitz 1764, S. $147 \mathrm{ff}$; insbesondere die Urkunden von 1232, 1255, 1266, 1293, 129'4 im Anhang Nr. XI, IV, XII, VIII, V; ferner v. Festenberg-Packisch, Der deutsche Bergbau, Berlin 1886, S. 7 und $29 \mathrm{f}$.

$\left.{ }^{73}\right)$ Kupfer, Zinn, Blei: Schiffrecht Art. 16 cc.; Wachs 16 bb; Fett $16 \mathrm{~mm}$; Pech 16pp; Asche $16 \mathrm{kk}$ und pp; Korn $16 \mathrm{aa}$; Waid 16nn; Wand, worunter gerade Leinen fallen dürfte, $16 \mathrm{xx}$.

74) Hans. Urkdb. I n. 351 und 505. 
Braunschweig Schutz zugestanden. Die ungehinderte Fahrt auf der Elbe durch die ganze Mark Brandenburg hin und zurück wird den Hamburgern mit ihren Waren in einer dem zweiten Viertel des 13. Jahrhunderts angehörenden Urkunde ${ }^{75}$ ) zugesichert. Aus dem Jahre 1262 ist eine weitere Urkunde ${ }^{76}$ ) des Markgrafen von Brandenburg erhalten, in welchem er auf Fürsprache der Salzwedeler den durch sein Gebiet reisenden Hamburgern, welche eine für Hamburg bestimmte Salzladung holen sollen, Schutz und Geleit in seinem Gebiete verspricht. Immerhin ist kein Anhalt dafür gegeben und wenig Wahrscheinlichkeit dafür vorhanden, daß die Hamburger selbst als Zwischenhändler in umfangreicherer Weise Erz und Metall von den Städten des Harzes und des Erzgebirges geholt haben; als Metallhändler kommen sie in den Urkunden nicht vor; der Zug des Welthandels trieb sie nach Westen; die binnenländischen Städte boten ihnen keinen konsumfähigen Markt.

Der binnensächsisch-flandrische Handel mit Metallen und Erzen war für Hamburg zum größten Teil ebenso wie der flandrisch-baltische Güteraustausch nur Durchgangsverkehr. Hamburgs eigener Anteil an diesem Verkehrszuge war vornehmlich auf den Gewinn aus der Frachtschiffahrt zwischen Hamburg und dem Westen beschränkt. Außer diesem hauptsächlich auf dem Erz- und Metallhandel beruhenden Durchgangsverkehr der Städter des hamburgischen Hinterlandes war indessen noch eine andere Handelsströmung aus einem engeren Umkreise dieses Gebietes auf Hamburg gerichtet, für welche die Stadt Zwischenhandelsmarkt war. Hamburg war nämlich der Stapelort ${ }^{i 7}$ ) für die Erträgnisse der oberhalb der Stadt die Elbe und ihre Nebenflüsse umschließenden ausgedehnten Waldungen und für die von einigen Teilen des Hinterlandes und von den Landschaften der Unterelbe ihm zugehenden Ge-

$\left.{ }^{75}\right)$ Hans. Urkdb. I n. 278.

${ }^{76}$ ) Ebenda n. 572.

77) Dieser Stapel war nur tatsächlicher, nicht rechtlicher Natur. Die Brandenburger führten ihr Getreide zum Teil selbst nach Flandern, wie die hamb. Zollrolle ausdrücklich sagt, n. 573, ebenso die Lüneburger s. n. 808 . 
treideladungen ${ }^{78}$ ). In den Verkehr mit diesen Erzeugnissen auf dem Hamburger Markte gibt uns das hamburgische Schuldbuch einen Einblick ${ }^{79}$ ). Lüneburg an der Ilmenau und in seiner Nachbarschaft Mechtersen, Mölln, Boitzenburg am Ausfluß der Boitze in die Elbe, Schwerin, Lenzen an der Löcknitz, Schnakenburg an der Seese, von dem Gebiete des Aland und seiner Nebenflüsse Seehausen am Aland, Osterburg an der Biese, Gardelegen an der Milde, Werben an der Taube, Stendal an der Uchte, von dem Flußgebiete der Stepenitz Wittenberge am Ausflusse der Stepenitz in die Elbe und Pritzwalk an der Dömnitz, Werben, von dem Flußgebiete der Havel Havelberg und Brandenburg, an der Jäglitz Kyritz, von den Spreeplätzen Berlin, Cölln und Spremberg, endlich Magdeburg und Braunschweig sind Städte, deren Kaufleute den Hamburger Markt beschicken und sich auch dort mit Rückfrachtartikeln versorgen. Welch große Mengen Holz in Hamburg zusammenströmen, lassen namentlich das Schiffrecht und das Schuldbuch erkennen. Das Schiffrecht ${ }^{80}$ ) unterscheidet eine große Anzahl verschiedener Hölzer: ,Sparren von $40 \mathrm{Fuß}$ “ und solche ,,von 24 Fuß", „Stender bis zu 14 Fuß", solche von , über 14 bis zu $20 \mathrm{Fuß}$ “ und solche ,,über $22 \mathrm{Fu} \beta^{\prime \prime}$, , Koggenbretter (Bretter zum Bau von Koggen, einem damaligen Schiffstyp), 40 Fuß lang" “ und solche ,,50 Fuß lang“", ,Remen (Ruderholz) über 20 Fuß“" und ,,unter $18 \mathrm{Fuß}$ ", ,,Wagenschotten“ (bestes, astfreies Eichenholz) ${ }^{81}$ ), ,,Lethölzer", ,,Stappen“, sämtlich ,,über 35 Fuß lang“, und Hölzer dieser drei Sorten unter 30 Fuß Länge, „Kanenblocke“ (Holz zum Bau von Kähnen) ${ }^{81}$ ), ,K Karholz (dünne eichene Bretter) ${ }^{81}$ ) von 24 Fuß oder mehr Länge" und solches ,,unter $20 \mathrm{Fu} 8$ “. 1290 sind in das hamburgische Schuldbuch, in welches doch nur Kreditkäufe eingetragen wurden, fünfzehn Lieferungsverträge übor Wagenschotten im Betrage von 580 Hundert Hölzern in Gesamtwerte von 10444 M. l. ein-

${ }^{78)}$ Vgl. auch hamb. Stadtrecht von 1270, VI. 27 (Korn- und Holzkauf aus einem Schiffe) bei Lappenberg, Hamb. Rechtsaltertümer, Bd. I.

$\left.{ }^{79}\right)$ S. Koppmann, Das hamb. Schuldbuch, i. Zeitschr. des Vereins f. hamb. Geschichte, Bd. VI, S. $495 \mathrm{ff}$.

$\left.{ }^{80}\right)$ Art. $16 \mathrm{ee}-16 \mathrm{ii}, 16 \mathrm{qq}, 16 \mathrm{rr}, 16 \mathrm{tt}$.

${ }^{81}$ ) Glossar z. Hans. Urkdb. Bd. III. 
getragen ${ }^{82}$ ). Die Herkunft des Holzes im einzelnen läßt sich nicht näher verfolgen. Der größte Teil wird zu Wasser nach Hamburg gelangt sein. Die Zollrolle führt die Zollsätze für die mit Holz von der Oberelbe ankommenden Schiffe an; sie enthält aber zugleich einen Zollsatz für die Wagen, welche aus dem Herzogtum Sachsen Eichenholz bringen, und für die Wagen, welche Balken oder Asche herbeiführen. Im Schuldbuch wird als Herkunftsort einer Holzsendung einmal Berlin, ein anderes Mal Lenzen erwähnt ${ }^{83}$ ). Auch die Lüneburger bringen übrigens $\mathrm{Holz}$ vom Inlande die Elbe hinab an der Ilmenau vorbei nach Hamburg ${ }^{84}$ ).

Außer Holz gelangen einige Holzfabrikate, wie Mulden, Mehlfässer und Woltfässer ${ }^{85}$ ) nach Hamburg; ebenso Holzasche und Pech ${ }^{86}$ ). Das Schiffrecht nennt die Elborte Boitzenburg, Bleckede, Hitzacker sowie Perleberg an der Stepenitz und Liebenwalde an der Havel als Herkunftsorte der Asche.

Neben Holz und Holzerzeugnissen ist Getreide Stapelartikel des Hamburger Marktes. Einerseits von der Mark ${ }^{87}$ ) und von der Stadt Braunschweig ${ }^{88}$ ), andererseits von der Unterelbe ${ }^{89}$ ) kommen Roggen, Hafer, Weizen, Gerste nach Hamburg. In dem Getreidehandel der Mark tritt namentlich Berlin hervor. Der Berliner Roggen galt als eine besondere Roggenart ${ }^{90}$ ). Berlin ist von den inländischen Plätzen derjenige, welcher im hamburgischen Schuldbuche am häufigsten vorkommt; auch von den ausländischen Plätzen ist nur Gent noch häufiger genannt. Nächst Berlin werden von inländischen Orten im Schuldbuch am häufigsten Havelberg, Lenzen, Salzwedel und Lüneburg erwähnt ${ }^{91}$ ). Die Zollrolle zeigt, daß auch

$\left.{ }^{82}\right)$ Koppmann, a. a. O. S. 507.

$\left.{ }^{83}\right)$ Koppmann, a. a. O. S. 506.

${ }^{84)}$ Hans. Urkdb. I n. 807.

$\left.{ }^{85}\right)$ Schiffrecht, Art. $16 \mathrm{ss}, 1611$.

${ }^{86}$ ) Art. $16 \mathrm{kk}, 16 \mathrm{pp}$.

${ }^{87}$ ) S. die Zollrollen ebenda n. 277, 571, 573.

${ }^{88)}$ Ebenda n. 573.

89) Ebenda.

${ }^{90}$ ) Koppmann, a. a. O. S. 508.

91) Ebenda S. 504; hinsichtlich des Getreidehandels der Lüneburger vgl. Hans. Urkdb. I n. 807, 808, 809. 
von der Unterelbe her Roggen, Weizen, Hafer und Gerste nach Hamburg zu Schiffe gebracht wurde. Das Schuldbuch ergibt, daß von der Unterelbe Kaufleute von Buxtehude, Stade, rom Lande Hadeln, von Ditmarschen und Krempe nach Hamburg kamen; an einer Stelle wird als Abgangsort einer Getreideladung Haseldorf an der Unterelbe genannt ${ }^{92}$ ).

Die Zufuhr dieser Stapelartikel überließen die Hamburger nicht den Binnenländern allein, sondern beteiligten sich auch selbst daran. Schon ein Privileg Heinrichs des Löwen, das die Hamburger von der Verpflichtung zur Zahlung des Zoll- und Geleitsgeldes an den Hebestellen zu Krauel, Eßlingen (d.i. Zollenspieker) und Geesthacht befreit, zeigt, daß sie die Elbe hinaufzufahren pflegten; ob in dem Privileg auch die Befreiung vom Zolle zu Lauenburg enthalten war, war streitig. Ein Privileg des Grafen Albrecht von Orlamünde aus dem Jahre $1216{ }^{93}$ ), welches auf das den Hamburgern von Heinrich dem Löwen gewährte Privileg Bezug nimmt und dasselbe bestätigt, bestimmte, daß ihre Schiffe auch in Lauenburg vom Zoll befreit bleiben sollten, falls sie den Nachweis erbrächten, daß Heinrich der Löwe ihnen auch diese Vergünstigung gewährt habe; bis dahin sollten sie in Lauenburg Zoll zahlen. Später wurde indessen in Lauenburg und auch in Eßlingen von den Hamburgern Zoll und Ungeld verlangt, denn in einer Urkunde ${ }^{94}$ ) des Herzogs Albrecht von Sachsen-Lauenburg aus dem Jahre 1252 wurde den Hamburgern zwar das Ungeld, ausgenommen für Getreide, an diesen Hebestellen erlassen, ihre Zollpflichtigkeit an beiden Zollstätten aber ausdrücklich aufrecht erhalten; für Getreide wurde der Geleitsgeldsatz auf die Hälfte des bisher üblichen Betrages herabgesetzt; 1274 und 1276 wurde dieses Privilegium erneut ${ }^{95}$ ). Weiter die Elbe hinauf folgten die Zollstätten Boitzenburg, Bleckede, Hitzacker, Dömitz. Von

92) Koppmann, S. 507; über den Getreidehandel Stades vgl. Hans. Urkdb. I n. 62, 83, 287, 410, 535, 819; über den Getreideverkehr von Stade nach Lüneburg n. 809; über den Getreidehandel Krempes n. 693.

$\left.{ }^{93}\right)$ Hans. Urkdb. I n. 133.

${ }^{94)}$ Ebenda n. 441 ; vgl. Koppmann, Die ăltesten Handelswege Hamburgs, i. Zeitschr. des Vereins für hamb. Geschichte, Bd. VI, S. $408 \mathrm{f}$.

$\left.{ }^{95}\right)$ Hans. Urkdb. I n. 725 und 777. 
dem Zolle bei Boitzenburg waren die Hamburger durch ein Privileg des Grafen Gunzelin von Schwerin vom Jahre 1241 befreit $\left.{ }^{96}\right)$. Zugleich war ihnen in diesem Privileg das Ungeld bei der Fahrt auf der Elbe erlassen; doch lag der untere Lauf des Flusses mit der Zollstätte Dömitz im Gebiete der Grafen von Dannenberg, ebenso wie die Zollstätte Dannenberg, die auf dem Wege von der Elbe nach Salzwedel zu passieren war. Während die Lübecker an diesen dannenbergischen Zollstätten vom Ungelde befreit waren, ist uns von einer solchen Vergünstigung für die Hamburger keine Nachricht erhalten. Ebensowenig erfahren wir irgend etwas von den weiter aufwärts folgenden brandenburgischen Zollstätten ${ }^{97}$ ) an der Elbe und Havel in den Urkunden der Hamburger. Es scheint, als wenn die Hamburger die Elbe nicht häufig weiter hinaufzufahren pflegten, wenn auch die Zusicherung freien Geleites und wohlwollender Förderung für ihre Schiffahrt in der Mark seitens der Markgrafen ron Brandenburg darauf hinweist, daß es nicht an Bestrebungen gefehlt hat, den Verkehr in dieser Richtung weiter auszudehnen.

Von dem häufigen Verkehr der Hamburger in Lüneburg zeugt schon eine Urkunde aus dem Jahre 1239, welche die den Hamburgern in Lüneburg widerfahrenen Benachteiligungen und Zollbedrückungen beseitigt; später hören wir von Zollermäßigungen an der Elbzollstätte Eßlingen für das in der Lüneburger Saline gewonnene Salz, welches die Hamburger von Lüneburg nach Hamburg ausführen ${ }^{99}$ ). In der schauenburgischen Zollrolle wird übrigens Salz gar nicht erwähnt; eine große Rolle scheint der Salzhandel im hamburgischen Verkehr nicht gespielt zu haben; der regelmäßige Weg für den Verkehr mit Salz führte vielmehr, wie die Lüneburger Zollrollen deutlich erkennen lassen, von Lüneburg die Ilmenau hinab und die Elbe und Stecknitz hinauf über die Zollstätten Lauenburg und Mölln nach Lübeck; dieser Weg bot nämlich den bei dem großen Vo-

$\left.{ }^{96}\right)$ Hans. Urkdb. I n. 314 .

${ }^{97}$ ) Tangermünde, ebenda n. 752. Mellingen n. 11 usw.

$\left.{ }^{98}\right)$ Ebenda n. 293, 294.

${ }^{99}$ ) Ebenda n. 1089. 
lumen der Salzladungen sehr wichtigen Vorzug, daß er großenteils die Beförderung zu Wasser ermöglichte; Heringsladungen bildeten die Rückfracht dieser Schiffe $\left.{ }^{100}\right)$.

Außer dem Holz- und Getreidemarkte spielte für den Eigenhandel der Stadt Hamburg schon im 13. Jahrhundert der Handel mit Bier eine beachtenswerte Rolle. Bier hatte in jener Zeit in Norddeutschland als Nahrungsmittel eine Bedeutung, von der wir uns heute schwer einen Begriff machen können $\left.{ }^{101}\right)$. In den Kriegskostenrechnungen der Kriege gegen Waldemar in der Mitte des 14. Jahrhunderts bildet die Ausgabe für Bier regelmäßig den Hauptposten. Von 750 Mark, die Stralsund damals für Verpflegung seiner Mannschaft vor Helsingborg ausgab, entfielen 560 Mark, von 2639 Mark, welche Lübeck auf die Rüstung zum Seekriege aufwendete, 1140 Mark $=2 / 5$, von 935 Pfund, welche die Hamburger aufwandten, 344 Pfund auf Bier; auf 20 Mann rechnete man durchschnittlich täglich eine Tonne (= 261 Liter), auf eine Klosterjungfrau jährlich 14 Tonnen. Das Schiffrecht der hamburgischen Hanse am Zwin nennt Bier bei der Festsetzung der Pacokille des Schiffsmannes für die Fahrt von Hamburg nach Flandern an erster Stelle unter den zur Verladung gelangenden Stapelartikeln. Zum Teil mag es sich dabei um auswärts gebrautes, in Hamburg eingeführtes Bier handeln. Die Einfuhr von Bier suchten die schauenburgischen Grafen offenbar zu heben, indem sie den Zoll auf diesen Artikel in der Zollrolle ganz aufhoben ${ }^{102}$ ). Im Schuldbuch kommt u. a. mehrere Male Lübecker Bier als Gegenstand des Handels in Hamburg ${ }^{{ }^{\prime}}{ }^{103}$ ). Nach der Zollrolle scheint Bier auch von den gerstebauenden Gegenden der Unterelbe hergekommen zu sein; mehrere Male wird im Schuldbuch der Herstellungsort des Bieres nicht besonders genannt; es wird sich also wohl schon um Hamburger Bier handeln. Das Schuldbuch weist Fälle auf, in denen Bier in Hamburg an

$\left.{ }^{100}\right)$ Ebenda n. 807; vgl. oben S. 55 f.

101) Vgl. über das folgende Schäfer, Die Hansestädte und König Waldemar, S. $306 \mathrm{f}$.

102) Hans. Urkdb. I n. 573.

${ }^{103)}$ Koppmann, a. a. O. S. 511. 
Utrechter ${ }^{104}$ ) und Dokkumer ${ }^{105}$ ) Bürger verkauft wird oder von Hamburg nach Flandern ${ }^{106}$ ) versandt wird. Auch in einer brüggischen Urkunde von 1278 und ebenso in einer solchen von 1307 ist schon von Hamburger Bier die Rede ${ }^{107}$ ). Bier bildete also schon einen häufig genannten Ausfuhrartikel Hamburgs, und die Vermutung spricht dafür, daß die Bierbrauerei, gestützt auf den hamburgischen Getreidestapel, schon damals eine bemerkenswerte Erwerbsquelle der Stadt bildete, wenn sie auch die hohe Bedeutung für den Wohlstand Hamburgs, der ihr am Ende des 14. Jahrhunderts innewohnt, erst später erlangt haben mag.

An den Handel mit den Stapelartikeln Holz und Getreide und mit Bier auf dem hamburgischen Markte schloß sich naturgemäß noch ein Umsatz nebensächlichen Umfangs von andern aus dem Inlande und der Umgegend kommenden Waren an. Selbst Kupfer, Zinn, Eisen, Wachs, Pech, Asche, Fett werden an einer Stelle der Zollrolle als Gegenstand des Verkaufes und Kaufes in Hamburg erwähnt ${ }^{108}$ ), wie wir denn ja schon hervor-

104) Koppmann, a. a. O. Note 159.

$\left.{ }^{105}\right)$ Ebenda Note 161.

${ }^{106}$ ) Ebenda S. 500 Note 95. Daß Flandern Bestimmungsort der Ladung ist, dürfte kaum zweifelhaft erscheinen.

${ }^{107)}$ Gillodts van Severn, Cartulaire de l'ancienne Estaple de Bruges, I n. 78 und 162.

${ }^{108}$ ) S. die Zollrolle Handschrift 2: qualiscumque hospes qui obligatus est dare theloneum em ens in civitate $\mathrm{Ham}$ m e n b r g cuprum vel stannum ferrum vel ceram aut alia, quae ponderantur ducendum ad mare dabit de quolibet last 4 o, de vase autem picis, de vase cinerum de vase ungenti de quolibet $4 \%$. Handschrift 1: Sciendum insuper quot homines marchionis de Brandenborg habent speciale jus in theloneo. Dant enim de plaustrata picis, quam v e $\mathrm{nd} \mathrm{u} \mathrm{n}$ in Hammenburg 8 r, etsi ducunt a d mare, dant de ipsa 16 r, de qualibet last cupri, quam d u cun t a d mare, dant $4 \curvearrowright$ ad theloneum, de last stanni $4 \mathrm{~g}$, de last ferri $4 \mathrm{~g}$, de last cere $4 \mathrm{~g}$, de vase cinerum $4 \mathrm{~g}$; habent etiam jamdicti homines specialem gratiam in theloneo, quod qualescunque merces e $\mathrm{munt}$ in $\mathrm{H}$ a m m e $\mathrm{nbor}$ ad reducendùm ad partes suas, nichil dant..... Item sciendum est, quod homines Misnensis et homines domini archiepiscopi Magdeburgensis et ducis Saxonie habent alia jura in theloneo. Dant enim de quolibet scippunt, quod e $\mathrm{m} \mathrm{unt}$ i $\mathrm{n} \mathrm{H}$ a $\mathrm{m} \mathrm{b}$ or $\mathrm{ch}$ ad reducendum ad partes suas tercium dimidium denarium. 
gehoben haben, daß die Kaufleute aus der Mark Meißen ihre Bergwerkserzeugnisse kaum selbst über Hamburg hinausgeführt haben werden. Weiter aber kommen, wie die Zollrolle und das Schuldbuch ergeben, von den Marschen der Unterelbe Vieh und Pferde, von Stade Rinder- und Hirschhäute, von dem Lande Jever und Norden Butter ${ }^{109}$ ) auf den Hamburger Markt, und auch diese Erzeugnisse wurden, wie z. B. die Lüneburger Zollrolle ${ }^{110}$ ) ergibt, nach Lüneburg und voraussichtlich ebenso nach andern Orten über den Hamburger Zwischenmarkt wieder ausgeführt.

Der Hamburger Eigenhandel mit Holz, Getreide, Bier u. dgl. m. war in der Hauptsache Zwischenhandel und vermittelte lediglich den Verkehr der von dem hamburgischen Markte abhängigen näheren und weiteren Umgegend der Stadt mit dem Weltmarkt Brügge. Eine Urkunde von 1238111), in welcher die von den Bürgern der flandrischen Stadt Aardenburg am Zwin in Holstein zu erlegenden Zölle auf Roggen, Gerste und Hafer ermäßigt werden, zeigt, daß dieser Verkehr schon in der ersten Hälfte des 13. Jahrhunderts entwickelt war. Nach dem Zwin flossen die Holzmassen und Getreidezufuhren, welche in Hamburg sich sammelten, wieder ab. Die schon angeführten Bestimmungen des Schiffrechtes der hamburgischen Hanse am Zwin geben Zeugnis für den großen Umfang insbesondere der Holzausfuhr Hamburgs dorthin. Allein da Hamburg für diese Artikel eben nicht nur Umschlagsplatz, sondern Zwischenhandelsmarkt war, so war der Anteil, der den Hamburgern selbst an diesem Handel zufiel, sehr viel größer als an dem baltisch-flandrischen und dem binnensächsischflandrischen Verkehrsstrome; nicht nur das Reedereigeschäft, sondern auch der Warenhandel lag bei diesen Artikeln in ihren Händen. Für ihre Stellung im Welthandel fiel freilich dieser für den Welthandel Brügges verhältnismäßig bescheidene Zufluß an Holz und Getreide aus den Elbgegenden weniger ins Gewicht.

Der Handel der Binnenlandstädte über Hamburg nach Flandern und ebenso der Handel der Hamburger mit Holz,

$\left.{ }^{109}\right)$ S. über Jever und Ostringen auch Hamb. Urkdb. I n. 923, 924.

$\left.{ }^{110}\right)$ Hans. Urkdb. I n. 807.

111) Hans. Urkdb. II n. 734. 
Getreide und Bier dorthin rief naturgemäß auch wiederum einen Gegenstrom von Gütern nach Hamburg hervor, der neben dem flandrisch-baltischen Verkehrszuge herging. Für die Ladungen, welche die von Flandern kommenden Braunschweiger, Salzwedeler, Magdeburger, Lüneburger usw. zurückbrachten, war Hamburg natürlich wieder im wesentlichen nur Umschlagsplatz ${ }^{112}$ ). Dagegen versorgten sich diejenigen Binnenländer, welche Holz und Getreide u. dgl. nach Hamburg brachten, auf dem Hamburger Markte zugleich auch mit Waren für das Binnenland. In diesem beschränkten Kreise war Hamburg infolgedessen auch Zwischenhandelsplatz für die Waren des flandrischen Weltmarktes. Den Hauptgegenstand der Rückfracht für alle die Erzeugnisse, welche vom flandrischen Markte Hamburg zuflossen, bildeten flandrische Wolltuche. Die Zollrolle spricht, indem sie die Fälle bestimmt, in welchen die Brandenburger ihre in Flandern eingetauschten Waren bei der Rückreise frei vom Ungeld sollen einführen dürfen, bezeichnenderweise nur von der Rückfracht von Tuch. Bei den Braunschweigern heißt es in der Zollrolle, ,wenn sie rom Meere kommen, sollen sie von jedem Packen Tuch 2 Solidi Ungeld geben“. „Der Fremde, der die Elbe hinauffahren will mit seinem Tuch", heißt es an einer andern Stelle, ,soll von jedem Packen Tuch 14 Solidi Ungeld zahlen." Auch in Hamburg selbst spielte der Tuchhandel bereits eine Rolle, indem flandrische Tuche der hauptsächlichste Artikel waren, den die Binnenländer, die in Hamburg Waren zu Markte brachten, in ihre Heimat zurückführten ${ }^{113}$ ). Außer Tuch nennen die Zollrollen ${ }^{114}$ )

112) Die Zollrollen bezeugen ausdrücklich, daß diese fremden Kaufleute die Waren durch Hamburg größteneils nur durchführten.

${ }^{113}$ ) Stadterbebuch zum Jahre 1267: statuerunt consules de generali consilio, ut quicunque burgensis voluerit incidere pulchros pannos, daret IIII marcas argenti. Qui vero voluerit incidere griseos pannos, daret III marcas argenti; s. Staphorst, Kirchengeschichte, Teil I, Bd. II, S. 109.

114) Hamb. Zollrolle n. 573 Handschrift 2; Lüneburger Zollrolle n. 808. Die Handschrift 2 der hamb. Zollrolle nennt auch Hering, vgl. jedoch oben S. 55 f. Zum Teil handelt es sich offenbar um einen Austausch der binnenländischen Produkte untereinander, indem z. B. die binnensächsischen Kaufleute von den Brandenburgern in Hamburg Leinen kaufen mochten. Im ganzen war dieser Umsatz sicherlich gering. 
im wesentlichen nur noch Wein, Pelzwerk, Häute, auch Leinen, ferner orientalische und südländische Erzeugnisse, wie indischen Pfeffer, Kümmel, ferner Weinstein, Schwefel, Thure, Mandeln, Feigen, Reis, Anis u. dgl., und endlich Pferde, Ochsen, Kühe.

Der hamburgische Zwischenmarkt wurde nun aber nicht nur von den Binnenstädtern der Umgegend Hamburgs, sondern auch von den Kaufleuten der flandrischen und friesisch-holländischen Verkehrsplätze des Westens aufgesucht. Vor allem brachten die Flanderer selbst hierher ihre Tuche, daneben auch Wein $\left.{ }^{115}\right)$. Obenan stehen unter den fremden Kaufleuten, die den Hamburger Markt aufsuchen, die von Gent; keine Stadt kommt so häufig im Hamburger Schuldbuch vor wie Gent ${ }^{116}$ ); daneben sind von flandrischen Plätzen Brügge, Mecheln, Ypern, St. Omer, Oudenaarde, Aardenburg als Herkunftsorte der in Hamburg verkehrenden Flanderer genannt ${ }^{117}$ ). Ein Schiedsspruch der Gräfin von Flandern aus dem Jahre 1268 ${ }^{118}$ ) über die Beilegung eines zwischen flandrischen und hamburgischen Kaufleuten ausgebrochenen Streites gibt einigen Einblick in ihren Verkehr in Hamburg. Sie dürfen ihre Tuche nicht nach der Elle, ihren Wein nicht nach Maß oder Krügen und ebensowenig andere Waren im Kleinen vertreiben, sondern ihre Handelsgüter nur im Großen verkaufen; der Kleinhandel ist den Bürgern vorbehalten; im übrigen sollen sie dieselben Rechte in Hamburg genießen, deren sich die Hamburger in Flandern erfreuen; namentlich soll jeder nur für seine eigenen Schulden haftbar gemacht und, wenn er ausreichende Bürgschaften oder Pfänder stellt, nicht wegen Klagen festgehalten werden dürfen. Wie die Deutschen in Flandern, waren die Flanderer in Hamburg berechtigt, ihre Güter nach Belieben bei den Einwohnern der Stadt unterzubringen und jederzeit wieder auszuführen. Für Wein scheint Hamburg ein nicht unbedeutender Stapelplatz gewesen zu sein. Schon in einem Zollprivileg für Utrecht vom Jahre $1244^{119}$ ) lernen wir Tuch und Wein als Handels-

$\left.{ }^{115}\right)$ Hans. Urkdb. I n. 660.

116) Koppmann, a. a. O. S. 504.

117) Ebenda S. 500 f.

${ }^{118)}$ Hans. Urkdb. I n. 660.

119) Ebenda n. 334. 
artikel kennen, welche die Hamburger Warenhändler auf der Heimreise von Flandern mit sich führen. Die schauenburgische Zollrolle hebt bei dem Zollsatze, welchen die Kaufleute der Herzogtümer Sachsen und Braunschweig, des Erzbistums Magdeburg und der Mark für Wein zu erlegen haben, hervor, daß es sich um Wein handelt, den sie in Hamburg kaufen. Auch die Lüneburger Zollrolle ${ }^{120}$ ) bemerkt bei dem Weinzolle, daß der Wein in Hamburg gekauft werde.

Außer den Flanderern zeigt uns das Schuldbuch namentlich eine Anzahl westfriesischer und holländischer Orte in Hamburg vertreten. Utrecht, Dokkum, Groningen, Leeuwarden, Harlingen, Workum, Enkhuisen, Alkmar, Harderwyk, Deventer sowie das seeländische Arnemuiden kommen als Heimatsorte in Hamburg aufhältlicher Gäste, und zwar zum Teil sogar sehr häufig, im Schuldbuch vor ${ }^{121}$ ). Die Harderwyker werden 1280 in Hamburg besonders in Schutz genommen ${ }^{122}$ ). Einige Male wird die Ausfuhr von Bier als Gegenstand des Geschäftes dieser Friesen und Holländer erwähnt ${ }^{123}$ ). Eine freilich nur verstümmelt erhaltene Urkunde aus dem Jahre $1296^{124}$ ) gibt auch Zeugnis von dem Verkehr der Hamburger in Stavorn, Franecker, Sneek und andern Plätzen Westfrieslands; auch hier deutet der in der Urkunde vorkommende Ausdruck lagena, der gerade sehr oft für das Faß Bier gebraucht wird, darauf hin, daß es sich für die Hamburger dort namentlich um den Vertrieb ihres Bieres handelte, wenn auch die Beschädigung der Urkunde näheres nicht mehr erkennen läßt. Im ganzen freilich werden wir kaum fehlgehen, wenn wir die Interessen, welche die Westfriesen, Holländer, Süderseeer und Seeländer nach Hamburg führten, weniger im Warenhandel als in der Schiffahrt suchen. Denn das Reedereigeschäft war es, was bei den meisten dieser Orte die wichtigste Stütze ihres Wohlstandes bildete. Im hamburgischen Schuldbuch kommen Alkmaar ${ }^{125}$ ) und Arnemui-

$\left.{ }^{120}\right)$ Hans. Urkdb. I n. 808.

121) Koppmann, a. a. O. S. $498 \mathrm{ff}$.

$\left.{ }^{122}\right)$ Hans. Urkdb. I n. 859.

123) Koppmann, a. a. O. S. 511.

124) Hans. Urkdb. I n. 1218.

${ }^{125)}$ Koppmann, a. a. O. S. 499, Nr. 90. 
den ${ }^{126}$ ) als Heimatshäfen ron Schiffern, die sich in Hamburg aufhalten, vor; eine Urkunde aus dem Jahre $1282^{127}$ ) erwähnt Harderwyker Schiffe in Hamburg, eine andere von etwa 1267 ${ }^{128}$ ) Kampener Schiffe auf der Elbe. Lübecker Schiffe scheinen dagegen an der Fahrt von Hamburg nach dem Westen nicht häufig teilgenommen zu haben; das Schiffrecht der Lübecker Hanse am Zwin führt bezeichnenderweise die Reise ron Hamburg nach dem Zwin nicht auf; auf dieser Route vermochten die Lübecker den Hamburgern offenbar keine Konkurrenz zu machen. Dagegen werden wir Bremer Schiffe wohl in bescheidenem Maße an diesem Verkehr beteiligt vermuten dürfen, wie auch die spätere Rezeption des hamburgischen Schiffrechts in Bremen annehmen läßt.

Die Zollrolle erwähnt ausdrücklich die fremden Seeschiffe in Hamburg, für welche der Zoll früher ein Vierding (= 4 Schillinge) betragen habe und nach der Zeit, da Graf Adolf IV. ins Kloster gegangen sei (1239), mit Zustimmung der versammelten, vom Meere herkommenden Kaufleute auf 22 Schillinge bei jeder Ankunft festgesetzt sei.

Von ausländischen Städten kommen im Schuldbuche außer den oben genannten nur noch Süderköping in Schweden und Nestved in Dänemark gelegentlich als Herkunftsorte in Hamburg handelnder Kaufleute vor $\left.{ }^{129}\right)$; bei beiden Stellen ist es jedoch höchst zweifelhaft, ob es sich überhaupt um Handelsbeziehungen Hamburgs zu diesen Plätzen handelt $\left.{ }^{130}\right)$. Von den deutschen Städten unterhielt Lübeck einige an den Durchgangsverkehr sich anschließende Verbindungen mit dem hamburgischen Zwischenmarkte, und in ähnlicher Weise bot der Umschlagsverkehr den Bürgern anderer deutscher Städte

${ }^{126)}$ Koppmann, a. a. O. S. 500 Note 95.

127) Hans. Urkdb. I n. 846, 847.

${ }^{128}$ ) Ebenda n. 637.

$\left.{ }^{129}\right)$ Koppmann, a. a. O. S. 501.

${ }^{130}$ ) In dem einen Falle handelt es sich um den Enkel eines Hamburgers, der, in Süderköping zu Hause, in Hamburg Rechte seines Großvaters, der Schiffspartenbesitzer ist, wahrnimmt; in dem andern Falle ist es zweifelhaft, ob Nestved Herkunftsbezeichnung oder Eigenname ist: in Lübeck war nämlich eine Familie de Nestvede ansässig; vgl. Hildebrandt, Rigisches Schuldbuch, S. 46, Note 1. 
gelegentlich Anlaß zu Geschäftsabschlüssen auf dem hamburger Zwischenmarkt. Denn wenn die Bremer, Osnabrücker, Dortmunder, Soester und sonstigen Kaufleute, wie das hamburgische Schuldbuch ${ }^{131}$ ) und andere Urkunden ${ }^{132}$ ) zeigen, gelegentlich in Hamburg Geschäfte abschlossen, so waren diese Geschäfte regelmäßig nicht auf ihre Heimatsstädte, sondern auf Flandern gerichtet, von wo aus sie über Hamburg und Lübeck nach dem Osten und Norden ausreisten und wohin sie vor allem auch ihre im baltischen Gebiet erworbenen Waren zurückführten. Eine Reihe von Urkunden des 13. Jahrhunderts zeigen uns diese Städter auf dem Wege zwischen Flandern und dem baltischen Gebiet über Hamburg und Lübeck ${ }^{133}$ ); insbesondere ist auch zwischen Bremen und Hamburg bei der Gleichartigkeit der Erzeugnisse, welche in beiden Orten zu Markte kamen, kaum ein irgend erheblicher unmittelbarer Austausch in jener Zeit denkbar; auch der Vertrag, den diese Städte 1259 schlossen und 1297 erneuerten ${ }^{134}$ ), gibt keinerlei Anhalt für solchen Verkehr, sondern zeigt nur, daß es vorkam, daß hamburgische oder bremische Bankrottierer durch die Flucht aus der einen Stadt in die andere sich ihren Gläubigern zu entziehen und von dort aus ihren Geschäftsbetrieb fortzusetzen versuchten, was um so leichter möglich sein mochte, als beide Orte in ähnlicher Weise am Verkehr der Harzstädte mit Flandern beteiligt waren; der Vertrag hatte nur den Zweck, in solchen Fällen den Schuldzeugnissen der beiderseitigen städtischen Behörden und den Schuldbeweisen der beiderseitigen Kaufleute in beiden Städten

131) Koppmann, a. a. O. S. 503.

${ }^{132}$ ) Soest mit Hamburg, Hans. Urkdb. I n. 311, mit Lübeck n. 306, $309,310,325$.

133) So auch die Bremer und Stader, welche 1234 in Lübeck vom Zoll befreit wurden, n. 262. Die Stader wurden ferner 1238 vom Zoll in Oldesloe befreit. Bremer und Stader erhielten die Rechte der Lübecker für ihren Durchgangsverkehr durch Holland und Seeland nach Flandern, n. 438, 443, 331. Bremer und Stader in Flandern, n. 650, 476. Dafür, daß auch die Kaufleute aus Holland und Geldern in Flandern den Mittelpunkt ihrer Geschäftstätigkeit hatten und also auch, wenn sie in Hamburg auftraten, den Verkehr mit Flandern werden vermittelt haben, s. oben S. $37 \mathrm{f}$.

${ }^{134}$ ) Hans. Urkdb. I n. 524, 1232. 
Gültigkeit zu sichern. Zum Abschluß eines solchen Vertrags aber mußte sich um so leichter Gelegenheit anbahnen, als die Bremer sowohl in Flandern als auch bei ihrer Durchreise über Hamburg nach dem Osten, für welchen Verkehr sie bereits 1234 mit den Stadern zusammen Zollfreiheit in Lübeck erlangten, in vielfache Berührung mit den Hamburgern kamen ${ }^{135}$ ).

Der Verkehr auf dem hamburgischen Zwischenmarkt wird sich im wesentlichen auf bestimmte Zeitpunkte im Jahre konzentriert haben. Zwei Jahrmärkte hatte das Privileg Kaiser Friedrichs I. den Hamburgern bewilligt, am Tage des heiligen Veit, d. i. am 15. Juni, und am Tage Mariä Himmelfahrt, also am 15. August. Der St. Veitsmarkt hat sich jahrhundertelang erhalten. Wie lange der Markt an Mariä Himmelfahrt üblich blieb, entzieht sich unserm Blick; im Anfang des 13. Jahrhunderts wird er noch erwähnt $\left.{ }^{136}\right)$; im 14. Jahrhundert bestand er indessen nicht mehr; ob anstatt seiner im 13. Jahrhundert in Hamburg schon andere Jahrmärkte, die wir im 14. Jahrhundert vorfinden, abgehalten wurden, können wir gleichfalls nicht verfolgen.

Die von Hamburg nach dem Westen ausgehenden Verkehrsströmungen, der vom baltischen Gebiet und der von den binnensächsischen Städten kommende Durchgangsverkehr, wie auch der in Hamburg selbst sich abspielende Zwischenhandel waren alle drei so gut wie ausschließlich auf Flandern gerichtet, wenn wir hier von der Bierausfuhr nach Westfriesland absehen. Der große Weltmarkt Brügge war es, der alle diese Zuflüsse aufsog. Ein irgend nennenswerter unmittelbarer Verkehr Hamburgs

${ }^{135}$ ) In späterer Zeit werden die Bremer, deren Stadt für den Ver. kehr vom baltischen Meere nach Flandern sehr wenig günstig gelegen war, immer mehr aus diesem Handelszuge herausgedrängt. Ihr Verkehr beschränkt sich am Ende des 13. Jahrhunderts und bis in die Mitte des 14. Jahrhunderts auf den Austausch Bremens und seines Hinterlandes (Harzstädte) mit Flandern und mit Holland (bremisches Bier) und auf die Versorgung Norwegens mit Mehl und Bier. Dem Verbande der übrigen deutschen Stådte gehören sie weder in Flandern noch in Norwegen an, erwerben vieImehr hier wie dort Sonderprivilegien. Am ganzen baltisch. flandrischen Handel haben sie keinen Anteil mehr.

$\left.{ }^{136}\right)$ S. Hamb. Urkdb. I n. 389, $483,486$. 
mit England kam damals noch gar nicht in Frage. Für die englische Wolle, den Stapelartikel der englischen Ausfuhr, bot sich in Hamburg kein Absatz, da Tuche weder hier, noch im Hinterlande Hamburgs über den lokalen Bedarf hinaus hergestellt wurden, auch die Vorbedingungen für eine größere Tuchindustrie hier fehlten; die englische Tuchindustrie selbst steckte noch in den Kinderschuhen; ihr Umfang war noch sehr unbedeutend, und wo gelegentlich einmal englische Tuche im Verkehr nach dem Norden und Osten in dieser Zeit erwähnt werden, handelt es sich in der Regel um Zufuhren über den flandrischen Markt. Von einer direkten Einfuhr von Hamburg nach England ${ }^{137}$ ) kann aber um so weniger die Rede gewesen sein, als die Einfuhr Englands im Vergleich zur Ausfuhr, wie wir gesehen haben, überhaupt nur klein war und, wie bereits dargelegt, natur-

137) In der Handschrift Nummer 2 Hans. Urkdb. I n. 573 der Zollrolle für Hamburg aus der Mitte des 13. Jahrhunderts heißt es von den Brandenburger Kaufleuten, die über Hamburg Waren ausführen: De omnibus jam bonis, si dederint ungeldum in Hamburg et ducunt in Flandriam vel i n A $\mathrm{ngli}$ a m sive alias et comparunt pannum de hiis, in reditu de ipso panno nichil dabunt. Sciendum praeterea, si aliquis istorum mercatorum purum argentum sive anglicos denarios vel alias merces, de quibus ungeldum non dedit, ducit i n F l a $\mathrm{n}$ d $\mathrm{r}$ i a $\mathrm{m}$ et comparat pannum de hiis, in reditu dabit de pacca illa XIIII solidos ad ungeldum. Die Worte ,vel in Angliam“ sind offenbar ein Einschiebsel aus späterer Zeit (s. nächste Note). In der Handschrift Nummer 1 der Zollrolle fehlen sie, und ebenso ist in dem Privilegium von 1236 für die Brandenburger, aus welchem diese Bestimmung genommen ist, nur Flandern genannt und von England keine Rede. Für den Eintausch von Tuchen für die nach dem Westen geführten Waren konnte England im 13. Jahrhundert in nennenswertem Umfang nicht in Frage kommen. - Eine Stelle im Schuldbuch, welche bisher auf den unmittelbaren Verkehr von Hamburg nach England gedeutet ist, spricht von einer Schuld für vier graue Tuche, die nach England geführt und dort verkauft werden sollen (Koppmann, a. a. O. S. 501, Note 103). Höchst wahrscheinlich befinden sich die Tuche in Flandern, und bezieht sich der freilich in Hamburg geschlossene Vertrag auf eine Reise von Flandern und nicht von Hamburg aus; denn von einer Tuchausfuhr von Hamburg nach dem Westen kann in jener Zeit keine Rede sein; es müßte sich denn eben um einen gänzlich regelwidrigen Ausnahmefall handeln; Hamburg bezog vielmehr Tuche in großer Menge vom Westen; dagegen war im flandrischenglischen Verkehr Tuch ein wichtiger Gegenstand des Austausches gegen englische Wolle. 
gemäß an den Markt gebunden war, auf den sich die Ausfuhr richtete. Von den Handelsartikeln der binnensächsischen Städte mag allerdings ein Teil der Ausfuhr des Erzes, insbesondere des Harzer Silbers, schließlich dem englischen Geldmarkte zugeflossen $\left.\operatorname{sein}^{138}\right)$; sicherlich waren es die eigenen wirtschaftlichen Interessen, die den Herzog von Braunschweig, welcher ja selbst erheblichen Anteil an dem Ertrage des Harzer Bergbaus hatte ${ }^{139}$ ), wiederholt veranlaßten, in England für die Hamburger, Bremer und Lübecker, mit deren Hilfe ja die Kaufleute der Harzstädte die Verfrachtungen der Harzer Erze nach England ausführten, Fürsprache einzulegen $\left.{ }^{140}\right)$. Zweifellos aber vollzog sich dieser ganze Verkehr durch Vermittlung des Brügger Marktes ${ }^{141}$ ); denn auf diesen ist auch der binnensächsische Verkehr und, wie die Zollrolle bekundet, insbesondere die Silberausfuhr gerichtet ${ }^{142}$ ), ganz abgesehen davon, daß an selbständige Verschiffungen ganzer Schiffsladungen von Silber überhaupt bei diesem Verkehre gar nicht gedacht werden darf.

Der Verkehr nach Flandern und überhaupt nach dem Westen vollzog sich von Hamburg aus regelmäßig zu Wasser ${ }^{143}$ );

${ }^{138}$ ) In diesem Sinne mögen auch die Worte vel in Angliam in der in der vorigen Note angeführten Urkunde aufzufassen sein.

${ }^{139}$ ) Vgl. Weiland, Goslar als Kaiserpfalz, in Hans. Geschichtsbl. 1884, S. $32 \mathrm{f}$.

$\left.{ }^{140}\right)$ Hans. Urkdb. I n. 893, 892.

141) Ebenda I n. 633, 635, 836.

${ }^{142}$ ) Vgl. auch das Gedicht Wilhelms des Bretonen (oben Note $2 \mathrm{zu}$ Kapitel 1), wo die Rede ist von den in Brügge zusammenströmenden argenti massae.

143) Koppmanns Ausführungen in ,Die ältesten Handelswege Hamburgs", Zeitschr. des Vereins f. hamb. Geschichte, Bd. 6, S. 420, sind irrtümlich. Das Vorhandensein der aus verschiedenen Urkunden bekannten Straße, die von Bremen über Wildeshausen nach Osnabrück führte, und auf der, wie Hirsch, Danzigs Handels- und Gewerbsgeschichte, S. 190 f. mitteilt, im Jahre 1407 einmal Danziger Kaufleute nachweisbar sind, beweist doch nichts für einen Warenverkehr zu Lande von Danzig über Hamburg nach Flandern, von dem sonst nie etwas erwähnt wird. Entweder werden jene Kaufleute von Bremen aus nach Westfalen oder aus Westfalen nach Bremen Waren transportiert haben oder aber sie reisten ohne Waren. Die Benutzung des Landweges von Reisenden (Gesandten, 
es fehlt nicht nur an jedem Anhalt dafür, daß im 13. und 14. Jahrhundert zu Lande Warenverkehr dorthin stattgefunden hätte, sondern das völlige Schweigen der Zollrolle über einen solchen Verkehrszug und die Tatsache, daß weder die Hamburger noch die Lübecker irgendwelche Privilegien für den Durchzug und Verkehr in den Ländern, durch welche der Landweg nach Flandern geführt haben würde, erworben haben, während sonst überall, wohin sie kamen, Privilegien ihren Handel zu sichern pflegten, beweisen auch, daß ein solcher Landverkehr von Hamburg aus überhaupt nicht bestand. Die Vorteile, welche der Wasserweg vor dem Landtransporte auf den unvollkommenen Wegen bot, fielen damals in ähnlichem Maße ins Gewicht wie etwa heute die Vorteile des Eisenbahnverkehrs vor dem Frachtwagenverkehre auf unseren Chausseen. Straßen,

Boten usw.) ist ja häufiger nachweisbar. - Genum in der von Koppmann angezogenen Urkunde ist nicht Genemuiden an der Vechte, sondern Het Gein bei Ijsselsteen, westlich von Utrecht (s. Hans. Urkdb. III Ortsver: zeichnis), womit Koppmanns Vermutungen ohne weiteres zusammenfallen. - Ebenso greift Bruns, Lübecks Handelsstraßen am Ende des Mittelalters, in Hans. Geschichtsbl. 1896. S. 44. durchaus fehl, wenn er glaubt, daß die von ihm konstruierten Straßen die Bedeutung von Hauptadern des hansischen Verkehrslebens gehabt hätten. Diese Bezeichnung trifft nur für die Straße von Lübeck nach Hamburg zu. Wenn im 15. Jahrhundert - für das 13. und 14. Jahrhundert fehlt es völlig an solchen Nachrichten im Oldenburgischen mehrfach Lübecker und Hamburger Kaufleute beraubt wurden (s. ebenda S. 54 f.), so 1433, 1452, 1464, 1472, so beweist das selbst für das 15. Jahrhundert noch nichts dafür, daß ein nennenswerter Warenzug von Hamburg zu Lande nach Flandern ging. Diese Straße hatte vielmehr in Bremen ihren natürlichen Endpunkt. Daß die Westfalen schon früh einerseits nach Flandern und anderseits nach Bremen zogen und somit sich durch die Westfalen und ferner durch die Kaufleute, welche westfälische Märkte, von Osten kommend, besuchten und mit den Einkäufen von den westfälischen Märkten nach Holland und Flandern weiterzogen, ein Verkehrszug zwischen Bremen einerseits und Holland und Flandern anderseits durch Westfalen hindurch entwickelte, kann kaum zweifelhaft sein. Im 15. Jahrhundert mögen die westfälischen Märkte und damit auch diese Straßen schon mehr von Kaufleuten anderer Städte besucht worden sein; nur werden auf der einen Seite Bremen, auf der andern Seite die geldrischen und holländischen Städte in der Regel der Endpunkt der Landreisen gewesen sein. Warentransporte von Lübeck nach Flandern zu Lande sind zweifellos auch im 15. Jahrhundert selten vorgekommen. 
auf denen Reisende wie Gesandte, Boten usw. unter Umständen den Weg nach dem Westen zu Lande zurücklegten, waren natürlich vorhanden.

Die Wasserstraße nach dem Westen zu sichern und zu verbessern, finden wir Hamburg von früher Zeit an eifrigst bemüht. Schon der Vertrag Hamburgs mit Lübeck von 1241 und die Verhandlungen der beiden Städte miteinander von 1259 beziehen sich auf den Schutz der Verkehrsstraße zwischen ihnen und bis zur Mündung der Elbe; der noch weitergehende Vertrag von 1255 schließt natürlich ebenfalls das Elbgebiet mit ein.

Die Freiheit der Schiffahrt auf der Elbe war den Hamburgern schon durch den Freibrief Friedrich Barbarossas von 1189 zugesichert. Aber ohne Waffengewalt hat Hamburg diese Rechte nicht behaupten können. Namentlich hat Stade dem Hamburger Verkehre auch im 13. Jahrhundert noch zeitweise empfindliche Schwierigkeiten bereitet. Als Erzbischof Hildebold 1259 sein Amt antrat, wurden die alten Ansprüche Stades auf den Elbzoll gegenüber den Hamburger Schiffen wieder aufgenommen ${ }^{\mathbf{1 4 4}}$ ). Wir finden den Erzbischof $1259 \mathrm{im}$ Bunde mit seinem Lehnsmanne Otto von Barmstede ${ }^{145}$ ), den er mit der Haseldorfer Marsch auf dem rechten Elbufer gegenüber Stade belehnt hatte, im Kampfe mit den Grafen von Holstein und den Hamburgern, welche den Grafen mit Kriegsschiffen unterstützen, und zwar richtete sich der Angriff der letzteren nicht nur gegen die Haseldorfer Marsch, sondern auch gegen die Schwinge $\left.{ }^{\mathbf{1 4 6}}\right)$. Der Streit, in welchem Otto von Barmstedt bereits $1259 \mathrm{zu}$ einem Vergleiche gezwungen wurde, nach einigen Jahren aber durch neue Gewalttätigkeiten wieder als Partei hervortrat ${ }^{147}$ ), dauerte bis 1266 und wurde schließlich durch ein Schiedsgericht beigelegt ${ }^{148}$ ). Auf Grund des Schiedsspruches erkannte der Erzbischof 1267 endlich die Freiheit der Ham-

144) Vgl. Soetbeer, Des Stader Elbzolles Ursprung, Hamburg 1839, S. 17.

$\left.{ }^{145}\right)$ Bramstedt in Holstein.

146) Hamb. Urkdb. I n. 648, 671, 808.

147) Ebenda n. 648, 713, 716.

148) Ebenda n. 704. 
burger von dem Stader Zolle an ${ }^{\mathbf{1 4 9}}$ ). Als die Stader sich auch dann noch nicht fügen wollten, erklärte der Erzbischof 1268, im Falle die Stader es dieserhalb mit Hamburg zum Kriege kommen ließen, die Zollstätte nach Bardesfleth verlegen zu wollen $\left.{ }^{150}\right)$. Nunmehr scheint Stade sich in sein Schicksal gefunden zu haben; wenigstens hören wir weiter nichts von der Angelegenheit.

Früh schon suchte Hamburg auch durch Verträge mit den Ufergemeinden der für die Schiffahrt so gefährlichen Elbmündung die Sicherheit seines Verkehrs zu erhöhen. Mit dem Lande Hadeln am linken Ufer der Unterelbe bestand bereits in der ersten Hälfte des 13. Jahrhunderts ein freundschaftliches Verhältnis. Es ergibt sich dies aus einem Vertrage, welchen die Hamburger 1238 mit dem Lande Wursten, der Landschaft jenseits der die Elbe und die Weser trennenden Landspitze nach der Wesermündung hin, abschließen ${ }^{151}$ ) und in welchem sie das Verhältnis, welches sie mit den Hadelern verbindet, auf das Land Wursten ausdehnen. Der Graf, die Schulzen und die Ratsmänner des Landes Wursten versprechen, wenn Hamburger Bürger an ihrer Küste mit ihren Schiffen auf dem Sande sitzen oder Schiffbruch erleiden, so solle die Schiffsladung, so lange noch einer der Schiffer am Leben sei und den Gewahrsam über die Waren ausübe, ungeschmälert geborgen werden dürfen und unangetastet bleiben. Im Jahre 1299 wurden den Hamburgern von den Herzögen Johann und Albrecht von Sachsen in einem Privilegium ${ }^{152}$ ) ihre Rechte auf der Unterelbe besonders verbrieft. Denn daß es sich hier im wesentlichen um Bestätigung geltenden Rechtes handelt, zeigen u. a. ein Schreiben der Hamburger an die Lübecker aus der Mitte des 13. Jahrhunderts ${ }^{153}$ ) und die Aufzeichnung des Schiffrechtes von 1292 ${ }^{154}$ ), in welchen z. B. schon zum Teil dieselben Bergelohnsätze als geltendes Recht bezeichnet werden, welche dieses Privileg fest-

$\left.{ }^{149}\right)$ Hamb. Urkdb. I n. 723, 724.

${ }^{150}$ ) Ebenda n. 730.

151) Hans. Urkdb. I n. 290.

$\left.{ }^{152}\right)$ Ebenda n. 1323.

153) Ebenda n. 538.

$\left.{ }^{154}\right)$ Art. 20. 
setzt, und ebenso der bereits angeführte Vertrag von 1238 mit dem Lande Wursten, der zugleich auch das in Hadeln geltende Strandrecht wiedergeben dürfte. Ungehindert und ohne eine Abgabe zu zahlen, bestimmt das Privilegium von 1299, sollen die Hamburger ${ }^{155}$ ) im Lande Hadeln und Wursten und in dem übrigen Küstengebiete der Herzöge, wozu wir namentlich die rechtselbischen Ufer der Unterelbe und die dithmarschener Küste zu rechnen haben werden, ihre Güter, soweit sie selbst dieselben bergen, behalten dürfen; wird aber die Hilfe der Strandbewohner in Anspruch genommen, so soll, wenn es sich um Strandung handelt, den Landesherren und Hilfeleistenden ein Zwanzigstel der Güter als Hilfslohn zufallen; wenn es sich aber um Schiffbruch außerhalb der Elbmündung jenseits der Sände handelt, so soll der Bergelohn ein Drittel des Güterwertes betragen. Auf der See gefundenes oder an den Strand getriebenes Gut soll Jahr und Tag unter obrigkeitlicher Sicherung für die Eigentümer aufbewahrt werden.

Mit den Landschaften des linken Ufers der Unterelbe ${ }^{156}$ ), vor allem mit den dithmarsischen Kirchspielen Brunsbüttel und Marne, und ebenso mit den Nordfriesen der Uthlande der schleswigschen ${ }^{157}$ ) Küste hatte Hamburg übrigens besondere Vereinbarungen zum Schutze seiner Schiffe gegen Seeräubereien und Vergewaltigungen getroffen.

Am Ausgange der Elbe, an der Landscheide zwischen Elbe und Weser, dort, wo die trügerischen Sände die Einfahrt und Ausfahrt in den Strom so besonders gefahrvoll machten, erbauten die Hamburger 1286 ,,mit den übrigen Kaufleuten und Männern, welche sich ihnen anschlossen“, auf Grund eines Privilegs, das ihnen der Erzbischof Giselbrecht von Bremen gewährte ${ }^{158}$ ), ein dauerndes Seezeichen auf einer damals neu entstandenen, mit $\mathrm{O}$ bezeichneten Insel, auf dem sie auf ihre Kosten dauernd ein Feuer unterhielten, damit es den Seefahrern Tag und Nacht als Wahrzeichen diene. In dem Privileg der

${ }^{155}$ ) Vgl. übrigens für die Lübecker Hans. Urkdb. I n. 1275

156) Ebenda n. 611, 879, 1006, 1086.

157) Ebenda n. 563.

${ }^{158)}$ Ebenda n. 1002. 
Herzöge von Sachsen von 1299159) wird auch dieses Recht mit den Worten bestätigt, daß sie auf der neuen Insel $\mathrm{O}$ ein Werk aus Stein oder Holz, hoch, tief, breit und dick, wie es ihnen nützlich scheint, sollen errichten dürfen und die Steine hierzu aus Wolde oder sonst aus dem Lande sollen holen dürfen.

Am Ausgange der Elbe teilten sich die Wege nach Flandern. Der eine, die Straße ,durch die wilde See“, ging über die freie Nordsee und näherte sich erst in den seeländischen Gewässern wieder dem Lande. Für die Fahrt durch die seeländischen Wasserarme erwarben ,die Hamburger und alle aus der Elbe kommenden Kauffahrer" 1266 von dem Kastellan von Seeland die Verbriefung sicheren Geleites ${ }^{160}$ ); alle Streitigkeiten unter sich oder mit den Flanderern sollten sie selbst durch ihre eigene Gerichtsbarkeit entscheiden dürfen, ausgenommen Totschlag, Raub und Verwundungen auf seeländischem Gebiete. Die Straße über die offene Nordsee war für Schwergutladungen und für Massenwaren der einzige Weg nach dem Westen. Der zweite Weg, der für die damalige Schiffahrt weniger gefahrvoll war und deshalb namentlich für kostbare Güter vorgezogen wurde, führte nahe an der Küste entlang durch die Watten nach der Zuidersee und von dort durch die Binnengewässer weiter zum Zwin. Gleichsam am Lande entlang tastend suchten diese Wattenfahrer ihren Weg. Nach der Umschiffung der westlichen Landspitze an der Elbmündung fuhren sie wahrscheinlich zunächst an der Küste des Landes Wursten entlang; eben hieraus erklärt sich der große Wert, den sie auf die Strandrechtsprivilegien im Lande Wursten legten; alsdann durchquerten sie die Wesermündung und den Jadebusen und erreichten jenseits die Küste der ostfriesischen Landschaft Rüstringen. Auch mit diesem Lande hatten sie deshalb alle Veranlassung, ein freundschaftliches Verhältnis zu unterhalten. Aus dem Jahre 1291 ist uns ein Vertrag Hamburgs mit dem Lande Rüstringen erhalten ${ }^{161}$ ), in welchem die Rüstringer versprechen, sich aller Gewalttaten gegen die Ham-

$\left.{ }^{159}\right)$ Vgl. übrigens für die Lübecker Hans. Urkdb. I n. 1323, 1340.

${ }^{160}$ ) Ebenda n. 631.

161) Ebenda n. 1084. 
burger zu enthalten und dieselben nach Möglichkeit zu fördern, insbesondere Schiffbrüchige an ihrer Küste nicht an der Bergung ihrer Güter zu hindern und im Falle der Hilfeleistung nur den rechtmäßigen Bergelohn zu fordern, ferner an den Strand getriebene Güter Jahr und Tag in der Kirche für den Eigentümer zu verwahren und nur den dritten Teil des Wertes als Lohn zu beanspruchen. Von der Küste Rüstringens ging die Fahrt weiter zwischen dem Festlande und der friesischen Inselkette hindurch durch das Vlie in die Zuidersee. Nachrichten über Verträge ${ }^{162}$ ) Hamburgs mit den Landschaften Harlingen und Franecker zeugen von freundschaftlichen Beziehungen zu den Westfriesen.

Von der Zuidersee ging es die Vecht hinauf nach Utrecht. Utrecht war Umschlagsplatz in diesem Verkehre; jenseits Utrecht bewegte sich derselbe auf den Binnengewässern des Landes weiter nach Flandern ${ }^{\mathbf{1 6 3}}$ ). In Utrecht wurden die Waren zu diesem Zwecke über einen Damm geschafft und jenseits desselben wieder zu Wasser gebracht; ob auch die Schiffe selbst über den Damm gezogen wurden, ist streitig; die Hamburger Schiffe scheinen jedenfalls nur den Verkehr bis Utrecht geleitet zu haben. Die Waren wurden zum Teil mit einem Kran über den Damm gehoben, zum Teil mit der Hand, auf der Schulter oder unter Zuhilfenahme von Tragbahren hinübergeschafft. Jenseits Utrecht gingen sie zu Schiff auf einem Wasserlaufe bis zu einem Orte Genum (het Gein) bei Ijsselsteen und von da den Leck hinab weiter an der holländischen Zollstätte Geervliet vorbei und durch die Wasserläufe zwischen den seeländischen Inseln hindurch nach dem Zwin. Bereits aus dem Jahre 1244 ist ein Privileg ${ }^{164}$ ) des Bischofs von Utrecht erhalten, in welchem er die Hamburger und Lübecker seines Schutzes und Geleites versichert, dessen Aufkündigung nur unter Innehaltung einer einjährigen Frist soll erfolgen können und in welchem er weiter die Zollsätze und die Gebühren, welche sie für den Transport ihrer Waren über

162) Vgl. übrigens für die Lübecker Hans. Urkdb. I n. 12ł0, 12\&1, 1218.

$\left.{ }^{163}\right)$ S. über das Folgende Hans. Urkdb. I n. 334; vgl. auch n. 5.18

${ }^{164)}$ Ebenda n. 334. 
den Damm zu zahlen hatten, festsetzte. Daß indessen dieser Verkehr schon älter war und das Privilegium nur eine Bestätigung des bestehenden Zustandes oder eine Neuordnung desselben bedeutete, lehrt eine andere Urkunde ${ }^{165}$ ) aus dem Jahre 1243, in welcher Graf Wilhelm von Südholland den Kaufleuten von Lübeck und Hamburg sicheres Geleit, gleichfalls unter Zusicherung einer einjährigen Kündigungsfrist, zusagt und die Zölle festlegt, welche sie bei Geervliet zu erlegen haben. Beide Urkunden bekunden ausdrücklich, daß es sich um den Verkehr der Hamburger und Lübecker nach und von Flandern durch das utrechtsche und holländische Gebiet handelt. 1249 und 1266 wurden den Hamburgern diese Privilegien für Holland erneuert $\left.{ }^{166}\right)$. Im seeländischen Gebiete sicherte, wie schon erwähnt, ein Privileg von 1266 die Fahrt der Hamburger.

Die große Bedeutung Utrechts im Verkehre zwischen Elbe und Flandern, insbesondere für die Hamburger, deren Schiffe die Waren nur bis Utrecht brachten, liegt hiernach auf der Hand. Es ist deshalb sehr natürlich, daß wir auch in Utrecht eine hamburgische Hanse vorfinden, welche in ihrer Organisation ganz mit derjenigen der Hamburger am Zwin übereinstimmt $\left.{ }^{167}\right)$. Wie dort, so steht auch hier ein Ältermann an der Spitze, auch hier werden Streitigkeiten durch die versammelte Genossenschaft in der Morgensprache entschieden unter Ausschluß der ausländischen Ortsgerichtsbarkeit; auch hier ist der Besuch der Morgensprache Pflicht jedes dort anwesenden Hamburgers; wie in Flandern wird auch in Utrecht von jedem Hamburger eine Abgahe, die hier allerdings nur auf 3 Solidi utrechtscher Währung bemessen ist, und daneben ein Betrag von zwei Pfennigen für ,unser Liebfrauen“ erhoben. Wie die hamburgische und die lübische Hanse am Zwin, so hat auch die hamburgische Hanse in Utrecht auf dem Wege der gewohnheitsrechtlichen Bildung ein besonderes Genossenschaftsrecht entwickelt, welches in der Aufzeichnung des hamburgischen Schiffrechtes von 1292 dem Statut der flandrischen Hanse

${ }^{165)}$ S. über das Folgende Hans. Urkdb. I n. 331.

$\left.{ }^{166}\right)$ Hans. Urkdb. I n. 373, 628.

$\left.{ }^{167}\right)$ S. Hamburgisches Schiffrecht Art. 1 c, 2 ff.; $17 \mathrm{a}-19^{\circ}$ und Th. Kiesselbach, Das hamb. Schiffrecht, S. $55 \mathrm{f}$. 
folgt. Dieses Genossenschaftsrecht der hamburgischen Hanse in Utrecht behandelt nur die Fahrt zwischen der Elbe und Utrecht; die Tatsache, daß es nur frachtrechtliche und schiffsrechtliche Bestimmungen enthält, erweist, daß auch die Interessen dieser hamburgischen Hanse vor allem in der Frachtschiffahrt bestanden. Die Rechtsbestimmungen dieser Hanse zeigen uns die Hamburger Schiffe an ihrem Liegeplatze auf der Vechte bei Marsen, etwa $8 \mathrm{~km}$ unterhalb Utrecht, auf Fracht wartend; die Vorschriften lassen erkennen, wie die Hamburger Schiffe dort oft lange Zeit liegen müssen, bis sie Fracht finden, wie der Schiffer selbst währenddessen sich in Utrecht aufhält und Fracht sucht, während die Schiffsleute auf dem Schiffe bleiben, wie es vorkommt, daß sie bei diesem Warten auf der Vechte einfrieren. Von dem Verkehr jenseits Utrecht auf dem Wege nach Flandern weiß das Genossenschaftsrecht dieser hamburgischen Hanse nichts; es ist bezeichnend, daß die Lübecker auch noch für die Weiterfahrt von Genum durch Südholland 1245 Strandrechtsprivilegien erwerben ${ }^{168}$ ), während den Hamburgern solche für diese Strecke nicht zuteil werden; die Hauptinteressen der Hamburger endeten eben auf dieser Route in Utrecht, bis wohin ihre Frachtschiffahrt ging, während die Lübecker, welche lediglich als Warenhändler auf diesem Wege verkehrten, in gleicher Weise an der Wegstrecke durch Holland interessiert waren, naturgemä $ß$ aber keine Hanse in Utrecht hatten ${ }^{169}$ ), das für sie nicht Endpunkt von Interessen, sondern lediglich Durchfuhrplatz war. Weiter aber zeigt das Schiffrecht der Hanse in Utrecht, daß der Verkehr Utrechts mit der Elbe keineswegs immer auf Hamburg, sondern vielfach noch auf Stade gerichtet war und daß die Hamburger Schiffe sich auch an dieser Frachtschiffahrt zwischen Stade und Utrecht beteiligten ${ }^{\mathbf{1 7 0}}$ ). Das Schiffrecht bestimmt den Lohnzuschlag, der dem Schiffsmanne zu zahlen ist, wenn der Schiffer nach Stade segelt, um nach Utrecht Ladung zu nehmen.

Welche Warenarten auf dem Wege über Utrecht und welche über die offene See nach Flandern gingen, vermögen

${ }^{168}$ ) Hans. Urkdb. n. 337.

$\left.{ }^{189}\right)$ Vgl. Th. Kiesselbach, Hamb. Schiffrecht, S. 56.

$\left.{ }^{170}\right)$ Art. 19. 
wir noch zum Teil zu verfolgen. Als Waren, welche in Utrecht mit dem Kran über den Damm gehoben werden, werden in dem Privilegium ${ }^{171}$ ) der Hamburger auf dem Hinwege nach Flandern Asche und Pech erwähnt; auch die russischen Pelze werden in der Regel diesen Weg gegangen sein $\left.{ }^{172}\right)$; auf dem Rückwege kommen Tuche und Wein als Handelswaren der Hamburger in Utrecht vor. Tuch und Wein werden ja auch, wie schon dargelegt, durch den Isthmus von Hamburg nach Lübeck befördert; dieselben Verkehrsstraßen werden vielfach die auf dem flandrischen Markte erworbenen orientalischen Gewürze und südländischen Früchte genommen haben. Über das offene Meer gelangten ausweislich des Schiffrechtes auf hamburgischen Schiffen nach dem Zwin die großen Holz- und Kornladungen, die Metallausfuhren, daneben auch Asche, Wachs, Pech, Fett; mit andern Ladungen wurden dann allerdings gelegentlich wohl auch wertvollere Sendungen, wie Tuche, südländische Früchte u. dgl., über die offene See versandt.

Wie schon erwähnt, hatte Hamburg im Verkehre mit dem Westen die Konkurrenz Stades nicht unerheblich zu empfinden. Zwang schon der Stader Zoll auf der einen Seite alle nichthamburgischen Schiffe, in Stade anzuhalten, so verstand Stade auch die Bande, welche den Verkehr dieser Stadt schon im 12. Jahrhundert mit Utrecht verbanden ${ }^{173}$ ), noch weiter $\mathrm{zu}$ festigen, indem es den Utrechtern 1270 für die Einfuhr von Tuchen, welche die Utrechter zweifelsohne entweder von Flandern holten oder in Utrecht von den Flanderern ${ }^{174}$ ) erhandelten, in Stade Zollfreiheit gewährte ${ }^{175}$ ). Stades Verbindungen nach dem Westen sind übrigens auch durch eine Reihe anderer Urkunden, insbesondere das Privileg ${ }^{176}$ ) von 1252, für ihren Ver-

171) Hans. Urkdb. I n. 334.

${ }^{172}$ ) Schon die Tatsache, daß das Pelzwerk noch im 13. Jahrhundert zum Teil von Hamburg über Stade nach dem Westen ging, weist auf die Wattenfahrt hin. S. unten S. 135.

$\left.{ }^{173}\right)$ Hans. Urkdb. I n. 42.

$\left.{ }^{174}\right)$ S. den Durchgangsverkehr der Flanderer bei der Zollstelle Geervliet ebenda n. 41; vgl. auch n. 20, 365, 492.

${ }^{175)} \mathrm{Vgl}$. ebenda n. 685.

${ }^{176}$ ) Ebenda n. 438. 
kehr durch Seeland nach Flandern belegt. Nicht minder ausgedehnt aber waren Stades Beziehungen nach dem Osten. Die Schauenburger Zollrolle für Hamburg erwähnt mehrfach den Verkehr Stades mit Hamburg, der in kleinen Kähnen vor sich ging; zwei Privilegien ${ }^{177}$ ) von 1238 und 1254, in welchen den Stadern des Recht zugestanden wird, in Oldesloe dieselben Zölle wie die Lübecker zu zahlen, und ein weiteres Privileg ${ }^{178}$ ) von 1234, durch das ihnen Zollfreiheit in Lübeck verliehen wird, werfen ein Licht auf ihren Verkehr mit dem Ostseegebiete; Stade gehört auch zu den Städten, welche 1295 um ihre Zustimmung zu dem Übergange der Appellationsinstanz gegen die Urteile des Nowgoroder Hofes von Wisby auf Lübeck angegangen werden und sich zustimmig erklären, war also wohl am Verkehr in Nowgorod selbst beteiligt. Auch die Tatsache, daß ein Teil des russischen Pelzwerks seinen Weg von Hamburg über Stade nach dem Westen nahm ${ }^{179}$ ), ist in hohem Grade beachtenswert. Übrigens unterhielten auch die Utrechter Beziehungen nach Gotland hin $\left.{ }^{180}\right)$. Nicht minder aber hatte Hamburg im Verkehre mit dem Binnenlande die Konkurrenz Stades zu überwinden. Urkunden aus dem Jahre 1249181), in denen Stade und Braunschweig sich gegenseitig Sicherheit des Verkehrs und freien. Zugang zusichern, lassen erkennen, daß Stades Handelsbeziehungen bis in das Herz des sächsischen Hinterlandes reichten. Eine Urkunde ${ }^{182}$ ) aus dem Jahre 1225, in welcher die Stader von Zollbelästigungen bei der Zollstätte Celle befreit werden, zeigt sie gleichfalls auf dem Wege nach den Harzstädten, vermutlich über Lüneburg, dessen Verbindungen nach Braunschweig ebenfalls urkundlich bezeugt sind ${ }^{183}$ ). Eine Zollrolle aus dem Jahre 1278 ${ }^{184}$ ) läßt erkennen, wie Stade

$\left.{ }^{177}\right)$ S. den Durchgangsverkehr der Flanderer bei der Zollstelle Geervliet ebenda n. 287 u. 410.

${ }^{178)}$ Hans. Urkdb. I n. 262.

179) S. oben S. 134.

$\left.{ }^{180}\right)$ Hans. Urkdb. I n. 521.

181) Ebenda n. 368-370.

$\left.{ }^{182}\right)$ Hans. Urkdb. I n. 183.

${ }^{183}$ ) Ebenda n. 218. (Zollfreiheit der Braunschweiger bei der Zollstătte Lüneburg.)

184) ก. 809. 
auch die Lüneburger durch besondere Zollvergünstigungen an seinen Markt zu fesseln bestrebt war; für alle Waren, die vom Meere kamen, genossen die Lüneburger Zollfreiheit in Stade; ebenso für Häute, die sie von Stade holten; die Urkunde ergibt zugleich, daß die Lüneburger vom stader Stapel Getreide und Vieh zu holen pflegten. Denn auch als Stapelmarkt des unterelbischen Gebietes für diese beiden Handelsgüter bereitete Stade Hamburg seit jeher Konkurrenz.

Den Einfluß der politischen Zustände auf die $\mathrm{H}$ andelsverhältnisse Hamburgs vermögen wir nicht näher zu verfolgen. Indessen wird es gewiß auch für die wirtschaftlichen Verhältnisse nicht ohne Bedeutung geblieben sein, daß nach dem Zusammenbruche der sächsischen Herzogsmacht Heinrichs des Löwen alsbald wieder die Dänen über die deutsche Grenze hereinzubrechen begannen und daß auch Lübeck und Hamburg während des ersten Viertels des 13. Jahrhunderts zum dänischen Reiche gehörten. Wiederholt wurde Hamburg selbst der Schauplatz der Kämpfe. Noch 1201, in demselben Jahre, in welchem die Dänenherrschaft begann, besetzte Graf Adolf IV. wieder Hamburg, allein kurz darauf fiel die Stadt den Dänen wieder in die Hände, und Adolf IV. mußte allen Ansprüchen auf Holstein entsagen. Nicht anders ging es, als 1215 Kaiser Otto IV. die Stadt besetzte; nach halbjähriger Belagerung erlag sie aufs neue den Dänen. Erst als es 1225 dem jungen Grafen Adolf IV. gelungen war, die Dänen aus Holstein zurückzudrängen, und als 1227 in der Schlacht von Bornhöved die dänische Macht endgültig gebrochen war, waren die Vorbedingungen für einen Aufschwung des wirtschaftlichen Lebens in Hamburg und Lübeck geschaffen.

Die dänische Herrschaft hat übrigens vielleicht zum Ausgleich innerer Gegensätze und zur Erstarkung des Gemeinwesens der Stadt beigetragen. Die Verschmelzung der ursprünglich bischöflichen Ansiedlung mit der gräflichen Neustadt vollzog sich' jedenfalls schon in der ersten Hälfte des Jahrhunderts ${ }^{185}$ ). Bald nach der Befreiung Hamburgs von

${ }^{185}$ ) Seit 1248 sind Stadterbebücher erhalten, die das ganze Stadtgebiet umfassen. 
der Dänenherrschaft sprach auch der Erzbischof, von dessen Rechten an Hamburg im 13. Jahrhundert kaum noch die Rede ist, ausdrücklich den Verzicht auf seine Rechte zugunsten des Grafen aus ${ }^{186}$ ).

Das Aufblühen Hamburgs im Laufe des 13. Jahrhunderts offenbart sich namentlich auch in der zunehmenden Selbständigkeit der städtischen Verwaltung. Neben dem Vogt ${ }^{187}$ ), durch den der Graf seine Obliegenheiten als Gerichtsherr und Inhaber der Polizeigewalt ausüben ließ, erscheinen schon 1190 in den Urkunden Ratmänner, consules, als Vertreter der städtischen Gemeinde. In der zweiten Hälfte des 13. Jahrhunderts ist nun die Stellung des Vogtes offenbar im Sinken. Seitdem der Rat das Stadtrecht hatte aufzeichnen lassen (1270), begann man gegen die Urteile des Vogtes, die in alter Weise nach Gewohnheitsrecht gesprochen wurden ${ }^{188}$ ), an das Buch auf dem Rathause, das der Rat verwahrte, zu appellieren ${ }^{189}$ ); das Schwergewicht der Rechtsprechung verschob sich nun entschieden zugunsten des Rates. Dem Vogte verblieb schließlich nur die niedere Strafgerichtsbarkeit. Sogar im Vogtgerichte wirkten übrigens zwei Ratmannen neben dem Vogte mit. Auch nach außen hin trat diese Veränderung in der Stellung des Vogtes sehr offensichtlich zutage; der Vogt, der früher in Urkunden vor den Ratmannen aufgeführt zu werden pflegte, wird nun in den Verträgen, welche die Stadt abschließt, nicht mehr erwähnt. Die Ratmannen vertreten die Stadt nach außen fortab regelmäßig allein. 1292 erhielt der Rat überdies das Recht der Küre, d. h. des selbständigen Erlasses von Rechtsbestimmungen, also gesetzgeberische Gewalt; 1293 brachte die Stadt durch Pacht auch die Münze in ihre Hand.

${ }^{186)}$ Vgl. Lappenberg, Hamb. Rechtsaltertümer, Bd. II Einl., S. 13 f.; Koppmann, Kleine Beiträge zur Geschichte der Stadt Hamburg, Bd. II S. $14 \mathrm{ff}$.

$\left.{ }^{187}\right)$ Über den Vogt s. Lappenberg, Hamb. Rechtsaltertümer, Hamburg 1845, Bd. I S. XXff.; Koppmann, Kleine Beiträge, Bd. II, S. $32 \mathrm{ff}$.

$\left.{ }^{188}\right)$ Erst 1292 erhielt das Vogtgericht einen Schreiber; s. Lappenberg, ebenda, Koppmann, a. a. O., S. 51.

$\left.{ }^{189}\right)$ Vgl. Koppmann, Beitr. II, S. 42. 
Im Ganzen werden wir uns sehr zu hüten haben, für das 13. Jahrhundert die Größe der Stadt und ihre Bedeutung im nordeuropäischen Verkehre zu hoch einzuschätzen. Der direkte Seeverkehr der Stadt beschränkte sich im wesentlichen, wie wir gesehen haben, auf den Verkehr nach Flandern und nach Friesland und Holland. Für die Holz- und Metallausfuhren Schwedens und Norwegens bot Hamburg ebensowenig einen konsumkräftigen Markt wie für die Erträgnisse des schonenschen und norwegischen Fischfanges und die Getreideausfuhren der Ostseeländer oder die Wollausfuhren Englands. Höchstens könnten Schiffe, die für die Fahrt von den Ostseeländern, von Schonen oder von Norwegen nach Flandern gemietet waren, manchmal von Hamburg aus ihre Ausreise angetreten haben; in der Regel werden aber der Natur der Sache nach die Schiffe für diese Fahrten an dem großen Mittelpunkte des Verkehrs, Brügge, wo die Schiffe in der Regel ihre Reisen beendeten, gemietet sein und von dort aus auch diese Reisen angetreten haben. Auch zeigen sich die Hamburger z. B. am norwegischen Handel im Vergleiche zu den wendischen Städten und Lübeck jedenfalls verhältnismäßig nur gering interessiert, so daß auch von einer bemerkenswerten Zufuhr von Mehl und Bier, wie sie die wendischen Städte und Lübeck dorthin unterhielten, bei Hamburg schwerlich die Rede sein konnte. In dieser Beziehung war die Lage der wendischen Städte und Lübecks namentlich auch im Verkehr mit Schonen sehr viel günstiger als diejenige Hamburgs. Es ist in hohem Grade beachtenswert, daß das im Jahre $1292 \mathrm{im}$ wesentlichen aus den bestehenden Genossenschaftssatzungen zusammengestellte hamburgische Schiffrecht keine Spur eines Verkehrs zwischen Hamburg und andern Ländern als Flandern und den Niederlanden enthält. Hätte ein irgend erheblicher regelmäßiger Verkehr Hamburger Schiffe von Hamburg aus mit andern Ländern damals bestanden, so hätte es gar nicht ausbleiben können, daß dieser Verkehr den Verhältnissen der damaligen Zeit entsprechend seinen Halt in einer Genossenschaft gefunden, und in ähnlicher Weise wie der Verkehr der Hamburger vom Zwin aus und der Verkehr zwischen Utrecht und der Elbe einen gewohnheitsrechtlichen Niederschlag erzeugt hätte, der Aufnahme im hamburgischen 
Schiffrechte gefunden haben würde. Für den baltisch-flandrischen Verkehr war Hamburg, wie wir gesehen haben, fast nur Durchfuhrplatz, und nicht viel anders lag es bei dem binnensächsisch-flandrischen Verkehrszuge. Die Grenzen des Gebietes aber, für welches Hamburg einen Markt abgab, waren, wie dargelegt, eng gezogen; so wichtig die Transporte der Massenartikel Getreide, Holz und Bier vom hamburgischen Zwischenmarkte für die Entwicklung der hamburgischen Reederei, welcher die Transporte von Pelzen, Wachs und Tuchen wegen des geringen Volumens dieser Waren im Verhältnis zum Werte weniger Nahrung boten, im Verkehre mit Flandern sein mochten, so spielte doch der hamburgische Zwischenmarkt im Welthandel eine untergeordnete Rolle. Der Umfang dieses ganzen Verkehrs wird in das richtige Licht gerückt, wenn wir uns vergegenwärtigen, daß der Ort um die Wende des 13. Jahrhunderts etwa 5000 bis 10000 Einwohner zählte $\left.{ }^{190}\right)$. Die Stellung, welche die Hamburger im nordeuropäischen Welthandel einnahmen, beruhte aber, wie dargelegt, in erster Linie nicht auf dem Umfange des Handels der Stadt, sondern auf der Bedeutung der Tätigkeit, welche die Hamburger von dem großen brüggischen Weltmarkte aus als Reeder und Kaufleute versahen.

$\left.{ }^{190}\right)$ Laurent, Das älteste Bürgerbuch, i. Zeitschr. des Vereins f. hamb. Geschichte I S. $141 \mathrm{ff}$, , berechnet die Einwohnerzahl auf Grund der hamburgischen Bürgerbücher für den Beginn des 14. Jahrhunderts auf etwa 7000 Einwohner; Stuhlmann, Statistik des hamb. Staates, 1869, Bd. 2, S. 1, hält diese Zahlen für um die Hälfte zu niedrig. Reißner, Die Einwohnerzahl deutscher Städte in früheren Jahrhunderten mit besonderer Berücksichtigung Lübecks, Jena 1903 (Abhandlungen des staatswissenschaftlichen Seminars zu Halle, Bd. XXXVI), behauptet (S. 68) auf der andern Seite, daß die von Laurent angewendete Rechnungsmethode wenigstens für Lübeck Resultate erzielt, die um die Hälfte zu hoch seien; sollte für Hamburg das Gleiche gelten, so würde sich also nach Reißner die Einwohnerzahl nur auf etwa 3500 Personen belaufen haben. 


\section{Zweiter Abschnitt.}

\section{Die beiden ersten Drittel des 14. Jahrhunderts.}

Drittes Kapitel.

Die Verschiebungen im wirtschaitlichen Auibau des westeuropäischen Seehandels und der Anteil der Deutschen, insbesondere auch der Hamburger, an diesem Handel während der ersten beiden Drittel des 14. Jahrhunderts.

Das 14. Jahrhundert bringt die im 13. Jahrhundert gepflanzten Keime des nordwesteuropäischen wirtschaftlichen Lebens zu voller Entfaltung. Es ist insbesondere auch die Blütezeit des hansischen Handelsverkehrs ${ }^{1}$ ).

Für den deutschen Seehandel und namentlich auch für den hamburgischen Handel hat Brügge bis gegen Ende des 15. Jahrhunderts die zentrale Bedeutung behalten, welche dieser Handelshafen schon im 13. Jahrhundert besaß, und auch für diesen Zeitabschnitt ist deshalb die Kenntnis der Entwicklung des brüggischen Marktes unumgängliche Voraussetzung für das Verständnis des deutschen Seehandels und insbesondere auch des hamburgischen Handelsverkehrs. Wir haben deshalb unsern Blick hier zunächst wieder dem großen flandrischen Emporium zuzuwenden.

Hatte Brügge mit dem Zwin schon im 13. Jahrhundert den Brennpunkt des ganzen nord- und südwesteuropäischen Handelsgetriebes abgegeben, so riß es nun auch das Erbe der Messen von der Champagne und Brie an sich und wurde zum Mittelpunkt des ganzen Welthandels. Zum Verständnis dieser

$\left.{ }^{1}\right)$ Vgl. auch Daenell, Die Blütezeit der deutschen Hanse, Berlin 1905, S. 9 . 
tiefgreifenden Wandlungen müssen wir vor allem den örtlichen Verschiebungen der Wolltuchindustrie folgen, deren Produkte, wie schon früher erwähnt, geradezu das Rückgrat des Welthandels im Mittelalter bildeten.

Schon im 13. Jahrhundert war neben den Tuchen Flanderns und seiner Nachbarschaft englische Wolle Gegenstand der Zufuhr von Flandern zu den Messen in der Champagne und Brie gewesen ${ }^{2}$ ); die Tuchindustrien in den Städten der Champagne, in Provins, Lagny, Chalons sur Marne usw., hatten ja auf dieser Zufuhr beruht ${ }^{3}$ ). Selbst Montpellier hatte bereits im 13. Jahrhundert neben dem Gewerbe der Veredelung der vom Norden kommenden Tuche eine, wie es scheint, nicht unbedeutende Tuchweberei aufzuweisen, welche englische Wolle verarbeitete ${ }^{4}$ ). Darüber hinaus hatte die englische Wolle indessen bis gegen Ende des 13. Jahrhunderts noch wenig Verbreitung gefunden. Zwar besaßen die Mittelmeerländer schon im 13. Jahrhundert eine bemerkenswerte Wolltuchfabrikation; wo diese Wolltuchindustrie eine höhere Entwicklung erreichte, wie in den lombardischen und toskanischen Städten Italiens ${ }^{5}$ ), insbesondere in Florenz, verarbeitete sie spanische $W_{0}$ lle $^{6}$ ); dieser Rohstoff stand jedoch der englischen Wolle erheblich nach ${ }^{7}$ ), und die Fabrikate der Italiener vermochten deshalb den Wettbewerb mit den flandrischen und nordfranzösischen Tuchen im Welthandel nicht aufzunehmen. Im Verkehr mit dem Orient mußten sich die Italiener deshalb, wie wir gesehen haben, in der Hauptsache auf den Vertrieb dieser fremden Webstoffe, die sie auf den französischen Messen und in Flandern erhandelten und in den

$\left.{ }^{2}\right)$ S. Bourquelot I S. 216.

3) Ebenda.

4) Die Montpellianer beziehen die Wolle aus Frankreich, also offenbar englische, nicht spanische; s. Germain, Histoire du commerce de Montpellier, I S. $296 \mathrm{f}$.

$\left.{ }^{5}\right)$ S. Schulte, Geschichte des mittelalterlichen Handels und Verkehrs zwischen Westdeutschland und Italien mit Ausschluß von Venedig, Leipzig 1900, S. $131 \mathrm{ff}$.

6) S. Doren, Die Florentiner Wollentuchindustrie vom 14. bis zum 16. Jahrh., Stuttgart 1901, S. 63 ff., 71; Schulte, S. 129. Schultes Ausführungen sind durch die Darlegungen Dorens in wichtigen Punkten berichtigt.

7) Doren, a. a. O. S. 68 ff. 
italienischen Städten dern orientalischen Geschmacke entsprechend herrichteten, beschränken ${ }^{8}$ ). Seit dem Ende des 13. Jahrhunderts begannen nun aber die italienischen Tuchmacher für ihre Fabrikation auch englische Wolle in größeren Mengen heranzuziehen ${ }^{9}$ ); die italienische Wolltuchindustrie, allen voran diejenige von Florenz, wurde nunmehr der französischen und flandrischen Industrie ebenbürtig und gewann jenen Konkurrenten den orientalischen Markt $\left.a b^{10}\right)$. Mit allen Mitteln suchte man in Frankreich dieser Wendung der Dinge zu begegnen und die Durchfuhr der englischen Wolle nach dem Süden zu verhindern; vergeblich wurde die Ausfuhr der Wolle und aller zur Herstellung und Bearbeitung der Wolle und Tuche erforderlichen Materialien erschwert, beschränkt, ja, ganz verboten $\left.{ }^{11}\right)$. Die italienische Wollindustrie entfaltete sich kräftig, und der Absatz der französischen und flandrischen Tuchindustrie in den Mittelmeerländern ging fühlbar zurück. Auf den Messen der Champagne und von Brie verlor der Handel mit Tuchen, der ehedem den Hauptgegenstand des Geschäftsverkehrs ge-

$\left.{ }^{8}\right)$ S. oben S. $33 \mathrm{f}$.

${ }^{9}$ Doren, a. a. O. S. $67 \mathrm{ff}$.

$\left.{ }^{10}\right)$ Italienische Tuche im Orient, s. Heyd, I S. 576, 599, II S. 11, 148, 351, 415, $696 \mathrm{f}$.

11) S. hierüber Doren, S. 36, Note 2; Bourquelot I S. 213 f. Schon 1278 erließ Philipp II. von Frankreich ein Wollausfuhrverbot, das 1288 zugunsten von Mailand in einen Ausfuhrzoll verwandelt wurde. 1303 erhielten drei Finanzagenten der Krone ein Ausfuhrmonopol für Wolle, das allerdings bald wieder aufgehoben wurde; aber 1316 wurde die Ausfuhr von Wolle, halbfertigen Tüchern und allen zur Herstellung und Bearbeitung der Wolle und Tuche dienenden Artikeln in Languedoc aufs neue verboten (Gilliodts van Severn, Cartulaire de Bruges, I n. 1193, 200). Die Wollausfuhr wurde fortan von besonderen Lizenzen ab. hängig. 1349 erließ Philipp V. wieder ein Wollausfuhrverbot, Hans. Urkdb. III n. 152. In den wahrscheinlich aus den Jahren 1315 bis 1322 stammenden Vorschlägen für die Reorganisation der Messen der Champagne wird wieder empfohlen, die Wollausfuhr zu verbieten, ,damit die Fremden fortfahren, unsere Tücher zu kaufen und ihre Produkte zu bringen" (Bourquelot, II S. 308). 1349 heißt es, die Wollausfuhr sei der Grund des Niederganges der ganzen Messen (Bourquelot, I S. 214). Erst 1359 wurde die volle Verkehrsfreiheit wieder hergestellt (ebenda). 
bildet hatte ${ }^{12}$ ), allmählich alle Bedeutung; im Jahre 1361 hatten die Kaufleute der flandrischen und nordfranzösischen Hanse, die im 13. Jahrhundert die Trägerin des Verkehrs mit flandrischen und nordfranzösischen Tuchen dorthin gewesen war ${ }^{13}$ ), aufgehört, die Messen zu besuchen ${ }^{14}$ ), und die im 13. Jahrhundert blühende Tuchindustrie der Städte der Champagne verfiel im Laufe des 14. Jahrhunderts vollständig ${ }^{15}$ ). Die flandrische Tuchindustrie fand dagegen in dem gesteigerten Absatze nach dem nördlichen Europa Ersatz ${ }^{16}$ ); in den Niederlanden und ihren Nachbargebieten rückte die ganze Wolltuchfabrikation infolgedessen im 14. Jahrhundert merklich nach dem Norden vor ${ }^{17}$ ), der dem Brügger Weltmarkte, von wo der Rohstoff kam und wohin die Tuche nunmehr so gut wie ausschließlich zur Ausfuhr gelangten, näher lag.

Mit dem Absterben der Wolltuchindustrie in der Champagne und dem Verfall des Handels mit französischen und flandrischen Tuchen nach dem Süden war auch das Schicksal der großen Messen der Städte in der Champagne und Brie besiegelt ${ }^{18}$ ). Zwar erhielten sich diese Messen noch lange Zeit;

12) Bourquelot, I 84 ff. Provins war, wie Höhlbaum mitteilt, nach dem Ausdruck einer Urkunde gegründet ,sur le fait de la marchandise de la drapperie“", Hans. Urkdb. III S. 15, Note zu n. 32.

$\left.{ }^{13}\right)$ Bourquelot, I S. 86 ff., ferner S. 28, 77, 135 ff. Ursprünglich Hanse der 17, später 24 Städte; vgl. über dieselbe Höhlbaum, Utber die flandrische Hanse von London, in hans. Geschichtsbl.1898, S. 158; Pirenne, La hanse flamande de Londres, in Bulletin de la Classe des Lettres et des sciences morales et politiques et de la Classe des beaux arts, 1899, Nr. 1, Bruxelles; Warnkönig, Flandrische Staats- und Rechtsgeschichte bis zum Jahre 1305, Tübingen 1838, S. $128 \mathrm{f}$.

14) Bourquelot II S. 312.

15) Bourquelot, II S.312. In Provins, wo am Anfang des Jahrhunderts 3200 Arbeiter in der Wolltuchmacherei beschäftigt waren, waren 1399 nur noch 30 Personen mit Tuchmacherei befaßt.

16) Die flandrische Tuchindustrie blühte nach dem französischen Kriege rasch wieder auf. In Ypern wurden 1306 zum Siegeln der Tuche 10500 Bleimarken verbraucht, $130833000,130963000,131087000$, 131392500 ; s. Pirenne, Gesch. Belgiens, I S. 475.

17) Pirenne, Geschichte Belgiens, I S. 301, auch 299.

$\left.{ }^{18}\right)$ Die dargelegten örtlichen Verschiebungen der Wollindustrie und der damit zusammenhängende Rückgang des Handels mit flandrischen 
auch die französisch-flandrischen Kriege vermochten diesen Verkehr nur vorübergehend zu unterbrechen; allein die frühere Lebenskraft dieses Handels erlosch allmählich ${ }^{19}$ ), und in der zweiten Hälfte des 14. Jahrhunderts verfiel er vollständig und verlor jede Bedeutung für den Welthandel $\left.{ }^{20}\right)$. Der Wollhandel, der wenigstens den Handel mit Tuchen zum Teil hätte ersetzen können, nahm nämlich vorwiegend andere Wege nach dem Süden. Die Ursache dafür wird zum Teil in den Erschwerungen und zeitweiligen Verboten der Ausfuhr von Wolle in Frankreich zu erblicken sein; indessen kamen andere Gründe hinzu.

Ein Rohstoff wie Wolle, dessen der Süden in großen Massen bedurfte, vermochte die hohen Kosten des langen Landtrans-

und französischen Tuchen nach dem Sïden sind der eigentliche wirtschaftliche Grund des Unterganges der Messen der Champagne und von Brie. Doren hat durch seine Untersuchungen über die Florentiner Wolltuchindustrie diese Tatsache vollends bloßgelegt, ohne indessen diese Folgerung $\mathrm{zu}$ ziehen. Die drückenden fiskalischen Abgaben, die wiederholte Vertreibung der ,Wucherer“, die flandrisch-französischen Kriege usw. haben wohl zur Beschleunigung dieser Entwicklung beigetragen, sind aber nicht, wie bisher so oft behauptet ist, die eigentlichen Ursachen des Verfalls der Messen gewesen.

$\left.{ }^{19}\right)$ Nach Bourquelot, I $190 \mathrm{ff}$. , II $301 \mathrm{ff}$. fällt der Rückgang der Messen in die erste Hälfte des 14. Jahrhunderts; s. u. a. auch Pirenne, Geschichte Belgiens, I S. 300 f., II S. 65 u. a. - Höhlbaum, Hans. Urkdb. III n. 658 n. 1 S. 455 und mit ihm Goldschmidt, Universalgeschichte, S. 234 Note 176, meinen, daß der Verfall der Messen erst in die zweite Hälfte des 14. Jahrhunderts falle, da gerade seit der Mitte des 14. Jahrhunderts der deutsche Verkehr dorthin gestiegen sei. Doch haben die Deutschen für die Märkte der Champagne überhaupt niemals eine große Bedeutung gehabt. Die flandrische Hanse und die Genossenschaft - universitas der italienischen Kaufleute, die Träger des Handels auf den Messen, verlieren sich schon bis zur Mitte des 14. Jahrhunderts im Dunkel der Geschichte. Die Einkünfte aus den Messen waren um 1340 stark gesunken (Bourquelot, II 308). Die von Bourquelot mitgeteilten Versuche der Reorganisation der Messen zeigen, daß der Meßverkehr nicht mehr auf der alten Höhe war, auch die Privilegien an die Deutschen (Hans. Urkdb. III n. 32 und 152), 1344 und 1349, dürften Versuche zur Wiederbelebung der Messen darstellen.

$\left.{ }^{20}\right)$ Bourquelot, I 190 ff.; II 301 ff., Finot, Étude historique sur les relations commercielles entre la France et la Flandre au moyen-âge, Paris 1894, u. a. S. 62 f.; Goldschmidt, Universalgeschichte des Handelsrechts, S. $234 \mathrm{f}$. 
portes durch den Kontinent von der flandrischen Nordseeküste bis zu den südfranzösischen Häfen oder gar über die Alpenpfade bis zur Lombardei offenbar sehr viel schwerer zu tragen als die kostbaren, weniger voluminösen Fabrikate der flandrischen Tuchindustrie. Für die Durchquerung des Kontinents von der atlantischen Küste zur Mittelmeerküste wurde bei Transporten von solchen Massengütern wie Wolle vorzugsweise der Isthmus zwischen Spanien und Frankreich gewählt, der schon im 13. Jahrhundert eine wichtige Durchgangsstraße gebildet hatte und auf deren Verkehr zum Teil die Bedeutung von Rochelle ${ }^{21}$ ) und Bayonne ${ }^{22}$ ) und wahrscheinlich auch die Blüte von Cahors beruhte. Vom flandrischen Weltmarkte wurde die Wolle zur See bis zur Mündung der Garonne gebracht und von dort über die Landenge nach einem französischen Hafen befördert, wo sie wieder zu Wasser weiter nach Italien verladen wurde. Pegolotti erwähnt in seinem Anfang der dreißiger Jahre des 14. Jahrhunderts geschriebenen Werke nur diese Straße als den Weg, auf dem die englische Wolle von Brügge nach Florenz gelangte ${ }^{23}$ ), und bezeugt damit zum mindesten, daß die Wolltransporte hauptsächlich auf diesem Wege den toskanischen Wollindustriestädten zugingen.

Indessen war dieser Weg nicht die einzige Route, auf welcher Italien Wolladungen bezog. Schon im 13. Jahrhundert sehen wir die Schiffahrt des Mittelmeeres sich in Sevilla mit derjenigen des atlantischen Gebietes berühren ${ }^{24}$ ). Schon damals mögen

$\left.{ }^{21}\right)$ S. Kaufleute von Toulouse auf der Flotte von Rochelle nach Flandern 1226; s. oben S. 75 Note 188.

$\left.{ }^{22}\right)$ Bayonner Kaufleute als regelmäßige Besucher der Märkte von Toulouse und Montpellier, s. J. Balasque, Études historiques sur la ville de Bayonne, Bayonne 1862, Bd. II, S. 344 und 674.

23) Doren, a. a. O. S. 108. Libourne an der Dordogne gibt Pegolotti als den Hafen an, wo die Wolle ausgeschifft wurde, Aigues Mortes in der Provence, wohin sie über Montpellier gelangte, als den Hafen der Wiedereinschiffung.

${ }^{24}$ ) Schon seit 1239 sind in Sevilla genuesische Kaufleute nachweisbar (s. Goldschmidt, Universalgeschichte des Handelsrechtes, S. 185, Note 151 Nr. 1). Bayonner Kauffahrer in Sevilla im 13. Jahrhundert, s. oben S. 76 und Note 190 daselbst. Neben den flandrischen und französischen Tuchen erwähnt die S. 35, Note 18, angeführte Urkunde auch Gewebe von Lucca, Montpellier, Syrien usw. auf dem Markte von Sevilla. 
Waren auf diesem Wege über die Zwischenmärkte des Südens der iberischen Halbinsel zwischen den Mittelmeerländern und Flandern ausgetauscht worden sein. Größere Bedeutung gewann dieser Verkehr indessen erst, seitdem im Anfange des 14. Jahrhunderts venetianische Galeeren und genuesische und katalonische Karakken die direkte Schiffahrt von den Häfen des Mittelmeeres nach Flandern aufnahmen ${ }^{25}$ ). Der Seeweg bot für die Beförderung von Massenartikeln vor dem Landwege zweifellos große Vorteile; selbst einen so wertvollen Rohstoff wie die englische Wolle sehen wir zu einem sehr erheblichen Teil diesen Wasserweg wählen. Indessen waren die Schwierigkeiten, welche bei diesen Seereisen um Spanien herum zu überwinden waren, zu einer Zeit, als die nautischen Hilfsmittel noch dürftigster Art waren ${ }^{26}$ ) und die Schiffer im wesentlichen auf Landmarken und auf die örtliche Kenntnis des Meeres und seiner Strömungen angewiesen waren ${ }^{27}$ ), so groß, daß der neue Seeweg den Landverkehr keineswegs zu verdrängen vermochte. Noch um die Mitte des 15. Jahrhunderts gibt Uzzano die Höhe der Assekuranzprämie für den Transport von Brügge

$\left.{ }^{25}\right)$ S. Heyd, Geschichte des Levantehandels, II $708 \mathrm{ff}$. Die Belege s. bei Gilliodts van Severn, Cartulaire de l'ancienne Estaple de Bruges, 190', I.

${ }^{26}$ ) Der Kompaß war in jener Zeit allerdings lange in Gebrauch. Schon der englische Gelehrte Neckam, der 1157-1217 lebte und in England und Paris tätig war, berichtet über den Gebrauch des Kompasses durch die Seefahrer; s. Schück. Die Kompaßsage in Europa (Flavio Gioja), die ersten Erwăhnungen desselben dortselbst und nationale Ansprüche an seine Erfindung (Separatabdruck aus "Ausland“ 1892, Nr. 35-39), S. 8 ff. Die Einrichtung des Magneten war freilich wohl noch sehr primitiv. Die syrischen Seeleute des 13. Jahrhunderts steckten eine Nadel quer durch ein Holzstäbchen oder einen Halm, so daß beide ein Kreuz bildeten und legten dieses Kreuz in ein Gefä $B$ mit Wasser; die Nadel wurde durch das Stäbchen an der Oberfläche getragen; sodann wurde die Nadel mit einem Magnetstein magnetisiert und richtete sich nach Norden; s. Schük, Hat Europa den Kompaß über Arabien erhalten oder hat ihn Arabien von Europa erhalten? (Separatabdruck aus „Ausland“ 1892, Nr. 8-10).

27) Noch im 15. Jahrhundert scheinen es spanische Lotsen der Insel Majorka gewesen zu sein, welche die italienischen Schiffe durch die Straße von Gibraltar in den Atlantischen Ozean führten; vgl. Finot, Étude historique sur les relations commerciales entre la Flandre et l'Espagne au moyen-âge, Paris 1899, S. 205 ff. 
nach Pisa bei Benutzung des Seeweges auf 12 bis $15 \%$ und bei Benutzung des Landweges auf 6 bis $8 \%$ an; die Gefahr des Seeweges war also noch doppelt so groß wie die des Landtransportes ${ }^{28}$ ). Es ist bezeichnend, daß Venedig, um seinen Galeeren in Flandern genügende Frachten zu sichern, seit 1331 die Wolle, die ihm von Flandern auf dem Landwege zuging, alljährlich bis zur Rückkehr der Flotten mit einem Zollzuschlag von $25 \%$ und nach Rückkehr der Galeeren mit einem Zuschlag von $3 \%$ zu belegen pflegte ${ }^{29}$ ).

Neben diesen Handelswegen ist noch eine weitere Straße nach dem Süden erwähnenswert, welche im 14. Jahrhundert neben den älteren Handelswegen durch Frankreich in den Vordergrund tritt. Mit dem 14. Jahrhundert zeigen nämlich die Verbindungen Flanderns mit den süddeutschen Handelsplätzen eine merkliche Verstärkung; Kaufleute der süddeutschen Städte, insbesondere die Nürnberger, erscheinen auf den flandrischen Märkten, der große Verkehr, welchen die süddeutschen Städte mit Italien, namentlich mit Venedig, über die Alpenpässe unterhielten, wird nunmehr auch für den flandrischen Warenverkehr von größerer Bedeutung; sowohl deutsche, als auch italienische Kaufleute sehen wir auf diesen Wegen Waren zwischen Italien und Flandern austauschen ${ }^{30}$ ). Vor-

$\left.{ }^{28}\right)$ S. Goldschmidt, Universalgesch. des Handelsr., S. 368 Note 105.

$\left.{ }^{29}\right)$ Gilliodts van Severn, Estaple de Bruges I, n. 239; das Dekret wiederholt sich jedes Jahr bis 1359 und ist auch noch später wieder erneuert worden.

$\left.{ }^{30}\right)$ Vgl. Schulte, Geschichte des mittelalterlichen Handels und Verkehrs zwischen Westdeutschland und Italien mit Ausschluß von Venedig, Leipzig 1900. Bd. II. Urkunden n. 188 (schon 1222 Kaufleute von Lille bei Como beraubt), n. 11, 400, 38; ferner Simonsfeld, Der Fondaco dei Tedeschi in Venedig und die deutsch-venetianischen Handelsbeziehungen, Stuttgart 1887, Bd. I, Urkunden n. 101, 133, 149, 155, 171, 176, 191, 200, 204, 207, 215. S. auch ebenda S. 69 und Note 7 daselbst. Über die Nürnberger in Brügge vgl. Daenell, Die Blütezeit der Hanse, I S. 23. Nürnbergs Beziehungen reichten auch weit nach dem Osten. Eine Kaufmannsstraße von Breslau nach Flandern führte über Nürnberg, Hans. Urkdb. III S. 276 f, Note 3. Der Rhein als Handelsstraße für von Polen, von Breslau, von Böhmen kommende Waren s. den kölnischen Zolltarif, Hans. Urkdb. III n. 545, 1 b Ziff. 43; 2 Ziff. 42; Nürnberger, Italiener usw. in Köln, ebenda 2 Ziff. 43, 44; 1b Ziff. 4 4. 
wiegend sind es natürlich die besonders kostbaren, leicht transportablen Waren gewesen, für welche dieser Weg gewählt wurde; aber auch die englische Wolle wird nicht selten unter diesen Waren erwähnt ${ }^{31}$ ), wie denn übrigens auch die Wege durch Frankreich über die Alpen nach Italien auch im 14. Jahrhundert für Sendungen englischer Wolle nicht unbenutzt geblieben sind ${ }^{32}$ ).

Alle diese Wege setzten voraus, daß der italienische Kaufmann nicht mehr die Märkte der Champagne, sondern Brügge zum Einkauf der Wolle aufsuchte. Was die Märkte der Champagne verloren, gewann somit Brügges Handel. Brügge wurde nunmehr zum ersten Stapelplatz auch der italienischen Kaufleute. Die Wege, welche Frankreich nicht berührten, boten den Italienern den Vorteil der Unabhängigkeit von den französischen Zwischenmärkten, ein Vorzug, der um so größer zu veranschlagen war, je mehr die Wolldurchfuhr durch Frankreich erschwert wurde.

Die tiefgreifenden Veränderungen, welche der Austausch Flanderns mit den Mittelmeerländern und dem Oriente erfuhr, waren für Flandern im ganzen von Vorteil. Brügges Handel erfuhr durch die Ausschaltung der französischen Zwischenmärkte einen bedeutenden Aufschwung; seine Verkehrsbeziehungen umfaßten auf der einen Seite Asien und die afrikanischen Küsten, auf der andern ganz Europa vom äußersten Norden bis zum Mittelmeer ${ }^{33}$ ). Die Waren der ganzen damals bekannten Welt trafen auf dem Brügger Markte zusammen ${ }^{34}$ ).

Über die Straße Venedig-Basel-Straßburg-Frankfurt-Mainz-Köln s. Hanserezesse I n. 226 am Schluß.

$\left.{ }^{31}\right)$ Schulte, Bd. II n. 24, 28, 20, 347 Ziff. 5, 191, auch S. 131.

$\left.{ }^{32}\right)$ Vgl. Schulte, Bd. II n. 3, 6, 39. Die Mailänder bringen die englische Wolle zur See nach Harfleur, von dort die Seine hinauf nach Paris; weiter an den Hafenplatz der Saone Saint-Jean de Losne n. 39. Auf der Bedeutung der Seine als Handelsstraße für den Verkehr beruht es, daß die Pariser Messen im 14. Jahrhundert nicht, wie die Messen der Champagne, untergehen.

${ }^{33}$ ) Vgl. das Verzeichnis der Länder, deren Produkte man in Brügge antraf, Hans. Urkdb. S. 419 Note 1.

${ }^{34}$ ) S. die Waren der verschiedenen Länder in dem in der vorigen Note erwähnten Verzeichnisse. Vgl. für den Verkehr mit dem Süden 
Der Nachteil, den die Konkurrenz der italienischen Tuchfabrikation dem Absatze der flandrischen Industrie im Mittelmeer und Orient brachte, wurde durch den vermehrten Absatz in andern Gegenden, vor allem im Norden, aufgehoben.

Die Steigerung der Beziehungen des flandrischen Weltmarktes zum Süden hatte naturgemäß auch eine Vergrößerung des Absatzes der Erzeugnisse des Nordens daselbst und damit eine Vermehrung des Handelsverkehrs mit dem Norden Europas, dessen Träger die Deutschen waren, zur Folge. Die Mitte des 14. Jahrhunderts ist deshalb die Zeit der höchsten Blüte sowohl Brügges, als auch des Handels der hansischen Kaufleute, der auch während dieses Zeitraumes gradeso wie im 13. Jahrhundert seinen Mittelpunkt in dem brüggischen Weltmarkte hatte.

Für die deutschen Kaufleute bildete auch während dieser ganzen Zeit der baltisch-flandrische Austausch das Rückgrat ihres Handelsverkehrs. Noch immer war der russische Handel mit Pelzen und Wachs auf der einen Seite und der Handel mit Wolltuchen vornehmlich aus Flandern auf der andern Seite der eigentliche Grundpfeiler dieses Verkehrs ${ }^{35}$ ). Noch immer gelang es den Deutschen, alle fremden Elemente von diesem Verkehr fernzuhalten ${ }^{36}$ ), und nach wie vor war dieser Verkehrs-

auch die Verordnung Brügges von 1304 über den Spezereihandel, Hans. Urkdb. III n. 624: Zucker von Malaga, Damaskus, Venedig, Babylonien (?), Alaun, Reis, Süßholz, Kümmel, spanische Wolle, Buchsbaumholz, Zinn, Quecksilber, Galläpfel, Schwefel, spanische Schminke (?), Garn, Papier, Baumwollgarn, Baumwolle, Rosinen von Korinth und von Malaga, spanisch Grün, Zinnober, spanisches Wachs (Siegellack?), Öl von der Bai usw.

${ }^{35}$ ) Vgl. u. a. die Bedeutung dieser Waren in den Urkunden des Hans. Urkdb. III n. 69, 564, 584-598; über die Bedeutung von Wachs und Salz als Handelsartikel in Pskow s. Hans. Urkdb. II n. 631. - Wie die Lakenzufuhr nach Nowgorod so gut wie ausschließlich von Brügge aus sich vollzog, lassen die Urkunden von 1354, 1355 und 1358, Hans. Urkdb. III n. 596, 597 und 598 deutlich erkennen. Daneben treten als Gegenstand der russischen Ausfuhr namentlich Korn, als Gegenstand der Einfuhr namentlich Salz und Wein, auch wohl Hering, hervor. S. die umgearbeiteten rigischén Statuten bei Napierski, Quellen des rigischen Stadtrechtes, S. 197, § 3 (Windegeld).

${ }^{36)}$ Etwa 1350 wird einem Lombarden, der nach Nowgorod kommt, der Zutritt zu dem deutschen Hofe verweigert, Hans. Urkdb. III n. 180; 
zug ausgesprochen auf Brügge gerichtet. Der russische Handel lag ganz überwiegend in den Händen der Ostseestädte; neben Lübeck sind namentlich auch die Kaufleute der wendischen Städte, insbesondere Stralsunds und Rostocks ${ }^{37}$ ), in dieser Zeit in Nowgorod nachweisbar; sie nahmen wahrscheinlich an dem russisch-lübischen Handelszuge nicht nur als Kaufleute, sondern auch als Reeder einen nicht zu unterschätzenden Anteil, der auch für die Interessengemeinschaft dieser Städte mit Lübeck nicht ohne Bedeutung gewesen sein dürfte; die westfälischen und binnensächsischen Kaufleute mögen auch in diesem Zeitraum noch in Nowgorod häufiger verkehrt haben; von den Nordseestädten kamen nur Hamburg und Stade in Frage, denn die Bürger niederländischer Städte wurden dort wahrscheinlich überhaupt ${ }^{38}$ ) nicht zugelassen, und Bremen hatte während der ersten Hälfte des 14. Jahrhunderts keinen Anteil an den Privilegien der Deutschen im Auslande. Unter den Ostseestädten überragte Lübeck natürlich alle andern in diesem Verkehr weit; bedeutenden Einfluß behauptete noch immer auch Wisby auf den Hof zu Nowgorod. Lübeck und Wisby übten gemeinsam eine Kontrolle des Hofes zu Nowgorod aus; sowohl das Ant des Oldermannes als auch das des Priesters zu Nowgorod war ausschließlich den Angehörigen von Lübeck und Wisby vorbehalten; nur den beiden Vormächten Lübeck und Wisby war der Oldermann des Nowgoroder Hofes Rechnung schuldig ${ }^{39}$ ). Neben Lübeck und Wisby strebten indessen immer heftiger auch die livländischen Städte, an ihrer Spitze Riga, nach der Vorherrschaft im russischen Handel, indem sie den Verkehr nach Nowgorod ausschließlich über ihre Häfen zu leiten und die übrigen Handelswege dorthin zu schließen suchten ${ }^{40}$ );

wiederholt dringt der Hof von Nowgorod bei dem deutschen Kontor in Brügge darauf, daß im Verkehre mit Rußland die Handelsgenossenschaft mit Flandern verhindert werde, ebenda S. 141, Note 1 und n. 321.

${ }^{37}$ ) Stralsunder in Nowgorod 1305, Hans. Urkdb. II n. 67; Rostocker daselbst etwa 1350, Hans. Urkdb. III n. 180.

$\left.{ }^{38}\right)$ S. unten S. $191 \mathrm{ff}$. und S. $272 \mathrm{ff}$. In Frage kommen könnten höchstens Deventer, Zütphen, Harderwijk und Elburg, s. unten S. 276 und Note 96 daselbst.

$\left.{ }^{39}\right)$ Winkler, Die deutsche Hansa in Rußland, Berlin 1886, S. 21 f.

${ }^{40}$ ) Winkler, a. a. O. S. 34 . 
1346 verbot das Kontor zu Nowgorod die Reisen mit Waren zu Pferde von Preußen oder von Schweden aus nach Nowgorod; nur über Riga, Reval und Pernau sollte die Ansegelung erfolgen dürfen ${ }^{41}$ ). Riga setzte es im Jahre 1363 endlich durch, daß ihm an der Einsetzung der Ältermannes neben Lübeck und Wisby Anteil gewährt und ein Schlüssel zu der Kiste, in der die Überschüsse des Kontors aufbewahrt wurden, zugestellt wurde, wie ihn Lübeck und Wisby hatten ${ }^{42}$ ). Um dieselbe Zeit wurde dem Hofe der Deutschen in Nowgorod von neuem eingeschärft, daß in Nowgorod kein Statut ohne vorgängige Genehmigung der Städte Lübeck und Wisby und der drei livländischen Städte Riga, Dorpat und Reval zustande kommen dürfe $\left.{ }^{43}\right)$. Auch wurde auf das Drängen der Livländer seit 1363 das Amt des Oldermannes zu Nowgorod wieder allen Kaufleuten zugänglich $\left.{ }^{44}\right)$.

Neben Rußland spielte Schweden nur eine bescheidene Rolle im Handel des baltischen Gebietes. Aber auch in Schweden lag die Ausfuhr ganz in Händen deutscher Kaufleute ${ }^{45}$ ). Auch in diesem Lande waren Handel und Gewerbe noch ganz unentwickelt, an Städten war das Land noch arm; in den wichtigsten Städten, welche es aufzuweisen hatte, bildeten die Deutschen die Mehrzahl der Einwohner. Die Hälfte der Ratsstellen war in manchen Städten den Deutschen vorbehalten. Der schwedische Handel war im Verhältnis zu dem russischen, dem schonenschen, dem preußischen allerdings unbedeutend; Kupfer und Eisen waren die wichtigsten Ausfuhrartikel des Landes. Neben diesen Bergwerksprodukten war als Erzeugnis der ausgedehnten Milchviehzucht Schwedens namentlich Butter in der Ausfuhr erwähnenswert ${ }^{46}$ ), auch schwedisches Pelzwerk wird gelegentlich in den Urkunden erwähnt ${ }^{47}$ ).

41) Hans. Urkdb. III n. 69.

42) Hanserezesse I n. 296 Ziff. 14; Hans. Urkdb. III n. 563.

43) Hans. Urkdb. III S. 360.

$\left.{ }^{44}\right)$ Hanserezesse I 1 n. 296.

$\left.{ }^{45}\right)$ S. über das Folgende Schäfer, Die Hansestădte und König Waldemar, S. 278; Daenell, Die Blütezeit der deutschen Hanse I S. 23 ff.

$\left.{ }^{46}\right)$ Wendt, Lübecks Schiffs- und Warenverkehr in den Jahren 1368 und 1369, Lübeck 1902, S. 58-60.

${ }^{47}$ ) Hans. Urkdb. III n. 63. 
Eine wesentlich größere Bedeutung als dem schwedischen Handel wohnte im 14. Jahrhundert dem Warenverkehr Preußens inne. Schon in den dreißiger Jahren des 13. Jahrhunderts waren an der Weichsel als deutsche Städte Kulm, Thorn und Elbing, in den fünfziger Jahren Königsberg am Pregel entstanden; im Anfange des 14. Jahrhunderts erwarb der Deutsche Orden auch Pommerellen, insbesondere war Danzig seit 1308 in seinem Besitz ${ }^{48}$ ). Preußens Handelsverbindungen reichten landeinwärts tief in den Kontinent bis in den Orient hinein. Von Thorns Handelsverbindungen mit Breslau, Plock und Sandomir, mit Krakau, Lemberg, Ungarn, Ruthenien, Südrußland geben zahlreiche Urkunden Nachricht ${ }^{49}$ ). Pelzwerk, Wachs, Seide, Pfeffer, Spezereien sehen wir von Wladimir, Lemberg und dem Oriente nach Thorn gehen ${ }^{50}$ ). Aus Ungarn wird über Krakau schon 1311 Kupfer nach Thorn exportiert ${ }^{51}$ ). 1301 werden Kulmer Bürgern 4000 Stück Pelzwerk und 10 Zentner Kupfer im Weichsellande geraubt ${ }^{52}$ ). Der Bestimmungsort dieser Waren kann nicht zweifelhaft sein; sie wandern nach dem brüggischen Weltmarkte weiter, wie schon die Herkunft der Waren, welche über Preußen dafür in das Innere des Kontinents eingeführt werden, verrät. Poperingische.

48) Hirsch, Handels- und Gewerbsgeschichte Danzigs, S. 7; Schäjer, Die Hansestädte und König Waldemar, S. 16.

49) Über Thorns Beziehungen nach Breslau s. Hans. Urkdb. III n. 147, 231, 532, 533, 542, 559, 674; nach Plock III n. 171, 227; nach Sandomir III n. 147, 156, 631; nach Krakau II S. 47, Note 2 und n. 236 und S. 195; III n. 59, 156, 532, 533, 631; nach Lemberg II n. 690, III n. 559; nach Ungarn II S. 47, Note 2 und 195, Note 1; III n. 156; nach Ruthenien III n. 159, 347; nach Südrußland II n. 371; nach Rußland III n. 351 ; nach Wladimir III n. 147, 559. Vgl. auch Hirsch, Danzigs Handelsund Gewerbsgeschichte, S. 172 ff.; Sattler, Handelsrechnungen des Deutschen Ordens, Leipzig 1887, Einl., S. 32 ff.

$\left.{ }^{50}\right)$ Hans. Urkdb. III n. 559.

$\left.{ }^{51}\right)$ Hans. Urkdb. II S. 47, Note 2; S. 195, Note 1; III n. 156. Eine andere Handelsverbindung Ungarns mit Flandern ging über Süddeutschland den Rhein hinab; 1344 sichert der König von Ungarn den Bürgern von Köln, Huy und den rheinischen Gegenden das Recht zu, daß sie nicht höhere Zölle bezahlen sollen, als die Kaufleute von Böhmen und Mähren, Hans. Urkdb. III S. 23, Note 1.

52) Hans. Urkdb. II n. 136. 
brüggische und andere flandrische Tuche sehen wir nämlich die Rückfracht bildẹn von Thorn nach Krakau ${ }^{53}$ ), Breslau ${ }^{54}$ ), Wladimir ${ }^{54}$ ) und Lemberg ${ }^{54}$ ). Krakauer Kaufleute begegnen uns 1311, über die Weichselmündung von Flandern kommend, auf dem Wege von Thorn nach ihrer Heimatstadt mit Waren ${ }^{55}$ ). 1324 verlieren Bürger von Breslau und Wladimir in einem bei Rügen strandenden Schiffe flandrische Tuche von Ypern, Dornik und Poperingen ${ }^{56}$ ); etwa 1360 haben Breslauer Bürger eine Ladung flandrischer Tuche in einem bei Helsingborg gestrandeten Schiffe geladen gehabt, und Danzig wird von Breslau um Unterstützung dieser Kaufleute bei der Wiedererlangung der Tuche ersucht ${ }^{57}$ ). Neben Tuchen gehen nach Wladimir und Lemberg ${ }^{58}$ ) von Thorn Biber- und Otternfelle, Wolfspelze, Lammfelle, Leinen, Heringe, nach Breslau Feigen, Öl, Spezereien, Heringe und andere Fische, während andererseits von Breslau, das auch über Prag mit Süddeutschland, insbesondere mit Nürnberg, sowie mit Italien und Flandern in Verbindung stand $\left.{ }^{59}\right)$, u. a. Wein, Spezereien, Barchent, Leinen und Hopfen nach Thorn gelangten. Die Produkte, welche wir über Lemberg und Wladimir Thorn zugehen sehen, spielten, wie es scheint, unter den Einfuhrartikeln der Preußen im Westen eine bemerkenswerte Rolle ${ }^{60}$ ). In dem Zollprivileg, welches die Preußen 1340 gemeinsam mit den Westfalen für ihre Durchfuhr durch Holland erwerben ${ }^{61}$ ), stehen an erster Stelle Pelzwerk, Wachs und Kupfer; neben ihnen werden die Produkte der Viehzucht, Schmalz und Butter, Häute, Felle von Schafen, Lämmern und Ziegen, auch Wolle, ferner die Waldprodukte Asche, Pech, Teer und Rauchwaren, worunter die Felle von Rehen, Hirschen und Hasen verstanden werden, endlich Bernstein und Stör-

$\left.{ }^{53}\right)$ Hans. Urkdb. III n. 59.

${ }^{54)}$ Ebenda n. 559 (Zolltarif aus der Mitte des 14. Jahrhunderts).

$\left.{ }^{55}\right)$ Hans. Urkdb. II S. 47, Note 2.

${ }^{86)}$ Ebenda n. 416, 420.

$\left.{ }^{57}\right)$ Ebenda III n. 536.

$\left.{ }^{58}\right)$ Ebenda n. 559.

$\left.{ }^{59}\right)$ Ebenda n. 506, Note 3; über den Verkehr der Nürnberger mit Flandern s. ebenda S. 29' , Note 4.

$\left.{ }^{80}\right)$ Ebenda n. 559.

61) Ebenda n. 658. 
fische, von gewerblichen Produkten nur Bier erwähnt. Der preußische Ausfuhrhandel beschränkte sich indessen keineswegs auf diese Waren. Wesentlich wichtiger für den Verkehr nach dem Westen waren die großen Überschüsse des Getreidebaues des preußischen Ordenslandes und seiner Hinterländer und die unermeßlichen Holzmassen, welche die ausgedehnten Waldungen Polens und Rußlands lieferten ${ }^{62}$ ).

Preußens Handel hat während der ersten Hälfte des 14. Jahrhunderts einen sehr bemerkenswerten Umfang erreicht, wie die in den preußischen Städten erzielten Einnahmen aus dem Pfundzolle, welcher in den sechziger Jahren von den Städten zur Aufbringung der Kosten der Kriege gegen Dänemark erhoben wurde, beweisen. 1362 betrug der in den preußischen Seestädten in der Hauptsache ${ }^{63}$ ) von der Ausfuhr der Waren und der Werte der ausgehenden Schiffe erhobene Pfundzoll insgesamt 1170 Mark lübisch, während die Städte des Odergebietes Stralsund, Greifswald, Anklam, Stettin und Stargard zusammen eine Einnahme von 1695 Mark lübisch aufzuweisen hatten ${ }^{64}$ ). 1368 belief sich die Pfundzolleinnahme in den preußischen Städten auf 1494 Mark lübisch, in den vorerwähnten Städten des Odergebietes auf 1603 Mark lübisch. Wir ersehen daraus, daß der Handel der Ausfuhrhäfen des Weichselgebietes

$\left.{ }^{62}\right)$ Wie die weiterhin im Texte dargelegten Tatsachen erkennen lassen, ist die herrschende Annahme, daß die Getreide- und Holzausfuhr in der ersten Hälfte des 14. Jahrhunderts im Rahmen des preußischen Handels nur erst eine unbedeutende Rolle spielte, nicht richtig. Die Pfundzolleinnahmen beweisen insbesondere, daß der Handelsverkehr in Preußen schon einen bedeutenden Umfang erreicht hatte, der ohne ausgedehnte Holz- und Getreideausfuhr kaum denkbar ist. Aber auch die Bedeutung der niederländischen Reederei im preußischen Handel schon während dieser Zeit läßt deutlich erkennen, welche wichtige Rolle $\mathrm{Holz}$ und Getreide schon in der Ausfuhr Preußens in dieser Zeit gespielt haben müssen.

${ }^{63}$ ) Der Zoll wurde erhoben von den ausgeführten Waren nach dem Werte, sowie von den auslaufenden Schiffen nach dem Werte der Schiffe; außerdem von den eingeführten Waren, sofern sie nicht aus einer Hansestadt kamen und nicht als in einer solchen bereits verzollt nachgewiesen werden konnten.

${ }^{64)}$ Stieda, Revaler Zollbücher und Zollquittungen des 14. Jahrhunderts, Halle 1887, S. 27. 
in dieser Zeit zwar den Umfang des Handels der Ausfuhrhäfen des Odergebietes wohl noch nicht erreicht hatte, aber demselben doch schon ziemlich nahe gekommen war ${ }^{65}$ ).

Auch in diesem Zeitabschnitte hat die Straße zwischen Lübeck und Hamburg wohl die wichtigste Verbindung zwischen dem baltischen Gebiete und Flandern gebildet. Der Verkehr mit russischen Waren nach Flandern vollzog sich ganz vorherrschend auf diesem Wege, und auch für den Handel Schwedens und Preußens behauptete diese Verkehrsstraße eine hohe Bedeutung. In Preußen lag ein großer Teil des Geschäftsverkehrs in den Händen der Lübecker, die schon im 13. Jahrhundert dort festen Fuß gefaßt hatten ${ }^{66}$ ), und ebenso spielten die Lübecker in Schweden eine Hauptrolle. Die schwedischen Kupferbergwerke des Atvidaberges befanden sich teilweise in Händen lübischer Bürger ${ }^{67}$ ). Über den Verkehr mit schwedischen Waren über Lübeck fließen unsere Quellen zufällig etwas reichlicher. Im Jahre 1368 wurden in Lübeck Waren im Werte von 32396 M. 1. als von Stockholm, Süderköping und Kalmar eingeführt verzollt, darunter Butter im Werte von 11 774 1/2 M. I. 1369 betrug die aus diesen Städten stammende, in Lübeck verzollte Warenmenge $21849 \frac{1}{2}$ M. 1., wovon $46601 / 2$ M. l. auf Butter entfielen ${ }^{68}$ ). Auch Kupfer und Eisen befanden sich in nicht unerheblichen Mengen u. a. unter den eingeführten Waren ${ }^{68}$ ), wenngleich diese Bergwerkserzeugnisse natürlich in der Regel zu Schiffe durch den Sund und nur selten über den Landweg verfrachtet wurden. Auch in dieser Zeit liefen also die wichtigsten Fäden des auf Flandern gerichteten Verkehrs des ganzen Ostseegebietes in Lübeck zusammen, um von dort

${ }^{65}$ ) Allerdings werden die Werte der Schiffe, welche zur Verzollung kamen, in Preußen sehr viel größer gewesen sein als in den Oderhäfen. Vgl. auch Wendt, Lübecks Schiffs- und Warenverkehr 1368 und 1369, Lübeck 1902, S. 44. Utbrigens wurde 1368 nur der halbe Wert der Schiffe dem Zoll unterworfen.

$\left.{ }^{66}\right)$ S. oben S. 99 f., ferner Hirsch, a. a. O. S. 192 ; Sattler, Ordensrechnungen, Einl. S. 30; vgl. auch Hans. Urkdb. II n. 598; III n. 186, Note 1.

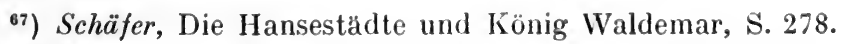

$\left.{ }^{68}\right)$ Wendt, a. a. O. S. $58-60$. 
durch den Isthmus über Hamburg nach Flandern weiterzuführen.

Indessen gewann in der ersten Hälfte des 14. Jahrhunderts doch auch schon der Weg durch den Sund nach Flandern eine merklich höhere Bedeutung als im 13. Jahrhundert. Wir haben schon im 13. Jahrhundert namentlich Erze oder Metalle, Getreide, Holz u. dgl. als Gegenstand der Verschiffung von Gotland, von Schweden, von den livländischen, polnischen und wendischen Städten durch den Sund nach Flandern kennen gelernt. Diese Verkehrsströmungen dauern im 14. Jahrhundert fort. Auf dem Markte von Brügge bilden gotländische Hölzer einen regelmäßigen Handelsartikel ${ }^{69}$ ). Das rigische Schiffrecht ${ }^{70}$ ) läßt als einen Hauptausfuhrartikel Korn erkennen, und die allerdings erst der zweiten Hälfte des 14. Jahrhunderts angehörenden Revaler Pfundzollbücher deuten darauf hin, daß auch diese Kornausfuhr wieder auf Flandern gerichtet war ${ }^{71}$ ). Von Stralsund ${ }^{72}$ ) geht $\mathrm{Holz}$ und Getreide, von Wismar und

$\left.{ }^{69}\right)$,Gothensche Sparren“" in der Maklerrolle für den Handel der Deutschen in Flandern von 1360, Hans. Urkdb. III n. 499; vgl. auch Hans. Urkdb. II n. 225: ein Schiff, das von Gotland ausgesegelt war, bei Skagen gestrandet, und ebenda III n. 6'2, Schiff eines Deutschen von Gotland bei Nieuport gescheitert.

$\left.{ }^{70}\right)$ S. Napierski, Quellen des rigischen Stadtrechtes, S. 197, §3.

$\left.{ }^{71}\right)$ S. die Revaler Pfundzollbücher und Quittungen, herausgegeben von Stieda, Halle 1887. Die Schiffe bringen Salz von Flandern nach Reval und nehmen als Rückfracht von Reval dorthin Roggen ein (mit solte in dem landen und mit roggen ut); vgl. n. 1353, 1363, 1379, 1381, 2129; ferner unter der Überschrift: ,, de ut Flandern quemen“ n. 1816 ff., sämtlich mit Salz; unter der Überschrift ,desse schepeden roggen wedder“ n. 1819 ff. Daß das Salz regelmäßig aus Flandern kam, s. n. 784, 875, 909, 995, 1089, 1090, 1353, 1806, 1809-1816, 2083, 2107, 2118, 2129, 2171, 2194, 2206, 2222. - Schiffe mit Roggen von Riga und Reval im Zwin um 1360, Hansarezesse I 3 n. 240, Ziff. 1d, 5, 6. - Beachtenswert ist übrigens, daß auch schon Pelzwaren zu Schiffe durch den Sund nach Flandern kamen, wenn auch die Hauptmasse dieses Verkehrs mit kostbaren Waren nach wie vor über Lübeck-Hamburg ging; vgl. z. B. Hans. Urkdb. II n. 725.

$\left.{ }^{72}\right)$ Vgl. Hansarezesse I 3 n. 240 Ziff. 5 No. 1 und 8. Stralsunds Verkehr durch den Sund war offenbar sehr viel größer als der von Rostock und Wismar, da Stralsund der Ein- und Ausfuhrhafen für das ganze Odergebiet war; vgl. Stettin als Stapelplatz für den Getreide- und Mehl- 
Rostock ${ }^{73}$ ) ebenfalls Getreide durch den Sund nach Flandern. Im 14. Jahrhundert beginnen nun die Getreide- und Holzverladungen Preußens wesentlich zur Verstärkung dieser Verkehrsströmung beizutragen.

Für die Ausfuhr dieser Waren bedurfte Preußen vor allen Dingen umfangreicher Schiffsräume. Nun hatten sich zwar Elbing, Braunsberg, Königsberg und Danzig als Verschiffungsplätze entwickelt ${ }^{74}$ ), und Schiffe dieser Heimatshäfen befuhren nicht nur die Ostsee, sondern auch die Nordsee; aber das Wachstum dieser preußischen Reederei vermochte offenbar nicht mit der Zunahme des Handels in diesen Erzeugnissen Schritt zu halten. Obwohl nämlich Preußens Schiffbau dank dem ungeheuren Holzreichtum seiner Hinterländer früh einen bedeutenden Umfang erreichte, standen der Entwicklung der eigenen Reederei des Landes doch, wie es scheint, gewisse natürliche Hemmnisse entgegen. Ostseeschiffahrt und Nordseeschiffahrt sind bis in unsere Zeit in ausgesprochenem Maße getrennt geblieben. Die Nordseeschiffahrt ist ungleich schwieriger und stellt sehr viel höhere Anforderungen an die Kenntnisse und Erfahrungen des Schiffers. Der Schifferbevölkerung des Ostseegebietes, die von Haus aus zunächst auf die sehr viel ungefährlichere und ganz anders geartete Fahrt auf dem Binnenmeere des Ostseebeckens, das nicht einmal Flut und Ebbe hat, angewiesen ist, fehlte offenbar die Schulung, die sich für die an der Nordseeküste beheimatete Schifferbevölkerung, deren natürliches Betätigungsfeld die Nordsee war, von Jugend auf alle Tage bot. $\mathrm{Zu}$ einer Zeit, wo die Schiffahrt außer auf Land-

handel auf der Oder, Jasnitz und im Frischen Haff, Hans. Urkdb. II S. 87 Note 3 ; über die Schiffahrt zwischen Stettin und Frankfurt a. O. s. Hans. Urkdb. III n. 302 und II n. 413. Charakteristisch ist, daß Rostock, wie das Handlungsbuch Johann Tölners n. 171 und 193 zeigt, die flandrischen Waren zum Teil von Lübeck oder von Stralsund bezog; vgl. auch Hans. Urkdb. III n. 474.

${ }^{73}$ ) S. oben S. $49 \mathrm{ff}$.

74) Für Elbing Hans. Urkdb. III n. 55 ł und S. 310, Anm. 2; Elbings Verkehr nach Flandern, ebenda n. 368 Note 1, 385, 386, 410, 527; nach England n. 685. Braunsbergs Verkehr nach Flandern III n. 410, 527 und Note 2. Königsbergs Verkehr mit Flandern III n. 410, mit London n. 373,375 . 
marken im wesentlichen auf die Gestirne, bei bedecktem Wetter auf eine ganz unzureichende Magnetnadel ${ }^{75}$ ) und im übrigen auf das Lot angewiesen war, muß die örtliche Kenntnis des Meeres noch eine ganz andere Bedeutung als heute bei der Seefahrt gehabt haben. Es ist also nur natürlich, daß einerseits in den preußischen Seestädten dauernd Mangel an Schiffern und Seeleuten herrschte, welche in der Lage waren, die schwierige Fahrt durch Skagerrak, Kattegat und Nordsee zu vollführen, und daß wir andererseits von je her an dem Schiffsverkehre der Ostseeländer nach Flandern besonders stark die Reedereien von Nordseehäfen beteiligt finden, wie denn auch der preußische Schiffsbau zu einem erheblichen Teile nicht für die preußische Reederei, sondern für Nordseehäfen arbeitete $\left.{ }^{76}\right)$. Wir haben bereits im 13. Jahrhundert die Schiffe vor allem der lübeckischen, aber auch der hamburgischen Niederlassung am Zwin den Verkehr der Ostseeländer nach der Nordsee unterhalten sehen; schon damals gehörte auch die Fahrt von dem noch polnischen Weichselgebiete nach Flandern zu den regelmäßigen Reiserouten der lübeckischen Schiffe ${ }^{77}$ ). Neben ihnen finden wir früh auch die niederländischen, namentlich die süderseeischen Schiffe am Verkehre in der Ostsee beteiligt ${ }^{77}$ ). In der die Zölle und Rechte der Umlandsfahrer auf Schonen regelnden Urkunde von $1251^{78}$ ) wird ausdrücklich auch der Fall behandelt, daß diese Umlandsfahrer von Schonen aus nicht nach der Nordsee hin, sondern in die Ostsee Fahrten unternehmen; für diesen Fall ist der Zoll niedriger bemessen. Schon damals bildete also Schonen für diese Umlandsfahrer, unter welchen wir vor allem die Süderseeer zu verstehen haben, einen Ausgangspunkt für ihre Schiffahrt ins Baltische Meer, einen Stützpunkt für den Verkehr zwischen Ostsee und Nordsee. Bis Schonen reichte die Ostseeschiffahrt. Sobald Nordseeschiffe

${ }^{75)}$ Vgl. S. 146 oben, Note 26.

$\left.{ }^{76}\right)$ Hirsch, Handels- und Gewerbegeschichte Danzigs unter der Herrschaft des Deutschen Ordens, Leipzig 1858, S. 125, 129, 134, 268.

$\left.{ }^{77}\right)$ S. oben S. 49 ; süderseeische Schiffe schon im 13. Jahrhundert am Verkehr der Oderhäfen beteiligt, s. oben Note 72 zu Kapitel 1; vgl. unten S. 159 und Note 80 daselbst.

${ }^{78)}$ Hans. Urkdb. I n. 411, 413. 
Schonen besuchten, bot sich hier eine günstige Beförderungsgelegenheit vom baltischen Gebiete nach dem Westen und umgekehrt für Waren, die wegen ihrer Massenhaftigkeit oder ihres schweren Gewichts nicht über die Verbindungsstraße Lübeck-Hamburg gehen konnten. Daß z. B. die Ostseeschiffe das Salz, welches die Nordseeschiffe vom Westen nach Schonen brachten, von dort, soweit es nicht zum Einsalzen der Heringe auf Schonen verbraucht wurde, in ihre Heimatsstädte, die überall der Einfuhr von Salz bedurften, mitnahmen, liegt sehr nahe; auf der andern Seite mögen die Nordseeschiffe in Schonen von den Ostseeschiffen früh Holz und andere Massenartikel des Ostseegebietes zur Weiterbeförderung übernommen haben. Daß die Nordseeschiffe von Schonen aus alsbald auch an der Ostseeschiffahrt teilnehmen, kann nicht wunder nehmen, da den Nordseeschiffern und ihren starken Fahrzeugen die Befahrung der Ostsee keine großen Schwierigkeiten bieten konnte. So erwuchs aus der Fahrt der Niederländer nach Schonen früh auch deren Schiffahrt in das baltische Gebiet selbst ${ }^{79}$ ). Von 32 im Jahre 1294 aus der Ostsee kommenden, nach Flandern bestimmten und nach England verschlagenen Schiffen waren mindestens die Hälfte in den Niederlanden oder Friesland beheimatet; es befanden sich darunter, 8 Stavorner, 2 oder 3 Kampener, 1 Harderwijker Schiff ${ }^{80}$ ). Unter den 1295 nach Skardeburg in England verschlagenen Schiffen waren wiederum 6 Stavorner und ein friesisches Schiff mit Holz, Pech, Asche und Hering, also Ladung, deren Herkunft auf das Ostseegebiet hinweist ${ }^{80}$ ). Unter $11 \mathrm{im}$ gleichen Jahre nach Newcastle verschlagenen Schiffen, die nach Flandern und Holland bestimmt waren, zählen wir 3 Stavorner, 6 Stralsunder und 2 Lübecker Schiffe mit Holz, Pech, Teer, Leinen und Häuten ${ }^{80}$ ). Deutlicher vermögen wir im 14. Jahrhundert zu erkennen, welch wichtigen Platz die süderseeische und holländische Schiffahrt in dem Verkehre von den Ostseestädten nach Flandern hat. Von den sieben Sendungen, über welche das Handlungsbuch Johann

${ }^{79}$ ) S. insbesondere Overijsselsche Stad, Dijk en Markeregten, I Deel, I Stuck, Boeck van Rechten der Stad Kampen. Dat Gulden Boeck, Zwolle 1875 I S. 31, 55.

$\left.{ }^{80}\right)$ Kunze, Hanseakten aus England n. 16. 
Tölners in Rostock aus den Jahren 1345 bis 1350 Aufschluß gibt, kommen zwei mit Kampener, eine mit einem Harderwijker Schiffe ${ }^{81}$ ). Kampener Schiffe unterhielten Fahrten von Riga, Reval und Pernau, von Stockholm, von Gotland, von Preußen, von den wendischen Städten und von Lübeck nach Schonen ${ }^{82}$ ). Wiederholt zeigen uns die Urkunden Kampener Schiffe in der Fahrt von der Ostsee nach Flandern ${ }^{83}$ ). 1363 werden 4 Koggen von Kampen und 1 von Harderwijk mit Stralsunder Ladung bei Bohus im Skagerrak beraubt ${ }^{84}$ ). Wir erfahren von Beziehungen auf Schonen aufhältlicher Kampener zu Elbing ${ }^{85}$ ). Aus einem Beschlusse der Schöffen und des Rates von Kampen von 1364 ersehen wir, daß die Kampener ,,vom Osten und vom Wendenlande" her Tonnen, vom Westen Wein und Salz nach Schonen zu bringen pflegten ${ }^{86}$ ), und ebenso enthält das allerdings wohl erst aus späterer Zeit stammende Kampensche Goldene Buch bei der Regelung der Rechenschaftsablage besondere Bestimmungen für den Fall, daß der Kaufmann von Schonen aus in ferne Lande ostwärts oder westwärts segelt und vor Pfingsten des nächsten Jahres nicht wieder nach Haus kommen kann ${ }^{87}$ ). Die Kampener stehen in diesem Schiffahrtsbetriebe allen voran; aber auch andere Niederländer finden wir an diesem Verkehre beteiligt. Harderwijker und Zütphener sehen wir Hölzer von Hiddensöe und vom Gellen holen ${ }^{88}$ ). 1335 wird ein Enkhuizener Schiff mit Holzladung im Sund erwähnt ${ }^{89}$ ). Amsterdamer Schiffe unterhalten

${ }^{81}$ ) Die vierte Sendung kommt mit einem Stralsunder Schiffe; bei den übrigen drei Sendungen ist der Heimatshafen des Schiffes nicht angegeben; zum Teil kommen diese letzterwähnten Sendungen über Stralsund; s. Koppmann, Johann Tölners Handlungsbuch, Rostock 1885, S. 3, 10, 6; S. 14 Nr. 171, S. 15 Nr. 193; auch Einl. S. 9.

$\left.{ }^{82}\right)$ Hans. Urkdb. III n. 230.

${ }^{83)}$ Ebenda n. 459 und 464.

84) Hanserezesse I n. $299 \S 17$.

$\left.{ }^{85}\right)$ Hans. Urkdb. III n. 640.

${ }^{86}$ ) Overijsselsche Stad-, Dijk- en Markeregten, S. 55.

87) Ebenda S. 133.

${ }^{88)}$ Hanserezesse I n. 495 Ziff. 7, n. 508, 509; Hans. Urkdb. III n. 551. Vgl. S. 49 ff. Note 72 daselbst.

${ }^{89}$ ) Hans. Urkdb. II n. 575, Note 1. 
Fahrten von Preußen, von den wendischen Städten, von Schweden, von Schonen, von Dänemark aus ${ }^{90}$ ). Auf einem Amsterdamer Schiffe begegnet uns ein Danziger Schiffsmann ${ }^{91}$ ). Ein Zierikseeer Schiffer wird in Danzig wegen eines Streites über Fracht verklagt ${ }^{92}$ ). Ein Stavorner Schiff, das 1345 in Seeland strandet, hat Kulmer Ladung ${ }^{93}$ ).

Die süderseeischen und neben ihnen die holländischen Schiffe waren es nun auch, die dem preußischen Warenhandel zu Hilfe kamen und die Getreide- und Holzladungen nach dem Zwin bringen halfen ${ }^{94}$ ). Das Interesse an dieser niederländischen Frachtschiffahrt bildete das Band, welches die preußischen Kaufleute so eng mit den Niederländern verknüpfte, wie wir noch weiter unten verfolgen werden. Daß auch für diese niederländischen Seefahrer das Zwin in ganz ähnlicher Weise wie für die Hamburger und Niederländer der Ausgangspunkt und das Endziel der Reisen war, haben wir schon für das 13. Jahrhundert nachgewiesen ${ }^{95}$ ).

Neben den Niederländern finden wir in Preußen sehr früh, wenn auch in bescheidenem Maße, Engländer als gerngesehene Handelsgäste $\left.{ }^{96}\right)$. Da die englische Ausfuhr gesetzlich und wirtschaftlich auf den Stapel in Flandern gerichtet war, die englische Tuchindustrie, die später in Preußen unmittelbar Absatz fand, bis zur Mitte des 14. Jahrhunderts auch noch kaum eine nennenswerte Ausfuhr lieferte, so können

9u) Hans. Urkdb. II n. 575.

91) Ebenda III n. 552.

92) Ebenda n. 436.

${ }^{93}$ ) Ebenda n. 51.

94) Hirsch sagt a. a. O. S. 133 treffend: ,Was diese Holländer nach Danzig bringen oder von dort ausführen, gehört nur zum kleinsten Teile ihrer Heimat an oder ist für dieselbe bestimmt; ersichtlich ist es ihnen hauptsăchlich um Frachtschiffahrt zu tun.“ Ferner S. 128: ,In unsern Handelspapieren geschieht im ganzen selbständiger, von Danzigern nach Holland gemachter Handelsunternehmungen selten Erwähnung. Diejenigen, deren gedacht wird, beschränken sich teils auf einzelne Fălle, wo Danziger Bürger in holländische Häfen kommen und dort sich Schiffe mieten, mit denen sie Baienfahrten unternehmen, teils darauf, daß Danziger Waren von Brügge aus durch Faktoren in hollăndische Städte versandt werden" usw.

95) S. oben S. 37 f.

96) Hanserezesse I 1 n. 403. 
Zufuhren von England nach Preußen in dieser Zeit allerdings noch kaum in irgend erheblichem Umfange in Frage gekommen sein; möglich, daß auch die Fahrten der Engländer nach Preußen nicht von England, sondern vom flandrischen Weltmarkt ihren Ausgang nahmen und daß auch diese Engländer mehr durch Interessen der Frachtschiffahrt als des Warenhandels in diesen Verkehr hineingezogen wurden. Dagegen mögen von Preußen nach England schon in dieser Zeit häufiger unmittelbare Verschiffungen vorgekommen sein ${ }^{97}$ ); insbesondere mag schon damals wie später $\mathrm{Holz}^{98}$ ), namentlich Eibenholz, dessen die Engländer in großen Massen für die Ausrüstung ihrer mit Bogen bewaffneten Heere bedurften und das Preußen aus seinen Hinterländern bezog ${ }^{99}$ ), in nicht unbeträchtlichen Mengen direkt nach England verladen sein, wenngleich der preußische Handel mit England gegenüber demjenigen mit Flandern gewiß noch ganz zurücktrat. Übrigens kommen englische Kaufleute schon in dieser Zeit auch in den wendischen Städten vor ${ }^{100}$ ), wenn auch seltener als in Preußen.

Eine hohe Bedeutung haben auch während dieses Zeitabschnittes die Märkte zu Skanör und Falsterbo, neben denen noch einige andere Plätze Schonens zur Geltung kamen ${ }^{101}$ ),

${ }^{97}$ ) Hans. Urkdb. III n. 373, 375: 1357 werden 39 Falken in dem Schiffe des Tidemann Sconeburgh von Preußen nach London befördert; ebenda n. 6851358 frachten zwei Engländer ein Schiff von Elbing nach London; Hanserezesse I 3 n. 2ł0 Ziff. 1 c: etwa 1358 ein Königsberger Schiff auf der Reise von Preußen nach England.

${ }^{98}$ ) ,,Borden“ (Hölzer) neben Hering in England als Gegenstand des Verkaufs der Deutschen, Hans. Urkdb. III n. 92, 93; s. auch Asche, Pech, Borden als Ladung eines vom Osten kommenden, nach England bestimmten Schiffes, Hans. Urkdb. II n. 167.

$\left.{ }^{99}\right)$ Vgl. Schäfer, Die Hansestädte und König Waldemar, S. 188.

$\left.{ }^{100}\right) 1311$ ein Schiffer aus Newcastle in Stralsund angehalten, Hans. Urkdb. II n. 189; 1312 werden in Stralsund Engländer mit ihren Waren im Werte von $1100 \mathrm{M}$ arrestiert, ebenda n. 206; 1329 Schiff eines Engländers aus Newcastle in Stralsund, ebenda II n. 481; 1343 Engländer in Stralsund, wo sie damals Getreide ausführen, ebenda III n. 7-11, 25.

101) Vgl. z. B. die societas inter Theutonicos terram Schone visitare solentes in subsidium et commodum divitum et pauperum hospitum ibidem scilicet Elenboghen (Malmö) venire solencium, Hans. Urkdb. II n. 486, der die universi mercatores de civitatibus Theutonicorum, qui velificant 
behauptete. Wie im 13. Jahrhundert lag der Fang der Heringe selbst hier fast ausschließlich in Händen der Dänen ${ }^{102}$ ), während die Deutschen das Einsalzen und Verpacken der Fische und die Ausfuhr besorgten ${ }^{103}$ ). An dem Verkehre auf Schonen waren einerseits Lübeck und die wendischen Städte Stralsund, Rostock, Wismar, Greifswald, Anklam, Demmin, Stettin usw., und andererseits vor allem die Süderseeer und Holländer und neben ihnen auch Westfalen beteiligt. Von den Niederländern sind hier zu nennen namentlich Kampen, neben ihm Harderwijk, Elborg, Zütphen, Amsterdam, Zieriksee, Briel, Doesborg, Nimwegen, S'Hertogenbusch, Stavorn und andere ${ }^{104}$ ). Auch Hamburg und Bremen hatten auf Schonen ihre eigenen Vitten ${ }^{105}$ ) Außer den deutschen und niederländischen Kaufleuten kamen auch noch Flanderer, Brabanter und Engländer in Schonen vor, aber ihre Zahl blieb gering ${ }^{106}$; nach dem Siege der Städte über König Waldemar wurde den Schotten, Engländern und Wallonen das Salzen der Heringe auf Schonen sogar ganz untersagt ${ }^{107}$ ).

Eine ganz besonders große Rolle spielten auf Schonen die Kampener. Der Umfang ihres Handelsbetriebes daselbst

ad oppidum scilicet Ellenboghen angehören, ebenda n. 485; die societas hat ihren Sitz in Malmö (ebenda); ferner Malmö und Lund, s. Hans. Urkdb. II n. 630 .

102) Schäfer, Das Buch des lübeckischen Vogts auf Schonen, S. $47 \mathrm{ff}$. ${ }^{103)}$ Ebenda S. 53 ff.

${ }^{104}$ ) Kampen, Harderwijk, Zütphen, Elborg, Amsterdam, Zieriksee, Briel hatten eigene Vitten auf Schonen, s. Stieda, Revaler Zollbücher, S. 47. - Kampener auf Schonen, Hans Urkdb. II n. 112, 115, 366, 431 Note 1, 452, 509, 559, 581, 591, 677, 701. III n. 148 Note 1, 168, 230, 322, 336-339, 343, 353, 365, 640; Harderwijker II n. 35, 283, 290, 449; Elborger II n. 523. Zütphener II n. 32, 286, 289, 450, 582, III n. 36, 86, 87, 301; Doesborger II n. 34; Nimweger II n. 33; S'Hertogenbuscher III n. 435 Note 4; Stavorner II n. 451, 557; Amsterdamer III n. 553; Zierikseer III n. 332, 435; sonstige Holländer, Seeländer, Friesen III n. 332; Kaufleute aus den Städten der Grafschaft Geldern und Diözese Utrecht II n. 32.Schonenfahrergilde in Dortmund, Hans. Urkdb. III S. 155, Note 1.

105) Hanserezesse I 1 n. 179, 180.

106) Ebenda n. 512.

${ }^{107)}$ Ebenda n. 510 § 11 Ziff. 11 u. n. 522 §, Lüb. Urkdb. III n. 730. Vgl. Daenell, Die Blütezeit der deutschen Hanse, I S. 60. 
überragte vielleicht noch den der Lübecker; wenigstens erzielte Lübeck 1368 auf seiner Vitte in Schonen nur 180 M. Pfundzoll, während Kampen 240 M. zu verzeichnen hatte $\left.{ }^{108}\right)$. Zum Teil mag dieses Übergewicht Kampens dort auf dem Umsatz zwischen Ostsee- und Nordseewaren beruhen, den die Kampener, wie oben dargelegt, dort vollzogen.

Was die niederländischen Schiffe rom Westen her nach Schonen brachten, war vor allem Salz, das ja zum Einsalzen der Heringe in großen Massen dort verbraucht wurde ${ }^{109}$ ). Aber auch Wolltuche und Leinen führten sie rom Westen herbei; der Handel mit Wolltuchen und Leinen spielte auf den Märkten von Schonen eine große Rolle, wie zahlreiche Urkunden erkennen lassen ${ }^{109}$ ); auch die Lübecker und die Bürger der wendischen Städte brachten diese Artikel, die sie, wenn sie nicht vom Zwin, sondern von ihren Heimatshäfen aus die Reise nach Schonen machten, über Hamburg-Lübeck vom Westen bezogen haben werden, neben Salz, Bier und andern Lebensmitteln nach Schonen auf den Markt $\left.{ }^{110}\right)$; von den livländischen Städten, von Gotland, von Preußen gelangten, zum Teil auf süderseeischen Schiffen, Wachs und Pelzwerk, Holz

${ }^{108)}$ Stieda, Revaler Zollbücher, S. 47.

${ }^{109}$ ) Vgl. die Privilegien der Kampener, Harderwijker, Stavorner und Zütphener auf Schonen von 1326, Hans. Urkdb. III n. 449-452; sie bringen laut diesen Urkunden Salz, Wolltuche, Leinen, Wachs, Pelzwerk und andere Waren; s. auch die Zolltarife, Hanserezesse I 1 n. 328, 435, 513, in denen als Waren, für welche Zoll erhoben wird, außer den Landes. produkten Schwedens und Dänemarks (Butter, Talg und andere Fettwaren; Kuhfleisch; Speck; Rindshäute; lebende Rinder und Pferde; Honig) einerseits Hering, anderseits Salz, Wolltuch und Leinewand genannt werden. - Aus einem Beschluß der Schöffen und des Rates von Kampen von 1364 ersehen wir, daß außer Salz auch Wein Gegenstand der Zufuhr der Kampener nach Schonen war. Overijsselsche Stad-, Dijk- en Markeregten, I deel, I Boeck, Zwolle 1875, S. 55.

$\left.{ }^{110}\right)$ Für Lübeck vgl. Hans. Urkdb. II n. 282 Ziff. 4, 448 Ziff. 2, III n. 246, Hanserezesse I 1 n 176 Ziff. 6, n. 178 (si aliquis mercator ibi deduxerit unum frustrum pannorum, quod duo equi trahere possunt...; si vero non poterit nisi quattuor equis trahi...); Stralsund Hans. Urkdb. II n. 294 Ziff. 4, 454 Ziff. 2; Greifswald ebenda 446 Ziff. 2; Rostock n. 474 Ziff. 4, III n. 247; vgl. ferner die Schadensaufstellungen über Beraubungen wendischer Kaufleute in Schonen, Kopenhagen usw., Hans. Urkdb. II n. 726 (Rostock), n. 727 (Stralsund). 
und andere Waren nach Schonen ${ }^{111}$ ). Von Lübeck gingen vor allem große Mengen Lüneburger Salzes ${ }^{112}$ ), von Lübeck und den wendischen Städten ferner namentlich Holztonnen ${ }^{113}$ ) zur Verpackung der Heringe, Bier ${ }^{114}$ ) u. a. m. dorthin; auch an diesen Transporten war die niederländische Schiffahrt nicht unbeteiligt ${ }^{115}$ ).

Die Waren, die nach Schonen kamen, dienten zunächst zum Eintausch der Heringe; wer keine Waren mitbrachte, mußte zum Einkauf der Heringe gemünztes oder ungemünztes Edelmetall verwenden ${ }^{116}$ ). Aus dem auf dieser Grundlage erwachsenden Zusammenflusse von Waren hatte sich, wie schon mehrfach erwähnt, ein bemerkenswerter Umsatz unter den die Schonensche Küste besuchenden Kauffahrern ent-

111) Über Wachs, Pelzwerk s. oben Note 109. Úber den Umschlagsverkehr mit Holz vgl. Ziff. 11 der Privilegien der Süderseeer (Kampen, Harderwijk, Zütphen, Stavorn) von 1326, Hans. Urkdb. II n. 449-452, wo der Fall behandelt wird, daß das Schiff mit Holz nach Schonen kommt und diese Ladung dort löscht, um von dort aus erst eine andere Reise zu machen und daß die Hölzer in Schonen später wieder eingeschifft und nach ihrem Bestimmungsort befördert werden; s. auch Hanserezesse I 3 n. $240 \S 5$ Ziff. 8, Stralsunder verschiffen von Schonen aus 4000 Wagenschotten in niederländischen Schiffen nach dem Zwin. - Ưber ,,andere Waren“ vgl. die ,Waren, die nach Gewicht verkauft werden“, Hans. Urkdb. II n. 449 Ziff. 3, vgl. 282 Ziff. 15, 294 Ziff. 5, 448 Ziff. 2.

112) Stieda, Schiffahrtsregister in Hans. Geschichtsbl. 1884, S. 83.

${ }^{113}$ ) S. Hans. Urkdb. II n. 667 Ziff. 6: Windegeldsätze, welche die Schiffsleute der Lübecker Schiffe für das Einladen von ,,Schwerem“ und von leeren Tonnen in Lübeck und für das Ausladen dieser Waren in Schonen erhalten. - Die Anfertigung von Heringstonnen auf Schonen war zugunsten der Böttcher in den wendischen Städten untersagt, s. Hans. Urkdb. II n. 699 Note 1 und Hanserezesse I n. 113.

114) Hans. Urkdb. II n. 474 Ziff. 4, auch 282 Ziff. 13 u. s. f.

$\left.{ }^{115}\right)$ S. Overijsselsche Stad-, Dijk- en Markeregten, I Deel, I Stuck, Zwolle 1875, S. 55. Beschluß der Schöffen und des Rates von Kampen von 1364: dat neghien man boeden macken zal to schoenen op onser vitte var sante Jacobs daeghe noch oec ghiene $t$ o $n$ n e $n$ legghen zal dan bij des weghe des boeden alze bij een pene van twintich ponden, dit is te verstane van denghone die van o e s t e n comen ende van w e $\mathrm{n} d$ e $\mathrm{n}$.

${ }^{116}$ ) Verwendet werden durfte nur Schonensche Münze, soweit solche bei den königlichen Wechslern auf Schonen erhăltlich war. Fremde Münzen und Silberbarren mußten bei den Wechslern gegen Schonensches Geld gewechselt werden, Hans. Urkdb. II n. 559. 
wickelt, und so waren die Märkte auf Schonen zu einem nicht unwichtigen Gliede in dem Austausche des Westens mit dem Norden und Osten geworden, und zwar namentlich für diejenigen Handelsartikel, welche ihrer Beschaffenheit wegen sich zur Beförderung über die Landstraße Lübeck-Hamburg nicht eigneten. Es hat übrigens nicht an Versuchen gefehlt, auch den Verkehr mit leicht beförderbaren Waren an diese Märkte zu ziehen; in dieser Beziehung ist vor allem an die 1363 bei den Friedensverhandlungen mit Dänemark auftauchende Forderung der Städte zu erinnern, daß jeder Kaufmann, der nach Schonen komme, sein Gut von dort von der Ostersee über Land nach der Westersee fahren und sich dort einschiffen dürfen solle ${ }^{117}$ ).

Nach wie vor war der Verkehr von Schonen zweifellos vor allem nach dem Westen, auf das Zwin, gerichtet ${ }^{118}$ ). Hierhin ging die Hauptmasse des Heringsfanges. Während 1368 182, 1369212 Schiffe von Lübeck nach Schonen ausliefen, kamen in dem erstgenannten Jahre nur 49, in dem letztgenannten 13 von Schonen in Lübeck an ${ }^{119}$ ); die übrigen brachten den Hering also nicht nach Lübeck, sondern nach einem andern Markte, und es kann kaum ein Zweifel sein, daß der Bestimmungsort dieser übrigen Schiffe ganz vorherrschend in Flandern zu suchen ist. So aussehließlich wie bei den meisten andern Waren war der Handel mit Hering indessen, wie wir schon im 13. Jahrhundert sahen, nicht auf Flandern konzentriert. Abgesehen von den nicht ganz unbeträchtlichen Mengen, welche

${ }^{117}$ ) Hanserezesse I 1 n. 306 § 17; vgl. Schäfer, Das Buch des lübeckischen Vogts auf Schonen, S. 46 Note 4. Hier vermögen wir also eine zweite Ostsee und Nordsee verbindende Handelsstraße, welche die cimbrische Halbinsel kreuzt, zu erkennen; es darf dabei an die alte Verkehrsstraße, die Schleswig mit dem Nordseehafen Huglestadt verband, erinnert werden, s. meinen Aufsatz über Schleswig in der Zeitschr. des Vereins für schleswigholsteinische Geschichte, Bd. 37, S. $156 \mathrm{ff}$.

118) Vgl. Hanserezesse I 1 n. 409 § 3, Rezeß zu Stralsund 1362: ut allecia salsa in Scania non ducantur per brachium Oressund versus Flandriam vel alibi.

$\left.{ }^{119}\right)$. Wendt, Lübecks Schiffs- und Warenverkehr 1368 und 1369. Vgl. übrigens Stieda, Schiffahrtsregister in Hans. Geschichtsbl. 1884, S. 82 f. Stieda gibt für 1368 die Zahl der von Lübeck nach Schonen ausgelaufenen Schiffe auf 160, der von Schonen in Lübeck eingelaufenen Schiffe auf 47 an. 
die wendischen Städte, wie im 13. Jahrhundert, unmittelbar in ihre Hinterländer vertrieben ${ }^{120}$ ), war noch immer England in immerhin bemerkenswertem Maße das Ziel von Schiffen mit Hering aus dem Osten und Norden $\left.{ }^{121}\right)$.

Eine ähnliche, wenn auch wesentlich bescheidenere Rolle wie Schorren spielten sowohl im Heringsfange als im Austausch zwischen Nordsee- und Ostseegebiet die dänischen Häfen auf Seeland, vor allem Kopenhagen und Dragör auf der Insel Amager ${ }^{122}$ ) und ferner Malmö ${ }^{123}$ ).

${ }^{120}$ ) Vgl. z. B. den Hering im Zolltarif Wismars von 1328 an erster Stelle Hans. Urkdb. II n. 476; es verkehren dort - vermutlich doch auch als Einkäufer des Herings - de van over Elbe und de van Parleberghe.

121) Hans. Urkdb. II n. 40. quando ad Lenniam cum piscibus veniemus usw., item anno transacto ad festum sancti Michaelis venerunt ad Lenniam 22 coggones cum piscibus u. s. f., auch die Stralsunder, Wismarer und Lübecker Schiffe, welche 1303 dem Verbote zuwider nach Lynn gekommen waren, werden Heringsladungen gehabt haben. Dagegen wird das Tuch, Wachs, Pelzwerk, Asche usw., welches als Gegenstand des Handels der Deutschen in Lynn erwähnt wird, aus Flandern dorthin geführt sein; s. auch Hans. Urkdb. II n. 467. - Hering als Gegenstand des Verkaufes der Deutschen in England s. ferner Hans. Urkdb. III n. 92, 93. - Vgl. aber auch Hans. Hans. Urkdb. III n. 683 (eine Ladung Hering 1354 von Sluys nach London verschifft).

${ }^{122}$ ) Privilegien für Kampen, Stavorn, Harderwijk und die übrigen Westseestädte für den Besuch der Märkte zu Kopenhagen und den Heringsfang bei Kopenhagen 1341 Hans. Urkdb. II n. 680. Die Kampener erhalten 1341 das Recht zur Ausübung der Gerichtsbarkeit in Kopenhagen, Dragör und Reveshol (bei Prästo auf Seeland), ebenda n. 701. Kampener, Harderwijker und Stavorner in Kopenhagen, III n. 157. Zütphen im Besitze einer Vitte auf der Insel Amager 1346, ebenda III n. 86. Kaufleute der rheinisch-westfälischen Städte in Kopenhagen 1357, s. III S.241, Note 4; Ordnung für die Bürger von Deventer, welche Kopenhagen und Dragör besuchen 1396, ebenda II S. 213, Note 2. Von den Ostseestädten in Kopenhagen vertreten: Lübeck 1340, Hans. Urkdb. II n. 682, Greifswalder-Kopenhagen Fahrergilde 1356, ebenda III S. 152, Note 3 und (?) II n. 493. Deutsche Kompanie in Kopenhagen, Hans. Urkdb. II S. 213, Note 2. Die deutschen Kaufleute wohnten daselbst in der ,Deutschenstraße“ zusammen. Aus Kopenhagen wie aus Malmö wird von deutschen Schustern berichtet, s. Schäfer, Die Hansestädte und König Waldemar, S. 174ff. - Harderwijker und Zütphener übrigens auch in Roskilde, Slagelse, Thornborg (bei Korsör), Nyborg auf Fünen, Tuchhandel treibend 1316, Hans. Urkdb. II n. $283,286$.

${ }^{123}$ ) Hans. Urkdb. II n. 559. 
Der übrige Handel Dänemarks hatte nur eine untergeordnete Bedeutung im Weltverkehre $\left.{ }^{124}\right)$. Außer dem Fischfang bildete die Landwirtschaft hier noch nahezu die einzige Erwerbsquelle. Städte hatte das Land noch kaum aufzuweisen; in Kopenhagen kommen einheimische Kaufleute vor dem 16. Jahrhundert kaum vor; Handel und Verkehr lagen noch ausschließlich in Händen der Fremden.

Im Nordseegebiete war auch in diesem Zeitabschnitte vor allem der Verkehr von England nach Flandern von hoher Bedeutung. Noch immer war der Wollhandel die Grundlage dieses ganzen Verkehrs ${ }^{125}$ ). Zwar begann die einheimische Tuchfabrikation Englands seit dem zweiten Viertel des 14. Jahrhunderts, sich in bemerkenswerter Weise zu entwickeln und auch für den auswärtigen Markt zu arbeiten $\left.{ }^{126}\right)$. Im ganzen

124) Schäfer, Die Hansestädte und König Waldemar, S. 174 ff.

${ }^{125}$ ) In der Königlichen Vorlage an das Parlament von 1353 über den Wollstapel wird die Wolle la sovereine marchandise et the jewel de son roialme d'Engleterre genannt. Hans. Urkdb. III S. 328, Note 1.

${ }^{126}$ ) Tuche von England werden in den romanischen Ländern gelegentlich schon im 13. Jahrhundert erwihnt, wenn sie auch neben den flandrischen Tuchen ganz zurücktreten. Wie es scheint, werden sie auch in einer dänischen Urkunde von 130' schon erwähnt (Hans. Urkdb. II n. 661, Note 1). Doch ist es nicht ausgeschlossen, daß die Bezeichnung der Herkunft sich in diesen Irkunden nur auf die Herkunft der Wolle im Gegensatz zu Tuchen aus einheimischer Wolle beziehen soll. In hansischen Urkunden des 13. Jahrhunderts finden sich englische Tuche noch nicht. Eine bemerkenswerte Rolle beginnen die englischen Tuche jedenfalls erst im 14. Jahrhundert im Welthandel zu spielen; erst 1347 wird ein Zollsatz für Tuche in den englischen Ausfuhrtarif aufgenommen; s. Kunze, Hanseakten aus England, S. 39 und 43; Tuche als Gegenstand der Ausfuhr der fremden Kaufleute aus England 13ł8 neben Wolle genannt, s. Hans. Urkdb. III S. 60-61, Note 1 und n. 570. Vgl. ferner die Urkunde Eduards IIl. von 1358, Hans. Urkdb. III n. 417, wo zunächst die bestehenden Zölle auf die von den Deutschen eingeführten Tuche, die jenseits des Meeres hergestellt werden, erwähnt werden und darauf weiter gesagt wird: ac postmodum pro eo, quod lane infra dictum regnum nostrum Anglie crescentes et de quibus, si extra idem regnum nostrum ad partes exteras traducte fuissent, custuma et subsidium nobis solvi debuissent, in non modica quantitate pannorum infra idem regnum nostrum operate et panni hujusmodi ad partes exteras educti fuerunt, per nos et consilium nostrum ordinatum fuisset, quod de singulis hujusmodi pannis infra dictum regnum nostrum Anglie factis et extra idem regnum 
aber verschwindet die Ausfuhr von Tuchen ebenso wie diejenige von Fellen, Blei, Zinn usw. noch immer hinter der gewaltigen Wollausfuhr ${ }^{127}$ ). Der Schwerpunkt der englischen Volkswirtschaft lag noch immer in der Landwirtschaft. Die Einfuhr war wie im 13. Jahrhundert im Vergleiche zur Ausfuhr unbedeutend. 1354 belief sich der Wert der Ausfuhr Englands auf £ 212338.5 .0; dieser Ausfuhr stand die Einfuhr mit einem Werte von $£ 38383.16 .10$ gegenüber. ${ }^{128}$ ) Zinn und Blei sowie einige andere weniger wichtige Ausfuhrartikel waren bei dieser Aufstellung gar nicht einmal berücksichtigt. Auf die Wollausfuhr allein entfielen nicht weniger als $£ 195982.1 .8$. Die englische Ausfuhr war, wie im 13. Jahrhundert, in der Hauptsache auf Flandern gerichtet. Insbesondeie war die Wollausfuhr bis über die Mitte des 14. Jahrhunderts hinaus

educendis viginti et unus denarii per mercatores extraneos loco custume et subsidii predictorum ad opus nostrum solverentur ... . Über die Ausfuhr englischer Tuche durch deutsche Kaufleute s. ferner Hans. Urkdb. III n. 397; englische Tuche durch deutsche Kaufleute nach Flandern gebracht 1359-1360, s. ebenda n. 430 Ziff. 19, 452 Ziff. 62, 495 Ziff. 24, 497 Ziff. 34 und Ziff. 51, ferner ebenda S. 262 Note 1. Englische Tuche von den Deutschen nach Rußland gebracht ebenda n. 321 und 597. Die Einfuhr der englischen Tuche war in Flandern bereits 1360 verboten. Die Erörterung dieses Verbotes und seiner schwerwiegenden Folgen in späterer Zeit liegt außerhalb des Rahmens dieser Arbeit.

127) S. die Artikel der Einfuhr und Ausfuhr in dem Privileg von 1303 für die ausländischen Kaufleute von Deutschland, Frankreich, Spanien, Portugal, Navarra, Lombardei, Toskana, Provence, Katalonien, Aquitanien, Toulouse, Cahors, Flandern, Brabant und andern Ländern; Einfuhr: Wein, Tuche, Gewürze und Spezereien, Seide und Stoffe aus Kleinasien und Syrien usw.; Ausfuhr: Wolle, Häute, Schafpelze, Hans. Urkdb. II n. 31; ferner 1348, Hans. Urkdb. III S. 60, Note 1 Einfuhr: Wein, Tuche, averia ponderis und andere Waren; Ausfuhr: Wolle, Tuche, und andere Waren. Einfuhrartikel der Deutschen auch Waid, s. Hans. Urkdb. III n. 367.

$\left.{ }^{128}\right)$ Macpherson, Annals of commerce, Vol. I S. 553; vgl. auch Hans. Urkdb. III S. 342. Der Wert der Wollausfuhr (einschl. Wollfelle) betrug $195982 \&$, der Wert der Tuchausfuhr $16266 \mathfrak{L}$ (und zwar 47741/2 Stück Tuch $=9549 \&$ und $80611 / 2$ Stück Worsteds $=6717 \& 18$ sh. 4 d.), der Wert der Häuteausfuhr $89 £ 5 \mathrm{sh}$. Von der Einfuhr entfielen $10986 \mathfrak{\&}$

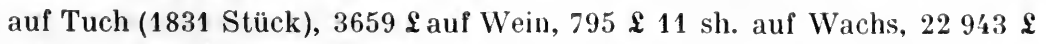
$6 \mathrm{sh} .10 \mathrm{~d}$. auf andere Waren (Leinwand, Kramwaren, Spezereien usw.). 
nicht nur tatsächlich, sondern auch gesetzlich auf Brügge konzentriert, ${ }^{129}$ ) indem England die Ausfuhr der englischen Wolle auf andere Plätze als den gesetzlich bestimmten Stapelort verbot, um den Wollstapel als politisches Machtmittel gegen die Länder des Kontinents, vielleicht auch zur Besteuerung des Wollhandels, benutzen zu können. Die Verlegung des Wollstapels von Flandern nach einem Orte außer-

${ }^{129}$ ) Ausgenommen immer nur vorübergehende Zeiten, wenn England den Stapel als politisches Machtmittel gegen Flandern benutzte. So war in dem flandrisch-französischen Kriege Aardenburg zeitweilig Stapel, s. Hans. Urkdb. II S. 63, Note 3. Ebenso im Jahre 130' und 1305 (Hans. Urkdb. II S. 3', Note 2), als Eduard III. durch das Verbot der Ausfuhr nach Flandern Brabant, dem dieses Verbot zu gute kam, mit Erfolg für seine Partei zu gewinnen suchte. (Vgl. in diesem Zusammenhange auch das große Privileg Brabants von 1305 für die Deutschen und Italiener, s. Hans. Urkdb. II n. 72, ferner 1313 s. Hans. Urkdb. II n. 231 vgl. auch in dieser Zeit die Privilegien des Königs von England 1313 an Dordrecht, ebenda n. 240 und Dordrechts an die Osterlinge 1313, ebenda n. 232). S. alsdann die englische Stapelverordnung von 1313 bei Gilliodts van Severn, Estaple de Bruges, I n. 183. 1315 gewährt der König von England den Bürgern von Brügge wieder freies Geleit, s. Hans. Urkdb. II S. 98, Note 1. Indessen scheint $\mathbf{1 3 1 5}$ noch Antwerpen Stapelort gewesen zu sein (s. Hans. Urkdb. II n. 267: Deutsche Kaufleute auf der Fahrt von London nach Antwerpen mit Wolle und das große Privileg des Herzogs von Brabant an die Deutschen für ihren Handel in Antwerpen und Bergen op Zoom von 1315, ebenda n. 266, wo Wolle an erster Stelle unter den Handelsartikeln steht; vgl. auch Hans. Urkdb. II S. 154, Note 1). 1316 war der Stapel wieder in Brügge, s. Gilliodts san Severn, Estaple de Bruges, n. 189, 195, 198, 199; ebenso 1318, ebenda n. 206. 1320 war die Ausfuhr von Wolle nach Flandern, Brabant, Artois vorübergehend verboten, Kunze, Hanseakten aus England, n. 69, 70; Hans. Urkdb. II n. 372.1336 wurde ein Wollausfuhrverbot erlassen, Pirenne, Geschichte Belgiens, II S. 119-123, Hans. Urkdb. II S. 268 Note 1, n. 600 und Note 2. Seit 1336 befand sich der Stapel in Antwerpen, ebenda S. 302 Note 2 und S. 337 Note 2. 1337 wurde wegen des Wollstapels mit Flandern verhandelt, Gilliodts van Severn, a. a. O. n. 249. 1338 wurde der Handelsverkehr mit Flandern wieder gestattet, Hans. Urkdb. II n. 617 und Note 2. 1339 scheint der Wollstapel noch in Antwerpen gewesen zu sein, Kunze, a. a. O. n. 110, vgl. auch Hans. Urkdb. II S. 284, Note 2 und Anhang I n. 9, 18, 26, 27, 29, 40. 1340-1353 war der Stapel in Brügge, Pirenne, Geschichte Belgiens II S. 143, Gilliodts van Severn, a. a. O. n. 259, 260, 261, 265, 270, 289, Hans. Urkdb. II n. 653 Note 4, III S. 26 Note 1 und n. 207. 
halb Flanderns war allemal das wirksamste Mittel, um Flandern zum Anschluß an England zu zwingen ${ }^{130}$ ). 1353 wurde zwar der gesetzliche Zwang, die Ausfuhr auf Brügge zu richten, aufgehoben und der Stapel in Verbindung mit dem Steuerapparat an eine Reihe englischer Ausfuhrhäfen verlegt, wo nunmehr die Wolle vor der Ausfuhr gestapelt werden mußte ${ }^{131}$ ); ja, die Ausfuhr wurde den englischen Kaufleuten überhaupt verboten und ganz den fremden Kaufleuten überlassen ${ }^{132}$ ). Damit hörte jedoch die Anziehungskraft des Weltmarktes Brügge für diesen Artikel nicht auf, und das Ziel der Ausfuhr blieb nach wie vor das Zwin ${ }^{133}$ ). Erst 1363 trat hierin eine Änderung ein $\left.{ }^{134}\right)$. Von Brügge, dem großen internationalen Markte für Wolle, nicht von England, holten die fremden Kaufleute, die Italiener, Spanier usw., die Wollvorräte, die sie ihrer Heimat zuführten ${ }^{135}$ ).

Der Handel Englands lag noch immer ganz überwiegend in Händen ausländischer Kaufleute $\left.{ }^{136}\right)$. Unter diesen errangen nun aber die Deutschen neben den Italienern den ersten Platz.

${ }^{130}$ ) Vgl. Pirenne, Geschichte Belgiens, I S. 438, II S. 119 f., 122 f., 151, 203 usw. Die England feindliche Politik des flandrischen Grafen Ludwig von Nevers beantwortete Eduard III. von England mit dem Verbote der Wollausfuhr nach Flandern und der Einfuhr flandrischer Tuche nach England 1336; die Folge war ein Notstand der Bevölkerung in den flandrischen Industriestädten und die Revolution in Flandern unter Jakob van Artefeldes Leitung.

131) Hans. Urkdb. III n. 571.

${ }^{132}$ ) Ebenda n. 571, Ziff. 3 und 6. Den schottischen und irischen Kaufleuten wurde gestattet, ihre Waren nach einem englischen Stapel, nicht aber nach dem Auslande, zu bringen, ebenda Ziff. 17.

${ }^{133}$ ) Die Engländer haben alsbald wieder ihre Genossenschaft und ein Haus für den Verkauf der Wolle in Brügge 1359, s. Gilliodts san Severn, a. a. O. n. 304, Ziff. 2, 26, 8, 20. Die englischen Kaufleute kaufen Tuch in Brügge ebenda Ziff. 2.

- 134) Gilliodts van Severn, a. a. O. n. 323. Der Stapel für Tuch, Blei, Zinn, Häute und andere Waren, ausgenommen Wolle, wurde schon 1350 von Brügge nach dem englisch gewordenen Calais verlegt, ebenda n. 270 .

${ }^{135}$ ) Wie die Italiener, Spanier usw. 1344 die englische Wolle in Brügge einkaufen, um sie von dort ihren Heimatsländern zuzuführen, s. Hans. Urbdk. III n. 569.

${ }^{136}$ ) Vgl. u. a. Schanz, Englische Handelspolitik gegen Ende des Mittelalters, I, S. 328. 
Es ist charakteristisch, daß bei der Aufhebung des englischen Wollstapels in Brügge und dessen Verlegung nach einer Reihe von englischen Ausfuhrhäfen im Jahre 1353 das Parlament beschloß, daß im Stapelgericht bei Klagen gegen Ausländer zwei fremde Kaufleute, einer aus dem Norden und der andere aus dem Süden, mitsitzen sollten, und daß die Kommissionen, deren Gutachten bei Streitigkeiten über die Vorschriftsmäßigkeit der Wolle und ihre Packung entscheiden sollten, aus zwei Engländern, zwei Deutschen und zwei Italienern bestehen sollten ${ }^{137}$ ); die ausländischen Kaufleute bildeten also die Mehrheit in diesen Kommissionen, und die Deutschen und Italiener waren es, welchen wegen ihrer alle andern überragenden Handelsstellung die Vertretung der Interessen aller Ausländer zufiel. Die Machtstellung der Deutschen war in England so groß, daß sie zeitweise dort auch die Italiener überflügelten ${ }^{138}$ ) und nicht nur vor den andern Fremden, sondern auch vor den einheimischen Kaufleuten Vorzüge genossen ${ }^{139}$ ).

Auch der Handel der Deutschen in England war natürlich ausschließlich auf den jeweiligen niederländisehen Stapelplatz, also abgesehen von den vorübergehenden Störungen der Beziehungen zu Flandern, auf das Zwin gerichtet. Es ist für die Bedeutung dieser Wollausfuhr nach Flandern bemerkenswert, daß in dem Privileg Aardenburgs an die Deutschen bei Verlegung des Stapels von Brügge nach Aardenburg im Jahre 1307 und in dem Privilegium Brügges bei der Rückverlegung des Stapels 1309, in welchen als Stapelartikel Wolle, Wachs, Pelzwerk, Kupfer und Korn hervorgehoben werden, die Wolle an erster Stelle genannt wird ${ }^{\mathbf{1 4 0}}$ ). Wie die Einfuhr der Deutschen nach England von Flandern aus sich abspielte, veranschaulicht u. a. das Verzeichnis der Waren, welche der englische König 1351 als Eigentum von Mitgliedern der deutschen Genossenschaft in Flandern in England beschlagnahmen ließ, weil die flandrische Gerichtsbarkeit infolge einer angeblich ungerechtfertigten Anklage der Deutschen einen Engländer hingerichtet

137) Hans. Urkdb. III n. 275 und n. 571, Ziff. 23.

${ }^{138}$ ) Kunze, a. a. O. S. 2, 14, 42, 43.

139) Ebenda S. 15, 39.

${ }^{140}$ ) Hanserezesse I 1 n. 84 und Hans. Urkdb. II n. 154. 
hatte. Es findet sich unter den beschlagnahmten Waren eine Menge Holz, Rheinwein, Gascogner Wein, Tuch, Pelzwerk, Kanevas usw. ${ }^{141}$ )

Noch immer war England vor allem wichtig als Geldplatz. Der große Überschuß der Ausfuhr über die Einfuhr machte nach wie vor die Anlage großer Kapitalien seitens der Kaufleute des Kontinents in England zum Ausgleiche der Handelsbilanz notwendig ${ }^{142}$ ). Das fortgesetzte Geldbedürfnis der englischen Könige für ihre Kriege bot die günstigste Gelegenheit $\mathrm{zu}$ vorteilhaften Geldanlagen in England. Im 14. Jahrhundert treten auch auf dem Geldmarkte, der im 13. Jahrhundert noch ganz in Händen der Italiener und Juden lag, die Deutschen in den Vordergrund. Während auf der einen Seite nun die leitenden italienischen Bankhäuser 1346 in England zusammenbrechen, sehen wir auf der andern Seite deutsche Kapitalisten, namentlich Kaufleute aus Köln, Dortmund und andern westfälischen Städten, als Gläubiger des Königs den englischen Außenhandel immer mehr ihrer Herrschaft unterwerfen. Gegen ihre Darlehen ${ }^{143}$ ) erlangen sie Zollfreiheit für ihre Wollausfuhren ${ }^{144}$ ), bringen zeitweise die Zölle in ihre Hände ${ }^{145}$ ), ja, selbst die Krone und die Kleinodien des Königs gelangen als Pfand in ihren Besitz $\left.{ }^{146}\right)$. 1344 erwerben vier kölnische Kaufleute mit einem Engländer zusammen vom König auf zehn Jahre das ausschließliche Recht zur Ausnutzung der sämtlichen Bergwerke in Northumberland, Cumberland und Westmoreland gegen Abgabe des fünfzehnten Teiles des gewonnenen reinen Erzes an Gold, Silber, Kupfer und Blei an den König ${ }^{147}$ ).

141) Hanserezesse I 1 n. 153-157.

$\left.{ }^{142}\right)$ Vgl. auch Schanz, I, S. 489.

${ }^{143}$ ) Vgl. z. B. Hans. Urkdb. III n. 648 Note 1; n. 649 (Darlehen von 5000 Goldgulden von Kölner Bürgern, 29. I. 1339), und n. 649 Note 1 (Darlehen kölnischer Bürger am 4. I. 1340 in Höhe von 5000 Gulden und 6. II. 1340 Schuld in Höhe von 64066 Gulden), n. 659 und Note 1 (Darlehen von 34 000 kleinen Gulden 1344 seitens Dortmunds).

144) Hans. Urkdb. II n. 112 und Anhang I n. 36, 47.

$\left.{ }^{145}\right)$ Ebenda n. 46, 73, 76, 88, 105, 506, 477, 608, III S. 37 Note 3, n. 100.

146) Ebenda II n. 82, 83, 86, 92, 95, 96, 103.

147) Ebenda III S. 25 Note 1, n. 637. 
1347 werden dem deutschen Kaufmann Tydemann Lymbergh der ganze Handel und Export von Zinn in Cornwall und Devonshire und die gesamten Einnahmen des Ausfuhrzolles für Zinn vom König übertragen ${ }^{148}$ ). Aus einer Urkunde von 1359 ersehen wir, daß der Kölner Bürger Tilmann von Köln in Alston More in Cumberland Gruben zur Gewinnung von Silber, Kupfer und Blei gepachtet hatte ${ }^{149}$ ). Einzelne deutsche Kaufleute, wie Tydemann Lymbergh, hatten bedeutenden Landbesitz in England ${ }^{150}$ ).

Der bedeutende Umfang der Kapitalanlagen der Fremden in England hatte zur Folge, daß trotz des großen Übergewichts der Ausfuhr über die Einfuhr das Edelmetall immer wieder von England nach dem Kontinent abfloß und in England derartiger Mangel an Edelmetall eintrat, daß das Land durch besondere Vorschriften die Zufuhr genügender Mengen von Edelmetall zu sichern suchte. Jeder, der Wolle ausführte so wurde 1339 bestimmt -, solle eine bestimmte Summe Geldes oder Edelmetall dafür einführen müssen ${ }^{151}$ ). Bald darauf wurde versucht, den Preis der Wolle durch Festsetzung obrigkeitlicher Taxen zu erhöhen, um dadurch mehr gutes Geld in das Land zu ziehen usw. Neue englische Sterlinge aus dem Lande auszuführen wurde verboten, die Einfuhr schlechter Münzen mit Todesstrafe bedroht, um das Eindringen minderwertigen Geldes zu verhindern; nur gute, im Werte der neuen Sterlinge geprägte flandrische Silbermünze sollte eingeführt werden dürfen ${ }^{152}$ ).

Die Deutschen bildeten, wie schon früher erwähnt, in England seit etwa dem letzten Viertel des 13. Jahrhunderts eine einzige festgeschlossene Genossenschaft, die hansa Alemannia ${ }^{153}$ ).

${ }^{148)}$ Hans. Urkdb. III n. 100.

${ }^{149)}$ Ebenda n. 438.

${ }^{150}$ ) Tydemann Lymbergh bestätigt der englische König 1348 und 1350 ,,auf tausend Jahre" mehrere Güter in Somerset, Wills, Southampton, Bucks, Nothhampton, Canterbury, Suffolk, Hans. Urkdb. III S. 37, Note 3.

151) Schanz, I, S. 495; erneuert 1343, Hans. Urkdb. III n. 568.

${ }^{152}$ ) Hans. Urkdb. III n. 568 Note 4; vgl. auch n. 27, ferner 1353 n. 571 Ziff. 13.

$\left.{ }^{153}\right)$ Hans. Urkdb. II 128, 170, 252, 708, III 14 Note 1, 44, 60 Note 1, 100 Note 2, 112, 123, 212, 214, 222, 235, 275, 279, 298, 397, 412, 417, 446 Note $5,678$. 
Ihr Schwerpunkt lag in London, doch hatten sie, wie im 13. Jahrhundert, auch in Lynn, Kingston upon Hull, Boston und andern Plätzen ihre Genossenschaften, die jedoch der deutschen Hanse in London untergeordnet wurden $\left.{ }^{15.1}\right)$.

Auch für Schottland und Irland, welche Länder in ähnlicher Weise wie England in der Wollproduktion ihren wirtschaftlichen Schwerpunkt hatten, war zweifellos, wie im 13. Jahrhundert, Brügge noch immer der kontinentale Stapelplatz, auf den sich ihre Zufuhren richteten ${ }^{155}$ ).

Sehr viel bescheidener im Vergleich zu dem englischen Handel blieb auch in dieser Zeit der Platz, den der norwegische Verkehr im Welthandel einnahm. Auch in Norwegen beherrschten die Deutschen in höherem Maße als im 13. Jahrhundert den Handel mit dem Auslande ${ }^{155 a}$ ). Neben Lübeck und den wendischen Städten ${ }^{156}$ ) finden wir hier auch im 14. Jahrhundert vor allem die Niederländer, namentlich die Kampener, nebst den Westfalen ${ }^{157}$ ), sowie die Bremer und Hamburger vertreten ${ }^{158}$ ). Noch immer bildeten Fischfang und Holzexport die wichtigsten Grundlagen der norwegischen Ausfuhr ${ }^{159}$ ).

154) Vgl. z. B. Hans. Urkdb. II n. 40, 170, 600, 609 usw., Anhang I n. 5,6 .

${ }^{155)}$ Vgl. z. B. Hans. Urkdb. III n. 579, 580.

155a) Vgl. im Einzelnen, Daenell, Blütezeit der Hanse, I S. 26 f.

${ }^{156)}$ Über Norwegens Verkehr mit Lübeck s. u. a. Hans. Urkdb. II n. $87,88,209,508,511,512,514,525,526$, III n. 13, $403,404,439,479$; mit den wendischen Städten II n. 78, 129 (Stralsund); 209 (Wismar, Rostock, Stralsund, Greifswald); 661 (Rostock); 686 (Wismar); III n. 13 (Wismar, Rostock, Stralsund, Greifswald); 429 (Stralsund, Rostock); 679 (Wismar).

$\left.{ }^{157}\right)$ Uber den Verkehr der Kampener mit Norwegen s. Hans. Urkdb. II n. $53,70,74,75,76,234,248,558,668,675,676,678$, III S. 446. Amsterdamer Schiffer in Norwegen III n. 553; Deventersche Kaufleute 1331, II n. 505; Oldenzaaler III n. 199, Note 1. Beteiligung westfälischer Kaufleute am Verkehre mit Norwegen, s. Hans. Urkdb. II n. 78 und 281, III n. 199 Note 1.

$\left.{ }^{158}\right)$ Hamburger am Handel mit Norwegen beteiligt, s. Hans. Urkdb. II n. 326, III n. 13; Bremer II n. 382, III n. 70, 72, 73, 119.

${ }^{159}$ ) Vgl. Ghysekenhout (Holz von der norwegischen Insel Giske?), Wicker Sparren, Bergher Sparren (Hölzer von Wik in Norwegen und von Bergen) in der Maklerrolle für den Handel der Deutschen in Flandern 
Der Fischfang an der norwegischen Küste blieb insbesondere auch eine wichtige Erwerbsquelle der in den deutschen und niederländischen Häfen der Nordsee und Ostsee beheimateten Reedereien; doch war es den Deutschen und den übrigen Fremden verboten, über Bergen hinaus nach dem Norden vorzudringen; den Fischfang und den gewinnreichen Walfang in den Gegenden des höheren Nordens und den Verkehr mit den nördlichen Teilen Norwegens und mit Island behielten sich die Norweger vor ${ }^{160}$ ); die Fremden vermittelten den Handel des Landes mit dem Auslande; der Überfluß Norwegens an Häuten, deren Leder für Schuhe geeignet war, führte außerdem zur Entstehung einer bedeutenden Schuhwarenindustrie in den norwegischen Küstenplätzen, welche von deutschen Handwerkern, die sich dort in großer Zahl niederließen, betrieben wurde und vermutlich für den Export arbeitete ${ }^{161}$ ).

Die Ausfuhr Norwegens war natürlich noch immer zum großen Teile auf das $Z$ win gerichtet ${ }^{162}$ ), wo übrigens die norwegischen Kaufleute auch selbst Privilegien besaßen ${ }^{163}$ ). Wie

1360, Hans. Urkdb. III n. 499. Schiff mit Heringen von Norwegen im Zwin etwa 1358, s. Hanserezesse I 3 n. 240, Ziff. 1h.; Mastbäume als Gegenstand des Handels 1340 in Norwegen, Hans. Urkdb. II n. 652. In einer Urkunde von 1316 kommen als Gegenstand des Handels in Norwegen vor: Stockfisch, Walfisch, Tran, Walroßzähne, Seehundsfelle; Rinderfelle, Bocksfelle, Ziegenlammfelle, Lammfelle, Fleisch, Butter, Marderfelle, Graufelle, Hirschfelle, Biberfelle, Otternfelle, Bärenfelle, Luchsfelle, Fuchsfelle; Teer, Baumharz, Färbemoos; Salz; Gerste; Schwefel; Watmal (nordisches Tuch), Wollengarn, Hans. Urkdb. II n. 284; in einer Urkunde von 1317 werden erwähnt: Mehl, Malz, Roggen, Weizen, Gerste, Feinmehl, Erbsen, Bohnen, Bier, Met, Honig, Tuch, Genter Tuch, S̉ai, Leinewand, Kanevas, Spezereien, Räucherwerk, Wachs, Fette, Speck, Butter, Hering, Stockfisch, Tran, Hans. Urkdb. II n. 311. 1318 Hans. Urkdb. II n. 320: Bier, Wein, Honig, Tuch, Watmal, Leinwand, Wachs, Lein; Hansarezesse I 1 n. 196 (1354): Malz, Bier, Mehl, Tuch, Hering. Nach Hans. Urkdb. III n. 13 soll der Schiffszoll in Getreide entrichtet werden.

$\left.{ }^{160}\right)$ Hans. Urkdb. II n. 15, 88, III n. 136.

161) In Bergen Hans. Urkdb. II n. 193, 495, in Opslo II 51, III 291, in Vagsbote II n. 144, 192.

$\left.{ }^{162}\right)$ S. oben S. 59.

${ }^{163)}$ Hans. Urkdb. II n. 150 Note 1. Straße der Norweger in Brügge 1308 Hans. Urkdb. III S. 474 Note 1. 
im 13. Jahrhundert ging ein Teil des norwegischen Heringsund Stockfischhandels auch nach England $\left.{ }^{164}\right)$; doch wurde auch der englisch-norwegische Verkehr zum großen Teile von deutschen Kaufleuten besorgt ${ }^{165}$ ). Ein bemerkenswerter Teil der Einfuhr Norwegens kam, wie früher, aus den wendischen Städten.

Auch in Norwegen finden wir im 14. Jahrhundert die deutschen Kaufleute zu einer Genossenschaft, einer Hanse, vereint. Seit etwa 1343 wird die Hanse der deutschen Kaufleute daselbst erwähnt ${ }^{166}$ ). Der Hauptsitz ihres Verkehrs war Bergen, aber auch Oslo bei Christiania und Tonsberg am Eingange des Christiania-Fjordes sowie Kungelf bei Göteborg waren Sitze ihres Handels ${ }^{167}$ ).

Über die Beteiligung hansischer Schiffe und Kaufleute an dem Verkehre der atlantischen Küsten Spaniens und Frankreichs, der in gleicher Weise wie der Verkehr des Nordens auf den Weltmarkt Brügge konzentriert war, fehlt es uns für diese Zeit völlig an Nachrichten. Die ausgedehnten Privilegien, welche die Kaufleute von Saint Jean d'Angely und La Rochelle 1331 am Zwin erwarben ${ }^{168}$ ), zeigen uns den Weinstapel dieser Genossenschaft wie im 13. Jahrhundert in Damme, dem bereits mehrfach erwähnten Hafenplatze Brügges, und lassen zugleich den gewaltigen Umfang, den dieser Weinhandel hatte, erkennen ${ }^{169}$ ). Daß an diesem Verkehre noch immer fremde Schiffer und Kaufleute teilnahmen, zeigen gelegentliche urkund-

164) S. Hans. Urkdb. II n. 189, 237 und Note 1 (englische Kaufleute in Bergen); II n. 209 Note 3, 600, 652 Note 3 (englische und schottische Kaufleute in Norwegen); III n. 166, 197; II n. 237 Note 1 (Norweger in Lynn); II n. 270 (Kaufmann mit getrockneten Fischen auf der Fahrt nach Ipswich); II n. 40 (si unus coggo venerit de Norweya cum allecis nach Lynn); n. 600.

${ }^{185}$ ) vgl. z. B. Hans. Urkdb. III n. 166, 197; II n. 40.

166) 1343 Hans. Ürkdb. III n. 13, 17; 1350 III n. 169; 1351 ebenda n. 199; 1354 Hansarezesse I 1 n. 196; 1367 aldermannus et communis mercator de Bergis Norwegie ebenda n. 402, Ziff. 13.

167) Hansarezesse I 1 n. 428; Hans. Urkdb. II n. 311, 312, 320.

${ }^{168)}$ Gilliodts van Severn, Estaple de Bruges, I n. 240.

${ }^{169}$ ) Uber die Bedeutung des Weinhandels in Flandern vgl. u. a. Hans. Urkdb. III n. 259 Note 1. 
liche Nachrichten, die uns z. B. von Kampener Schiffen mit Wein auf dieser Fahrt ${ }^{170}$ ), von Dordrechter Schiffern ${ }^{171}$ ), in diesem Verkehre von flandrischen Kaufleuten in Bayonne ${ }^{172}$ ), von bayonner und kastilianischen Schiffen ${ }^{173}$ ), die französischen Kaufleuten gehörigen Wein nach Flandern führen, usw. berichten. Handelsprivilegien für den Verkehr der Bayonner in Flandern sind aus dem Jahre 1359 erhalten ${ }^{174}$ ). Da spätere Nachrichten uns auf dieser Route ebenso wie am Ende des 13. Jahrhunderts auch deutsche Schiffe beschäftigt zeigen, so werden wir wohl kaum fehlgehen, wenn wir vermuten, daß auch in dieser Zeit die deutsche Schifffahrt vom Zwin aus an dem Verkehr mit Wein und Salz von der französischen Küste nach dem Zwin beteiligt geblieben ist.

Einen bedeutenden Umfang hatten in dieser Zeit die Schiffahrt und der Handel der Spanier nach dem Zwin erreicht. Die Spanier spielten schon im 13. Jahrhundert am Zwin eine wichtige Rolle ${ }^{175}$ ). Die Privilegien, welche ihnen im Jahre 1343 für ihren Stapel am Zwin verliehen wurden ${ }^{176}$ ), lassen vor allem auch die Bedeutung, welche der Schiffahrt ${ }^{177}$ ) der Kastilianer innewohnte, erkennen; das Privileg ist ,an den Admiral, die Kaufleute, Schiffsherren und Seeleute für ihre Schiffe, Güter und Waren" gerichtet, und der Raum, den die Regelung ihres Schiffsverkehrs in dem Privileg einnimmt, zeigt deutlich die bedeutenden Reedereinteressen, die diese Fremden am

${ }^{170)}$ Hans. Urkdb. III n. 653.

171) Ebenda S. 422, zu n. 71.

172) Finot, Étude historique sur les relations commerciales entre la France et la Flandre au moyen-âge, Paris 1894, S. 122 ff., 136.

${ }^{173)}$ F inot, Étude historique sur les relations commerciales entre la Flandre et l'Espagne au moyen-âge Paris, 1899, S. 43.

174) Hans. Urkdb. III n. 578.

${ }^{175)}$ S. oben S. $35,75 \mathrm{ff}$.

176) Hans. Urkdb. II S. 346; 1348 erneuert, s. ebenda III n. 143 Note 2; 1366 ausgedehnt. Gilliodts van Severn, Estaple de Bruges, I n. 332. 177) Über die Schiffahrt der Kastilianer vgl. auch Finot, Relations commerciales entre la Flandre et l'Espagne S. 43, 52, 59 f., 66, 70, $77 \mathrm{f}$. 94-95 usw. (Die Urkunde von 1361 (S. 328) hat Finot falsch verstanden; es handelt sich um Gut, das von der See ausgeworfen war; dasselbe soll den Eigentümern freigegeben werden; soweit es verkauft ist, soll Ersatz geleistet werden; die Freigabe des Gutes soll gegen Bezahlung der durch die Bergung entstandenen Kosten erfolgen.) 
Zwin vertraten. Übrigens sehen wir auch portugiesische Kaufleute ${ }^{178}$ ) und von der spanischen Mittelmeerküste ${ }^{179}$ ) namentlich Schiffe von Majorka und Barcelona regelmäßig am Zwin ein- und ausgehen. Spuren dafür, daß die hansischen Schiffer in diesem Zeitraume schon über Rochelle hinausgefahren seien, sind indessen nicht vorhanden.

Vom Zwin aus besuchten die hansischen Kaufleute, wie im 13. Jahrhundert, die flandrischen und brabantischen Handelsund Industriestädte, insbesondere die Märkte von Antwerpen und Bergen op Zoom ${ }^{180}$ ); wenn wir sie über Benachteiligungen im Tuchhandel in Maubeuge 1346 gemeinsam mit den Spaniern, Portugiesen und Italienern Beschwerde erheben und darauf auch gemeinsam mit diesen dort Privilegien erwerben sehen, so geschah dies, wie schon der Ort der Abfassung der Beschwerde ergibt, von Brügge aus ${ }^{181}$ ), und ebenso werden sie von Brügge aus Aardenburg, Poperingen und die übrigen flandrischen Plätze, wo wir sie regelmäßig Tuche einkaufen sehen ${ }^{182}$ ), besucht haben. Über die Zollstätte Bapaume verkehrten sie von Brügge aus, wie im 13. Jahrhundert, auf den Messen der Champagne ${ }^{183}$ ). Über Köln und Frankfurt nahmen die deutschen Kaufleute ferner an der Vermittlung des Austausches zwischen Brügge einerseits und Süddeutschland und Italien andererseits Teil, und zwar finden wir neben den rheinischen und süddeutschen Kaufleuten vor allem auch die Lübecker ${ }^{184}$ ) von ihrem Stapel

${ }^{178)}$ Straße der Portugiesen in Brügge seit 1308 s. Hans. Urkdb. III S. 474, Note 1; Portugiesen neben Kastilianern, Aragonesen usw. am Tuchhandel in Maubeuge 1346 beteiligt s. Hans. Urkdb. III n. 81.

${ }^{179}$ ) Vgl. Finot, Relations commerciales entre la Flandre et l'Espagne, S. 43 f., $52 \mathrm{f}$.

$\left.{ }^{180}\right)$ S. die Privilegien von 1315, Hans. Urkdb. II n. 266. Die Dortmunder hatten in Antwerpen eine Hanse, in welche sie 1329 auf Fürsprache von Soest und Lübeck auch die Braunschweiger aufnahmen, Hans. Urkdb. II n. 492.

181) Hans. Urkdb. III n. 81-83.

182) Ebenda n. 114, 115, 116, 163.

${ }^{183}$ ) Lübecker bei Bapaume 1302, Hans. Urkdb. II S. 12 Note 1, III n. 152, 32 und Note 1 und 658 Note 1.

184) Hans. Urkdb. III S. 301 Note 2. Die Kaufleute der Länder vom Rhein bis Lübeck in Köln s. Köllnischer Zolltarif von 1350-1360; Hans. Urkdb. III n. 545 1b Ziff. 16, 2 Ziff. 46. 
in Brügge aus an diesem Verkehrszuge beteiligt, wenngleich wir sie in Italien in diesem Zeitabschnitte noch nicht nachweisen können.

Fragen wir nun, nachdem wir auf dem Weltmarkt Brügge Umschau gehalten und das Getriebe der verschiedenen Nationen dort überblickt haben, nach dem Anteil, den die Hamburger an diesem Weltverkehre nahmen, so können wir zunächst feststellen, daß noch wie im 13. Jahrhundert Brügge mit dem Zwin der Mittelpunkt ihrer Schiffahrt und ihres Handelsbetriebes war. Zwar sind die Nachrichten aus diesem Zeitabschnitte sehr lückenhaft. Aber aus der Hamburger Bursprake von 1358, welche die Vorschrift enthielt ${ }^{185}$ ): ,,.Morgensprake unde hanse scolen use borghere holden in Vlandern, in Engeland ende in anderen steden als id jhe heft en sede gewesen", und aus einem Verzeichnis der Kaufleute und Antsmeister Hamburgs aus dem Jahre $1375^{186}$ ), das an erster Stelle die Kaufleute aufführt und davon 84 als mercatores de Flandria und 35 als mercatores de Anglia bezeichnet, vermögen wir zu erkennen, daß die große Mehrzahl der Hamburger Kaufleute und Reeder, wie im 13. Jahrhundert, der Genossenschaft, welche ihren Sitz am Zwin hatte, angehörte und der Schwerpunkt ihrer Tätigkeit noch in Flandern lag.

Der Handels- und Schiffahrtsbetrieb der Hamburger vom Zwin aus scheint sich auch in dieser Zeit auf alle die Reiserouten erstreckt zu haben, auf welchen wir ihn schon im 13. Jahrhundert sich betätigen sehen. Neben dem Handelsverkehr zwischen Hamburg und dem Zwin, auf den wir später noch zurückkommen, finden wir die Hamburger auch in dieser Zeit in dem Verkehre von der Ostsee, von Schonen, von Norwegen und von England nach dem Zwin und vom Zwin nach alle diesen Ländern beteiligt. Das Handlungsbuch des Hamburger Kaufmanns Vicko van Geldersen zeigt uns diesen zusammen mit andern Hamburgern, wenn auch in etwas späterer Zeit, nämlich in den Jahren 1376 bis 1380, im Be-

185) Hans. Urkdb. III n. 399 Note 1.

186) Westphalen, Hamburgs Verfassung und Verwaltung, Ham. burg 1846, S. 421 . 
sitze eines Schiffes ${ }^{187}$ ), in welchem der Sehiffer und Mitreeder Swartecop Salz, welches er für Rechnung Geldersens 1374 in Flandern gekauft hatte, nach Preußen brachte, um es dort zu verkaufen; Swartecop scheint wiederholt mit dem Schiffe solche Fahrten nach Preußen unternommen zu haben ${ }^{188}$ ), denn eine Eintragung des Handlungsbuches von 1376 spricht wiederum von Geld, das Swartecop in Danzig stehen gelassen hatte und das dann ein anderer dort für Geldersen zu erheben beauftragt wurde. Swarteeop sehen wir 1376 auf der andern Seite in Flandern dem meist dort ansässigen Geschäftsteilhaber und Onkel Geldersens Albert von Lüneburg Rechnung legen und den Reedereigewinn auszahlen. Wir gewinnen hier also Einblick in den Geschäftsbetrieb einer der hamburgischen Reedereien, die am Zwin ihren Sitz hatten. Übrigens war Geldersen an mehreren Schiffen beteiligt; unter andern an einem Holk, den Hinrik Swartecop im Mai 1377 bezeichnenderweise am Zwin kaufte ${ }^{\mathbf{1 8 9}}$ ). Verschiedene Privilegien aus diesem Zeitabschnitte, welche die Rechte der Bürger hansischer Städte in Schweden, Schonen und Norwegen sichern und bestätigen, führen neben Lübeck und den wendischen Städten ausdrücklich auch Hamburg auf ${ }^{190}$ ) und geben uns damit einen Hinweis darauf, daß die Hamburger Schiffer und Kaufleute auch in dieser Zeit an dem Verkehre jener Länder, der, wie dargetan, ebenfalls vorherrsehend auf das Zwin gerichtet war, teilnahmen.

187) Nirrnheim, Das Handlungsbuch Vickos von Geldersen, Hamburg und Leipzig 1895 , § 711.

188) Vgl. auch 1322 ein Hamburger auf der Reise von Preußen und der Ostsee nach Großbritannien, der dem Könige von England Getreide und Lebensmittel für den Krieg gegen die Schotten zuführt, Hans. Urkdb. II n. 399.

189) S. Nirnheim a. a. O. $\S 698$.

$\left.{ }^{190}\right)$ Vgl. Urkunden des Königs Magnus 1343 an Lübeck, Hamburg, Rostock, Wismar, Stralsund und Greifswald für den Verkehr in Schweden und auf Schonen, Hans. Urkdb. III n. 6; Privileg Erichs von Dänemark an die Hamburger, soweit sie die Ausfuhr Dänemarks nicht nach Deutsch: land richten, 1312, Hans. Urkdb. II n. 218. Urkunde Hakons V. an Ham. burg für den Verkehr in Norwegen 1318, ebenda n. 326. Privileg des Königs Magnus 1343 an Lübeck, Hamburg, Wismar, Rostock, Stralsund, Greifswald für den Verkehr in Norwegen, Hans. Urkdb. III n. 13. 
Eine Hamburger Bursprake aus dem Anfange der sechziger Jahre über die Schonenfahrt ${ }^{191}$ ) zeigt uns ebenfalls, daß die Hamburger an dem Handels- und Schiffahrtsverkehre Schonens teilnahmen, wie denn übrigens auch in dem Handlungsbuche Vicko van Geldersens gelegentlich bei den Schiffen, in denen er Parten hat, von Schonenfahrten die Rede ist ${ }^{192}$ ). Auch die Fahrten der Hamburger Schiffe zwischen Rochelle und dem Zwin werden vermutlich in diesem Zeitraume weiter bestanden haben. Vor allem aber hat eine große Bedeutung auch in diesem Zeitraume der Verkehr zwischen England und Flandern für die Hamburger gehabt.

Schon die Scheidung der auswärts tätigen Hamburger Kaufleute in solche der flandrischen Genossenschaft und solche der englischen Genossenschaft weist darauf hin, daß nächst Flandern England für den Gesehäftsbetrieb der Hamburger besonders wichtig war. Fünfunddreißig Hamburger Kaufleute gehörten 1375 der englischen Genossenschaft an. Eine Reihe urkundlicher Nachrichten bestätigt die rege Anteilnahme der Hamburger an dem von England aus betriebenen Handel. 1309 werden drei hamburgische Schiffe voll Ladung in London erwähnt ${ }^{193}$ ); 1310 werden Hamburger Kaufleute in Kingston upon Hull geschädigt ${ }^{194}$ ); unter den Kaufleuten, welche zu derselben Zeit in Boston verhaftet und alsbald wieder freigelassen werden, befindet sich neben drei Elburgern, einem Harderwijker, einem Dortmunder und einem Rostocker auch ein Hamburger ${ }^{195}$ ). 1311 werden wiederum wegen angeblicher Beraubung eines Schiffes Kaufleute aus Hamburg, Lübeck, Köln und Kampen in England verhaftet und wieder freigelassen ${ }^{196}$ ); ebenso 1316 Kaufleute aus Hamburg, Köln, Dortmund, Soest, Recklinghausen, Münster, Osnabrück, Lübeck,

191) Lappenbers-Sartorius, Urkundliche Geschichte des Ursprungs der Hanse, II S. 465.

192) Nirrnheim, a. a. O. $\S 612$, auch $\S 553$, wo es sich allerdings um ein Darlehn an einen über Lübeck nach Schonen reisenden Kaufmann handelt.

193) Hans. Urkdb. II n. 147.

194) Ebenda n. 168.

195) Ebenda n. 171.

${ }^{196}$ ) Ebenda n. 195 und 198, 210, 238. 
Greifswald ${ }^{197}$ ). 1350 lesen wir von Schulden eines Hamburgers an einen Engländer ${ }^{198}$ ). Unter den deutschen Kaufleuten, welche 1352 in England wegen der Hinrichtung eines Engländers verhaftet und, nachdem sie geschworen hatten, daß sie der deutschen Hanse in Flandern nicht angehörten, wieder freigelassen wurden, befanden sich ebenfalls Hamburger ${ }^{199}$ ); 1352 erhält Hennekin Benestryth von Hamburg sicheres Geleit in England ${ }^{200}$ ). Daß dieser ganze Handelsbetrieb der Hamburger von England aus auf das Zwin gerichtet war, kann nach dem früher Gesagten nicht zweifelhaft sein.

Der Mittelpunkt des ganzen nordwesteuropäischen Seehandels war, wie wir im vorstehenden verfolgt haben, das Zwin, der Hafen Brügges. Es vernotwendigt sich, diesem Hafenbassin hier eine nähere Betrachtung zu widmen. Brügge selbst war, wie bereits oben erwähnt, schon im 13. Jahrhundert für Seeschiffe nicht mehr erreichbar. Nur bis nach Damme und den weiter unterhalb am Zwin gelegenen, zum Bezirk von Damme gehörenden Nebenplätzen Dammes Ostkerke, Monekerede und Houcke konnten die Seeschiffe noch kommen. Im Hamburger Schiffrecht wird, wie schon früher ausgeführt ist, noch Ostkerken als Sitz der hamburgischen Hanse genannt; wenig später sehen wir dann Houcke an die Stelle Ostkerkes treten. Im 14. Jahrhundert wird Ostkerke nicht mehr erwähnt; Damme, Houcke und Monekerede sind jetzt allein noch die Liegeplätze ${ }^{201}$ ) der Schiffe. Nach der Stapelverordnung des Grafen von Flandern ${ }^{202}$ ) aus dem Jahre 1323 sollten gesalzene Fische, Getreide, Holz, Teer, Masten und Schiffsgeräte, also jene Waren, welche sowohl für die Schiffahrt von der Ostsee her um Skagen herum als auch für die Schiffahrt von Hamburg die Hauptstapelartikel

197) Hans. Urkdb. II n. 291, 341.

198) Ebenda III n. 167.

${ }^{199}$ ) Ebenda n. 238 und Hansarezesse I 1 n. 152.

${ }^{200}$ ) Ebenda III S. 107 Note 1.

$\left.{ }^{201}\right)$ Wie die deutschen Schiffer hier auf den Schiffen lebten, veranschaulicht z. B. Hansarezesse I 3 n. 2'0 Zifr. 4 Note 4, wo es heißt, daß der Bailiff einen Stralsunder „ut dem watere“ (d. h. vom Schiffe) nimmt und ihn gefangen setzt.

$\left.{ }^{202}\right)$ Hans. Urkdb. II n. 401. 
bildeten, zu Houcke und Monekerede gelandet und verkauft werden dürfen. Auch Salz darf hier gehandelt werden. Korn, Holz und Salz, also gerade die für die Ostseeschiffahrt wichtigsten Bulkartikel, brauchen überhaupt nicht ans Land gebracht zu werden, sondern dürfen von Schiff zu Schiff verkauft und übergeladen werden. Es erhellt daraus, daß diese Waren vielfach vom Zwin wieder ausgeführt wurden, ohne Flandern weiter zu berühren; im Zwin trafen eben die Kaufleute aus allen Teilen der Welt mit ihren Waren zusammen zu wechselseitigem Austausche. Die Revaler Zollbücher aus dem letzten Viertel des 14. Jahrhunderts zeigen, daß die Revaler Ausfuhr, soweit sie durch den Sund nach Flandern ging, ganz regelmäßig Getreide, und zwar hauptsächlich Roggen, zum Gegenstande hatte und daß die Rückfracht, welche die Schiffe brachten, so gut wie ganz aus Salz bestand. Zahlreiche Eintragungen bezeugen aber ausdrücklich, daß dieses Salz aus Flandern kam ${ }^{203}$ ). 1358 beschweren sich die Preußen, daß sie am Zwin den Einkauf von Salz nicht mehr ohne Makler, wie das gewiß bis dahin beim Verkauf von Schiff zu Schiff üblich gewesen war, sollten vornehmen dürfen ${ }^{204}$ ). Auf den Salzstapel am Zwin muß also, wie wir das auch schon für das 13. Jahrhundert nachgewiesen haben, der Verkehr mit Salz von Rochelle und von der wohl erst im Laufe des 14. Jahrhunderts in dieser Beziehung bemerkenswerten Bai von Bourgneuf gerichtet gewesen sein; hier nahmen die von der Ostsee mit Holz und Getreide kommenden Schiffe ihre Salzrückfrachten ein.

Damme am Zwin war nach wie vor der Stapelplatz für den Wein, und zwar nicht nur für den französischen und spanischen ${ }^{205}$ ), sondern auch für den rheinischen ${ }^{206}$ ). Denn auch der Verkehr der rheinischen Kaufleute spielte sich im wesentlichen über das Zwin ab. Die Kölner klagen 1358, daß sie, wenn sie mit Hering in das Zwin kommen, der nach Köln bestimmt

203) S. oben S. 75.

204) Hanserezesse I 3 n. 240 Ziff. 1a, No. 1.

${ }^{205}$ ) Finot, Étude historique sur les relations commerciales entre la Flandre et l'Espagne au moyen-âge, S. $100 \mathrm{f}$.

${ }^{206}$ ) Hanserezesse I 3 n. 240, Ziff. 8 No. 9-13. 
ist, gezwungen werden, denselben in Damme zu stapeln ${ }^{207}$ ), und demselben Zwange würden sie unterworfen, wenn sie mit Wein nach Sluys kämen, den sie nach England oder nach der Ostsee verschiffen wollten ${ }^{208}$ ). Das Zwin ist eben der Ausgangspunkt für die Schiffahrt nach allen Teilen der Welt; hier laufen alle Schiffahrtsrouten zusammen und findet sich regelmäßig Frachtgelegenheit nach allen Teilen der Welt; von hier aus nehmen deshalb auch die Kölner ihre Verschiffungen nach dem Osten wie nach England vor. Auch für Asche, gewisse Felle, Pferde und Vieh, Butter und anderes mehr war Damme Stapelplatz. In einer Urkunde von 1360 wird ein Haus der Deutschen zur Lagerung der Asche dort erwähnt ${ }^{209}$ ), und mehrere Urkunden zeigen, daß deutsche Kaufleute dort Asche verkauften $\left.{ }^{210}\right)$. So waren für die meisten schwer transportablen Massenartikel, welche nur mit großen Kosten und Mühen nach Brügge hätten hinaufgeschafft werden können, Stapelplätze am Zwin selbst unmittelbar bei den Liegeplätzen der Schiffe vorgesehen. Alle anderen Waren, von den Waren der hansischen Kaufleute insbesondere also Pelzwerk, Wachs, Wolle, Kupfer usw., und ebenso die Gewürze und Kostbarkeiten der Italiener u. a. m. mußten zum Stapel nach Brügge geschafft werden, wo namentlich auch der Tuchstapel war.

Die Wasserverhältnisse des Zwin waren um die Mitte des 14. Jahrhunderts bereits so schlecht geworden, daß die Schiffe sehr oft nicht mehr nach Damme oder Houcke und Monekerede heraufkommen konnten und weiter unterhalb am Zwin liegen bleiben mußten. Diesem Umstande verdankt offenbar das weiter unterhalb am Zwin gelegene Sluys, das seit dem Ende des 13. Jahrhunderts emporzuwachsen beginnt ${ }^{211}$ ), seine Ent-

${ }^{207}$ ) Hanserezesse I 3 n. 240, Ziff. 8 No. 8.

${ }^{208}$ ) Ebenda No. 9. Über das Zwin wird regelmäßig das Schiffahrtsgut, das aus Frankreich, England und Preußen über See kam (s. Kölner Zolltarif von etwa 1350-1360, Hans. Urkdb. III n. 545 Ziff. 50), nach Köln gelangt sein.

${ }^{209}$ ) Hansarezesse I 1 n. 249.

210) Ebenda I 1 n. 249, 251, I 3 n. 236.

211) Pirenne, Geschichte Belgiens, übers. von Arnheim, Gotha 1899, I S. 312. - Häpke, Die Entstehung von Sluys in den Hans. Geschichtsbl. 1904-05, S. 65 ff. 
stehung und Entwicklung. 1358 klagen die Kölner ${ }^{212}$ ), daß die Wasserverhältnisse so mangelhaft sind, daß sie oft drei bis vier Wochen liegen müssen, ehe der Wasserstand ausreichend ist, um zu dem Stapel nach Damme kommen zu können, und daß ihnen, wenn sie mit ihren Waren nach Damme kommen und der Wasserstand so niedrig ist, daß sie nicht in ihr Kreuz (cruytze) ${ }^{213}$ ), das ist wohl ihr Liegeplatz, gelangen können, doch nicht gestattet wird, ihre Waren zu verkaufen, ehe sie in ihr Kreuz gekommen sind, und daß sie oft hierdurch in große Gefahr kämen ${ }^{214}$ ). Aus den Klagen der Deutschen in jener Zeit ergibt sich weiter, daß schon damals die Schiffe mit Holz und Getreide vielfach bei Sluys lagen und dort ihre Waren verkauften ${ }^{215}$ ). Aus dem Privileg, welches 1367 den Kastilianern verliehen wird $\left.{ }^{216}\right)$, geht hervor, daß auch. die Schiffe der Spanier bereits ihren Liegeplatz regelmäßig zu Sluys hatten; dort sollten die spanischen Schiffe nach diesem Privileg bis zu fünf in einer Reihe liegen dürfen; den Schiffern sollte gestattet sein, ihre Schiffe zu Sluys aufs Land zu ziehen, um sie nachzusehen und zu reparieren usw. Doch mußte der spanische Wein nach wie vor nach Damme gebracht werden. In Damme sollten die Spanier die Weine nach ihrem Belieben auf ihren Schiffen oder auf dem Kai verkaufen dürfen, ohne gezwungen zu sein, sie in die Keller dort zu bringen; bei hohem Wasserstande scheinen die spanischen Schiffe also auch wohl noch selbst nach Damme gekommen zu sein; doch behandelt das Privileg ausdrücklich auch den Fall, daß ein Leichterschiffer zu Sluys Wein und andere den Spaniern gehörende Waren einnimmt, um sie nach Damme zu führen, und Eisen und andere Waren von ihnen empfängt, um sie nach Brügge zu bringen. Außer dem Holz- und Getreidehandel scheint auch der Salz-

${ }^{212)}$ Hansarezesse I 3 n. 240. Ziff. 8 No. 8.

${ }^{213}$ ) Durch die Kreuze scheint das Weichbild der Stadt begrenzt zu sein. So war das Weichbild des Ortes Muiden am Zwin durch 4 Kreuze, die teils auf dem Lande, teils im Wasser aufgestellt waren, abgegrenzt, s. Häpke, Die Entstehung von Sluys, i. Hans. Geschichtsbl. 1904-05, S. 72.

214) Hansarezesse I 3 n. 240 Ziff. 8, No. 10.

${ }^{215}$ ) Ebenda I 1 n. 249 I 3 n. 240, Ziff. 1d, 4b, 5 No. 1, 8 No. 9.

${ }^{216}$ ) Finot, a. a. O. S. $97 \mathrm{ff}$. 
handel damals bereits bei Sluys seinen Sitz gehabt zu haben. Die Bestimmung des Privilegs von 1360 an die Deutschen, daß die Zahl der Salzmakler zu Sluys nicht kleiner als vier sein sollte ${ }^{217}$ ), läßt erkennen, daß die Ostseefahrer ihre Salzrückfrachten hier erhielten.

Das Verbot dieses Geschäftsbetriebes bei Sluys und der von Brügge damals ausgeübte Zwang, Getreide und Holz sogar nach Brügge zum Stapel hinaufzuschaffen, sind, wie die Klagen der Kaufleute ergeben, offenbar einer der wesentlichsten Punkte der Beschwerden, welche zur Verlegung des Stapels führten. Die Zulassung des Handels in und bei Sluys war eine derjenigen Fragen, über welche am schwersten eine Einigung zwischen den Flamländern und den Deutschen erzielt werden konnte. Die Entwürfe der neuen Privilegien der flandrischen Städte und des flandrischen Grafen von 1359 sahen ausdrücklich die Bestimmung vor, daß die deutschen Kaufleute einerseits ihre Waren, die sie in das Zwin einführten, zum Stapel nach Brügge, Damme, Monekerede und Houcke hinaufbringen müßten, andererseits mit den Gütern, die sie in Flandern erwürben, überall außer nach Sluys hinziehen dürften ${ }^{218}$ ); Korn, Holz und Salz sollten sie zwar im Zwin von Schiff zu Schiff laden, aber nicht zu Sluys landen dürfen ${ }^{219}$ ). Auf diese Bestimmungen weigerten sich indessen die Deutschen, sich einzulassen. Erst als der Graf und die drei flandrischen Städte sich bereit erklärt hatten, die auf Sluys bezüglichen Bestimmungen gänzlich aus dem Privileg zu streichen ${ }^{220}$ ), fanden sich die Deutschen zur Annahme der Privilegien und Rückkehr nach Brügge bereit. Ob damit aber die Landung von Waren in Sluys wirklich zugestanden sein sollte, muß allerdings dahingestellt bleiben. Zehn Jahre später hören wir jedenfalls von neuem Klagen der hansischen Kaufleute darüber, daß sie zu Sluys keine Waren landen dürften ${ }^{221}$ ).

${ }^{217}$ ) S. Hans. Urkdb. III n. 497 Ziff. 45.

$\left.{ }^{218}\right)$ Ebenda n. 430 Ziff. 17, 452 Ziff. 65.

219) Ebenda n. 452 Ziff. 6.

${ }^{220}$ ) Hansarezesse I 1 n. 238 ff.

${ }^{221}$ ) Ebenda n. 518. 
Was Brügge mit allen diesen Mitteln verhindern wollte, war die Verschiebung des Weltmarktes von Brügge nach Sluys, die freilich höchst wahrscheinlich eingetreten sein würde, wenn Brügge nicht durch die Stapelbestimmungen mit solcher Rücksichtslosigkeit Sluys niedergehalten hätte. Denn Sluys war für die Seeschiffe noch gut zu erreichen und wurde mehr und mehr der Liegeplatz der Schiffe, die deshalb auch dort am liebsten . ihre Ladung landeten. Leidenschaftlich bekämpfte Brügge diese Rivalin. Als 1323 der Graf von Flandern die Stadt Sluys dem Grafen von Namur zu Lehen gegeben hatte und zu befürchten stand, daß Sluys nunmehr sich des Sehutzes eines mächtigen Lehnsherrn erfreuen und mit dessen Hilfe die Stapelrechte Brügges durchbrechen würde, da erhob sich sofort die Bürgerschaft Brügges, erstürmte Sluys, brannte den Ort nieder und setzte den Grafen von Namur ${ }^{222}$ ) gefangen; der Graf von Flandern aber sah sich angesichts dieser Haltung Brügges veranlaßt, die alten Stapelrechte Brügges sogleich in unveränderter Weise aufs neue zu verbriefen ${ }^{223}$ ).

Die vorstehenden Ausführungen sollen veranschaulichen, wie der Verkehr der verschiedenen Haupt- und Nebenplätze am Zwin wirtschaftlich eine Einheit bildete, die ihren Mittelpunkt in dem Weltmarkt Brügge besaß; sie lenken die Aufmerksamkeit zugleich auf die Veränderungen, welche das Zwin durchmachte und welche in späterer Zeit von so weittragender Bedeutung werden sollten.

Kehren wir nun zu unserem Ausgangspunkt, dem Verkehr der Deutschen am Zwin, zurück. Wie im 13. Jahrhundert treffen wir hier Kaufleute aus allen Hansestädten des Ost- . und Nordseegebietes an, Bürger von Riga, Reval, Wisby, den wendischen Städten, Lübeck, Hamburg, Köln, den westfälischen Städten, Goslar, Braunschweig, Hildesheim, Göttingen, Hameln und andern sächsischen Städten, brandenburgischen Örtern wie Perleberg, Preußen usw. ${ }^{224}$ ). Der Geschäftsbetrieb der Deutschen

222) Pirenne, Geschichte Belgiens, übers. von Arnheim, II S. 95.

${ }^{223}$ ) Hans. Urkdb. II n. 401.

224) Vgl. z. B. Hanserezesse I 3 n. 240; ferner Hans. Urkdb. III n. 216 (Göttingen), 221 (Hameln), 393 (Braunschweig, Goslar). 
am Zwin hatte nach wie vor seinen Stützpunkt in den dort ansässigen Genossenschaften, die freilich in diesem Zeitraume erhebliche Wandlungen erfuhren. Im 13. Jahrhundert sahen wir dort vier Gruppen von deutschen Kaufleuten nebeneinander bestehen, die Kaufleute der Genossenschaft von Gotland, die kölnischwestfälische Genossensehaft und die beiden Genossenschaften der Lübecker und Hamburger mit ihren Gefolgschaften. Von einem Zusammenschlusse dieser Gruppen zu einer einheitlichen Hanse, wie sie in England sehon seit dem letzten Drittel des 13. Jahrhunderts bestand, hören wir in Flandern erst um die Mitte des 14. Jahrhunderts, und zwar noch etwas später als in Bergen in Norwegen, wo die hansa teutonica schon im Jahre 1343 als geschlossene Einheit erwähnt wird. Erst dem Jahre 1347 gehören die ersten Nachrichten über eine einheitliche Genossenschaft der deutschen Kaufleute in Flandern an. Es sind die Statuten, welche die deutschen Kaufleute in Flandern in diesem Jahre gemeinsam beschlossen. Diese Satzungen der Gesamtgenossenschaft von 1347 zeigen, daß die verschiedenen Genossenschaften zu einer Gemeinschaft mit einheitlicher Vertretung nach außen und einer Reihe wichtiger gemeinsamer Einrichtungen zur inneren Ordnung ihrer Verhältnisse in Brügge und ihres von dort ausgehenden Handelsbetriebes zusammengetreten waren. Die Eingangsworte der Satzungen besagen, daß die gemeinen Kaufleute aus dem römischen Reiche von Alemannien in diesem Jahre zu Brügge im Reventer des Karmeliterklosters sich versammelt und besehlossen hatten, ,dat se wolden hebben ende halden en ghemene bok, da er men in screve alle ordinancien ende wilcore", die sie machten und was sie an costumen ende usazien halten sollten. Es ist nach diesem Wortlaute also wohl anzunehmen, daß eine losere Verbindung unter den deutschen Kaufleuten schon vorher bestanden hatte, die nun festere Gestalt erhielt, zu einer Genossenschaft oder Hanse, wie man damals sagte, wurde. Zwar kommt das Wort Hanse in dem Beschlusse von 1347 nicht vor; es ist lediglich von den ghemenen copluden die Rede. Aber in einer wenige Jahre jüngeren Urkunde dieser Genossenschaft finden wir diese, die kaufmännische Genossenschaft bezeichnende Benennung ausdrüeklich für die Vereini- 
gung der deutschen Kaufleute in Flandern gebraucht ${ }^{225}$ ), und ebenso benennen sich in dem Beschlusse der zu Lübeck 1358 versammelten Städtegesandten, welcher die Verlegung des Stapels von Brügge nach Dordrecht zum Gegenstand hatte, die Ratmannen der Städte Lübeck, Goslar, Hamburg, Rostock, Stralsund, Wismar und Braunschweig als die Vertreter van unsem driddendiele aller koplude des Romesschen rikes van Alemannien van der Dudeschen hanse, de to Brugge in Vlandern pleghen to wesende ${ }^{226}$ ).

Indessen waren die früheren Einzelgenossenschaften keineswegs in dieser Gemeinschaft aufgegangen; als Unterabteilungen dieses Bundes bestanden sie weiter und führten in mancher Beziehung, so namentlich in bezug auf ihre Finanzorganisation, ein durchaus selbständiges Leben, gleichsam wie Bundesstaaten im Einheitsstaat, fort. Im einzelnen hatten diese Genossenschaften sehr bemerkenswerte Veränderungen erfahren, und während wir am Ende des 13. Jahrhunderts noch vier solche Genossenschaften in Flandern nebeneinander bestehen sahen, finden wir un die Mitte des 14. Jahrhunderts daselbst nur noch deren drei.

${ }^{225}$ ) Beschluß der Genossenschaft von 1350 (Hans. Urkdb. III n. 160): so droch de mene copm a n $n$ over e e n end ordineerde dese ponte, de hirna stan bescreven:

1. Dat is te wetene, dat nen $\mathrm{c}$ o $\mathrm{p} \mathbf{m}$ a $\mathrm{n} n$, de to der $\mathrm{D} u \mathrm{~d}$ e $\mathrm{s} \mathbf{c h}$ e $\mathbf{n}$ h e $\mathrm{z}$ e behort, sal nene gheselscap noch wedderlegginge maken noch holden stille noch openbare met Tidemanne Blomenroed vorseyt.

2. Vortmer in wat scepe Tidemann vorseyd of sine gheselscap er gud in scepen, dat dar nen copmann, de to der D u d e s c h e $\mathrm{n}$ he nze behore, sin gud inschepen sol noch leghen.

3. Vort so ne sal neyn scephere, de ghewonnen were of ghevrachtet van den he n z e broders, Tidemanns vorseyd noch siner ghesellen god voren noch unthalen.

Wie soll die Genossenschaft in Flandern berechtigt sein, einen Kaufmann aus der „Hanse“ auszuschließen, wenn unter der Hanse an dieser Stelle nicht die Genossenschaft in Flandern zu verstehen ist, sondern, wie Stein, Die Genossenschaft der deutschen Kaufleute zu Brügge in Flandern, Breslau 1890, S. 15, mit Koppmann meint, die Stădtehanse, deren stimmberechtigte Mitglieder allein die Stadtobrigkeiten sind?

226) Hansarezesse I 1 n. 212, 213. Die von Stein, a. a. O. S. 15 mit Koppmann beliebte Deutung des Wortes Hanse an dieser Stelle als der Städtehanse widerspricht dem klaren Wortlaute der Urkunde. 
Eine von diesen ist die Genossenschaft der deutschen Kaufleute auf Gotland, in der auch die Kaufleute der livländischen Städte und die deutschen Kaufleute, die von schwedischen Plätzen aus Handel trieben ${ }^{227}$ ), Aufnahme gefunden hatten. Der Kern des Interesses, welches die Deutschen von Wisby und die livländischen Städte in Flandern zusammenhielt, war der russische Handel.

In der zweiten der Genossenschaften, derjenigen der Kaufleute aus den rheinisch-westfälischen Städten, hatten inzwischen auch die preußischen Kaufleute Aufnahme gefunden ${ }^{228}$ ). Wir haben bereits oben die außerordentliche Bedeutung, welche die süderseeische Schiffahrt im Verkehre Preußens mit Flandern hatte, betont. An der süderseeischen Schiffahrt waren zugleich die Westfalen in hohem Grade interessiert. Diese gemeinsamen Schiffahrtsinteressen sind es offenbar gewesen, welche die Preußen und Westfalen zum Anschluß aneinander in Flandern führten.

Die Niederländer selbst standen in der Hauptsache außerhalb der Gemeinschaft der deutschen Kaufleute. An dem russischen Handel, dem Rückgrat des ganzen hansischen Verkehrs, hatten weder die Süderseeer ${ }^{229}$ ) noch die Holländer oder See-

${ }^{227}$ ) Über die Abhängigkeit des schwedischen Handels von Gotland s. oben S. 47.

${ }^{22}$ ) Über die bisherigen, sămtlich ergebnislosen Versuche, die Verbindung der Preußen mit den Westfalen in Flandern zu erklären,, s. Sattler, Das Ordensland und die Hanse bis zum Jahre 1370, in Preuß. Jahrbüchern 1879, Aprilheft S. 336. Derselbe, Das westfälisch-preu Bische Drittel der Hanse, in Hans. Geschichtsbl. 1879, S. 69. Koppmann, Hans. Geschichtsbl. 1879, S. 75 ff. Schäfer, Die Hansestädte und König Waldemar S. 250 Note 2, und Hans. Geschichtsbl. 1880-81, S. 140 ff. - Bereits Sattler hat gegenüber Schäfer treffend betont, daß die Gründe der Dritteilung der Hanse in Flandern nicht in der Ordensgeschichte, wie Schäfer meint, zu suchen seien, Hans. Geschichtsbl. 1879, S. 73. Auch Schäfer gibt zu, daß die Drittteilung bis 1370 fast nur bei Beratungen über flandrische Angelegenheiten Anwendung finde. - Die Tatsache, daß neben Lübeck und Wisby 1363 auch Riga zur Oberleitung des Kontors zu Nowgorod zugelassen wurde, somit also auch hier eine Dreizahl vorlag (Koppmann, a. a. O. S. 76 f.), hat nichts mit der Dritteilung der Hanse zu tun. Vgl. auch Daenell, Die Blütezeit der deutschen Hanse, I S. 308.

229) Vgl. oben Note 38. 
länder Anteil; unter den Städten, welche gegen Ende des 13. Jahrhunderts zur Abgabe ihrer Stimme über die Frage aufgefordert wurden, ob die Berufung gegen die Entscheidungen des Hofes zu Nowgorod fortan an Lübeck oder an Wisby gehen solle, ist keine einzige niederländische Stadt ${ }^{230}$ ). Diese Tatsache bestätigt, daß die Niederländer am Handel des Hofes zu Nowgorod nicht beteiligt waren; sie hatten dort keinen $\mathrm{Zu}$ tritt. Dementsprechend finden wir die Niederländer in der Hauptsache auch in Flandern von den deutschen Genossenschaften gesondert. Zwar lehnten sich die Kaufleute einer Reihe von kleineren Städten der Südersee und Frieslands, wie Harderwijk, Zütphen, Deventer, Groningen, vielleicht auch Arnhem und Nymwegen, in Flandern an die deutsche Genossenschaft $a^{231}$ ) und fanden hier, vermutlich bei der westfälischen Gruppe, Schutz und Anteil an den Vorteilen, welche die Deutschen in Flandern genossen, wie denn in dieser Zeit eine strenge Abschließung in der deutschen Genossenschaft in Flandern in dieser Beziehung überhaupt nicht geübt wurde und mancherlei Gäste aus nichthansischen Plätzen geduldet wurden ${ }^{232}$ ). Da-

${ }^{230}$ ) Die Versendung erfolgt an Köln und die binnenländischen Stădte Westfalens und Sachsens, an die wendischen, preußischen und livländischen Städte nebst Wisby ; von den Nordseestädten nur an die Elbstädte Hamburg und Stade. Bremen, das in der ersten Hălfte des 13. Jahrhunderts, ebenso wie Groningen, noch eine so große Rolle im russischen Handel gespielt hatte, war seit 128' aus der Gemeinschaft der Städte ausgeschlossen; Groningen trat schon in der zweiten Hälfte des 13. Jahrhunderts ganz zurück und hatte keinen Anteil mehr am Ostseehandel. Im Jahre 1358 beklagte es sich unter Bezugnahme auf seine einstmalige Teilnahme am großen Handelsverkehr, daß Lübeck es nicht mehr als Mitglied der Hanse in Flandern behandele, und versprach, die Beschlüsse der Hanse zu befolgen. Hans. Urkdb. III n. 389.

231) Vgl. Hansarezesse I 2 n. $192 \S 19$. Die hansischen Vertreter wollen 1379-80 sich bei Zütphen und den andern Städten, die dabei belegen sind, erkundigen, ob es wahr ist, daß die Arnheimer früher, wie sie behaupten, zum hansischen Kontor von Brügge zugelassen sind. Ebenso n. 342 \$14: Die Kaufleute des Kontors in Brügge wollen 1387 sich bei Deventer und Harderwijk erkundigen, ob es wahr ist, daß die Nymweger früher Zutritt zur deutschen Genossenschaft in Brügge gehabt haben. Hinsichtlich Groningens vgl. Hans. Urkdb. III n. 389; s. hierzu unten S. 272 ff.

${ }^{232}$ ) Vgl. Stein, Die Genossenschaft der deutschen Kaufleute in Flandern, S. 19 f. 
gegen finden wir die Kampener am Zwin durchaus von den Deutschen getrennt; sie aber waren die eigentlichen Repräsentanten der Süderseeer; wie weit sie die übrigen überragten, zeigt sich z. B. 1315, als der Graf von Holland zum Kampfe gegen Flandern Schiffe aufbietet und Kampen nicht weniger als 18 Koggen stellt, während Zwolle und Stavorn je zwei, Harderwijk, Zütphen und Wilsum je eine Kogge, Dordrecht und Briel je einen Holk liefern ${ }^{233}$ ). 1358 sehen wir die Kampener bei dem Zerwürfnisse der Deutschen mit den Flamländern sogar auf die Seite der Flanderer treten; als die deutschen Städte die Zufuhren aus der Ostsee nach Flandern abschneiden wollen und ein Verkehrsverbot erlassen, halten die Kampener diesen Verkehr aufrecht ${ }^{234}$ ) und erwerben 1359, 1360 und 1361 gesondert von den Deutschen Privilegien ${ }^{235}$ ): Ebenso sehen wir sie in Norwegen, ungeachtet des zeitweiligen Zusammengehens mit den Deutschen, doch durchaus selbständig neben diesen Privilegien erwerben; 1305 verpflichtete sich Kampen ja sogar dem norwegischen Könige gegenüber, den Verkehr nach Norwegen aufrecht $\mathrm{zu}$ erhalten, auch wenn die wendischen Städte denselben einstellen sollten ${ }^{236}$ ). Auch die Niederländer, welche in der deutschen Genossenschaft in Flandern geduldet wurden, erlangten damit nicht etwa die Rechte, die dem Kaufmanne der an dem hansischen Handel beteiligten deutschen Städte in andern fremden Ländern zustanden; die Kontore zu Norwegen ${ }^{237}$ ), $\mathrm{zu}$ Nowgorod usw. wurden ihnen dadurch nicht geöffnet, sie blieben lediglich Gäste der flandrischen Genossenschaft. Nur in England scheinen die Niederländer wohl Auf-

$\left.{ }^{233}\right)$ Hans. Urkdb. II n. 262; vgl. auch Schäfer, Die Hansestädte und König Waldemar, S. 458.

234) Hans. Urkdb. III n. 459, 464.

${ }^{235}$ ) Ebenda n. 464, 497-500, 508, 518.

${ }^{236}$ ) Ebenda II n. 70 Ziff. 7. Hanserezesse I n. 1 S. 53.

${ }^{237}$ ) Es erhellt dies deutlich aus Hanserezesse I 1 n. 510 \$ 7 , wo 1369 den Ratsherren von Deventer, Ellburgh und Zütphen von den Hansestädten Briefe für die Leiter des hansischen Kontors in Bergen mitgegeben werden, damit die Leiter des Kontors den Bürgern dieser Städte Zutritt zu den.Höfen der Deutschen in Bergen gestatteten; sie hatten also an sich keinen Zutritt dort, wurden auch dort nur Gäste. 
nahme in die dortige deutsche Hanse gefunden $\mathrm{zu}$ haben ${ }^{238}$ ), freilich nicht auf Grund eines Beschlusses der flandrischen Genossenschaft, sondern kraft autonomer Entscheidung der deutschen Genossenschaft in England. Bei den Verhandlungen und Beratungen der deutschen Städte über flandrische Angelegenheiten sind dagegen die süderseeischen Städte ebenso wie die holländischen und seeländischen nie beteiligt.

Indessen bestand ein höchst wichtiger Unterschied zwischen den Süderseeern und den Holländern und Seeländern. Die Süderseeer wurden nämlich von den Deutschen auf Gotland zum Verkehre zugelassen, wenn sie auch nicht in die deutsche Genossenschaft dort aufgenommen wurden ${ }^{239}$ ). Den Holländern und Seeländern blieb dagegen der Zutritt in Gotland verwehrt. Schon aus den beiden den létzten Jahrzehnten des 13. Jahrhunderts angehörenden Schreiben ${ }^{2 \cdot 10}$ ), in welchen Kampen und Zwolle Lübeck danken, daß es dem alten Rechte wieder Anerkennung verschafft habe, nach welchem Friesen und Flanderer nicht in die Ostsee nach Gotland, die Goten nicht in die Westsee fahren dürften, geht hervor, daß den Kampenern und ihren Nachbarn in der Südersee die Fahrt um Jütland herum nach Gotland offenstand ${ }^{241}$ ). Auch im 14. Jahrhundert sehen wir wiederum Kampener Schiffe regelmäßig ${ }^{242}$ ) die Reise von Got-

${ }^{238}$ ) S. Hans. Urkdb. II n. 69 u. ebenda S. 336. Hinsichtlich Deventers vgl. die Unterzeichnung des Schreibens der Londoner Hanse an Rostock 1303 durch einen Bürger von Deventer (Lappenberg-Sartorius, Urkundl. Gchesichte des Ursprungs der deutschen Hanse I, S. 308). Ebenso haben die Dinanter Aufnahme in der Hanse der deutschen Kaufleute in England gefunden, ohne je zur Städtehanse hinzugezogen zu werden.

${ }^{239}$ ) Hans. Urkdb. III n. 277. Wisby schreibt 1353, als Kampener Schiffer seinen Bürgern im Sund Waren geraubt hatten, an Lübeck, daß es mit Kampen im Frieden sei, daß es den Kampenern zur Zeit des Raubes Sicherheit beim Verkehr in Wisby wie dem deutschen Kaufmann gewährt habe usw. Kampen gehörte also offenbar nicht zu ,dem deutschen Kaufmanne" dort.

${ }^{240}$ ) Hans. Urkdb. I n. 1154, 1155.

241) Non solum ad utilitatem vestram vel $\mathrm{n}$ os $\mathrm{tr}$ a $\mathrm{m}$, schreiben Kampen und Zwolle ebenda.

${ }^{242}$ ) Hans. Urkdb. III n. 230. Die Festsetzung der Lohnsătze für Schiffsleute auf Kampener Schiffen in den Fällen, welche die Urkunde 
land durch den Sund zurücklegen, während Holländer und Friesen in dieser Fahrt nicht erwähnt werden ${ }^{243}$ ). Die Fahrten der Süderseeer nach Gotland und den livländischen Städten werden es den Süderseeern auch ermöglicht haben, Pelzwerk und Wachs den Märkten in Schonen zuzuführen, wie wir schon oben verfolgt haben; aber diese russischen Waren konnten sie nur aus zweiter Hand erwerben; der Zutritt zu den deutschen Kontoren in Rußland blieb ihnen verschlossen. Ihre Erklärung findet diese verschiedene Stellung der Süderseee und der übrigen Niederländer offenbar in den engen Beziehungen, in denen die Süderseeer zu den Westfalen standen.

Der Kampener Zolltarif aus der Zeit von $1340^{244}$ ) nennt die Westfalen an erster Stelle; er bezeugt ausdrücklich, daß die Westfalen über Kampen die Ausreise machen; er sieht besondere Zollvergünstigungen für die Rückfracht vor für den Fall, daß sie binnen Jahresfrist dahin zurückkehren. Es kam also offenbar wohl auch vor, daß die Rückkehr nicht innerhalb Jahresfrist erfolgte, daß also die Rückreise vom Auslande ein anderes Reiseziel als Kampen hatte. Als Gegenstand ihrer Rückverfrachtungen nennt er Hering und Tran; als Ausfuhrartikel bei der Ausreise nur Stahl in Fässern. Die Gegenstände der Rückfracht lassen erkennen, daß es sich um Reisen von Schonen oder von Norwegen handelte. Wie schon die genannten Artikel der Aus- und Einfuhr erkennen lassen, hat es sich bei diesem von Kampen ausgehenden und auf diesen Ort gerichteten Verkehr nicht um einen Arm des Welthandelstromes, sondern um einen bescheidenen Nebenzweig des Nordseehandels gehandelt. Es kann kein Zweifel sein, daß für die Handelsunternęhmungen der Westfalen von Schonen und Norwegen aus geradeso wie für alle andern Deutschen das Hauptziel nicht etwa Kampen, sondern das Zwin, der große Weltmarkt Brügges, war, wo ja übrigens auch für

behandelt, läßt ohne weiteres auf ein regelmäßiges Vorkommen dieser Fälle schließen.

${ }^{243}$ ) Die Amsterdamer unterhalten z. B. Fahrten von den wendischen Städten, von Preußen, von Schweden, von Dănemark, Hans. Urkdb. III n. 553. Gotland wird nicht erwähnt.

244) Hans. Urkdb. II n. 668. 
die Niederländer in ähnlicher Weise wie für die Lübecker, Hamburger und übrigen hansischen Kaufleute der Mittelpunkt ihrer Geschäftstätigkeit war, wie wir für das Ende des 13. Jahrhunderts schon oben dargelegt haben ${ }^{245}$ ), und wie urkundliche Nachrichten aus dem 14. Jahrhundert uns ebenfalls bestätigen ${ }^{246}$ ). Das Bestehen einer Schonenfahrergilde in Dortmund ${ }^{247}$ ), einer Genossenschaft ,der Kaufleute, die Kopenhagen und Dragör besuchen "in Deventer ${ }^{245}$ ), lassen erkennen, daß die westfälischen und overijsselschen Kaufleute sich am Verkehr auf Schonen in bemerkenswertem Umfange beteiligten. Die Vermutung liegt nahe, daß die Westfalen in Ermangelung eigener Schiffe vornehmlich die Schiffe ihrer benachbarten Hafenstädte für ihre Ausreisen und dementsprechend auch weiter für ihre Handelsfahrten zwischen den ausländischen Plätzen, zwischen denen sich ja ihr Handel rorwiegend abspielte, benutzten. In dieser Beziehung sind auch die zahlreichen Stellen des Kampener Rechtsbuches, welche von den Gästen auf den Kampener Schiffen und auf der Vitte zu. Schonen reden, zu beachten. ${ }^{249}$ ) Die enge Verbindung der süderseeischen und westfälischen Städte im norwegischen Handel erhellt u. a. aus dem gemeinsamen Schreiben ${ }^{250}$ ), das Wismar 1285 bei den Verwicklungen der am Handel mit Norwegen beteiligten deutschen Kaufleute namens der wendischen Städte an Osnabrück, Münster, Koesfeld, Soest, Dortmund, Kampen, Zwolle, Deventer, Zütphen, Harderwijk, Muiden, Stavorn, Leuwarden, Groningen, sowie Stade richtet; es ist in hohem Grade beachtenswert, daß von dieser ganzen Gruppe nur die Seestädte Kampen und Stavorn schließlich an den Verhandlungen teilnehmen, wie - denn auch 1293250) wiederum. Kampen und Stavorn die Interessen der Deutschen in Norwegen mit den wendischen Städten

$\left.{ }^{245}\right)$ S. oben S. $37 f f$.

$\left.{ }^{246}\right)$ Hans. Urkdb. II n. 388 u. 719.

$\left.{ }^{247}\right)$ Ebenda III S. 155 Note 1.

$\left.{ }^{248}\right)$ Ebenda II n. 493 Note 2; vgl. auch III S. 156 Note 1.

${ }^{249}$ ) Overijsselsche Stad, Dijk en Markeregten, I Deel, I Stuck, Zwolle 1875, S. 52 LXXXII ,Elc von onsen borghern ofte de mit onsen borg hernvaren“, S. 127 u. S. 128 (,,Bürger oder Gast" auf den Kampener Schiffen); ebenso S. 223.

${ }^{250}$ ) Hansarezesse I 1 n. 44; vgl. ebenda n. 45, 49, 50, 51, 56. 
zusammen wahrnehmen. Offenbar sind sie die gemeinschaftlichen Vertreter dieser ganzen Städtegruppe, weil auf ihren Schiffen die Kaufleute aller dieser verschiedenen Städte die norwegischen und schonenschen Reisen zurücklegen. Urkundliche Nachrichten aus dem 14. Jahrhundert über die Anwesenheit von Bürgern aus Münster, aus Hamm, aus Oldenzaal ${ }^{251}$ ), aus Deventer ${ }^{252}$ ) in Norwegen belegen auch für diese Zeit die Beteiligung der Westfalen am norwegischen Handel.

Der norwegische Verkehr der Westfalen wird auf ihre Beziehungen zu den Preußen allerdings kaum von Einfluß gewesen sein, wohl aber der Verkehr von Schonen, der, wie wir gesehen haben, im Welthandel eine ungleich wichtigere Rolle spielte als der norwegische Handelszug. In dieser Beziehung ist an die große Bedeutung Schonens als Umschlagsplatz und Zwischenstation zwischen Nordsee und Ostsee zu erinnern. Wir haben schon oben verfolgt,, wie die Kampener von Gotland, von den livländischen Städten, von Preußen usw. ihre Fahrt auf Schonen zu richten pflegten, um ihre Ladungen hier zu löschen und die so zusammengeführten Waren von hier nach dem Westen weiter zu verfrachten. Die auf das Zwin gerichteten gemeinsamen Fahrten der Westfalen und Preußen namentlich von Schonen aus auf den Schiffen der Süderseeer sind höchst wahrscheinlich die Ursache gewesen, daß die Preußen sich in Brügge an die Westfalen anschlossen. Aus dieser gemeinsamen Benutzung der niederländischen Frachtschiffe ergab sich höchstwahrscheinlich ein gemeinsames Interesse der Westfalen und Preußen, dessen Spitze gegen Lübeck gerichtet war. Wir haben schon oben erwähnt, daß, so lebhaft die Verkehrsbeziehungen der Preußen zu Lübeck waren, doch das Sehwergewicht ihrer Stellung in Flandern auf ihrem Verkehre durch den Sund lag, eben weil der von Preußen über LübeckHamburg nach Flandern führende Verkehrszug sich zu einem sehr erheblichen Teile in Lübecks Händen befand, während

251) Hans. Urkdb. III S. 97 Note 1.

${ }^{252}$ ) Ebenda II n. 504, III n. 376 Note 1; vgl. auch S. 161 Note 1 ebenda.

${ }^{253)}$ Ebenda n. 62, 63. 
sich der Verkehr Preußens durch den Sund dieser Vorherrschaft Lübecks naturgemäß entzog. Die Stärkung dieses Verkehrszuges durch den Sund bedeutete deshalb für die Preußen eine größere Unabhängigkeit und Selbständigkeit ihres Handelsverkehrs gegenüber Lübecks Vorherrschaft. In diesem Punkte begegneten sie aber höchstwahrscheinlich bei den Westfalen, deren Einfluß auf die Verhältnisse des russischen Handels seit dem Rückgange Wisbys und dem Aufsteigen Lübecks beständig im Sinken begriffen war, lebhaften Sympathien. Gerade der Verkehr über Schonen mit dem baltischen Gebiete bot auch den Westfalen die einzige Möglichkeit, sich dieser Bevormundung Lübecks zu entziehen und mag deshalb gern von ihnen gewählt sein. Jedenfalls erklärt dieser Gegensatz gegen die Stellung der Lübecker in Flandern vollends, warum es den Preußen ganz fern lag, dort Anschluß an die Lübecker zu suchen ${ }^{254}$ ).

Wahrseheinlich nur als eine Folge dieses Zusammenschlusses der Westfalen und Preußen in Flandern werden wir es anzusehen haben, wenn wir sie 1340 und 1346 gemeinsam Zoll- und Strandrechtsprivilegien ${ }^{255}$ ) für ihre Durchfuhr in Holland erwerben sehen. Wenigstens sind die in dem Privileg benannten Waren keineswegs nur solche, welche auf dem Wege durch den Sund befördert zu werden pflegten, sondern in erster Linie solche, welche für gewöhnlich den Weg über Lübeck-Hamburg nahmen; wir müßten sonst etwa gemeinsame Fahrten der Westfalen und Preußen auf süderseeischen und holländischen Schiffen auch auf dem Wege zwischen der Elbe und Flandern annehmen wollen.

$\left.{ }^{254}\right)$ Auch die wendischen Städte hatten allerdings in ganz ähnlicher Weise wie die preußischen bedeutendes Interesse an der niederländischen Schiffahrt, wie bereits oben nachgewiesen ist. Indessen waren sie einerseits durch eine Reihe gemeinsamer Interessen infolge ihrer Lübeck benachbarten Lage auf das engste von jeher mit Lübeck verbunden, und anderseits waren ihre Interessen an der Sundschiffahrt doch wesentlich geringer als die der Preußen (s. unten S. $263 \mathrm{ff}$., insbesondere S. $265 \mathrm{ff}$.), so daß es nicht wunder nehmen kann, daß wir sie auch am Zwin mit den Lübeckern vereint finden. Ebenso überwogen bei den livländischen Städten, welche gleichfalls an der niederländischen Schiffahrt interessiert waren, doch die mit Gotland gemeinsamen Interessen am russischen Verkehr.

${ }^{255}$ ) Hans. Urkdb. II n. 658, 674; III n. 88, 89, 669, 670. 
Der Anschluß der Preußen an die rheinisch-westfälische Genossenschaft in Flandern trug, wie wir sehen, eine Spitze gegen Lübecks Vorherrschaft in dem baltisch-flandrischen Verkehre. Vermutlich als Rückwirkung dieses Vorganges tritt uns nun gleichzeitig der Zusammenschluß der beiden Genossenschaften, welche vor allem das Interesse an dem baltischflandrischen Warenzuge über die Linie Lübeck-Hamburg vertraten, entgegen: wir finden die Lübecker und Hamburger nunmehr in Flandern zu einer Genossenschaft verschmolzen. Schon am Ende des 13. Jahrhunderts erkennen wir aus der weitgehenden, vielfach wörtlichen Übereinstimmung der Schiffrechte der lübischen und hamburgischen Hanse am Zwin, daß schon damals eine enge Verbindung zwischen den beiden Hansen bestanden haben muß; doch wies jede von ihnen noch eine gesonderte Organisation mit selbständigem Oldermann und getrennter, sogar wesentlich verschieden gestalteter Finanzordnung auf. Nunmehr finden wir die Lübecker und Hamburger mit ihren beiderseitigen Gefolgschaften in einer Organisation vereinigt. Diese neue Genossenschaft wird durch zwei aus ihrer Mitte gewählte Olderleute, welche sehr oft beide Lübecker sind, geleitet, die Besteuerung der Mitglieder ist für alle gleich, die Kasse eine einheitliche geworden. Zwar scheint die Körperschaft der Hamburger am Zwin noch nicht in jeder Hinsicht aufgelöst worden $\mathrm{zu}$ sein; wenigstens finden wir am Anfange des nächsten Jahrhunderts eine hamburgische Genossenschaft in Sluys erwähnt, welche aber der deutschen Genossenschaft in Brügge untergeordnet war und nach außen hin von dieser mit vertreten wurde. $\mathrm{Ob}$ es sich bei dieser hamburgischen Genossenschaft in Sluys um eine Fortsetzung der hamburgischen Hanse, die früher in Ostkerke und später in Houcke ihren Sitz hatte, handelt, oder ob hier eine neue Schöpfung vorlag, muß freilich dahingestellt bleiben. Alle wesentlichen Aufgaben der ehemaligen Hamburger Hanse am Zwin waren jedenfalls auf die vereinigte Genossenschaft der Lübecker und Hamburger mit ihren Genossen, den wendisehen und sächsischen Kaufleuten, übergegangen.

Diese drei Genossenschaften werden seit 1347 als die drei Drittel der gemeinen Kaufleute aus dem römischen Reiche von 
Alemannien in Flandern bezeichnet. Ihre Organisation war durch den Beschluß von 1347 dahin geregelt, daß jedes Jahr am achten Tage nach Pfingsten jedes Drittel zwei Älterleute aus seiner Mitte wählen sollte. In ihrer Hand lag die Vertretung des gemeinen Kaufmannes nach außen und die Sorge für die Beobachtung und Aufrechterhaltung der Satzungen. Die Abstimmung erfolgte getrennt nach Dritteln; jedes Drittel hatte eine Stimme; bei Veinungsverschiedenheiten entschied Stimmenmehrheit. Die beiden Älterleute hatten aus ihrem Drittel sechs Männer zu wählen, die aus den drei Dritteln zusammen den Achtzehnerausschuß bildeten. Dieser Achtzehnerausschuß vertrat gleichsam die Gesamtheit und war zuständig, in Gemeinschaft mit den Älterleuten zahlreiche Fragen, zu deren Erledigung eine allgemeine Versammlung der Kaufleute nicht berufen werden konnte, selbständig zu erledigen. Jedes Drittel hatte seine Kasse für sich; die gemeinsamen Unkosten wurden von den Dritteln zu gleichen Teilen getragen. Ihren Sitz hatte die Gesamtgenossenschaft aber nicht mehr in einem der Hafenplätze am Zwin, wie einst die lübeekische und die hamburgische Hanse am Ende des 13. Jahrhunderts in Ostkerke oder Houcke, sondern in Brügge selbst, wo sie im Karmeliterkloster ihre $\mathrm{Zu}$ sammenkünfte abhielt.

Wie im 13. Jahrhundert hat es auch in diesem Zeitabschnitte nicht an Reibungen und zeitweise sogar an ernsten Zerwürfnissen des gemeinen Kaufmannes mit den flandrischen Behörden gefehlt. Von 1307 bis $1309^{256}$ ) war der Stapel aus solchen Anlässen nach Aardenburg am Zwin oder einem Zuflusse zu demselben, von 1358 bis 1360 nach Dordrecht ${ }^{257}$ ) verlegt. Auch im Jahre 1351 wurde die Frage der Verlegung des Stapels ernstlich in Erwägung gezogen ${ }^{258}$ ). $\mathrm{Zu}$ einem gemeinsamen Vorgehen mit den romanischen Kaufleuten kam es nur im Jahre 1346, wo sich die Kaufleute von Deutschland mit denen von Kastilien, Portugal und Aragon, sowie von

${ }^{256}$ ) Hans. Urkdb. II n. 150, 154, 155; Hansarezesse I 1 S. 44 ff.

$\left.{ }^{257}\right)$ Vgl. hierüber $\therefore$. d. Osten, Die Handels- und Verkehrssperre des deutschen Kaufmannes gegen Flandern 1358-1360.

${ }^{258}$ ) Hảns. Urkdb. III n. 212, $217,221$. 
Piacenza wegen Benachteiligungen ihres Tuchhandels in Maubeuge vereinigten und gemeinsame Privilegien erwarben ${ }^{259}$ ).

Der nordwesteuropäische Verkehr und damit auch der Verkehr Brügges hat, wie schon erwähnt, in der ersten Hälfte des 14. Jahrhunderts einen gewaltigen Aufschwung durchgemacht. Noch im 13. Jahrhundert vollzog sich selbst auf dem Weltmarkte der Städte der Champagne und ebenso in den flandrischen Verkehrsmittelpunkten der Austausch im wesentlichen auf Messen und Jahrmärkten, wenngleich die sechs großen Messen in Lagny sur Marne, Bar sur Aube, Provins und Troyes sich schon im 13. Jahrhundert derart aneinanderreihten, daß sie eine fast ununterbrochene, nur noch örtlich wechselnde Meßzeit bildeten. Auch die fünf flandrischen Jahrmärkte, die im 13. Jahrhundert in Thourout, Ypern, Messines, Lille und Brügge abgehalten wurden und auf denen sich der große flandrische Tuchhandel abspielte, waren so über das Jahr verteilt, daß keiner mit dem andern zeitlich zusammenfiel und sie fast alle in mehrwöchigen Zwischenräumen aufeinander folgten $\left.{ }^{260}\right)^{\circ}$. Mit dem Ende des 13. Jahrhunderts hörten diese. flandrischen Messen auf. Der Verkehr war so groß geworden, daß es einer zeitlichen Konzentration von Angebot und Nachfrage in diesen Industriestädten nicht mehr bedurfte, eine solche vielmehr als eine schädliche Beschränkung des Handelsverkehrs empfunden wurde ${ }^{261}$ ). Damit hörten die fremden

$\left.{ }^{259}\right)$ Hansarezesse I 1 S. 81 ff.

${ }^{260}$ ) Stein, Über die ältesten Privilegien der deutschen Hanse in Flandern, in Hans. Geschichtsbl. 1902, S. 107 f. Pirenne, Geschichte Belgiens, Bd. I S. 192.

261) Pirenne, Geschichte Belgiens, Bd. I S. 300 f. Er verkennt jedoch ebenso wie Stein, Hans. Geschichtsbl. 1902, S. 110 f., die wirtschaftlichen Ursachen des Untergangs der Jahrmärkte, indem er sie ,in der Zunahme des überseeischen Verkehrs" zu finden glaubt und meint. die fremden Kaufleute hătten sich jetzt im Gegensatz zu früher von den Seestädten, von Brügge aus, nach den Städten des inneren Flandern begeben. Dieser Verkehr der Fremden, und zwar Deutschen, Gascogner, Spanier usw., von Brügge aus in das Innere Flanderns bestand schon im 13. Jahrhundert geradeso, nur daß er jetzt sehr zunahm und daß auch die Italiener, welche bisher wohl zum Teil von der Champagne aus die flandrischen Plätze besucht haben mochten, jetzt den Schwerpunkt ihres Warenhandels nach Brügge verlegten. 
Kaufleute, wie wir gesehen haben, nicht etwa auf, vom Zwin aus in die Städte der flandrischen Tuchproduktion, nach Ypern, Lille, Messines usw., zu reisen und dort ihre Tuche einzukaufen. Dieser Verkehr nahm vielmehr im Gegenteil ebenso wie die Tuchproduktion so zu, daß die gleichzeitige Verteilung desselben auf die verschiedenen Handelsplätze während des ganzen Jahres möglich und wünschenswert geworden war. Diese $\mathrm{Zu}$ nahme lag zum Teil in dem Zuwachs, den Flandern und sein Handelszentrum Brügge durch den Verfall der flandrischen Messen und die Übernahme des bisherigen Verkehrs derselben, insbesondere des Verkehrs der Italiener, erfuhren. Vor allem aber hatte auch der Handel der Deutschen in diesem Zeitraume einen gewaltigen Aufsehwung erfahren. Im englischen Handel sahen wir die Deutschen an die erste Stelle treten, in Norwegen den Verkehr der Engländer immer weiter zurückdrängen, von den Schonenschen Märkten nach dem zweiten dänischen Kriege die andern Fremden ausschließen, im russischen Verkehr sowohl den Wettbewerb der Goten als auch den Aktivhandel der Russen erdrücken. Der Höhepunkt ihrer Handelsvorherrschaft im nordwesteuropäischen Verkehr ist erreicht; schon treten gegen Ende dieses Zeitraumes sogar die ersten Anzeichen eines Rückganges derselben in die Erscheinung.

Es ist in hohem Grade bemerkenswert, daß der flandrische Aktivhandel in dieser Zeit in demselben Maße sinkt, in welchem Brügge zum Weltmarkt aufsteigt. Mit dem Verfall der Messen der Champagne verfiel natürlich auch der Tuchhandel der flandrischen Kaufleute dorthin; aber auch im englischen Handel, in welchem die flandrischen Kaufleute doch im 13. Jahrhundert noch stark in den Vordergrund getreten waren, spielen sie im 14. Jahrhundert nur noch eine bescheidene Rolle. Auch im nordischen Verkehre bedeuten sie im 14. Jahrhundert ebensowenig wie im 13. Jahrhundert. Ihre Erklärung findet diese Erscheinung in dem gewaltigen Aufschwung, den das Maklergewerbe und die Lagerhalterei und Fremdenbeherbergung in dieser Zeit in Brügge nahm ${ }^{262}$ ). Schon im Jahre 1285 stand

${ }^{262}$ ) Vgl. über das Folgende Ehrenberg, Makler Hosteliers und Börse in Brügge vom 13. bis zum 16. Jahrhundert, in Goldschmidts Zeitschrift des gesamten Handelsrechts, Bd. XXX, 1885, S. 403 ff., insbesondere S. $412 \mathrm{f}$. 
die Maklerzunft in Brügge an zweiter Stelle unter den Zünften Brügges und wurde nur von der Zunft der Tuchweber überragt. Seit dem Beginne des 14. Jahrhunderts hatte das Maklergewerbe auch die Tuchweberei in Brügge an Bedeutung überflügelt, indem es gleichzeitig sich mit dem Gewerbe der Fremdenbeherbergung und Speichereivermietung verschmolz. Die Bewältigung dieser Geschäfte auf dem Brügger Weltmarkte selbst nahm offenbar infolge des riesigen Wachstums des Fremdenzuflusses die Kräfte der Brügger Kaufmannschaft so in Anspruch, und der Gewinn aus dieser Geschäftstätigkeit war so viel müheloser, daß die Brügger Kaufleute zu einem nennenswerten Aktivhandel mit dem Auslande weder sich mehr instande sahen, noch Neigung fanden. Ihre Schiffahrt vollends war schon im 13. Jahrhundert von untergeordneter Bedeutung.

Was dem westeuropäischen Seehandel im 13. und 14. Jahrhundert ein so besonderes Gepräge gibt und den Weltmarkt Brügge so sehr in den Mittelpunkt unserer Betrachtung rückt, das ist die eigenartige Konzentration dieses ganzen Seeverkehrs auf den brüggischen Welthafen, das Zwin. Was England, Rußland, Schonen, Skandinavien, Preußen, die Gebiete der Oder, Elbe und Weser an Überschüssen ihrer wirtschaftlichen Produktion an den Handel abgeben, das fließt im wesentlichen dem flandrischen Markte zu. Der wirtschaftliche Austausch, der neben dem flandrischen Handelszuge besteht, ist gering und beschränkt sich zum größten Teil auf Lokalverkehr, tritt jedenfalls hinter dem flandrischen Verkehre überall ganz zurück. Auf dem flandrischen Weltmarkte vollzieht sich in der Hauptsache der Austausch aller dieser Länder untereinander und mit den Mittelmeerländern und Südwesteuropa. Die Bedeutung aber der deutschen Kaufleute im westeuropäischen Seehandel liegt darin, daß sie den Verkehr Rußlands, Englands, Schonens, Norwegens, Schwedens, des deutschen Inlandes und zu einem bescheidenen Teile auch wohl Südwestfrankreichs mit dem Weltmarkt Brügge als Reeder und Warenhändler besorgen. In diesem Zwischenhandel, der Vermittlung des Verkehrs zwischen Ausland und Ausland, liegt das eigentliche Wesen des deutschen Seehandels in dieser Zeit. 


\section{Viertes Kapitel.}

\section{Die Stadt Hamburg als Umschlagsplatz und Zwischenmarkt während der beiden ersten Drittel des 14. Jahrhunderts.}

Der Handel, der von der Stadt Hamburg selbst ausging oder wenigstens über sie führte, bewegte sich in der ersten Hälfte des 14. Jahrhunderts in den gleichen Bahnen wie im 13. Jahrhundert. Allem voran stand natürich noch immer die Vermittlung des großen baltisch-flandrischen Verkehrszuges. Wie im 13. Jahrhundert lag der Warenhandel in diesem Verkehre vorwiegend in Händen fremder Kaufleute, namentlich der Lübecker, während den Hamburgern vor allem die Transportgewerbe zufielen. Wie im 13. Jahrhundert sehen wir Hamburg vor allem bestrebt, die Landstraße nach Lübeck und die Wasserstraße nach Flandern sich zu sichern.

Zahlreich sind auch in diesem Zeitraume wieder die Verträge, welche Lübeck und Hamburg zum Schutze ihrer Verbindung abgeschlossen haben. Am 20. November 1304 vereinbaren sie bis Ostern 1306 die gemeinsame Einrichtung eines bewaffneten Geleites auf dieser Straße $\left.{ }^{1}\right)$. Vierzig berittene Bewaffnete wollten die Städte dauernd zu diesem Zwecke unterhalten; 32 sollte Lübeck, 8 Hamburg stellen; jeder Wagen sollte für jede Reise eine Abgabe von 1 Mark Pfennige dafür zahlen, und es sollten jedesmal mindestens zehn Wagen zusammen fahren; wollten ausnahmsweise weniger als zehn Wagen die Reise machen, so sollten sie dennoch die Mindestsumme von 10 Mark Pfennigen zusammen vergüten. Die Einnahmen sollten zu vier Fünfteln Lübeck und zu einem Fünftel Hamburg zufallen; unvorhergesehene besondere Ausgaben sollten im gleichen

1) Hans. Urkdb. II n. 62, 63. 
Verhältnis auf beide verteilt werden; Schaden, den Räuber und Angreifer den Bewaffneten zufügen, sollte jede Stadt selbst tragen. Im April 1306 wird dann dieser Vertrag auf weitere vier Jahre verlängert ${ }^{2}$ ). 1309 wird der Vertrag abermals erneuert und u. a. die. Bestimmung hinzugefügt, daß es jedermann zwar freistehen solle, einen oder mehrere Tage vor oder nach dem Abgange des mit Geleit reisenden Warenzuges auf eigene Gefahr ohne das Geleit die Reise zu machen, daß er aber in solchem Falle schwören müsse, keinem Fürsten oder Herrn Geld für seinen Schutz gegeben oder versprochen zu haben ${ }^{3}$ ). 1306 hatten sich die beiden Städte überdies zur Zerstörung der Schlösser Wohldorf, Ahrensfelde (= Ahrensburg?) und Travemünde, von denen die ersten beiden die Verbindung zwischen Lübeck und Hamburg, das dritte die Einund Ausfahrt der Trave beherrschten, gegen den Grafen von Holstein, den Lehnsherrn dieser Festen, verbündet ${ }^{4}$ ). Auch die Herzöge von Sachsen und eine Anzahl aus Holstein vertriebener Adligen wurden von den beiden Städten für den Plan gewonnen $\left.{ }^{5}\right)$. Der Graf Gerhard von Holstein schloß diesem drohenden Angriffe gegenüber ein Bündnis mit dem Herzoge von Mecklenburg und dem Herrn von Werle. Lübeck war durch die Feste zu Travemünde in schwere Bedrängnis versetzt. Die Grafen unterbanden aber nicht nur die Verbindung Lübecks mit dem Meere, sondern errichteten auch zu Oldesloe Befestigungen und hinderten somit den Verkehr mit Hamburg; Lübeck geriet dadurch in die äußerste Not. Als 1307 sich König Erich von Dänemark in die Angelegenheit einmischte, warf sich Lübeck ihm in die Arme und erkaufte

2) Hans. Urkdb. n. 85.

$\left.{ }^{3}\right)$ Ebenda n. 140.

$\left.{ }^{4}\right)$ Ebenda n. 89, 90, 95. Auch hier ist das Augenmerk der Städte für die Dauer der Vorbereitungen des Feldzuges vor allem auf die Sicherstellung der Verbindung der Ostsee zur Nordsee gerichtet: Si praeterea medio tempore in loco, qui Priwalc dicitur et ab illo loco et a Travemunde ascendendo usque Lubeke et a Lubeke versus terram Holsacie intra duo miliaria et abinde usque Oldeslo et ab Oldeslo usque Hamborgh et $a b$ Hamborgh $a b$ ista parte Albee versus terram Holsacie intra duo miliaria aliqua municia vel structura facta fuerit usw.

5) Ebenda n. 97. 
gegen eine Summe von 750 Mark jährlich auf zehn Jahre seinen Schutz ${ }^{6}$ ). Der König führte einen vorläufigen Vergleich herbei, in welchem die Grafen die Verpflichtung übernahmen, den Verkehr von dem Turme zu Travemünde aus nicht zu stören und die bei Oldesloe während des Krieges errichteten Befestigungen zu beseitigen; über den Besitz des Turmes zu Travemünde sollte der Kaiser entscheiden ${ }^{7}$ ). Im September 1307 tritt der König von Dänemark erneut den Grafen von Holstein gegenüber für den Schutz der Lübecker bei ihren Reisen durch Holstein ein ${ }^{8}$ ). Längere Zeit sind wir dann über die Maßnahmen zum Schutze der Straße nicht unterrichtet. Erst mit dem Jahre 1324 beginnen wieder die Nachrichten. Aus diesem Jahre ist eine Urkunde erhalten, laut welcher die Grafen Gerhard III. und Johann III. von Holstein das Geleit für den Verkehr zwischen Lübeck und Hamburg übernehmen und die gräflichen Mannen und Vasallen, welche die Warenzüge begleiten, ihres besondern Schutzes versichern ${ }^{9}$ ). 1327 beurkunden die beiden Grafen einen mit Lübeek und Hamburg abgeschlossenen Landfrieden und versprechen für Raub an den Stapelartikeln dieses Verkehrs, Wachs, Pelzwerk und Tuch, für welche Waren das vorgeschriebene Geleitsgeld von zwei Mark Pfennigen für den Wagen zu erheben ist, Ersatz zu leisten; für alle anderen Waren soll das Geleit unentgeltlich sein, doch leisten sie für Schaden an solchem Gute keinen Ersatz, sondern sichern nur Verfolgung auf dem Rechtswege $\mathrm{zu}^{10}$ ). 1328 wird dieses Abkommen für die Zeit bis zum 11. November erneuert ${ }^{11}$ ). 1333 schließen die beiden Städte mit den Herzogen von SachsenLauenburg und den Grafen von Holstein auf ein Jahr einen Landfriedensbund ab. Beraubung und Gefangennahme lübi-

$\left.{ }^{6}\right)$ Hans. Urkdb. n. 190; Hansarezesse I 1 S. 49 f.

$\left.{ }^{7}\right)$ Hans. Urkdb. II n. 105 und S. 45 Note 2. 1320 verspricht der Graf Johann III. von Holstein nach Úbereinkunft mit Lübeck den Turm zu Travemünde und dessen Festungswerke gegen Zahlung von $7000 \mathrm{~m}$. lüb. Pfennigen dem Erdboden gleich zu machen, Hans. Urkdb. II n. 374.

8) Ebenda n. 114.

9) Ebenda n. 421.

10) Ebenda n. 461.

11) Ebnnda n. 469. 
scher, hamburgischer oder ausländischer Bürger oder Kaufleute soll mit der Zerstörung der Feste des Räubers und schwerer Strafe geahndet werden ${ }^{12}$ ). Im folgenden Jahre wird dieses Bündnis erneuert ${ }^{13}$ ). 1338 kam wiederum zwischen Lübeck, Hamburg, Rostock, und Wismar ein Landfriedensbündnis mit den Herzogen von Sachsen, den Grafen von Holstein, den Grafen von Schwerin, dem Herzoge von Schleswig, dem Herzoge von Stettin und anderen Herren zustande ${ }^{14}$ ). In demselben Jahre versprach der Herzog von Sachsen-Lauenburg allen Kaufleuten Sicherheit auf den Straßen seines Landes ${ }^{15}$ ). Im August 1340 versichert Graf Johann III. von Holstein von neuem alle Kaufleute seines Schirmes und Geleites zwischen Lübeck und Hamburg bis Ostern 1341 ${ }^{16}$ ). 1341 geloben die Grafen wiederum für alles Gut zu Lande und zu Wasser zwischen beiden Städten Geleit und Schutz; für Schaden an Tuch, Wachs und Pelzwerk, von denen stets Geleitsgeld zu entrichten ist, versprechen sie wiederum Ersatz, für Schädigung an allem andern Gut, das unentgeltliches Geleit hat, wie früher, Verfolgung des Schadenstifters auf dem Rechtswege ${ }^{17}$ ). 1347 gewann Hamburg die Grafen von Holstein zur Bekämpfung verschiedener holsteinischer Raubritter, welche das Land unsicher machten, unter andern der Ritter von Hummersbüttel und der Schloßherren von Wohldorf und Stege an der oberen Alster, und die Grafen versprachen, die Schlösser zu Wohldorf und Stege zu zerstören, niemals an ihrer Stelle wieder Festen zu erbauen und sowohl die Alster als auch die alte Königstraße für ewig freizulassen ${ }^{18}$ ). Auch Lübeck wurde dann in den Streit mit diesen Raubrittern hineingezogen ${ }^{19}$ ). 1349 erfolgte der Abschluß eines neuen Landfriedensbündnisses zwischen den Herzogen von Sachsen und den Grafen von Holstein mit Hamburg und Lübeck auf drei

12) Hans. Urkdb. n. 536.

13) Ebenda n. 551 .

14) Ebenda n. 606; Hansarezesse I 1 S. 62 f.

$\left.{ }^{15}\right)$ Hans. Urkdb. II n. 625.

${ }^{16)}$ Ebenda n. 664 .

17) Ebenda n. 669.

${ }^{18)}$ Ebenda III n. 110.

19) Ebenda Note 2. 
Jahre $\left.{ }^{20}\right)$. Wie unsicher der Verkehr auf der Straße zwischen Hamburg und Lübeck trotz aller dieser Schutzmaßnahmen blieb, stellen die Beschwerden ins Licht, welche Lübeck und Hamburg 1342 gegen die Grafen zusammenstellten, als diese sich zum Austrage eines Streites mit ihnen und den wendischen Städten einem Schiedsgerichte unterwarfen ${ }^{21}$ ). Namentlich waren es die Ritter von dem Crummendike und die Herren von Hummersbüttel, über welche die beiden Städte sich beschwerten; sie hätten die lübischen Bürger und deren Gäste auf der Straße zwischen Lübeck und Hamburg beraubt, klagen die Lübecker, und als sie zur Herausgabe des Geraubten vom Grafen verurteilt seien, hätten sie den Lübeckern das Ihrige zurückgegeben, nicht aber den fremden Kaufleuten; oft seien ihre Bürger trotz des gräflichen Geleites beraubt, wenn die gräflichen Geleitsleute dabei geritten hälten; viele ihrer Bürger und Gäste hätten trotz des Geleites eine Menge Waren verloren ${ }^{22}$ ). Dieselbe Klage erheben die Hamburger: häufig seien ihre Bürger und Gäste trotz des gräflichen Geleites ihrer Waren beraubt, wenn die Geleitsleute daneben geritten hätten; zwei Fälle führten sie unter Nennung der Namen der Beraubten an; es seien aber noch viele andere derartige Fälle vorgekommen ${ }^{23}$ ).

Die Beförderung der Waren erfolgte bis Oldesloe zum größten Teile mit Wagen ${ }^{24}$ ) auf der Landstraße, die wohl schon damals über Ahrensburg nach Oldesloe führte. Vierzig Fuhrmeister - in dem Verzeichnis der Kaufleute und Amtsmeister Hamburgs von 1375 ,,de lubecker Vaar" genannt ${ }^{25}$ ) - lebten

$\left.{ }^{20}\right)$ Hans. Urkdb. III n. 139, 153.

21) Ebenda II n. 710 ff.

22) Ebenda n. 725.

${ }^{23}$ ) Ebenda n. 728. Die Grafen von Holstein versprechen 1343, die Ritter von Crummendik, von Porswelde, Blocksberg und Musgard, falls sie der von den Grafen mit der Stadt geschlossenen Sühne nicht beiträten, zu befehden, ihre Festen zu brechen usw., Hans. Urkdb. III n. 21; 1345 erklären die Ritter von Crummendik ihren Beitritt zu der Sühne, ebenda n. 57 .

24) Vgl. Wendt, Lübecks Schiffs- und Warenverkehr 1368 und 1369. Lübeck 1902, S. 36 f.

${ }^{25}$ ) Westphalen, Hamburgs Verfassung und Verwaltung 1841, Bd. I, S. 366 . 
in Hamburg von diesem Fuhrverkehr. Sehr viel größer noch mag die Zahl der in Lübeck beheimateten, mit diesen Transporten befaßten Fuhrmeister gewesen sein, wie auch die Verteilung der für den Schutz der Straße gemeinsam aufgewandten Kosten, von denen vier Fünftel Lübeck und nur ein Fünftel Hamburg trugen, annehmen läßt. Außer dem Transporte mit Wagen fand aber höchstwahrscheinlich auch schon, wie in der zweiten Hälfte des 14. Jahrhunderts, die Beförderung in Nachen auf der Alster bis zu einem Punkte an der oberen Alster mittels Leinenzuges und von dort zu Wagen nach Oldesloe statt. Die große Bedeutung, welche dem Besitze der Schlösser zu Wohldorf und zu Stegen an der Alster von beiden Städten beigelegt wurde, und die Zusicherung der Grafen, die Alster ebenso wie die alte via regia zwischen Hamburg und Lübeck für ewig freizulassen, weist deutlich darauf hin, daß dieser Wasserweg schon damals benutzt wurde. Zwischen Oldesloe und Lübeck wurde ein nicht unbedeutender Teil der Waren auf der Trave befördert ${ }^{26}$ ). In den Pfundzollbüchern Lübecks für das Jahr 1368 sind nach Wendt 51 Schiffe, nach Stieda 52 Schiffe als von Oldesloe in Lübeck eingelaufen, und nach Wendt 75, nach Stieda 93 als nach Oldesloe abgegangen aufgeführt ${ }^{27}$ ); es ist aber wohl zweifelhaft, ob überhaupt alle Schiffe eingetragen sind; vielleicht war die Zahl derselben in Wirklichkeit erheblich größer.

Schon die oben angeführte Taxe für das gräfliche Geleitsgeld, welches nur für die Stapelprodukte dieses Verkehrs, Pelzwerk und Wachs einerseits und Tuche andererseits, erhoben wurde, führt uns wiederum vor Augen, daß der Handel nach und von Rußland den Grundstock dieses Warenzuges bildete; auf den Schutz der russischen Waren und der flandrischen Tuche kam es im wesentlichen nur an; diese Waren bildeten die Hauptmasse des Verkehrs; wenn dieser Warenzug gesichert war - und der Graf übernahm ja die Haftung für diese Waren gegen die Zahlung des Geleitsgeldes -, war der Kaufmann

${ }^{26)}$ Vgl. Bruhns, Lübecks Handelsstraßen am Ende des Mittelalters, in Hans. Geschichtsbl. 1896, S. 46.

${ }^{27}$ ) Wendt, a. a. O. S. 42 f., Tab. Ia und lb.; Stieda, Schiffahrtsregister, in Hans. Geschichtsbl. 1884, S. 82 f. 
gegen alle schweren Verluste geschützt. Nach den lübeckìschen Pfundzollbüchern ${ }^{28}$ ) wurden im Jahre 1368 Waren im Werte von $1364431 / 4$ M. l., von Oldesloe kommend, in Lübeck verzollt; darunter nahmen Tuche den Betrag von 105623 M.l. ein; außerdem waren noch Tuche mit andern von Oldesloe kommenden Waren zusammen verzollt worden, deren Menge nicht mehr erkennbar ist, aber möglicherweise nicht unbeträchtlich war, da es sich um einen Posten von insgesamt $145401 / 2$ M. l. handelt, und endlich sind noch weitere Tuche im Werte von $6072 \frac{1}{2}$ M. l. in Lübeck 1368 zur Einfuhr gelangt, ohne daß als Herkunftsort Oldesloe ausdrücklich angegeben ist ${ }^{29}$ ); auch diese werden aber höchst wahrscheinlich von Hamburg hergekommen sein. Überdies wurden folgende Wertmengen ${ }^{\mathbf{3 0}}$ ) Tuch bei der Ausfuhr aus Lübeck verzollt, hatten also entweder bei der Einfuhr noch nicht dem Zoll unterlegen, oder ihre Verzollung bei der Einfuhr konnte infolge Besitzwechsels usw. bei der Ausfuhr nicht mehr nachgewiesen werden:

\begin{tabular}{|c|c|c|}
\hline \multirow{3}{*}{ Nach } & $\begin{array}{l}1368 \\
\text { Wert M. l. }\end{array}$ & $\begin{array}{c}1369 \\
\text { Wert M. } 1 .\end{array}$ \\
\hline & Riga....... 54101/4 & 12639 \\
\hline & Pernau .... $6049^{3 / 4}$ & $2400^{1 / 2}$ \\
\hline , & Reval ..... $3756^{1 / 2}$ & 3830 \\
\hline , & Gotland .... 1099 & $1506^{1 / 2}$ \\
\hline & zusammen & 20375 \\
\hline
\end{tabular}

Demnach entfielen von den Warenwerten, welche 1368 bei der Einfuhr von Hamburg nach Lübeck in letzterer Stadt verzollt wurden, mindestens 80 bis $90 \%$ auf Tuche.

Neben Tuchen bewegten sich natürlich noch mancherlei andere Erzeugnisse, wenn auch nicht in so großen Mengen, auf der Straße von Hamburg nach Lübeck. 1368 wurden in Lübeck, von Oldesloe kommend, folgende Waren dem Pfundzolle unterworfen ${ }^{31}$ ):

$\left.{ }^{28}\right)$ Wendt, a. a. O. S. 62-63. Hamburg erhob 1368 wenigstens bis zum 8. Oktober keinen Pfundzoll; so kam es, daß dieser von den vom Westen kommenden durchgehenden Waren erst in Lübeck erhoben wurde.

29) Wendt, a. a. O. Anhang S. 65.

so) Wendt, a. a. O. S. 50 ff.

31) Wendt, a. a. O. 
Wert M. l. Safran ............. 48

Tuche............ 102812

Sallun ............. 45

6 Terlinge $^{32}$ ) $\ldots \ldots \ldots .61218$

Laken............. $\quad 318$

Engl. Tuche ........ 1275

Zusammen 105623

ferner Öle ........... $9891 / 2$

Git (schwarzer Kümmel)

$6871 / 2$

Reifentonnen ..........

525

Fässer ............. 237

Spezereien

Pelzwerk

360

Häute.

354

Wein

$352^{1 / 2}$

Leinwand

224

Waffen... $220^{1 / 2}$

Hering ...............

Pfeffer

Käse.

132

Seide

Wolle

Eisen

Alaun

Bargeld . 50

Seife

Schuhriemen

Salz .............. 40

Kessel ............. 33

Butter .............. $31^{1 / 2}$

Rauchwaren (Hirschfelle usw.) ........... 28

Lein .............. 27

Lammfelle ........... 27

Kabelgarn ........... 13

1000 Wagenschoß ..... 12

Korduanleder ........ 9

Fische ............. 8

Garn.............. 8

corum?........... $\quad 1^{1 / 2}$

Sammelposten $^{33}$ ) ......145041/2

69 Tonnen (Inhalt)?.... 3094

9 Stück?........... 25741/2

2 Packen............ 193

5 Lasten ............ 30

4 kleine Stücke....... 27

Verschiedenes ........ 3267

Ohne Angabe der Waren 15281/2

48

Zusammen $\overline{136443^{1 / 4}}{ }^{34}$ )

Indessen bleibt der Gesamtwert der in Lübeck als von Oldesloe kommend verzollten Waren hinter dem Gesamtwert der tatsächlich von dort eingeführten Waren zweifellos noch erheblich zurück, da nur diejenigen Waren verzollt wurden,

32) Terling ist ein Maß, welches nur im Tuchhandel gebräuchlich ist; s. Stieda, Revaler Zollbücher und Quittungen, Halle 1887, S. 125.

33) Dieser Sammelposten umfaßte: 10 Tonnen Alaun, 13 Fässer, 4 Fässer und 2 Tonnen Git, 6 Schiffspfund Kabelgarn, 1 Kiste, 40 wernesche Laken, 26 Zimmer Lasten, 1/2 Faß Mandeln, 21/2 Last Osemund, 4 Pfund Pfeffer, 1 Reifentonne, 1 Tonne Safran, 37 schenesen, 3 Kisten Seife, 2 Stück, 7 Terlinge, 18 Tonnen, 16 Stück, 1 Terling, 1 Packen Tuch, 4 boten Wein, 3000 winninghe, 1 Sack Wolle, 1 Tonne Zucker, ferner un. bestimmte Mengen Alaun, Bargeld, Butter, Garn, Git, Kabelgarn, Käse, Lein, Rauchwaren, Tonnen, Tuch, Wachs, winninghe, Baumwolle; s. Wendt, a. a. O. S. 63 , Note 2.

34) Außerdem 4 Panzer, 20 Tonnen, 9 Stück, 3 Terlinge und 1 Packen Tuch ohne Wertangabe, s. Wendt, a. a. O. S. 63, Note 3. 
welche nicht schon in einer andern der Kölner Konföderation angehörenden Seestadt verzollt waren. Zwar wurde in Flandern und in Hamburg damals kein Pfundzoll erhoben; ein erheblicher Teil der Waren, welche von Flandern dem baltischen Gebiete zugingen, nahm aber wie im 13. Jahrhundert seinen Weg durch Holland und wurde dort bei der Verschiffung in Amsterdam bereits dem Pfundzoll unterworfen; auch was in Kampen verzollt wurde, dürfte zum großen Teile von Flandern hergekommen sein. Beide Städte hatten 1368 erhebliche Pfundzolleinnahmen aufzuweisen ${ }^{35}$ ), die vorwiegend aus der Verzollung der nach dem Osten gehenden Güter hergerührt haben dürften, da die vom Osten kommenden größtenteils bereits verzollt ankamen. Immerhin-geben uns die Zahlen dieser Statistik eine Vorstellung von dem Warenzuge, der sich auf der Straße von Hamburg nach Lübeck zu bewegen pflegte.

Über den Verkehr, der vom baltischen Gebiete über Lübeck nach Hamburg sich abspielte, vermögen uns die Lübecker Pfundzollaufzeichnungen dagegen keinen Überblick zu geben ${ }^{36}$ ),

35) Kampen 1368205 M. l., Amsterdam 185 M. I. (gegen 1442 M. in Lübeck, 218 M. in Wismar, 136 M. in Rostock): stıeda, a. a. O S. 28.

$\left.{ }^{36}\right)$ Immerhin mag die Statistik der bei der Ausfuhr nach Oldesloe in Lübeck verzollten Waren für das Jahr 1368 (s. Wendt, a. a. O. S. 54 f.) hier einen Platz finden:

\begin{tabular}{|c|c|c|c|}
\hline & M. 1. & $\ldots \ldots \ldots$ & $73^{1 / 2}$ \\
\hline Aal $\ldots \ldots \ldots \ldots \ldots \ldots$ & 4 & Honig............... & 42 \\
\hline Biberfell............. & 135 & 1 Kiste...$\ldots \ldots \ldots$ & 20 \\
\hline Bier ............... & 296 & Kupfer............ & $1019^{1 / 2}$ \\
\hline budelle (?)........... & 30 & Kammwaren $\ldots \ldots \ldots$ & 116 \\
\hline Butter ............. & $4335^{1 / 2}$ & Lammfelle .......... & 113 \\
\hline Korduan ............ & 200 & 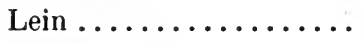 & 1159 \\
\hline Draht $\ldots \ldots \ldots \ldots \ldots$ & $7 / 1 / 2$ & Leinwand ........... & 205 \\
\hline Eisen $\ldots \ldots \ldots \ldots \ldots$ & 352 & 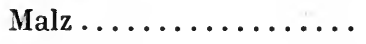 & 9 \\
\hline Fässer ........ & 177 & Osemund ............ & $335^{1 / 2}$ \\
\hline Fett .............. & 177 & 9 Packen............. & 196 \\
\hline Fibere $\ldots \ldots \ldots \ldots \ldots$ & 45 & ? Packen ............ & 52 \\
\hline Fische $\ldots \ldots \ldots \ldots \ldots$ & $1733 / 4$ & Rauchwaren ......... & 49 \\
\hline Fleisch ............. & 15 & Reisesack........... & 6 \\
\hline Git ....... & 150 & 1 Reifentonne ........ & 240 \\
\hline Häute............ & 69 & Roggen $\ldots \ldots \ldots \ldots \ldots$ & $28^{1 / 2}$ \\
\hline Hering...$\ldots \ldots \ldots \ldots$ & 3175 & 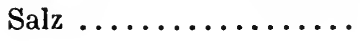 & 139 \\
\hline
\end{tabular}


da die Waren, welche von der Ostsee nach Lübeck kamen, regelmäßig schon in den hansischen Ostseehäfen, aus denen sie nach Lübeck ausgeführt wurden, verzollt waren, demnach sowohl bei der Einfuhr in Lübeck als auch bei der Ausfuhr von Lübeck nach Oldesloe zollfrei waren. Nur solche Waren, die nicht aus hansischen Häfen stammten, oder die durch außerordentliche Umstände bei der Ausfuhr aus hansischen Häfen von der Verzollung freigeblieben waren, gelangten bei der Einfuhr in Lübeck zur Verzollung ${ }^{37}$ ); bei der Ausfuhr aus Lübeck in der Richtung nach Oldesloe endlich wurde nur von solchen Waren Zoll erhoben, hinsichtlich deren nicht nachgewiesen werden konnte, daß für sie schon bei der Ausfuhr aus einer andern Stadt der Konföderation oder bei der Einfuhr in Lübeck Pfundzoll bezahlt war, ein Fall, der hauptsächlich wohl vorgekommen sein dürfte, wenn die Waren in Lübeck ihren Besitzer gewechselt hatten. Bei der Einfuhrvon der Ostsee her wurden nach Wendt in Lübeck 1368 dem Pfundzoll unterworfen Waren im Werte von 83176 M.l., davon aus:

Schweden (Stockholm, Süderköping, Nyköping, Kalmar)...............

livländischen Städten (Riga, Aa, Reval, Pernau)

$32506^{3} / 4$ M. l. $195241 / 2$,

\begin{tabular}{|c|c|c|c|}
\hline Schuhriemen. & $315^{1 / 2}$ & Wachs .... & $1466^{1 / 2}$ \\
\hline Schymmessen (= Ballen) & $1008^{1 / 2}$ & 200 Wagenschoß & 113 \\
\hline Speck ............ & 30 & Weinstein $\ldots$. & 9 \\
\hline Steine.............. & 24 & Pelzwerk ....... & 1315 \\
\hline Talg ...... & $44^{1 / 2}$ & Verschiedenes......... & 1358 \\
\hline Teer ...... & $71 / 2$ & Sammelposten ........ & $84791 / 2$ \\
\hline $\operatorname{Tran} \ldots . . . .$. & 224 & Ohne Angabe der Ware & 785 \\
\hline Tonnen ............ & $5171 / 2$ & Zusammen & $\overline{\left.29029^{1}\right|_{2}}$ \\
\hline Tuch ............... & $100^{1 / 2}$ & & \\
\hline
\end{tabular}

${ }^{37}$ ) Bei der Einfuhr wurden nach Wendt 1368 in Lübeck verzollt Pelzwerk von Riga im Werte von 228 M. l., von Reval im Werte von 1028 M. l. Im ganzen wurden nach Wendt bei der Einfuhr in Lübeck dem Pfundzoll unterworfen:

1368 Wachs im Werte von 1446 1/2 M. l., Pelzwerk im Werte von 1315 M. l. $1369, \quad, \quad, \quad, 7935 \quad, \quad, \quad, \quad, \quad, \quad, \quad 8151 / 2,,$,

Es wird sich, soweit hansische Ausffuhrhăfen in Frage kommen, vielleicht um Fälle handeln, in denen der Pfundzoll gestundet war. 
Gotland........................ preußischen Städten (Danzig, Elbing, Königsberg) ..................... wendischen Städten (Wismar, Rostock, Stralsund).......................

Nur die Zahlen für Schweden entprechen vermutlich dem Umfange des wirklichen Verkehrs; alle andern umfassen nur die verhältnismäßig ganz verschwindenden Mengen von Waren, welche ausnahmsweise nicht schon im Abgangshafen verzollt waren.

Es kann kein Zweifel sein, daß der Verkehr in der Richtung von Lübeck nach Hamburg auf der die beiden Städte verbindenden Handelsstraße noch erheblich lebhafter war als in umgekehrter Richtung, da die Ausfuhr der niedrig zivilisierten Länder des baltischen Gebietes sicherlich die Einfuhr wesentlich überwog. Pelzwerk und Wachs werden in diesem Warenzuge in ähnlichem Maße vorherrschend gewesen sein wie in dem Verkehr nach der Ostsee die Tuche. Nimmt man mit Stieda ${ }^{38}$ ) das Verhältnis des Zollsatzes zum Warenwerte bei dem Pfundzoll des Jahres $1368=1: 288$ an, so berechnet sich die Höhe der in den livländischen Städten 1368 dem Pfundzoll unterworfenen Werte auf 167328 M. l.; in dieser Summe sind enthalten: 1. die dort seewärts ausgeführten Waren, 2. der halbe Wert der von dort ausgelaufenen Schiffe, und seit Juni 1368 auch der Wert ihrer Nettofracht ${ }^{39}$ ), beides, soweit die Schiffe ihre Reise nicht in einer andern Hansestadt angetreten und schon dort Pfundzoll erlegt hatten, 3. der Wert der seewärts eingeführten Waren, soweit sie nicht aus einer Stadt der Konföderation kamen oder dort ausnahmsweise nicht verzollt waren, im wesentlichen also nur des Salzes, das aus Flandern durch den Sund kam. Dieser letzte Posten wird also verhältnismäßig klein sein. Was den auf die Schiffe und Fracht entfallenden Wert anlangt, so ist, wenn wir die aus den lübischen Pfundzollbüchern sich ergebenden Zahlen in Rücksicht ziehen ${ }^{40}$ ),

$\left.{ }^{38}\right)$ Stieda, a. a. O. S. 32.

$\left.{ }^{39}\right)$ Hansarezesse I 1 n. 469 Ziff. 1.

40) Der auf die 1966 verzollten Schiffe entfallende Wert belief sich nach Wendt in Lübeck 1368 auf 147994 M. 1., während der Wert der ver- 
anzunehmen, daß der Betrag desselben wesentlich geringer ist als der Wert der verzollten Waren; wir werden also kaum fehlgehen, wenn wir die größere Hälfte der in Livland verzollten Werte auf die Warenausfuhr seewärts rechnen, die wiederum ganz vorwiegend Lübeck zugegangen sein wird. Indessen scheint die Ausfuhr der livländischen Städte im Jahre 1368 außergewöhnlich gering gewesen zu sein; während nämlich in Reval 1368 nur Werte im Betrage von 53040 M.l. zur Verzollung gelangten, wurden 1378 daselbst Werte von $1389821 \frac{1}{2}$ M. l., 1379 von 227410 M. l., 1381 von 78446 M. l., 1382 von 129587 M. 1., 1383 von 108967 M. 1., 1384 von 131085 M. l. verzollt ${ }^{41}$ ); Rigas Verkehr war aber jedenfalls größer als der Revals; seine Zolleinnahme belief sich 1368 auf 268 M. 1., während die Revals 221 M. l. 4 B, die von Pernau 90 M.l., von Lemsal 9 M. l. betrug ${ }^{42}$ ). Erscheint es schon nach diesen Zahlen, von denen die größere Hälfte immer auf die Einfuhr nach Lübeck gerechnet werden darf, einleuchtend, daß die von den russischen Häfen Riga, Reval, Pernau usw. kommenden Warenmengen, die über die Straße Lübeck-Hamburg gingen, sehr bedeutend waren, so ist bei Abschätzung des Gesamtverkehrs, der sich in dieser Richtung über die Lübeck-Hamburger Straße bewegte, zu bedenken, daß außer dieser Zufuhr aus Livland, welche allerdings den Hauptposten gebildet haben wird, noch erhebliche Einfuhren aus den preußischen, aus den wendischen Städten und aus Schweden sich von Lübeck auf dieser Straße dem Westen zu weiterbewegten; in den Urkunden wird gelegentlich z. B. die Verschiffung von schwedischem Pelzwerk, von schwedischem Kupfer und schwedischem Eisen von Hamburg nach Flandern erwähnt ${ }^{43}$ ), und es kann kein Zweifel sein, daß diese

zollten Waren 1368423688 M. l., $1369259891^{1 / 2}$ M. l. betrug. 2369 Schiffe waren 1368 im ganzen in Lübeck eingelaufen.

41) Stieda, a. a. O. S. 58 f.

${ }^{42}$ ) Hansarezesse I 1 S. 430.

$\left.{ }^{43}\right)$ S. das Ladungsverzeichnis des 1345 vor der Maas verunglückten Hamburger Schiffes, das, wie die Mengen Goslarschen Kupfers, Getreide usw., die es an Bord hatte, zeigen, jedenfalls von Hamburg ausgegangen war; Hans. Urkdb. III n. 63. Wir finden unter der Ladung 47 timber operis Suevici, 23 mesas cupri Suevici, 8 timber operis Suevici, neben 
Waren auf dem Wege von Lübeck nach Hamburg gekommen waren.

Unter den Kaufleuten, welche sich auf dieser Handelsstraße bewegten, standen naturgemäß obenan die Lübecker. Sie genossen, wie im 13. Jahrhundert, sowohl in Oldesloe als auch in Hamburg Zollfreiheit ${ }^{44}$ ). Noch 1302 wurde ihnen dieses Privilegium in Anlaß der Beilegung eines Streites von den Grafen von Holstein für alle Zeit bestätigt. Wir sehen die Lübecker auf den alt betretenen Wegen durch Holland nach Flandern weiterziehen. 1302 wird ihnen nach längerer Störung des Handelsverkehrs vom Bischof von Utrecht von neuem Schutz und Geleit für die Fahrt von Muiden nach Utrecht zugesichert ${ }^{45}$ ). 1316, 1338, 1349 uud 1357 werden ihnen von dem Grafen von Holland die älteren Privilegien erneuert ${ }^{46}$ ). 1327 sehen wir sie Zollermäßigungen für ihren Verkehr durch Holland erwirken ${ }^{47}$ ); Pelzwerk und Wachs stehen auch in diesem Zolltarif wieder an erster Stelle, daneben Hirschfelle; weiterhin spielen die Produkte der Rinder- und Schweinezucht, Butter, Talg und Schmalz, eine Rolle ${ }^{48}$ ); von den Artikeln der Rückfracht wird nur Tuch erwähnt; bei der Einfahrt in die Maas sollen von einem Schiffe, das nicht nach Lübeck gehört, aber Waren Lübecker Bürger führt, keine Abgaben bei Geervliet erhoben werden, wohl aber von seiner Ladung. Mehrfach werden Lübecker Kaufleute auf der Straße zwischen Lübeck und Hamburg erwähnt. Um 1340 wird ein Wagen mit Stahl und Draht Lübecker Kaufleuten auf dieser Straße bei Rumplingen geraubt ${ }^{49}$ ).

einer Menge von Pelzwerk, Hăuten, Getreide, Goslarschem Kupfer, Leinen, rigischem Wachs usw.

${ }^{44)}$ Hans. Urkdb. II n. 20, 26.

$\left.{ }^{45}\right)$ Ebenda n. 16.

${ }^{46}$ ) Ebenda n. 276, 610; III n. 142, 371.

47) Ebenda II n. 464, 465.

${ }^{48}$ ) Rindertalg und Schweineschmalz finden sich u. a. auch unter den Gegenstănden der russischen Ausfuhr und derjenigen der wendischen Städte (vgl. z. B. Zolltarif von Wismar von 1328, Hans. Urkdb. II n. 479); es sind außer Häuten fast die einzigen Erzeugnisse der Viehzucht, welche auf weite Strecken hin ohne Gefahr für den Verderb der Waren transportabel sind.

49) Hans. Urkdb. II n. 725; vgl. Bruhns, Lübecks Handelsstraßen am Ende des Mittelalters, i. Hans. Geschichtsbl. 1896, S. 49. 
Um 1360 werden lübischen Kaufleuten 406 Packen englischen und irischen Tuches auf dem Wege zwischen Hamburg und Lübeck weggenommen ${ }^{50}$ ). Andere Urkunden zeigen uns die Kölner, die Westfalen, die Binnensachsen, die Bremer, die Niederländer und Friesen und die wendischen Kaufleute auf der Straße zwischen Hamburg und Lübeck. In den dreißiger Jahren werden Waren, welche den kölnischen Bürgern Engelbrecht van dem Herte, Bruno vam Overe und Johann Ruger gehören, auf der Straße zwischen Hamburg und Lübeck geraubt $\left.{ }^{51}\right)$. König Ludwig der Baier erläßt wiederholt an Lübeck und einmal auch an Hamburg den Befehl, die Dortmunder zollfrei zu lassen ${ }^{52}$ ). Eine Ladung Wachs, die 1333 auf der Elbe als lübeckisches Gut beschlagnahmt wird, stellt sich als Eigentum Dortmunder Bürger heraus ${ }^{53}$ ). In einem der ersten Hälfte des 14. Jahrhunderts angehörenden Schreiben erinnert Hamburg Osnabrück an die Gunst, die es den Osnabrücker Kaufleuten stets in Hamburg erwiesen habe ${ }^{54}$ ). 1344 wird auch ein Bürger von Herford, der Heringstonnen mit sich führt, in Lübeck erwähnt ${ }^{55}$ ). 1358 hören wir in Flandern von Hildesheimer Kaufleuten, welche von Hamburg mit Pelzwerk und Wachs sich nach Flandern eingeschifft haben und zweifellos von Lübeck gekommen seien werden ${ }^{56}$ ). Mehrfach ist die Benutzung der Straße über Oldesloe nach Lübeck seitens der Bremer Kaufleute bezeugt ${ }^{57}$ ). 1340 verheißen die Grafen von Holstein an Lübeck, Stralsund, Rostock, Wismar, Kampen,

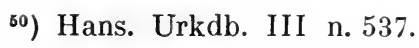

s1) Hans. Urkdb. II n. 725. Vgl. auch III n. 682: Bestimmungen über den Detailhandel in Lübeck mit kölnischer have (Habe, d. i. Garn, Band, Seide, blaue Leinwand, burdoks [grobes wollenes Zeug, Pariser Borden, vergoldetes und versilbertes Leder, tzetere (ostindisches Baumwollenzeug]), Haartuchen, nürnbergischen Messern, Dolchen, Schlössern, Paternostern, Papier, irischen Laken, Sardok, Seidentuch, Thymian, Mandeln.

52) Ebenda II n. 415, 529, 530.

53) Ebenda n. 541.

${ }^{54)}$ Ebenda III n. 638.

$\left.{ }^{55}\right)$ Ebenda n. 28.

$\left.{ }^{56}\right)$ Hansarezesse I 3 Ziff. 5, Note 7.

57) Bruhns, a. a. O. S. 48. 
Stavorn, Harderwijk, die andern Städte der Südersee und alle Kaufleute Frieden und Geleit zwischen Lübeck und Hamburg und vollen Ersatz allen Schadens ${ }^{58}$ ). Eine Urkunde von 1350 spricht von Gütern, die einem Bürger von Jever durch Kampener auf der Elbe geraubt sind ${ }^{59}$ ). 1359 begegnen wir Utrechter Bürgern auf der Straße von Hamburg nach Lübeck mit Tuchen aus Valenciennes und Kortryk, Mandeln, Reis, Öl, Zucker, Pfeffer, Fellen und andern Waren $\left.{ }^{60}\right)$. Eine Urkunde von 1347 meldet von Emsgauer Kaufleuten gehörenden Waren, die bei Oldesloe beschlagnahmt sind ${ }^{61}$ ). Es kann keinem Zweifel unterliegen, daß die Kaufleute fast aller hansischen und vieler nichthansischen Städte auf diesem Wege den Handel zwischen dem baltischen Gebiete und Brügge betrieben.

Ehe wir indessen die Straße von Hamburg nach Brügge weiter verfolgen, müssen wir hier Halt machen, um wieder die Verkehrsströmungen ins Auge zu fassen, welche sich vom Inland kommend in Hamburg an den Handelszug nach Flandern anschlossen. Die Nachrichten hierüber sind für diese Zeit sehr lückenhaft. Aber wir werden kaum fehlgehen, wenn wir an erster Stelle hier wieder des Handels mit Bergwerksproduktèn vom Harz und vermutlich auch vom Erzgebirge her gedenken. Daß die Harzstädte, vor allem Braunschweig und Goslar, auch in diesem Zeitabschnitte am Handel mit Flandern lebhaft teilnahmen, zeigen uns eine Reihe von Urkunden ${ }^{62}$ ). Zu einem erheblichen Teile vollzieht sich dieser Verkehr allerdings über Stade oder über Bremen $\left.{ }^{63}\right)$.. In der Zollrolle ${ }^{64}$ ), welche der Herzog von Braunschweig im Anfange des 14. Jahrhunderts für

${ }^{58)}$ Hans. Urkdb. II n. 664.

${ }^{59)}$ Ebenda III n. 173.

$\left.{ }^{80}\right)$ Ebenda n. 444.

${ }^{61)}$ Ebenda n. 102.

$\left.{ }^{62}\right)$ Ebenda II n. 156, 157, 162-165, 327; III n. 303, 461.

$\left.{ }^{63}\right)$ Braunschweiger Gut auf einem bremischen Schiffe nach Flandern, ebenda II n. 327, 329. Den Braunschweigern, Goslarern, Hannoveranern und Hamelern gestattet Bremen den Verkauf ihres Getreides in Bremen unter den gleichen Bedingungen wie den eigenen Bürgern, ebenda III n. 184. Über Hannovers Beziehungen zu Bremen s. auch Hans. Urkdb. II n. $5-8$.

64) Hans. Urkdb. II n. 45. 
den Verkehr Braunschweigs seewärts festlegt, wird Hamburg nicht erwähnt und nur Bremens und Stades gedacht, und als Zollstätten, welche auf dem Wege dahin zu passieren sind, werden Celle und Gifhorn genannt. Kupfer, Zinn, Blei finden sich auch hier wieder unter den Gegenständen der Ausfuhr; als Waren, welche der Verzollung zu Celle oder Gifhorn zu unterwerfen sind, werden ferner aufgezählt Leder, Talg, Butter, Stockfisch und andere Fische, Tran, Wachs; auch Korn, Hopfen, Honig, Wein, Bier, Schmalz, Laken und Leinen. Verschiedene Urkunden, u. a. ein Streit wegen eines in Hamburg in Strafe genommenen Braunschweigers im Jahre $1325^{65}$ ), zeigen aber, daß die Braunschweiger nach wie vor auch über Hamburg Handel trieben. 1314 verlieren Goslarer Bürger Kupfer in einem Hamburger Schiffe und bitten Hamburg um Beistand zur Wiedererlangung desselben ${ }^{66}$ ); auch das Hamburger Schiff, das 1345 auf dem Wege von Hamburg an der Mündung der Maas strandet ${ }^{67}$ ), hatte Goslarer Kupfer an Bord. Die Bergwerksprodukte des Harzes nahmen also offenbar auch in dieser Zeit zum Teil über Hamburg ihren Weg nach Flandern. Auch Vicko van Geldersen sehen wir übrigens mit Braunschweig in Handelsverbindung stehen, wenn er allerdings auch nicht Bergwerksprodukte von dort erhält ${ }^{68}$ ). Die Verbindungen Hamburgs reichten die Elbe bis Böhmen hinauf. Für den Handelsverkehr der Kaufleute von Prag und ganz Böhmen setzte 1304 der Herzog von Braunschweig-Lüneburg die Durchgangszölle für Tuch fest und sicherte ihnen für die Strecke von Hamburg bis an die brandenburgische Grenze seinen Schutz $\mathrm{zu}^{69}$ ). Nach wie vor bildete natürlich Magdeburg ein wichtiges Glied in dem Warenaustausche, der sich zwischen Flandern und dem Gebiete der Oberelbe vollzog; 1295 werden Genter Tuche für Dresden in Magdeburg erwähnt, 1325 rheinische und poperingische Tuche und französische Weine bei der Zollstätte Pirna usf. ${ }^{70}$ ).

${ }^{65}$ Hans. Urkdb. III n. 435, 436.

66) Hans. Geschichtsbl. S. $141 \mathrm{ff}$.

${ }^{67}$ ) Hans. Urkdb. III n. 63.

${ }^{68}$ ) Nirnheim, a. a. O. S. 52.

$\left.{ }^{69}\right)$ Hans. Urkdb. II S. 25.

$\left.{ }^{70}\right)$ Ebenda III S. 168, Note 1. 
Unter den brandenburgischen Städten stehen im Verkehre mit Flandern noch immer die Städte der Altmark voran. Mehrere Urkunden zeigen z. B. Stendaler im Verkehr mit Flandern ${ }^{71}$ ). Die über See handelnden Kaufleute Stendals bildeten schon 1304 eine besondere Gilde in ihrer Heimatsstadt ${ }^{72}$ ). Im Brandenburgischen genossen die Stendaler weitgehende Zollfreiheiten ${ }^{73}$ ). Salzwedeler und Ülzener Leinwand versendet Vicko van Geldersen nach Flandern ${ }^{74}$ ). Eine Urkunde von 1359 zeigt uns außer Salzwedel und Stendal auch Gardelegen, Werben, Seehausen, Havelberg, Berlin, Cöln a.d. Spree, Pritzwalk, Perleberg am flandrischen Handel interessiert ${ }^{75}$ ).

Unter den hannoverschen Städten sehen wir 1349 die Hannoveraner auf dem Wege nach Hamburg bei Eislingen (Zollenspieker) Zollermäßigungen erwirken ${ }^{76}$ ). Von Hannover werden die „Ysern" gekommen sein, die in den Verladungen Vickos nach Flandern eine große Rolle spielen. Eine Bestätigung und Erweiterung der Privilegien Lüneburgs für ihren Verkehr auf der Elbe vom Jahre 1341 zeigt uns die Bewohner dieser Stadt in alter Weise in Verbindung mit Hamburg ${ }^{77}$ ). Eine Urkunde von 1344 enthält eine Entscheidung über die Verpflichtung der Lüneburger zur Zahlung von Zoll bei der Zollstätte Eislingen (Zollenspieker) für irische und andereTuche die sie von Hamburg nach Lüneburg bringen ${ }^{78}$ ). Ob diese Städte zwischen dem Harz und der Nordsee auch in diesem Zeitraume noch so lebhaft an dem Zwischenhandel mit Kupfer und andern Bergwerksprodukten des Harzes und Erzgebirges beteiligt waren, vermögen wir infolge der Dürftigkeit unseres Quellenmaterials nicht $\mathrm{zu}$ verfolgen. Von eigenen Produkten

71) Hans. Urkdb. II n. 71.

$\left.7^{2}\right)$ Ebenda n. 48; vgl. über diese Loesch, Die Stendaler Seefahrer, in Hans. Geschichtsbl. 1906, 2. Heft, S. 335 ff.

${ }^{73}$ ) Hans. Urkdb. III n. 67.

${ }^{74)}$ Handlungsbuch Nirrnheim S. 60 und $\$ 644$; über den Schifffahrtsverkehr zwischen Ülzen und Lüneburg 1348 s. Hans. Urkdb. III S. 65 Note 3.

${ }^{75}$ ) Hans. Urkdb. III n. 433.

${ }^{76}$ ) Ebenda n. 141.

$\left.{ }^{77}\right)$ Ebenda II n. 672.

${ }^{28}$ ) Ebenda III n. 24. 
der Städte ist nach wie vor namentlich der Leinwand zu gedenken, die in großen Mengen in der Altmark hergestellt wurde und z. B. unter den Artikeln, welche Vicko van Geldersen von Hamburg nach Flandern versandte, einen wichtigen Platz einnahm.

1322 wird das den Hamburgern im 13. Jahrhundert erteilte Zollprivileg für Salz, das die Hamburger von Lüneburg nach Hamburg führen, erneuert $\left.{ }^{79}\right)$. Indessen hat der Salzhandel auch im 14. Jahrhundert in Hamburg keine Rolle gespielt. Lüneburgs Salzhandel war vielmehr, wie im 13. Jahrhundert, ganz ausgesprochen auf die Ostseeküste gerichtet; zahlreiche Urkunden geben uns Zeugnis von der Lebhaftigkeit dieses Verkehrs. 1320 verleiht die Herzogin von Sachsen-Lauenburg den Lüneburgern Schutz für den Durchzug mit Salz und andern Waren durch ihr Gebiet ${ }^{80}$ ) und verspricht gleichzeitig auch den Lübeckern sicheres Geleit und Ersatz für Schaden, den Lübecker Kaufleute und Fuhrherren in ihrem Lande etwa erleiden sollten ${ }^{81}$ ). 1323 wird ihnen von neuem vom Herzog Schutz und Geleit für den Verkehr mit Salz durch SachsenLauenburg, insbesondere bei Artlenburg und Lauenburg, zugesichert ${ }^{82}$ ). Artlenburg war die Zollstätte für das Salz, das zu Wagen von der Elbe nach Lübeck gebracht wurde; im Winter wurde es, wenn die Elbe gefroren war, sogar über die Elbe zu Wagen gebracht, bei offenem Wasser gelangte es zu Schiff nach Artlenburg; hier errichteten 1335 die Herzöge von Sachsen eine Niederlage für alles Tonnenholz aus ihren Waldungen, denn das Salz mußte für den Wagentransport hier erst in Tonnen gefüllt werden; der Herzog siedelte dort Tonnenmacher an. Die Rückfracht für diese Verladungen bildeten auch jetzt noch Heringssendungen, mit denen das Gebiet der mittleren und oberen Elbe versorgt sein wird. Eine Urkunde von 1335 bestimmt, daß der Hering, den die Lüneburger über Mölln bringen, wie früher dort verzollt werden soll ${ }^{83}$ ).

79) Hans. Urkdb. II n. 392; vgl. I n. 1089 und oben S. 114.

$\left.{ }^{80}\right)$ Ebenda II n. 354.

81) Ebenda n. 355.

82) Ebenda II n. 407.

${ }^{83)}$ Ebenda II n. 576. 
1341 verleiht der Herzog von Sachsen-Lauenburg den Lüneburger Kaufleuten Geleit und Schutz für den Transport von Hering und andern Gütern durch sein Land ${ }^{84}$ ). Es kann kaum ein Zweifel sein, daß die Delvenau schon im 13. Jahrhundert für den Transport des Salzes bis nahe an Mölln benutzt worden ist; nur so wird die Bedeutung, die Lauenburg in diesem Verkehre hatte, verständlich ${ }^{85}$ ). In den 30er Jahren wurde, wie es scheint, schon die Anlegung eines künstlichen Wasserweges, der bis nach Lübeck weiterführte, geplant ${ }^{86}$ ). Urkunden aus den nächsten Jahren lassen erkennen, daß die Stecknitz durch künstliche Stauung vertieft worden war ${ }^{87}$ ). Das Wasser wurde während der Jahreszeit, wo es nicht in genügender Menge vorhanden war, jedesmal durch eine Schleuse von Mölln aus einen Tag, nachdem es die Kaufleute bestellt hatten, hineingelassen; es sollten mindestens 24 bis 30 Prahme mit Salz jedesmal erst in Mölln angesammelt werden, ehe man das Wasser einlaufen ließe. Privilegien von 1348 und 1349 regeln wiederum den Salzzoll, den die Lüneburger auf diesem Wege erlegen sollten ${ }^{88}$ ). 1359 wird die Verbindung Lübecks über Mölln nach der Elbe noch als die königliche Straße in Erinnerung an alte Zeiten bezeichnet ${ }^{89}$ ). 1357 erhalten die

84) Hans. Urkdb. n. 683.

$\left.{ }^{85}\right)$ Schäfer, Die Hansestădte und König Waldemar, S. 193 Note 1, bemerkt treffend: Wurde Salz von Geesthacht über Lauenburg nach Mölln gebracht, so ging es jedenfalls zu Schiff.

$\left.{ }^{86}\right)$ Hans. Urkdb. II n. 576.

$\left.{ }^{87}\right)$ Ebenda II n. 704. Vgl. Brehmer, Zur Vorgeschichte des Stecknitzkanals, i. d. Mitteil. des Vereines für lüb. Geschichte I S. 56-60; Koppmann, Die Landwehr zwischen dem Ratzeburger und dem Möllner See, i. Hans. Geschichtsbl. 1894 S. 97 ff. An die Herstellung eines Wasserweges von Artlenburg durch das Land nach Mölln kann man m. E. schon der Terrainverhältnisse wegen unmöglich gedacht haben. Die Delvenau wird nicht immer schiffbar gewesen sein; deshalb ging auch ein Landweg von Lauenburg nach Mölln, dessen Ausgangspunkt Artlenburg wurde. Daß eine Wasserverbindung Möllns mit Lübeck bestand, beweisen auch die Lübecker Pfundzollquittungen, welche 1368 sieben Schiffe als von Lübeck nach Mölln mit Bier, Hering usw. fahrend bezeichnen; s. Wendt, a. a. O. S. 55 .

${ }^{88)}$ Hans. Urkdb. III n. 132 und 151.

${ }^{89}$ ) Ebenda n. 442 und Note 2. 
Lüneburger die Zusicherung des herzoglichen Schutzes für ihren Verkehr elbaufwärts über Geesthacht, Lauenburg und Boizenburg und in ganz Sachsen-Lauenburg90). 1359 verkaufen die Herzöge von Sachsen die Stadt und Herrschaft Mölln an Lübeck, verpflichten sich zur Beschirmung Möllns und der königlichen Straße und geloben den Zoll nicht von Mölln zu verlegen ${ }^{91}$ ). Zwei Urkunden von 1333 und 1357 zeigen, daß auch die Hannoveraner und, wie es scheint, auch die Ülzener einen regelmäßigen Verkehr nach Lübeck auf dem Wege über Lüneburg und Mölln unterhielten und von Lübeck oder den wendischen Städten Hering bezogen ${ }^{92}$ ).

Außer dem Durchfuhrhandel, den die binnensächsischen Städte über Hamburg mit Flandern betrieben, war Hamburg nach wie vor der Stapelplatz für die Getreide- und Holzmassen, welche ihm von seinem Hinterlande zu Wasser zugingen. Ein Privileg des Herzogs von Sachsen-Wittenberg und der Markgräfin von Brandenburg aus dem Jahre 1319 sichert den Bürgern von Cöln a. d. Spree und Berlin die unge-

90) Hans. Urkdb. n. 372.

91) Ebenda n. 442.

${ }^{92}$ ) Ebenda II n. 535, III n. 381. Der von Lübeck ausgehende Verkehr mit Salz, der vorwiegend Lüneburger Salz zum Gegenstand gehabt haben dürfte, war recht bemerkenswert. Nach den Pfundzollbüchern wurden in Lübeck folgende Mengen Salz 1368 und 1369 bei der Ausfuhr dem Pfundzolle unterworfen (Wendt, a. a. O., Tabellen IIa 2):

Bestimmungsort: $1368 \quad 1369$

Wert M. l. Wert M. l.

\begin{tabular}{|c|c|c|}
\hline Schonen ......... & $19816^{1 / 2}$ & 36398 \\
\hline Wismar .......... & $1242^{1 / 4}$ & 1045 \\
\hline Rostock........... & 1056 & 1312 \\
\hline Stralsund ... & 651 & 202 \\
\hline Stettin........... & 4002 & $7023^{1 / 2}$ \\
\hline 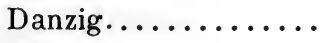 & $7660^{1 / 2}$ & 5444 \\
\hline Elbing . . . . . . & 3722 & $62771 / 2$ \\
\hline Riga....... & $1038^{1 / 2}$ & 43 \\
\hline Pernau ........... & $60493 / 4$ & $2400^{1 / 2}$ \\
\hline Reval............. & $4039^{1 / 4}$ & 2169 \\
\hline Stockholm ........ & $2178^{1 / 2}$ & $1335^{1 / 2}$ \\
\hline Süderköping........ & $3609^{1 / 2}$ & $3232^{1} / 2$ \\
\hline Kalmar .......... & $1500^{1 / 2}$ & $1569^{1 / 2}$ \\
\hline Gotland........... & 1625 & 1428 \\
\hline
\end{tabular}


hinderte Abfuhr ihres Getreides nach Hamburg zư $\left.{ }^{93}\right) . \quad 1358$ führen zwei Havelberger Bürger mit einem Böhmen und seinem Gesellen, von denen ersterer Magdeburger Bürger ist, einen Streit über die Fracht für die Verschiffung von Korn, die sie für den Böhmen und seinen Gesellen vor einigen Jahren ausgeführt haben ${ }^{94}$ ); der Rat von Havelberg bittet zugleich im Namen des Rates von Magdeburg den Hamburger Rat, den beiden Schiffern von den Böhmen Befriedigung ihrer Ansprüche zu verschaffen, ein Zeichen dafür, daß sowohl diese Böhmen, als auch die beiden Schiffer von Havelberg und Magdeburg regelmäßig nach Hamburg kamen. Es scheint hiernach, daß schon Beziehungen bis Böhmen hinauf bestanden und Magdeburg, wo alles die Elbe herabkommende Getreide gestapelt werden mußte, das Bindeglied zwischen Böhmen und Hamburg war $\left.{ }^{95}\right)$. Auch an der Unterelbe werden gelegentlich Hamburger als Händler mit Getreide erwähnt ${ }^{96}$ ). Eine. Partie Getreide (200 tritici) findet sich auch unter der Ladung des 1345 an der Maasmündung gestrandeten, von Hamburg kommenden Schiffes ${ }^{97}$ ), und auch Vicko van Geldersen sehen wir gelegentlich Getreide nach dem Westen versenden ${ }^{98}$ ): Auch $\mathrm{Holz}$ bildet, wie im 13. Jahrhundert, einen wichtigen Gegenstand der Verschiffung von Hamburg und Stade nach dem Westen ${ }^{99}$ ). Für die hamburgische Schiffahrt im Verkehr zwischen Hamburg und Flandern werden auch in dieser Zeit Getreide und Holz

${ }^{93)}$ Hans. Urkdb. II n. 343 .

${ }^{94)}$ Stein, Beiträge zur Geschichte der deutschen Hanse, S.45, meint, daß die beiden Böhmen die Schiffer gewesen seien. In der Urkunde, Hans. Urkdb. III n. 387 heißt es aber: ,umme dat korne, dat se em neder vorden umme vrucht. Mit dem Singular ,em" können aber die beiden Havelberger Hannes Tempeler und Wytzen nicht gemeint sein, sondern nur Nychels Pels der Böhme, während auf den Gesellen, der nebensăchlich ist, in dem Nebensatze nicht mehr Bezug genommen wird.

${ }^{95}$ ) Hans. Urkdb. II n. 159.

$\left.{ }^{96}\right)$ Ebenda n. 728. Nikolaus Heygen und seiner Kumpanie wird Hafer zu Bruchtorf geraubt.

97) Ebenda III n. 63.

$\left.{ }^{98}\right) \mathrm{Vgl}$. Handlungsbuch $\S 718$.

${ }^{99}$ ) Hans. Urkdb. III n. 476, Urkunde von 1360. S. über die Verschiffung des Holzes aus dem Sachsenwalde zu Geesthacht (Hachede) Hans. Urkdb. II n. 576 (nach Lüneburg). 
neben dem gleich noch zu erwähnenden Bier die wesentlichsten Massenartikel gewesen sein.

$\mathrm{Zu}$ diesen Warenmassen, die vom baltischen Gebiete und vom Binnenlande über Hamburg nach Flandern sich bewegten, kamen nämlich noch zwei für Hamburg sehr wichtige Ausfuhrerzeugnisse, welche die Stadt selbst hervorbrachte: Bier und Holzfässer. In dem Verzeichnisse der Kaufleute und Amtsmeister Hamburgs aus dem Jahre 1375, welches insgesamt 1175 Personen aufführt ${ }^{100}$ ), finden sich nicht weniger als 457 Bierbrauer und 104 Böttchermeister. Die Bierbrauerei Hamburgs scheint im 14. Jahrhundert einen mächtigen Aufschwung genommen $\mathrm{zu}$ haben ${ }^{101}$ ), sie arbeitete vor allem für den Export; in Holland und auf dem flandrischen Markte fand das hamburgische Bier einen massenhaften Absatz. Diese hamburgischen Bierbrauer übten nun aber nicht nur ihr Bierbrauergewerbe aus, sondern waren zugleich Kaufleute. Das Brauen des Bieres war überhaupt auf eine bestimmte Zeit des Jahres beschränkt; in der Hand dieser Brauer lag aber zugleich die Ausfuhr des Bieres und der Vertrieb desselben im Auslande. Ein bemerkenswerter Teil des Bieres ging nach Flandern; die nach Holland und Friesland ihr Bier - vertreibenden Brauer hatten in der hamburgischen Hanse in Amsterdam und später auch in einer Hanse in Stavorn ihren Stützpunkt. Nächst der Bierbrauerei war das für den Wohlstand der Stadt wichtigste Gewerbe die Böttcherei, die auf dem Massenverbrauche von Holzfässern, vor allem für die Verpackung der Heringe auf Schonen ${ }^{\mathbf{1 0 2}}$ ), zugleich aber auch wohl für die hamburgische Bierbrauerei beruhte. Für dieses Gewerbe war die Holzzufuhr und der Holzstapel Hamburgs natürlich von hoher Bedeutung. Welche Wichtigkeit der Herstellung der Heringstonnen in Hamburg-Lübeck und den wendischen Städten beigemessen wurde, zeigen die wieder-

${ }^{100}$ Westphalen, Hamburgs Verfassung und Verwaltung, 1846, zweite Aufl. S. 420 f.

101) Rynsberg-Schene in Lappenberg, Geschichtsquellen des Erzstiftes und der Stadt Bremen. Bremen 1841, S. 85 und 118.

$\left.{ }^{102}\right)$ Vgl. Schäfer, Das Buch des lübeckischen Vogts auf Schonen, Halle 1887, S. $60 \mathrm{ff}$. 
holten Vereinbarungen dieser Städte über die Vorschriften für das Böttchergewerbe, in denen Maximallöhne für die Böttchergesellen festgesetzt, die Ausstoßung von Böttchergesellen, wenn sie zwei Mal ihren Dienstherrn verlassen haben, in allen beteiligten Städten vereinbart wird, die Annahme von Böttchergesellen unter dem Zugeständnis, daß sie zur Zeit, wo die Leute nach den Schonenschen Märkten abreisen, frei vom Dienste sein sollen, verboten wird usw. Schon 1321 werden diese Bestimmungen von den Städten Lübeck, Hamburg, Wismar, Rostock und Stralsund vereinbart ${ }^{103}$ ), und zwar werden dieselben von Hamburg und Lübeck festgelegt und von den anderen genehmigt ${ }^{104}$ ); offenbar spielt also Hamburgs Böttcherei in dieser Beziehung eine wichtige Rolle unter den Städten. An den Verhandlungen, welche Lübeck 1337 und 1342 mit den wendischen Städten wegen der Unzuträglichkeiten, die sich aus der Verschiedenheit der Größe der Heringsfässer ergeben hätten, anknüpfte, scheint Hamburg freilich keinen Anteil genommen zu haben ${ }^{105}$ ). In dem Beschlusse der wendischen Städteversammlung zu Rostock am 6. Dezember 1358 $\left.{ }^{106}\right)$, an der außer Lübeck und den wendischen Städten auch Hamburg teilnahm, wurde jedoch für alle diese Städte ein gleiches Maß für die Tonnen in Aussicht genommen; Wismar . sollte sein Tonnenmaß den Städten Lübeck, Hamburg, Rostock, Greifswald und Stralsund mitteilen. 1342 verboten die Ostseestädte, alte Fässer auf Schonen auszubessern ${ }^{107}$ ). 1366 wurden die Beschlüsse von 1321 unter Teilnahme Hamburgs erneuert ${ }^{108}$ ). Auf welchem Wege diese Heringstonnen nach Schonen gelangten, ob sie etwa über Lübeck gingen oder ob die Hamburger sie selbst von Hamburg aus um Jütland herum nach Schonen brachten, entzieht sich unserer Kenntnis; ein Mittelpunkt des Heringshandels ist Hamburg im 14. Jahrhundert jedenfalls ebensowenig wie im 13. Jahrhundert gewesen.

103) Hanserezesse I 1 n. 105-110.

104) S. Koppmann, ebenda S. 57.

${ }^{105)}$ Lüb.: Urkdb. 2 n. 647 , Hansarezesse I 1 S. 64

106) Hansarezesse I 1 n. 223.

107) Hansarezesse I 1 n. 113.

108) Ebenda n. $376 \S 19$, n. 388 §. 
Dem Verkehrsstrome, der sich vom baltischen Gebiete und vom sächsischen Binnenlande über Hamburg nach Flandern hinzog, entsprach eine Gegenströmung, deren Grundstock noch wie im 13. Jahrhundert in flandrischen Tuchen bestand. Dieser Verkehr mit flandrischen Tuchen war, wie früher, zum größten Teil nur Durchgangsverkehr, der den Hamburger Markt nicht berührte, nur der verhältnismäßig kleine Teil der Binnenländer, der seine Waren in Hamburg absetzte, kaufte hier seine Gegenwerte ein. Die diesen Zwischenhandel besorgenden hamburgischen Kaufleute hießen nach dem Stapelartikel ihrer Einfuhr, dem Hauptgegenstande ihres Handels, die Gewandschneider (pannicidae). Die Bezeichnung Gewandschneider rührte daher, daß sie das Tuch nicht nur, wie die Fremden, in den im Großhandel üblichen ganzen Stücken, sondern auch geschnitten, d. h. in kleineren Stücken - im Detail, wie wir es heute nennen würden -, verkaufen durften. Da das flandrische Tuch überall auch im Binnenlande der Haupteinfuhrartikel war, so bestanden Gilden solcher Gewandschneider fast in allen Städten der Küste wie des Binnenlandes, und es ist wiederum charakteristisch für die Rolle, die das flandrische Tuch als Handelsware überall spielte, daß die Gewandschneidergilden in allen Städten mit an erster Stelle in der Bürgerschaft standen ${ }^{109}$ ). In Hamburg bildeten sie schon mindestens seit der Mitte des 13. Jahrhunderts eine Genossenschaft, eine societas $\left.{ }^{110}\right)$. Die Zahl dieser Gewandschneider betrug in Hamburg im Jahre 1375 ausweislich des mehrfach bereits erwähnten Verzeichnisses 19. Wenn wir erwägen, daß der Hanse in Flandern damals 84, der Hanse in England 35 Hamburger angehörten, so erhellt für uns deutlich, in wie viel geringerem Grade dieser in Hamburg sich abspielende Zwischenhandel zwischen dem Binnenlande und Flandern die Erwerbsquelle der hamburgischen Kaufleute bildete, als das vom Auslande, von Flandern und von England aus betriebene Reederei- und Waren-

$\left.{ }^{109}\right)$ Vgl. u. a. Keutgens Aufsatz über den Großhandel im Mittelalter, in Hans. Geschichtsbl. 1901 S. 67 ff.; ferner Frensdorff, Aus belgischen Städten und Stadtrechten, i. Hans. Geschichtsbl. 1878 S. 53.

$\left.{ }^{110}\right)$ S. u. a. Nirnheim, a. a. O. S. 26. 
geschäft. Der in Hamburg selbst sich vollziehende Zwischenhandel war eben nur von recht bescheidenem Umfange.

In den Geschäftsbetrieb eines solchen in Hamburg tätigen Gewandschneiders gibt uns das Handlungsbuch des Vicko van Geldersen, der zu den Gewandschneidern in Hamburg gehörte, einen interessanten Einblick. Die Gewandschneider befaßten sich, wie uns dies Handlungsbuch zeigt, keineswegs nur mit Tuchhandel. Sie kauften von den Binnenländern die verschiedensten Waren, um sie nach Flandern zu versenden, und führten auf der andern Seite auch mancherlei Waren außer Tuch ein. Vicko van Geldersen sandte ausweislich seiner Handlungsbücher viel Leinwand $\left.{ }^{111}\right)$, Eisen ${ }^{112}$ ) und Honig ${ }^{113}$ ), nicht selten ferner Schweinefleisch ${ }^{114}$ ), höchst wahrscheinlich in gesalzenem Zustande, und anderes mehr nach dem Zwin. Sehr erhebliche Beträge sandte er auch in gemünztem Gelde nach Flandern zum Einkauf. Unter den Waren, die er von Flandern bezog, nahmen, wie bereits hervorgehoben, Tuche bei weitem den ersten Platz ein. Daneben kommen Öl115), Mandeln ${ }^{116}$ ), Ingwer ${ }^{117}$ ), Feigen ${ }^{118}$ ), Reis ${ }^{119}$ ) u. dgl. südliche Waren vor. Leider gibt uns das Handlungsbuch keinen Überblick über

111) S. z. B. $\$ 744$ (9 Hundert Leinentücher weniger 141/2 Ellen); $\S 724$ (20 Hundert Leinwand, 1 Rolle Leinwand, 1 Rolle Leinwand); 7714 (13 Hundert und 19 Ellen und 1 Rolle Leinwand; ferner 6 Hundert Leinwand weniger 27 Ellen, 13 Repe Pechtlinges); $\$ 559$ (61/2 Hundert und 10 Ellen Leinwand, 100 Pechtlinghes weniger 15 Ellen) usw.

112) $\S 724$ (2 Last und 35 wasa Osemund); $\$ 599$ (3 Last Ysernes); $\S 572$ (6 Schippunt Ysernes); $\S 573$ (1/2 Last Osemund und 1/2 Last Osemund) u. s. f.

${ }^{113}$ ) 559 (22 Travetonnen und 1/1/2 große Tonnen Honig); $\$ 572$ (9 Tonnen Honig, 6 Tonnen Honig); $§ 574$ (19 Tonnen Honig, darunter 3 hamburgische Tonnen, 20 Tonnen Honig, darunter 1 hamburgische Tonne); $\$ 652$ ( 4 hamburgische Tonnen und 6 Travetonnen Honig); $\S 653$ (16 große Tonnen Honig, 1 Travetonne); §729 (9 Travetonnen Honig).

114) $\S 652$ (8 Tonnen Schweinefleisch und 1 Travetonne mit 13 Schinken); $§ 653$ (19 Schweinefleisch); $\$ 692\left(11^{1 / 2}\right.$ Schweinefleisch) u. s. f.

115) §581 (3 Pipen Öl); § 696 (4 Pipen Öl).

116) $\S 581$ ( $1 / 2 \mathrm{Faß}$ und $1 / 2 \mathrm{FaB}$ Mandeln). $\S 715$ (1/2 Faß Mandeln).

117) $\$ 581$ (1 Tonne und 59 Pfd. Ingwer).

$\left.{ }^{118}\right) \S 715$ (1 Koppel Feigen).

${ }^{119)} \S 715$ (2 Ballen Reis; 1/2 Faß Reis). 
den Gesamtumfang des Geschäftes Vickos, da er nur solche Geschäfte, die nicht bar abgewickelt wurden, sondern bei denen er kreditierte, eintrug, und da wir nicht wissen, welchen Umfang damals die Bargeschäfte in einem derartigen Kaufmannsbetriebe einnahmen.

Bei den Tuchen, welche Vicko von Flandern her zugehen, ist in zahlreichen Fällen der Herstellungsort angegeben ${ }^{120}$ ); 309 mal ist es ein flandrischer Ort; 59 mal werden Orte im Brabantischen, Antwerpischen und im Hennegau genannt; in 20 Fällen werden die Tücher als englische bezeichnet; 7 mal kommt Holland, 1 mal Seeland und 1 mal Geldern, 2 mal

$\left.{ }^{120}\right)$ Als Herstellungsort kommen vor:

260 mal Westflandern, und zwar:

171 mal Brügge (es ist wohl fraglich, ob Brügge in allen diesen Fällen Herstellungsort und nicht vielmehr Einkaufsort ist; es wird sich aber auf jeden Fall um Tuch nach Brügger Art handeln)

27 mal Meniers

18 , Dixmuide

19 ," Roulers

13 ,, Courtray

5 ,, Vernier

3 ,, Comines

3 , Ypern

1 ,, Warneton

49 , Ostflandern und zwar:

18 , Gent

16 ,, Grammont

7 , Ecloo

6 ,, Audenarde

2 ,, Termonde.

10 ,, das Land Antwerpen, und zwar:

7 , Herenthals

3 , Mecheln

33 ,, das übrige Brabant

16 ," Henegau

368 mal Flandern nebst Brabant u. s. w. zusammen.

Ferner 20 ,, England

7 , Holland

1 , Geldern

1 ,, Seeland

2 ,, Hessen. 
Hessen vor. Einmal wird auch braunschweigisches Tuch erwähnt, das Vicko jedoch nicht ankauft, sondern von einem insolventen Schuldner in Zahlung nimmt. Wir ersehen auch aus diesen Zahlen wieder, welch ungeheures Übergewicht noch immer die flandrische Tuchindustrie in dieser Zufuhr hatte. Zwar hatte die Tuchweberei, die als Gewerbe sich in nahezu allen Städten Deutschlands schon im 13. Jahrhundert vertreten findet, fast überall seit dem 13. Jahrhundert bemerkenswerte Fortschritte gemacht und bereits an vielen Stellen begonnen, ihre Produktion über den Bedarf des örtlichen Marktes hinaus zu erheben. Nicht nur in Brabant und England sowie im Rheinischen, wo unter andern Köln und Aachen ${ }^{121}$ ) Sitze einer Tuchmanufaktur geworden waren, welche auch für den Norden gewisse Sorten von Tuch lieferte, sondern auch in Hessen, in Speier ${ }^{122}$ ), im Elsa ${ }^{123}$ ), in Friesland ${ }^{122}$ ), in Braunschweig usw. ${ }^{124}$ ), weiter östlich namentlich in Preußen ${ }^{125}$ ) und auch in den wendischen Städten ${ }^{126}$ ) sehen wir die Tuchweberei bereits Überschüsse für den Ausfuhrhandel liefern. In Norwegen ${ }^{127}$ ) und auch in den Ostseestädten ${ }^{128}$ ) kommt schon im 13. Jahrhundert ein grobes Wolltuch - watmal genannt - vor, das rom Osten her auch dem Brügger Weltmarkte zugeführt wurde ${ }^{129}$ ). In

121) Tuche (capellaken aus Aachen und Köln) 1327 in Nowgorod, s. Hans. Urkdb. III n. 585.

${ }^{122}$ ) Laken von Speier und von Friesland 1337, Hans. Urkdb. III S. 478 Note 1 .

123) Ebenda n. 682 u. S. 484 Note 1 ebenda.

$\left.{ }^{124}\right)$ S. auch z. B. Stendaler Tuch, Hans. Urkdb. II n. 48.

${ }^{125}$ ) Über die Tuchweberei in Thorn s. die Verordnung von 1349, Hans. Urkdb. III S. 76 Note 2; s. ferner Thorner Tuche als Ausfuhrartikel nach Wladimir und Lemberg, ebenda n. 559. Dagegen sind die 1324 bei Rügen gestrandeten, aus Flandern kommenden panni Dornenses offenbar nicht Thorner Ursprungs, sondern aus Dornik.

${ }^{126}$ ) Stralsunder Tuch (pannum griseum Sundensem), Hans. Urkdb. II n. 727; Parchimer Tuch in der Anklamer Zollrolle, ebenda n. 21.

127) Hans. Urkdb. II n. 284, 320, 502.

$\left.{ }^{128}\right)$ Lübecker Bürgern größere Mengen watmal von dem Grafen von Holstein geraubt, Hans. Urkdb. II n. 727; watmal in der Stettiner Zollrolle von 1270 , Hans. Urkdb. I n. 687.

$\left.{ }^{129}\right)$ S. Zollrolle für Damme von 1252 panni, qui Teutonice dicuntur, wanmael, ebenda I n. 432 . 
der Mitte des 14. Jahrhunderts wird der grauen Laken (grisei panni), die von ostwärts kommen, schon eingehender in den flandrischen Privilegien gedacht; die Deutschen bedingen sich aus, daß diese Tuche in Flandern nicht dem Hallengeld unterliegen und zollfrei verkauft werden dürfen $\left.{ }^{130}\right)$. Auch die oostersche Wolle kommt neben den ,grauen Laken“ in der Maklerrolle für den Verkehr der Deutschen in Flandern aus dieser Zeit vor $\left.{ }^{131}\right)$. Im Vergleiche zu dem Umfange der flandrisch-brabantischen Tuchindustrie tritt aber die Wolltuchproduktion aller dieser deutschen Städte und Landschaften ganz in den Hintergrund, und an Güte stand das in Flandern und Brabant erzeugte Tuch dank der Feinheit des Rohstoffes, den die Industrie dort verarbeitete, unerreicht da. Hamburg selbst hatte so gut wie gar keine Tuchindustrie, es gab hier ausweislich des Verzeichnisses von 1375 nur sechs Wollwebermeister ${ }^{132}$ ). Beachtenswert ist namentlich das häufigere Vorkommen englischer Tuche in dem Geschäftsbetriebe Vickos; wir sehen diese Tuche seit etwa der Mitte des Jahrhunderts, wie schon oben erwähnt, auch über Lübeck nach dem Norden weitergehen. Unter den Tuchen, welche 1368 von Hamburg kommend in Lübeck dem Pfundzoll unterworfen werden, sind englische Tuche im Werte von 1275 M. l. erwähnt; wenn die übrigen einen Wert von 104348 M. l. darstellenden Tuche sämtlich nichtenglischen Ursprungs sind, so würden allerdings die englischen Tuche im Welthandel noch ganz zurücktreten, wie denn ja auch im Geschäfte Vickos der Umsatz in englischen Tuchen neben dem Handel mit flandrischen Tuchen noch verschwindend klein ist. Immerhin hatte sich das englische Tuch doch bereits den Weg nach dem Osten und Norden gebahnt. Etwa 1360 wird eine große Menge englischen und irischen Tuches auf der Straße zwischen Hamburg und Lübeck geraubt ${ }^{133}$ ). Auch in Urkunden des Hofes von Nowgorod wird englisches Tuch schon mehrfach,

$\left.{ }^{130}\right)$ Hans. Urkdb. III n. 403 Ziff. 16, 451, 452 Ziff. 52 bzw. 54;

495, 496 Ziff. 26; 497 Ziff. 35.

131) Ebenda n. 499.

132) Westphahlen, a. a. O.

$\left.{ }^{133}\right)$ Hans. Urkdb. III n. 357. 
zuerst 1355, erwähnt ${ }^{134}$ ). Auch das englische Tuch ging übrigens Hamburg auf dem Wege über das Zwin zu. Ausdrücklich wird den deutschen Kaufleuten in dem Privileg von 1260 das Recht zugestanden, englisches Tuch in das Zwin einzuführen, um es von dort zur Ausfuhr nach dem Westen weiterzuschiffen. Von einem nennenswerten unmittelbaren Verkehre Hamburgs mit England kann auch für die erste Hälfte des 14. Jahrhunderts nicht die Rede sein ${ }^{135}$ ), da die Ausfuhr Englands, wie wir gesehen haben, bis 1353 gesetzlich auf Brügge konzentriert war, die Einfuhr aber nach England, ganz abgesehen davon, daß sie im Verhältnis zur Ausfuhr sehr klein war, infolge der Richtung der Ausfuhr naturgemäß ebenfalls vom flandrischen Weltmarkte abhängig war.

Ob etwa die Hamburger selbst die Elbe hinauffuhren und im Inlande Handel trieben, vermögen wir infolge der Lückenhaftigkeit unserer Quellen nicht zu erkennen. Allem Anschein nach kamen die binnenländischen Kaufleute mehr nach Hamburg als die Hamburger ins Binnenland ${ }^{136}$ ). Vicko beschränkte sich jedenfalls darauf, in Hamburg an die Inländer zu verkaufen. Bemerkenswert ist aber, daß die Soester, höchtstwahrscheinlich von Hamburg aus, die Städte der Mark Brandenburg besuchten ${ }^{137}$ ). Daß die Inländer Hamburg besuchen, ersehen wir zur Genüge aus Vickos Handlungsbuch. Unter seinen Kunden finden wir zahlreiche Kaufleute aus Lüneburg, Ülzen,

134) Hans. Urkdb. III n. 321, 597.

$\left.{ }^{135}\right)$ In dem Handlungsbuche Vickos kommt zweimal eine Verschiffung von Leinwand nach England vor. Ob es sich dabei aber überhaupt um unmittelbare Verschiffungen ohne Berührung des Zwin handelt, muß dahingestellt bleiben.

136) Vgl. auch Stein, Beiträge zur Geschichte der deutschen Hanse, S. $44 \mathrm{f}$.

$\left.{ }^{137}\right)$ Hans. Urkdb. II n. 139. Die Strandrechtsprivilegien, welche den Soestern in Brandenburg gewährt wurden, weisen deutlich darauf hin, daß sie dorthin zu Schiffe auf den Flüssen kamen, nicht zu Lande von Westfalen aus, wie Hans. Urkdb. II n. 139 Note.1 andeuten zu wollen scheint; die Urkunde betrifft den Zoll von Wagen und Karren aller Güter, die durch Westfalen zwischen Rhein und Weser fahren und dürfte sich auf den Verkehr Soests über Wildeshausen nach Bremen bezogen haben; von dieser Verkehrsstraße haben wir viele Nachrichten. 
Hannover, Salzwedel, Boitzenburg, Dannenberg, Lüchow, Dömitz, Parchim, Lenzen, Seehausen, Perleberg, Werben, Magdeburg, Braunschweig, auch aus Kiel, Neumünster, Rendsburg, Schleswig, Flensburg $\left.{ }^{138}\right)$. Lebhafte Handelsbeziehungen unterhielt Vicko mit Stade. Eine andere urkundliche Nachricht zeigt uns Hamburger Kaufleute auf dem Markte von Itzehoe, im Lande Ditmarschen und in Rendsburg ${ }^{139}$ ). Auch Verbindungen mit den wendischen Städten werden einigemal in dem Handlungsbuche Vickos erwähnt; namentlich mit Stralsund, einmal auch mit Wismar ${ }^{140}$ ). Daß sich die Beziehungen der Hamburger bis zu den wendischen Städten ausdehnten, zeigt auch der Wismarer Zolltarif von $1328^{141}$ ), der die Hamburger, wenn auch nur beiläufig, erwähnt und sie den andern von der Elbe her Kommenden gleichstellt. Eine irgend erheblichere Bedeutung hat dieser Verkehr aber nicht besessen.

Wie im 13. Jahrhundert waren die Hamburger auch in diesem Zeitraume eifrig bemüht, den Wasserweg die Elbe hinab bis nach Flandern zu sichern. 1309 sehen wir die Hamburger mit den Stadern ein Bündnis abschließen ${ }^{142}$ ) zur Befriedung der Elbe von Hamburg bis zur Mündung, erforderlichenfalls mit Waffengewalt; Hamburg soll gegebenenfalls drei Viertel, Stade ein Viertel der Streitkräfte stellen. 1304 erneuert Hamburg seine Verträge mit Ditmarschen über den Schutz des Handels auf der Elbe und die Unterdrückung und Verfolgung von Raub seitens der Ditmarschener ${ }^{143}$ ); 1305 kam es zu einem Verbote des Handels auf Ditmarschen seitens der Hamburger und der übrigen beteiligten Kaufleute, da die Ditmarschener auf Elbe und Eider erneut Raub begangen hatten ${ }^{\mathbf{1 4 4}}$ ). 1307 schloß Hamburg wiederum eine Vereinbarung mit Ditmarschen über den Schutz der Elbe $a b^{145}$ ). Im folgenden Jahre beur-

$\left.{ }^{138}\right)$ Nirnheim, a. a. O. Einleit. S. $51 \mathrm{ff}$.

$\left.{ }^{139}\right)$ Hans. Urkdb. II n. 728.

$\left.{ }^{140}\right)$ Nirrnheim, a. a. O. S. 53.

141) Hans. Urkdb. II n. 476.

142) Ebenda n. 148.

${ }^{143)}$ Ebenda n. 52.

144) Ebenda n. 82.

${ }^{145}$ ) Ebenda n. 101. 
kundet Ditmarschen Verträge ähnlichen Inhaltes zwischen dem Ditmarschener Kirchspiele Brunsbüttel und Hamburg und die Beilegung eines Streites zwischen beiden ${ }^{146}$ ). 1316 wird wiederum eine Fehde zwischen Hamburg und Brunsbüttel geschlichtet und die Sicherheit der Elbe und die nachdrückliche Verfolgung von Raub seitens der Brunsbüttler gewährleistet ${ }^{147}$ ). 1323 gelobt das Land Ditmarschen bei Beilegung eines Streites mit den Grafen von Holstein wiederum u. a. Sicherheit für den Verkehr auf der Elbe ${ }^{148}$ ). Nicht minder als unter den Ditinarschener Seeräubern sehen wir den Handel unter den holsteinischen Piraten leiden. 1311 geloben zwar die Grafen von Holstein, von ihrer Feste Hatzberg bei Wedel aus keinen Kaufmann $\mathrm{zu}$ belästigen ${ }^{149}$ ). Aber 1341 lesen wir von grausamer Rache, die eine Flotte von etwa 100 Schiffen, welche auf der Stör liegt - es scheinen vorwiegend lübische Kaufleute auf ihr gewesen zu sein --, an dem Vogt von Steinburg bei Krempe und an dem Orte Ivenfleth an der Stör übt $\left.{ }^{150}\right)$. Ungefähr um dieselbe Zeit schließt Hamburg ein Bündnis mit Lübeck gegen die von Crummendik (bei Itzehoe), verpflichtet sich, hundert bewaffnete Reiter zu einem Feldzuge gegen diesen Feind zu stellen und nötigenfalls auch zu Wasser einen Angriff auszuführen, sofern nicht binnen vier Wochen von dem Herrn von Crummendik Genugtuung für begangene Schädigung geleistet wird ${ }^{151}$ ). Zahlreich sind die Klagen, welche die Hamburger und Lübecker über die Unsicherheit auf der Elbe und namentlich über die Gewalttaten der Ritter von Crummendik 1342 gegen deren Lehnsherren, die Grafen von Holstein, vor dem gemeinsam bestellten Schiedsrichter erheben ${ }^{152}$ ). Wenn die Schiffe auf der Strecke zwischen der See und Hamburg bei Ebbe auf Grund gerieten, so kảmen die gräflichen Vögte der benachbarten Gegenden mit ihren Leuten und beraubten die Schiffe.

\footnotetext{
146) Hans. Urkdb. II n. 127.

147) Ebenda n. 273.

148) Ebenda n. 408.

${ }^{149}$ ) Ebenda n. 200.

${ }^{150)}$ Ebenda n. 685.

151) Ebenda n. 688.

152) Ebenda n. 725 u. 728.
} 
Graf Gerhard habe den Hamburgern auf der Stör ein Schiff genommen mit 40 Fuder Bier im Werte von 200 Mark; der Ritter von Crummendik habe bei Brockdorff Hamburgern 13 Scheffel Hafer geraubt; andern Hamburgern seien vor der Stör Geld und Jagdfalken weggenommen; dem Hamburger Kaufmann Bertram Tolner und seinen Gesellschaftern seien auf der Stör Bier und Salz im Werte von 70 M. von dem gräflichen Vogt genommen; einem andern Hamburger war auf der Stör Bier im Werte von 184 Mark geraubt; 1333 hatten die Ritter von Crummendik einen beladenen hamburgischen Kahn auf der Elbe weggenommen und in die Stör entführt; vergeblich hatten die Hamburger Klage bei den Grafen von Holstein erhoben; wiederholt hätten diese, so heißt es in der Beschwerde, zwar Gerichtstage zur Schlichtung des Streites angesetzt, aber niemals hätten die Herren von Crummendik den Ladungen Folge geleistet. Die Lübecker klagen gleichfalls über die von Crummendik, die ihnen u. a. bei Blankenese ein Schiff geraubt hätten usw. 1356 sehen wir die Hamburger und Stader gemeinsam gegen Räuber auf der Stör kämpfen ${ }^{153}$ ).

Mehrfach begegnen wir auch Maßnahmen zur Sicherung des Handels gegen die linkselbischen Hadelner. 1310 sichert Hadeln den Hamburgern Schutz namentlich gegen Beraubung durch Leute aus Steinmarne, Duhnen und Stickenbüttel $\mathrm{zu}^{154}$ ). 1357 verbündet sich Hamburg mit den Herzögen von SachsenLauenburg gegen einige Räuber im Lande Hadeln ${ }^{155}$ ); zugleich sichern die Herzöge den Hamburgern Schutz gegen Raub seitens der Hadelner zu und nehmen sie und alle andern Kaufleute für die Fahrt auf der Elbe von Hamburg bis zur Mündung in ihr Geleit ${ }^{156}$ ). 1349 verpflichten sich die Ritter von der Lappe, welche am Ausgang der Elbe in Ritzebüttel ihren Sitz hatten, den Hamburgern gegenüber auf ein Jahr, alle Kaufleute, mit Ausnahme der Dänen, gegen Raub beim Besuche der Elbe, soweit ihre Gerichtsbarkeit reicht, zu schützen und

${ }^{153)}$ Hans. Urkdb. II S. 154 Note 2.

154) Ebenda n. 181.

${ }^{155)}$ Ebenda III n. 379.

${ }^{156)}$ Ebenda n. 380. 
auch außerhalb ihres Gerichtssprengels nach Möglichkeit ihnen Beistand zu leisten ${ }^{157}$ ). 1351 und 1358 wird dieser Vertrag mit den Rittern von der Lappe erneuert ${ }^{158}$ ). Am Ausgange der Elbe ließ Hamburg sich die Verbesserung des Leuchtturmes zu Neuwerk sehr angelegen sein. Es wurde, wie es scheint, am Anfange des 14. Jahrhunderts dort der Bau des Turmes erneuert und für diesen Bau eine Abgabe von den Waren und Schiffen in Höhe von 1/2 Pfennig von je 28 Schillingen in Hamburg erhoben. Über diese Abgabe geriet Hamburg 1309 mit den Lübeckern, welche dieselbe nicht zahlen wollten, in einen Streit, der durch ein Schiedsgericht dahin beigelegt wurde, daß die Lübecker die Abgabe drei Jahre lang entrichten sollten ${ }^{159}$ ). 1357 nahm der Herzog von Sachsen die Anlage des Leuchtturmes tesonders in seinen Schutz und verbot, in größerer Nähe als bisher geschehen, andere Gebäude aufzurichten, um den Leuchtturm von allen Seiten möglichst sichtbar $\mathrm{zu}$ erhalten ${ }^{160}$ ). Aus derselben Urkunde ersehen wir, daß Hamburg auf dem Turme zu Neuwerk einen Mann wohnen ließ $\left.{ }^{161}\right)$, und eine Urkunde von 1340 läßt erkennen, daß zu Neuwerk, wenigstens von Schiffen, die nach Stade fuhren, ein Zoll - wahrscheinlich jene Abgabe, die bei den nach Hamburg bestimmten Schiffen in Hamburg zur Erhebung gelangte beansprucht wurde, von dem aber die Stader selbst und die Strandfriesen, die nach Stade fuhren, befreit waren ${ }^{162}$ ). Auch mit dem Hadeln benachbarten Lande Wursten schlossen die Hamburger 1316 einen Vertrag zum Schutze des Leuchtturms zu Neuwerk $\left.{ }^{163}\right)$. 1335 und 1336 sagte Wursten von neuem den Hamburgern Schutz und Geleit $\mathrm{zu}^{164}$ ).

Am Ausgange der Elbe trennten sich, wie wir bereits früher gesehen haben, die Wege, die nach Flandern führten. Für die

157) Hans. Urkdb. III n. 138.

${ }^{158)}$ Ebenda n. 200 u. 360.

${ }^{159)}$ Ebenda II n. 137/138.

${ }^{160}$ ) Ebenda III n. 380.

161) Diesem Turmwärter wird für sich und sein Vieh besonderer Schutz vom Herzog zugesichert.

${ }^{162}$ ) Hans. Urkdb. II n. 659, 660.

${ }^{163)}$ Ebenda n. 273.

${ }^{164)}$ Ebenda n. 572, 585. 
Fahrt durch die offene See war Helgoland, dessen Hafen den Kauffahrern bei schlechtem Wetter eine Zufluchtsstätte gegen die See bot, nicht ohne Bedeutung. Als 1356 der König von Dänemark begann, Befestigungen auf der Insel zu errichten, sandten die Hamburger sogleich eine Gesandtschaft an ihn mit der Bitte, daß er ihnen und dem gemeinen Kaufmann keine Nachteile aus derselben erwachsen lassen möge ${ }^{165}$ ).

In der Zuidersee trat an die Stelle Utrechts im Laufe der ersten Hälfte des 14. Jahrhunderts Amsterdam als Endpunkt der Wattenfahrt; wir haben schon am Ende des 13. Jahrhunderts gesehen, daß die Hamburger Schiffe nicht mehr bei Utrecht selbst, sondern weiter flußabwärts bei Marsen auf Fracht zu warten pflegten; höchst wahrscheinlich trat in der ersten Hälfte des 14. Jahrhunderts eine weitere Verschlechterung des Fahrwassers der Vechte ein; die Seeschiffe vermochten nicht mehr die Vechte hinaufzukommen und fuhren nur noch nach Amsterdam ${ }^{166}$ ). Die hamburgische Hanse zu Utrecht verschwindet infolgedessen, und anstatt ihrer begegnen wir nunmehr einer Hamburger Hanse in Amsterdam ${ }^{167}$ ). Im Jahre 1358 scheinen die Verhältnisse dieser Hanse - gheselscap die tot Amsterdam pleghen to ligghen ${ }^{168}$ ) - von der damals zu Dordrecht residierenden flandrischen Hanse der Deutschen umgestaltet worden zu sein; wir erfahren, daß der Ältermann des lübischen Drittels, Manegolt Sosendorp, von dem gemeinen deutschen Kaufmanne zu Dordrecht bevollmächtigt wurde, nach Amsterdam zu fahren und dort zwei Älterleute einzusetzen und diese zur Ordnung der Angelegenheiten in Amsterdam im Interesse des deutschen Kaufmanns zu bevollmächtigen, und daß Sosendorp diesen Auftrag ausführte und Gerbert Ghulsowen und Jan Papen zu Amsterdam als Älterleute einsetzte. Jan Papen war, wie

${ }^{165)}$ Hans. Urkdb. III n. 363.

168) 1302 erwerben die Lübecker noch wieder Privilegien für den Weg von Muiden nach Utrecht, Hans. Urkdb. II n. 16.

167) Lappenberg in der Zeitschrift für hamb. Geschichte, Bd. 4, S. 299; Sartorius-Lappenberg, Urkundl. Geschichte der Entstehung der Hanse I 268. ${ }^{168)}$ Hans. Urkdb. III S. 180 Note 1. 
wir aus einer andern Urkunde ersehen ${ }^{169}$ ), jedenfalls Hamburger Bürger.

Neben Flandern kamen für die Ausfuhr aus Hamburg seewärts hauptsächlich nur noch Holland und Friesland in Betracht, wo das hamburgische Bier einen bedeutenden Absatz fand. Amsterdam und Stavorn waren die Stapelplätze, von denen aus die Hamburger dasselbe vertrieben. Auch in Stavorn bestand, wie schon bemerkt, eine hamburgische Hanse. 1365 kam der Ältermann der Hamburger Genossenschaft in Stavorn nach Amsterdam und bat um eine Abschrift der Privilegien des Rechts, der Ordinancien und Costumen der Amsterdamer Hanse, da es ihrer Herren von Hamburg Wille sei, daß sie zu Stavorn ebenso ihre Hanse halten sollten, wie man es zu Amsterdam tue $\left.{ }^{170}\right)$. Ein von dem Grafen von Holland erlassenes Verbot der Einfuhr des hamburgischen Bieres nach dem Kennemerland und Friesland im Jahre 1321 verursachte empfindliche Schädigungen dieser Gegenden ${ }^{171}$ ); lange wird es kaum in Kraft gewesen sein. 1323 errichtete der Graf von Holland bei Medemblik und bei Amsterdam Zollstätten zur Verzollung des aus dem Ostlande und dem Stifte Utrecht nach dem Kennemerland und Westfriesland kommenden Bieres ${ }^{172}$ ) und befahl, daß alle Schiffe mit Bier an einer dieser beiden Zollstätten den Zoll erlegen sollten; als Ausweis über die Erlegung des Zolles sollte ihnen ein Zeichen eingehändigt werden, das sie in andern Städten vorzeigen sollten. Die Einfahrt in die Zuidersee nach Holland durch eine andere Fahrrinne unter Umgehung des Zolles wurde verboten und mit Konfiskation des Schiffes und seiner Ladung bedroht. 1351 wurde in Holland zugunsten der Bierbrauer Haarlems der Gebrauch ausländischen Bieres außer dem hamburgischen Bier und dem Ummelandsbier (d. i. Bier aus den Ostseestädten, das um Skagen herum dem Westen zugeführt zu werden pflegte) verboten; nur in Amsterdam sollte Bier jeder Art verkauft werden dürfen ${ }^{173}$ ).

169) Hans. Urkdb. III n. 374.

170) Ebenda IV n. 164.

171) Ebenda II S. 161 Note 1.

172) Ebenda n. 409.

173) Ebenda III n. 223. 
Auch in Stavorn unterlagen die Hamburger Kaufleute, die ihr Bier dorthin einführten, einem Zolle $\left.{ }^{174}\right)$. Bei der Verkehrssperre der Hansa gegen Flandern 1360 wurde bezeichnenderweise Hamburg, Stade und Bremen gestattet, Bier und $\mathrm{Holz}$ westwärts bis zum Vlie zu führen, wenn es nur nicht in die Hände der Flanderer gelangte ${ }^{175}$ ).

Eine Reihe von Urkunden bezeugt die engen Beziehungen, die Hamburg mit West- und Ostfriesland und Halland unterhielt. Die Beziehungen zu Stavorn erfuhren in den dreißiger Jahren eine Störung durch einen Zwist, der zwischen Lübeck und Stavorn ausbrach und in den auch Hamburg hineingezogen wurde. Die Stavorner hatten von Lübeck Ersatz für einen Schaden gefordert, den ihnen jene bei Halland im Sund zugefügt haben sollten und bestanden auf dieser Forderung, obwohl Lübeck versicherte, daß die Übeltäter nicht Angehörige Lübecks seien ${ }^{176}$ ); Gewalttaten zwischen Lübeckern und Stavornern auf Schonen scheinen hinzugekommen zu sein ${ }^{177}$ ). Die Folge war, daß Stavorn lübische Waren und Schiffe wegnahm und Lübeck mit ähnlichen Maßnahmen sich wehrte. Die Stavorner hatten es vor allem auf den Verkehr der Lübecker von der Elbe nach dem Westen abgesehen, und so kam es, daß auch hamburgische und andere fremde Güter und Schiffe als lübisches Eigentum von den Stavornern weggenommen wurden, zumal Stavorn die Hamburger im Einverständnis mit den Lübeckern glaubte. Ein Schiedsspruch legte im Jahre 1335 diese Streitigkeiten bei ${ }^{178}$ ). Als 1345 ein Krieg zwischen Friesland und Holland ausgebrochen war, bat Hamburg 1346 den Abt des Klosters Aduard im Lande Groningen, daselbst auf die Grietmannen und Richter Frieslands einzuwirken, daß sie die hamburgischen Kaufleute, die ja Friesland und Holland in gleicher Weise besuchten, nach wie vor wohlwollend aufnehmen und dort Handel treiben lassen möchten $\left.{ }^{179}\right)$. Zwar ließ sich der Abt das

174) Hans. Urkdb. III n. 182.

${ }^{175)}$ Ebenda n. 476.

176) Ebenda II n. 487.

${ }^{177)}$ Ebenda n. 557.

${ }^{178)}$ Vgl. ebenda II n. 487, 539-541, 549, 550, 554, 556, 557, 560, 563.

$\left.{ }^{179}\right)$ Ebenda III n. 74, 75. 
Wohl der Hamburger angelegen sein, doch vermochte er nicht, sie vor Schädigungen zu schützen ${ }^{180}$ ); so wurden denn Hamburger Kaufleute in Friesland gefangen genommen, Hamburger Waren geraubt usw. ${ }^{181}$ ). Im April des Jahres 1347 berichteten die Richter des friesischen Amtes zu Termünten im heutigen Groningerlande an Hamburg über die Genugtuung, welche den gefangenen Hamburgern zuteil geworden sei ${ }^{182}$ ). Einige Monate später sandten die Richter des Emsgaues Boten an Hamburg und baten, ihre Landesangehörigen freundschaftlich aufzunehmen; Hamburg erteilte darauf in einem Schreiben an die Äbte, Geistlichen und Vorsteher von Friesland deren Boten Geleit für die Fahrt nach Hamburg zur Herstellung des Friedens ${ }^{183}$ ). Wenig später muß es zu einem Einvernehmen mit den Emsgauern gekommen sein. Die in Hamburg arrestierten Emsgauer wurden entlassen und die Geistlichen, Räte und Richter des Emsgaues gelobten, die Hamburger überall zu fördern und versprachen, die durch einige Übeltäter den Hamburgern zugefügten Unbilden nach Kräften auszugleichen; sie baten Hamburg, die Wiedererstattung einiger emsgauischen Kaufleuten durch den Vogt von Oldesloe genommenen Güter $\mathrm{zu}$ vermitteln ${ }^{184}$ ). Um dieselbe Zeit richtete das Land Harlingen ein Schreiben an Hamburg, in welchem es um Freigabe der in Hamburg gefangenen Harlinger bat, da es mit den Westfriesen, den Gegnern der Hamburger, in Feindschaft lebe; zugleich sicherte es den hamburgischen Kaufleuten Sicherheit des Verkehrs in Harlingen zu ${ }^{185}$ ). Im Juli 1347 forderten die Äbte, Geistlichen, Vorsteher und Richter von Westergo, des friesischen Gebietes um Stavorn herum, von Hamburg die Entlassung ihrer gefangen gehaltenen Landesangehörigen und versprachen, auch Hamburger und hamburgisches Gut, wenn solches bei ihnen nachgewiesen werde, freizugeben ${ }^{186}$ ). Eine

$\left.{ }^{180}\right)$ Hans. Urkdb. III n. 122.

181) Ebenda n. 95, 107.

$\left.{ }^{182}\right)$ Ebenda n. 95.

$\left.{ }^{183}\right)$ Ebenda n. 98.

184) Ebenda n. 102.

$\left.{ }^{185}\right)$ Ebenda n. 101.

${ }^{186)}$ Ebenda n. 103. 
Urkunde aus dem August d. J. meldet von Friedensbestrebungen des Landes Norden gegenüber Hamburg und enthält das Versprechen sicheren Geleits für die hamburgischen Kaufleute im Lande Norden ${ }^{187}$ ). 1347 schlossen Weißastringien (das heutige Friesland) und der Distrikt Winninghe daselbst, die Städte Leuwarden und Dokkum, die Klöster Klaarkamp, Dokkum und Foswert in holländisch Friesland, der Hunsegau, der Abt und Konvent des Klosters zu Termünten, das Kloster Aduard und Richter, Ratmänner und Gemeinde des friesischen Altamtes im heutigen Groningen, das Land Harlingen in Ostfriesland, Astringien im heutigen Oldenburg uud Jever eine Sühne $a b$ mit Hamburg und dessen Kaufleuten wegen der seit 1346 vorgekommenen Beraubungen und Schädigungen ${ }^{188}$ ). Eine Urkunde von 1348 handelt von der Beilegung des Zwistes Hamburgs mit den Lande Norden ${ }^{189}$ ). Erst 1355 scheinen die Verhandlungen Hamburgs mit den friesischen Klöstern Klaarkamp, Aduard, Jerusalem, Mariengaard, Dokkum und Foswert über die Schäden endgültig abgeschlossen zu sein $\left.{ }^{190}\right)$. 1359 hören wir wiederum von einem Vergleiche Hamburgs mit einem Häuptling in Pilsum in Ostfriesland zur Herstellung des Friedens ${ }^{191}$ ).

Auch in diesem Zeitabschnitte sind Stade und Lüneburg bestrebt gewesen, im Wettbewerb mit Hamburg an dem Handel des Binnenlandes und des baltischen Gebietes mit dem Westen teilzunehmen. Im ganzen war indessen Stade offenbar hinter Hamburg immer weiter zurückgetreten. Zwar sehen wir Stade nach wie vor auf den alten Wegen durch Holland hindurch mit Flandern in Beziehung stehen ${ }^{192}$ ). Eine Bestimmung der Statuten der Gewandschneider in Stade von 1311 ${ }^{193}$ ) bezeugt, daß die Friesen dorthin graue Tuche und ,,sardok" genannte Tuche bringen und diese sogar im Kleinhandel dort vertreiben dürfen. Auch die

187) Hans. Urkdb. n. 106.

$\left.{ }^{188}\right)$ Ebenda n. 107-109, 121, 122.

189) Ebẹnda n. 126.

190) Ebenda n. 341.

191) Ebenda n. 463.

$\left.{ }^{192}\right)$ Ebenda n. 193, 288, 471.

${ }^{193)}$ Ebenda II S. n. 89 Note 3. 
Stader selbst sehen wir Küstenverkehr mit Ripen unterhalten, von wo sie Butter, Häute, Talg, lebendes Vieh, Bier, Watmal und Fische holen ${ }^{194}$ ). Aber zahlreiche Eintragungen in dem Handelsbuche Vickos van Geldersen beweisen, daß die Stader die flandrischen Tuche zum mindesten vielfach nicht mehr unmittelbar von Flandern holten, sondern in Hamburg kauften. Zwar zwang der Stader Zoll nach wie vor alle Schiffe, die nicht ausschließlich Eigentum Hamburger Bürger führten, in Stade anzulegen, noch 1340 wurde die Freiheit der Hamburger vom Stader Zoll und von der Verpflichtung, dort mit ihren Schiffen anzulegen, in einem unter Lübecks, Lüneburgs und Bremens Vermittlung zwischen Stade und Hamburg abgeschlossenen Vergleich ${ }^{195}$ ) aufs neue bestätigt, wofür den Stadern und den nach Stade fahrenden Strandfriesen Freiheit vom Neuwerker Zolle zugestanden wurde; nur wenn sie fremdes Eigentum nicht hamburgischer Bürger an Bord hatten, sollten die Hamburger Schiffe zu dessen Verzollung in Stade anlegen müssen. Aber die Lage Hamburgs bot namentlich für den baltischen Verkehr zu große Vorzüge vor derjenigen Stades, so daß dieser Verkehr, ungeachtet des Stader Zolles, ganz Hamburg zufiel. Stades Handelsbedeutung sank offenbar immer tiefer herab; sein Verkehr wurde immer mehr lokaler Art; als die Stadt 1368 ein Schiff gegen Dänemark ausrüsten sollte, erklärte sie, daß sie kein Seeschiff besitze $\left.{ }^{196}\right)$.

Sehr viel besser als Stade hat Lüneburg seine ehemalige Handelsbedeutung zu behaupten vermocht. Dank seiner Saline hatte es einen sehr umfangreichen Verkehr nach der Ostsee hin, insbesondere mit Lübeck, festzuhalten vermocht, und die großen Massen von Salz, welche sich auf diesem Wege bewegten, erzeugten nach wie vor einen Gegenstrom vom baltischen Gebiete, der Lüneburg zu einem wichtigen Verkehrsplatze, insbesondere als Heringsmarkt, für das Binnenland machte. Noch um die Mitte des 14. Jahrhunderts sehen wir deshalb Lüneburg z. B. auch mit Braunschweig in Verbindung stehen ${ }^{197}$ ). Aus

194) Hans. Urkdb. III n. 183.

195) Ebenda II n. 659, 660.

$\left.{ }^{196}\right)$ Hanserezesse I 1 n. 434.

$\left.{ }^{197}\right)$ Hans. Urkdb. III n. 461. 
der bedeutenden Stellung, welche sich Lüneburg auf diese Weise im Verkehr bewahrte, erklärt es sich auch, daß wir die Lüneburger auch am Verkehre mit Flandern, wie früher, beteiligt finden ${ }^{198}$ ), wenn auch der unmittelbare Anteil der Lüneburger am flandrischen Verkehre nur bescheiden gewesen sein mag; denn zahlreiche Eintragungen des Handlungsbuches Vickos van Geldersen sowie eine Urkunde von 1344 über den Zoll, den die Lüneburger für die Zufuhr von irischem Tuch, von Sayen (Tuch) und Lebensmitteln von Hamburg nach Lüneburg bei Eßlingen zu erlegen hatten ${ }^{199}$ ), zeigen uns, daß auch die Lüneburger die flandrischen Tuche und andere Waren jedenfalls $\mathrm{zu}$ einem bedeutenden Teile in Hamburg einkauften. Übrigens finden wir die Lüneburger auch in Beziehung zu Norderditmarschen ${ }^{200}$ ).

Hamburgs Bedeutung im Welthandel lag nach wie vor in der Hauptsache in der Vermittlung des baltisch-flandrischen Verkehrs. 1362 wurde auch in Hamburg Pfundzoll erhoben; derselbe ergab den Ertrag von 2145 M. l. Es müssen demnach, wenn wir mit Stieda ${ }^{201}$ ) die Höhe des Zolles auf 1/96 des Wertes der verzollten Gegenstände annehmen, insgesamt Werte im Betrage von 205920 M. l. verzollt sein. In dieser Summe wird enthalten sein: 1. die ganze von Flandern und vom übrigen Westen herkommende, nach Lübeck bestimmte Warenmasse ${ }^{202}$ ). Der Wert dieser Durchfuhr belief sich 1367, wie wir gesehen haben, auf mehr als 136000 M.l., wobei die über Amsterdam und Kampen gegangenen und daselbst verzollten Waren 1367 noch nicht einmal mitgerechnet waren. 2. Dagegen werden von den Warenmengen, welche vom baltischen Gebiete her über Lübeck nach Hamburg kamen, nur wenige in Hamburg verzollt sein, da diese Waren durchweg bereits in den hansischen Ausfuhrhäfen der Ostsee oder in Lübeck verzollt worden

${ }^{198)}$ Hans. Urkdb. III n. 461.

$\left.{ }^{199}\right)$ Ebenda n. 24.

${ }^{200}$ ) Ebenda n. 370.

201) Stieda, Revaler Zollbücher und Quittungen, S. 27 ff., 57.

${ }^{202}$ ) In Flandern und den niederländischen Stădten wurde 1362 kein Pfundzoll erhoben; diese Waren unterlagen also alle erst in Hamburg der Zollpflicht. 
sein werden und deshalb in Hamburg vom Pfundzoll frei waren $\left.{ }^{203}\right)$. 3. In der Summe sind ferner enthalten der, Wert der Waren, welche vom Binnenlande kommend über Hamburg nach Flandern gingen, und der in Hamburg erzeugten Waren, wie Bier u. dgl., welche nach dem Westen ausgeführt wurden, sowie ferner 4. der Wert der Waren, die vom Westen kommend nach Hamburg gelangten, um von hier in das Binnenland zu gehen oder in Hamburg verbraucht zu werden. 5. Endlich enthält die Summe auch noch den Wert der Seeschiffe, welche von Hamburg ausliefen. Welche Summen auf die Posten unter 3., 4. und 5. entfielen, entzieht sich unserem Auge. Nur soviel vermögen wir mit Sicherheit zu erkennen, daß der Gesamtwert des Handels, der sich zwischen dem sächsischen Binnenlande und Flandern über Hamburg abspielte, und des Handels mit Hamburger Erzeugnissen, wie Bier und Tonnen, gegenüber dem Gesamtwerte des sich über Hamburg bewegenden flandrischbaltischen Verkehrs ganz zurückgetreten sein muß. Denn wenn dieser flandrisch-baltische Verkehr möglicherweise auch großen Schwankungen unterlag und der Warenzug von Flandern nach Lübeck im Jahre 1367 mit mehr als 136000 M. 1., möglicherweise eine außergewöhnliche Höhe erreichte, so ist doch zu bedenken, daß mit dieser Ziffer von mehr als 136000 M.l. nur die eine Hälfte des sich über Hamburg-Lübeck vollziehenden Austausches zwischen Flandern und dem baltischen Gebiete erfaßt ist und daß der Gegenstrom, der vom baltischen Gebiete über Lübeck-Hamburg nach Flandern ging, sicherlich noch erheblich größer war ${ }^{204}$ ), so daß allein der Austausch zwischen

203) Nur die aus Gotland kommenden Waren wurden in Hamburg anfangs ungeachtet ihrer Verzollung in Wisby dem Pfundzoll unterworfen, da man Wisby als dänische Stadt ansah, bis Wisby hiergegen Einspruch erhob; vgl. Schäfer, Die Hansestädte und König Waldemar, S. 358.

${ }^{204}$ ) Zwar war der in Lübeck eingenommene Pfundzoll vielfach geringer als die Einnahmen Hamburgs, s. Stieda, Revaler Zollbücher, S. 57; es wird dies darin seine Erklärung haben, daß die Lübeck vom Osten her zugehenden Waren regelmäßig größtenteils schon in den livländischen, preußischen oder wendischen Ausfuhrhäfen oder in Wisby, die Lübeck vom Westen her zugehenden Güter aber in Hamburg verzollt waren, während die Hamburg vom Westen her zugehenden Waren, wenn die Niederländer, wie 1362, keinen Pfundzoll erhoben, sämtlich unverzollt, und 
dem baltischen Gebiete und Flandern über Hamburg in manchen Jahren schon die Summe von 205000 M.l. Weit überstieg, während der übrige über Hamburg sich abspielende Handel doch nur einen verhältnismäßig kleinen Teil dieser Summe ausgemacht haben kann ${ }^{205}$ ).

Die Bedeutung der Stadt Hamburg als Handelsplatz lag also wie im 13. Jahrhundert in seiner Eigenschaft als Umschlagsplatz in dem baltisch-flandrischen Handelsaustausche, die Bedeutung der Hamburger Kaufleute und Reeder in dem Anteil, den sie vom Mittelpunkt des Welthandels, von Brügge und vom Zwin aus, am Welthandel nahmen, sowie in der Tätigkeit, die sie von England aus als Exporteure der englischen Wolle, des großen Welthandelsartikels, von dem das Wohl der flandrischen Stapelindustrie, der Tuchindustrien Italiens und anderer Länder abhing, nach dem Zwin hin entfalteten.

Schon die dargelegten Tatsachen weisen darauf hin, daß wir uns von der Größe und Bedeutung Hamburgs als Handelsplatz und Stadt auch für diese Zeit nur recht bescheidene Vorstellungen machen dürfen. Der eigene Handel der Stadt spielte im Weltverkehre noch eine untergeordnete Rolle. Daß ihr direkter Seeverkehr auch in dieser Zeit sich noch auf Flandern und die Niederlande beschränkte, zeigt deutlich das schon mehrfach erwähnte Verzeichnis der Kaufleute und Amtsmeister aus dem Jahre 1375, das außer den pannicidae in Hamburg und den Bierbrauern der Hansen von Stavorn und Amsterdam nur mercatores de Flandria und mercatores de Anglia kennt, welch letztere aber, wie dargelegt, nicht nach Hamburg, sondern nach Flandern handelten. Die Einwohnerzahl Hamburgs hat

wenn die Niederländer Pfundzoll erhoben, doch zum größeren Teile unverzollt eingingen.

${ }^{205}$ ) Würden wir den Wert der von Flandern via Hamburg Lübeck zugegangenen Waren für 1362 auf 136000 M. l., wie im Jahre 1367, annehmen wollen, so würden noch etwa $70000 \mathrm{M}$. l. übrig bleiben. Yon dieser Summe müßte der gewiß nicht ganz unbedeutende Wertbetrag der verzollten Schiffe abgezogen werden, um im wesentlichen die Summe desjenigen Ausfuhrhandels nach dem Westen und Einfuhrhandels von da zu erhalten, den Hamburg neben dem baltisch-flandrischen Durchgangsverkehr besaß. 
Laurent auf Grund der Hamburger Bürgerbücher für die sechziger Jahre des Jahrhunderts auf etwa 14000 berechnet; da die Lübecker Bürgerverzeichnisse etwa dreimal so starke Register aufweisen, ist Lübecks Einwohnerzahl auf das Dreifache dieser Zahl, also auf etwa 40000 , geschätzt worden. Andere Berechnungen setzen die Einwohnerzahl dieser Städte sogar nur auf die Hälfte dieser Summen an ${ }^{206}$ ). Wir sehen also, es handelte sich in Hamburg damals noch um sehr kleine Verhältnisse.

${ }^{206)}$ Vgl. Schäfer, Die Hansestädte und König Waldemar, S. 220/221. Pauli hat allerdings Lübecks Einwohnerzahl für diese Zeit auf 70000 bis 80000 geschätzt; ebenda. Reißner, Die Einwohnerzahl deutscher Städte in früheren Jahrhunderten mit besonderer Berücksichtigung Lübecks, in Abhandl. des staatswissenschaftl. Seminars zu Halle XXXVI, Jena 1903, S. 68, 75, berechnet die Einwohnerzahl Lübecks für das Ende des 14. Jahrhunderts auf 17200-22300 Seelen und hält 17200 für die wahrscheinlichere Zahl. Hiernach würde sich die Einwohnerzahl Hamburgs, welche auf den dritten Teil der lübeckischen zu veranschlagen sein dürfte, nur auf 6000 bis 7000 belaufen haben. 


\section{Fünftes Kapitel.}

\section{Der Ursprung der Städtehanse.}

Die deutschen Kaufleute selbst, nicht ihre Landesfürsten oder heimischen Obrigkeiten sind es, wie wir gesehen haben, gewesen, die dem deutschen Handel im Auslande zunächst die Bahnen gebrochen haben. Die Genossenschaften, zu denen wir sie durch gemeinsames Interesse und vor allem auch wohl durch gemeinsame Reisen im Auslande verbunden sehen, sind zunächst nicht Organe der Heimatsstädte dieser Kaufleute, sondern ganz unabhängige Vereinigungen der Kaufleute selbst. Die deutschen Landesfürsten standen den Interessen der Kaufleute meist fern und nahmen sich ihrer in der Regel nur dann, wenn ihre Einnahmen aus den Zoll- und Verkehrsabgaben berührt wurden oder sonstige besondere Vorteile im Einzelfalle ihre Interessen mit denen der Kaufleute verbanden, im Auslande an. Die deutschen Städte waren allerdings frühzeitig bemüht, ihre Angehörigen im Auslande zu stützen. Das Interesse ihrer Kaufleute im Auslande, die ja dorthin nicht dauernd auswanderten, sondern schließlich immer wieder in die Heimatstädte zurückkehrten, war natürlich mit ihrem eigenen Interesse auf das engste verbunden ${ }^{1}$ ), und da der Rat der Städte überall

1) Aus dieser natürlichen íbereinstimmung der Handelsinteressen der ausländischen Niederlassungen und der Heimatstädte erklärt es sich, daß die Genossenschaft auf Wisby 1287 beschließen kann, daß alle Städte, in deren Nähe Güter durch Schiffbruch oder Raub verloren gegangen sind, den Kauf oder Verkauf dieser Güter in öffentlicher Bursprake verbieten sollen; es spricht sich darin der tatsächliche Einfluß der Kaufmannschaft in den Verwaltungen der Städte aus; an eine staatsrechtliche oder völkerrechtliche Unterordnung der Städte unter die Genossenschaft in Wisby, wie Schäfer, Die Hansestädte und König Waldemar, S. 47, sie anzunehmen scheint, kann dabei natürlich nicht gedacht werden. Die Genossenschafts- 
aus Kaufleuten zu bestehen pflegte, kannten die Stadtverwaltungen die Interessen ihrer Angehörigen auf das Genauste und blieben über dieselben auch fortgesetzt unterrichtet. Im Anfang war freilich die eigene Macht der Städte noch zu schwach, um ihren Angehörigen in der Fremde viel nützen zu können. Je mehr aber die Selbständigkeit der Städte mit der Entfaltung ihrer wirtschaftlichen Blüte und dem Verfall der landesherrlichen Gewalten wuchs, um so mehr waren die Städte in der Lage, sich der Interessen ihrer Angehörigen im Auslande anzunehmen und dieselben dort zu vertreten. Diejenigen unter den Städten, deren Selbständigkeit sich am frühesten entwickelte, standen in dieser Beziehung natürlich obenan, allen voran Lübeck, das schon 1226 freie Reichsstadt wurde.

In Flandern liefen die großen Interessen des baltischen Verkehrs mit denen des gesamten Nordseehandels zusammen. Die flandrischen Interessen vereinten deshalb alle am nordwesteuropäischen Seehandel beteiligten deutschen Kaufleute, sei es, daß sie die deutschen Höfe in Rußland, die schonenschen Märkte oder die deutschen Niederlassungen in Norwegen oder England besuchten. So standen für die deutschen Städte von Livland und Gotland an bis zum Rhein, deren Bürger ja den auf Brügge gerichteten Handelsverkehr von diesen verschiedenen Ausgangspunkten des Auslandes aus unterhielten, die Angelegenheiten der deutschen Genossenschaft an dem Mittelpunkte des Welthandels Brügge im Vordergrunde des Interesses. Die aus der flandrischen Interessengemeinschaft erwachsende Verbindung der Städte ist deshalb von ganz besonderer Bedeutung; sie ist die Grundlage des sogenannten Hansabundes der Städte und der ausschlaggebende Faktor bei der Entwicklung desselben gewesen. Entscheidend für die volle Mitgliedsberechtigung in dieser Hanse der Deutsehen am Zwin ist aber die Zugehörigkeit zu dem Kreise derer, die den russi-

mitglieder übernehmen durch den Beschluß die Verpflichtung, dafür zu sorgen, daß demselben in ihren Heimatstädten entsprochen wird; die Erfüllung dieser Verpflichtung ist von vornherein im wesentlichen dadurch gesichert, daß ja die Verwaltung der Heimatstädte in den Händen der Kreise der Kaufleute liegt. Als Zwangsmittel bedient sich die Genossenschaft erforderlichenfalls des Ausschlusses aus der Genossenschaft. 
schen Handel betreiben. In England, in Norwegen, auf Schonen, in Schweden, in Rochelle sind überall neben den Deutschen mehr oder weniger Kaufleute anderer fremder Nationen am Handelsverkehre beteiligt; hatten diese zwar nicht an den Privilegien der Deutschen Anteil, so genossen sie doch gleiche oder ähnliche Privilegien in diesen Ländern. Nur der russische Handel war allen andern Nationen verschlossen: denn die Berechtigung der Gotländer zur Teilnahme an diesem Handel kam tatsächlich nicht mehr in Betracht, da die Gotländer ebenso wie die Russen Aktivhandel nach dem Westen nicht mehr betrieben. Der russische Handel, der, wie schon wiederholt betont, das Rückgrad des ganzen hansischen Verkehrs bildet, scheidet den hansischen Kaufmann von dem nichthansischen. Ausdrücklich wurde auf dem Städtetage zu Lübeck 1366 der Grundsatz ausgesprochen, daß niemand in Nowgorod zugelassen werden dürfe, wenn er nicht sei in jure et hansa Theutonicorum comprensus ${ }^{2}$ ). Die Kaufleute der deutschen Städte, deren Angehörige von alters her den Zwischenhandel zwischen Rußland und dem flandrischen Weltmarkte betrieben haben und zum Hofe von Nowgorod und den übrigen deutschen Höfen in Rußland von jeher Zutritt gehabt haben, sind die Träger der Genossenschaft der Deutschen am Zwin. Wer etwa sonst noch in dieser Genossenschaft geduldet wird, ohne zum russischen Handel berechtigt zu sein, ist nicht vollberechtigtes Mitglied.

Sehr früh sehen wir die Städte bei der Ordnung der flandrischen Angelegenheiten in Mitwirkung treten. Schon bei der Erwirkung der Privilegien von 1252-53 erscheinen die Vertreter der Deutschen offenbar nicht nur als die Bevollmächtigten der deutschen Kaufleute in Flandern, sondern auch als Delegierte der Obrigkeiten der beteiligten Städte. Ein Ratsherr von Lübeck und ein Ratsnotar von Hamburg sind die Wortführer der Deutschen gegenüber den flandrischen Behörden. Bei der Verlegung des Stapels von Brügge nach Aardenburg im Jahre 1280 leitet der Rat der Stadt Lübeck die Angelegenheit; er führt mit einer ganzen Anzahl anderer Städte

2) Hanserezesse I n. $376 \$ 13$. 
dieserhalb Verhandlungen und sein Gesandter vertritt lange Zeit allein die Interessen der Deutschen in Flandern ${ }^{3}$ ). Als sich um die Wende des 13. Jahrhunderts die flandrischen Verhältnisse infolge des flandrisch-französischen Krieges aufs neue verwickelt hatten, sehen wir wiederum Lübeck mit den wendischen, den sächsichen, den westfälischen, den preußischen und den livländischen Städten und Wisby zur Ordnung der Verhältnisse in Verbindung treten und sie sämtlich zu einer Versammlung nach Lübeck laden ${ }^{4}$ ).

Auch im 14. Jahrhundert sehen wir die flandrischen Angelegenheiten den Heimatstädten der in Flandern verkehrenden deutschen Kaufleute wiederholt Anla $\beta$ zu gemeinsamen Beratungen und Verhandlungen geben. Bezeichnend für die durch diese Interessen verbundene Städtegemeinschaft ist zunächst auch hier wieder wie im 13. Jahrhundert die leitende Stellung, welche Lübeck, die große Vermittlerin des baltischflandrischen Verkehrs, des Schwerpunktes des ganzen hansischen Handels, bei allen diesen Anlässen einnimmt. Der Rat von Lübeck ist es, der die Verhandlungen über die Verlegung des Stapels von Brügge nach Aardenburg während der Jahre $1305^{5}$ ) und $1307-1309^{6}$ ), über die Beschwerden der Deutschen zu Brügge über die dortigen Behörden im Jahre $\left.1351^{7}\right)$, über die Errichtung einer eigenen Wage in Brügge $\left.1352^{8}\right)$ und über die Verlegung des Stapels von Brügge nach Dordrecht 1358 und die Rückkehr nach Brügge $1360^{\circ}$ ), unter

3) Hans. Urkdb. I n. 885. Hanserezesse I 1 n. 12-21, 25-27. Wie sich die Teilnahme der Städteverwaltungen an den Angelegenheiten der ausländischen Kontore gestaltete, zeigen z. B. die Schreiben Münsters und Goslars an Lübeck, in welchen sie mitteilen, daß sie ihre in Flandern weilenden Bürger beauftragen wollen, mit Rat und Tat diejenigen Kaufleute zu unterstützen, welche die Verhandlungen dort führen. (Hansarezesse I 1 n. 18, 19.)

4) Hanserezesse I 1 n. 77-79.

5) Ebenda 1 n. 81-83.

${ }^{6}$ ) Ebenda n. 86 (Lübeck und Dortmund) u. S. 44 daselbst; Hans. Urkdb. II n. 71.

7) Hanserezesse I 1 S. 81 u. n. 160, 162-166.

8) Ebenda n. 169-171.

9) Ebenda S. 125 u. n. 212-214; S. 146 u. n. $224-227$, 228. S. 167 n. $238-240,246-248$. 
Zustimmung und zum Teil unter Mitwirkung der andern Städte, leitet $\left.{ }^{10}\right)$. Bei den wiederholt aus diesen Anlässen stattfindenden Versammlungen von Gesandten der Stadtverwaltungen ist dementsprechend Lübeck auch regelmäßig der Ort der Zusammenkunft ${ }^{11}$ ).

Mit der Gründung der einheitlichen deutschen Genossenschaft in Flandern im Jahre 1347 gewinnt sofort auch die Gemeinschaft der Heimatstädte der in Flandern verkehrenden deutschen Kaufleute eine ganz andere Beständigkeit als bisher. Zwar ist von einem förmlichen Bunde unter den Städten nicht die Rede, an einer Verfassung oder Satzung fehlt es dieser Gemeinschaft der Städte gänzlich; ihre ganze Grundlage bleibt immer die wirtschaftliche Interessengemeinschaft der nunmehr $\mathrm{zu}$ einer einzigen Genossenschaft vereinigten Deutschen in Flandern. Es ist in hohem Grade bemerkenswert, daß die Verhältnisse der flandrischen Niederlassung auch für die Gruppierung der Heimatstädte der Flandern besuchenden Kaufleute bei ihren Verhandlungen bestimmend sind. Mit der Gliederung des gemeinen Kaufmannes in Flan-

$\left.{ }^{10}\right)$ Nur in älterer Zeit finden wir gelegentlich auch die westfälischen Städte an der Leitung der Verhandlungen mitbeteiligt (vgl. 1280 Hanserezesse I 1 n. 26, 27; 1307 Hans. Urkdb. II n. 121); hierhin gehört auch die ablehnende Antwort Soests 1305, s. Hans. Urkdb. II n. 79. 1309 korrespondiert der Graf von Flandern mit Hamburg wegen der Zurückverlegung des Stapels nach Brügge (Hans. Urkdb. II n. 150); das Privileg wird Braunschweig, Goslar, Magdeburg, dem Sachsenlande und dem gemeinen Kaufmanne ausgestellt (II n. 162); offenbar war Lübeck damals verhindert; deshalb auch der Vorbehalt, daß man Briefe an die Städte vom Ostland senden sollte, ob ihnen die Privilegien genügten (II n. 155, 161).

11) S. die Versammlungen zu Lübeck um 1300 ebenda S. 38; 1305 S. 43 ; 1352 S. $81 ; 1352$ S. $99 ; 1356$ S. 125 , 1358 S. $135 ; 1358$ S. $146 ; 1359$ S. $151 ; 1360$ S. $158 ; 1360$ S. 167 . Eine Ausnahme macht die Versammlung zu Greifswald 1359, Hanserezesse I 1 S. 150 und n. 226. Die Versammlung zu Rostock am 6. Dezember 1358 kann man kaum zu den Ausnahmen rechnen; der Inhalt des Rezesses der letzteren zeigt, daß man sich nur mit andern Angelegenheiten befaßt hatte und bei dieser Gelegenheit eine allgemeine Versammlung zur Beratung der flandrischen Angelegenheiten auf den 24. Juni 1359 nach Lübeck verabredete. Inzwischen fand dann am 31. Mărz 1359 noch der Tag in Greifswald statt, wo mit flandrischen Gesandten verhandelt wurde. 
dern in drei Drittel sehen wir alsbald auch die Städte in ebendieselben Gruppen der drei Drittel sich sondern. Es zeigt sich dies sofort bei den Verhandlungen über die Verlegung des Stapels von Brügge wegen des Verhaltens der brüggischen Stadtobrigkeit gegen die Deutschen bei ihrem Konflikte mit dem König von England und über die Errichtung eines eigenen Wagehauses in Brügge in den Jahren 1351 und 1352 ${ }^{12}$ ), wo die Städte, ganz der wenige Jahre vorher in Brügge getroffenen Dritteilung der deutschen Genossenschaft entsprechend, in Drittel gruppiert auftreten. In dem Beschlusse von 1358 ${ }^{13}$ ), betr. die Verlegung des Stapels von Brügge nach Dordrecht, bezeichnen sich die Ratmannen der Städte Lübeck, Goslar, Hamburg, Rostock, Stralsund, Wismar, Braunschweig ausdrücklich als die Vertreter der stede van unsem driddendiele aller koplude des romeschen rikes van Alemannien $\mathrm{v}$ a $\mathrm{n}$ de $\mathrm{r}$ dudeschen hense, de to Brugge in Vlandern pleghen to wesende. Der Beschluß bekundet also ausdrücklich, daß die Vereinigung, um die es sich hier handelt, aus den Städten besteht, deren Kaufleute das Drittel der deutschen Genossenschaft in Brügge bilden. Zur Ordnung der Verhältnisse der Genossenschaft in Brügge finden wir 1356 vom lübischen Drittel der Städte einen Lübecker, einen Hamburger und einen Stralsunder, von dem preußisch-westfälischen einen Dortmunder, einen Soester, einen Thorner und einen Elbinger, vom gotlänidschen Drittel einen Gotländer und einen Livländer nach Flandern entsandt.

Nicht weniger bezeichnend ist es, daß, sobald wir die Einzelgenossenschaften der deutschen Kaufleute in Flandern zu einer einheitlichen Hanse, der dudeschen hense de to Bruggen in Vlandern pleghen to wesende, zusammengeschlossen sehen, wir auch die Bezeichnung, ,Städte der deutschen Hanse“ auf die Gemeinschaft der Städte, deren Bürger der deutschen Hanse in Flandern angehören, übertragen sehen ${ }^{\mathbf{1 4}}$ ). Auch hierin

12) Hanserezesse I 1 n. 162, 163, 169, 170.

13) Ebenda n. 212.

14) Vgl. namentlich ebenda n. 212 Ziff. 4: Wer ok, dat eyn scheph eder schephere eder kopmann, de in der Dudeschen hense (d. i. der 
offenbart sich wieder, wie diese Städteverbindung nichts anderes ist als das Spiegelbild der deutschen Genossenschaft in Flandern, das in die Erscheinung tritt mit dem Augenblicke, wo die Genossenschaft der deutschen Kaufleute in Flandern Gestalt annimmt. Nur dadurch, daß die Städtehanse in der Hanse der deutschen Kaufleute in Flandern eine durch Satzungen festgelegte Unterlage hatte, wird es auch verständlich, daß sie als ein Städtebund dastehen konnte, ohne daß irgend ein Bündnis der Städte untereinander zugrunde lag.

Zunächst befaßt sich diese Städtegemeinschaft meist nur mit rein flandrischen Angelegenheiten ${ }^{15}$ ). 1356 greift sie, wie schon erwähnt, bereits in die inneren Verhältnisse der flandrischen Genossenschaft, welche diese bisher selbständig geordnet hatte, ein; Ratssendeboten der Städte erscheinen, um innere Streitigkeiten der Genossenschaft $\mathrm{zu}$ schlichten und mit den Älterleuten und Achtzehnmännern die Satzungen festzulegen ${ }^{16}$ ). Doch bleibt die Tätigkeit der Städtehanse auf die flandrischen Angelegenheiten nicht beschränkt. Sehr bald werden auch andere Angelegenheiten vor das Forum der Städtehanse gezogen ${ }^{17}$ ), so 1366 die Verhältnisse des nowgorodschen und auch des bergenschen Kontors ${ }^{18}$ ), 1367 vor allem die norwegischen und dänischen Streitigkeiten ${ }^{19}$ ); seit 1374 sehen wir die Städte auch in die Angelegenheiten der deutschen Genossenschaft in England eingreifen, und zwar auf die eigene Bitte der deutschen Genossenschaft in England, welche an den

Hanse der Kaufleute in Flandern) nicht en were, queme in ene havene eder s t a d, de in der d u d e s che n hense were (d. h. eine Stadt, deren Bürger der deutschen Hanse in Flandern angehören oder, was dasselbe ist, eine Stadt der Städtehanse). Ebenso Ziff. 7; ferner Ziff. 8: Wer ok jenich $\mathrm{s} t \mathrm{ad}$ van de $\mathrm{r} \mathrm{Dudes} \mathrm{ch}$ e $\mathrm{h}$ e $\mathrm{nse}$, de sich mit vrevele ut desseme ghesette wolde werpen und des nicht wolde holden, $\mathrm{d}$ e s t a d s chal ewichliken ute der D udeschen hense blyven und des Dudeschen rechtes ewichliken entberen.

$\left.{ }^{15}\right)$ Vgl. Schäfer, Die Hansestädte und König Waldemar, S. 250 Note 2. Sattler, Hans. Geschichtsbl. 1879, S. 71.

16) Hanserezesse I 1 n. 199, 200.

$\left.{ }^{17}\right)$ Vgl. Koppmann, Hans. Geschichtsbl. 1879, S. 76/77.

$\left.{ }^{18}\right)$ Hanserezesse I 1 n. 376, 384, 385, 387.

19) S. unten S. 269. 
vereinigten Städten einen Rückhalt zu gewinnen sucht ${ }^{20}$ ). Früh begann die Städtehansa auch in die inneren Angelegenheiten einzelner einheimischer Städte einzugreifen, so schon auf dem Hansetage von 1366 in die Verhältnisse Bremens ${ }^{21}$ ) und 1374 in die braunschweigischen Wirren. Als sich nämlich 1374 die Handwerker in Braunschweig der Herrschaft der Stadt bemächtigt hatten und den alten Rat zum Teil hingerichtet, zum Teil vertrieben hatten, wurde die Stadt von den Städten aus dem Hansabunde ausgeschlossen, die Zulassung ihrer Kaufleute auf den auswärtigen Niederlassungen verboten und jeder Verkehr mit ihr untersagt.

Es ist in hohem Grade beachtenswert, daß bis zum Jahre $1374^{22}$ ) auf keiner der Versammlungen der Städte, über die uns aus dem 13. und 14. Jahrhundert Nachrichten vorliegen, Angelegenheiten des englischen Handels und der deutschen Genossenschaft in England den Gegenstand der Verhandlung gebildet haben. Weder die auf der Grundlage der gemeinschaftlichen Interessen in Flandern erwachsenen Städtevereinigung, noch der wendische Bund, noch die auf der Kölner Konföderation beruhende Städteverbindung haben sich bis dahin mit den englischen Angelegenheiten befaßt. Diese Tatsache ist der schlagendste Beweis dafür, daß die Verbindung der Städte, welche seit der Mitte des 14. Jahrhunderts unter der Bezeichnung der Hanse erscheint, nicht aus der Interessengemeinschaft und Vereinigung der Deutschen in England erwachsen ist.

Ebensowenig hat die Organisation der Deutschen auf Gotland auf die Entstehung des hansischen Städtebundes maßgebenden Einfluß gehabt. Zwar ist diese Genossenschaft insofern von hoher geschichtlicher Bedeutung für die spätere Städtehanse, als sie zuerst den Kreis der deutschen Kaufleute, welche den Handel mit Rußland betrieben, organisch verband und damit gegen die Kaufmannschaft anderer Nationen abschloß. Auf der Tatsache, daß die Niederländer im 13. Jahr-

$\left.{ }^{20}\right)$ S. Daenell, Die Blütezeit der deutschen Hanse, I S. 48 f.

21) Ebenda S. 37.

22) Hansarezesse I 2 n. $77 \S 2$. 
hundert nicht zu diesem Kreise gehörten ${ }^{22 a}$ ), beruht es ja offenbar, daß die niederländischen Städte im 14. Jahrhundert, als die Städtehanse in die Erscheinung tritt, nicht Mitglieder derselben sind. Indessen hatte die gotländische Genossenschaft im 14. Jahrhundert schon ihre Lebenskraft verloren. Im 13. Jahrhundert stand sie unter Leitung von vier Städten, nämlich Lübeck, Wisby, Dortmund und Soest. Mit dem wirtschaftlichen Übergewichte von Lübeck und dem Aufblühen der livländischen Städte tritt sie schon in der zweiten Hälfte des 13. Jahrhunderts allmählich zurück; zwar scheint ihre Organisation noch um die Mitte des 14. Jahrhunderts bestanden zu haben. Aus einem Schreiben Dortmunds aus dieser Zeit ersehen wir, daß Dortmund noch immer das Recht der Bestellung eines Ältermannes in Wisby ausübte; aber der neue Ältermann, den Dortmund an Stelle seines verstorbenen bisherigen Ältermannes auf Gotland bestellte, war bezeichnenderweise nicht ein Bürger von Dortmund, sondern ein Ratmann von Wisby ${ }^{23}$ ). Seit dem Ausgange des 13. Jahrhunderts hatte die Stadt Wisby die Erbschaft der deutschen Genossenschaft angetreten; westfälische Kaufleute hielten sich dort wohl kaum noch dauernd auf; die Formen des Geschäftsverkehrs hatten sich verändert; der Kaufmann begleitete nicht mehr selbst seine Ware ${ }^{24}$ ), soweit der russische Handel sich überhaupt noch über Gotland abspielte, besorgten wisbysche Bürger die Spedition der Waren. Wisby wird sogar als Mitglied der Städtehanse betrachtet ${ }^{25}$ ). Zur Zeit, als die Hanse der Städte in die Erscheinung trat, führte die deutsche Genossenschaft auf Gotland nur noch ein Schattendasein und spielte wirtschaftlich kaum noch eine Rolle.

22a) S. oben S. $191 \mathrm{ff}$.

23) Hans. Urkdb. III n. $18 \%$

24) S. Sattler, Der Handel des deutschen Ordens in Preußen zur Zeit seiner Blüte, i. Hans. Geschichtsbl. 1877 S. 67. Auch das Handlungsbuch des Vicko van Geldersen zeigt zur Genüge, daß die Kaufleute nicht mehr regelmäßig die Waren begleiteten; auf der andern Seite erweisen die Schiffrechte Hamburgs und Lübecks, daß dies noch am Ende des 13. Jahr. hunderts anders war; s. z. B. hamb. Schiffr. Art. 28.

${ }^{25}$ ) Schäfer, Die Hansestădte und König Waldemar, S. 59, 72. 
Auch die Organisation der Deutschen zu Nowgorod hat, so entscheidend die Berechtigung zum russischen Handel für die Zugehörigkeit zur Städtehanse war, auf die Entstehung des Hansabundes doch keinen unmittelbaren Einfluß geübt. Die Leitung des Nowgoroder Hofes, die ursprünglich gerade so wie die Leitung der wisbyschen Genossenschaft in Händen von Lübeck, Dortmund, Soest und Wisby gelegen hatte ${ }^{26}$ ), lag in der ersten Hälfte des 14. Jahrhunderts ausschließlich bei Lübeck und Wisby, zu denen seit 1363 auch Riga gleichberechtigt hinzutrat. Als Lübeck etwa 1366 Angelegenheiten des Hofes von Nowgorod vor die Versammlung der Städte zog, erhob Wisby hiergegen Einspruch, weil diese Angelegenheiten nicht vor die Städte gehörten, sondern allein der Entscheidung von Wisby und Lübeck unterlägen ${ }^{27}$ ).

Selbstverständlich hat der gemeinsame Handelsbetrieb der Bürger der verschiedenen deutschen Städte auch in den andern ausländischen Niederlassungen der Deutschen außerhalb Flanderns die Entstehung einer Gemeinschaft auch der Städte mit gefördert; aber die Grundlage, auf der die Städtehanse erwachsen ist, ist die Genossenschaft der Deutschen in Flandern, welche den Mittelpunkt des ganzen wirtschaftlichen Lebens der hansischen Kaufleute bildete und in der alle die Verkehrsinteressen der Vereinigungen der deutschen Kaufleute in England, in Bergen, auf Schonen, auf Wisby und zu Nowgorod zusammenliefen.

Neben dieser auf der Grundlage der Gemeinschaft der Interessen der Städte an den flandrischen Angelegenheiten, insbesondere an dem flandrisch-russischen Verkehre, erwachsenen Verbindung, welche nicht minder die Städte des rheinischwestfälischen, sächsischen und preußischen Binnenlandes als die deutschen Küstenstädte der Ost- und Nordsee umfaßte, tritt gleichfalls früh eine engere Verbindung zwischen Lübeck und den wendischen Städten in die Erscheinung, welche zunächst auf dem gemeinsamen Interesse an der Ostseeschiffahrt und dem gemeinsamen Verkehre im Ostseegebiete beruht,

26) Hansarezesse I 1 S. 31.

${ }^{27}$ ) Hansarezesse I 1 n. 387. 
bald aber auch die damit in Verbindung stehenden gemeinsamen Interessen dieser Städte an den Quellen des Wohlstandes der wendischen Städte, nämlich dem Heringshandel auf Schonen und dem Verkehr mit Norwegen, welch letzteres Land für diese Städte ein wichtiger Abnehmer der Getreideüberschüsse ihrer Hinterländer war, in ihren Bereich zog; weitere aus der benachbarten Lage der Städte sich ergebende Interessen kamen dann noch hinzu. Schon 1259 sehen wir Lübeck, Wismar und Rostock ein Schutzbündnis zur Befriedung der See schließen $\left.{ }^{28}\right)$; ähnliche Bündnisse folgen etwa 1260 und $\left.1265^{29}\right)$. Auf der Versammlung von 1265 beschlossen die Städte, jährlich einmal eine Zusammenkunft abzuhalten. 1283 wird das Landfriedensbündnis von seiten der Städte Lübeck, Wismar, Rostock, Stralsund, Greifswald, Stettin, Demmin, Anklam mit den Territorialfürsten abgeschlossen ${ }^{30}$ ). 1293 und 1296 folgen weitere Schutzbündnisse unter den wendischen Städten und Lübeck ${ }^{31}$ ).

Schon im Jahre 1278 werden die Deutschen in Norwegen als eine Gemeinschaft behandelt, indem der communitas multarum civitatum Teutonice und vor allen den Lübeckern in Norwegen Privilegien erteilt werden ${ }^{32}$ ). 1284 sehen wir Lübeck und die wendischen Städte zum ersten Male gegen Norwegen wegen Unbilden, die ihre Kaufleute dort erfahren haben, gemeinsam vorgehen ${ }^{33}$ ). Indessen blieb diese Angelegenheit doch nicht Sache des wendischen Bundes allein; auch die übrigen am norwegischen Handel interessierten Städte, Hamburg, die Städte der Südersee und Westfalens und Riga und Wisby wurden hineingezogen und von den Beschlüssen der wendischen Städte verständigt, wenn auch die Unternehmung selbst ganz in Händen des wendischen Bundes lag. Die Ausfuhr nach

$\left.{ }^{28}\right)$ Hanserezesse I 1 n. 3.

29) Ebenda n. 7 u. 9.

${ }^{30}$ ) Ebenda S. 16.

31) Ebenda n. 64, 73 ff.

$\left.{ }^{32}\right)$ Hans. Urdb. I n. 818.

${ }^{\text {s3) }}$ Ebenda n. 931, 935, 936, 938, 956-959, 961, 966, 967, 969. 970, 974-979, 985-987, 989, 993-997, 1008, 1026, 1030; Hanserezesse I 1 S. 17 ff. 
Norwegen wurde verboten, der Sund für die Norweger gesperrt, bis Norwegen sich 1285 bereit fand, Genugtuung zu leisten und sich dem Schiedsspruch des Königs von Schweden unterwarf. 1293 finden wir die wendischen Städte und Lübeck wiederum mit den Süderseeern und mit Wisby und Riga zu einem Bündnis gegen Norwegen geeint ${ }^{34}$ ), und ebenso übernehmen es 1298 die wendischen Städte im Namen aller beteiligten Städte -als solche sind wiederum einerseits die westfälischen Plätze und andererseits Wisby und Riga erkennbar - Beschwerden über den ungebührlichen Heringszoll in Norwegen zu erheben ${ }^{35}$ ). Gegen Ende des 13. Jahrhunderts sehen wir die wendischen Städte und Lübeck Privilegien für ihren Handel auf Schonen wiederholt gemeinsam erwirken ${ }^{36}$ ).

Im Beginne des 14. Jahrhunderts lockerte sich die Gemeinschaft Lübecks mit den wendischen Städten vorübergehend, indem Lübeck sich 1307 unter den Schutz des Dänenkönigs stellte, während Rostock und Wismar sich bald darauf im Kampfe mit ihm befanden ${ }^{37}$ ). 1308 schließen Wismar, Rostock, Stralsund und Greifswald ein Schutzbündnis ohne Beteiligung Lübecks $\mathrm{ab}^{38}$ ). Aber schon 1310 finden wir Lübeck wieder an einem Schutzbündnisse mit ihnen beteiligt, wenngleich noch unter dem Vorbehalt, nichts gegen den König von Dänemark zu unternehmen ${ }^{39}$ ). Bei den Verhandlungen mit Norwegen $1301^{40}$ ) und später wiederum 1312 ${ }^{41}$ ) und $1332^{42}$ ) sehen wir Lübeck ebenfalls mit den wendischen Städten zusammenstehen. Ebenso sind sie alle einmütig beteiligt an den

$\left.{ }^{34}\right)$ Hans. Urkdb. I n. 1114, 1115, 1117, 1118, 1144, 1149, 1151; Hanserezesse n. 62, 63 .

$\left.{ }^{35}\right)$ Hans. Urkdb. I n. 1299.

$\left.{ }^{36}\right) 1278$ Lübeck, Wismar, Rostock, Stralsund, Greifswald und Stettin, Hans. Urkdb. I n. 812; 1283 diese nebst Anklam und Demmin, Hans. Urkdb. I n. 925.

${ }^{37}$ ) Hanserezesse I 1 S. 153 ff., Hans. Urkdb. II n. 98 u. Note 2.

$\left.{ }^{38}\right)$ Hanserezesse I 1 n. 92-95.

${ }^{39}$ ) Ebenda 97-101; Hans. Urkdb. II n. 175 ff.

40) Hans. Urkdb. II n. 22.

41) Ebenda n. 209 und Hansarezesse I 1 n. 103, 104.

42) Hanserezesse I 1 S. $61 \mathrm{f}$. 
Landfriedensbündnissen 1338 und 133943), an den Verhandlungen und Kämpfen mit dem König von Dänemark im Anfange der vierziger Jahre ${ }^{44}$ ) und an den Verhandlungen mit dem König Magnus von Schweden 1343/44 ${ }^{45}$ ) und 1352/53 ${ }^{46}$ ). 1352 und 1358 schließen wiederum Lübeck, Wismar, Rostock und Stralsund Bündnisse gegen die Seeräuber ab; 1352 ist auch Stettin beteiligt ${ }^{47}$ ).

Hamburg hatte am wendischen Bunde und an den Schutzbündnissen Lübecks mit den wendischen Städten naturgemäß keinen Anteil, da sie sich auf die Befriedung der Ostsee bezogen; nur an den Landfriedensbündnissen, welche sich auf die Sicherheit der holsteinischen Lande zwischen Lübeck und Hamburg erstreckten, war es beteiligt. Ebenso tritt es bei den gemeinsamen politischen Unternehmungen der wendischen Städte gegen die nordischen Könige, seinen geringeren Interessen an dem Handel mit diesen Reichen entsprechend, im ganzen zurück. 1285 und ebenso $1343^{48}$ ) ist es in die Privilegien, welche die Ostseestädte in Norwegen erreichen, ausdrücklich eingeschlossen.

Dieser wendische Bund hat die politische Macht Lübecks außerordentlich gestärkt und ist insofern für die Vorherrschaft Lübecks in der auf der flandrischen Interessengemeinschaft beruhenden Städtehanse und damit unmittelbar auch für die Entstehung und Gestaltung der Städtehanse von wesentlicher Bedeutung gewesen. Aus dem wendischen Bunde aber ist die Städtehanse nicht erwachsen ${ }^{48 a}$ ); sie beruht auf ganz anderer wirtschaftlicher Grundlage. Zwar sind die Mitglieder des wendischen Bundes zugleich auch Mitglieder der Städtehanse, aber die Interessenkreise der beiden Städtegemeinschaften decken sich nicht; der Interessenkreis des wendischen Bundes ist wesentlich enger; sein Wirkungsfeld liegt hauptsächlich in Schonen und Norwegen und im Gebiete des Ostsee-

43) Hanserezesse I 1 S. 62/63.

44) Vgl. Schäfer, Die Hansestädte und König Waldemar, S. $127 \mathrm{ff}$.

45) Hanserezesse I 1 n. 137-141; Hans. Urkdb. III n. 6, 13.

46) Hanserezesse I 1 n. 172-180 und S. 103

47) Ebenda n. 183 und 218.

48) Hans. Urkdb. I n. 970, III n. 6 und 13.

48a) Vgl. auch Daencll, Blütezeit der Hanse I S. 31. 
verkehrs; auch das Verhältnis der wendischen Städte untereinander findet im wendischen Bunde in vieler Beziehung seine Regelung. Charakteristisch ist für den wendischen Bund, daß Lübeck in ihm nicht entfernt eine so beherrschende Stellung einnimmt wie in der Städtehansa. Bei den Verhandlungen des wendischen Bundes und der norwegischen Angelegenheiten sind viel häufiger als Lübeck andere wendische Städte Ort der Zusammenkünfte und Leiter der Verhandlungen ${ }^{49}$ ). Auch seiner rechtlichen Natur nach unterschied sich der wendische Bund von der auf der flandrischen Genossenschaft beruhenden Städtehanse, indem dem wendischen Bunde zahlreiche Verträge der wendischen Städte und Lübecks zugrunde lagen, während der Städtehanse eine solche völkerrechtliche Grundlage gänzlich fehlte. Übrigens blieb der wendische Bund zunächst noch neben der Städtehanse bestehen.

Neben der Städtehanse und dem wendischen Bunde tritt in der zweiten Hälfte des 14. Jahrhunderts noch ein dritter Kreis am nordwesteuropäischen Seehandel beteiligter Städte $\mathrm{zu}$ einer Gruppe zusammen. In der Mitte des 14. Jahrhunderts kam es nämlich zu einem Kampfe der wendischen Städte und Lübecks mit dem König von Dänemark. Den Anlaß zum Ausbruche des Krieges gab die plötzliche Eroberung und Vergewaltigung des für den russisch-lübischen Handel noch immer nicht bedeutungslosen Stapelplatzes Wisby durch König Waldemar von Dänemark 1361 mitten im Frieden. Der hansische Handel war bei dieser Eroberung schwer geschädigt. Zwar hatte Wisby das hansische Gut in der Stadt mit den Waren seiner eigenen Bürger von der unmittelbaren Plünderung von dem Eroberer freigekauft ${ }^{50}$ ), aber die Eroberer hatten, wie es scheint, große Mengen Geldes und viele Reichtümer mit sich

49) Vgl. Versammlung zu Wismar 1260-64: Hansarezesse I 1 S. 3; Wismar 1284 ebenda S. 16; Wismar 1285 S. 20 ; Rostock 1285 S. 23; Rostock 1293 S. 30, Rostock 1297 S. 37; Greifswald 1308 S. 49, Rostock 1310 S. 51 ; Stralsund 1312 S. 53; Lübeck 1354 S. 122 ; Rostock 1358 S. 145; Stralsund 1361 S. 180; Lübeck 1361 S. 180; Rostock 1361 S. 181.

$\left.{ }^{50}\right)$ Schäfer, Die Hansestädte und König Waldemar S. 273; Hanserezesse I 1 n. 290. 
geführt $\left.{ }^{51}\right)$. Lübeck und die wendischen Städte griffen zu den Waffen; Hamburg und Kiel standen ihnen zur Seite; es wurde ein Bündnis mit den Gegnern des dänischen Königs, den Königen Magnus von Schweden und Hakon von Norwegen abgeschlossen; auch die Preußen waren alsbald zur Stelle, aber ihre Beteiligung blieb lau; getroffen war durch die Ereignisse ja der russische Handel, die Verbindung Lübecks mit Rußland; die preußischen Kaufleute waren an diesem Handelszuge weniger beteiligt; sie fanden sich im Hinblick auf ihre Interessen an der unbehinderten Fahrt durch den Sund ${ }^{52}$ ) zwar wohl zu einer Geldbeisteuer durch Erhebung des sogenannten Pfundzolles, nicht aber zu Waffenhilfe bereit. Die Niederländer, welche gleichfalls um Waffenhilfe und Erhebung des Pfundzolles angegangen waren ${ }^{53}$ ), verhielten sich ganz passiv ${ }^{54}$ ); sie hatten keinen Anteil an dem russischen Handelsverkehre ${ }^{55}$ ) und mochten deshalb keine Veranlassung zu einer Beteiligung an dem Kampfe für diese Interessen finden. Auch die livländischen Städte, die in Wisby ihre Rivalin sahen und denen deshalb die Vernichtung der Stadt nicht einmal ganz unlieb gewesen sein mag, blieben untätig. Lübeck, Wismar, Rostock, Stralsund, Greifswald, Kolberg, Stettin, Anklam, Kiel, Hamburg und Bremen rüsteten Kriegs-

51) Schäfer, S. 270, 339, 340. Nach der Sage war Wisbys Reichtum so groß gewesen, daß die Schweine dort aus silbernen Trögen gefüttert wurden. Ebenda S. 264.

$\left.{ }^{52}\right)$ Hanserezesse I 1 n. 284; Schäfer, a. a. O. S. 330.

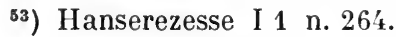

${ }^{54}$ ) Zwar werden auch niederländische Schiffe bei den Kämpfen im Sunde erwähnt; sie nehmen aber keinen Teil an dem Kampfe; ihr Zweck ist vermutlich nur die Sicherung der Durchfahrt der niederländischen Kauffahrteischiffe durch den Sund während der Kriegswirren gewesen; von diesen niederländischen Schiffen werden die hansischen Schiffe, um deren Unterstützung jene gebeten waren, sogar im Stich gelassen. Vgl. Schäfer, a. a. O. S. 289, 300, 318 und namentlich Exkurs III S. 587 ff. Nur liegt m. E. kein Anlaß vor, eine ,Entfremdung und Loslösung“ der süderseeischen Städte von den wendischen anzunehmen (ebenda Schäfer, S. 331), es ist vielmehr ein natürlicher Gegensatz der Interessen, der die Niederländer von den wendischen Städten nach wie vor trennt, wenn auch Waldemar diesen Gegensatz vermutlich nicht ungenutzt gelassen haben wird.

$\left.{ }^{55}\right)$ S. oben S. 150,191 ff. und unten S. 282 ff. 
schiffe aus und sandten dieselben in den Sund. Die Unternehmung schlug dann freilich gänzlich fehl. Nachdem bei der Belagerung von Helsingborg 1362 die Truppenmacht der Städter überfallen und in die Flucht geschlagen war, kam es im November $1362 \mathrm{zu}$ einem Waffenstillstand ${ }^{56}$ ) zwischen den Parteien. Vergeblich versuchten die wendischen Städte die preußischen, livländischen und niederländischen Städte zu Waffenhilfe zu veranlassen, um einen erneuten Vorstoß unternehmen zu können; den preußischen Städten, welche mit den westfälischen über den Besitz der Urkunden über die flandrischen Privilegien im Streite lagen, sprachen sie diese Schriftstücke zu und lieferten sie ihnen aus, den livländischen Städten räumten sie den lange beanspruchten Anteil der Verwaltung des Nowgoroder Kontors ein, von beiden aber vermochten sie nicht mehr zu erreichen, als daß sie sich zur Weitererhebung des Pfundzolles bereit fanden ${ }^{57}$ ) und daß die Preußen sich erboten, auf Wunsch der Städte nach Kampen zu senden, um diese Stadt zur Sendung einiger Schiffe in den Sund gegen Überweisung des in Preußen eingenommenen Pfundzolles zu veranlassen ${ }^{58}$ ); die Kampener aber dachten natürlich nicht daran, sich in ein derartiges Unternehmen einzulassen ${ }^{59}$ ). Nach langen Verhandlungen zwischen den Städten und dem Dänenkönige kam es gegen Ende des Jahres 1365 endlich zu dem Abschlusse des Friedens von Wordingborg ${ }^{60}$ ).

Wenige Jahre darauf rief ein anderer Anlaß einen wesentlich größeren Kreis von Städten zu einem Bündnisse gegen Dänemark zusammen, das zu einer bedeutsamen völkerrechtlichen Vereinigung der Städte neben der Städtehanse und dem wendischen Bunde sich entwickelte. Schon bei ihren Unternehmungen gegen Norwegen im Jahre 1284 und ebenso im Jahre 1293 hatten die wendischen Städte sich vorübergehend mit den am norwegischen Handel beteiligten niederländischen Städten ver-

$\left.{ }^{56}\right)$ Schäfer, a. a. O. S. 320 ; der Waffenstillstand wurde 1364 verlängert, Hanserezesse I 1 n. 327 ff.

$\left.{ }^{57}\right)$ Schäfer, a. a. O. S. 342 f.

$\left.{ }^{58}\right)$ Ebenda S. 361, 366.

${ }^{59}$ ) Ebenda S. 366, 367.

$\left.{ }^{60}\right)$ Ebenda S. $366-385$. 
bündet ${ }^{61}$ ), während freilich 1305 Kampen sich von den wendischen Städten trennte und dem Könige von Norwegen versprach, sein Land auch zu besuchen, wenn die deutschen Ostseestädte ein Verkehrsverbot gegen dasselbe erlassen sollten ${ }^{62}$ ). Nunmehr brachte eine neue Kombination die wendischen Städte mit den Niederländern und den Preußen in eine Verbindung von längerer Dauer.

Wie es scheint, waren süderseeische und preußische Schiffe mit Ladung aus Preußen 1366 von den Königen von Norwegen und Dänemark, die seit 1365 miteinander verbündet waren, im Sunde vergewaltigt ${ }^{63}$ ). Der Verkehr der preußischen und niederländischen Frachtfahrer, welche die preußischen Waren durch den Sund nach Flandern zu bringen pflegten, war durch die beiden nordischen Könige in einer Weise geschä-

61) Hanserezesse I 1 n. 44, 45, 49, 50, 51, 56, 62, 63.

${ }^{62}$ ) Ebenda S. 53.

${ }^{63}$ ) Vgl. die Eingangsworte des Bündnisses der Preußen und Niederländer vom 11. Juli 1367, Hanserezesse I 1 n. 403: Alz wissentlich is, das der konig van Denemarken und der konik van Norwegen s u n d e r alleschult und darzcu unentsaytgrossen schaden hat getan uns an libe und ouch an gute usw., und am Schlusse: Were ouch das is Got vugete, das sulcke schelunge zcu enigen tagen vorsunet worde, und die konige darnach enige site van diser sache w e d e r a $\mathrm{n} g \mathrm{r}$ if f e $\mathrm{n} \mathrm{mit} \mathrm{u} \mathrm{n} \mathrm{e} \mathrm{c} \mathrm{h} \mathrm{t} \mathrm{e,} \mathrm{so} \mathrm{solde} \mathrm{wir} \mathrm{weder} \mathrm{inander} \mathrm{mit} \mathrm{truwen}$ helfen weren usw. 1370 erklärt Hakon von Norwegen, den Krieg cum illis de Campen ac pluribus civitatibus maris occidentalis begonnen $\mathrm{zu}$ haben wegen Klagen, welche die Hansestädte bei ihm erhoben hätten; die Hansestädte hätten dann Kampen und den andern Städten der Westsee Hilfe geleistet und ihm großen Schaden zugefügt. Diese Äußerung kann sich, wie schon Koppmann bemerkt (Hanserezesse I 1 S. 328 f.), nur auf den Kampf von 1367 beziehen. Schon auf dem Städtetage zu Lübeck am 24. Juni 1366 klagen die Preußen über den Raub preußischer Güter im Sunde, Hansarezesse I 1 n. 367 §. Am 30. Juni urkundet aber Hakon zu Kopenhagen über einen mit Kampen abgeschlossenen Waffenstillstand (ebenda S. 328; vgl. Schäfer, a. a. O. S. 391). Offenbar sind aber die Versprechungen Hakons nicht erfüllt oder nachher neue Feindseligkeiten gegen die Süderseer und Preußen verübt. Denn auf dem Städtetage zu Rostock am 16. Dezember dringen die Preußen entschieden auf Krieg gegen Hakon und Waldemar und wenige Monate später hören wir von einem Bündnis der Preußen mit den Süderseeern in dieser Sache, Hansarezesse I 1 n. $400 \S 3,402 \S 1$. 
digt, die für die Zukunft das Schlimmste befürchten ließ ${ }^{64}$ ). Der Verkehr durch den Sund und damit die wichtigsten Interessen der preußischen Kaufleute und der niederländischen Reeder standen auf dem Spiele. Die Preußen und Niederländer traten deshalb sogleich zusammen. Auf der Versammlung, welche die beteiligten Städte aus diesem Anlaß am 11. Juli 1367 zu Elbing abhielten ${ }^{65}$ ), finden wir neben den preußischen Städten Kampen, Stavorn, Harderwijk, Elburg, Zieriksee, Amsterdam und Dordrecht vertreten. Wir sehen sie ein Schutzund Trutzbündnis abschließen und jeden Verkehr mit Norwegen und Dänemark verbieten. Von der Einstellung der Fahrt durch den Sund, deren Aufrechterhaltung für den preußischflandrischen Warenzug eine Lebensfrage war, ist nicht die Rede, aber die Schiffe sollten sich bei dieser Fahrt zu gemeinsamen Flotten vereinigen und jeder sollte bei einem Angriffe dort verpflichtet sein, dem andern beizustehen. Auch die in Preußen anwesenden Flanderer und Engländer wurden in den Vertrag hineingezogen. Zugleich wurde eine weitere Zusammenkunft noch für November desselben Jahres angesetzt, welche zu Köln abgehalten werden sollte und auf welcher die kriegerischen Maßnahmen gegen die Könige vorbereitet und festgelegt werden sollten, falls nicht inzwischen Sühne geleistet werde $\left.{ }^{66}\right)$. Die erste Versammlung findet charakteristischerweise in dem damaligen Haupthafen Preußens, die zweite in der Metropole des rheinisch-niederländischen Handels statt. Die wendischen Städte, welche durch die Vergewaltiguing der Preußen und Niederländer nicht unmittelbar berührt waren, waren jetzt nicht geneigt, für die Preußen und Niederländer die Kohlen aus dem Feuer zu holen, obwohl sie selbst inzwischen schon

${ }^{64}$ ) S. Hanserezesse I 1 n. 403: ,und wol zcu vorchtene stet, das in zcukomer zcyt sulche unfuge und obirtat zcunemen sulle und vorgrosen welle van scutunde der vorgenannten koninge und yrer helfere ab man yn bescheydenheyt nicht wederstet.

$\left.{ }^{65}\right)$ Ebenda. Schon vor dem 11. Juli 1367 bestand eine diesbezügliche Einigung unter den Städten; s. auch Schäfer, a. a. O. S. 390, Note 1.

$\left.{ }^{66}\right)$ guten rat zcu habene uf alle sache, alz wir hir vor uns haben, wi man is wetertagen vorder und sterker angrifen wolle, als verre als binnen der zcyt nicht wird vorsunet. 
wieder Anlaß zu Klagen gegen den König ron Dänemark hatten, indem dieser in Schonen ungererechtfertigte Gelder erhob und ihnen schiffbrüchige Güter in Dänemark weggenommen waren ${ }^{67}$ ). Die wendischen Städte erinnerten jetzt in ihrer ablehnenden Antwort vom 17. Dezember 1366 die Preußen an ihr Verhalten, als die Preußen von ihnen um Waffenhilfe gebeten seien ${ }^{68}$ ). Auf den Städtetagen zu Rostock und Stralsund am 30. Mai, 24. Juni und 29. Juli des nächsten Jahres hielten die wendischen Städte noch an ihrer ablehnenden Haltung gegen kriegerische Maßnahmen fest; einem Zusammengehen mit den Preußen waren sie nicht abgeneigt, wenn es sich um Erzielung eines Ausgleiches auf friedlichem Wege handelte ${ }^{69}$ ). Indessen beschlossen sie auf dem Städtetage zu Rostock am 6. Oktober 1367 doch, die auf den 11. November von den verbündeten Preußen und Niederländern nach Köln berufene Versammlung zu besuchen ${ }^{70}$ ); mehrfache neue Beraubungen ihrer Schiffe und Güter dänischerseits während dieses Jahres mögen mit dazu beigetragen haben, sie zu diesen Entschlusse zu bestimmen ${ }^{71}$ ). Charakteristisch für die Verschiedenheit der Interessen der Preußen und Niederländer einerseits und der wendischen Städte andererseits ist auch ihre verschiedene Stellung zu der Frage des Verkehrs mit Dänemark und der Durchfahrt durch den Sund. Die Niederländer und Preußen hatten sofort auf dem Tage zu Elbing am 11. Juli 1367 den Verkehr ihrer Städte mit Dänemark verboten, wollten aber natürlich die Fahrt durch den Sund, von der der ganze preußische Getreide- und Holzexport und die niederländische Schiffahrt in der Ostsee abhängig war, mit allen Mitteln sichern und offen halten und verabredeten sich deshalb, nur in starken gemeinschaftlichen Flotten die Fahrt zu machen. Den wendischen Städten, deren Wohlstand in erster Linie von dem schonenschen Heringsfange abhing, war vor allem darum zu tun, den

${ }^{67}$ ) Schäfer, a. a. O, S. 388 .

${ }^{68)}$ Hanserezesse I 1 n. 391 und n. 388 §. Schäfer, a. a. O. S. 389.

${ }^{\text {69) }}$ Hanserezesse I 1 n. 399, $400 \S 2$ und $3,402 \S 1,2,4 ; 40$ \& $\$ 6$, $409 \S 1$.

$\left.{ }^{70}\right)$ Ebenda n. $411 \S 1$.

${ }^{71)}$ Schäfer, a. a. O. S. 389, 393, 394. 
Besuch Schonens sich offen zu halten ${ }^{72}$ ). Sie verboten zwar schon auf dem Tage zu Stralsund am 24. Juni 1367 die Zufuhr von Eisen, Stahl und Waffen sowie von Herings- und Biertonnen nach Dänemark und Norwegen ${ }^{73}$ ); nur vorläufig bis zur Rückkehr ihrer Boten von Dänemark entschlossen sie sich auf dem Rezesse zu Stralsund am 29. Juli des Jahres zum Verbote des Besuches von Schonen, weil sie neue Räubereien in den dänischen Gewässern erlitten hatten und für die Sicherheit ihrer Angehörigen in Schonen fürchteten ${ }^{74}$ ); erst auf dem Rezesse zu Rostock am 1. September des Jahres erließen sie das Verbot endgültig ${ }^{75}$ ). Auf der andern Seite waren die wendischen Städte entschieden für ein Verbot der Fahrt durch den Sund; zwar waren die Fahrten durch den Sund gar nicht auf Dänemark gerichtet, standen also mit der Versorgung Dänemarks gar nicht unmittelbar in Zusammenhang; aber sie boten den Dänen die bequeme Gelegenheit, die hansischen Schiffe $\mathrm{zu}$ überfallen und wegzunehmen und auf diese Weise sich mit Waren, insbesondere mit Getreide, das ja in großen Mengen von den wendischen Städten nach Flandern ging, ferner mit Bier und andern Lebensmitteln und Bedarfsartikeln für den Krieg zu versehen; die Flotten der wendischen Städte, die durch den Sund gingen, waren nämlich nicht immer so stark, daß sie gegen die Dänen genügend gesichert waren; dieser Verkehr der wendischen Städte war nicht so groß wie der Preußens durch den Sund, oft mußten die Schiffe allein fahren oder fanden wenigstens nur wenig andere, welche dieselbe Reise vorhatten ${ }^{76}$ ). Auf der Kölner Versammlung wurde

${ }^{72)}$ Schäfer, a. a. O. n. $400 \S 3,402 \S 2,3,4$.

${ }^{73}$ ) Hansarezesse I 1 n. $402 \S 5$; ebenso 29. Juli n. $405 \S 4$ (nunmehr auch Salz, Hopfen und Bier).

$\left.{ }^{74}\right)$ Ebenda n. $405 \$ 2,3$.

${ }^{75}$ ) Ebenda n. $409 \S 3,411 \S 8$; vgl. auch Schäfer, a. a. O. S. 390 Note 1, 392, 393, 394. Schon im Juni 1368 beschlossen die Städte, die Reise nach Schonen wieder zu eröffnen, Hansarezesse I 1 n. $469 \S 6$ :

$\left.{ }^{76}\right)$ Hansarezesse I 1 n. 411 2: ,quia non semper convenire poterimus ad transeundum per Noressund et repertranseundum, unde pericula poterint evenire; Schäfer, a. a. O. S. 397, 398, irrt m. E., wenn er in dem Verlangen der wendischen Städte nach dem Verbote der Fahrt ein Zeichen größerer Kriegslust und klügerer Politik der wendischen Städte 
dann aber der Krieg auch unter Zustimmung der wendischen Städte beschlossen; die wendischen Städte mochten es denn doch für richtiger halten, diese Gelegenheit, wo sich ihnen so

sieht und daraus folgert, daß die wendischen Städte nunmehr die treibende Kraft, die den Krieg herbeiführt, gewesen seien, (ebenda S. 397, 432). Die preußischen und niederländischen Städte hatten ja schon zu Elbing in Aussicht genommen, in Köln energischere Maßregeln zu verabreden, falls nicht bis dahin Sühne geleistet sei. Welchen andern Grund, als den im Texte dargelegten, übrigens durch die Quellen belegten, hat denn die verschiedene Stellung der wendischen Städte und der Preußen-Niederländer in diesem Punkte? Und welchen Zweck verfolgen die wendischen Städte mit dem Verbote der Fahrt durch den Sund? Die Politik der vereinigten Preußen und Niederländer ist entschieden sehr viel energischer als die der wendischen Städte, indem jene im Gegensatze zu diesen jeden Verkehr mit Dänemark von vornherein abbrechen. - Schon auf dem Städtetage zu Greifswald 1363 hatten die wendischen Städte beschlossen, daß der Kaufmann zur größeren Sicherheit nicht mehr durch den Sund fahren, sondern die Waren über Hamburg-Lübeck gehen lassen sollte (Hansarezesse 1 I n. 307 §). Die preußischen und die niederländischen Städte kümmerten sich aber um dies Verbot nicht (s. ebenda n. $325 § 16$ und 19). 6 Danziger, 3 Elbinger, 3 Königsberger, 3 Braunsberger, 4 Drelleborger, 1 Zütphener, 1 Deventerscher Schiffer und mit ihnen 7 Stralsunder, 2 Greifswalder, 1 Wismarer, 1 Lübecker und 1 Bremer Schiffer beachteten das Verbot nicht und segelten rom Zwin nach dem Sund ab; die Älterleute von Brügge zeigten diese Schiffer den Städten an (vgl. Schäfer, a. a. O. S. 364). Aus der Nichtachtung des Verbotes seitens der Kampener dürfte sich auch das Verhältnis der Städte zu den Kampenern in dieser Zeit erklären, s. Schäfer S. 367. - Kunze bekämpft in den Hans. Geschichtsbl. 1894 S. 157, Daenells Auffassung, daß den Preußen hauptsächlich an der Sundstraße, den wendischen Städten mehr an dem Schonenschen Verkehre gelegen gewesen sei, zu Unrecht. Der Verkehr der Lübbecker und wendischen Kaufleute in England war gar nicht auf die Heimatstädte dieser Kaufleute, wie Kunze voraussetzt, gerichtet, sondern, wie ich dargelegt habe, in erster Linie auf Flandern. Soweit die Lübecker und wendischen Kaufleute aber einen Verkehr von der Ostsee nach England unterhielten, betraf er in der Hauptsache schonensche Heringe, die von Schonen aus, nicht von den Heimatstädten der Kaufleute, nach dem Westen verladen wurden. Der Handel nach Bergen spielte für die wendischen Stădte im Vergleiche zu ihrem übrigen Handel, insbesondere zu dem schonenschen Verkehre, doch eine weniger bedeutende Rolle, stand übrigens während des Kriegszustandes mit Norwegen überhaupt still. Auf dem Handel von Preußen durch den Sund nach Flandern beruhte dagegen die ganze Stellung der Preußen in Flandern und das große Interesse der niederländischen Reederei an diesem Verkehre. 
mächtige Bundesgenossen boten, zur Niederwerfung des Feindes nicht unbenutzt vorübergehen zu lassen. Von den preußischen Städten waren Kulm, Thorn und Elbing, von den Niederländern Kampen, Harderwijk, Elburg, Amsterdam und Briel, von den wendischen Städten Lübeck, Rostock, Stralsund und Wismar vertreten. Es wurde verabredet, daß die wendischen und preußischen Städte sich am Gellen treffen sollten; zu Pfingsten sollten sie von dort und die Niederländer von ihrer Heimat nach dem Sunde absegeln, wo sich die Flotten vereinigen sollten. Das allgemeine Verkehrsverbot gegen Dänemark und Norwegen wurde erneuert, auch die Flanderer und Engländer sollten zur Innehaltung desselben angehalten werden ${ }^{7}$ ). Von Einstellung der Fahrt durch den Sund, auf deren Aufrechterhaltung es den Preußen und Niederländern ja gerade ankam, war auch jetzt keine Rede; die Handelsschiffe sollten aber nur unter dem Schutze der Kriegsschiffe durch den Sund segeln dürfen und sämtlich bewaffnet sein ${ }^{78}$ ). Städte des Hansabundes und ebenso niederländische Städte, welche sich den Vereinbarungen der Verbündeten nicht fügen wollten, sollten von allem Ver-

$\left.{ }^{77}\right)$ Schon in Elbing sehen wir die dort aufhältlichen Flanderer und Engländer zu dem preußisch-niederländischen Bunde hinzugezogen werden (Hanserezesse I 1 n. 403); denn unter den „Englischen“ und „Vlamingen" dürften hier nicht die deutschen Hansen in England und Flandern, wie Schäfer, a. a. O. S. 462, meint, zu verstehen sein, sondern die Engländer und Flanderer in Preußen. - Die Preußen, später die Lübecker und Wismarer, übernehmen es, an die Fläminger und Engländer zu schreiben (Hanserezesse I 1 n. 420 \$ 9, 421 § 16). Flandern lehnte die Zumutung, den Verkehr mit Dänemark und Norwegen einzustellen, ab, da es seinen Kaufleuten nicht verbieten könnte, mit den Dänen und Norwegern Handel zu treiben (ebenda n. $479 \S 2$ ). Norweger und Dănen genossen ja in Flandern auch Privilegien (Hans. Urkdb. II S. 62 Note 1). Infolge dieser Haltung Flanderns zogen die Städte im Frühjahre 1368 die Verlegung ihres Stapels von Brügge nach Dordrecht in Erwägung (Hanserezesse I 1 n. 450, 451). Auf der Versammlung zu Lübeck am 24. Juni 1368 wurde von neuem beschlossen, Briefe an den König von England, den Graien von Flandern, die Städte in England und in Flandern zu senden, mit der Bitte, Norwegen und Dänemark zu meiden (ebenda n. $469 \S 2)$.

${ }^{78}$ ) Hanserezesse I 1 n. 413. Im Juni 1368 wurde diese Bestimmung bereits wieder aufgehoben, ebenda n. 467 . 
kehre mit den verbündeten Städten ausgeschlossen sein ${ }^{79}$ ). Die wendischen und preußischen Städte übernahmen es, die übrigen Städte des Hansabundes heranzuziehen. Die wendischen Städte wollten die sächsischen, livländischen und übrigen wendischen Städte, die preußischen Städte dia Westfalen zum Beitritt veranlassen. Die niederländischen Städte übernahmen es, die übrigen Niederländer zum Anschluß an den Bund zu bestimmen. So wurde das Unternehmen zu einer Angelegenheit der ganzen Städtehansa ${ }^{80}$ ) im Bündnis mit den außerhalb derselben stehenden Niederländern. Die wendischen Städte verpflichteten sich, gemeinsam mit den Livländern, 10 Koggen mit je 100 Mann Besatzung, bei jeder Kogge eine Schute und eine Snikke ${ }^{81}$ ) zu stellen, die preußischen Städte in gleicher Weise 6 Koggen, die Kampener 1 Kogge und 2 Rheinschiffe, die von Seeland 2 Koggen, die von Dordrecht, Amsterdam, Stavorn, Harderwijk und die übrigen Städte der Südersee ebenfalls $1 \mathrm{Kogge}^{82}$ ). Die wendischen Städte zogen im Laufe des Winters noch den König von Schweden, die Fürsten von Mecklenburg und Holstein und den Adel von Jütland in ihren Bund ${ }^{83}$ ). Im Frühjahre 1368 brachen die Niederländer über Norwegen herein und verwüsteten und verheerten eine Menge Städte und Dörfer, unter anderen auch Bergen, auf das Furchtbarste $\left.{ }^{84}\right)$. Gleichzeitig rückte von der Ostsee her die vereinigte Flotte der wendischen und preußischen Städte gegen Dänemark vor. Den Oberbefehl über die gesamte Kriegsmacht hatte der Lübecker Bürgermeister Bruno Warendorp. Schon am

$\left.{ }^{79}\right)$ Hanserezesse I 1 n. 413.

$\left.{ }^{80}\right)$ Schäfer, a. a. O. S. $446 \mathrm{ff}$.

${ }^{81}$ ) Hiervon stellte Lübeck 3 Koggen mit 300 Mann, Stralsund 2 mit 200 Mann, Rostock 2 mit 140 Mann, Wismar 1 mit 100 Mann, Stettin und Stargard zusammen 1 mit 100 Mann, Greifswald eine mit 60 Mann, Kolberg eine mit 40 Mann. Hamburg und Bremen haben keine Waffenhilfe geleistet; dagegen haben die Livländer eine Kogge ausgerüstet; s. Schäfer, a. a. O. S. $446 \mathrm{ff}$.

$\left.{ }^{82}\right)$ Hanserezesse I 1 n. 413.

$\left.{ }^{83}\right)$ Ebenda n. 413; 421 § 23, 24;422-425;427 §1 und 2;436-439; 441 ; 442 ; Schäfer, a. a. O. S. 436.

84) Schäfer, a. a. O. S. 429,480 f. und Note 3 ; über das Folgende s. ebenda S. $476 \mathrm{ff}$. 
2. Mai fiel Kopenhagen, die Beherrscherin des Sundes, in die Hand der verbündeten Städte; gemeinsam mit den Schweden eroberten sie Schonen, Ystad, Cimbrisham, Lund, Malmö und das Schloß Werpinge (jetzt Trolleberg bei Lund); dann wurden Moen, Falster und Laaland unterworfen; gleichzeitig eroberte der Graf von Holstein im Bunde mit den jütischen Adligen ganz Jütland. Fünen gehörte damals überhaupt noch zum Teil den Grafen von Holstein. So waren die Verbündeten bis zum Ende des Sommers 1368 im Besitz von fast ganz Dänemark; nur die Feste Helsingborg, die den Nordeingang des Sundes beherrschte, wie Kopenhagen den Südeingang, hielt noch stand. Zur Belagerung Helsingborgs blieben die Verbündeten den Winter über unter Waffen; erst im September des nächsten Jahres, 1369, ergab sich endlich auch dieser Platz. Kopenhagen und Helsingborg wurden nun dem Erdboden gleich gemacht und die Festungswerke gänzlich zerstört, um die dänische Macht am Sunde ein für allemal zu brechen. Um Dänemark vollends mürbe zu machen, wurde das Verbot der Zufuhr von Nahrungsmitteln und Waren erneut eingeschärft; im Bewußtsein ihrer Stärke scheuten sich die Städte sogar nicht, dasselbe jetzt auch gegen die Engländer, Schotten, Flanderer, Schweden und Norweger zur Geltung zu bringen; wer dem Verbote zuwiderhandelte, sollte vogelfrei sein ${ }^{85}$ ). Als dann am 24. Mai 1370 zu Stralsund der Friede mit Dänemark zustande kam, wurden den Städten für fünfzehn Jahre zwei Drittel der Einkünfte zu Skanör und Falsterbo auf Schonen und zu Malmö und Helsingborg zugesprochen und ihnen als Sicherheit für die gleiche Zeit die festen Schlösser an diesen Plätzen und ferner das Schloß Warberg in Halland überlassen; ihre früheren Rechte wurden erneuert, ja der Nachfolger Waldemars sollte vom Reichsrate nicht als König angenommen werden dürfen ohne Einwilligung der Städte. Mit Norwegen war schon 1368 ein Waffenstillstand zustande gekommen, der 1370 ebenfalls unter Bestätigung der alten Rechte der Städte in Norwegen in einen endgültigen Frieden verwandelt wurde.

${ }^{85}$ ) Hanserezesse I 1 n. 510 § 11 Ziff. 5. 
Hamburg, das zum ersten Kriege gegen Waldemar 1362 2 Koggen mit 200 Mann gestellt hatte, hat im zweiten Kriege keine Waffenhilfe geleistet. Schon im ersten Kriege hatte es sich nach der Niederlage von Helsingborg entschieden von weiterer kriegerischer Anteilnahme ferngehalten, da es seine Kräfte zur Verteidigung der Schiffahrt auf dem Elbstrome gegen den ihm feindlichen Grafen Adolf von Holstein daheim gesammelt halten mußte $\left.{ }^{86}\right)$. Die Städteversammlungen $\mathrm{zu}$ Rostock am 16. Dezember 1366 und 30. Mai 1367 und zu Stralsund am 29. Juli 1367 wurden von Hamburg nicht beschickt ${ }^{87}$ ). Als auf der Versammlung zu Rostock am 1. Januar 1368, wo die Leistungen zum Kriege unter den wendischen Städten und ihren Genossen festgesetzt wurden, von Hamburg die Ausrüstung eines Schiffes mit 100 Mann verlangt wurde, erbat Hamburg vorerst Auskunft, was die Städte tun wollten, wenn die Elbe angegriffen werde ${ }^{88}$ ). Selbst als die Städte ihre Forderung auf 60 Mann ermäßigten, lehnte Hamburg ab, wenn die Städte sich nicht zur Hilfe bei der Verteidigung der Elbe verpflichten wollten; nur zur Erhebung des Pfundzolles erklärte es sich bereit ${ }^{89}$ ). Es kam so weit, daß die Städte berieten, ob sie Hamburg aus der Hanse ausschließen sollten; gegen das Versprechen, 900 M. l. Pfennige Kriegsbeisteuer zu leisten sowie Pfundzoll zu erheben und dessen Ertrag an die Städte abzuliefern, wurde indessen von weiteren Maßregeln gegen Hamburg seitens der Städte Abstand genommen ${ }^{90}$ ).

Es ist erklärlich, daß die großen kriegerischen Erfolge und die Machtstellung, welche die Bundesgenossen durch sie in Dänemark und Norwegen errangen, dieser Vereinigung der Städte eine hohe politische Bedeutung verliehen. Der gemeinsame Besitz der fünf dänischen Schlösser hatte zur Folge, daß der kölnische Bund auch nach Beendigung des Krieges noch Jahrzehnte seine Lebenskraft behielt. Als aber 1385 die

\section{S. $248 \mathrm{ff}$.}

${ }^{86)}$ Schäfer, a. a. O. S. 374, 376. Schleswig-holstein-lauenb. Urkdb. II

87) Hanserezesse I 1 n. $388 \S 1 ; 400 \S 1 ; 407$.

$\left.{ }^{88}\right)$ Ebenda n. $411 \S 9$.

${ }^{80)}$ Ebenda n. $427 \S 12$.

90) Ebenda n. $436 \S 5$. 
Schlösser beide an Dänemark zurückgegeben waren, traten die Preußen sogleich in Stralsund mit den wendischen Städten, den Süderseeern und den Livländern wegen Verlängerung des Bundes in Verbindung ${ }^{91}$ ). Sie waren sich der Bedeutung der Vereinigung für die Sicherung der Durchfahrt durch den Sund vollauf bewußt.

Auf die Entwicklung der Städtevereinigung, welche mit dem Namen der deutschen Hansa bezeichnet wurde, hat dieser Krieg gegen Dänemark und Norwegen insofern einen höchst wichtigen Einfluß geübt, als er die Städte zum Bewußtsein der großen politischen Macht ihrer vereinigten Streitkräfte brachte und damit den einzelnen das Interesse, das sie an dem Bunde hatten, vor Augen stellte; vor allem wurde Lübecks Machtstellung durch den Krieg und den Bund wesentlich vergrößert. Auf die völkerrechtliche oder staatsrechtliche Gestaltung des Hansabundes hat die auf den Beschlüssen von Köln beruhende Konföderation dagegen gar keinen Einfluß geübt. Die ausschlaggebenden Interessen des deutschen Handels, der russisch-flandrische Verkehrszug, wurde durch die Angelegenheiten dieses Bundes überhaupt nicht berührt; der schonensche Heringshandel und der norwegische Verkehr, so maßgebend beide für den lokalen Wohlstand der wendischen Städte ${ }^{92}$ ) waren, traten gegenüber jenem vornehmlichsten Handelsinteresse der deutschen Kaufleute doch immer in den Hintergrund. So kam es, daß die Zugehörigkeit zu diesem Bunde für die Teilhaberschaft an der deutschen Städtehansa ohne Bedeutung blieb. Die Süderseeer und Holländer waren Angehörige dieses Bundes, ohne zur deutschen Hanse zu gehören ${ }^{93}$ ). Als Mit-

๑) Hanserezesse I 2 n. $306 \S 22,23 ;$ n. 308.

$\left.{ }^{92}\right)$ Wozu ich Lübeck an dieser Stelle mit rechne.

${ }^{93}$ ) So schon Sattler, Das preußisch-westfälische Drittel, in Hans. Geschichtsbl. 1879 S. 71. Es herrscht die denkbar größte Verwirrung in der hansischen Geschichtschreibung über diesen Punkt, weil die Historiker die verschiedenen wirtschaftlichen Interessen der Städte nicht erkannt haben und deshalb die aus ihnen erwachsenen verschiedenen Städteverbindungen durcheinander werfen. Vgl. für die im Texte vertretene Auffassung Hanserezesse I 1 n. 413 (1367): were ok zake dat genich stad van der wendeschen zyden, van Prusen, van Lyfland unde va $\mathbf{n} \mathbf{d e r}$ $\mathrm{D} u \mathrm{~d}$ es che $\mathrm{n}$ hen $\mathrm{z}$ e $\mathrm{g}$ h e m e n like n, van der Zuderzee van Hol. 
glieder der deutschen Städtehanse gelten eben nur diejenigen Städte, deren Bürger zu vollem Umfange die Rechte genossen,

land unde van Seelande hyr nicht thu dun wolde usw. Hier werden also die wendischen, preußischen und livländischen mit den übrigen Städten zusammen als die deutsche Hanse zusammengefaßt und gegenübergestellt den Niederländern von der Zuidersee, Holland und Seeland; ferner n. 428 (1368) quod nullus nostratum in hansa existens, nec aliquis de Hollandia seu Seelandia; hier werden allerdings die von der Südersee nicht besonders aufgeführt, sondern unter Holland mit inbegriffen; ferner ebenda: in omnibus civitatibus que in hansa et in aliis, que nobiscum sunt in ista confoederacione. - Harderwijker behaupten 1305 einmal dem Könige von England gegenüber (Hans. Urkdb. II n. 69), sie seien Mitglieder der deutschen Hanse und ihre Vaterstadt gehöre nicht zu Geldern und Seeland, gegen deren Angehörige ein Arrestierungsgebot verhängt war, sondern zum Deutschen Reiche. Gemeint ist an dieser Stelle mit der ,,deutschen Hanse" die Genossenschaft der deutschen Kaufleute in England, zu der die Harderwijker offenbar Zutritt hatten, nicht aber der Städtebund, für den diese Bezeichnung überhaupt erst seit der Mitte des 14. Jahrhunderts in Gebrauch ist. - Daß die Kampener zur Zeit des zweiten Krieges gegen Waldemar nicht als Glieder der Hanse angesehen werden, hebt schon Schäfer, Die Hansestädte und König Waldemar, S. 343 Note 4, hervor; s. auch S. 450, Note und 478, Note 3. Seines Erachtens gehörten früher und später die utrechtschen und geldernschen Städte zum Hansabunde, ebenda und Hans. Geschichtsbl. 1880/81, S. 140; auch Kampen, meint er, habe vorher und nachher zur Städtehansa gehört; s. auch Die Hansestädte und König Waldemar, S. 343 Note 1, 391, 448. Schäfer beruft sich dafür auf folgende Stellen in den Hansarezessen:

1. Hanserezesse I 1 n. $510 \S 7$, n. 511. Hier wird den Ratsherren von Deventer, Elburg und Zütphen ein Brief übergeben ihrer Bitte gemăB, der durch sie selbst an die Älterleute der Kaufleute zu Bergen in Norwegen übersandt werden soll, in welchem den Älterleuten geschrieben wird, daß die Bürger dieser Städte zu den officiales plateas durch die hansischen Vorsteher derselben zugelassen werden möchten und sie dasselbe Recht genießen sollen, wie die Bürger der andern Städte (ut ipsorum [d. h. der Stădte Deventer, Elburg und Zütphen] concives plateis officialibus ibidem per nostros [d. h. doch die hansischen] officiales ibidem admittantur); m. E. geht daraus hervor, daß diese Städte nicht zur Hanse gehörten, ihre Bürger also nicht ohne weiteres an den auswärtigen Kontoren der Deutschen Anteil hatten, sondern hier nach dem Kriege zur deutschen Genossenschaft in Bergen auf besonderen Beschluß der Hansestădte zugelassen wurden; damit sind sie doch nicht zur Stăd tehanse zugelassen, ist ihnen insbesondere doch nicht der Zutritt zu den Kontoren in Nowgorod und im übrigen Ruß. land eingerăumt. Wenn die Stădte Zütphen und Deventer auf Grund dieses Beschlusses das Schreiben n. 511 der wendischen, preußischen und 
deren sich die Deutschen, die sich in Flandern zu einer Genossenschaft zusammengeschlossen hatten, erfreuten, die also

livländischen Städte, daß sich an 1., ,alle unse lyve borgh e re unde 2. alle koplude der dudeschen hense“ wendet, mit unterzeichnen, so geht daraus natürlich keineswegs hervor, da $B$ Deventer und Zütphen selbst zur Hanse gehören. Das Schreiben gilt vielmehr den Bergenfahrern aller Hansestädte und den Bergenfahrern von Deventer und Zütphen, welch letztere unter unse lyve borghere fallen. Der Auftrag selbst richtet sich nicht etwa an ,alle Kaufleute der Hanse“ oder dergl., sondern an ,,alle unsen borgheren, de to Berghen in Norweghen syn ofte komen".

2. n. $325 \S 19$. In diesem Schreiben teilen die Älterleute der Genossenschaft von Brügge die Namen einer Reihe von preußischen, niederländischen und wendischen Schiffern mit, die, ohne das von den wendischen Städten erlassene Verbot der Fahrt durch den Sund zu beachten, vom Zwin aus die Reise durch den Sund nach der Ostsee angetreten haben. Es zeigt sich hierin, wie schon oben bemerkt, daß die Preußen und Niederländer, die an dieser Fahrt in hohem Grade interessiert waren, dieselbe nicht aufgeben wollten und sich um das Verbot der wendischen Städte nicht kümmerten. Die niederländischen Schiffer werden mitaufgeführt, nicht weil sie zur Hanse gehören, sondern weil sie als nichthansische Schiffer hansischer Kaufleute ständig den Verkehr zwischen dem Zwin und Preußen bzw. den wendischen Städten vermitteln. Die wendischen Schiffer werden sich der preußisch-niederländischen Flotte angeschlossen haben, weil sie in dieser Gemeinschaft sicher waren und, wenn jene sich um das Verbot nicht kümmerten, auch sich den Frachtgewinn nicht entgehen lassen mochten.

3. n. 251. In der Urkunde des Grafen von Flandern und der Städte Gent, Brügge und Ypern von 1360 über den dem Kaufmann der deutschen Hanse von ihnen zugesagten Schadenersatz wird ein Schiffer von Harderwijk mit unter den Geschädigten aufgeführt. Es sind zwei Elbinger, ein Braunsberger, ein Harderwijker und ein Stralsunder Schiffer vor Antwerpen von den Flanderern arrestiert worden. Die Verhandlungen über den Ersatz waren in Lübeck geführt worden. Es handelte sich auch hier wieder um eine preußisch-niederländische Flotte, die in die Ostsee bestimmt war; auch der Harderwijker Schiffer wird Gut hansischer Kaufleute geladen gehabt haben oder haben laden sollen. Ladung ist allerdings nicht geraubt, die Schiffe mußten dieselben vielmehr wieder ausladen (ebenda I 1 n. 249 S. 176. I 3 n. 240 Ziff. 1e u. Ziff. 5, Note 1). Es ist verständlich, daß die Städtehanse hier für den niederländischen Schiffer, der hansisches Gut nach einem hansischen Bestimmungsorte mit andern hansischen Schiffern zusammen bringen sollte, mit eintrat, zumal die Harderwijker in Flandern in der Genossenschaft der Deutschen geduldet wurden. Aus dieser Tatsache ist aber nicht notwendig auf die Zugehörigkeit Harderwijks zur Städtehanse zu schließen. Vgl. übrigens das Schreiben Harderwijks in dieser Sache, Hansarezesse I 3 n. 240 Ziff. 1e, welches nicht an die Hanse, 
vor allem an dem Handel mit Rußland Anrecht besaßen ${ }^{94}$ ). Das Monopol des russischen Handels ist es, was die Deutschen von den Niederländern getrennt hält, und diese Scheidung verhindert auch, daß die Deutschen im 13. und 14. Jahrhundert sich in Schonen und in Norwegen mit den Niederländern dauernd zu einer Gemeinschaft verschmelzen, so oft sie auch hier sich zu gemeinsamem Handeln vereinigen; auch in Flandern scheinen die Bürger der wenigen niederländischen Städte, deren Angehörige dort überhaupt zur Genossenschaft der Deutschen Zutritt

sondern an die Vläminger gerichtet ist, was gleichfalls darauf hindeutet, daß die Stadt nicht in der Städtehanse ihre Vertretung sah.

4. II 2 n. 192 § 19. Arnheim bittet um die Aufnahme in die Hanse der Deutschen in Brügge und behauptet, früher zu dieser Hanse gehört zu haben. Es wird von der Genossenschaft in Brügge beschlossen, bei Zütphen und den Zütphen benachbarten Städten zunächst Erkundigungen einzuziehen, ob es wahr ist, daß Arnheim früher zur deutschen Hanse in Flandern zugelassen worden ist, da keiner der auf dem Kontor anwesenden Kaufleute sich dessen entsinnen kann. Hier handelt es sich um die $\mathrm{Zu}$ lassung zur Genossenschaft der Deutschen in Flandern, wie schon oben ausgeführt ist, nicht zur Städtehanse. Die niederländischen Kaufleute wurden, wie oben bemerkt ist, zum Teil von der deutschen Genossenschaft in Flandern unter ihren Schutz genommen, ohne daß sie damit die Rechte der deutschen Kaufleute auf den andern ausländischen Kontoren, insbesondere in Rußland, gewannen und ohne daß ihre Heimatstädte damit als Mitglieder des Bundes der deutschen Hansestädte gelten.

5. Ebenso liegt es bei der Stelle Hanserezesse I 2 n. 342 \$14, wo Nymwegen die Bitte ausspricht, zur deutschen Hanse in Flandern zugelassen zu werden und die Kaufleute sich ebenfalls erst bei Deventer und Harderwijk erkundigen wollen, ob es wahr ist, daß die Nymweger, wie sie behaupten, früher zum deutschen Kontor in Flandern Zutritt gehabt haben. Diese Stădte wurden eben in der flandrischen Genossenschaft der deutschen Kaufleute geduldet, ohne damit, wie in Ziff. 1 dargelegt ist, den Zutritt zu den übrigen ausländischen Kontoren zu gewinnen.

6. Die von Schäfer weiter angeführten Urkunden Hans. Urdkb. II n. 651, 655 behandeln einen Fall, wo Güter, welche Bürgern mehrerer niederlăndischer und wendischer Städte seitens des Königs von England mít Beschlag belegt werden. Der Text der Urkunden ist im hans. Urkundenbuche nicht abgedruckt. Die Urkunde n. 655, welche im Lüb. Urkdb. II 2 n. 1077 abgedruckt ist, enthält m. E. nichts, was darauf hindeutete, daß Zwolle zur Städtehanse gehört, die Urkunde n. 651 ist mir nicht zugängig. Darüber, daß Zwolle erst 1407 in die Städtehanse aufgenommen wurde s. Daenell, Die Blütezeit der deutschen Hanse, Bd. II, Berlin 1906, S. 298.

๑) S. oben S. 249, Note 2. Vgl. Stein, Beitrăge S. 113. 
fanden, doch immer nur Gäste der Deutschen geblieben zu sein, so daß die Heimatstädte dieser in der Hanse der Deutschen in Flandern hospitierenden niederländischen Kaufleute im 14. Jahrhundert nicht in die Hanse der Städte hineingezogen wurden.

Die kölnische Vereinigung, der gemeinsame Waffenerfolg und das den Krieg überdauernde Bündnis der Niederländer mit den wendischen und preußischen Städten hatte nun zwar eine Annäherung der niederländischen, insbesondere auch der süderseeischen Städte an die Städte der deutschen Hanse zur Folge. 1383 bitten Kampen und Stavorn ${ }^{95}$ ), daß man sie teilnehmen lasse an allen weiteren Privilegien, welche die Städte der deutschen Hanse in Zukunft in Norwegen, Dänemark, Holland und Flandern erwerben würden; von der Teilnahme an den Privilegien in Rußland ist bezeichnenderweise nicht die Rede; ihre Zulassung zum russischén Handel war von vornherein ausgeschlossen; indessen scheint auch dem Antrage auf Zulassung zu den andern Kontoren der deutschen Kaufleute damals nicht entsprochen zu sein; erst im 15. Jahrhundert ist die Zulassung niederländischer Städte zur Städtehanse erfolgt $\left.{ }^{96}\right)$.

${ }^{95}$ ) Hanserezesse I 2 n. $266 \S 8,270 \S 5$.

$\left.{ }^{96}\right)$ Vgl. Daenell, Die Blütezeit der deutschen Hanse, Berlin 1906, Bd.'II, S. 297 ff.: 1402 Nymwegen, 1407 Zwolle, 1412 Stavorn, 1422 Groningen, 1441 Kampen, Arnheim und Roermond. Daenell nennt als vollwertige Hansestädte in den Niederlanden noch Deventer, Zütphen, Elburg und Harderwijk. Richtig ist, daß Deventer, Zütphen und Harderwijk zur Genossenschaft des deutschen Kaufmanns in Flandern Zutritt hatten (s. oben Note 93 Ziff. 4 und 5). Daß aber Deventer und Zütphen ebenso wie Elburg bis 1369 , nicht Mitglieder der Städtehanse waren, ergibt meines Erachtens die Tatsache, daß sie an den Privilegien der Deutschen in Bergen bis 1369 keinen Anteil hatten (s. oben Note 93 Ziff. 1). Daß auch Harderwijk höchstwahrscheinlich damals ebenfalls nicht zur Hanse gehörte. und jedenfalls der Beweis seiner Zugehörigkeit für jene Zeit fehlt, s. oben dieselbe Note Ziff. 3. Zugegeben werden muß allerdings, daß Harderwijk und die andern drei Städte im 15. Jahrhundert zur Städtehanse gehörten, daß über ihre spätere besondere Aufnahme in die Städtehanse keine urkundlichen Nachrichten vorliegen und daß auch bei den übrigen vorerwăhnten Städten im 15. Jahrhundert regelmäßig von ihrer ,Wiederaufnahme“ die Rede ist, als ob sie früher in 
Die Beziehungen der Niederländer zu den Deutschen sind dadurch so sehr verwickelt, daß sie sich in den verschiedenen ausländischen Niederlassungen verschieden entwickelt haben. Jede dieser ausländischen Kaufmannsgenossenschaften hat eben ihre vollständig selbständige Geschichte auch hinsichtlich der Begrenzung des Kreises der Heimatstädte, deren Bürger als Zugehörige angesehen wurden. In England wurden die Kaufleute von Dinant, Harderwijk, Deventer und ebenso vielleicht von andern niederländischen Städten zur dortigen Hanse der deutschen Kaufleute gerechnet ${ }^{97}$ ), in der Genossenschaft am Zwin hatten die Bürger von Harderwijk, Deventer, Zütphen und seinen Nachbarn Zutritt zur Kaufmannshanse und damit Anteil an den Privilegien der Deutschen in Flandern ${ }^{98}$ ) in Bergen wurde nach dem gemeinsamen Kriege gegen Dänemark und Norwegen 1369 die Kaufleute von Deventer, Elburgh und Zütphen zur dortigen Kaufmannshanse zugelassen ${ }^{99}$ ), in Schonen, wo keine dauernde Niederlassung der Kaufleute bestand, kam es überhaupt nicht zur Bildung einer gemeinsamen, andere ausschließenden Genossenschaft der Deutschen, auch in Schweden, wo die Deutschen zum großen Teil dauernd einwanderten und in den Städten Bürger wurden, fehlte eine solche genossenschaftliche Abscheidung der Deutschen von den Kaufleuten anderer Nationen, in Rußland dagegen vermochten

der Hanse gewesen wăren. Indessen hat schon Stein in seinen Beiträgen zur Geschichte der deutschen Hanse, S. 148 Note 6, meines Erachtens treffend darauf hingewiesen, daß bei ihnen weder eine frühere Teilnahme an dem Recht des deutschen Kaufmanns, noch ein früherer Ausschluß aus demselben nachweisbar ist und $\mathrm{da} B$ die Städte selbst einen solchen Nachweis augenscheinlich nicht haben führen können. Stein sagt mit Recht, „der Zweck ihrer Behauptung ist ja ersichtlich. Für die Hanse kam wohl der Gesichtspunkt in Betracht, daß eine ,Wiederaufnahme“ sich dem Auslande gegenüber, welches sich wie Norwegen und besonders England über die Aufnahme neuer Städte in das Recht der Hanse beklagte, leichter rechtfertigen lieB“. Auch bei der Aufnahme Kampens ist an einer Stelle bezeichnenderweise von der Wiederaufnahme die Rede, obwohl Kampen, wie sich sowohl im 13. wie in der ersten Hälfte des 14. Jahrhunderts wiederholt zeigt, offenbar niemals zur Hanse gehört hatte.

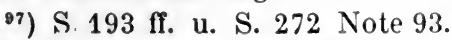

$\left.{ }^{98}\right)$ S. 272 Note 93 Ziff. 4 u. 5.

$\left.{ }^{9}\right)$ Ebenda Ziff. 1. 
die Deutschen den Kreis der am Handel Beteiligten auf die Bürger der niederdeutschen Städtegruppen zu beschränken, deren Angehörige sich den Zutritt hier im 12. und in der ersten Hälfte des 13. Jahrhunderts zu verschaffen und zu sichern verstanden hatten, und zu diesen gehört offenbar keine der niederländischen Städte ${ }^{100}$ ). Als nun auf der Grundlage der deutschen Kaufmannshanse am flandrischen Weltmarkte, in der, wie wir gesehen haben, die Interessen aller dieser auslëndischen Niederlassungen zusammenliefen, sich die Gemeinschaft der Städte, deren Kaufleute in dieser Hanse vereinigt waren, erhob, blieben die wenigen niederländischen Plätze, deren Angehörige in Flandern an der Genossenschaft und den dortigen Privilegien teilgehabt hatten, zunächst außerhalb dieser Städtegemeinschaft stehen, da sie an dem Hauptinteresse, daß die deutschen Kaufleute und Städte in Flandern zu vertreten hatten, dem russisch-flandrischen Handel, keinen Anteil besaßen, wie denn die niederländischen Städte wenigstens nach dem vorliegenden Urkundenmateriale auch an keiner der Versammlungen und Beratungen teilgenommen haben, welche die niederdeutschen Städte unter Lübecks Leitung im 13. und in der ersten Hälfte des 14. Jahrhunderts vor der Entstehung der einheitlichen Genossenschaft in Flandern 1347, wie wir oben verfolgt haben, über flandrische Angelegenheiten hatten.

So ist denn der Weltmarkt Brügge nicht nur Mittelpunkt des deutschen Seehandels und des Handels der Hamburger insbesondere, sondern auch die Heimstätte der großen wirtschaftlichen Kräfte gewesen, welche die deutsche Städtehanse erzeugt haben.

$\left.{ }^{100}\right)$ S. oben S. 192 Note 230. 


\section{Orts-, Personen- und Sach-Register.}

Aa (Rußland) 213.

Aachen 81, Tuchweberei 230.

Aardenburg 75 Note 188, 85, 89, 117, 119, 170 Note 123, 172, 179, 193

Note 76, 249, 250; Stapelplatz der

'Deutschen 92, 200; Mitglied der Londoner Hanse 68.

Abel, Herzog von Jütland 96.

Adalbert, Erzbischof von Hamburg 17.

Adolf II, Graf von Holstein 20, 23.

Adolf III, Graf von Holstein 24, 25, $26,27$.

Adolf IV, Graf von Holstein 100, 121, 136.

Aduard, Kloster in Friesland $239 \mathrm{f}$. Ahrensburg 208.

Ahrensfelde 205.

Aigues Mortes 145 Note 23.

Albert von Lüneburg, Hamburger Bürger 181.

Albrecht der Bär 20.

Albrecht, Graf von Orlamünde 113. Albrecht, Herzog von Sachsen 96, 101, 104, 113, 128.

Aldenburg 9, 18.

Alkmar 120.

Alpenpăsse 147, 148.

Ältermann der Deutschen in England 73; englischer Ältermann der Deutschen daselbst 72; der hamburgischen Hanse am Zwin 79; der hamburgischen Hanse in Utrecht 132; der Deutschen in Brügge 200; in Dordrecht 236; der Hamburger in Amsterdam und Stavorn 238; der Lübecker in Wisby 44; der Dortmunder in Wisby 255.

Alster 12, 24, als Verkehrsstraße 207, 209.
Alston More in England 174.

Amager 167.

Amiens, Hanse in London 68.

Amsterdam 264, 268, 269; Schonen 163; Schiffahrt in der Ostsee 160, 161, 195; Hamburger Hanse in A. 225, 237; Bierzoll 238; Pfundzoll 212.

Anisals Handelsartikel in Hamburg 119. Anklam 98, 154, 257, 258, 261 ; Schonen 53, 163; Holzhandel 49.

Ansgar, Bischof von Hamburg 13, $14,18$.

Antwerpen 77, 170 Note 129, 179; Hamburger in A. 78.

Appellation gegen d e Urteile des Hofes zu Nowgorod 45 Note 55, 135, 192.

Aquitanien 169 Note 127.

Aragon 76, 92, 200.

Arnemuiden 120.

Arnhem 192, 275, 276.

Arnulf, König von Deutschland 15.

Artlenburg 220, 222. Vgl. Erteneburg. Arras, Tücher von A. 34 Note 11, 35. Asche als Handelsartikel 167 Note 121;

Stapel in Damme 185; von den wendischen Städten 49; von Preußen 153; Hamburg 109, 112, 116, 134. Assekuranzprämien 146, 147.

Asti 34 Note 13.

Astringien 241.

Atvidaberg in Schweden 155.

Audenaarde s. Oudenaarde.

Avaren 5, 19.

Bai von Bourgneuf 184.

Bailleul 75 Note 188.

Bank der Lübecker in Wisby 44 und Note 52 daselbst, 86; am Zwin 83, 85, 86. 
Bapaume 74 Note 185, 179.

Barcelona 179.

Bardesfleth 128.

Bardowik 4-6, 8-11, 18 f., 21, 23 bis 25, 28 f., 99, 100 Note 23, Markt und Zollstätte 9; Stade 9; Harz 10; Stapel 10.

Barmstede, Ritter von 97 f., 127.

Barmstede, Otto von 98.

Bar sur Aube (Messe) 201.

Basel 198 Note 30.

Bayern (-Köln) 89.

Bayonne 35, 75 ff., 94, 144 Note 22 und 24, 178; Verkehrsbedeutung 145.

Bennestryth, Hennekyn, Hamburger Bürger 183.

Bentschen 54 Note 98.

Bergelohn 128, 129, 131.

Bergen in Norwegen 176, 177, 189, 193. Bergen op Zoon 75 Note 188, 77, 170 Note 129, 179, 253, 277.

Bergwerkserzeugnisse $104 \mathrm{ff} ., 218 \mathrm{ff}$.; vom Harz 4, 10, 104 f., 218 f.; von Meißen 109; von Schweden 47, s. auch Metall.

Berlin, Holz und Getreide $111 \mathrm{f}$. ; Hamburg 111, 232; Flandern 220.

Bernhard II., Herzog von Sachsen 16. Bernstein als Handelsartikel 3, 49, 153.

Bezelin, Erzbischof 9, 16.

Biarmien 42.

Bier als Handelsartikel 54 f., 57; Hamburger Bierhandel 115 f., 120, 123, 219, 225, 235; Hamburger Bier 115 f., 225, 238, 239; wendisches 51, 60, 164 f.; Ummelandbier 238; Lübecker Bier 115, $164 \mathrm{f}$.; preußisches 154; Haarlemer und holländisches 238.

Bille 11.

Birten 2.

Bishopsgate, Stadttor in London 72.

Blankenese 235.

Bleckede, Zollstelle 113; Asche von B. 112.
Blei als Handelsartikel 62, 103 Note 42, 105, 109, 169, 173, 219.

Blocksberg, Ritter von 208.

Böhmen, Hamburg 219, 224; Köln 89, 147 Note 1.

Bohus 160.

Boitzenburg 11, 223, 233, Zollstelle 113, 114; Asche von B. 112.

Boitzenburg, Wirad von 24.

Bolsward, Münzstätte 8 .

Bornhöved, Schlacht bei 136.

Boston 175, 182.

Böttcherei in Hamburg und den wendischen Städten $225 \mathrm{f}$.

Brabant, Flandern 77, 78; England 169 Note 127; Schonen 163.

Brandenburger, in Hamburg 56, $105 \mathrm{ff}$., 109 ff., 114, 118, 220, 224, 233, 242 ; in Holland 89 Note 234.

Braunsberg 157, 267.

Braunschweig 190, 251 f., 254; Hamburg 56, $105 \mathrm{ff.}, 109 \mathrm{ff.,} \mathrm{118,} 218 \mathrm{f}$, 220, 224, 233, 242; Flandern 118, 188; Bremen 218 Note 63; Stade 135; Antwerpen 179 Note 180 ; Tuchweberei 230 .

Bremberg 5.

Bremen 10, 13, 14, 15, 37, 121, 122, $123,125,126,150,239,242,254$, 261, 267, 269, Münzstătte 8; Handelsstellung 123 Note 135; Hamburg 122, 217; Norwegen 60 f.; Schonen 163; Braunschweig, Goslar, Hannover, Hameln 106, 218, 219; Ripen 10; Holland, Flandern 89 Note 234. Ausschluß aus der hansischen Gemeinschaft 192 Note 30.

Brescia, Tuchfärberei 34 Note 11. Breslau 147 Note 30; Preußen 152 f. Brie, Messen von 30 .

Briel 163, 193, 268.

Brockdorff in Holstein 234.

Brokate als Handelsartikel 34 .

Brügge 30 ; s. im übrigen Flandern, Stapel, Tuche, Zwin.

Brunsbüttel 129, 234. 
Bucks in England 174 Note 150. Buku 20.

Butter als Handelsartikel 216, 219; in Hamburg 117; Preußen 153, Schweden 151, 155; Stapel in Damme 185.

Buxtehude 113.

Byrger, Herzog von Schweden 47.

Cahors 76 Note 193; Handelsbedeutung 145; England 169 Note 127.

Cambrai, Tuche von 35; Hanse in England 68.

Canterbury 174 Note 150.

Celle, Zollstätte 135, 219.

Chalons sur Marne 141; Tuche von 34 Note 11.

Champagne, Messen 30, 33-36, 140, 141, 148, 179, 201, 202.

Christiania 177.

Cimbrisham 270.

Cölln a. d. Spree 111, 220, 223.

Comines, Tuche von $35,229$.

Corbie, Hanse in England 68.

Corveysche Abtei zu Groningen bei Halberstadt 10 Note 32.

Courtray, Tuche von 229.

Cremona, Tuchfärberei 34 Note 11. Crummendik, Ritter von 208, $234 \mathrm{f}$.

Damaskus 149 Note 34.

Damme 31, $38 \mathrm{ff}$., 75 Note 188,90 , 183, 185; Weinstapel 177, $184 \mathrm{f}$; Mitglied der Londoner Hanse 68; Zölle 91 .

Dänemark 13, 15, 21, 57, 121, 136, 168.

Dannenenberg 114, 233.

Danzig 125 Note 143, 152, 157, 181, 214, 223, 267.

Delvenau als Verkehrsstraße 222.

Demmin 53, 98, 257, 258; Schonen 163. Densche Wyk 51 Note 74 .

Deventer 38, 92, 120, 150, 193 Note 237, 267, 273, 275; Kopenhagen, Dragör 167 Note 122, 196; Norwegen 196, 197; in der deutschen Hanse in
London 9' Note 238, 277; in der Hanse in Flandern 192; in der Hanse in Bergen 277.

Dinant, in der deutschen Hanse in England 194 Note 238, 277.

Ditmarschen 113, 129, 233, 23' 243. Dixmuiden, Mitglied derLondoner Hanse 68; Tuche 229.

Doesborg 163.

Doest, Zisterzienserabtei bei Brügge 81.

Dokkum 116, 120; Münzstätte 8; Kloster 241.

Dömitz 233; Zollstelle 113, 114.

Dordrecht 38, 62, 91, 92, 170 Note 129, 178, 190, 193, 200, 237, 250, 252, 264, 268, 269.

Dornik 230.

Dorpat 151.

Dortmund, Flandern 81, 89 Note 234; England 73, 173, 182; Gotland 44 Note 52, 255; Norwegen 196; Rußland 256; Schonen 163 Note 104, 196; Hamburg 122, 217.

Douai, Hanse in England 68; Tuche von 35 .

Dragör: 167.

Drelleborg 267.

Dresden 219.

Dritteilung der Hanse 199, 200, $251 \mathrm{ff}$. Duero 35.

Duhnen 235.

Duisburg 2.

Ecloo, Tuche von 229.

Eduard I., König v. England 62.

Eider 4, 11, 15.

Einwohnerzahl Hamburgs und Lübecks 138, 246 .

Eisen als Handelsartikel 116, 227; von Hannover 106, 220; von Schweden $151,155,215$.

Eisenach 54 Note 28.

El Ferol 75.

Elbe 4, 6, 9, 11, 12, 21. 96, 97, 113, 114, $118,127 \mathrm{ff} ., 233 \mathrm{ff}$. 
Elbing 49, 103 Note 42, 152, 157, 160, 162 Note 97, 214, 223, 264, 267, 268. Elborg 150, 163, 182, 193 Note 237, 264, 268, 273, 275, 277.

Ellenboghen 162 Note 101.

Elsaß, Tuchweberei 230.

Emden, Münzstätte 8 .

Emsgau 218, 240.

England 2, 7, 40, 41; Wollproduktion und Wollausfuhr 32, $61 \mathrm{ff} ., 141 \mathrm{ff}$., 168 ff.; Ausfuhr anderer Waren 62, 169 f., 173 f., Geldmarkt 63 f., 173 ff.; Handelsbilanz 63 f., 169, 173; Tuchindustrie 124, $168 \mathrm{f} ., 231$; Handel mit Flandern 61 ff., 168 ff.; mit Norwegen 57,177; mit den Ostseeländern (Preußen) 161 f., 268; (wendische Städte) 162; (Schonen) 55, 163; fremde Kaufleute in England: flan. drische 64, 67 ff., 169; hamburgische 65 ff., 73, 182 ; lübeckische 65 ff., 73; kölnisch-westfälische 65, 73; gotländische Genossenschaft 67; deutsche im allgemeinen $64 \mathrm{fr} ., 71 \mathrm{ff}$., 171 ff. ; italienische 6', 67, 171 ff.; spanische 169, 171 Note 35; französiche 64, 68, 169; brabantische, holländische usw. 68, 169.

Enkhuisen 120, 160.

Erfurt 5.

Erich, König von Dänemark 205.

Erteneburg 21, 24, 99, 100, s. auch Artlenburg.

Erzbistum Hamburg 12-16.

Erze als Handelsartikel 105 ff., 156, $218 \mathrm{ff}$.

Eßlingen (Zollenspieker) 23, 113, 114, $220,243$.

Ethelret, König von England 64, 65.

Falsterbo 162, 270.

Färberei der Tuche in Südfrankreich und Italien $33 \mathrm{f}$.

Faro 75.

Farwe in Holstein 9, 10.

Fehmarn 103 Note 42.
Feigen 228.

Felle 169, 185, 216, 218.

Fette 96, 104, 109, 116, 134.

Fische 40, 175 f., 183.

Flandern, Mittelpunkt des westeuropäischen Handels 2, 30, 140; des Welthandels 140 ff., 183 ff.; des Handels der Hamburger 36 ff., 40 ff., 79 180 f.; des Handels der Lübecker 37, 46, 81 ff.; des Handels der Deutschen 36-9'́, 149-202; des Handels der Niederländer 37, 38, 157 ff., 191 ff.; des südwest-europäischen Handels (Spanien, Portugal, Frankreich) 35 f., 75 ff., 186; des Handels der Italiener 35, $144 \mathrm{ff}$.; Handel mit Rußland und Gotland 41 ff., 149 ff.; mit Schonen 52 ff., 162 ff.; mit den wendischen Städten 49 ff.; mit Preußen 49, $152 \mathrm{ff}$. mit Schweden 47 ff., 151 ff.; mit Norwegen 56 ff., 175 ff.; mit England $61 \mathrm{ff} ., 12$ ', $168 \mathrm{ff}$; mit Rochelle und Gascogne 73 ff., 177 f.; mit Spanien 75 ff., 178; mit der Champagne und Südfrankreich $32 \mathrm{ff}$., 77, 141 ff., 179; mit Italien 32 ff., 144 ff.; mit Antwerpen und Bergen op Zoon 77, 179; mit Köln 78 ff., 89, 185; mit den deutschen Binnenstădten 89; Verkehrsroute Hamburg-Flandern 94-139, 204-246; Tuchindustrie 1, $32 \mathrm{ff}$., $141 \mathrm{ff}$.; Flanderer in der Champagne 143 (flandrische Hanse), in England (flandrische Hansen) $67 \mathrm{ff}$; in Hamburg 103, 117, 119; in Bayonne 178; in Schonen 163; Aktivhandel 94, 202, 203; Reederei 203.

Flensburg 233.

Florenz 34 Note 13; Wollindustrie 142, 145; Tuchfärberei 34 Note 11.

Florenz V., Graf von Holland 38. Forchheim 5.

Foswert, Kloster in Friesland 241.

Frachtschiffahrt, hamburgische 110, 133 f., 139. 
Franecker 120, 131.

Frankfurt a. M. 148 Note 30, 179.

Frankfurt a. d. O. 49 Note 72, 157 Note 72.

Frankreich 7, 33 ff., 46, 64, 177 f.; Tuchindustrie $32 \mathrm{ff} ., 141 \mathrm{ff}$; Messen s. Champagne.

Freiberg in Sachsen 109.

Fremdenrecht in England und Flandern 88, 93.

Friedrich I., Kaiser von Deutschland 26, 99, 127.

Friedrich II, Kaiser von Deutschland $65,95,99$.

Friesen als Kaufleute 1, 2, 3, 7, 9, 10, 20; als Träger des Ostseeverkehrs 7 Note 24, 93; friesische Tuche 2 f., 230; Hamburg 99, 103, 120, $128 \mathrm{ff}$, $238 \mathrm{ff}$.

Fuhrmeister in Hamburg 206, 208.

Gardelegen 111, 220.

\section{Garonne 77.}

Gascogne 74, 75, 94.

Geervliet 131, 132.

Geesthecht 23, 113, 223, 224 Note 99. Geldersen, Vicko van 180 ff., 219 ff., 224, 228 ff., 242, 243.

Geldhandel in England 63, 64, 173, 174.

Gellen 50, 160, 268.

Genemuiden 126 Note 143.

Genossenschaften s. Hansen.

Gent 75 Note 188; Hanse in England 68; Hanse in Hamburg 112, 119; Tuche von $35,229$.

Genua 34, 146; Sevilla 145 Note 24; Tuchfärberei 34 Note 11.

Genum 33 Note 9, 126 Note 143, 131, 133.

Gerbert Ghulsowen 237.

Gerhard Graf von Holstein 55 Note 103, 96, 205, 206.

Gerichtsbarkeit der hamburgischen und lübischen Hansen am Zwin 79, 80, 85, 86, 87; der hamburgischen Hanse in Utrecht 132; der deutschen Genossenschaft in Brügge 83; flandrische Fremdengerichtsbarkeit 90, 91; der Deutschen in England 72.

Getreide als Handelsartikel am Zwin 134, 172, 183, 184-187; in Hamburg 109-113, 116, 117, 134, 219, 223 f.; in Stade 136; von Preußen 49, 154 ff., 161; von den wendischen Städten $49-51,60$; von Rußland 48, 149 Note 35; nach Norwegen 57, 60.

Gewandschneider 227, 228, 241.

Gewürze als Handelsartikel 3́; ; Stapel in Brügge 185.

Gibraltar 146 Note 27, 147.

Gifhorn (Zollstätte) 219.

Gildhalle in London 65, 72.

Giselbrecht, Erzbischof von Hamburg 129.

Gnesen 54 Note 98.

Goldgewinnung in England 173.

Goslar 105, 190, 218, 219, 250, 251, 252; Hamburg 106; Flandern 106, 188; Bremen 218 Note 63.

Göteborg 177.

Gotland 40, 43, 46, 67, 81, 83, 87, 88, 101, 103 Note 42, 135, 156, 160, 164, 169,170,189, 191, 194, 195, 197, 210, 214, 223, 248, gotische Kaufleute 43; gotländ. Genossenschaft in Flandern 46, $80 \mathrm{ff}$., $191 \mathrm{ff}$., in England 67, $71 \mathrm{ff}$.; Gotänder in Greifswald 103 Note 42; Gotländer Zollfreiheit in Hamburg 100-101; Salzeinfuhr in Gotland 223.

Göttinger in Flandern 188.

Gottschalk, Hamburger Schiffer in England 65.

Grafen in Hamburg 17.

Grammont, Tuche von 229.

Gravesend, Deutsche daselbst 67 .

Gravelingen 74 Note 187,75 Note 188.

Greifswald 98, 102 Note 39, 103 Note 42, 154, 251, 258, 260, 261, 267, Bött. chergewerbe 226; Flandern 49, 50, 
51, 55; Schonen 53, 163; Kopenhagen 167; England 182; Dänen und Gotländer in G. 103 Note 42.

Grenzmärkte 5, 19.

Groningen 37, 276; Stellung zur Hanse 19 Note 230, 192; Münzstätte 8; Norwegen 57, 196; Hamburg 120. Gunzelin, Graf von Schwerin 98, 114.

Haarlem (Bierbrauerei) 238.

Hadeln, Land 113, 228, 129, 135.

Hakon, König von Norwegen 261.

Halasat 5.

Halberstadt 106.

Halland 239.

Hamburg 11-28; Verkehr mit Flandern 14, 29, $41 \mathrm{ff} ., 88$ f., 103-139, 180 f., 188, 199, 218-245; flandrische Kaufleute in Hamburg. von Aardenburg 117, 119; Gent, Brügge, Mecheln, Ypern, St. Omer, Oudenaarde 119; Verkehr mit Holland und Friesland 120, 123, 131 ff., 225, 237 f., 239 ff.; friesische und holländische Kaufleute in Hamburg von Utrecht, Kampen, Stavorn, Harderwijk 120, $216 \mathrm{ff}$; von Leuwarden 99, 120; von Dokkum, Groningen, Harlingen, Werkum, Enkhuisen, Alkmar, Deventer, Arnemuiden, Franecker, Sneek 120; kein unmittelbarer Verkehr mit England 71, 123 f., 232 ; kein unmittelbarer Verkehr mit Schonen 55 f.; Verkehr mit Dänemark (Nestved)? 121 ; mit Schweden (Süderkoping) 102, 121 ?; mit Gotland $100 \mathrm{f}$; Anteil am russischen Handel 46 ff., 102; Verkehr mit Lübeck 95-103, 104, 204-218; mit wendischen Städten 102 f., 233; mit den Städten der Mark Brandenburg 106 ff., 112, 220 f., 231 f., mit Salzwedel 106, 108, 109, 112, 220, 232; Stendal, Pritzwalk, Gardelegen, Werben, Seehausen, Havelberg, Berlin, Cölln a. d. Spree 111 f., 220, auch
223 f., 232 ; Osterburg, Brandenburg, Kyritz, Spremberg, 111, Perleberg 112, 220, 232; Ưlzen 220, 232; mit Braunschweig $105 \mathrm{ff}$., 109 f., 111, 112 f., 218 f., 233; mit Goslar und den Harzstädten 105 f., 218 f.; mit der Mark Meißen (Freiberg in Sachsen) 109; mit Magdeburg 106, 111, 21', 219, 22', 233; mit Lüneburg 108, 111, 112, 220 ff., 232; mit Hannover 106, 120, 233; mit Pirna 219; mit Böhmen 219, 224; mit Stade $25 \mathrm{ff}$., 113, 117, 135, 2'1 f.; mit Boitzenburg Bleckede, Hitzacker, Schwerin, Lenzen, Schnakenburg, Wittenberge, Dannenberg, Dömitz, Parchım 111, 112, 232; mit Itzehoe, Rendsburg, Neumünster, Kiel, Schleswig, Flensburg 233; Hamburger Münze 17 f.; Zoll 99 ff., Geleitgeld (Umgeld) 96 f., 107 f., $204 \mathrm{ff}$; Einwohnerzahl 139, 245 f.; Tuchweberei 71, 231; im Kriege gegen Dănemark 271; Schiffrecht $56,57,59,62,63,71,73,78,79$, $80,82,83$; Hamburger Kaufleute in Flandern $36 \mathrm{fr}$., $79 \mathrm{ff}$.; in England $65 \mathrm{fr} ., 71,73,180,182 \mathrm{f}$; in Irland und Schottland 73; in Schonen 53, 163, $181 \mathrm{f}$.; in Gotland 47; in Norwegen $56 \mathrm{ff} ., 175,181$; in Schweden 47 ff., 181; in Rochelle 75, 182; in Bergen op Zoon und Antwerpen $77 \mathrm{f}$.; in Köln 78 f.; Kaufleute aus Lübeck, Köln, Bremen, Dortmund, Soest, Osnabrück, Herford, Hildesheim, Stralsund, Rostock, Wismar in Hamburg $122 \mathrm{f}$., $216 \mathrm{ff}$.

Hameln 188 (Flandern); 218 Note 63 (Bremen).

Hamm 197.

Hannover 220, 223 (Hamburg, Flandern); 218 Note 63 (Bremen); 106 (Eisengewinnung).

Hansen (Genossenschaften), hamburgische Hanse am Zwin 36 ff., 79-90, 180 ff., 199 f., lübeckische am Zwin 
$37,40,44,46,81-84,90,199 \mathrm{ff}$; kölnisch-westfälische in Brügge 65 Note 148, $80 \mathrm{ff}$., $191 \mathrm{ff}$., gotländische in Brügge 46, 80 ff., 191 ff.; der deutschen Kaufleute in Flandern $83 \mathrm{ff}$., $188 \mathrm{ff}$., $248 \mathrm{ff}$.; hamburgische in England 66, 71 ff., 180, 182 f., 127 ; lübeckische in England 66, $71 \mathrm{ff}$; kölnisch-westfälische 65 ff., 71 ff.; gotländische in England 67, $71 \mathrm{ff}$; der Deutschen in England 71 ff., 88, 93, 174 f., 254; hamburgische Hansen in Utrecht 132 f., 225, 237; in Amsterdam 225, 237 f.; in Stavorn 225, 238 ; Dortmunder Hanse in Antwerpen 179; lübeckische in Wisby 44 und Note 52 daselbst, 86; Hanse (Genossenschaft) der Deutschen auf Gotland $43 \mathrm{ff}$., 100 f., 194, 254 f.; Hanse der Deutschen in Norwegen 177, 256, 257; Hof zu Nowgorod 43, 150 f., 256, 249; Niederländer in der deutschen Hanse in Flandern 192 ff., 277 ; in der deutschen Hanse in England $193 \mathrm{f} ., 277$; in der deutschen Hanse in Norwegen 193, 272, 277; flandrische Hansen in England $67 \mathrm{ff}$.; in der Champagne 143.

Harburg 27.

Harderwijk 193, 264, 268, 269, $273 \mathrm{ff}$., 277; Hamburg 120 f., 218; Flandern 55 Note 101, 192, 277; Ostseeschifffahrt 159, 160; England 182, 277; Schonen 163; Kopenhagen, Amager 167. Note 122; Norwegen 196; russ. Handel 150.

Harlingen 131, 241; Hamburg 120, 240. Harmouth 67.

Harz 4, 10.

Haseldorfer Marsch 97, 113, 127.

Hatzberg bei Wedel 234 .

Häute als Handelsartikel in Hamburg 117, 119; in England 62; von der Ostsee 153 (Preußen), 159; in Stade 136; in Norwegen 176.

Havel 111, 114.
Havelberg 111; - Hamburg 112, 224; -Flandern 220.

Heinrich der Löwe 20, 22, 23, 28, 100, $113,136$.

Heinrich III., Kaiser 17.

Heinrich, Slavenfürst 20.

Helgoland 237.

Helmstedt 10 Note 32 ; - HamburgFlandern 106.

Helsingborg 153, 262, 270, 271.

Herenthal, Tuche von 229.

Herford-Lübeck 217.

Heridac, Priester in Hamburg 12, 14.

Hering als Handelsartikel 56, 59, 60; Schonen 52, 53, 54, 149 Note 35, 163 , 165, 166, 257, 272; Norwegen 57, 59, 177 ; in den wendischen Städten 55 , 103 Note 42 (Greifswald), 115, $165 \mathrm{ff}$.; Lüneburg 115, 221, 222, am Zwin 165 ff., 184; Kampen 195.

Heringsfett (smer) 562.

Herte, Engelbrecht van dem, Kölner Bürger 217.

Het Gein 126 Note 143, 131.

Hiddensee 50, 160.

Hildebold, Erzbischof 127.

Hildesheim 54 Note 98; - Hamburg 106, 217; -Flandern 106, 188.

Hitzacker 108, 113.

Holland 43, 46, 89 Note 234, 126 Note 143, 131, 132, 133; Hamburg 103, 120 ; Verhältnis der holländischen Städte zur Hanse $272 \mathrm{ff}$.

Holsteiner 12; in Greifswald 103 Note 42.

Holz als Handelsartikel 134, 159, 239; über Hamburg 111, 112, 117, 224 ff.; von Preußen 49, 154, 157, 162; von den wendischen Städten 49, 51 Note 76, 103; von Gotland und Schweden 47; auf Schonen 164, 165; durch den Sund 156, 157, 159; von Norwegen $56,58,59,60,175$ f.; Holzstapel am Zwin 173, 183, 184, 185, 186, 187. 
Holzfabrikate im hamb. Handel 112, $225,226$.

Holzfässer und Tonnen 52, 165, 225, 226.

Honig als Handelsartikel 219, 227.

Hopfen als Handelsartikel 219.

Houcke 40, 82, 86 Note 230, 183, 184, 185, 187, 199, 200.

Hovede 41 Note 43.

Huglestad 166 Note 117.

Hull 67.

Hummersbüttel, Ritter von 207, 208. Huy 152 Note 51.

Hrodnace (Renaix), Kloster in Flan. dern 14.

Ilmenau, Fluß 6, 19, 111, 11't.

Ingwer als Handelsartikel 228.

Irrland 73, 175.

Island $\mathbf{1 7 6 .}$

Italiener 43, 46, 141, 148; in Flandern 171, 179; in England 64, 67, 68, $69,172,173,179$; in der Champagne 32,33 .

Itzehoe 16 Note 35, 233.

Iwenfleth 23'.

Jahrmärkte in Hamburg 123.

Jerusalem, Kloster in Friesland 2:1.

Jever 8, 117, 218, 241.

Johann, Graf von Holstein 97, 55 Note 103, 206, 207.

Johann, Herr von Mecklenburg 99.

Johann, Herzog von Sachsen 128.

Johann, Graf von Braunschweig-Lüneburg 198.

Juden in England 173.

Julinum 18.

Jütland 103.

Kalmar 155, 213, 223.

Kampen 243, 262, 263, 264, 268, 269, 273, 276, Pfundzoll 216; Ostseeschifffahrt $159,160,193,195,196$, Gotland 194; Schonen 53, 163, 164; Norwegen 57, 175, 176, Kopenhagen
Amager Dragör 167 Note 122; England 182; am Zwin 38, 92, 95, 55 Note 101, 193: Hamburg 121, 217, 218; an der französischen Küste 178.

Kanevas als Handelsartikel 173.

Karl der Große 3, 5, 11, 12, 13, 14.

Kastilien 76, 92, 178, 186, 200.

Katalonien 34, 35, 146, 169 Note 127.

Kattegat 42.

Katzand 31.

Kiel 11 Note 35, 261; Hamburg 233; Schonen 53.

Kingston 175, 182.

Kirchengut, hamburgisches in Flandern 14.

Klaarkamp, Kloster in Friesland 241. Kleinhandel, Verbot für die Vlamländer in Hamburg 119.

Knocke 31.

Koesfeld 196.

Köln 2, 5, 9, 81, 83, 148 Note 30, 173, 179, 264; Handelsstellung 89; England $65,66,67,72,73,182$; Flandern $78,86,184,185,186,188,189,191$; Kölner in Hamburg 217; Tuch. weberei 230 .

Kölner Konföderation $262 \mathrm{fff}$.

Kolberg 261.

Kompaß 146, 158.

Königsberg 152, 157, 162, Note 92 214, 267; Flandern in England 157 Note 74 .

Konrad, Kaiser von Deutschland 9. Konzentration des Welthandels am Zwin 203.

Kopenhagen 167, 263, 270.

Korduanleder als Handelsartikel 34.

Korinth 149 Note 34.

Krakau 152, 153.

Krauel 23, 193.

Krempe 113, 234.

Kulm 152, 268.

Kümmel als Handelsartikel 119.

Kungelf 177. 
Kupfer. Stapel in Brügge 172, 185; vom Harz 9, 105 ff., 219, 220; von Meißen 109; von Preußen 152 f.; von Schweden 151, 155, 215; von England 103 Note 42, 173; in Hamburg 105 ff., 116, 219.

Kyritz 111.

Lagerhalterei in Flandern 202, 203.

Lagny sur Marne 141, 201.

Landstrasse Hamburg-Lübeck $95 \mathrm{ff}$., $204 \mathrm{ff}$.; von Hamburg westwärts $125 \mathrm{ff}$. von Maaß nach dem Harz 4.

Languedoc 35, 142 Note 11.

v. d. Lappe, Ritter $235 \mathrm{f}$.

Lauenburg 23 Note 65, 108, 113, 114, 220, 221, 223.

Leder als Handelsartikel 219.

Leinen als Handelsartikel 153; Salzwedeler und Ülzener 109, 220; in Hamburg 109, 119, 219, 220, 221, 228; am Zwin 109, 164, 220 f., 227; auf Schonen 164.

Lemberg 152, 153, 230.

Lemsal 215.

Lenzen 111; Hamburg 112, 233.

Leuchtturm zu Neuwerk 129, 130, 236.

Leuwarden 8, 24, 99, 120, 196.

Libourne 145 Note 23.

Lille 75 Note 188; Messen 202; Tuche 35; Mitglied der Londoner Hanse 68.

Lombardische Kaufleute 34, 35, 169 Note 127.

London 64, 65, 66, 88, 162 Note 97, 170 Note 129, 175; als Geldmarkt 64 ; Londoner Hanse 68; Zollrolle 7, 8. Lorch 5.

Lucca 34 Note 13; Tuchfärberei 34 Note 11.

Ludwig der Fromme 13.

Lübeck $5,20-24,28,29,249-252$, 255-261, 268, 269, 272; Handelsstellung $44 \mathrm{f}, 102$; Ein- und Ausfuhr $210 \mathrm{ff}$; Verkehr in Flandern $36 \mathrm{ff} ., \quad 41 \mathrm{ff} ., \quad 80 \mathrm{ff} ., \quad 88 \mathrm{ff} ., \quad 93 \mathrm{f}$., 126, 131 ff., 158, 159, 166, 188,
189, 190 ff., 197 ff., 232; von Flandern nach der Champagne 77, 179; nach Italien 197; nach Süddeutschland 78, 197; Verkehr in Gotland $43 \mathrm{ff}$., $212 \mathrm{ff}$., 255; in Nowgorod $43 \mathrm{ff} ., 150,151,256$; in England 65 ff., 125, 182; kein direkter Verkehr zwischen Lübeck und England 71; Verkehr in Schonen $53 \mathrm{ff} ., 163$, 166, 181; in Kopenhagen 163 Note 122; in Schweden 48, 155, 181, 212 ff., in Preußen 49, 155, 158, $212 \mathrm{ff}$; in Schottland und Irrland 73; mit den wendischen Städten 212 ff.; mit Riga, Reval usw. 48, $212 \mathrm{ff}$; mit Uelzen, Stendal, Salzwedel, Lüneburg 55 , 115 f., 221 ff., 242 f.; Lübeck-Hamburg 95-104, 121, 155, 204-218, 234, $243 \mathrm{ff.}$; Zollfreiheit in Hamburg 99 ff., 216; in Sachsen 21; Einwohnerzahl 246; Böttcherei 226; Lüb. Bier 115.

Lübecker Schiffrecht 37, 82, 83, 85, 87. Lübecker Vaar 208.

Lüchow 933.

Lüneburg, Hamburg 108, 111, 112, $114,117,118,220,221,232,242$, 243; Lübeck 55, 114, 221 ff., 242; -Flandern 108, 118, 242, 243 ; Braunschweig 242, 243; -Stade 135, 136 ; Salzhandel 55, 114, 221; Holzhandel 112; Metallhandel 106; Heringshandel 55, 115, 221 f., 242. Lund 270.

Lymbergh, Tydemann 174.

Lynn 67, 167 Note 121, 175.

Maas 2, 4, 216, 219, 224.

Magdeburg 4, 5; Hamburg 56, 106, 111, 118, 219, 233; Flandern 118, 251 ; Getreidestapel 224; Münzen 4. Magnus, König von Schweden 259, 261. Mailand 34 Note 13, 142 Note 11.

Mainz 2, 5, 148 Note 30.

Majorka 146, 179.

Makler in Flandern 184, 202, 203. 
Malaga 144 Note 34.

Malmö 162 Note 101, 167, 270.

Mandeln als Handelsartikel 119, 218, 228.

Manegolt Sosendorp, Ältermann der deutschen Hanse in Dordrecht 237.

Mariengaard, Kloster in Friesland 241.

Marienkirche 80 Note 112.

Marktabgabe in Lübeck 21, 22 Note 62 und in Bardovik 23.

Marktrecht in Hamburg 24, 28.

Marne 129.

Marseille 32 Note 9; Tuchfärberei 34 Note 11.

Marsen in Holland 113, 237.

Masten als Handelsartikel am Zwin 183.

Maubeuge 179.

Mecheln 119.

Mechtersen 111.

Medemblik 238.

Mehlhandel nach Norwegen 58 Note $118,60$.

Meißen, Mark 109, 117.

Meniers, Tuche 229.

Messen, der Champagne 77, 94, $141 \mathrm{ff}$., 201 f.; Pariser 30, 148 Note 32; flandrische $35,77,201 \mathrm{f}$.

Messines, Messen von 201, 202.

Metallhandel 2, 3, 105-109, 110, 134, 156, $218 \mathrm{ff}$.

Minden 216.

Minho 35.

Mission im Norden 12-14.

Mittelrhein 2.

Mölln 111, 114, 221, 222, 223.

Monikerede 40, 75 Note 188, 183, 184, 185, 187.

Montpellier 14 Note 11 (Färberei), 32 Note 9, 145 Note 22, 23.

Morgensprachen der Hamburger Hanse am Zwin 79; in Utrecht 132; der Lüb. Hanse am Zwin 85, 87.

Mue, de la 75 Note 188.

Muiden 196.

Münster 81, 250; England 182; Norwegen 196, 197.
Münzen, deutsche 8, 17; magdeburgische 4; Bardowiker 5, 6; Stader 9; englische 64 .

Münzrecht in Hamburg und Bremen $17,28$.

Musgard, Ritter von 208.

Narbonne 33 Note 9.

Nautik 146, 157, 158.

Navarra 76, 92, 169 Note 127.

Neckam, englischer Gelehrter 146 Note 26.

Nesle, Hanse in England 68.

Nestved 121.

Neudamme 39.

Neumünster 233.

Neuwerk 129, 130, 236; Zoll 242.

Newcastle 66, 162 Note 100.

Niclot, Slavenfürst 10.

Nicolaikirche 25.

Nicolaus Heygen, Hamburger Bürger 224 Note 96.

Nicolaus, Graf von Schwerin 99.

Niederlande 7, 10; Schiffahrt in der Ostsee 158, 159, 160,161, 165; in Flandern 193, 194, 195, 196, 197; Rußland 150; Norwegen 175; Stade 9; Verhăltnis zur Städtehanse $191 \mathrm{ff.}$. $272,277,278$.

Nîmes 33 Note 9 .

Nordalbingien 11, 15.

Norden in Friesland 117, 241.

Normannen 2, 13, 14, 16.

Northhampton 174 Note 150.

Norwegen 7, 8, 21, 89 Note 235, 257 f., 262 f.; Flandern $56 \mathrm{ff}$., $175 \mathrm{ff}$.; Lübeck 40, 175, 257; Hamburg $57 \mathrm{ff}$., 98, 175, 257; England 57; Niederlande und Westfalen 93, 175, 195-197, 257; wendische Städte 60 f., 103, 175, 257; Greifswald 103 Note 42; Heringshandel 55 Note 100, 102; Tuchweberei 230 .

Nowgorod 4; Flandern $41 \mathrm{ff} ., 149 \mathrm{ff}$. , 231 f., 249, 256; Gotland 43, 45, 156 f.; Lübeck 42 ff., 45, 150 f.; 
Hamburg 45; wendische Städte 102 Note 38, 150; Stade 135; Westfalen und sachsen 150; Niederländer $192 \mathrm{f}$.

Vïrnberg 1'\%, 153.

Nyborg 167 Note 122.

Nychels Pels von Böhmen 224 Note 9'. Nyköping 213.

Nymwegen 163, 192, 275, 276.

Obotriten 19.

Oder 11, 93, 154, 155.

Öl als Handelsartikel 69, 70 Note 171, 218228.

Oldenzaal 197.

Oldesloe 95, 97, 98, 99, 100, 101, 135, $205,206,208,209,210,211,212$, $213,216,217,218,240$.

Olérons, Seerecht 74, 9'.

Oostburg, Mitglied der Londoner Hanse 68.

Orchies, Mitglied der Londoner Hanse 68.

Oslo 177.

Osterburg 111.

Osterland 7 und Note 24 daselbst.

Ostkerke 40, 82, 83, 183, 199, 200.

Osnabrück 125 Note 143; Hamburg 122, 217; England 182; Norwegen 196.

Olto III, Kaiser von Deutschland 17. Otto IV, Kaiser von Deutschland 136. Oudenaarde 119, 229 (Tuche).

Oudenburg, Mitglied der Londoner Hanse 68.

Overe, Bruno van, Köölner Bürger 217.

Pakotille 40, 41, 115.

Papen, Jan 237.

Parchim 233.

Parkentin 96.

Paris, Messen 30, 148 Note 32.

Pech als IIandclsartikel in Hamburg 109, 112, 116; Preußen 153; von der Ostsee 49, 159.

Pelzhandel 3, 41, 42, 46, 78, 139, 14?, 153, 157 Note 71, 167 Note 121.

Kiesselbach, Deutsche Hanse.
209 fr., 216, 217: Stapel in Brügge 172, 173; Handel narh England 63 Vote 35, 69 Vote 71, 131; russischer 41 ff., 46, 149; preußischer 49, 152: schwedischer 151, 215; in Hamburg 10', 119, 206, 207; über Stade 135: Beteiligung der süderseeer 16't, 195; auf Schonen 164, 195.

Perleberg, Flandern 188, 220; Hamburg 233.

Pernau 151, 160, 210, 213, 215, 223. pertinentia von Damme 40.

Pfeffer als Handelsartikel 119, 152, 218. Pferde als Handelsartikel 185, 117, 119. Pfundzoll 210 ff., 243 ff., 261 f., 271 ; der livländischen Städte $214 \mathrm{fr}$; der preußischen und wendischen Städte 154; Hamburgs 271.

Piazenza 34́ Noten 11 (Tuchfärberei) und 13, 200.

Pisa 33 Note 9, 34 und Note 13, 147. Pilsum in Ostfriesland 2:1.

Pirna 219.

Pistoja 34 Note 13.

Plock 152.

Poitou 74, 75.

Polabinger 19.

Polen 89, 147 Note 30.

Pommern 93.

Poperingen 179; Mitglied der Londoner Hanse 68; Tuche 35.

Porswelde, Ritter von 208.

Porthmouth 65.

Portugal 35, 76; Flandern 92, 179, 200 ; England 169 Note 127.

Posen 54 Note 98.

Prag 219.

Preußen 49, 52, 151, 152 fff., 162, 18', 188, $197 \mathrm{ff}$; ; in der kölnisch-west. fälischen Genossenschaft in Flandern 191 ff., 197; 'Tuchweberei 230.

Prilzwalk 111, 220.

Provence 33 Note 10, 35, 92 (Flandern); 141, 169 Note 127 (England); 143 Note 15 (Tuchindustrie), 201 (Messen). 
Quedlinburge loti

Ratmänner in Hamburg 132.

Rauchwaren 153 (von Preußen).

Recklinghausen 182 (England).

Reederei, preußische 157, 162 ff.: niederländische $162 \mathrm{ff}$.

Regensburg 5.

Reis als Handelsartikel 119, $218,228$.

Reiserouten des Hamburger Schiff. rechtes 40 , 1 .

Rendsburg 233.

Reval 48, 52. 101, 151. 176 Note 71, 188, 210, 213, 215, 223.

Reveshol 167 Note 122.

Rhein 4, 8, 13, 78, 147 mint Note 30 daselbst.

Riga, Lübeck.Flandern 12 Note i万. 4.3 Note 49, 44 f., 52, 156 Note 71. 188, 210, 213, 215, 223: Nowgoro!1 150, 151; Schonen 53, 160; Nor. wegen 257, 258; in Greifswald $10 \% 3$ Note 42; Rigaisches Schiffrecht 5.3. 156; Zollfreiheit der Rigaer in Ham. burg 102: Salzeinfuhr 223.

Ripen 10, 242.

Ritzebüttel 235.

Rochelle 36, 40, 74. 75, 77, 94, 145, $177,179,182,184$.

Roermond 276.

Rom 39 Note 13.

Roskilde 167 Note 122.

Rostock 98, 207, 251, 252, 257, 258. $259,260,261,265,266,268,269$, 271; Flandern 51, 52, 86 Note 230 (Houcke), 190; Schonen 53, 102 Note 39, 163, 181; Norwegen 181; Schweden 181; England 182; Ham. burg 217; Rußland 150; Lübeck 157 Note 72, 214; Salzhandel 223: Böttcherei 226.

Roulers, Tuche von 229.

Ruden, Insel, als Hafen von Greifswald 50,51 .

Rügen 55 Note 100, 102 (Heringe). Ruger, Johann, Kölner Bürger 217.
Rumplingen in Holstein 216.

Rußland 't, 21, 29, 41-44, 47, 48, 93, 102, 149 ff., 192, 209.

Rüstringen 130 .

Ruthenien 152.

Sarhsen 7, 9, 11, 12, 13, 20, 112.

Saintongue 75 .

Salzhandel, Lüneburg 55 Note 100. 11', 115. 222, 242: Ausfuhr Lübecks 223: Frankreich 75, 178; Salzhandel am Zwin 75, 181, 184, 187; nach sichonen 52, 151, 160, 164, 165; nach RuBland 149 Note 35: nach Prenßen 181: Hamburg 221, 235; auf d. Stör 10 Note 35 ; in Salzwedel 55 Note 100.

Sialzwedel 55 Vote 100: in Flandern 86, 108, 118. 220; Wisby 86, 108; Hamburg 106. 109, 110, 112, 114, $118,220,233$.

sandomir 152.

St. Anna ter Muiden 39.

St. Denys 2, 7 Note 21, 30 Note 4.

St. Jean d'Angely 75,148 Note 32 , 172.

St. Omer 35, 36 (Tuche); 68 (England), 119.

St. Sebastian 76.

Scheeßel 4.

Schelde 14.

Schıffahrt, Eröffnung und Schluß 79.

Schiffbau in Preußen $15 \%$.

Schiffrecht, bremisches 37; hamburgisches $36,37,40,46,47,52,56$, $75,109,111,115,117,121,128$, 132 f.. 138, 139, 183, 199; lübisches $37,40,44$ Note $52,46,47,48,49$, $50,62,63,75,121$ : rigaisches 53 , 156.

Schiffsgerät als Stapelartikel am Zwin 183.

Schleswig 2, 4, $7, \quad 15, \quad 19,29,103$ Note 42, 233.

Schmalz als Handelsartikel 216 und Note 48, 153, 219. 
Schnackenburg 111.

Schonen, Flandern 40, 52 If., 59; England 5' f., 167; Lübeck und wendische Städte $55,102,163 \mathrm{fl}$., 223, 226, 239, 257, 265 f.; Nieder. länder 54 fr., 158 ff., 163 ff., 195 f., 197, 239, 277; Flandern, Brabanter Engländer 163; Hamburger 40, 53, 181 f., 225; Westfalen $195 \mathrm{f}$.

schottland 73, 175.

Schwaben, Köln 89.

Schwartau 20.

Schweden 4, 21, 47, 121, 151, 156; Hamburg 102, 155; Greifswald 103 Note 42.

schwefel als Handelsartikel 119.

Schweinefleisch als Handelsartikel 228. Schwerin 111.

Schwinge 9, 19, 25, 26, 127.

Schuhmacher, deutsche in Norwegen 175; in Kopenhagen 167 Note 122. Schutzmaßregeln lür die Straße Hamburg-Lübeck 95 ff., 20 ff.

Schuldbuch, hamburgisches 10', 111, 112, 115, 120, 122.

Sconeburgh, Tidemann 162 Note 97.

Seehausen 111, 220, 233.

Seeland 120, 130, 135; Verhältnis zur Hanse 272 fi.

Seeraub 6.

Seide als Handelsartikel 3', 152.

Sevilla 35, 76, 145 Note 24.

s'Hertogenbusch 163.

Siegel, gemeinsames der deutschen

Kaufleute 8' Note 225.

Siena 3't Note 13.

Silberhandel 105, 108, 125, 173,174 .

Skagerak 42.

Skanör 162, 270.

Skardeburg 159.

Slagelse 167 Note 122.

Slaven $3,5,11,16,17,19,20,23$.

Sluis 31, 185-189, 199.

Sneek 120.

Soest, Flandern 81, 89 Note 234, 251;

Gotland 4t Note 52, ?55; Norwegen
196; Nowgorod 256; Engrand 182; Brandenburg 232; Antwerpen 179 Note 180; IIanburg 122.

Somerset 17' Note 150.

Southhampton 17' Note 150.

Spanien, Flandern 46, 76, 171, 178, 179, 186; England 169 Note 127.

Spezerei als Handelsartikel 70 Nol. 171.

Speier, Tuchweberei 230 .

Spremberg 111.

Stade 8, 9, 10, 23, 25, 26, 27, 29, 89

Note 234, 113, 117, 122 Note 13:3,

$123,127,128,133,135,136,196$,

$219,224,233,236,239,241,242$;

Zoll 25 ff., 134.

Stadtrecht, Hamburger 137.

Stapel der Deutschen am Zwin 91, 92,

183, 185, 186, 187, 200, 201; stapel

Englands in Brügge 169, 170.

stargard 9, 10, 15', 269.

Stavorn 8, 193, 264, 269, 270; Ham. burg 120, 218, 225, 238, 239; Schonen 163; Norwegen 57, 196; Kopenhagen, Amager 167 Note 122; England 65;

Ostseefahrt 159, 160.

Stecknitz 100, 114, 222.

Stege 207, 209.

Steinmarne 235.

Stendal 55, 111, 220 .

Stettin 53, 98, 154, 156 Note 72, 163, $257,261,269,323$.

Stickenbüttel 235.

Stockfisch 177, 219.

Stockholm 155, 160, 213, 223.

Stör, Fluß, 10 Note 35, 12, 25, 234, 235.

störfisch 153.

Stormarn 12, 18, 19.

Stralsund 98, 115, 154, 252, 257, 258, $259,260,261,265,266$ 11., 272; Schonen 53, 102 Note 39, 163; RuBland 150; Flandern 49, 50, 55 Note 100, 156, 190; England 162 Note 100; Hamburg 217, 233; lübeck 157 Note 7, 214, 223; Nordseefahrt 159; Bötteherei 226 . 
Strandfriesen 236, 2'2.

slrandrecht 129-131; in Dimemark 5 5; in Sichweden 48, England 66; Flandern 90; im Lande Wursten 128 ; in Holland 133.

strabburg 148 Nole 30.

Sïderköping 121, 155, 123, 22:3.

süderseeer, Schiffahrt mach der Ustsere

152, 158, 159, 191, 19' l. (Gol-

land); Hamburg 120; Verhällnis

zur Hanse 120, 19's.

siudrubland, Preuben 152.

silfolk 17's Note 150.

Sundfahrt $17-51,57,156-159.197 \mathrm{f}$, $261-266,272$.

siverrir, liönig von Norwegen 57.

swatecop, Himric, Hamburger liarger

$181 \mathrm{f}$.

synter als llandelsartikel 103.

sirien 169 Vote 127.

Talge 216 und Note as disellost, 219.

Terep als llandelsartiliel 153. 159, 183.

Templer, Hammes, aus Havelberg 20'

Nole 9's.

Tremonde, Tuche von 229.

Termünten 2:0, 2:1.

Thorn 49, 152, 153, 268.

Thornberg 167 Nole 12:.

'Thourout 1'; Messen 77, 201: \%ollslatte 91; Milglied der lomdoner linanse 68.

'Tiel $5,9,66$.

'Tilmann von Köln 174.

'Tolner, Berlram 235.

'T'ölner, Johann 160.

Tommenhandel 52, 160, $165 \quad 2.25$ IT.; Fabrikation bei Artlenburg 221.

'Tonsberg 177.

Toulouse 75 Note 188, 145 Note 22, 169 Note 127.

Tournay, Tuche 35; Mitglied der Londoner Hanse 68.

Toskana 169 Note 127.
T'ran als Ilandelsartikel 195.

Trave 11, 20, 96, 97, 10', 205, 209, 219.

Travenünde 205, 206.

Troyes, Messen von 201.

Tuche 2 f., 32, 139, 209, 210, 216, 219, 230 fr.; flandrische $2,29,30-32,3$, $35,36,41,42,62,65,66,69,104,107$, $108,109,118,119,120,134,141,142$, 145, 149, 152, 153, 16', 167 Note 121, $171,173,185,201,202,203,206,207$, $218,219,243$; fianzösische 32-34, 35, 1'1 fl., 14', 145; brabantische und hemmegauische 229-231; anl. werpensche 230 : italienische 33 f., $141-145 ;$ rheinische $29,219,230$; pren Bische 230 : hollandische, geldem sche und seelindische 230 ; englisehe 12 ' 168 II., 217, 229, 231 f.; irische $217,220,231,243$; friesische 2 f., 230 ; hessische 229, 230; elsässische 230; graue (grisei) $230,231,241$. Im ein\%elnen Tuche aus folgenden Städten: liringge 35, 152 f.; Gent 29, 35, 219, 229 ; Y pern 35,143 Note $16,153,202$, 229 ; Poperingen 29, 35, 152, 153, 219; Dornik 152, 153; Kortryk 218; Valenciennes 35,218 ; Arras 34,35; St. Omer 35, 36; Cambray 35, Doua 35; Tournay 35; Lille 35, 202; Comines 35, 229; Messines 202; Meniers 229; Dixmuiden 229; Roulers 229; Courlray 229; Vernier 229; Warneton 229: Grammont 229; Ecloo 229; Oudenaarde 229; Termonde 229; Herenthal 229; Mecheln 229; Chalons sur Marne 34; Köln 230; Aachen 230; Speier 230; Braunschweig 101, 230; stralsund 220; Parchim 220.

Tuchweberei in Flandern s. Tuche in Flandern; in Hamburg 124, 231; in Norwegen 230; in Holland 67 Note 164.

Ülzen 220 Note 74, 223; Heringshandel 55 ; Hamburg 233.

Umlandsfahrer 53 Note 91, 158. 
Ungarn 89, 152.

muiversilats mercalorum is Note 58 , s'

Note 225, 101.

I'llwan, El'zbischol 16.

Cinterelbe 9, 3i Note 13, 110, 112, 11:3, $115,117$.

Itlaude, lriesische 109.

Ltrecht, \%ollrolle 7, 9, 10; Münzstallı 8; Inanburg 116, 120, 126 Note 1'i:, $131,132,133,134,138,216,218,237$ : state 9; Schonen 53; Gotland 135.

Valentemnes, Tuche von 35, 218.

Vichle 126 Note 143, 131, 237.

Venedig 32 Note 9, 34 Note 13 ('Tuche),

1'7, 1'48, 149 Tuche 3' (Zucker), 1'́6,

$147,148$.

Verdun 13.

Vermandois, Hanse in England 68.

Vernier, Tuche 229.

Veurne Belle, Mitglied der Londoner Hanse 68.

Viehhandel 117, 119, 136, 185.

Vlie 131, 239.

Vogt, gräflicher, in Hamburg 137.

Wachs 41, 42 Note 47, 46, 139, 153, 167

Note 121, 195, 206, 207, 209 11., 216, 217, 219; Wachsstapel in Brügge 172, 185; Hamburg 10', 116, 13'; Schonen 164; Preußen 152; russisches 1:4; England 63 Note 135, 69 Note 171.

Wagrien 19.

Waid, Handelsartikel 109 (Hamlsurg).

Waldemar, König von Dänemark 260 ll. 263.

Waldemar, Herzog von Schleswig 99. Warberg, Schloß auf Halland 270.

Warendorp, Bürgermeister von Lü beck 269.

Warneton (Tuche) 229.

watmal 230.

Wattenfahrt 25, 136.

Weichsel 3, 11, 153, 15'.

Wein, französischer $62,73,74,75,91$ (Rochelle), 177, 178, 219 (in Sach. sen): rhemischer 65, 78; Winstapel an \%win 78, 172, 18', 185, 1 sti; England 65, 173; schonen 160) Riubland 1:9 Vote 35; dureh IIolland 13'; in Hamburg 96, 10's, 119, 120; in Greil's. wald 103 Note 42.

Weinstein als IIandelsartikel 119.

Wreißastringien in Friesland 2 't.

Wendische Stälte, Handelsstellumgr 102 f.; am Zwin 86; Hund 256 fl.

Werben 111; Flandern 220; IIamburge 233.

Wernigerode-Hamburg-Flandern 106 .

Werpinge, Schloß bei Lund 270 .

Westergo 240.

Westfalen 126 Note 1't3; Flandern sti; England 65; Preuben 198, 199; S.hornen 163; Norwegen 175; Ostseeverkehr 93; niederländische Schiffahrl 195 f.

Wildenscharen $9 \%$.

Wildeshausen 125 Note 143.

Wilhelm, Gral von südlholland 13:.

Wills in England 17' Note 150.

Wilsum 38, 193.

Windegeld 50 Note 73, 78.

Winninghe in Friesland 2'1.

Winnoxbergen, Mitglied der Londoner' Ilanse 68.

Winsum 92.

Wisby 191, 192, 19' Note 239, 198, 2'4, 257, 258, 260; deutsche Genossenschaft daselbst 43, 4' $, 86,247,250$. 255; Flandern 51, 188; Nowgorod 150, 151, 256; Hamburg 45, 101; Lübeck 83, 135.

Wismar 98, 156 und Note 72 daselbst, 167 Note 120, 190, 196, 207, 211, 257-261, 267-269; in der lüb. Hanse an Kwin 86; Hamburg 216, 217; Schonen 53, 103 Note 39, 163 ; Bötlcherei 226; Salzeinfuhr 226.

Wittenberge 111.

Wladimir 153, 2:30.

Wohldorf 205, 207, 209. 
Wolgast (Holmbatulel) 49.

Wolle, englische 32, 61, 692, 63, 64, 65, (6f), 67, 68, 69, 71, 9', 12', 141, 1'2 1 1'6, 1'8, 168, 169, 170, 171, 172, 173, 174, 175, Wollstapel in Brügge usw. 6i2, 169, 170, 171, 172, 185; auf lranzösischen Messen 1'3-148: den schottische und irische 73 ; preußisilhe 153 ; ostersche 231 .

Wordingberg 262.

Workum 120.

Worms 2.

Wursten, Land 128-1:30, 2:36.

Wytren, Bürger von llavelberg 2.2' lote 9's.

link 2.

Ipren 75 Vote 188, 119; Tuehe :35, 14:3 Vinte 16, 202, 229; 11essen 35, 261, 202; Milglied der Londoner llanse 68.

Istad 250.

Cicriksce 91, 161, 16i3, 16it.

Kinnhandel vom IIar\% 105, 219; voll IeiBen 109; cuglisches 62. 169, 172; in Hamburg 116; in Greifswald 103 Note $\{2$.

Zoll zu Tiel, Köln, Mainz, Bardowik 5. 23: Stade 9, 242; zu Lübeck 23; zu Oldesloe 99 ff.; zu Hamburg 99 tî.; zu Yeuwerk 236, 2'2; Zollfreiheit der Hamburger in Sachsen 25, 27, 28; der Lübecker in Sachsen 21; der Hamburger in Schweden 48.

\%ollenspieker s. EBlingen.

Zucker als Handelsartikel 218.

Zuidersee 38, 37, 130, 131.

'ziitphen 150; Anlehnung an die Hanse in Flandern 192, 275, 277; Schonen 153; Nopwegen 193, 196, 273; Amager 167 Jote 122.

/win 30, 31, 37-40, 183-187; 44, 46, 47, 59, 60, 71, 73, 75, 77, 78, 79, $80,82,83,84,86,87,88,91,93,94$, $109,117,121,130-132,134,138$, $1 \% 0,158,161,164,166,171,172$, $175,17 \%, 178,179,180,181,188$, $189,193,195,199,200,202,228$, $232,245,248,249,275$.

/wolle 38, 92, 193, 19', 196, 276. 


\section{Druckfehlerberichtigung.}

Es ist zu lesen

auf S. 31 Note 4a: anslatt, Merkutors" — ,Mercators“.

auf S. 66 Zeile 7 von unten: anstatt, Standrecht" - ,slrandrecht".

auf S. 178 Zeile 2 von oben: anstatt, ,von Dordrechtern Schiffern, in diesem Verkehre von usw." - ,von Dordrechter Schiffern in diesem Verkehre, von usw".

auf S. 239 Zeile 8 von oben: anstatt ,IIalland“ — ,Holland“. 





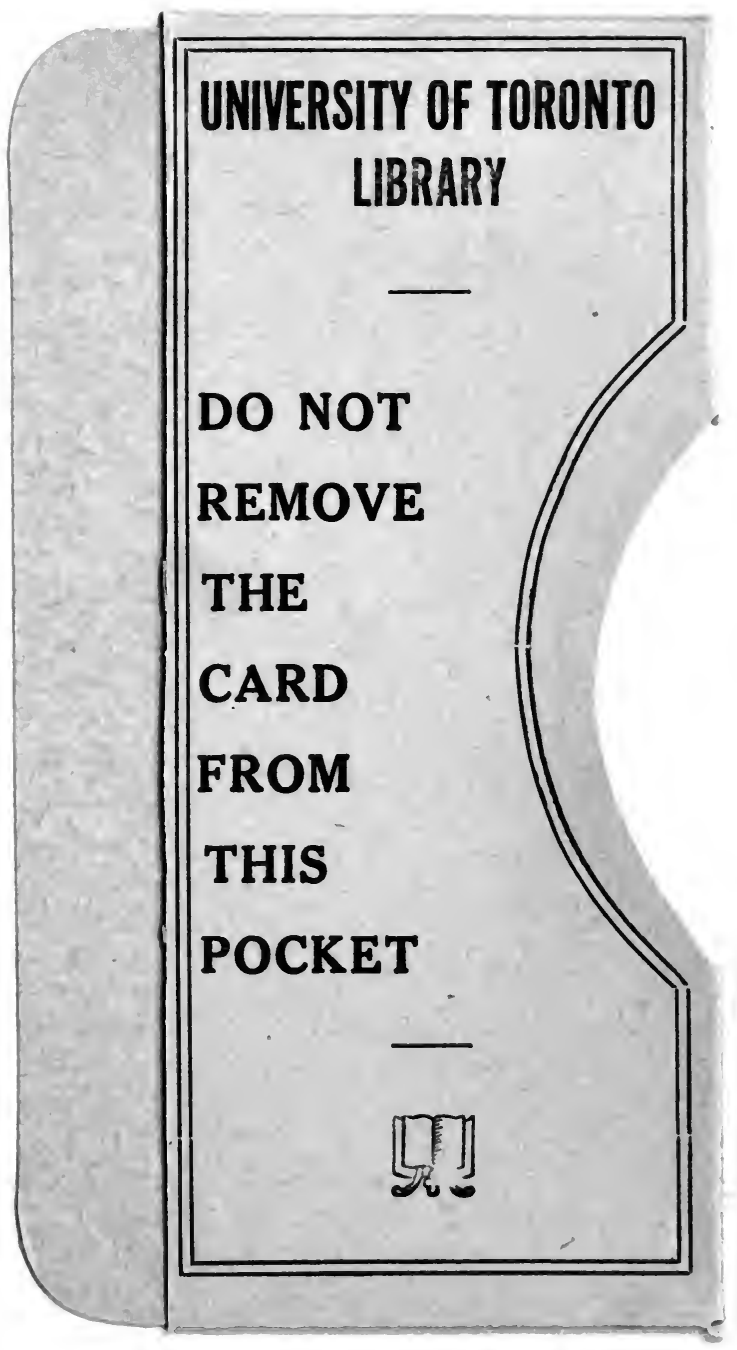


